QA: QA

MDL-WIS-PA-000003 REV 02

August 2005

\title{
Seismic Consequence Abstraction
}

Prepared for:

U.S. Department of Energy

Office of Civilian Radioactive Waste Management

Office of Repository Development

1551 Hillshire Drive

Las Vegas, Nevada 89134-6321

Prepared by:

Bechtel SAIC Company, LLC

1180 Town Center Drive

Las Vegas, Nevada 89144

Under Contract Number

DE-AC28-01RW12101 


\section{DISCLAIMER}

This report was prepared as an account of work sponsored by an agency of the United States Government. Neither the United States Government nor any agency thereof, nor any of their employees, nor any of their contractors, subcontractors or their employees, makes any warranty, express or implied, or assumes any legal liability or responsibility for the accuracy, completeness, or any third party's use or the results of such use of any information, apparatus, product, or process disclosed, or represents that its use would not infringe privately owned rights. Reference herein to any specific commercial product, process, or service by trade name, trademark, manufacturer, or otherwise, does not necessarily constitute or imply its endorsement, recommendation, or favoring by the United States Government or any agency thereof or its contractors or subcontractors. The views and opinions of authors expressed herein do not necessarily state or reflect those of the United States Government or any agency thereof. 
QA: QA

\section{Seismic Consequence Abstraction MDL-WIS-PA-000003 REV 02 August 2005}


2. Type of Mathematical Model

\section{Proceśs Model}

$\bigotimes$ Abstraction Model

\section{System Model}

Describe Intended Use of Model

This abstraction defines the damage to the waste package, drip shield, and fuel rod cladding from seismic hazards and recommends a methodology for using these abstractions in the seismic scenario class for TSPA-LA.

\section{Title}

Seismic Consequence Abstraction

4. DI (including Rev. No.):

MDL-WIS-PA-000003 REV 02

\begin{tabular}{|c|c|c|c|}
\hline & Printed Name & Signature & Date \\
\hline 5. Originator & Michael Gross & & \\
\hline $\begin{array}{l}\text { 6. Independent Technical } \\
\text { Reviewer }\end{array}$ & Rob Howard & & 29 \\
\hline 7. Checker & Ming Lin & & \\
\hline 8. QER & Darrell Svalstad & & \\
\hline 10. Responsible Manager & Richard Quittmeyer & & \\
\hline
\end{tabular}

Errata 1 (DC 38392) was addressed in REV 01. A single CD with 16 files (see Appendices F and G) is included with this report.

\section{Change History}

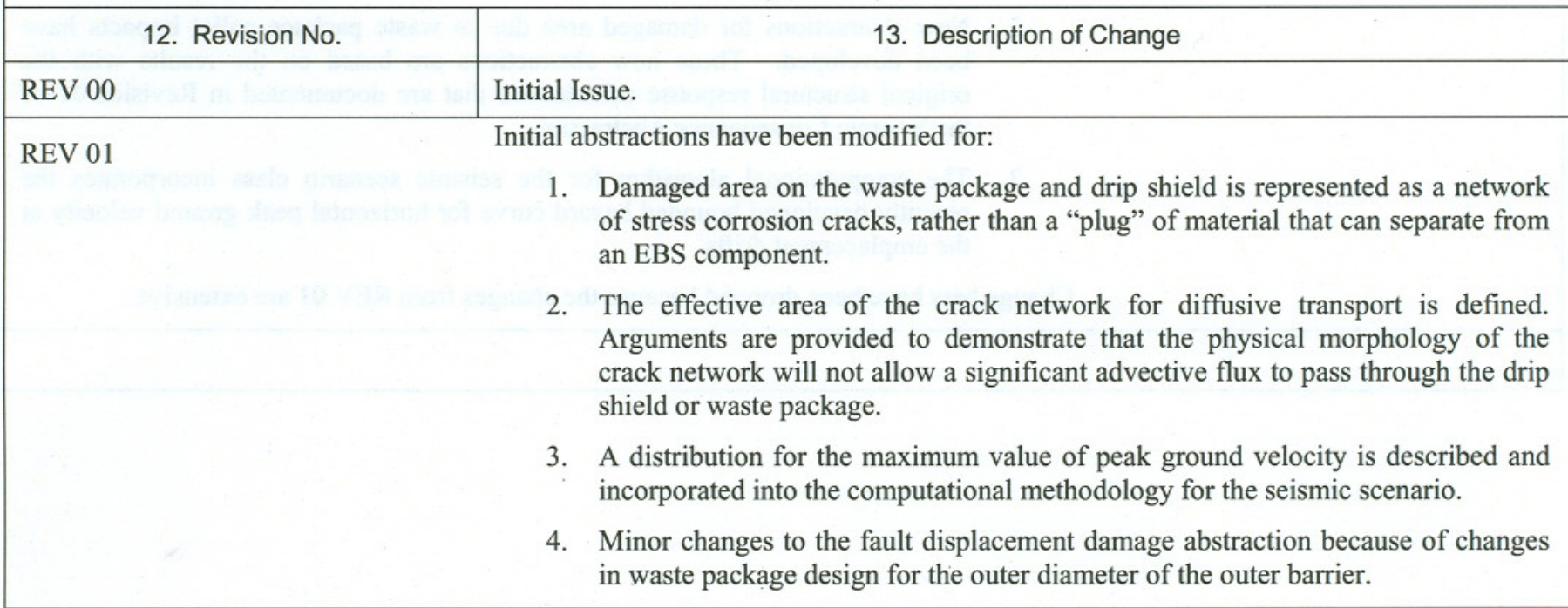




\section{BSC}

\section{Model Signature Page/Change History (Continued) \\ Complete only applicable items.}

2. Type of Mathematical Model

$\square$ Process Model

$\bigotimes$ Abstraction Model

System Model

Describe Intended Use of Model

This abstraction defines the damage to the waste package, drip shield, and fuel rod cladding from seismic hazards and recommends a methodology for using these abstractions in the seismic scenario class for TSPA-LA.

\section{Title}

Seismic Consequence Abstraction

4. DI (including Rev. No.):

MDL-WIS-PA-000003 REV 02

\section{Change History (Continued)}

12. Revision No.

REV 01 (Continued)
Initial abstractions have been modified for (continued):

5. Changes in waste package temperature and waste package relative humidity if a drift collapses in the lithophysal zones are incorporated into the seismic scenario.

The entire document was revised because of extensive changes. Changes to this version are too extensive to be indicated by change bars.

REV 02 are as follows:

1. New abstractions for damaged area due to end-to-end impacts of adjacent waste packages have been developed. These new damage abstractions are based on the results from kinematic calculations for the response of multiple waste packages to vibratory ground motions.

2. New abstractions for damaged area due to waste package-pallet impacts have been developed. These new abstractions are based on the results with the original structural response calculations that are documented in Revision 01 of the Seismic Consequence Abstraction.

3. The computational algorithm for the seismic scenario class incorporates the recently developed bounded hazard curve for horizontal peak ground velocity at the emplacement drifts.

Change bars have been dropped because the changes from REV 01 are extensive. 


\section{CONTENTS}

Page

ACRONYMS xiii

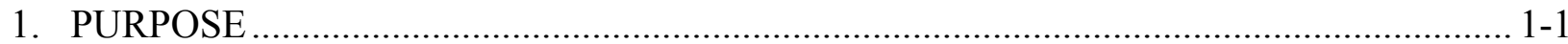

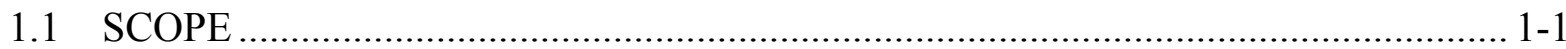

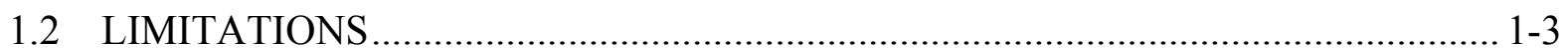

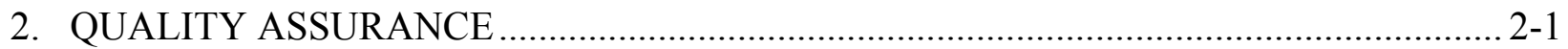

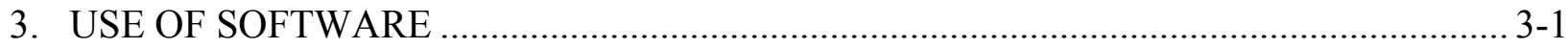

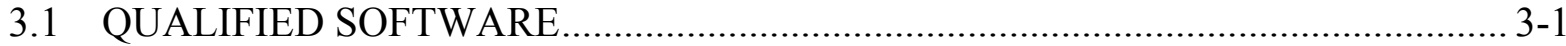

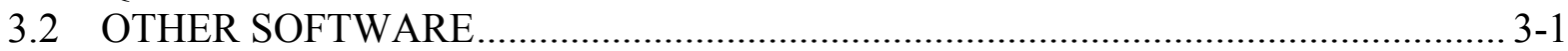

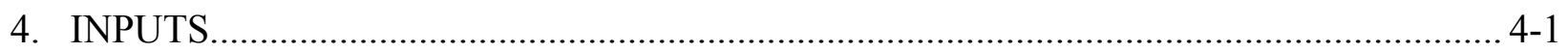

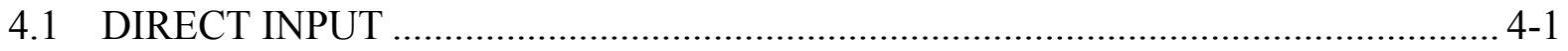

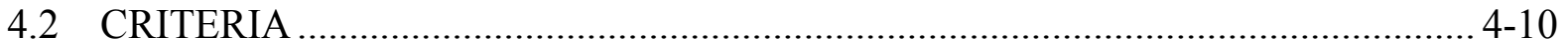

4.3 CODES, STANDARDS, AND REGULATIONS .......................................... 4-13

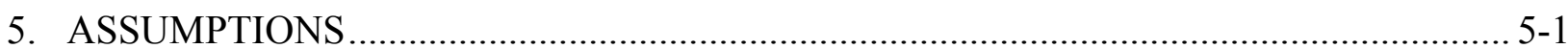

5.1 PAGANY WASH AND SEVER WASH FAULT DISPLACEMENTS ................... 5-1

5.2 RANDOMNESS OF SEISMIC EVENTS ............................................................ $5-2$

5.3 SUMMARY OF MAJOR ASSUMPTIONS IN SUPPORTING CALCULATIONS .......................................................................................... 5-2

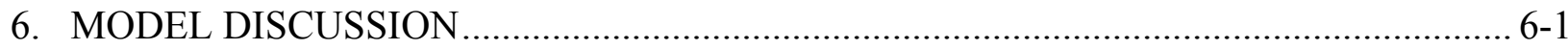

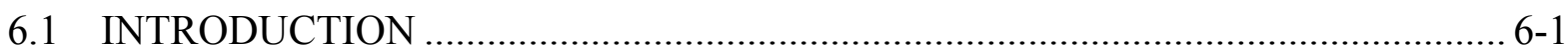

6.1.1 Information Sources........................................................................... $6-1$

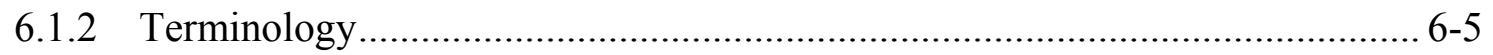

6.1.3 Corroborating Information ......................................................................... 6-6

6.2 RELEVANT FEATURES, EVENTS, AND PROCESSES FOR THE SEISMIC SCENARIO CLASS ................................................................................... 6-9

6.3 FAILURE MECHANISM, RESIDUAL STRESS THRESHOLDS, AND FAILURE MORPHOLOGY FOR THE WASTE PACKAGE AND DRIP

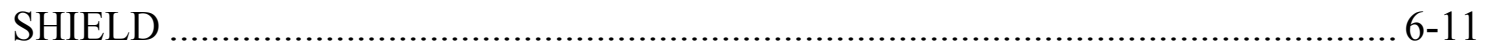

6.3.1 Failure Mechanisms Under Seismic Loads.................................................. 6-11

6.3.2 Residual Stress Damage Threshold for the Waste Package............................ 6-15

6.3.3 Residual Stress Damage Threshold for the Drip Shield ............................... 6-15

6.3.4 Morphology of Damage on the Waste Package........................................... 6-16

6.3.5 Effective Area for Transport From the Waste Package ................................ 6-17

6.3.6 No Advective Flow Through the Drip Shield.......................................... 6-20 


\section{CONTENTS (CONTINUED)}

6.4 GROUND MOTIONS AT THE EMPLACEMENT DRIFTS ………………......... 6-20

6.4.1 Probabilistic Seismic Hazard Analysis ...................................................... 6-20

6.4.2 Site-Specific Ground Motions ............................................................... 6-22

6.4.3 Bounded PGV Hazard Curve at the Emplacement Drifts.............................. 6-25

6.5 DAMAGED AREA ABSTRACTIONS FOR VIBRATORY GROUND

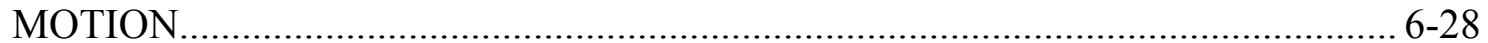

6.5.1 Abstraction for Waste Package Damage from End-to-End Impacts .............. 6-29

6.5.1.1 Kinematic Calculations for End-to-End Impacts ........................... 6-30

6.5.1.2 Catalog of Damaged Areas for End-On Impacts ............................ 6-39

6.5.1.3 Calculation of Damaged Areas for End-to-End Impacts ................ 6-45

6.5.1.4 Abstraction of Damaged Areas for End-to-End Impacts ................ 6-46

6.5.1.5 Abstraction of Damaged Areas for LS-DYNA Results with 80 Percent Residual Stress Threshold........................................... 6-48

6.5.1.6 Conversion to Percent Surface Area ……………......................... 6-55

6.5.2 Abstraction for Damage from Waste Package-Pallet Impacts........................ 6-56

6.5.2.1 Damage from Waste Package-Pallet Impacts ................................ 6-58

6.5.2.2 Abstraction of Damaged Areas from Waste Package-Pallet Impacts ............................................................................... 6-60

6.5.2.4 Conversion to Percent Surface Area …………………………...... 6-69

6.5.3 Final Abstraction for Waste Package Damage ……….................................... 6-69

6.5.3.1 Analysis of Waste Package-Drip Shield Impacts .......................... 6-69

6.5.3.2 Total Damage Abstraction for the Waste Package ......................... 6-72

6.5.4 Drip Shield Damage from Ground Motion..................................................... 6-74

6.5.4.1 Structural Response Calculations ……………….........................6-75

6.5.4.2 Drip Shield Damage................................................................... 6-76

6.5.5 Rockfall Prevents Drip Shield Separation .................................................... 6-77

6.5.6 Failure Abstraction for the Fuel Rod Cladding from Ground Motion............ 6-80

6.5.6.1 Structural Response Calculations ……………………………..... 6-80

6.5.6.2 Cladding Failure from Buckling ................................................. 6-81

6.5.6.3 Abstraction for Cladding Failure ………………........................... 6-82

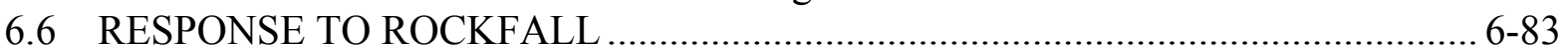

6.6.1 Drip Shield Damage from Rockfall in the Nonlithophysal Zone ................... 6-84

6.6.1.1 Nonlithophysal Rockfall Analyses ...............................................6-84

6.6.1.2 Structural Response Calculations ..................................................6-85

6.6.2 Drip Shield Damage from Rockfall in the Lithophysal Zone........................ 6-87

6.6.2.1 Lithophysal Rockfall Analyses ..................................................... 6-87

6.6.2.2 Structural Response to Static Loads …………………………...... 6-88

6.6.3 Damage to the Waste Package and Cladding from Rockfall .......................... 6-89

6.7 RESPONSE TO FAULT DISPLACEMENT ………........................................... 6-89

6.7.1 Clearance Between EBS Components and the Drift.................................... 6-90

6.7.2 Faults Intersecting Emplacement Drifts.................................................... 6-94

6.7.2.1 Location of Known Faults................................................................ 6-94

6.7.2.2 Faulting Other Than at Known Faults ........................................... 6-95 


\section{CONTENTS (CONTINUED)}

Page

6.7.3 Fault Displacement Hazards

$6-97$

6.7.4 Consequence for the Waste Packages

6.7.5 Damage Abstraction for Fault Displacement. 6-104

6.7.6 An Alternative Conceptual Model for Damage from Fault Displacement ... 6-105

6.7.7 Failure by Waste Package Type for Criticality Studies

6.8 POST-SEISMIC CHANGES IN THE LOCAL ENVIRONMENT 6-110

6.8.1 Change in Seepage Flux into the Drifts 6-111

6.8.2 Changes for a Collapsed Drift.

6.9 SEISMIC SCENARIO CLASS

6.9.1 Computational Approach

6-117

6.9.2 Computational Algorithm

6-119

6.9.3 Limitations ... 6-138

6.10 VERIFICATION OF SCIENTIFIC ANALYSES 6-139

7. VALIDATION .................................................................................................. $7-1$

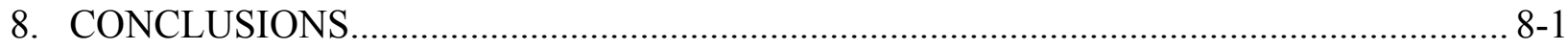

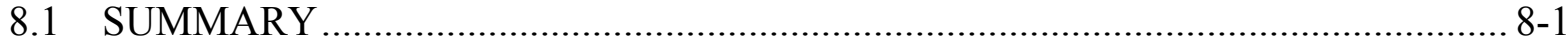

8.2 HOW THE ACCEPTANCE CRITERIA ARE ADDRESSED ................................. 8-3

9. INPUTS AND REFERENCES .......................................................................... 9-1

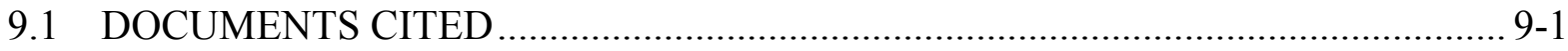

9.2 CODES, STANDARDS, REGULATIONS, AND PROCEDURES ........................ 9-6

9.3 SOURCE DATA, LISTED BY DATA TRACKING NUMBER …......................... 9-7

9.4 PRODUCT OUTPUT, LISTED BY DATA TRACKING NUMBER ....................... 9-8

APPENDIX A - SPREADSHEET FOR CALCULATION OF MEAN DAMAGED AREAS FROM END-ON IMPACTS AND SPREADSHEETS FOR DAMAGED AREA CALCULATIONS FROM END-TO-END IMPACTS

APPENDIX B - SPREADSHEETS FOR DAMAGED AREA ABSTRACTIONS FROM END-TO-END IMPACTS AND FROM WASTE PACKAGE-PALLET IMPACTS B-1

APPENDIX C - INDEPENDENT TECHNICAL REVIEW BY PROF. C. ALLIN CORNELL OF WASTE PACKAGE DAMAGE ABSTRACTION FROM VIBRATORY GROUND MOTION.

APPENDIX D - INDEPENDENT TECHNICAL REVIEW BY DR. ROBERT P. KENNEDY OF WASTE PACKAGE DAMAGE ABSTRACTION FROM VIBRATORY GROUND MOTION. 


\section{CONTENTS (CONTINUED)}

Page APPENDIX E - SPREADSHEET FOR FAULT DISPLACEMENT DAMAGE ABSTRACTION...................................................................................

APPENDIX F - LISTING OF ELECTRONIC FILES ON CD (APPENDIX G) ...................... F-1 APPENDIX G - CD WITH ELECTRONIC FILES ………………………………............ G-1 


\section{FIGURES}

Page

6.1-1. Schematic Diagram of the EBS Components in a Typical Emplacement Drift 6-2

6.3-1. Permanent Deformation from Plastic Yielding Generates Residual Stress ................. 6-14

6.3-2. Typical Example of TGSCC in Stainless Steel..................................................... 6-18

6.3-3. Parallel Rows of Randomly Oriented Flaws, with Row Spacing Equal to Wall Thickness, $t$................................................................................................. 6-19

6.4-1. Schematic Diagram Showing Location of Points A and B 6-24

6.4-2. Bounded and Unbounded Hazard Curves for Horizontal Peak Ground Velocity at Point B, the Repository Waste Emplacement Level

6.5-1. Finite-Element Representation for the LS-DYNA Calculations 6-31

6.5-2. Geometry of 21-PWR and DHLW Long Packages, Shown from the Symmetry Plane Side. Adjacent Waste Packages Are Initially $10 \mathrm{~cm}$ Apart.. 6-31

6.5-3. Geometric Representation for the Two-Dimensional UDEC Calculations 6-35

6.5-4. Comparison of the Actual Geometry and its Representation in the Numerical Analysis

6.5-5. Displacement Contours (m) At The End of Ground Motion 7 at the $5.35-\mathrm{m} / \mathrm{s}$ PGV Level 6-38

6.5-6. Catalog of Damaged Area Data for End-On Impact of a Waste Package on an Elastic Surface

6.5-7. Mean Value of Damaged Area for Impact Angles of $1^{\circ}, 5^{\circ}$ and $8^{\circ}$ at a Given Impact Velocity in the Catalog of Damaged Area Data for End-On Impact of a Waste Package

6.5-8. Mean Damaged Areas as a Function of Impact Velocity for a Residual Stress Threshold of 80 Percent of Yield Strength. .............................................................. 6-44

6.5-9. Probability of No Damage As a Function of PGV .................................................. 6-51

6.5-10. Power Law Fit to the Nonzero Damaged Areas for LS-DYNA with a Residual Stress Threshold of 80 Percent of the Yield strength of Alloy 22 ............................. 6-52

6.5-11. Comparison of the Cumulative Distribution for the Natural Logarithm of the Residuals for Nonzero Damaged Areas with a Cumulative Normal Distribution...... 6-53

6.5-12. Quantile Plot for the Natural Logarithm of the Residuals for Nonzero Damaged Areas Versus a Normal Distribution. 6-54

6.5-13. Comparison of Data for Nonzero Damaged Areas With the 0.05 and 0.95 Nonexceedance Probability Curves for the Ln-Normal Distribution.

6.5-14. Distribution of Damaged Area Data (All Points) as a Function of PGV-Longitudinal. 


\section{FIGURES (CONTINUED)}

Page

6.5-15. Probability of No Damage as a Function of PGV-Longitudinal

6-63

6.5-16. Comparison of Power Law and Linear Least Squares Fits to the Damaged Area Data.

6.5-17. Comparison of Power Law and Linear Least Squares Fits At Smaller Values of PGV

6.5-18. Comparison of the Cumulative Distribution for the Residuals for Nonzero Damaged Areas in Ln-Ln Space with a Cumulative Normal Distribution. 6-66

6.5-19. Quantile Plot for the Residuals for Nonzero Damaged Areas in Ln-Ln Space Versus a Normal Distribution 6-66

6.5-20. Three Data Classes for Calculation of Standard Deviation are Identified by the Dashed Lines and Red Arrows

6.5-21. Comparison of Data for Nonzero Damaged Areas With the 0.05 and 0.95 Nonexceedance Probability Curves for the Ln-Normal Distribution .... 6-68

6.5-22. Collapse of Emplacement Drifts for the Full Range of Rock Qualities of Lithophysal Rock for Peak Ground Velocity of $333 \mathrm{~cm} / \mathrm{sec}$ $6-78$

6.5-23. Geometry of the Drip Shield - Side View

6.5-24. Damage Abstraction for Cladding Failure Via Perforation ..................................... 6-83

6.7-1. Schematic Diagram of EBS Components Illustrating the Clearances for Fault Displacement $6-90$

6.8-1. Thermal-Hydrologic Response for the 21-PWR Absorber Plate CSNF (pwr1-2) Waste Package 6-113 


\section{TABLES}

Page

1-1. $\quad$ Major References for Seismic Damage Abstractions .................................................. 1-2

4-1. Direct Input Information for Seismic Consequence Abstractions ................................ 4-2

6.1-1. Corroborating Input Information for Seismic Consequence Abstractions .................... 6-7

6.2-1. FEPs Included in Seismic Consequence Abstractions, their Disposition in TSPA-LA, and the Relevant Sections of this Report.................................................. 6-9

6.2-2. FEPs Excluded from Seismic Consequence Abstractions and the Relevant

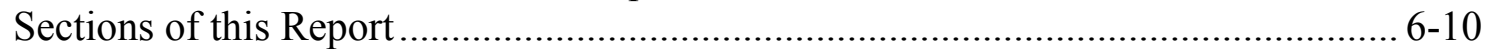

6.4-1. Bounded Hazard Curve for Horizontal PGV at the Emplacement Drifts .................... 6-26

6.5-1. Summary of Impact Data from LS-DYNA Kinematic Calculations ........................... 6-34

6.5-2. Summary of Impact Data from UDEC Kinematic Calculations................................. 6-39

6.5-3. Catalog of Damaged Areas from End-On Impact of a 21-PWR Waste Package on an Elastic Surface...................................................................................... 6-41

6.5-4. Mean Damaged Areas for $1^{\circ}, 5^{\circ}$, and $8^{\circ}$ End-On Impacts of a 21-PWR Waste Package on an Elastic Surface ............................................................................. 6-44

6.5-5. Illustration of Damaged Area Calculation - Realization 3 at 2.44-m/s PGV for

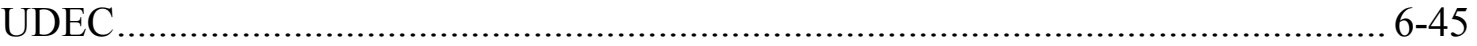

6.5-6. Listing of Spreadsheets with Damaged Area Calculations for the Kinematic Calculations.

6.5-7. Damaged Areas from the LS-DYNA Analyses for the Three Central Waste Packages with a Residual Stress Threshold of 80 Percent of the Yield Strength of Alloy 22

6.5-8. Data Points for Abstraction of the Probability of No Damage ................................... 6-50

6.5-9. Damaged Area from Waste Package-Pallet Impacts at $2.44-\mathrm{m} / \mathrm{s}, 5.35-\mathrm{m} / \mathrm{s}$, and 1.05-m/s PGV Levels.................................................................................... 6-59

6.5-10. Data Points for Probability of No Damage ……....................................................... 6-63

6.5-11. Standard Deviations of the Three Classes ……….................................................. 6-68

6.5-12. Comparison of Damaged Areas $\left(\mathrm{m}^{2}\right)$ From End-On and Side-On Impacts of a Waste Package for a Residual Stress Threshold of 80 percent of the YS of Alloy 22

6.5-13. Comparison of Damaged Areas $\left(\mathrm{m}^{2}\right)$ From End-On and Side-On Impacts of a Waste Package for a Residual Stress Threshold of 80 percent of the YS of Alloy 22

6.5-14. Comparison of Maximum Waste Package-Drip Shield Impact Velocities from the Cross-Drift Calculations with PGV Values for the Transverse and Vertical Components at the $2.44-\mathrm{m} / \mathrm{s}$ PGV Level. 


\section{TABLES (CONTINUED)}

Page

6.5-15. Fuel Assembly Accelerations from Waste Package-to-Waste Package Impact Calculations for a 450 Hertz Cutoff Frequency ....................................................... 6-81

6.5-16. Abstraction for Cladding Failure from Vibratory Ground Motion.............................. 6-82

6.6-1. Summary of Rockfall Damage to EBS Component ……………………………..... 6-85

6.6-2. Damaged Area from Individual Rock Blocks Impacting the Drip Shield ................... 6-87

6.7-1. Emplacement Drift Configuration Dimensions that are Independent of the Waste Package

6.7-2. Waste Package Dimensions and Clearance Between Drip Shield and Waste Package

6.7-3. Maximum Allowable Displacement Before Waste Package is Pinned ...................... 6-94

6.7-4. Intersections of Known Faults with Emplacement Drifts......................................... 6-96

6.7-5. Fault Displacement from Mean Hazard Curves.......................................................... 6-99

6.7-6. Design Basis Waste Package Dimensions and Inventory....................................... 6-100

6.7-7. Parameters for Simplified Groups of Waste Packages ............................................... 6-101

6.7-8. Maximum Allowable Fault Displacements Before a Waste Package Group Is Pinned ......................................................................................................... 6-102

6.7-9. Fault Exceedance Frequencies (per year) That Cause Failure in the Lower Lithophysal Zone ${ }^{\mathrm{a}}$......................................................................................... 6-103

6.7-10. Expected Number of Waste Packages Emplaced on Faults in Lithophysal Zones... 6-104

6.7-11. Expected Waste Package Failures versus Annual Exceedance Frequency .............. 6-104

6.7-12. Calculation of Probability-Weighted Waste Package Failures ................................... 6-106

6.7-13. Parameters for Simplified Inventory for Criticality ................................................ 6-107

6.7-14. Maximum Allowable Displacement With Drift Collapse Before Waste Package

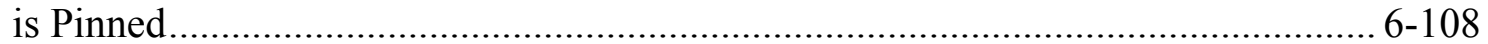

6.7-15. Fault Exceedance Frequencies (Per Year) That Cause Failure in Lithophysal Zones ${ }^{\mathrm{a}}$

6.7-16. Expected Number of Waste Package Types Emplaced on Faults ............................. 6-110

6.7-17. Failure of Waste Package Types by Annual Exceedance Probability ....................... 6-110

6.8-1. Thermal Conductivity of Rubble …………….................................................. 6-112

6.8-2. Maximum Temperature Change for MSTHM Configurations with Low Thermal

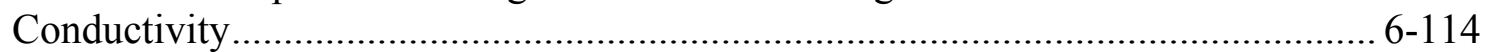

6.9-1. Definition of Parameters for the Seismic Scenario Class ......................................... 6-128

8.2-1. Comparison of Seismic Abstractions with Objective Evidence .................................. 8-15

A-1. Catalog of Damaged Areas from End-On Impact on an Elastic Surface..................... A-2

A-2. Mean Damaged Areas for $1^{\circ}, 5^{\circ}$, and $8^{\circ}$ End-On Impacts on an Elastic Surface ........ A-2

A-3. Listing of Excel Files with Damaged Area Calculations for the Kinematic

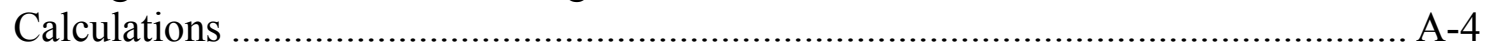

F-1. Listing of Electronic Files on CD (Appendix G) ................................................... 


\section{ACRONYMS}

\begin{tabular}{|c|c|}
\hline AP & absorber plate \\
\hline BSC & Bechtel SAIS Company, LLC \\
\hline BWR & boiling water reactor \\
\hline $\mathrm{CD}$ & compact disk \\
\hline CDSP & codisposal \\
\hline COR & coefficient of restitution \\
\hline $\mathrm{CR}$ & control rod \\
\hline CRWMS & civilian radioactive waste management system \\
\hline CSNF & commercial spent nuclear fuel \\
\hline DHLW & defense high-level radioactive waste \\
\hline DOE & U.S. Department of Energy \\
\hline DTN & data tracking number \\
\hline EBS & engineered barrier system \\
\hline ECRB & enhanced characterization of the repository block \\
\hline FEPs & features, events, and processes \\
\hline g & the acceleration of gravity \\
\hline g-load & acceleration measured as the number of g's required to fail cladding \\
\hline HLW & high-level radioactive waste \\
\hline LA & license application \\
\hline $\ln$ & natural logarithm \\
\hline $\log$ & common logarithm to base 10 \\
\hline $\mathrm{MCO}$ & multicanister overpack \\
\hline MSTHM & Multiscale Thermohydrologic Model \\
\hline MT & metric ton $(=1,000 \mathrm{~kg})$ \\
\hline $\mathrm{NRC}$ & U.S. Nuclear Regulatory Commission \\
\hline PGV & peak ground velocity \\
\hline PSHA & probabilistic seismic hazard analysis \\
\hline PWR & pressurized water reactor \\
\hline RMEI & reasonably maximally exposed individual \\
\hline $\mathrm{SC}$ & safety category \\
\hline SCC & stress corrosion crack \\
\hline
\end{tabular}




\section{ACRONYMS (CONTINUED)}

TGSCC transgranular stress corrosion cracking

TSPA total system performance assessment

TSPA-LA total system performance assessment for the license application

TWP technical work plan

YS yield strength 


\section{PURPOSE}

The primary purpose of this report is to develop abstractions for the mechanical response of engineered barrier system (EBS) components to seismic hazards at a geologic repository at Yucca Mountain, Nevada, and to define the methodology for using these abstractions in a seismic scenario class for the total system performance assessment for the license application (TSPA-LA). A secondary purpose of this report is to provide additional information for criticality studies that required definition of waste package failures from fault displacement at a finer level of detail than is retained in TSPA.

The seismic hazards addressed herein are vibratory ground motion, fault displacement, and rockfall due to ground motion. The major EBS components addressed in this report are the drip shield, the waste package, and the fuel rod cladding because failure of these components has the potential to directly release radionuclides or to form diffusive or advective transport pathways. The drift invert and pallet are included in the kinematic and structural response calculations for the EBS; however, it is not necessary to develop damage abstractions for the invert and pallet because they retain their functionality and do not form new pathways for transport and release of radionuclides after strong vibratory ground motion events (Section 6.1.1). The waste package internals and the waste form are also considered in structural response calculations, but separate damage abstractions are not needed because the failure of fuel rod cladding at relatively low PGV levels negates the mechanical response of the internals and waste form (Sections 6.5.6.3 and 6.1.1). The requirements for development of the abstractions and the associated algorithms for the seismic scenario class are defined in Technical Work Plan For: Analysis of Waste Package and Drip Shield Response to Vibratory Ground Motion and Revision of the Seismic Consequence Abstraction (BSC 2005 [DIRS 173171]).

The development of these abstractions will provide a more complete representation of flow into and transport from the EBS under seismic events. The results from this development will also address portions of integrated subissue ENG2, Mechanical Disruption of Engineered Barriers, including the acceptance criteria for this subissue defined in Section 2.2.1.3.2.3 of Yucca Mountain Review Plan, Final Report (NRC 2003 [DIRS 163274]).

\subsection{SCOPE}

The scope of this report is limited to abstracting the mechanical response of EBS components to seismic hazards during the postclosure period and defining algorithms for the seismic scenario class. The abstractions are based on the results from kinematic and structural response calculations for the response of EBS components to vibratory ground motion ${ }^{1}$ and from analyses

\footnotetext{
1 Vibratory ground motion is the time-dependent, three-dimensional motion of the earth during a seismic event. Each ground motion time history defines the displacement, velocity, and acceleration in three component directions as a function of time at a specific repository location. The three components of each ground motion time history are applied simultaneously to determine structural response of EBS components. Ground motion amplitude is identified by a horizontal component of the peak ground velocity (PGV), usually referred to as horizontal PGV or simply PGV in this document. This horizontal component may be oriented in the longitudinal direction (along the axis of the emplacement drift) or in the transverse direction (in the horizontal plane and perpendicular to the axis of the emplacement drift) for the structural response calculations. Note that the peak velocities for the second horizontal and vertical components of ground motion are not fixed, but will vary substantially even when the PGV for the first horizontal component is at a fixed value. The process to generate the ground motion time histories is summarized in Section 6.4.2.
} 
for fault displacement. The kinematic and structural response calculations are not documented in this report; rather, the results from these design calculations provide the input data on which the abstractions are based. The major design calculations and model report that provide input information for the abstractions are identified in Table 1-1 and Section 6.1.2. The sources for direct input data and corroborating input data are identified in Tables 4-1 and 6.1-1, respectively. The outputs from this document are identified in Section 8.1.

Table 1-1. Major References for Seismic Damage Abstractions

\begin{tabular}{|c|c|}
\hline Damage Process & Summary Report \\
\hline $\begin{array}{l}\text { Summary of kinematic calculations for the response } \\
\text { of multiple waste packages to vibratory ground } \\
\text { motion and of structural calculations for the response } \\
\text { of a single waste package to seismic hazards }\end{array}$ & $\begin{array}{l}\text { Mechanical Assessment of the Waste Package Subject to } \\
\text { Vibratory Ground Motion CAL-WIS-AC-000001 REV OB } \\
\text { (BSC } 2005 \text { [DIRS 173172]) }\end{array}$ \\
\hline $\begin{array}{l}\text { Summary of kinematic and structural calculations for } \\
\text { the response of the drip shield to seismic hazards }\end{array}$ & $\begin{array}{l}\text { Mechanical Assessment of the Drip Shield Subject to } \\
\text { Vibratory Motion and Static and Dynamic Rock Loading } \\
\text { CAL-WIS-AC-000002 REV 00A (BSC } 2004 \\
\text { [DIRS 169753]) }\end{array}$ \\
\hline Damage Process & Calculation Report \\
\hline $\begin{array}{l}\text { Damage to the waste package from vibratory ground } \\
\text { motion. }\end{array}$ & $\begin{array}{l}\text { Structural Calculations of Waste Package Exposed to } \\
\text { Vibratory Ground Motion 000-00C-WIS0-01400-000-00A } \\
\text { (BSC } 2004 \text { [DIRS 167083]). }\end{array}$ \\
\hline $\begin{array}{l}\text { Calculation of damaged area caused by end-to-end } \\
\text { impacts of adjacent waste packages for a predefined } \\
\text { set of impact velocities and impact angles. }\end{array}$ & $\begin{array}{l}\text { 21-PWR Waste Package End Impacts - A Mesh Study } \\
\text { 000-00C-WIS0-02100-00B (BSC } 2005 \text { [DIRS 173178]) }\end{array}$ \\
\hline $\begin{array}{l}\text { Acceleration of the fuel assemblies from end-to-end } \\
\text { waste package impacts. }\end{array}$ & $\begin{array}{l}\text { Maximum Accelerations on the Fuel Assemblies of a } \\
\text { 21-PWR Waste Package During End Impacts } \\
\text { 000-0C-SU0-1100-000-00A (BSC } 2003 \text { [DIRS 162602]). }\end{array}$ \\
\hline $\begin{array}{l}\text { Damage to the drip shield from vibratory ground } \\
\text { motion. }\end{array}$ & $\begin{array}{l}\text { Structural Calculations of Drip Shield Exposed to } \\
\text { Vibratory Ground Motion 000-00C-WIS0-02500-000-00A } \\
\text { (BSC } 2004 \text { [DIRS 172448]). }\end{array}$ \\
\hline $\begin{array}{l}\text { Damage to the drip shield from impact of large rock } \\
\text { blocks. }\end{array}$ & $\begin{array}{l}\text { Drip Shield Structural Response to Rock Fall } \\
\text { 000-0C-SE0-00300-000-00A (BSC } 2004 \text { [DIRS 168993]). }\end{array}$ \\
\hline Damage Process & Model Report \\
\hline Rockfall induced by vibratory ground motion. & $\begin{array}{l}\text { Drift Degradation Analysis ANL-EBS-MD-000027 REV } 03 \\
\text { (BSC } 2004 \text { [DIRS 166107]). }\end{array}$ \\
\hline $\begin{array}{l}\text { Limitation of peak ground velocity by the dynamic } \\
\text { load bearing capability of the rock at Yucca Mountain }\end{array}$ & $\begin{array}{l}\text { Peak Ground Velocities for Seismic Events at Yucca } \\
\text { Mountain, Nevada ANL-MGR-GS-000004 REV } 00 \\
\text { (BSC } 2005 \text { [DIRS 170137]) }\end{array}$ \\
\hline
\end{tabular}

The damage abstractions for EBS components include both model abstractions and scientific analyses. The abstractions for damage to the waste package in response to vibratory ground motion are treated as models because they rely on analyses of structural response over a range of ground motions that is wider than typically covered by seismic designs for buildings or nuclear power plants. These model abstractions have been validated to the requirements in LP-SIII.10Q-BSC, Models, through an independent technical review and through a comparison of the abstraction to computational data. The abstractions for damage to the fuel rod cladding and for damage from fault displacement are considered scientific analyses because the cladding abstraction uses a simple, bounding approach and because the damage abstraction for fault displacement is based on design clearances between EBS components. Although scientific 
analyses are not validated to the requirements in LP-SIII.10Q-BSC, Models, Section 6.10 provides a discussion of verification for these abstractions.

The technical work plan (TWP) for this report identifies requirements for two revisions of this report during calendar year 2005 (BSC 2005 [DIRS 173171], Section 2.2.2.1). However, this revision (REV 02) incorporates information on damage assessments for a collapsed emplacement drift from Mechanical Assessment of the Waste Package Subject to Vibratory Ground Motion (BSC 2005 [DIRS 173172]), as required by the TWP for a future revision (REV 03). Consequently, that future revision of this report is not necessary and is no longer planned for calendar year 2005 .

This report does not address the performance of naval spent nuclear fuel during seismic events. The Naval Nuclear Propulsion Program Technical Support Document for the License Application will provide the seismic analysis for naval spent nuclear fuel.

\subsection{LIMITATIONS}

The major limitations of the postclosure abstractions for the seismic scenario class are as follows:

- The structural response calculations include corrosion of the waste package and drip shield over a 20,000-year time frame, which includes the initial 10,000 years following repository closure (Assumption 5.3). The 20,000-year duration for the seismic analyses is designed to demonstrate that repository performance remains robust well after the initial 10,000 years after repository closure has ended. Calculations of the seismic scenario class beyond 20,000 years may require new structural response calculations with higher levels of structural corrosion.

- The computational algorithm for the seismic scenario class assumes that a single seismic event occurs in each realization of TSPA. Coupled effects from multiple seismic events, whereby the first event changes the in-drift conditions and damage associated with a second event, are not considered because seismic hazards with the potential to have a significant impact on engineered barriers are anticipated to occur very rarely during the 10,000 years following repository closure. More specifically, seismic hazards with the greatest potential to damage the engineered barriers correspond to very large disruptive events with annual exceedance frequencies much less than $10^{-4}$ per year (Section 6.5 in this report), so there is only a very small probability that multiple events with the potential to induce significant damage will occur over a 10,000 year or 20,000 -year period following repository closure.

- Spatial variability has not been represented in the damage abstractions for EBS components under ground motion (Sections 6.5.3 and 6.5.6.3). In other words, damage to the waste package and fuel rod cladding from vibratory ground motion is constant throughout the repository for TSPA. Although spatial variability is not included within TSPA, it has been included in the kinematic calculations through the variability of friction factors on a package-by-package basis and in the abstraction of damaged areas for the three central waste packages in the kinematic calculations. 
Lack of spatial variability is reasonable for estimating the mean dose from the seismic scenario class but overestimates the coefficient of variation for the dose. The mean dose is accurately estimated because the sum of the mean doses from groups of waste packages with different damage levels is equal to mean of the sum of the doses from the individual groups. In other words, using a constant mean value for the damage is an accurate approach for calculating the mean total dose. On the other hand, the coefficient of variation (i.e., the variability about the mean) of the total dose over all realizations is overestimated without spatial variability. If the waste package damage is constant and perfectly correlated everywhere in the repository, realizations with very high or very low damage produce a more extreme response for the dose than a realization with damage that varies spatially between the high and low values.

- Structural response calculations are based on the 21-pressurized water reactor (PWR) waste package (Sections 6.5.1 and 6.5.2). The 21-PWR waste package is the most common package type in the repository (BSC 2005 [DIRS 173501], Table 13). The design for the 21-PWR package is very similar to the design of the 44-boiling water reactor (BWR) package, and these two package types account for almost 65 percent of the packages in the inventory for TSPA-LA (BSC 2005 [DIRS 173501], Table 13, for the 21-PWR absorber plate (AP), 21-PWR control rod (CR), and 44-BWR AP). It is reasonable to base damage estimates on the 21-PWR waste package because it is the dominant package design in the repository. Note that the LS-DYNA kinematic calculations discussed in Section 6.5 represent both 21-PWR and defense high level waste-long (DHLW-Long) types of waste packages, although only the kinematic information for the central 21-PWR package type is abstracted for the seismic scenario class. 


\section{QUALITY ASSURANCE}

Preparation of this model report and its supporting technical activities has been performed in accordance with the appropriate requirements of the quality assurance program. This document is also prepared in accordance with the applicable technical work plan (TWP) (BSC 2005 [DIRS 173171]), which directs the work identified in work package ADEM21, Post Closure Seismic Modeling. Analysis and modeling activities performed under this TWP are subject to the requirements of Quality Assurance Requirements and Description (DOE 2004 [DIRS 171539]) because they are associated with the characterization of the waste form and waste package in support of performance assessment (BSC 2005 [DIRS 173171], Section 8). The technical work plan was prepared in accordance with LP-2.29Q-BSC, Planning for Science Activities. Input information for this model report are identified and tracked in accordance with LP-3.15Q-BSC, Managing Technical Product Inputs. No qualified software was used to develop the abstractions documented in this report, so LP-SI.11Q-BSC, Software Management, is not applicable. The methods used to control the electronic management of data, as required by AP-SV.1Q, Control of the Electronic Management of Information, are identified in Section 8 of the TWP.

This model report presents information on the mechanical response of EBS components that are important to waste isolation performance for the seismic scenario class. The following systems/subsystems are relevant to seismic damage abstractions, have been identified as important to waste isolation, and are classified as safety category (SC) in the Q-List (BSC 2005 [DIRS 174269], entries on p. A-6 under Engineered Barrier System and on p. A-9 under Subsurface Facility/Emplacement):

- Drip shield

- Waste package (including internals)

- Waste package emplacement pallet

- Waste form

- Cladding

- Drift invert (ballast).

The mechanical response of the drip shield, waste package, and Zircalloy cladding to vibratory ground motion, fault displacement, and rockfall induced by vibratory ground motion are the central focus of this report. The drift invert and the waste package internals are considered in structural response calculations, but are not represented as separate damage abstractions because they do not directly control the release radionuclides or the formation of advective flow pathways. The mass of the waste form is included in the structural response calculations, but the mechanical strength of a stack of uranium oxide pellets or of a vitrified waste form is not significant in comparison to the mechanical strength of the inner stainless steel shell and outer Alloy 22 shell of the waste package. Finally, non-Zircalloy cladding is not considered here because it has no contribution to barrier capability.

This document is prepared in accordance with LP-SIII.10Q-BSC, Models, and reviewed in accordance with LP-2.14Q-BSC, Document Review, as directed in the TWP. 
INTENTIONALLY LEFT BLANK 


\section{USE OF SOFTWARE}

\subsection{QUALIFIED SOFTWARE}

No qualified software is used to develop the seismic consequence abstractions. These abstractions are based on the results of structural response calculations that are performed with qualified software and that are documented in separate design calculation reports identified in Table 1-1. The qualified software programs for the structural response calculations, LS-DYNA and UDEC, are not directly used in the abstraction process and are therefore not listed here. These abstractions are also based on the results of: (1) rockfall analyses that are performed with qualified software (Table 1-1), and (2) thermohydraulic analyses and seepage analyses that are performed with qualified software and that are documented in separate model reports identified in Sections 6.8.1 and 6.8.3. The qualified software packages for rockfall analyses and thermohydraulic analyses are not directly used in the abstraction process and hence are not listed here.

\subsection{OTHER SOFTWARE}

Microsoft Excel for Windows, Version Excel 97 SR-2, running under the Microsoft Windows 2000 Professional operating system on an IBM-compatible personal computer, has been used to develop the abstractions for damage from seismic hazards. The standard functions in Microsoft Excel, including its statistical package, are sufficient for these analyses. No macros, codes, or software routines are required for or developed during this work. Relevant Microsoft Excel files are included as appendices to this report. As used to develop abstractions, Microsoft Excel 97 SR-2 is not required to be qualified or documented in accordance with LP-SI.11Q-BSC, Software Management. The formulas, inputs to the formulas, and outputs from the formulas are identified in Appendices A, B and E, as required by LP-SIII.10Q-BSC, Models, Attachment 2. 
INTENTIONALLY LEFT BLANK 


\section{INPUTS}

\subsection{DIRECT INPUT}

Table 4-1 presents the direct input information for abstraction of damage to EBS components from seismic hazards. The information in Table 4-1 has been categorized into seven areas that are relevant to the abstractions in this report: (1) seismic failure criterion; (2) effective transport area for a network of stress corrosion cracks (SCCs) ${ }^{2}$; (3) damage to the waste package from vibratory ground motion; (4) damage to the fuel rod cladding from vibratory ground motion; (5) damage to the drip shield from rockfall and from vibratory ground motion; (6) damage to the waste package, drip shield, and cladding from fault displacement; and (7) parameters for the seismic scenario class. The numerical values in Table 4-1 are presented with the same number of significant figures as presented in the source. For consistency, the data in Table 4-1 preserve the same units as the source documents, even when the use of millimeters results in large values with five or six significant figures for waste package lengths and waste package diameters.

The technical product inputs identified in Table 4-1 are appropriate for the development of model abstractions and scientific analyses for the seismic scenario class. Table 4-1 includes the direct input information for the development of the new waste package damage abstraction documented in Sections 6.5.1 through 6.5.3 of this report. This new damage abstraction completely replaces and supersedes the waste package damage abstraction documented in previous versions of this report.

For project-historical reasons, the sources in Table 4-1 generally identify ground motion levels by the value of the annual exceedance frequency. This report identifies ground motion level by the value of horizontal peak ground velocity (PGV), rather than exceedance frequency. PGV is a unique and unambiguous measure of the amplitude of the ground motions. The rationale for using PGV, rather than exceedance frequency, is explained further in Section 6.1.3. For the reader's convenience, the following list identifies the correspondence between PGV and the values of annual exceedance frequency in the sources for Table 4-1:

- $\mathrm{PGV}$ of $0.19 \mathrm{~m} / \mathrm{s}$ corresponds to the $5 \times 10^{-4}$ per year exceedance frequency in the sources in Table 4-1.

- PGV of $0.384 \mathrm{~m} / \mathrm{s}$ corresponds to the $10^{-4}$ per year exceedance frequency in the sources in Table 4-1.3.

- PGV of $1.05 \mathrm{~m} / \mathrm{s}$ corresponds to the $10^{-5}$ per year exceedance frequency in the sources in Table 4-1.

\footnotetext{
${ }^{2}$ Effective transport area is defined as the ratio of the crack area to the "damaged area". The area of material that exceeds the residual stress threshold for accelerated stress corrosion cracking is referred to as the "damaged area" throughout this report. The basis for this damage mechanism is explained in Section 6.3.1.

This single ground motion was developed for design purposes and matches the target design spectrum. The PGV value of $0.384 \mathrm{~m} / \mathrm{s}$ differs slightly from the PGV value on the hazard curve at Point B for an annual exceedance frequency of $10^{-4}$ per year, which is $0.4019 \mathrm{~m} / \mathrm{s}$.
} 
- PGV of $2.44 \mathrm{~m} / \mathrm{s}$ corresponds to the $10^{-6}$ per year exceedance frequency in the sources in Table 4-1.

- PGV of $5.35 \mathrm{~m} / \mathrm{s}$ corresponds to the $10^{-7}$ per year exceedance frequency in the sources in Table 4-1.

These PGV values are based on the unbounded PGV hazard curve at the emplacement drifts, which was the only PGV hazard curve available when many of the sources in Table 4-1 were completed. This original hazard curve is unbounded in the sense that PGV continues to increase with decreasing values of the exceedance frequency. A second hazard curve was subsequently developed that incorporates limits for the maximum shear strain in the lithophysal rock, as discussed in Section 6.4.3. The maximum shear strain can be related to the in situ response by using the site response model, resulting in a bounded hazard curve for PGV at the repository horizon (DTN: MO0501BPVELEMP.001 [DIRS 172682]). The differences between the PGV values on the unbounded and bounded hazard curves are illustrated in Figure 6.4-2 in Section 6.4.3. The difference in the hazard curves illustrates the rationale for identifying ground motion level by PGV, which is uniquely associated with each ground motion, rather than by the annual exceedance frequency that can change with the hazard curve.

Section 8.2 identifies the uncertainties in input information and parameters for the damage analyses of EBS components and explains how these uncertainties are propagated into the abstractions for the seismic scenario class.

Table 4-1. Direct Input Information for Seismic Consequence Abstractions

\begin{tabular}{|c|c|c|}
\hline Input Information & Value & Source \\
\hline \multicolumn{3}{|l|}{ Seismic Failure Criterion: } \\
\hline $\begin{array}{l}\text { Residual stress threshold for initiation of stress } \\
\text { corrosion cracking on a smooth surface of Alloy } 22\end{array}$ & $\begin{array}{l}90 \text { percent of the } \\
\text { yield strength of } \\
\text { Alloy } 22\end{array}$ & $\begin{array}{l}\text { BSC } 2004 \text { [DIRS 172203], } \\
\text { Section } 6.2 .1 \text {, 2nd paragraph on } \\
\text { page } 6-7\end{array}$ \\
\hline \multicolumn{3}{|c|}{ Effective Transport Area for a Network of Stress Corrosion Cracks: } \\
\hline $\begin{array}{l}\text { Ratio of crack area to damaged area) for a densely } \\
\text { packed network of stress corrosion cracks in Alloy } 22 \\
\text { at room temperature }\end{array}$ & $\begin{array}{l}0.00328 \text { to } \\
0.0131\end{array}$ & $\begin{array}{l}\text { DTN: MO0403SPASCRKD.000 } \\
\text { [DIRS 168105]; see values under } \\
\text { Crack Area Density at room } \\
\text { temperature }\end{array}$ \\
\hline \multicolumn{3}{|c|}{ Damage to the Waste Package from Vibratory Ground Motion: } \\
\hline $\begin{array}{l}\text { Damage statistics for waste package-pallet impacts, } \\
\text { based on a sampling of vibratory ground motions at the } \\
2.44 \mathrm{~m} / \mathrm{s}\left(10^{-6} \text { per year exceedance frequency) PGV }\right. \\
\text { level }\end{array}$ & $\begin{array}{l}\text { See Table } 1 \\
\text { in source; } \\
\text { numerical values } \\
\text { identified in } \\
\text { Table } 6.5-9\end{array}$ & BSC 2005 [DIRS 173500], Table 1 \\
\hline $\begin{array}{l}\text { Damage statistics for waste package-pallet impacts, } \\
\text { based on a sampling of vibratory ground motions at the } \\
5.35 \mathrm{~m} / \mathrm{s}\left(10^{-7} \text { per year exceedance frequency) PGV }\right. \\
\text { level }\end{array}$ & $\begin{array}{l}\text { See Table } 2 \\
\text { in first source; } \\
\text { see BSC } 2004 \\
\text { [DIRS 171717] } \\
\text { for Realization } \\
11 ; \text { numerical } \\
\text { values identified } \\
\text { in Table } 6.5-9\end{array}$ & $\begin{array}{l}\text { BSC } 2005 \text { [DIRS 173500], Table 2; } \\
\text { BSC } 2004 \text { [DIRS 171717], } \\
\text { Table 6.1-4 for Realization } 11\end{array}$ \\
\hline
\end{tabular}


Table 4-1. Direct Input Information for Seismic Consequence Abstractions (Continued)

\begin{tabular}{|c|c|c|}
\hline Input Information & Value & Source \\
\hline \multicolumn{3}{|c|}{ Damage to the Waste Package from Vibratory Ground Motion (Continued): } \\
\hline $\begin{array}{l}\text { Damage statistics for waste package-pallet impacts, } \\
\text { based on supplemental calculations for vibratory } \\
\text { ground motions at the } 5.35 \mathrm{~m} / \mathrm{s}, 2.44 \mathrm{~m} / \mathrm{s} \text {, and } \\
1.05 \mathrm{~m} / \mathrm{s} \text { PGV levels }\end{array}$ & $\begin{array}{l}\text { See Table } 6.1-4 \\
\text { in source for data } \\
\text { at } 5.35 \mathrm{~m} / \mathrm{s} \text {; } \\
\text { See Table } 6.2-7 \\
\text { in source for data } \\
\text { at } 2.44 \mathrm{~m} / \mathrm{s} \text {; } \\
\text { See Table } 6.3-6 \\
\text { in source for data } \\
\text { at } 1.05 \mathrm{~m} / \mathrm{s} \text {; } \\
\text { numerical values } \\
\text { identified in } \\
\text { Table } 6.5-9 \text { of } \\
\text { this report }\end{array}$ & $\begin{array}{l}\text { BSC } 2004 \text { [DIRS 171717], } \\
\text { Tables 6.1-4, 6.2-7, and 6.3-6 }\end{array}$ \\
\hline $\begin{array}{l}\text { Surface area of the } 21-P W R \text { waste package design for } \\
\text { the single waste package calculations }\end{array}$ & $28.2 \mathrm{~m}^{2}$ & $\begin{array}{l}\text { BSC } 2004 \text { [DIRS 167083], } \\
\text { Section } 6.1 .1\end{array}$ \\
\hline $\begin{array}{l}\text { Catalog of damaged areas from end-on impacts of a } \\
\text { waste package on an elastic surface with a residual } \\
\text { stress threshold of } 80 \text { percent of the yield strength of } \\
\text { Alloy } 22\end{array}$ & $\begin{array}{l}\text { See Table } 2 \text { in } \\
\text { source; numerical } \\
\text { values identified } \\
\text { in Table } 6.5-3 \text { of } \\
\text { this report }\end{array}$ & BSC 2005 [DIRS 173178], Table 2 \\
\hline $\begin{array}{l}\text { Catalog of damaged areas from end-on impacts of a } \\
\text { waste package on an elastic surface with a residual } \\
\text { stress threshold of } 90 \text { percent of the yield strength of } \\
\text { Alloy } 22\end{array}$ & $\begin{array}{l}\text { See Table } 3 \text { in } \\
\text { source; numerical } \\
\text { values identified } \\
\text { in Table } 6.5-3 \text { of } \\
\text { this report }\end{array}$ & BSC 2005 [DIRS 173178], Table 3 \\
\hline $\begin{array}{l}\text { Kinematic parameters from UDEC calculations of } \\
\text { end-to-end impacts of multiple waste packages in } \\
\text { response to ground motions at the } 1.05 \mathrm{~m} / \mathrm{s}, 2.44 \mathrm{~m} / \mathrm{s} \text {, } \\
\text { and } 5.35 \mathrm{~m} / \mathrm{s} \text { PGV levels }\end{array}$ & $\begin{array}{l}\text { See files in DTN; } \\
\text { numerical values } \\
\text { are documented } \\
\text { in the Excel files } \\
\text { identified in } \\
\text { Table A-3 and } \\
\text { provided } \\
\text { electronically in } \\
\text { Appendix G of } \\
\text { this report }\end{array}$ & $\begin{array}{l}\text { DTN: MO0503SPAUDECW.000 } \\
\text { [DIRS 173337] }\end{array}$ \\
\hline $\begin{array}{l}\text { Kinematic parameters from LS-DYNA calculations of } \\
\text { end-to-end impacts of multiple waste packages in } \\
\text { response to ground motions at the } 1.05 \mathrm{~m} / \mathrm{s}, 2.44 \mathrm{~m} / \mathrm{s} \text {, } \\
\text { and } 5.35 \mathrm{~m} / \mathrm{s} \text { PGV levels }\end{array}$ & $\begin{array}{l}\text { See files in DTN; } \\
\text { numerical values } \\
\text { are documented } \\
\text { in the Excel files } \\
\text { identified in } \\
\text { Table A-3 and } \\
\text { provided } \\
\text { electronically in } \\
\text { Appendix G of } \\
\text { this report }\end{array}$ & $\begin{array}{l}\text { DTN: MO0504SPALSDYN.000 } \\
\text { [DIRS 173338] }\end{array}$ \\
\hline $\begin{array}{l}\text { PGV for the second horizontal ground motion } \\
\text { component (PGV-Longitudinal) when the first } \\
\text { horizontal component is scaled to } 1.05 \mathrm{~m} / \mathrm{s}\end{array}$ & $\begin{array}{l}\text { See Table X-2 in } \\
\text { source; numerical } \\
\text { values identified } \\
\text { in Table } 6.5-9 \text { of } \\
\text { this report }\end{array}$ & $\begin{array}{l}\text { BSC } 2004 \text { [DIRS 166107], } \\
\text { Appendix X, Table X-2 }\end{array}$ \\
\hline
\end{tabular}


Table 4-1. Direct Input Information for Seismic Consequence Abstractions (Continued)

\begin{tabular}{|c|c|c|}
\hline Input Information & Value & Source \\
\hline $\begin{array}{l}\text { PGV for the second horizontal ground motion } \\
\text { component (PGV-Longitudinal) when the first } \\
\text { horizontal component is scaled to } 2.44 \mathrm{~m} / \mathrm{s}\end{array}$ & $\begin{array}{l}\text { See Table X-3 in } \\
\text { source for the } \\
\text { revised set of } \\
\text { ground motions; } \\
\text { See Table X-4 in } \\
\text { source for the } \\
\text { original set of } \\
\text { ground motions; } \\
\text { numerical values } \\
\text { identified in } \\
\text { Table } 6.5-9 \text { of } \\
\text { this report }\end{array}$ & $\begin{array}{l}\text { BSC } 2004 \text { [DIRS 166107], } \\
\text { Appendix X, Tables X-3 and X-4 }\end{array}$ \\
\hline $\begin{array}{l}\text { PGV for the second horizontal ground motion } \\
\text { component (PGV-Longitudinal) when the first } \\
\text { horizontal component is scaled to } 5.35 \mathrm{~m} / \mathrm{s}\end{array}$ & $\begin{array}{l}\text { See Table X-5 in } \\
\text { source; numerical } \\
\text { values identified } \\
\text { in Table } 6.5-9 \text { of } \\
\text { this report }\end{array}$ & $\begin{array}{l}\text { BSC } 2004 \text { DIRS 166107], } \\
\text { Appendix X, Table X-5 }\end{array}$ \\
\hline $\begin{array}{l}\text { Damaged areas from end-on and side-on impacts of } \\
\text { the waste package for impact velocities between } 1 \text { and } \\
10 \mathrm{~m} / \mathrm{s} \text { and impact angles of } 1^{\circ} \text { and } 8^{\circ} \text { for a residual } \\
\text { stress threshold of } 80 \% \text { of the Alloy } 22 \text { yield strength }\end{array}$ & $\begin{array}{l}\text { Numerical values } \\
\text { are identified in } \\
\text { Table } 6.5-12 \text { of } \\
\text { this report }\end{array}$ & BSC 2003 [DIRS 162293], Table 4 \\
\hline $\begin{array}{l}\text { Number of lateral impacts and maximum lateral impact } \\
\text { velocities between waste package and drip shield, } \\
\text { based on a sampling of vibratory ground motions at the } \\
2.44 \mathrm{~m} / \mathrm{s} \text { PGV level. }\end{array}$ & $\begin{array}{l}\text { Numerical values } \\
\text { are identified in } \\
\text { Table } 6.5-13 \text { of } \\
\text { this report }\end{array}$ & $\begin{array}{l}\text { BSC } 2004 \text { [DIRS } 167083] \\
\text { Tables } 6.1 .3-1 \text { to } 6.1 .3-5\end{array}$ \\
\hline $\begin{array}{l}\text { Maximum lateral impact velocities between the waste } \\
\text { package and drip shield, based on two-dimensional } \\
\text { cross-drift calculations for a waste package and drip } \\
\text { shield in a rubble-filled drift, based on a sampling of } \\
\text { vibratory ground motions at the } 2.44 \mathrm{~m} / \mathrm{s} \text { PGV level } \\
\text { ground motions }\end{array}$ & $\begin{array}{l}\text { Numerical values } \\
\text { are identified in } \\
\text { Table } 6.5-14 \text { of } \\
\text { this report }\end{array}$ & $\begin{array}{l}\text { BSC } 2005 \text { [DIRS 173172], } \\
\text { Attachment V, Table V-5 }\end{array}$ \\
\hline \multicolumn{3}{|c|}{ Damage to the Fuel Rod Cladding from Vibratory Ground Motion: } \\
\hline $\begin{array}{l}\text { Maximum peak acceleration of fuel assemblies due to } \\
\text { waste package-to-waste package impacts. }\end{array}$ & $\begin{array}{l}\text { See Table } 3 \\
\text { in source; } \\
\text { numerical values } \\
\text { are identified in } \\
\text { Table } 6.5-15 \text { of } \\
\text { this report }\end{array}$ & BSC 2005 [DIRS 173500], Table 3 \\
\hline $\begin{array}{l}\text { Average peak acceleration of fuel assemblies due to } \\
\text { waste package-to-waste package impacts. }\end{array}$ & $\begin{array}{l}\text { See Table } 4 \\
\text { in source; } \\
\text { numerical values } \\
\text { are identified in } \\
\text { Table } 6.5-15 \text { of } \\
\text { this report }\end{array}$ & BSC 2005 [DIRS 173500], Table 4 \\
\hline $\begin{array}{l}\text { Number of impacts and statistics for maximum axial } \\
\text { impact velocities between adjacent waste packages, } \\
\text { based on a sampling of vibratory ground motions at the } \\
2.44 \mathrm{~m} / \mathrm{s} \text { ( } 10^{-6} \text { per year exceedance frequency) PGV } \\
\text { level. }\end{array}$ & $\begin{array}{l}\text { Maximum impact } \\
\text { velocities vary } \\
\text { between } 1.4 \mathrm{~m} / \mathrm{s} \\
\text { and } 4.5 \mathrm{~m} / \mathrm{s}\end{array}$ & $\begin{array}{l}\text { BSC } 2004 \text { [DIRS } 167083] \\
\text { Tables } 6.1 .2-1 \text { to } 6.1 .2-15\end{array}$ \\
\hline $\begin{array}{l}\text { Statistics for maximum axial impact velocities between } \\
\text { adjacent waste packages, based on a sampling of } \\
\text { vibratory ground motions at the } 5.35 \mathrm{~m} / \mathrm{s}\left(10^{-7} \text { per year }\right. \\
\text { exceedance frequency) PGV level. }\end{array}$ & $\begin{array}{l}\text { Maximum impact } \\
\text { velocities vary } \\
\text { between } 1.3 \mathrm{~m} / \mathrm{s} \\
\text { and } 6.5 \mathrm{~m} / \mathrm{s}\end{array}$ & $\begin{array}{l}\text { BSC } 2004 \text { [DIRS } 167083 \text { ], } \\
\text { Tables } 6.2 .2-1 \text { to } 6.2 .2-15\end{array}$ \\
\hline
\end{tabular}


Table 4-1. Direct Input Information for Seismic Consequence Abstractions (Continued)

\begin{tabular}{|c|c|c|}
\hline Input Information & Value & Source \\
\hline $\begin{array}{l}\text { Axial impact velocity between adjacent waste } \\
\text { packages for the single vibratory ground motion at the } \\
0.190 \mathrm{~m} / \mathrm{s}\left(5 \times 10^{-4} \text { per year exceedance frequency) }\right. \\
\text { PGV level. }\end{array}$ & $\begin{array}{l}\text { Relative } \\
\text { displacement of } \\
\text { waste package } \\
\text { and pallet nodes } \\
\text { is less than } \\
\pm 0.01 \mathrm{~mm} \\
\end{array}$ & $\begin{array}{l}\text { BSC } 2004 \text { [DIRS 167083], } \\
\text { Figures } 10 \text { and } 11\end{array}$ \\
\hline $\begin{array}{l}\text { Axial impact velocity between adjacent waste } \\
\text { packages for the single vibratory ground motion at the } \\
0.384 \mathrm{~m} / \mathrm{s}\left(1 \times 10^{-4} \text { per year exceedance frequency) }\right. \\
\text { PGV level. }\end{array}$ & $\begin{array}{l}\text { Relative } \\
\text { displacement of } \\
\text { waste package } \\
\text { and pallet nodes } \\
\text { is less than } \\
\pm 0.07 \mathrm{~mm}\end{array}$ & $\begin{array}{l}\text { BSC } 2004 \text { [DIRS 167083], } \\
\text { Figures } 20 \text { and } 21\end{array}$ \\
\hline \multicolumn{3}{|c|}{ Damage to the Drip Shield from Rockfall and from Vibratory Ground Motion: } \\
\hline $\begin{array}{l}\text { Damage to the drip shield due to impact by single rock } \\
\text { blocks from the } 2.44 \mathrm{~m} / \mathrm{s}\left(10^{-6} \text { per year exceedance }\right. \\
\text { frequency) PGV level. }\end{array}$ & $\begin{array}{l}\text { See Table } 2 \text { in } \\
\text { source; numerical } \\
\text { values are } \\
\text { identified in } \\
\text { Table } 6.6-2 \text { of } \\
\text { this report }\end{array}$ & BSC 2005 [DIRS 173303], Table 2 \\
\hline $\begin{array}{l}\text { Damage to the drip shield due to impact by maximum } \\
\text { rock block from the } 5.35 \mathrm{~m} / \mathrm{s}\left(10^{-7} \text { per year }\right. \\
\text { exceedance frequency) PGV level. }\end{array}$ & $\begin{array}{l}\text { See Table } 3 \text { in } \\
\text { source; numerical } \\
\text { values are } \\
\text { identified in } \\
\text { Table } 6.6-2 \text { of } \\
\text { this report }\end{array}$ & BSC 2005 [DIRS 173303], Table 3 \\
\hline $\begin{array}{l}\text { Maximum dynamic displacement in the longitudinal } \\
\text { stiffener during vertical impact of the } 11.5 \text { metric ton } \\
\text { rock block }\end{array}$ & $\begin{array}{l}25.4 \mathrm{~cm} \text {; drip } \\
\text { shield does not } \\
\text { buckle }\end{array}$ & $\begin{array}{l}\text { BSC } 2004 \text { [DIRS 168993] } \\
\text { Figure II-5 and Section } 6\end{array}$ \\
\hline $\begin{array}{l}\text { Maximum permanent deflection for edge-on and } \\
\text { corner-on rock block impacts }\end{array}$ & $\begin{array}{l}0.114 \mathrm{~m} \\
\text { (edge-on) and } \\
0.129 \mathrm{~m} \\
\text { (corner-on) }\end{array}$ & $\begin{array}{l}\text { BSC } 2005 \text { [DIRS 174052], } \\
\text { Tables } 7-5 \text { and } 7-6\end{array}$ \\
\hline Drip shield configuration after rock block impact & $\begin{array}{l}\text { Drip shield does } \\
\text { not buckle or } \\
\text { collapse }\end{array}$ & $\begin{array}{l}\text { BSC } 2005 \text { [DIRS } 174052] \\
\text { Figures } 7-14 \text { through } 7-20\end{array}$ \\
\hline $\begin{array}{l}\text { Damage to the drip shield for the single vibratory } \\
\text { ground motion at the } 0.190 \mathrm{~m} / \mathrm{s}\left(5 \times 10^{-4} \text { per year }\right. \\
\text { exceedance frequency) PGV level. }\end{array}$ & No damage & $\begin{array}{l}\text { BSC } 2005 \text { [DIRS 173303], } \\
\text { Calculation Results I }\end{array}$ \\
\hline $\begin{array}{l}\text { Damage statistics for the area of the drip shield } \\
\text { exceeding the residual stress threshold at the } 2.44 \mathrm{~m} / \mathrm{s} \\
\left(10^{-6} \text { per year exceedance frequency) PGV level. }\right.\end{array}$ & $\begin{array}{l}\text { Mean percent } \\
\text { damaged area is } \\
0.70 \text { percent and } \\
\text { the maximum } \\
\text { percent damaged } \\
\text { area is } \\
2.13 \text { percent; } \\
\text { there is no } \\
\text { separation of drip } \\
\text { shields }\end{array}$ & BSC 2005 [DIRS 173303], Table 4 \\
\hline $\begin{array}{l}\text { Damage statistics for the drip shield in an unfilled drift, } \\
\text { based on a sampling of vibratory ground motions at the } \\
5.35 \mathrm{~m} / \mathrm{s}\left(10^{-7} \text { per year exceedance frequency) PGV }\right. \\
\text { level. }\end{array}$ & $\begin{array}{l}\text { Drip shields } \\
\text { separate for the } \\
\text { analyzed ground } \\
\text { motions }\end{array}$ & $\begin{array}{l}\text { BSC } 2005 \text { [DIRS 173303], } \\
\text { Calculation Results III }\end{array}$ \\
\hline
\end{tabular}


Table 4-1. Direct Input Information for Seismic Consequence Abstractions (Continued)

\begin{tabular}{|c|c|c|}
\hline Input Information & Value & Source \\
\hline $\begin{array}{l}\text { Kinematic studies of drip shield motion for an open drift } \\
\text { and for a drift partly and completely filled with rockfall }\end{array}$ & $\begin{array}{l}\text { Drip shields do } \\
\text { not separate for } \\
\text { an open drift. } \\
\text { Frictional forces } \\
\text { from small } \\
\text { amount of rockfall } \\
\text { stabilize drip } \\
\text { shield motion and } \\
\text { prevent } \\
\text { separation. }\end{array}$ & $\begin{array}{l}\text { BSC } 2004 \text { [DIRS 169753], } \\
\text { Section } 5.3\end{array}$ \\
\hline \multicolumn{3}{|c|}{ Damage to the Waste Package, Drip Shield and Fuel Rod Cladding from Fault Displacement: } \\
\hline Emplacement Drift Diameter & $5.5 \mathrm{~m}$ & BSC 2005 [DIRS 173498], Figure 1 \\
\hline $\begin{array}{l}\text { Height of Steel Invert Structure (maximum thickness of } \\
\text { invert) }\end{array}$ & $863.6 \mathrm{~mm}$ & $\begin{array}{l}\text { BSC } 2004 \text { [DIRS 170074], drawing } \\
\text { for 21-PWR package }\end{array}$ \\
\hline Drip Shield Nominal Height - Exterior & $2,885.62 \mathrm{~mm}$ & BSC 2005 [DIRS 173303], Table 1 \\
\hline Drip Shield Height - Interior & $2,716 \mathrm{~mm}$ & BSC 2004 [DIRS 168489], Figure 1 \\
\hline $\begin{array}{l}\text { Outside Diameter of 44-BWR Waste Package Outer } \\
\text { Barrier }\end{array}$ & $1,675.1 \mathrm{~mm}$ & $\begin{array}{l}\text { BSC } 2005 \text { [DIRS 173501], Table 1, } \\
\text { to drawing } \\
\text { 000-MW0-DSU0-00502-000-00A } \\
\text { with source data }\end{array}$ \\
\hline $\begin{array}{l}\text { Outside Diameter of 24-BWR Waste Package Outer } \\
\text { Barrier }\end{array}$ & $1,294.1 \mathrm{~mm}$ & $\begin{array}{l}\text { BSC } 2005 \text { [DIRS 173501], Table 1, } \\
\text { to drawing } \\
\text { 000-MW0-DSU0-00602-000-00A } \\
\text { with source data }\end{array}$ \\
\hline $\begin{array}{l}\text { Outside Diameter of 21-PWR Waste Package Outer } \\
\text { Barrier }\end{array}$ & $1,637 \mathrm{~mm}$ & $\begin{array}{l}\text { BSC } 2005 \text { [DIRS 173501], Table 1, } \\
\text { to drawing } \\
\text { 000-MW0-DSU0-00402-000-00B } \\
\text { with source data }\end{array}$ \\
\hline $\begin{array}{l}\text { Outside Diameter of 12-PWR Waste Package Outer } \\
\text { Barrier }\end{array}$ & $1,313.2 \mathrm{~mm}$ & $\begin{array}{l}\text { BSC } 2005 \text { [DIRS 173501], Table 1, } \\
\text { to drawing } \\
\text { 000-MW0-DSU0-00302-000-00A } \\
\text { with source data }\end{array}$ \\
\hline $\begin{array}{l}\text { Outside Diameter of Naval-Long Waste Package Outer } \\
\text { Barrier }\end{array}$ & $1,863.7 \mathrm{~mm}$ & $\begin{array}{l}\text { BSC } 2005 \text { [DIRS 173501], Table 1, } \\
\text { to drawing } \\
\text { 000-MW0-DNF0-00102-000-00A } \\
\text { with source data }\end{array}$ \\
\hline $\begin{array}{l}\text { Outside Diameter of Naval-Short Waste Package } \\
\text { Outer Barrier }\end{array}$ & $1,863.7 \mathrm{~mm}$ & $\begin{array}{l}\text { BSC } 2005 \text { [DIRS 173501], Table 1, } \\
\text { to drawing } \\
\text { 000-MW0-DNF0-00202-000-00A } \\
\text { with source data }\end{array}$ \\
\hline $\begin{array}{l}\text { Outside Diameter of 5-DHLW/DOE Spent Nuclear } \\
\text { Fuel-Short Waste Package Outer Barrier }\end{array}$ & $2,044.7 \mathrm{~mm}$ & $\begin{array}{l}\text { BSC } 2005 \text { [DIRS 173501], Table 1, } \\
\text { to drawing } \\
\text { 000-MW0-DS00-00102-000-00A } \\
\text { with source data }\end{array}$ \\
\hline $\begin{array}{l}\text { Outside Diameter of 5-DHLW/DOE Spent Nuclear } \\
\text { Fuel-Long Waste Package Outer Barrier }\end{array}$ & $2,044.7 \mathrm{~mm}$ & $\begin{array}{l}\text { BSC } 2005 \text { [DIRS 173501], Table 1, } \\
\text { to drawing } \\
\text { 000-MW0-DS00-00202-000-00A } \\
\text { with source data }\end{array}$ \\
\hline $\begin{array}{l}\text { Outside Diameter of 2-multicanister overpack } \\
\text { (MCO)/2-DHLW Waste Package Outer Barrier }\end{array}$ & $1,749.4 \mathrm{~mm}$ & $\begin{array}{l}\text { BSC } 2005 \text { [DIRS 173501], Table 1, } \\
\text { to drawing } \\
\text { 000-MW0-DS00-00302-000-00A } \\
\text { with source data }\end{array}$ \\
\hline
\end{tabular}


Table 4-1. Direct Input Information for Seismic Consequence Abstractions (Continued)

\begin{tabular}{|c|c|c|}
\hline Input Information & Value & Source \\
\hline 44-BWR Waste Package Nominal Length & $5,024.4 \mathrm{~mm}$ & BSC 2005 [DIRS 173501], Table 1 \\
\hline 24-BWR Waste Package Nominal Length & $5,024.4^{4} \mathrm{~mm}$ & BSC 2005 [DIRS 173501], Table 1 \\
\hline 21-PWR Waste Package Nominal Length & $5,024.4 \mathrm{~mm}$ & BSC 2005 [DIRS 173501], Table 1 \\
\hline 12-PWR Waste Package Nominal Length & $5,560.4 \mathrm{~mm}$ & BSC 2005 [DIRS 173501], Table 1 \\
\hline Naval-Long Waste Package Nominal Length & $5,837.4 \mathrm{~mm}$ & BSC 2005 [DIRS 173501], Table 1 \\
\hline Naval-Short Waste Package Nominal Length & $5,202.2 \mathrm{~mm}$ & BSC 2005 [DIRS 173501], Table 1 \\
\hline $\begin{array}{l}\text { 5-DHLW/ DOE Spent Nuclear Fuel-Short Waste } \\
\text { Package Nominal Length }\end{array}$ & $3,452.8 \mathrm{~mm}$ & BSC 2005 [DIRS 173501], Table 1 \\
\hline $\begin{array}{l}\text { 5-DHLW/DOE Spent Nuclear Fuel-Long Waste } \\
\text { Package Nominal Length }\end{array}$ & $5,059.4 \mathrm{~mm}$ & BSC 2005 [DIRS 173501], Table 1 \\
\hline 2-MCO/2-DHLW Waste Package Nominal Length & $5,059.4 \mathrm{~mm}$ & BSC 2005 [DIRS 173501], Table 1 \\
\hline $\begin{array}{l}\text { Clearance between Top of 21-PWR Waste Package } \\
\text { and Underside of Drip Shield Peripheral Bulkhead }\end{array}$ & $806.2 \mathrm{~mm}$ & $\begin{array}{l}\text { BSC } 2004 \text { [DIRS 170074], drawing } \\
\text { for 21-PWR package }\end{array}$ \\
\hline $\begin{array}{l}\text { Clearance between Top of 12-PWR Waste Package } \\
\text { and Underside of Drip Shield Peripheral Bulkhead }\end{array}$ & $1,132.1 \mathrm{~mm}$ & $\begin{array}{l}\text { BSC } 2004 \text { [DIRS 170074], drawing } \\
\text { for 12-PWR package }\end{array}$ \\
\hline $\begin{array}{l}\text { Clearance between Top of 44-BWR Waste Package } \\
\text { and Underside of Drip Shield Peripheral Bulkhead }\end{array}$ & $765.2 \mathrm{~mm}$ & $\begin{array}{l}\text { BSC } 2004 \text { [DIRS 170074], drawing } \\
\text { for 44-BWR package }\end{array}$ \\
\hline $\begin{array}{l}\text { Clearance between Top of Naval Waste Package and } \\
\text { Underside of Drip Shield Peripheral Bulkhead }\end{array}$ & $562.1 \mathrm{~mm}$ & $\begin{array}{l}\text { BSC } 2004 \text { [DIRS 170074], drawing } \\
\text { for Naval package }\end{array}$ \\
\hline $\begin{array}{l}\text { Clearance between Top of 5-DHLW/DOE Waste } \\
\text { Package and Underside of Drip Shield Peripheral } \\
\text { Bulkhead }\end{array}$ & $367.1 \mathrm{~mm}$ & $\begin{array}{l}\text { BSC } 2004 \text { [DIRS 170074], drawing } \\
\text { for 5-DHLW/DOE package }\end{array}$ \\
\hline $\begin{array}{l}\text { Emplacement Drift Numbers and Rock Type } \\
\text { Intersected by the Sundance fault } \\
\text { (Rock type or types identified in parentheses) }\end{array}$ & $\begin{array}{l}\text { 1-6 (Tptpll) } \\
1-7 \\
\text { (Tptpll/Tptpmn) } \\
\text { 1-8 (Tptpmn) } \\
\text { 2-1 (Tptpmn) } \\
\end{array}$ & $\begin{array}{l}\text { DTN: MO0012MWDGFM02.002 } \\
\text { [DIRS 153777], } \\
\text { File in Earthvision: Horizon } \\
\text { from/usr6/restored/ism4/Faults/f00 } \\
\text { Sundance.2grd }\end{array}$ \\
\hline $\begin{array}{l}\text { Emplacement Drift Numbers and Rock Type } \\
\text { Intersected by the Drill Hole Wash fault } \\
\text { (Rock type or types identified in parentheses) }\end{array}$ & $\begin{array}{l}\text { 4-1 (Tptpll) } \\
\text { 4-2 (Tptpll) } \\
\text { 3-4 W (Tptpll) } \\
\text { 3-5 W (Tptpll) } \\
\text { 3-6 W (Tptpll) } \\
\text { 3-7 W (Tptpll) } \\
\text { 3-8 W (Tptpll) } \\
\text { 3-9 W (Tptpll) } \\
\text { 3-10 E (Tptpmn) } \\
\text { 3-11 E (Tptpmn) } \\
\text { 3-12 E (Tptpmn) } \\
\text { 3-13 E (RHHtop/ } \\
\text { Tptpmn) } \\
\text { 3-14 E (RHHtop) } \\
\text { 3-15 E (RHHtop) } \\
\text { 3-16 E (RHHtop) } \\
\text { 3-17 E (RHHtop) }\end{array}$ & $\begin{array}{l}\text { BSC } 2004 \text { [DIRS 168180], Table } 9 \\
\text { for drift numbers; } \\
\text { DTN: MO0012MWDGFM02.002 } \\
\text { [DIRS 153777], for rock type; } \\
\text { RHHtop is the lowermost portion of } \\
\text { the Tptpul. } \\
\text { File in Earthvision: Horizon } \\
\text { from/usr6/restored/ism4/Faults/f00 } \\
\text { drill.2grd }\end{array}$ \\
\hline
\end{tabular}

4 Table 1 of IED Waste Package Configuration [Sheet 1 of 1] (BSC 2005 [DIRS 173501]) has 5,024.5 mm as the length of the 24-BWR waste package. This appears to be a conversion error, because 197.81 -in $=5,024.4 \mathrm{~mm}$, not 5,024.5 $\mathrm{mm}$ as stated in Table 1 of the reference. The corrected value is listed in Table 4-1. 
Table 4-1. Direct Input Information for Seismic Consequence Abstractions (Continued)

\begin{tabular}{|c|c|c|}
\hline Input Information & Value & Source \\
\hline $\begin{array}{l}\text { Emplacement Drift Numbers and Rock Type } \\
\text { Intersected by the Pagany Wash Fault } \\
\text { (Rock type or types identified in parentheses) }\end{array}$ & $\begin{array}{l}\text { 3-1 W (Tptpll) } \\
\text { 3-1 E (Tptpll) } \\
\text { 3-2 E (Tptpll) } \\
\text { 3-3 E (Tptpll) } \\
\text { 3-4 E (Tptpll) } \\
\text { 3-5 E (Tptpmn) } \\
\text { 3-6 E (Tptpmn) } \\
\text { 3-7 E (Tptpmn) }\end{array}$ & $\begin{array}{l}\text { BSC } 2004 \text { [DIRS 168180], Table } 9 \\
\text { for drift numbers; } \\
\text { DTN: MO0012MWDGFM02.002 } \\
\text { [DIRS 153777], for rock type; } \\
\text { File in Earthvision: Horizon } \\
\text { from/usr6/restored/ism4/Faults/fO0 } \\
\text { pagany.2grd }\end{array}$ \\
\hline $\begin{array}{l}\text { Emplacement Drift Numbers and Rock Type } \\
\text { Intersected by the Sever Wash Fault } \\
\text { (Rock type or types identified in parentheses) }\end{array}$ & $\begin{array}{l}\text { 3-2 E (Tptpll) } \\
\text { 3-3 E (Tptpll) }\end{array}$ & $\begin{array}{l}\text { BSC } 2004 \text { [DIRS 168180], Table } 9 \\
\text { for drift numbers; } \\
\text { DTN: MO0012MWDGFM02.002 } \\
\text { [DIRS 153777], for rock strata; } \\
\text { File in Earthvision: Horizon } \\
\text { from/usr6/restored/ism4/Faults/f00 } \\
\text { sever.2grd }\end{array}$ \\
\hline $\begin{array}{l}\text { Emplacement Drift Numbers Intersected by the } \\
\text { western splay off the main Ghost Dance Fault }\end{array}$ & $\begin{array}{l}2-17,2-18,2-19 \\
2-20,2-21,2-22 \\
2-23,2-24,2-25 \\
2-26, \text { and } 2-27\end{array}$ & BSC 2004 [DIRS 168180], Table 9 \\
\hline $\begin{array}{l}\text { Fault Displacement Hazard at Site } 3 \text { on the Drill Hole } \\
\text { Wash Fault }\end{array}$ & $\begin{array}{l}\text { See the Excel file } \\
\text { Appendix E } \\
\text { Rev02.xIs, } \\
\text { worksheet } \\
\text { "Table } 6.7-5 \\
\text { Calculations" in } \\
\text { Appendix G for } \\
\text { the mean hazard } \\
\text { curve data at } \\
\text { Site } 3\end{array}$ & $\begin{array}{l}\text { DTN: MO0401MWDRPSHA.000 } \\
\text { [DIRS 166962], file: } \\
\text {./displ/tot_haz/s3.frac_mean.gz }\end{array}$ \\
\hline $\begin{array}{l}\text { Fault Displacement Hazard at Site } 5 \text { on the Sundance } \\
\text { Fault }\end{array}$ & $\begin{array}{l}\text { See the Excel file } \\
\text { Appendix E } \\
\text { Rev02.xIs, } \\
\text { worksheet } \\
\text { "Table } 6.7-5 \\
\text { Calculations" in } \\
\text { Appendix G for } \\
\text { the mean hazard } \\
\text { curve data at } \\
\text { Site } 5\end{array}$ & $\begin{array}{l}\text { DTN: MO0401MWDRPSHA.000 } \\
\text { [DIRS 166962], file: } \\
\text {./displ/tot_haz/s5.frac_mean.gz }\end{array}$ \\
\hline $\begin{array}{l}\text { Fault Displacement Hazard at Site } 7 \mathrm{a} \text {, a generic } \\
\text { repository location, approximately } 100 \mathrm{~m} \text { east of the } \\
\text { Solitario Canyon Fault, with a hypothetical small fault } \\
\text { with } 2-\mathrm{m} \text { offset }\end{array}$ & $\begin{array}{l}\text { See the Excel file } \\
\text { Appendix E } \\
\text { Rev02.xIs, } \\
\text { worksheet } \\
\text { "Table } 6.7-5 \\
\text { Calculations" in } \\
\text { Appendix G for } \\
\text { the mean hazard } \\
\text { curve data at } \\
\text { Site } 7 a\end{array}$ & $\begin{array}{l}\text { DTN: MO0401MWDRPSHA.000 } \\
\text { [DIRS 166962], file: } \\
\text { /displ/tot_haz/s7a.frac_mean.gz }\end{array}$ \\
\hline
\end{tabular}


Table 4-1. Direct Input Information for Seismic Consequence Abstractions (Continued)

\begin{tabular}{|c|c|c|}
\hline Input Information & Value & Source \\
\hline $\begin{array}{l}\text { Fault Displacement Hazard at Site } 8 \text { a, a generic } \\
\text { repository location, midway between the Solitario } \\
\text { Canyon and Ghost Dance Faults, with a hypothetical } \\
\text { small fault with a 2-m offset. }\end{array}$ & $\begin{array}{l}\text { See the Excel file } \\
\text { Appendix E } \\
\text { Rev02.xIs, } \\
\text { worksheet } \\
\text { "Table } 6.7-5 \\
\text { Calculations" in } \\
\text { Appendix G for } \\
\text { the mean hazard } \\
\text { curve data at } \\
\text { Site 8a }\end{array}$ & $\begin{array}{l}\text { DTN: MO0401MWDRPSHA.000 } \\
\text { [DIRS 166962], file: } \\
\text {./displ/tot_haz/s8a.frac_mean.gz }\end{array}$ \\
\hline $\begin{array}{l}\text { Fault Displacement Hazard at Sites } 7 b, 7 c \& 7 d- \\
\text { generic repository locations, approximately } 100 \text { meters } \\
\text { east of the Solitario Canyon fault. Site } 7 b \text { has a } \\
\text { hypothetical shear with } 10-\mathrm{cm} \text { offset, site } 7 \mathrm{c} \text { has a } \\
\text { hypothetical fracture with no cumulative displacement, } \\
\text { and site } 7 \mathrm{~d} \text { is intact rock. }\end{array}$ & $\begin{array}{l}\text { See the Excel file } \\
\text { Appendix E } \\
\text { Rev02.xIs, } \\
\text { worksheet } \\
\text { "Table } 6.7-5 \\
\text { Calculations" in } \\
\text { Appendix G for } \\
\text { the mean hazard } \\
\text { curve data at } \\
\text { Sites } 7 \mathrm{~b}, 7 \mathrm{c}, \\
\text { and } 7 \mathrm{~d}\end{array}$ & $\begin{array}{l}\text { DTN: MO0401MWDRPSHA.000 } \\
\text { [DIRS 166962], files: } \\
\text {./displ/tot_haz/s7b.frac_mean.gz,./ } \\
\text { displ/tot_haz/s7c.frac_mean.gz, } \\
\text { and } \\
\text { displ/tot_haz/s7d.frac_mean.gz, }\end{array}$ \\
\hline $\begin{array}{l}\text { Fault Displacement Hazard at Sites } 8 b \text { and } 8 c- \\
\text { generic repository locations, midway between the } \\
\text { Solitario Canyon and Ghost Dance faults. Site } 8 b \text { has } \\
\text { a hypothetical shear with } 10 \mathrm{~cm} \text { offset and site } 8 \mathrm{c} \text { has } \\
\text { a hypothetical fracture with no cumulative } \\
\text { displacement. }\end{array}$ & $\begin{array}{l}\text { See the Excel file } \\
\text { Appendix E } \\
\text { Rev02.xls, } \\
\text { worksheet } \\
\text { "Table } 6.7-5 \\
\text { Calculations" in } \\
\text { Appendix G for } \\
\text { the mean hazard } \\
\text { curve data at } \\
\text { Sites 8b and 8c }\end{array}$ & $\begin{array}{l}\text { DTN: MO0401MWDRPSHA.000 } \\
\text { [DIRS 166962], files: } \\
. / \text { displ/tot_haz/s8b.frac_mean.gz } \\
\text { and } \\
. / \text { displ/tot_haz/s8c.frac_mean.gz }\end{array}$ \\
\hline $\begin{array}{l}\text { Nominal Quantity for LA of 21-PWR Waste Packages } \\
\text { with Absorber Plates. }\end{array}$ & 4,299 & $\begin{array}{l}\text { BSC } 2005 \text { [DIRS 173501], } \\
\text { Table } 13\end{array}$ \\
\hline $\begin{array}{l}\text { Nominal Quantity for LA of 21-PWR Waste Packages } \\
\text { with Control Rods. }\end{array}$ & 95 & $\begin{array}{l}\text { BSC } 2005 \text { [DIRS 173501], } \\
\text { Table } 13\end{array}$ \\
\hline $\begin{array}{l}\text { Nominal Quantity for LA of 12-PWR Long Waste } \\
\text { Packages with Absorber Plates. }\end{array}$ & 163 & $\begin{array}{l}\text { BSC } 2005 \text { [DIRS 173501], } \\
\text { Table } 13\end{array}$ \\
\hline $\begin{array}{l}\text { Nominal Quantity for LA of 44-BWR Waste Packages } \\
\text { with Absorber Plates. }\end{array}$ & 2,831 & $\begin{array}{l}\text { BSC } 2005 \text { [DIRS 173501], } \\
\text { Table } 13\end{array}$ \\
\hline $\begin{array}{l}\text { Nominal Quantity for LA of 24-BWR Waste Packages } \\
\text { with Absorber Plates. }\end{array}$ & 84 & $\begin{array}{l}\text { BSC } 2005 \text { [DIRS 173501], } \\
\text { Table } 13\end{array}$ \\
\hline $\begin{array}{l}\text { Nominal Quantity for LA of } 5 \text { HLW Short/1 DOE Spent } \\
\text { Nuclear Fuel Short Waste Package. }\end{array}$ & 1,147 & $\begin{array}{l}\text { BSC } 2005 \text { [DIRS 173501], } \\
\text { Table } 13\end{array}$ \\
\hline $\begin{array}{l}\text { Nominal Quantity for LA of } 5 \text { HLW Long/1 DOE Spent } \\
\text { Nuclear Fuel Long Waste Package. }\end{array}$ & 1,406 & $\begin{array}{l}\text { BSC } 2005 \text { [DIRS 173501], } \\
\text { Table } 13\end{array}$ \\
\hline $\begin{array}{l}\text { Nominal Quantity for LA of } 2 \mathrm{MCO} / 2 \text { HLW Waste } \\
\text { Package. }\end{array}$ & 149 & $\begin{array}{l}\text { BSC } 2005 \text { [DIRS 173501], } \\
\text { Table } 13\end{array}$ \\
\hline $\begin{array}{l}\text { Nominal Quantity for LA of } 5 \text { HLW Long/1 DOE Spent } \\
\text { Nuclear Fuel Short Waste Package. }\end{array}$ & 31 & $\begin{array}{l}\text { BSC } 2005 \text { [DIRS 173501], } \\
\text { Table } 13\end{array}$ \\
\hline $\begin{array}{l}\text { Nominal Quantity for LA of } 5 \text { HLW Long Only Waste } \\
\text { Package. }\end{array}$ & 679 & $\begin{array}{l}\text { BSC } 2005 \text { [DIRS 173501], } \\
\text { Table } 13\end{array}$ \\
\hline $\begin{array}{l}\text { Nominal Quantity for LA of Naval Short Waste } \\
\text { Package. }\end{array}$ & 144 & $\begin{array}{l}\text { BSC } 2005 \text { [DIRS 173501], } \\
\text { Table } 13\end{array}$ \\
\hline
\end{tabular}


Table 4-1. Direct Input Information for Seismic Consequence Abstractions (Continued)

\begin{tabular}{|c|c|c|}
\hline Input Information & Value & Source \\
\hline $\begin{array}{l}\text { Nominal Quantity for LA of Naval Long Waste } \\
\text { Package. }\end{array}$ & 156 & $\begin{array}{l}\text { BSC } 2005 \text { [DIRS 173501], } \\
\text { Table } 13\end{array}$ \\
\hline \multicolumn{3}{|l|}{ Parameters for the Seismic Scenario Class: } \\
\hline $\begin{array}{l}\text { Horizontal PGV for the } 10^{-5} \text { per year mean annual } \\
\text { exceedance frequency on the unbounded hazard } \\
\text { curve at Point B, the waste emplacement level. }\end{array}$ & $1.05 \mathrm{~m} / \mathrm{s}$ & $\begin{array}{l}\text { DTN: MO0401SEPPGVRL.022 } \\
\text { [DIRS 169099] }\end{array}$ \\
\hline $\begin{array}{l}\text { Horizontal PGV for the } 10^{-6} \text { per year mean annual } \\
\text { exceedance frequency on the unbounded hazard } \\
\text { curve at Point B, the waste emplacement level. }\end{array}$ & $2.44 \mathrm{~m} / \mathrm{s}$ & $\begin{array}{l}\text { DTN: MO0303DPGVB106.002 } \\
\text { [DIRS 162712] }\end{array}$ \\
\hline $\begin{array}{l}\text { Horizontal PGV for the } 10^{-7} \text { per year mean annual } \\
\text { exceedance frequency on the unbounded hazard } \\
\text { curve at Point B, the waste emplacement level. }\end{array}$ & $5.35 \mathrm{~m} / \mathrm{s}$ & $\begin{array}{l}\text { DTN: MO0210PGVPB107.000 } \\
\text { [DIRS 162713] }\end{array}$ \\
\hline $\begin{array}{l}\text { Bounded horizontal peak ground velocity hazard curve } \\
\text { at Point } B \text {, the waste emplacement level. }\end{array}$ & $\begin{array}{l}\text { See DTN for } \\
\text { data; numerical } \\
\text { values are } \\
\text { identified in } \\
\text { Table } 6.4-1\end{array}$ & $\begin{array}{l}\text { DTN: MO0501BPVELEMP.001 } \\
\text { [DIRS 172682] }\end{array}$ \\
\hline $\begin{array}{l}\text { PGV values at Point B for the single ground motion } \\
\text { corresponding to the } 1 \times 10^{-4} \text { per year mean annual } \\
\text { exceedance frequency. This ground motion was } \\
\text { developed for design purposes and matches the target } \\
\text { design spectrum. The resulting PGV value of } 38.38 \\
\mathrm{~cm} / \mathrm{s} \text { differs by about } 10 \text { percent from the PGV value } \\
\text { on the hazard curve at Point B for the } 10^{-4} \text { per year } \\
\text { mean annual exceedance frequency (Table } 6.1-1) \text {. }\end{array}$ & $\begin{array}{l}38.38 \mathrm{~cm} / \mathrm{s} \text { for } \\
\text { the first horizontal } \\
\text { component, } \\
\text { rounded to } \\
0.384 \mathrm{~m} / \mathrm{s} \text {; } \\
43.78 \mathrm{~cm} / \mathrm{s} \text { for } \\
\text { the second } \\
\text { horizontal } \\
\text { component; } \\
47.51 \mathrm{~cm} / \mathrm{s} \text { for } \\
\text { the vertical } \\
\text { component }\end{array}$ & $\begin{array}{l}\text { BSC } 2004 \text { [DIRS 166107], } \\
\text { Table X-1 }\end{array}$ \\
\hline
\end{tabular}

NOTES: tptpll refers to the lower lithophysal stratum at the repository horizon. tptpmn refers to the middle nonlithophysal stratum at the repository horizon RHHTop refers to the top of the repository host horizon, encompassing the lower part of the upper lithophysal zone.

\subsection{CRITERIA}

General programmatic requirements for this document are listed in Technical Work Plan For: Analysis of Waste Package and Drip Shield Response to Vibratory Ground Motion and Revision of the Seismic Consequence Abstraction (BSC 2005 [DIRS 173171]). The TWP specifies that this document and the analyses described herein must adhere to the requirements of LP-SIII.10Q-BSC, Models. The TWP specifies that this document must discuss the barrier function of the EBS components (waste package, drip shield, and emplacement pallet) that may be affected by seismically-induced hazards. The TWP also specifies that the acceptance criteria in Yucca Mountain Review Plan, Final Report (NRC 2003 [DIRS 163274]) must be addressed.

The general requirements for the TSPA are stated in 10 CFR 63.114 [DIRS 173273]. Section 2.2.1.3.2.3 of Yucca Mountain Review Plan, Final Report (NRC 2003 [DIRS 163274]) provides guidance regarding the acceptance criteria that may be used by the U.S. Nuclear Regulatory Commission (NRC) staff to determine whether the technical requirements have been met by the seismic consequence abstractions. The five general acceptance criteria in Section 2.2.1.3.2.3 are listed below, along with the subcriteria specifically addressed by this 
report. Where a subcriterion includes several components, only some components may be addressed. Section 8.2 provides a detailed discussion of how the seismic abstractions and the seismic scenario class meet the applicable acceptance criteria from Yucca Mountain Review Plan, Final Report (NRC 2003 [DIRS 163274]).

\section{Acceptance Criteria from Section 2.2.1.3.2.3, Mechanical Disruption of Engineered Barriers}

\section{Acceptance Criterion 1: System Description and Model Integration Are Adequate.}

(1) Total system performance assessment adequately incorporates important design features, physical phenomena, and couplings, and uses consistent and appropriate assumptions throughout the mechanical disruption of engineered barrier abstraction process.

(2) The description of geological and engineering aspects of design features, physical phenomena, and couplings, that may affect mechanical disruption of engineered barriers, is adequate. For example, the description may include materials used in the construction of engineered barrier components, environmental effects (e.g., temperature, water chemistry, humidity, radiation, etc.) on these materials, and mechanical-failure processes and concomitant failure criteria used to assess the performance capabilities of these materials. Conditions and assumptions in the abstraction of mechanical disruption of engineered barriers are readily identified and consistent with the body of data presented in the description.

(3) The abstraction of mechanical disruption of engineered barriers uses assumptions, technical bases, data, and models that are appropriate and consistent with other related U.S. Department of Energy abstractions. For example, assumptions used for mechanical disruption of engineered barriers are consistent with the abstraction of degradation of engineered barriers (Section 2.2.1.3.1 of the Yucca Mountain Review Plan). The descriptions and technical bases provide transparent and traceable support for the abstraction of mechanical disruption of engineered barriers.

(4) Boundary and initial conditions used in the total system performance assessment abstraction of mechanical disruption of engineered barriers are propagated throughout its abstraction approaches.

(5) Sufficient data and technical bases to assess the degree to which features, events, and processes have been included in this abstraction are provided.

Subcriterion (6) is not discussed here because it is related to transient criticality and beyond the scope of this report. Subcriterion (7) is not discussed here because there are no activities related to peer review or qualification of existing data discussed in this report. 


\section{Acceptance Criterion 2: Data Are Sufficient for Model Justification.}

(1) Geological and engineering values, used in the license application to evaluate mechanical disruption of engineered barriers, are adequately justified. Adequate descriptions of how the data were used, interpreted, and appropriately synthesized into the parameters are provided.

(3) Data on geology of the natural system, engineering materials, and initial manufacturing defects, used in the total system performance assessment abstraction, are based on appropriate techniques. These techniques may include laboratory experiments, site-specific field measurements, natural analog research, and process-level modeling studies. As appropriate, sensitivity or uncertainty analyses used to support the U.S. Department of Energy total system performance assessment abstraction are adequate to determine the possible need for additional data.

(4) Engineered barrier mechanical failure models for disruption events are adequate. For example, these models may consider effects of prolonged exposure to the expected emplacement drift environment, material test results not specifically designed or performed for the Yucca Mountain site, and engineered barrier component fabrication flaws.

Subcriterion (2) is not discussed here because data collection activities related to the geology of the natural system engineering materials, and initial manufacturing defects are beyond the scope of this report.

\section{Acceptance Criterion 3: Data Uncertainty Is Characterized and Propagated Through the Model Abstraction.}

(1) Models use parameter values, assumed ranges, probability distributions, and bounding assumptions that are technically defensible, reasonably account for uncertainties and variabilities, and do not result in an under-representation of the risk estimate.

(2) Process-level models used to represent mechanically disruptive events, within the emplacement drifts at the proposed Yucca Mountain repository, are adequate. Parameter values are adequately constrained by Yucca Mountain site data, such that the effects of mechanically disruptive events on engineered barrier integrity are not underestimated. Parameters within conceptual models for mechanically disruptive events are consistent with the range of characteristics observed at Yucca Mountain.

(3) Uncertainty is adequately represented in parameter development for conceptual models, process-level models, and alternative conceptual models considered in developing the assessment abstraction of mechanical disruption of engineered barriers. This may be done either through sensitivity analyses or use of conservative limits; and Review Plan for Safety Analysis Report 2.2-33.

Subcriterion (4) is not discussed here because an expert elicitation was not performed during the development of the seismic damage abstractions. 


\section{Acceptance Criterion 4: Model Uncertainty Is Characterized and Propagated Through the Model Abstraction.}

(2) Consideration of conceptual model uncertainty is consistent with available site characterization data, laboratory experiments, field measurements, natural analog information and process-level modeling studies; and the treatment of conceptual model uncertainty does not result in an under-representation of the risk estimate.

(3) Appropriate alternative modeling approaches are investigated that are consistent with available data and current scientific knowledge, and appropriately consider their results and limitations using tests and analyses that are sensitive to the processes modeled.

Subcriterion (1) is not discussed here because alternate modeling approaches for features, events, and processes is beyond the scope of this report.

\section{Acceptance Criterion 5: Model Abstraction Output Is Supported by Objective Comparisons.}

(1) Models implemented in this total system performance assessment abstraction provide results consistent with output from detailed process-level models and/or empirical observations (laboratory and field testings and/or natural analogs).

(2) Outputs of mechanical disruption of engineered barrier abstractions reasonably produce or bound the results of corresponding process-level models, empirical observations, or both.

(3) Well-documented procedures, that have been accepted by the scientific community to construct and test the mathematical and numerical models, are used to simulate mechanical disruption of engineered barriers.

Subcriterion (4) is not discussed here because sensitivity studies or bounding analyses are not provided to TSPA within this report.

\subsection{CODES, STANDARDS, AND REGULATIONS}

No codes or standards are applicable to the development of the seismic consequence abstractions. The regulation that is applicable to the development of this abstraction is 10 CFR Part 63, Energy: Disposal of High-Level Radioactive Wastes in a Geologic Repository at Yucca Mountain, Nevada [DIRS 173273], specifically 10 CFR 63.114, Requirements for Performance Assessment, which requires providing the technical basis for the data, models, parameter uncertainties, and alternative conceptual models that are included in TSPA, and 10 CFR 63.115, Requirements for Multiple Barriers, which requires providing the technical basis for the barriers that are important to waste isolation.

The technical basis for the damage abstractions for the waste package and cladding in response to vibratory ground motion is described in Section 6.5. The technical basis for the response of EBS components to rockfall is described in Section 6.6. The technical basis for the response of 
EBS components to fault displacement is described in Section 6.7. The recommended methodology for incorporating the seismic damage abstractions into the seismic scenario class for TSPA is described in Section 6.9. These damage abstractions and the computational methodology provide a basis for evaluating the performance of the EBS barriers that are important for waste isolation in the seismic scenario class.

Data uncertainty is explicitly included in the seismic abstractions for TSPA-LA. In the PSHA, parameter uncertainty and model uncertainty were directly incorporated into the seismic hazard curves that are direct inputs to the fault displacement damage abstraction and the computational methodology for the seismic scenario class. Parameter uncertainty is also included in the ground motion time histories that are direct inputs to the rockfall analyses, structural response calculations, and kinematic calculations that provide the basis for the damage abstractions. Uncertainty in the input parameters is directly represented in the input data for the structural response calculation, kinematic calculations, and rockfall analyses. Further details on data and parameter uncertainty for the seismic damage abstractions can be found in Section 8.2.

The development of seismic consequence abstractions also considered alternative conceptual models. The damaged areas for end-to-end impacts of adjacent waste packages are based on kinematic calculations with multiple waste packages. Kinematic calculations have been performed with LS-DYNA and UDEC using slightly different modeling approaches and modeling assumptions (Section 6.5.1.1). The uncertainty in the kinematic approaches has been propagated into the abstraction for TSPA-LA by providing separate damage abstractions for UDEC and for LS-DYNA. This approach directly maintains the uncertainty in damaged area due to the computational approaches in the seismic scenario class for TSPA.

Model uncertainty has also been directly incorporated into the hazard curves that are direct inputs to the fault displacement analysis and the computational methodology for the seismic scenario class. Finally, the damage abstraction for fault displacement has been compared to an alternative conceptual model proposed by Waiting et al. (2003 [DIRS 164449]). Again, further details on model uncertainty and alternative conceptual models for the seismic damage abstractions can be found in Section 8.2. 


\section{ASSUMPTIONS}

\subsection{PAGANY WASH AND SEVER WASH FAULT DISPLACEMENTS}

Assumption: The fault displacement hazard curves for the Pagany Wash and Sever Wash faults can be considered equal to the fault displacement hazard curve for the Drill Hole Wash fault (DTN: MO0401MWDRPSHA.000 [DIRS 166962], file: ./displ/tot_haz/s3.frac_mean.gz).

Basis: The assumption of equivalency is justified by the results of field investigations that are summarized by Menges and Whitney (1996 [DIRS 106342], Section 4.2.4.10). The reasoning that supports the assumption of equivalency is as follows:

1. Previous geologic studies have consolidated discussion of the three faults based on similar characteristics and apparent similarity in fault development in response to the extensional environment. These faults are characterized as northwest-trending faults that are extensional structures related to the left-oblique component of displacement along the north-trending faults. They are, generally, strike-slip faults with a right lateral movement (Menges and Whitney 1996 [DIRS 106342], Section 4.2.4.10 and Table 4.2.1.2).

2. The field data for the three sites includes surface exposures and trench studies for Pagany Wash fault and Sever Wash fault, and drill core data for the Drill Hole Wash fault. Because of the existence of subsurface data, and consistent with the choice of representative locations used by the expert elicitation panel as presented in Probabilistic Seismic Hazard Analysis for Fault Displacement and Vibratory Ground Motion at Yucca Mountain, Nevada (PSHA) (CRWMS M\&O 1998 [DIRS 103731], Section 4.3.2), it is reasonable to use the response of the Drill Hole Wash fault as the basis for the seismic hazard.

3. None of the faults suggest displacement in Quaternary alluvial terraces, so it is appropriate to assume a low probability of significant displacement for these three faults.

4. The scale of vertical displacement is less than 5 to 10 meters for each structure (Menges and Whitney 1996 [DIRS 106342], Table 4.2.1.2), consistent with a maximum displacement of approximately 2 meters for a single low probability event (CRWMS M\&O 1998 [DIRS 103731], Figure 8.4).

5. Total fault length, an important factor in seismic hazard assessment, is similar for the three faults and ranges from $2 \mathrm{~km}$ for the Drill Hole Wash fault to $4 \mathrm{~km}$ for the other faults.

6. Spatial orientation to the Solitario Canyon and Bow Ridge faults, also an important factor in a hazard assessment, is similar for the three faults as illustrated in Figure 4.2.2 of Seismotectonic Framework and Characterization of Faulting at Yucca Mountain, Nevada and described by Menges and Whitney (1996 [DIRS 106342], Section 4.2.4.10). Spatial orientation to more distant seismic sources is also similar. 
It is, therefore, reasonable to treat the Drill Hole Wash fault, the Sever Wash fault, and the Pagany Wash fault in a similar manner with regard to the potential seismic hazard.

Confirmation Status: This assumption does not require confirmation. Probabilistic Seismic Hazard Analyses for Fault Displacement and Vibratory Ground Motion at Yucca Mountain, Nevada (CRWMS M\&O 1998 [DIRS 103731]) defines fault displacement hazards at 15 faulting conditions within the immediate vicinity of Yucca Mountain. The PSHA did not characterize closely spaced faults separately because their displacements during a seismic event are expected to be similar. Assumption 5.1 follows the same approach used during the PSHA to characterize the response at representative fault locations (CRWMS M\&O 1998 [DIRS 103731], Section 4.3.2).

Use In Model: This assumption is used in Section 6.7.3.

\subsection{RANDOMNESS OF SEISMIC EVENTS}

Assumption: Seismic events occur in a random manner, following a Poisson process, over long periods of time.

Basis: The assumption that the behavior of the earth is generally random (i.e., a Poisson process) is a common assumption in seismology. In other words, earthquakes are considered as independent events with regard to magnitude, time, and location. This assumption is similar to Assumption 6.4.2 in Characterize Framework for Seismicity and Structural Deformation at Yucca Mountain, Nevada (BSC 2004 [DIRS 168030]). Although there may be cases where sufficient data and information exist to depart from this assumption, the Poisson process is generally an effective representation of nature and represents a compromise between the complexity of natural processes, availability of information, and the sensitivity of results of engineering relevance.

Confirmation Status: This assumption does not require confirmation because it is a common engineering assumption in seismology and because it is an implicit assumption in the development of hazard curves for the seismic scenario class (BSC 2004 [DIRS 168030], Section 6.4.2).

Use In Model: This assumption is used in Section 6.1.2.

\subsection{SUMMARY OF MAJOR ASSUMPTIONS IN SUPPORTING CALCULATIONS}

The seismic consequence abstractions are based on the results from three main sources:

- Structural response calculations for EBS components in response to vibratory ground motion

- Analyses of rockfall induced by vibratory ground motion, and

- Analysis of the effective transport area through the dense network of stress corrosion cracks that is postulated to exist within the damaged areas on EBS components. 
The structural response calculations and rockfall analyses are summarized in Table 1-1 but are not described in this report; rather, the results from these engineering calculations and scientific analyses provide the input data that the abstractions are based on. The structural response calculations and rockfall analyses include several major assumptions that are not directly used in the abstraction process, but are noteworthy enough to deserve repeating here. Similarly, the major assumptions for the determination of the effective transport area through a crack network are also summarized here.

The structural response calculations for the waste package and drip shield incorporate assumptions for structural thickness (degradation) and for material properties of Alloy 22 and of Titanium Grade 7. The thicknesses of the drip shield plates and the waste package outer barrier have been reduced by 2-mm to conservatively represent the potential degradation of these structures by general corrosion over the first 10,000 years after repository closure. The material properties of Alloy 22 and of Titanium Grade 7 have been evaluated at an elevated temperature $\left(150^{\circ} \mathrm{C}\right)$ that provides conservative values for mechanical properties over 97 percent of the 10,000-year duration for an unfilled drift. The rationale for the temperature assumption is discussed below. The rationale for the thickness reduction is discussed in more detail in several design calculations (BSC 2004 [DIRS 167083], Assumption 3.21; BSC 2004 [DIRS 172448], Assumption 3.10).

A temperature of $150^{\circ} \mathrm{C}$ is an appropriate and reasonable assumption for evaluation of material properties at the time of the seismic event. This value $\left(150^{\circ} \mathrm{C}\right)$ is conservative for evaluation of material properties during 97 percent of the first 10,000 years after repository closure. This result is based on a series of thermal analyses that account for uncertainty in host-rock thermal conductivity and percolation flux for an unfilled drift (BSC 2005 [DIRS 173944], Figure 6.3-67). Results are presented for peak waste package temperature, which also provides an upper bound for the peak drip shield temperature. The peak waste package temperature ranges from $102.0^{\circ} \mathrm{C}$ to $203.1^{\circ} \mathrm{C}$ (BSC 2005 [DIRS 173944], Table 6.3-38). The waste package temperature time histories demonstrate that temperature exceeds $150^{\circ} \mathrm{C}$ for, at most, the first 270 years after ventilation ceases. In some cases, the temperature never exceeds $150^{\circ} \mathrm{C}$ for certain percolation fluxes and host rock thermal conductivities. Since the time period when temperature exceeds $150^{\circ} \mathrm{C}$ is not greater than 270 years, it follows that evaluating material properties such as the yield strength at $150^{\circ} \mathrm{C}$ is conservative for at least 97 percent of the 10,000 years following repository closure.

The rockfall analyses for the lithophysal zones also make a key assumption. In the lithophysal zone, the block size distribution is assumed to be a function of the inter-lithophysal fracture density and the lithophysae spacing (BSC 2004 [DIRS 166107], Assumption 5.2.2). This assumption is relevant to the abstraction process because the size, mass, and velocity of the fragmented rock are related to the potential damage to the drip shield and waste package from drift collapse in the lithophysal zone, as discussed in Sections 6.6.2 and 6.6.3.

The effective cross-sectional area for transport through a network of stress corrosion cracks is a distribution of values based on two alternative conceptual models (BSC 2004 [DIRS 172203], Section B6.4; DTN: MO0403SPASCRKD.000 [DIRS 168105]). The first conceptual model is based on a hexagonal array of randomly oriented cracks, while the second conceptual model is 
based on a hexagonal array of cracks in parallel rows. The use of a distribution directly represents the uncertainty in these two alternative conceptual models in the TSPA.

Both conceptual models assume a hexagonal array of cracks because this leads to the closest packing of crack centers on a surface. Both conceptual models are based on recommendations from previous analyses (BSC 2004 [DIRS 172203], Sections 6.5.1 and 6.5.2) regarding the estimated length, intercrack spacing, and crack opening shape and size for the weld region in the waste package lid. For example, the spacing between crack centers is at least the wall thickness because cracks with more closely spaced centers will be arrested before penetrating completely through the wall thickness. In addition, the cross-sectional area of a crack is assumed constant through the wall thickness, although cracks tend to narrow at the crack tip (Figure 6.3.2 in this report). The minimum spacing between crack centers and the constant cross-sectional area are conservative features of either model. 


\section{MODEL DISCUSSION}

\subsection{INTRODUCTION}

\subsubsection{Information Sources}

This report presents the abstractions for damage to EBS components due to seismic hazards and the computational methodology for the seismic scenario class for TSPA-LA. These abstractions and the computational methodology are the outputs from this model report. The intended use of this output is to define the seismic scenario class for TSPA-LA. The report includes discussion of:

- The criteria for determining the damaged areas of the waste package and drip shield under vibratory ground motions

- The morphology and abstraction of these damaged areas as a function of the seismic hazard

- Damage to EBS components from fault displacement

- The abstraction of fuel rod cladding failure in response to waste package impacts

- The algorithms for including the damage abstractions in the seismic scenario class

- Post-seismic event changes in seepage, temperature, and relative humidity due to drift collapse.

Figure 6.1-1 illustrates the major components of the EBS in a typical emplacement drift. The major EBS components addressed in this report are the drip shield, the waste package, and the fuel rod cladding because failure of these components has the potential to directly release radionuclides or to form diffusive or advective transport pathways into the unsaturated zone. The drift invert and emplacement pallet are included in the kinematic and structural response calculations for the seismic scenario class, but it is not necessary to develop damage abstractions for these components because they retain their functionality after strong ground motions. The crushed tuff in the invert does not lose its integrity and the other EBS components rest on the invert even after strong vibratory ground motions (BSC 2005 [DIRS 173172], Section VIII-4.2). The emplacement pallet also retains its functionality of separating the waste package from the invert because it does not collapse from waste package impacts under strong ground motions and because the connecting tubing within the pallet does not fail during strong ground motions (BSC 2005 [DIRS 173172], Attachment XI). The waste package internals and mass of the waste form are considered in structural response calculations, but are not represented as separate damage abstractions because the fuel rod cladding failure fails for strong ground motions (Section 6.5.6.3). In this situation, the mechanical response of the waste form and the waste package internals to strong ground motions is not significant for TSPA. Figure 6.1-1 also shows the steel sets that will be added as ground support in some drifts. Steel sets are not considered in postclosure seismic analysis because rapid corrosion of mild steel is anticipated to limit their effectiveness in the postclosure repository environment. 
The effectiveness of these barriers is potentially compromised by the direct effects from an earthquake, including vibratory ground motion, fault displacement, and rockfall induced by ground motion. The effectiveness of these barriers is also potentially compromised by indirect effects after an earthquake, including changes in seepage, temperature, and relative humidity if an emplacement drift collapses completely during a very low probability earthquake.

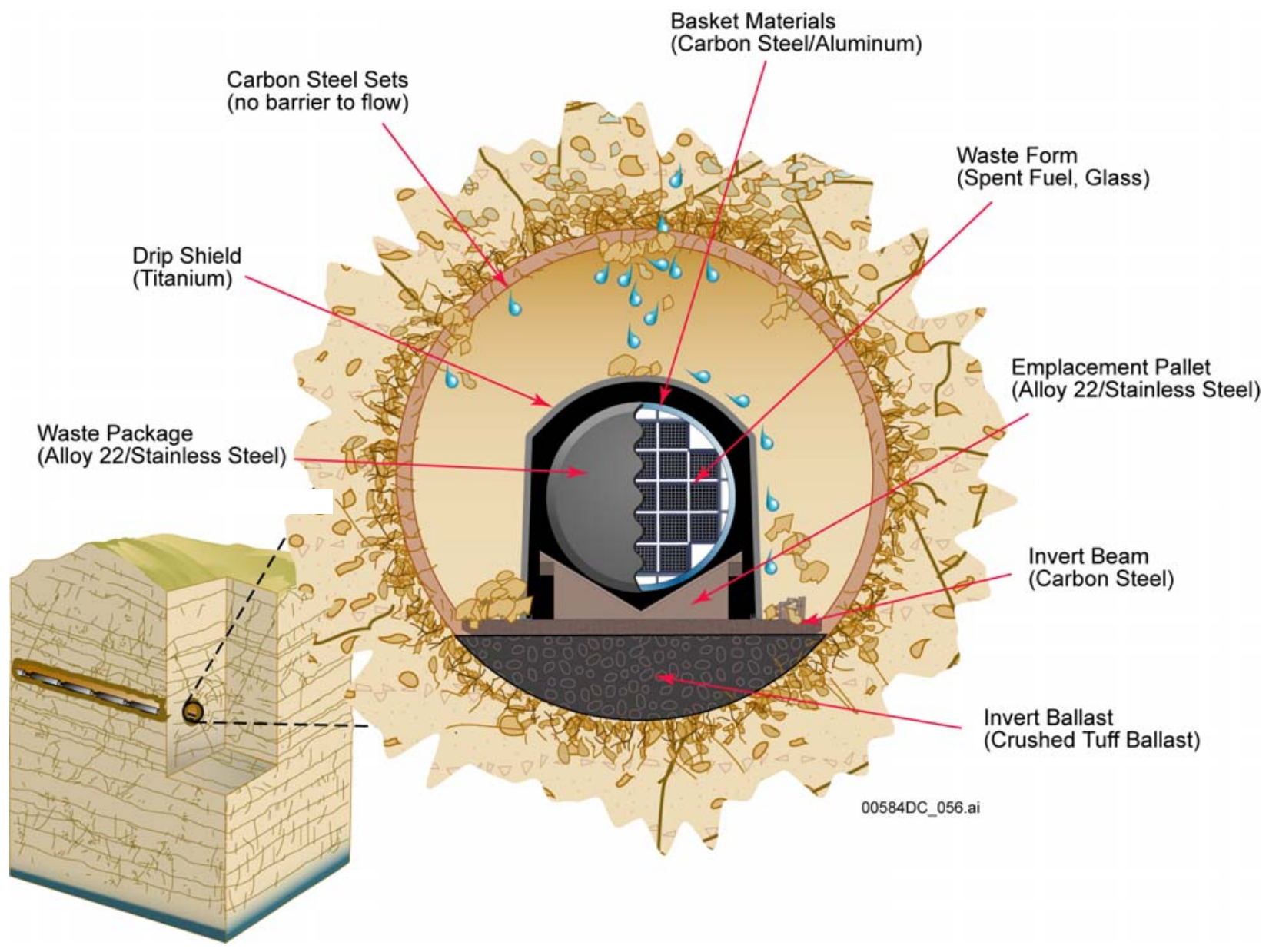

Figure 6.1-1. Schematic Diagram of the EBS Components in a Typical Emplacement Drift

Mathematically, the response of the EBS components to ground motion and fault displacement can be represented by the following vector, $\vec{A}$, that provides a conceptual representation of the major input parameters, the key damage mechanisms, and the post-seismic event changes for the seismic scenario class. In effect, Sections 6.3 through 6.9 provide a definition, an abstraction, or a computational algorithm for each term on the right-hand side of this vector:

$$
\begin{gathered}
\vec{A}=(t, v, \vec{d}, f W P A, f D S A, f C L D, n P W R F D, a P W R F D, n B W R F D, a B W R F D, n N V L F D, \\
a N V L F D, n H L W F D, a H L W F D, c S E E P, c T E M P, c R H),
\end{gathered}
$$

where $\quad t$ is the time (year) after repository closure when the seismic hazard occurs;

$v$ is the amplitude $(\mathrm{m} / \mathrm{s})$ of the ground motion from the bounded hazard curve, 
measured in terms of horizontal PGV;

$\vec{d}$ is a vector of displacements (m) for known faults that intersect emplacement drifts;

fWPA is the fraction of waste package surface area damaged by ground motion. The abstraction for damage to the waste package as a function of $v$ is defined in Sections 6.5.1 through 6.5.3, based on information in Mechanical Assessment of the Waste Package Subject to Vibratory Ground Motion (BSC 2005 [DIRS 173172]);

fDSA is the fraction of drip shield surface area damaged by ground motion. The drip shields are predicted to remain intact during vibratory ground motion and rockfall induced by vibratory ground motion, as described in Sections 6.5.4, 6.5.5, and 6.6), based on information in Structural Calculations of Drip Shield Exposed to Vibratory Ground Motion (BSC 2004 [DIRS 172448]) and in Drift Degradation Analysis (BSC 2004 [DIRS 166107]). An abstraction for fDSA is not included in the seismic scenario class because the drip shields remain intact;

$f C L D$ is the fraction of fuel rod cladding perforated by the vibratory ground motion. The abstraction for damage to the cladding as a function of $v$ is defined in Section 6.5.6, based on information in Maximum Accelerations on the Fuel Assemblies of a 21-PWR Waste Package During End Impacts (BSC 2003 [DIRS 162602]) and in Structural Calculations of Waste Package Exposed to Vibratory Ground Motion (BSC 2004 [DIRS 167083]);

$n P W R F D$ is the number of PWR waste packages failed due to fault displacement. The abstraction for the number of failed waste packages as a function of exceedance frequency is defined in Section 6.7.5, based on design information and on the mean hazard curves in the probabilistic seismic hazard analyses (DTN: MO0401MWDRPSHA.000 [DIRS 166962]). Exceedance frequency is defined as a function of $v$ through the bounded hazard curve for horizontal PGV at the emplacement drifts;

aPWRFD is the damaged area $\left(\mathrm{m}^{2}\right)$ on PWR waste packages and their associated drip shield and fuel rod cladding resulting from fault displacement. The abstraction for waste package damaged area and for damage to drip shield and cladding is defined in Section 6.7.5;

$n B W R F D$ is the number of BWR waste packages failed due to fault displacement. The abstraction for the number of failed waste packages as a function of exceedance frequency is defined in Section 6.7.5, based on design information and on the mean hazard curves in the probabilistic seismic hazard analyses (DTN: MO0401MWDRPSHA.000 [DIRS 166962]). Exceedance frequency is defined as a function of $v$ through the bounded hazard curve for horizontal PGV at the emplacement drifts; 
aBWRFD is the damaged area $\left(\mathrm{m}^{2}\right)$ on BWR waste packages and their associated drip shields and fuel rod cladding resulting from fault displacement. The abstraction for damaged area and for damage to drip shield and cladding is defined in Section 6.7.5;

$n N V L F D$ is the number of Naval waste packages failed due to fault displacement. The abstraction for the number of failed waste packages as a function of exceedance frequency is defined in Section 6.7.5, based on design information and on the mean hazard curves in the probabilistic seismic hazard analyses (DTN: MO0401MWDRPSHA.000 [DIRS 166962]). Exceedance frequency is defined as a function of $v$ through the bounded hazard curve for horizontal PGV at the emplacement drifts;

aNVLFD is the damaged area $\left(\mathrm{m}^{2}\right)$ on Naval waste packages and their associated drip shields and fuel rod cladding resulting from fault displacement. The abstraction for damaged area and for damage to drip shields is defined in Section 6.7.5;

nHLWFD is the number of HLW waste packages failed due to fault displacement. The abstraction for the number of failed waste packages is defined in Section 6.7.5, based on design information and on the mean hazard curves in the probabilistic seismic hazard analyses (DTN: MO0401MWDRPSHA.000 [DIRS 166962]). Exceedance frequency is defined as a function of $v$ through the bounded hazard curve for horizontal PGV at the emplacement drifts;

aHLWFD is the damaged area $\left(\mathrm{m}^{2}\right)$ on HLW waste packages and their associated drip shields and fuel rod cladding resulting from fault displacement. The abstraction for damaged area and for damage to drip shields is defined in Section 6.7.5;

cSEEP is an indicator variable (dimensionless) for the change in seepage flux in the lithophysal zone if a seismic event with intensity measure $v$ collapses the emplacement drifts, as described in Section 6.8.1;

CTEMP is an indicator variable (dimensionless) for the change in temperature on the waste packages in the lithophysal zone if a seismic event with intensity measure $v$ collapses the emplacement drifts, as described in Section 6.8.3;

$c R H$ is an indicator variable (dimensionless) for the change in relative humidity on the waste packages in the lithophysal zone if a seismic event with intensity measure $v$ collapses the emplacement drifts, as described in Section 6.8.3;

The level of ground motion is based on the mean bounded hazard curve defined in DTN: MO0501BPVELEMP.001 [DIRS 172682]. The levels of fault displacement are based on the mean hazard curves defined in DTN: MO0401MWDRPSHA.000 [DIRS 166962], (the relevant data files in this DTN are defined in Table 4-1 of this report), based on the Probabilistic Seismic Hazard Analyses for Fault Displacement and Vibratory Ground Motion at Yucca Mountain, Nevada (PSHA) (CRWMS M\&O 1998 [DIRS 103731]). The structural response of the EBS components incorporates an allowance for corrosion and degradation of the waste package and drip shield over the 10,000 years following repository closure (see Assumption 5.3). 
The seismic scenario class has been designed to accurately represent the seismic hazards that cause significant structural damage, and considers hazards with an annual exceedance probability of $10^{-8}$ per year or greater, per 10 CFR 63.114(d) [DIRS 173273].

\subsubsection{Terminology}

The terminology for the seismic hazard curves and for the suite of ground motions corresponding to a given exceedance frequency is explained here. In addition, the difference between a damage abstraction and a response surface is briefly explained.

A mean hazard curve defines the relationship between the mean estimate of the mean annual frequency of exceedance and the amplitude of the seismic effect, either for vibratory ground motion (measured by PGV) or for fault displacement (measured by a vertical displacement). The mean annual exceedance frequency represents the mean value of the frequency in any year with which future seismic events will exceed a given value of the PGV or fault displacement.

The mean annual exceedance frequency spans many orders of magnitude, from a minimum of $10^{-8}$ per year to a maximum of 1 per year (or greater). The frequency is defined as the number of observed events, divided by the time interval of observation. This calculated value and hence the frequency vary randomly from one observation to the next. We use the mean of this random frequency as a measure of how likely an event is over any future year. When the mean annual exceedance frequency of interest is much less than 1, as it is here, the mean annual exceedance frequency and the annual exceedance probability are essentially equal. ${ }^{5}$ This report uses the term exceedance frequency because it is more general, although the annual exceedance frequency and annual exceedance probability are interchangeable for the very infrequent seismic hazards considered in this study.

All hazard curves in this report are based on the mean annual exceedance frequency. The mean estimate of the mean exceedance frequency is used for the seismic scenario class because a primary objective of TSPA is to estimate mean dose for the reasonably maximally exposed individual. The uncertainty in the mean exceedance frequency is characterized in the PSHA (CRWMS M\&O 1998 [DIRS 103731]).

The effect of vibratory ground motion on the EBS components is assessed for a set of ground motions with a given value of the horizontal PGV. Sets of 17 three-component ground motions have been developed for horizontal PGVs of $1.05 \mathrm{~m} / \mathrm{s}, 2.44 \mathrm{~m} / \mathrm{s}$, and $5.35 \mathrm{~m} / \mathrm{s}$. These ground motion sets are often referred to in this project and in some of its reports as the $10^{-5}$ per year, the $10^{-6}$ per year and the $10^{-7}$ per year ground motions (respectively) because PGV values of $1.05 \mathrm{~m} / \mathrm{s}, 2.44 \mathrm{~m} / \mathrm{s}$, and $5.35 \mathrm{~m} / \mathrm{s}$ correspond to these frequency values on the unbounded hazard curve at Point B (the emplacement drifts). However, a seismic event with (say) a PGV of $2.44 \mathrm{~m} / \mathrm{s}$ will not occur with a frequency of $10^{-6}$ per year. The correspondence of $2.44 \mathrm{~m} / \mathrm{s}$ with $10^{-6}$ per year on the mean hazard curve means that ground motion events with a PGV equal to or greater than $2.44 \mathrm{~m} / \mathrm{s}$ occur with a mean annual frequency of $10^{-6}$ per year. In other words, the

5 The probability of one or more events for a Poisson process (Assumption 5.2) with annual rate $\lambda$ over duration $T$ is given by $\left(1-\mathrm{e}^{-\lambda T}\right)$. When $\lambda$ is small enough, the probability that one or more events occur in an interval $T$ becomes $\left(1-\mathrm{e}^{-\lambda T}\right)=1-$ $\left(1-\lambda T+1 / 2(\lambda T)^{2}-\ldots\right) \approx \lambda T$, so the annual probability for one or more events is given by $(\lambda T) / T=\lambda$, the annual frequency of events. A typical criterion for the accuracy of this expansion is for $\lambda T \leq 0.1$. 
ensemble of seismic ground motions with PGV exceeding $2.44 \mathrm{~m} / \mathrm{s}$ will occur with a mean frequency of $10^{-6}$ per year. To make an additional point, the probability of encountering an earthquake with a PGV of exactly $2.44 \mathrm{~m} / \mathrm{s}$ is zero, and will certainly not occur with a frequency of $10^{-6}$ per year.

In this report, ground motions are identified by the appropriate value of PGV. The value of PGV provides a unique and unambiguous identifier for each set of ground motions, even when multiple hazard curves have been developed for a site. In fact, the multiple hazard curves in Figure 6.4-2 (Section 6.4.3) illustrate the problem with identifying ground motion amplitude by exceedance frequency because a given value of PGV can be associated with multiple values of the exceedance frequency.

The value of PGV refers to the peak ground velocity of the first horizontal component of the ground motions. This first horizontal component may be oriented in the longitudinal direction, parallel with the drift axis, or in the transverse direction, perpendicular to the drift axis but still in the horizontal plane. Both orientations have been used in the structural response calculations, as discussed in Sections 6.5.1 and 6.5.2.

The horizontal PGV is appropriate for parameterizing the damaged area as a function of ground motion amplitude, and does not imply that the second horizontal and vertical velocity components have the same PGV value. In fact, ground motion time histories that preserve intercomponent variability (see discussion in Section 6.4.2) have substantial variability in the $\mathrm{PGV}$ values among the three components of the ground motion.

Finally, the damage abstractions for EBS components are defined in a different manner than fragility curves or than response surfaces. A fragility curve is defined as the probability of a binary event; for example, a fragility curve can define the probability of damaged area exceeding 1 percent of the surface area of the waste package, as a function of PGV. While it is possible to produce a family of fragility curves for multiple damage levels, such as for 0.2 percent, 0.5 percent, 1 percent, 2 percent, and so on, this is an awkward methodology to incorporate into a Monte Carlo approach, such as the TSPA for the Yucca Mountain Project. A typical response surface represents the mean damage and its standard deviation, often as normal or lognormal distributions whose parameters are functions of the amplitude of the ground motion or fault displacement. A response surface is more amenable to a Monte Carlo approach, provided the deviation about the mean is sampled in an appropriate manner. The damage abstractions for the waste package are similar to a response surface, in the sense that they are based on a power law representation for the median damage (also called the geometric mean) and a log-normal distribution of the residuals about the mean value. This approach provides a simple, transparent, and accurate representation of the variability and uncertainty in seismically-induced damage based on Monte Carlo sampling for TSPA.

\subsubsection{Corroborating Information}

The abstractions for damage to EBS components from seismic hazards are based on the direct input information in Table 4-1 of Section 4.1 and on the corroborating information in Table 6.1-1. 
Table 6.1-1. Corroborating Input Information for Seismic Consequence Abstractions

\begin{tabular}{|c|c|c|}
\hline Input Information & Value & Source \\
\hline \multicolumn{3}{|l|}{ Seismic Failure Criteria: } \\
\hline $\begin{array}{l}\text { Residual stress threshold for initiation of stress } \\
\text { corrosion cracking on a smooth surface of Titanium } \\
\text { Grade } 7\end{array}$ & $\begin{array}{l}50 \text { percent of the yield } \\
\text { strength of Titanium } \\
\text { Grade } 7\end{array}$ & $\begin{array}{l}\text { BSC } 2004 \text { [DIRS 172203], } \\
\text { Section } 6.2 .1,2^{\text {nd }} \text { paragraph on } \\
\text { page } 6-7\end{array}$ \\
\hline \multicolumn{3}{|c|}{ Damage to the Waste Package from Vibratory Ground Motion: } \\
\hline $\begin{array}{l}\text { Damage to the waste package for the single vibratory } \\
\text { ground motion at the } 0.190 \mathrm{~m} / \mathrm{s} \text { and } 0.384 \mathrm{~m} / \mathrm{s} \text { PGV } \\
\text { levels, corresponding to unbounded annual } \\
\text { exceedance frequencies of } 5 \times 10^{-4} \text { per year and of } \\
1 \times 10^{-4} \text { per year }\end{array}$ & No damage & $\begin{array}{l}\text { BSC } 2004 \text { [DIRS 167083], } \\
\text { Section 6.3, last paragraph, and } \\
\text { Section } 6.4 \text {, last paragraph }\end{array}$ \\
\hline $\begin{array}{l}\text { The top surface of the invert can be represented as a } \\
\text { rigid surface for the kinematic and structural response } \\
\text { calculations. }\end{array}$ & $\begin{array}{l}\text { The rigid representation } \\
\text { has relatively little } \\
\text { impact on amplification } \\
\text { of ground motions or on } \\
\text { permanent deflection of } \\
\text { the invert surface. }\end{array}$ & $\begin{array}{l}\text { BSC } 2005 \text { [DIRS 173172], } \\
\text { Attachment VIII }\end{array}$ \\
\hline \multicolumn{3}{|c|}{ Damage to the Fuel Rod Cladding from Vibratory Ground Motion: } \\
\hline $\begin{array}{l}\text { Range of axial g-loads for cladding failure due to } \\
\text { buckling }\end{array}$ & 82 g's to 252 g's & $\begin{array}{l}\text { Chun et al. } 1987 \text { [DIRS 144357], } \\
\text { Table } 4\end{array}$ \\
\hline Range of g-loads for cladding failure from side drops & 63 g's to 211 g's & $\begin{array}{l}\text { Chun et al. } 1987 \text { [DIRS 144357], } \\
\text { Table } 4\end{array}$ \\
\hline \multicolumn{3}{|c|}{ Rockfall Induced by Ground Motion in the Lithophysal Zone: } \\
\hline $\begin{array}{l}\text { Damage statistics for a drift in the lithophysal zone, } \\
\text { based on a sampling of vibratory ground motions at } \\
\text { the } 2.44 \mathrm{~m} / \mathrm{s}\left(10^{-6} \text { per year) PGV level }\right.\end{array}$ & $\begin{array}{l}\text { Drift collapses for } \\
\text { ground motions with } \\
\text { PGV }>2 \mathrm{~m} / \mathrm{s}\end{array}$ & $\begin{array}{l}\text { BSC } 2004 \text { [DIRS } 166107] \text {, } \\
\text { Section } 6.4 .2 .2 .2,4^{\text {th }} \text { bullet under } \\
\text { subheading Discussion }\end{array}$ \\
\hline $\begin{array}{l}\text { Damage to a drift in the lithophysal zone for the } \\
\text { single vibratory ground motion at the } 0.190 \mathrm{~m} / \mathrm{s} \text { PGV } \\
\text { level }\end{array}$ & $\begin{array}{l}\text { No rockfall for rock mass } \\
\text { categories } 2-5 \text {; minor, } \\
\text { low-energy rockfall for } \\
\text { rock mass category } 1\end{array}$ & $\begin{array}{l}\text { BSC } 2004 \text { [DIRS 166107], } \\
\text { Section } 6.4 .2 .2 .1\end{array}$ \\
\hline $\begin{array}{l}\text { Creep response of the drip shield to long-term static } \\
\text { loading from lithophysal rockfall }\end{array}$ & $\begin{array}{l}\text { The maximum creep } \\
\text { displacement after } \\
10,000 \text { years is } \\
\text { approximately } 5.5 \mathrm{~cm} \text {, } \\
\text { and the maximum creep } \\
\text { strain is less than } \\
5 \text { percent, which is well } \\
\text { below the tertiary creep } \\
\text { rupture strain limit for } \\
\text { titanium }\end{array}$ & $\begin{array}{l}\text { BSC } 2005 \text { [DIRS 174715], } \\
\text { Section 3.2, Assumption 3.2.9 }\end{array}$ \\
\hline \multicolumn{3}{|c|}{ Damage to the Waste Package and Drip Shield from Fault Displacement: } \\
\hline $\begin{array}{l}\text { Fault Displacement Hazard at Site } 2 \text { - on the Solitario } \\
\text { Canyon fault }\end{array}$ & See Figure 8-3 in source & $\begin{array}{l}\text { CRWMS M\&O } 1998 \\
\text { [DIRS 103731], Figure 8-3 }\end{array}$ \\
\hline $\begin{array}{l}\text { Fault Displacement Hazard at Site } 4 \text { - on the Ghost } \\
\text { Dance fault }\end{array}$ & See Figure $8-5$ in source & $\begin{array}{l}\text { CRWMS M\&O } 1998 \\
\text { [DIRS 103731], Figure 8-5 }\end{array}$ \\
\hline $\begin{array}{l}\text { Fault Displacement Features of the Sever Wash fault } \\
\text { and the Pagany Wash fault }\end{array}$ & $\begin{array}{l}\text { Similar to Drill Hole } \\
\text { Wash fault }\end{array}$ & $\begin{array}{l}\text { Menges and Whitney } 1996 \\
\text { [DIRS 106342], Section } 4.2 .4 .10, \\
\text { and Section } 5.1 \text { of this report }\end{array}$ \\
\hline $\begin{array}{l}\text { Fault Displacement Hazard at Site } 8 d-\text { generic } \\
\text { repository location, midway between the Solitario } \\
\text { Canyon and Ghost Dance faults. Site } 8 d \text { has intact } \\
\text { rock. }\end{array}$ & $\begin{array}{l}\text { Displacement is below } \\
0.1 \mathrm{~cm} \text { down to } 10^{-8} \mathrm{per} \\
\text { year }\end{array}$ & $\begin{array}{l}\text { CRWMS M\&O } 1998 \\
\text { [DIRS 103731], Section 8.2.1, } \\
\text { first paragraph }\end{array}$ \\
\hline
\end{tabular}


Table 6.1-1. Corroborating Input Information for Seismic Consequence Abstractions (Continued)

\begin{tabular}{|c|c|c|}
\hline Input Information & Value & Source \\
\hline \multicolumn{3}{|c|}{ Damage to the Waste Package and Drip Shield from Fault Displacement (Cont.): } \\
\hline $\begin{array}{l}\text { PGV level for complete drift collapse in lower } \\
\text { lithophysal }\end{array}$ & $2.0 \mathrm{~m} / \mathrm{s}$ & $\begin{array}{l}\text { BSC } 2004 \text { [DIRS } 166107] \\
\text { Section } 6.4 .2 .2 .2,4^{\text {th }} \text { bullet under } \\
\text { subheading Discussion }\end{array}$ \\
\hline $\begin{array}{l}\text { Subsurface facility layout and numbering of } \\
\text { emplacement drifts }\end{array}$ & See Figure 1 in source & $\begin{array}{l}\text { BSC } 2004 \text { [DIRS 172801], } \\
\text { Figure } 1\end{array}$ \\
\hline $\begin{array}{l}\text { Alternative conceptual model for probability-weighted } \\
\text { number of waste package failures from fault } \\
\text { displacement }\end{array}$ & $1.91 \times 10^{-4}$ to $1.91 \times 10^{-6}$ & $\begin{array}{l}\text { Waiting et al. } 2003 \\
\text { [DIRS 164449] }\end{array}$ \\
\hline $\begin{array}{l}\text { Alternative conceptual model for number of fault } \\
\text { intersections with emplacement drifts }\end{array}$ & 191 & $\begin{array}{l}\text { Waiting et al. 2003 } \\
\text { [DIRS 164449] }\end{array}$ \\
\hline \multicolumn{3}{|l|}{ Parameters for the Seismic Scenario Class: } \\
\hline $\begin{array}{l}\text { Horizontal PGV at Point } B \text { for the single ground } \\
\text { motion corresponding to the } 5 \times 10^{-4} \text { per year mean } \\
\text { annual exceedance frequency }\end{array}$ & $\begin{array}{l}19.00 \mathrm{~cm} / \mathrm{s} \\
\text { (rounded to } 0.190 \mathrm{~m} / \mathrm{s} \text { ) }\end{array}$ & $\begin{array}{l}\text { BSC } 2004 \text { [DIRS 166107] } \\
\text { Table X-1 }\end{array}$ \\
\hline $\begin{array}{l}\text { Horizontal PGV for the } 10^{-4} \text { per year mean annual } \\
\text { exceedance frequency on the unbounded hazard } \\
\text { curve at Point } B \text {, the waste emplacement level }\end{array}$ & $40.19 \mathrm{~cm} / \mathrm{s}$ & $\begin{array}{l}\text { DTN: MO0404PGVRL104.000 } \\
\text { [DIRS 170437] }\end{array}$ \\
\hline \multicolumn{3}{|l|}{ Changes Due to Drift Collapse: } \\
\hline $\begin{array}{l}\text { Seepage abstraction if ground motion amplitude } \\
\text { (PGV) is large enough to collapse the drifts }\end{array}$ & $\begin{array}{l}\text { See DTN file } \\
\text { ResponseSurfaceSMPA } \\
\text { CollapsedDrift.dat }\end{array}$ & $\begin{array}{l}\text { DTN: LB0307SEEPDRCL.002 } \\
\text { [DIRS 164337] }\end{array}$ \\
\hline $\begin{array}{l}\text { Change in temperature of waste package if seismic } \\
\text { hazard is large enough to collapse the drifts }\end{array}$ & $\begin{array}{l}\text { See DTN files: } \\
\text { Twp_dhlw-I1_3case.dat, } \\
\text { Twp_dh/w-s1_3case.dat } \\
\text { ' } \\
\text { Twp_bwr1-1_3case.dat, } \\
\text { Twp_bwr1-2_3case.dat, } \\
\text { Twp_bwr2-1_3case.dat, } \\
\text { Twp_pwr1-1_3case.dat, } \\
\text { Twp_pwr1-2_3case.dat, } \\
\text { and } \\
\text { Twp_pwr2-1_3case.dat }\end{array}$ & $\begin{array}{l}\text { DTN: LL040310323122.044 } \\
\text { [DIRS 168769] }\end{array}$ \\
\hline $\begin{array}{l}\text { Change in relative humidity on the waste package if } \\
\text { seismic hazard is large enough to collapse the drifts }\end{array}$ & 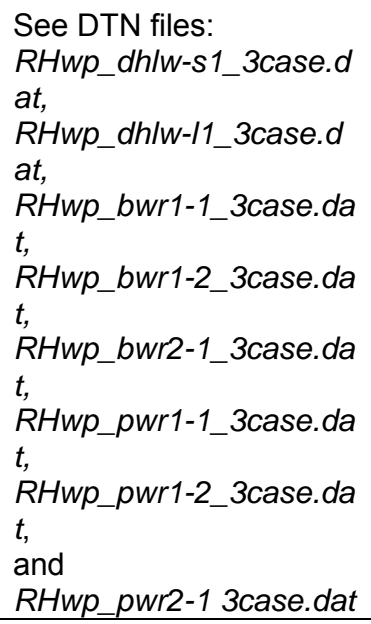 & $\begin{array}{l}\text { DTN: LL040310323122.044 } \\
\text { [DIRS 168769] }\end{array}$ \\
\hline
\end{tabular}




\subsection{RELEVANT FEATURES, EVENTS, AND PROCESSES FOR THE SEISMIC SCENARIO CLASS}

The development of a comprehensive list of features, events, and processes (FEPs) potentially relevant to postclosure performance of the potential Yucca Mountain repository is an ongoing, iterative process based on site-specific information, design, and regulations. The content of this report is relevant to the list of seismic-related FEPs extracted from the LA FEP list (DTN: MO0407SEPFEPLA.000 [DIRS 170760]) and shown in Tables 6.2-1 and 6.2-2. The damage abstractions for the waste package and cladding provide the basis for screening of the listed FEPs, based on the relevant sections of this report identified in Tables 6.2-1 and 6.2-2. Table 6.2-1 identifies the TSPA-LA FEPs that are included in the seismic scenario class and the Section in this report where each FEP is addressed. Table 6.2-2 identifies the TSPA-LA FEPs that are excluded from the seismic scenario class and the Section in this report where the screening argument is discussed.

Table 6.2-1. FEPs Included in Seismic Consequence Abstractions, their Disposition in TSPA-LA, and the Relevant Sections of this Report

\begin{tabular}{|c|c|c|}
\hline FEP \# & FEP Name & Section Where FEP is Addressed \\
\hline 1.2.02.03.0A & $\begin{array}{l}\text { Fault displacement } \\
\text { damages EBS } \\
\text { components }\end{array}$ & $\begin{array}{l}\text { Section } 6.7 \text { defines the damage abstraction for the waste package, drip } \\
\text { shield, and fuel rod cladding in response to fault displacement. Operation } \\
11 \text { in Section } 6.9 .2 \text { provides an algorithmic description and definition of } \\
\text { output parameters for the fault displacement damage abstraction for the } \\
\text { EBS components. Table } 6.9-1 \text { summarizes the } 24 \text { output variables for } \\
\text { TSPA-LA that specifically relate to damage from fault displacement. }\end{array}$ \\
\hline 1.2.03.02.0A & $\begin{array}{l}\text { Seismic ground } \\
\text { motion damages EBS } \\
\text { components }\end{array}$ & $\begin{array}{l}\text { Sections } 6.5 .1 \text { through } 6.5 .3 \text { define the damage abstraction for the waste } \\
\text { package in response to vibratory ground motion. Operations } 3 \text { through } 7 \\
\text { in Section } 6.9 .2 \text { provide an algorithmic description and definition of output } \\
\text { parameters for the damage abstractions for this barrier. Table } 6.9-1 \\
\text { summarizes the } 43 \text { output variables for TSPA-LA that specifically relate to } \\
\text { damage to the waste package from vibratory ground motion. } \\
\text { Sections } 6.5 .4 \text { and } 6.5 .5 \text { provide the basis for screening out damage to the } \\
\text { drip shield from vibratory ground motion for the TSPA-LA. } \\
\text { Section } 6.5 .6 \text { defines the damage abstraction for the fuel rod cladding } \\
\text { under vibratory ground motion. Operation } 10 \text { in Section 6.9.2 defines the } \\
\text { algorithm for the damage abstraction for cladding in the TSPA-LA. } \\
\text { Table 6.9-1 identifies the single output variable for the abstraction of } \\
\text { cladding damage. }\end{array}$ \\
\hline $\begin{array}{l}1.2 .03 .02 .0 \\
D\end{array}$ & $\begin{array}{l}\text { Seismic-induced drift } \\
\text { collapse alters in-drift } \\
\text { thermohydrology }\end{array}$ & $\begin{array}{l}\text { Section } 6.9 .2 \text { summarizes the changes in the in-drift environment after a } \\
\text { seismic event. Operations } 12 \text { and } 13 \text { in Section } 6.9 .2 \text { summarize the } \\
\text { methodology for the post-seismic event changes for TSPA. }\end{array}$ \\
\hline
\end{tabular}


Table 6.2-2. FEPs Excluded from Seismic Consequence Abstractions and the Relevant Sections of this Report

\begin{tabular}{|c|c|c|}
\hline FEP \# & FEP Name & Section Where FEP is Addressed \\
\hline 1.2.03.02.0B & $\begin{array}{l}\text { Seismic-induced } \\
\text { rockfall damages } \\
\text { EBS components }\end{array}$ & $\begin{array}{l}\text { Damage to EBS components from the seismically-induced fall of individual } \\
\text { rock blocks is excluded from the seismic scenario class for TSPA-LA. A } \\
\text { detailed technical discussion of the screening arguments for excluding this } \\
\text { FEP is presented in Features, Events, and Processes: Disruptive Events } \\
\text { (BSC } 2005 \text { [DIRS } 173981] \text {, Section 6.2.1.4). Selected analyses in } \\
\text { Section } 6.6 \text { support the screening arguments for this FEP and are } \\
\text { summarized here. } \\
\text { In the nonlithophysal zones, large rock blocks can be shaken free from the } \\
\text { walls and drop onto the drip shield under the influence of gravity. } \\
\text { Section } 6.6 .1 \text { provides a description of the rock block calculations and the } \\
\text { drip shield structural response calculations for impacts by individual rock } \\
\text { blocks. Analysis of en masse rockfall in the lithophysal zones is discussed } \\
\text { under FEP 1.2.03.02.0C (the next FEP in this table). } \\
\text { The damage to the drip shield from the impact of large rock blocks is not } \\
\text { included TSPA-LA. Damaged areas on the drip shield are susceptible to } \\
\text { accelerated stress corrosion cracking (Section } 6.3 .3 \text { ). However, the } \\
\text { quantity of liquid that can advectively flow through the resulting crack } \\
\text { network and impinge on the waste package will be insignificant, as } \\
\text { discussed in Engineered Barrier System Features, Events and Processes } \\
\text { (BSC } 2005 \text { [DIRS } 173781 \text { ], Section } 6.2 .64 \text { ). In this situation, damage to } \\
\text { the drip shield from discrete rock blocks is not included in the seismic } \\
\text { scenario class for TSPA-LA. } \\
\text { Damage to the waste package or fuel rod cladding from rock blocks is also } \\
\text { not included in the seismic scenario class for TSPA-LA. The drip shield } \\
\text { remains intact during the first 10,000 years to } 20,000 \text { years after repository } \\
\text { closure. In addition, the drip shield will not separate in response to } \\
\text { vibratory ground motions (Section } 6.5 .5 \text { ). The drip shield will deflect rock } \\
\text { blocks away from the waste package and cladding without collapsing or } \\
\text { contacting the waste package, even for the largest blocks (Section 6.6.1.2). } \\
\text { It follows that the drip shield provides protection for the waste package and } \\
\text { cladding from rockfall, so this damage mechanism is not included in } \\
\text { TSPA-LA. }\end{array}$ \\
\hline 1.2.03.02.0C & $\begin{array}{l}\text { Seismic-induced drift } \\
\text { collapse damages } \\
\text { EBS components }\end{array}$ & $\begin{array}{l}\text { Damage to EBS components from the en masse fall of rock due to } \\
\text { vibratory ground motion in the lithophysal zones is analyzed but not } \\
\text { abstracted into the seismic scenario class for TSPA-LA. A detailed } \\
\text { technical discussion of the screening arguments for excluding this FEP is } \\
\text { presented in Features, Events, and Processes: Disruptive Events } \\
\text { (BSC } 2005 \text { [DIRS } 173981 \text {, Section } 6.2 .1 .5 \text { ). Selected analyses in } \\
\text { Section } 6.6 \text { of this report support the screening arguments for this FEP, } \\
\text { and are summarized here. } \\
\text { Damage to EBS components from seismically-induced rockfall in the } \\
\text { lithophysal zones is analyzed but not abstracted into the seismic scenario } \\
\text { class for TSPA-LA. Vibratory ground motion can cause failure of the host } \\
\text { rock around the emplacement drifts, but is anticipated to cause insignificant } \\
\text { damage to the drip shield, waste package, and fuel rod cladding. The } \\
\text { lithophysal rock will fragment into small rock fragments that have little } \\
\text { capability to damage the drip shield, either from individual impacts or from } \\
\text { their static load, as discussed in Sections } 6.6 .2 \text { and } 6.6 .2 .1 \text {, respectively. } \\
\text { Damage to EBS components from lithophysal rockfall is not included in } \\
\text { TSPA on this basis. }\end{array}$ \\
\hline
\end{tabular}


The seismic scenario class is based on two modeling cases: (1) a case with mechanical damage from vibratory ground motion, and (2) a case with mechanical damage from fault displacement. Vibratory ground motions can cause impacts between the waste package, drip shield, pallet, and invert. These impacts may form through wall stress corrosion cracks, resulting in transport pathways for release of radionuclides from the EBS. Fault displacement causes the disruption of the drip shield, which can allow seepage water to initiate localized corrosion on the waste package under certain geochemical conditions. Either case has a single seismic event that occurs at a randomly chosen time in each realization of the TSPA-LA. Seismic events with PGV levels greater than $0.4019 \mathrm{~m} / \mathrm{s}$ (exceedance frequencies less than $10^{-4}$ per year on the bounded hazard curve at Point B, the emplacement drifts) are considered here because the associated ground motions and fault displacements have the potential to cause damage to the EBS components (Sections 6.5 and 6.7). The mechanical response of the drip shield, waste package, and fuel rod cladding to this single seismic event is represented through damage abstractions for vibratory ground motion and for fault displacement.

The mechanical response of the drip shield, waste package, and Zircalloy cladding to vibratory ground motion, to fault displacement, and to rockfall induced by vibratory ground motion are the central focus for the seismic scenario class. The drift invert and the waste package internals are considered in structural response calculations or rockfall analyses but are not represented as separate damage abstractions because they do not directly control the release radionuclides or the formation of advective flow pathways. The mass of the waste form is included in the structural response calculations but the mechanical strength of a stack of uranium oxide pellets or of a vitrified waste form is not significant in comparison to the mechanical strength of the inner stainless steel shell and outer Alloy 22 shell of the waste package. Finally, non-Zircalloy cladding is not considered here because it has no contribution to barrier capability.

The areas on the waste package and drip shield that exceed a residual stress threshold are susceptible to accelerated stress corrosion cracking, resulting in a network of stress corrosion cracks that has the potential to provide a pathway for transport through the engineered barrier system. Once radionuclides are released from the waste package, flow and transport in the unsaturated zone and the saturated zone are based on the same models and algorithms as for the nominal scenario class, with the exception of changes to the in-drift environment caused by drift collapse in the lithophysal zones of the repository. Biosphere calculations are also unchanged from those for the nominal scenario class.

\subsection{FAILURE MECHANISM, RESIDUAL STRESS THRESHOLDS, AND FAILURE MORPHOLOGY FOR THE WASTE PACKAGE AND DRIP SHIELD}

\subsubsection{Failure Mechanisms Under Seismic Loads}

Mechanical processes that occur during a significant seismic event (i.e., an event with PGV greater than $0.4019 \mathrm{~m} / \mathrm{s}$, with the capacity to damage the waste package) have the potential to compromise the functionality of the waste packages, drip shields, and fuel rod cladding as barriers to radionuclide release. These mechanical processes include impacts caused directly by vibratory ground motion during an earthquake, impacts caused by rock blocks and rockfall induced by vibratory ground motions, and mechanical loading from fault displacement. 
Under significant vibratory ground motions, impacts can occur between adjacent waste packages and between the waste package and its emplacement pallet, the surrounding drip shield, and the invert. Impacts can also occur between the drip shield and the emplacement pallet, the invert, and even the drift wall. Rockfall induced by vibratory ground motions can result in impacts on the drip shield in the postclosure period and impacts on the waste packages in the preclosure period, when drip shields are not yet in place. Rockfall induced by vibratory ground motion in the lithophysal zones may collapse the drifts, resulting in static loads from the mass of rubblized rock surrounding the drip shield. Finally, mechanical loads may be generated by fault displacement within the repository block. In this case, EBS components may become pinned if fault displacement is greater than the available clearances between components.

These mechanical processes are associated with a number of potential failure mechanisms, each of which is discussed below:

- Peak dynamic loads have the potential to result in immediate puncture or tearing of an EBS component if the localized strain exceeds the ultimate tensile strain. A puncture provides a potential pathway for seepage to flow into and radionuclide transport out of an EBS component.

- Impact-related dynamic loads may dent a component, resulting in permanent structural deformation with residual stress. High levels of residual tensile stress may lead to local degradation from accelerated corrosion processes. Areas that are breached from corrosion processes provide a potential pathway for radionuclide transport out of an EBS component.

- Static loads from rockfall may collapse or buckle the drip shields. Buckling or collapse represents a change in the physical shape of the drip shield, potentially compromising its ability to deflect seepage and rockfall away from the waste package.

- Impacts between adjacent waste packages impose dynamic loads on waste package internals. These dynamic loads may result in buckled fuel rods and perforated fuel rod cladding. Failure of cladding provides a potential pathway for release of radionuclides from fuel rods.

- Large displacements on known faults in the repository block may shear waste packages and drip shields if the EBS components become pinned by the fault response. Sheared components provide potential pathways for flow into and radionuclide transport out of the damaged components.

The outer wall of the waste package is fabricated from Alloy 22, which is very ductile. Immediate puncture or tearing of waste package outer wall would be accompanied by large distortions that produce high strains and stresses in a significant volume of material. Supporting calculations for waste package drops on the emplacement pallet were performed using a refined finite-element representation of a waste package. These supporting calculations used impact velocities that are similar to those observed in the kinematic calculations for end-to-end impacts of adjacent waste packages (Section 6.5.1). The supporting calculations indicate that the maximum stress intensity developed in the outer wall of the waste package is significantly below the ultimate tensile strength of Alloy 22 (BSC 2003 [DIRS 165497]). A localized puncture or 
tearing due to the impacts caused by vibratory ground motions is not expected during a seismic event and is therefore not included in the seismic scenario class.

The presence of high residual tensile stress has the potential to result in accelerated stress corrosion cracking (Sections 6.3.2 and 6.3.3). This combined mechanical-corrosion failure mechanism is expected to be the cause of failure for the waste package and drip shield from impact processes caused by vibratory ground motions and by rockfall induced by vibratory ground motions. The areas that exceed the residual tensile stress threshold are referred to as the damaged area throughout this document. The effective area for radionuclide transport through the damaged areas will be substantially less than the damaged area because the cross-sectional area of the stress corrosion cracks is much less than the total surface area that exceeds the residual stress threshold, as derived in Sections 6.3.5 and 6.3.6.

Application of a residual tensile stress threshold for seismic failures is nonmechanistic in the sense that detailed calculations with accelerated corrosion rates or crack propagation are not used to determine the actual failure time after a seismic event. Rather, a network of SCCs is considered to immediately form once the residual tensile stress threshold is exceeded, providing potential pathways for radionuclide transport through the areas exceeding the residual tensile stress threshold. The residual tensile stress threshold is often referred to as the residual stress threshold or more simply the stress threshold, with the understanding that the principal residual stress must always be tensile to initiate an accelerated corrosion process.

Figure 6.3-1 is a simplified illustration of how residual stress is generated by permanent (plastic) deformation in a simple uniaxial strain model. The loading path in Figure 6.3-1 has three phases: (1) elastic loading until reaching the yield strength, (2) plastic loading above the yield strength, and (3) elastic unloading when the external load reduces the local stress. Figure 6.3-1 also shows that plastic deformation does not always generate a damaged area because the final residual stress state may be compressive or, if tensile, may be below the tensile threshold to initiate accelerated localized corrosion or stress corrosion cracking.

The static loads from rockfall may initiate plastic deformation, potentially leading to buckling or collapse of the drip shield (Section 6.6.2.2). The appropriate failure criterion for the onset of plastic deformation is the yield strength, which corresponds to the point at the top of the elastic loading path in Figure 6.3-1. The physical configuration of the drip shield can change when local stresses exceed the yield strength, resulting in plastic deformation of the structure. It is important to differentiate between the two failure criteria for the drip shield. For impact loading, an area may be damaged as a barrier when it exceeds the residual stress threshold of Titanium Grade 7, as discussed in Section 6.3.3. This failure is a combined mechanical-corrosion response of a cold-worked material to dynamic impacts. For plastic deformation from static loading of the drip shield, failure is determined by the yield strength at the onset of plastic yielding, as discussed in Section 6.6.2.2. These criteria are applied separately and independently because the appropriate failure mechanisms are distinct physical responses to different loading conditions and failure modes.

The dynamic loads on fuel rods from end-to-end impacts of adjacent waste packages have the potential to buckle the fuel rods and fail the fuel rod cladding. The primary cladding failure mechanism is perforation due to accelerations when the waste package impacts the emplacement 
pallet or when there is an end-to-end impact of adjacent waste packages (see discussion in Section 6.5.6). The $g$-loads required to buckle fuel rods are estimated from a simple analytic model based on Euler buckling of a column in Impact Effects on Spent Fuel Assemblies (Chun et al. 1987 [DIRS 144357]). It is estimated that the cladding fails when the impact accelerations are in the range of $82 \mathrm{~g}$ to $252 \mathrm{~g}$ for axial impacts and $63 \mathrm{~g}$ to $211 \mathrm{~g}$ for lateral impacts (Chun et al. 1987 [DIRS 144357], Table 4).

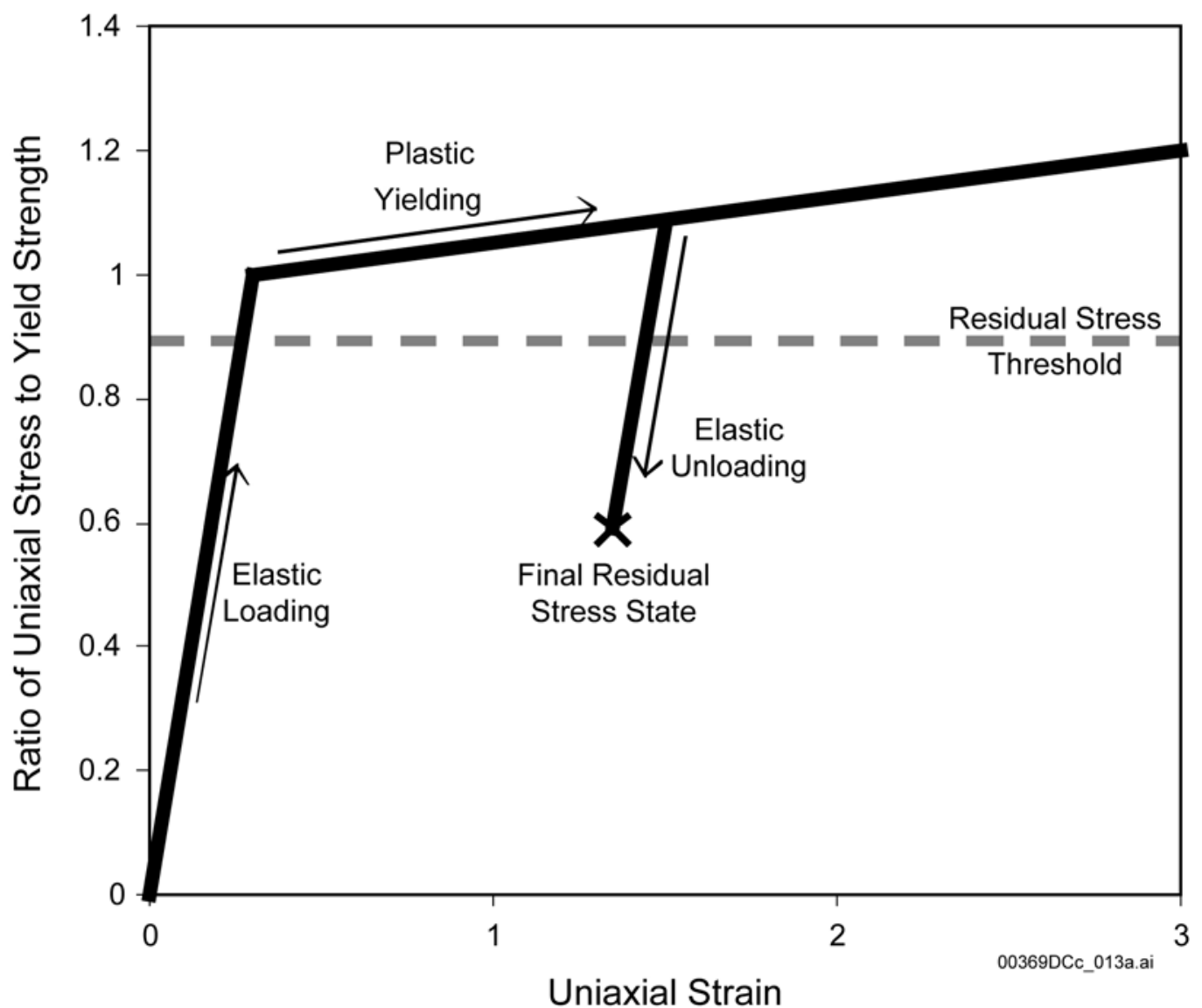

Figure 6.3-1. Permanent Deformation from Plastic Yielding Generates Residual Stress

Large displacements on known faults in the repository block have the potential to shear waste packages and drip shields if the EBS components become pinned by the fault response. The response of EBS components to fault displacement is discussed in Section 6.7. Given the complexity of the response of EBS components and the invert to a fault displacement, a simplified failure criterion has been applied to determine shear failure in a collapsed drift. If the fault displacement is greater than the clearance between the top of a waste package and the underside of the drip shield, the waste package is modeled as failing from shear. This simple failure criterion is appropriate because shear failure from fault displacement only occurs from extremely low-frequency, high-amplitude fault displacements, corresponding to an annual exceedance frequency of less than or equal to $2 \times 10^{-7}$ per year.

Accelerated stress corrosion cracking from high residual stress is expected to be the cause of failure for the waste package from impact processes in the seismic scenario class. The residual 
stress thresholds for seismic response are similar to the criteria for initiation of stress corrosion cracking on smooth surfaces of Alloy 22 (BSC 2004 [DIRS 172203], Section 6.2.1, with thresholds defined on p. 6-7). The use of a stress corrosion cracking initiation criterion is appropriate for seismic analysis because regions where the residual stress from mechanical damage exceeds the tensile failure criterion are expected to be extensively cold-worked and, hence, potentially subject to enhanced stress corrosion cracking.

A residual stress threshold is a conservative failure criterion because detailed corrosion models will have a delay time until failure. This approach is appropriate because it is consistent with other tensile failure criteria (BSC 2004 [DIRS 172203], Section 6.2.1, second paragraph on p. 6-7) and because it is easily applied to the output from structural response calculations.

\subsubsection{Residual Stress Damage Threshold for the Waste Package}

The residual stress threshold for failure of the waste package is represented by a uniform distribution with a lower bound of 80 percent of the yield strength of Alloy 22 and an upper bound of 90 percent of the yield strength of Alloy 22. The upper bound is based on experimental data and conservatively incorporates a safety factor of 2.2 because of the very long lifetime of the waste package (BSC 2004 [DIRS 172203], Section 6.2.1, second paragraph on p. 6-7). The lower bound is introduced to evaluate the effect of the potential uncertainty in the residual stress threshold on the damaged area. This residual stress criterion ( 80 to 90 percent of the yield strength) is also consistent with the failure criterion for initiation of stress corrosion cracking in other waste package analyses.

In practice, the damage to the waste package has been evaluated at the extremes of the uniform distribution. The results from each structural response calculation are postprocessed to determine the elements in the outer barrier of the waste package whose residual stress exceeds 80 percent of the yield strength of Alloy 22 and to determine the elements in the outer barrier of the waste package whose residual stress exceeds 90 percent of the yield strength of Alloy 22 . These elements are then converted into an area susceptible to accelerated stress corrosion cracking at the 80 and 90 percent criteria. The appropriate areas at intermediate values of the residual stress threshold can then be defined by linear interpolation between the extremes. The elements that exceed 90 percent of the yield strength are always a subset of the elements that exceed 80 percent of the yield strength. In other words, the damaged area for the 90 percent residual stress threshold is always less than or equal to the damaged area for the 80 percent residual stress threshold.

\subsubsection{Residual Stress Damage Threshold for the Drip Shield}

For the titanium plates on the drip shield, the residual stress threshold for failure is represented by a fixed lower bound of 50 percent of the yield strength of the drip shield plate material (Titanium Grade 7) (BSC 2004 [DIRS 172203], Section 6.2.1, second paragraph on p. 6-7). The fixed bound is based on experimental data and conservatively incorporates a safety factor of 2.2 because of the long lifetime of the drip shield (BSC 2004 [DIRS 172203], Section 6.2.1, second paragraph on p. 6-7). The following discussion is abridged from Stress Corrosion Cracking of the Drip Shield, the Waste Package Outer Barrier, and the Stainless Steel Structural Material 
(BSC 2004 [DIRS 172203], Section 6.2.1), where a more detailed discussion of the experimental data and the technical basis for this threshold can be found.

There is extensive experimental data for Titanium Grade 7 that justifies the use of 50 percent of yield strength as a stress corrosion cracking initiation criterion. These data include long-term constant load tests in a concentrated brine environment ( $\sim 15$ percent Basic Saturated Water, designated as $\mathrm{J}-13$ ) at $105^{\circ} \mathrm{C}$ with specimens loaded to stresses of 110 percent to 140 percent of the yield strength. Some specimens failed relatively early ( $\leq 168$ hours) at applied stresses in excess of 110 percent of yield strength. At 110 percent of yield strength, there is a mixture of failure and non-failure run out times from about 200 hours for first failure to greater than several thousand hours without failure. These data are consistent with a failure threshold that is less than 110 percent of yield strength.

A second source of information regarding the stress corrosion cracking initiation criterion for Titanium Grade 7 comes from U-bend tests. Initiation of stress corrosion cracking is not observed in fixed deflection U-bend tests on Titanium Grade 7 exposed for one year and Titanium Grade 16 (an analogous titanium/palladium alloy) exposed for five years to a range of relevant aqueous environments at $60^{\circ} \mathrm{C}$ and $90^{\circ} \mathrm{C}$ in the Lawrence Livermore National Laboratory Long Term Corrosion Test Facility. These U-bend tests are more representative of secondary residual stress loading that might result from deformation following seismic loadings. These U-bend specimens are deflected and then restrained to give apex strains (cold-work level) of greater than 10 percent, which results in sustained stress levels near the yield strength. A very conservative value of 50 percent of yield strength is selected as a threshold criterion for Titanium Grade 7, even though the initiation of stress corrosion cracking is not observed for residual stresses greater than yield strength.

\subsubsection{Morphology of Damage on the Waste Package}

The material for the waste package outer corrosion barrier, Alloy 22, has been shown to be potentially susceptible to stress corrosion cracking under environmental conditions that are relevant to the repository. The stress corrosion cracking mode (morphology) is transgranular stress corrosion cracking (TGSCC), rather than the intergranular stress corrosion cracking which is commonly observed in pressurized systems, such as pipelines or light water reactor components (Andresen et al. 2001 [DIRS 167840]). The primary issue for the seismic scenario class is to define the effective area and transport mode (advective or diffusive) resulting from seismically-induced deformation and the associated TGSCC through the outer corrosion barrier of the waste package. The conditions leading to TGSCC and the potential geometry of the crack system have therefore been investigated in Stress Corrosion Cracking of the Drip Shield, the Waste Package Outer Barrier, and the Stainless Steel Structural Material (BSC 2004 [DIRS 172203], Sections B6.1 through 6.3), and are summarized below.

Seismically induced deformation has the potential to initiate and propagate cracks on the outer barrier of the waste package. A range of aqueous brine type environments may form on the waste package outer corrosion barrier, producing the requisite concurrent conditions for accelerated stress corrosion cracking: (1) high residual tensile stress, (2) an environment that supports corrosion, and (3) a material that has been cold worked during the seismic event. Once initiated, the strain fields (residual stresses) produced by the seismically induced impacts can 
drive crack growth. Depending on the stress distribution, cracks may propagate through-wall if the stress intensity factor remains positive. If multiple cracks are initiated in the same general area, it is theoretically possible, but not expected, that multiple cracks can intersect or coalesce, creating a continuous crack around the deformed region.

There is a very low probability that a residual stress profile would be created that would allow an initiated stress corrosion crack to propagate both through-wall and circumscribing a dent or deformed area. Any through-wall residual stress fields resulting from seismic impact loads would be a secondary type stress (displacement controlled). There is no significant stress from other sources, such as stress induced by internal pressure. In addition, stresses and strains are generally of higher magnitude at the outer surface and tend to decrease through the thickness for the deformation-induced damage from a seismic event. In this situation, any crack that initiates and propagates may arrest before penetrating the full thickness of the outer barrier and is not expected to have a positive stress intensity factor throughout that could result in both through-wall and $360^{\circ}$ cracking around the entire dent (BSC 2004 [DIRS 172203], Sections B6.1 and B6.3).

Even postulating that a through-wall crack occurs and circumscribes the dented area, the nature of stress corrosion cracking will preclude the dented area from falling out. Cracks in Alloy 22 are transgranular, but whether transgranular or intergranular, the crack path has complex local branches with a roughness and tortuosity, as illustrated in Figure 6.3-2 (BSC 2004 [DIRS 172203] Figure B-1), that make it geometrically impossible for an inner "plug" to disengage from the vessel in the absence of a superimposed primary load (i.e., significant internal pressure). Any internal pressure that develops from heat up to about $150^{\circ} \mathrm{C}$ and/or corrosion-generated gas with the small amount of internal water vapor that is available would not be sufficient to force the dented area from the wall.

This analysis is consistent with many years of experience with stress corrosion cracks in light water reactor components and other internally pressurized systems (BSC 2004 [DIRS 172203], Section B6.3). A number of incidents of stress corrosion cracking have been observed in light water reactors involving both austenitic stainless steels and nickel-based alloys. The observed stress corrosion cracking has been extensive in many of these incidents, sometimes becoming fully circumferential in response to weld-induced residual tensile stress and pressure-induced primary stresses. Even under these conditions, which are more severe than in the post-seismic environment, there has not been a documented case where any Section of material dropped out as a result of the observed cracking (BSC 2004 [DIRS 172203], Section B6.3).

\subsubsection{Effective Area for Transport From the Waste Package}

Since the expected failure mechanism from a seismic event is accelerated stress corrosion cracking and since the damaged areas that exceed the residual stress failure for Alloy 22 are expected to remain physically intact, it is reasonable to represent these areas as a dense network of stress corrosion cracks, rather than as a plug of material that separates from the outer barrier. The effective area for transport through the crack network has been estimated with the following procedure. 


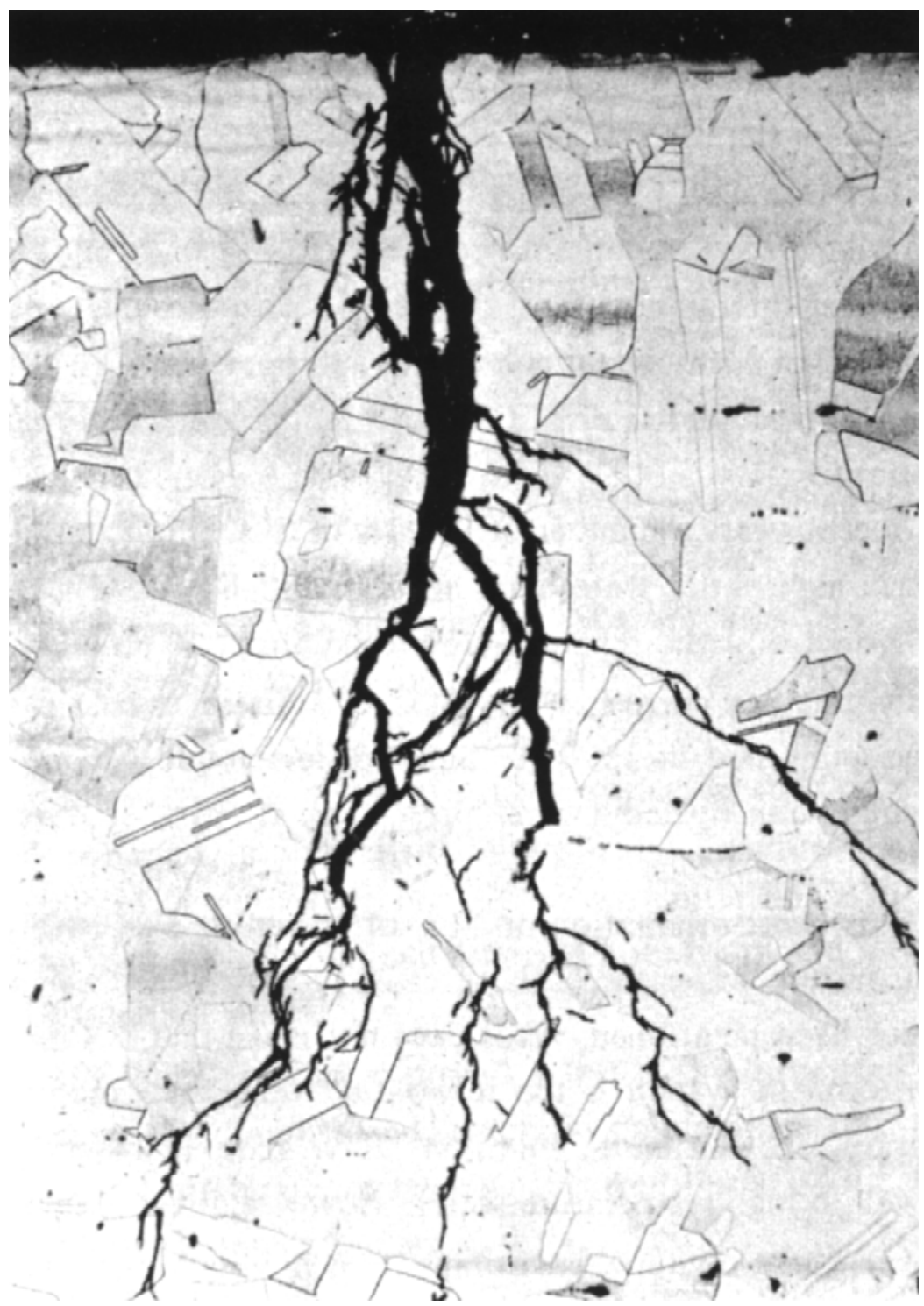

Source: BSC 2004 [DIRS 172203], Figure B-1.

Figure 6.3-2. Typical Example of TGSCC in Stainless Steel

The range of crack densities and crack widths has been estimated for four closely spaced networks of cracks (BSC 2004 [DIRS 172203] Section B6.4; DTN: MO0403SPASCRKD.000 [DIRS 168105]). Figure 6.3-3 presents one of these hexagonal arrays, with parallel rows of randomly oriented cracks. In this approach, centers of through-wall cracks are located in a densely packed hexagonal array and are separated by at least a wall thickness. The wall thickness is anticipated to be the minimum possible separation because stress relief from propagation of adjacent cracks relieves the local stress intensity factor, preventing tighter spacing between through-wall cracks. The width of each crack is estimated by assuming an elliptical opening with constant through-wall stress given by the yield strength. This is a conservative approach because the crack tips tend to narrow at the inner surface (Figure 6.3-2) and because stress relief from adjacent cracks will again tend to reduce the local stress levels at a crack. 


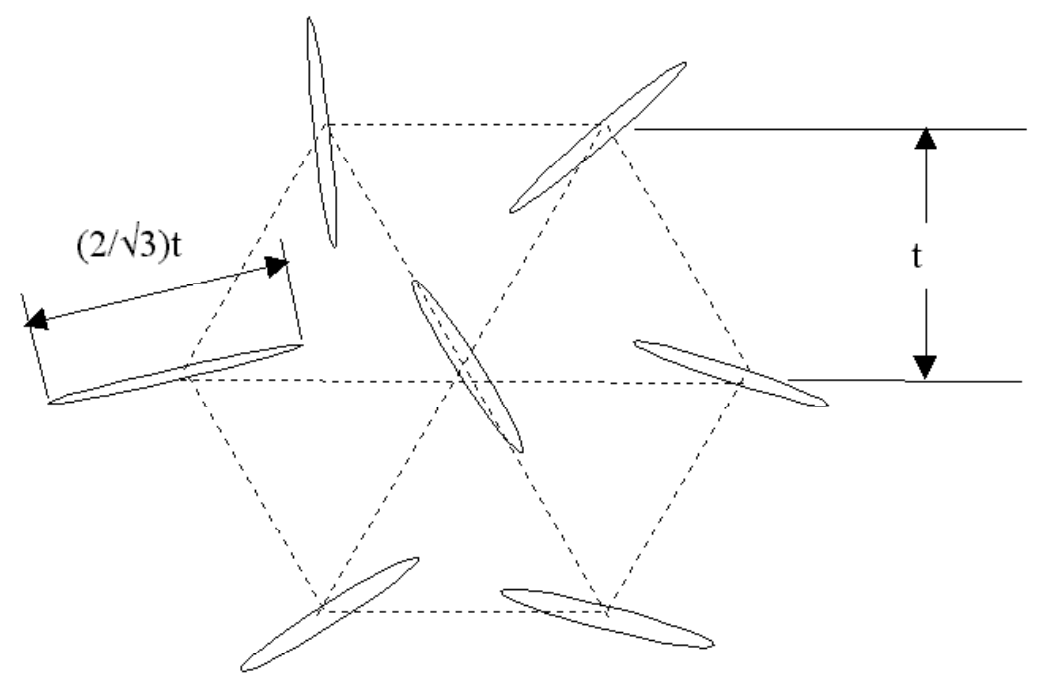

Source: BSC 2004 [DIRS 172203], Figure B-4.

NOTE: Not drawn to scale.

Figure 6.3-3. Parallel Rows of Randomly Oriented Flaws, with Row Spacing Equal to Wall Thickness, $t$

The hexagonal network of closely spaced cracks is a convenient conceptual model for estimating a range of crack densities and crack opening areas for TSPA-LA. However, this crack geometry is not commonly observed in industrial systems. Rather, an axisymmetric dent often produces cracks that are oriented circumferentially around the center of the dent because the circumferential direction is normal to the main stress gradients in the radial direction. An analysis for circumferential cracks (BSC 2004 [DIRS 172203], Section B6.4.3) indicates that the effective area of a typical circumferential crack network is within the range of uncertainty from the hexagonal model.

The effective cross-sectional area for transport out of the waste package per unit damaged area is given by the product of the crack density per unit surface area, $\rho_{S C C}$, and the gap area per crack, $A_{S C C}$. The product, $\rho_{S C C} A_{S C C}$, ranges from 0.00328 to 0.0131 (BSC 2004 [DIRS 172203], Table B-2) for the four crack networks. Stated differently, the effective transport area through the crack network is a factor of 76 to 305 less than the failed surface area that exceeds the residual stress threshold. The product has been evaluated using material properties for room temperature because this is slightly more conservative than material properties at $150^{\circ} \mathrm{C}$.

A comprehensive analysis of the potential for advective flow through the stress corrosion crack (SCC) network in the waste package indicates that advective flux will be insignificant (BSC 2005 [DIRS 173781], Section 6.2.63). Advection of liquid and solid material through SCCs in the waste package outer barrier is limited, and is not expected to admit significant quantities of liquid water into the waste package. The potential flow through stress corrosion is so small that its omission from TSPA has an insignificant effect on the magnitude and time of radionuclide releases to the accessible environment. Advective flow of seepage through SCCs on the waste package outer barrier is excluded from TSPA on the basis of low consequence. 
The SCC network does provide a potential pathway for diffusive transport of radionuclides out of the waste package. The effective area for diffusive transport from the waste package is determined by the product of two random parameters, $\rho_{S C C} A_{S C C}$. The first parameter is the factor defining the ratio of effective area for diffusive transport to damaged area on the waste package. This factor is determined in each realization of the seismic scenario class by sampling a uniform distribution with a lower bound of 0.00328 and an upper bound of 0.0131 . The second parameter is the damaged area on the waste package, which is a random distribution whose upper bound is a function of PGV of the seismic disturbance. The product of these two parameters determines the effective area for diffusive transport from the waste package in each realization.

\subsubsection{No Advective Flow Through the Drip Shield}

Advection of liquids and solids through cracks in the drip shield is excluded on the basis of low consequence. A comprehensive technical analysis of the potential for advective flow through an SCC network on the drip shield indicates that advective flux will be insignificant (BSC 2005 [DIRS 173781], Section 6.2.64). This conclusion is based on the combination of several factors: (1) there are few damaging rockfall events, (2) creep and stress relaxation in dented areas on the drip shield may eliminate formation of through-wall cracks, and (3) capillary effects, evaporation, and plugging in tight cracks can significantly limit the amount of seepage water that can flow through cracks in the drip shields. Because the advection of liquid and solids through the drip shield will be minor, its omission from TSPA-LA will have an insignificant effect on the magnitude and time of the resulting radionuclide releases to the accessible environment. The complete technical discussion for this FEP exclusion argument is in BSC 2005 ([DIRS 173781], Section 6.2.64 and Appendix C).

\subsection{GROUND MOTIONS AT THE EMPLACEMENT DRIFTS}

\subsubsection{Probabilistic Seismic Hazard Analysis}

A PSHA was performed to assess the seismic hazards of vibratory ground motion and fault displacement at Yucca Mountain. The PSHA (CRWMS M\&O 1998 [DIRS 103731]) provides quantitative hazard results to support an assessment of the repository's long-term performance and to form the basis for developing seismic design criteria for the license application. Key attributes of the PSHA methodology for Yucca Mountain are: (1) utilization of an extensive geologic and seismologic database developed over a 20-year period in the Yucca Mountain region; (2) explicit consideration and quantification of uncertainties regarding alternative seismic-source, ground-motion, and fault-displacement models; and (3) use of a formal, structured expert elicitation process to capture the informed scientific community's views of key inputs to the PSHA.

The PSHA methodology for vibratory ground motions has become standard practice for deriving vibratory ground motion hazards for design purposes. Less commonly, probabilistic fault displacement analyses are conducted to provide quantitative assessments of the location and amount of differential ground displacement that might occur. Both analyses provide hazard curves, which express the annual frequency of exceeding various amounts of ground motion (or fault displacement). The resulting seismic hazard curves represent the integration over relevant 
earthquake sources and over the magnitudes of the frequency of future earthquake occurrence and, given an occurrence, its effect at a site of interest.

The basic elements of a PSHA for vibratory ground motions are:

a) Identification of seismic sources that contribute to the vibratory ground motion hazard at Yucca Mountain and characterization of their geometry;

b) Characterization of seismic sources by the recurrence rate of earthquakes of various magnitudes and the maximum magnitude;

c) Attenuation relations that define a specified ground motion parameter (such as peak ground velocity) as a function of magnitude, source-to-site distance, local site conditions, and, in some cases, seismic source characteristics;

d) Integration of the seismic source characterization and ground motion attenuation evaluations, including associated uncertainties, into a seismic hazard curve and associated uncertainty distribution.

Probabilistic fault displacement hazard analysis follows a similar path:

a) Identification of fault sources of fault displacement (principal faults);

b) Characterization of the frequency, size, and locations of displacements on principal faults;

c) Characterization of the amounts and locations of subsidiary displacements as a function of distance from principal faults and magnitudes;

d) Integration of source characterization and distance distribution, including associated uncertainties, into a fault displacement hazard curve and associated uncertainty distribution.

The PSHA incorporates both variability and uncertainty. Variability, also termed randomness or aleatory uncertainty, is the natural randomness in a process. For discrete variables, the randomness is parameterized by the probability of each possible value. For continuous variables, the randomness is parameterized by the probability density function. An example of variability is the range of amplitudes of ground motions that would occur at a particular location from repeated earthquakes having exactly the same magnitude at exactly the same distance (say, magnitude 6 at 25-km distance). Variations in ground motion amplitude are expected due to unknowable complexities in earthquake-to-earthquake source properties and in the propagation path.

Uncertainty, also termed epistemic uncertainty, is the scientific uncertainty in the model of the process. It is due to limited data and knowledge. The uncertainty is characterized by alternative models and/or parameter values. For discrete random variables, the epistemic uncertainty is modeled by alternative probability distributions. For continuous random variables, the uncertainty is modeled by alternative probability density functions. Examples of uncertainty are 
alternative ground motion attenuation relations that express the median amplitude of ground motion at a particular site as a function of distance to the source and earthquake magnitude. Unlike variability, uncertainty is potentially reducible with additional knowledge and data.

Given the input evaluations, the hazard calculation method integrates over of the full range of the variables and estimates the annual frequency of exceedance of any ground-shaking amplitude at the site. The hazard curve quantifies the variability of the earthquake occurrence and ground-shaking attenuation. In addition to the variability of the seismic hazard, however, is uncertainty about the seismotectonic environment of a site. Significant advances in development of methodology to quantify uncertainty in seismic hazard have been made in the past 20 years, as discussed in Probabilistic Seismic Hazard Analysis: Guidance on the Uncertainty and Use of Experts (Budnitz et al. 1997 [DIRS 103635]). These advances involve the development of alternative interpretations and representations of the earthquake sources and of the propagation of ground motions from the sources to the site. Evaluations by multiple experts are made within a structured expert elicitation process designed to minimize uncertainty due to uneven or incomplete knowledge and understanding (Budnitz et al. 1997 [DIRS 103635]). The weighted alternative interpretations are expressed by use of logic trees. Each pathway through the logic tree represents a weighted interpretation of the seismotectonic environment of the site for which a seismic hazard curve is computed. The result of computing the hazard for all relevant pathways is a distribution of hazard curves representing the full variability and uncertainty in the hazard at a site.

The seismic scenario class for TSPA-LA uses the mean hazard curves for peak ground velocity and for fault displacement. Each mean hazard curve, which is defined as the mean estimate or average of the distribution of hazard curves referred to in the preceding paragraph, typically lies above the 80th percentile of the distribution because the average is dominated by the larger values of the distribution. The use of the mean hazard curves simplifies the Monte Carlo sampling process for TSPA and provides an accurate representation for the mean dose to the reasonably maximally exposed individual, as required to demonstrate acceptable repository performance over 10,000 years.

\subsubsection{Site-Specific Ground Motions}

Site-specific ground motions are needed for the structural response calculations and rockfall analyses supporting postclosure performance assessment. Ground motion results from the PSHA are for a hypothetical reference rock outcrop and do not reflect site-specific soil and rock properties at the locations for which the ground motions are needed (e.g., the emplacement area level). The PSHA was conducted in this fashion because the site-specific rock and soil properties were not characterized at the time of the PSHA. Thus, further analyses are carried out to modify the PSHA results to reflect the appropriate site-specific conditions for the site of interest. These site-specific analyses are briefly described here, based on the detailed description in Development of Earthquake Ground Motion Input for Preclosure Seismic Design and Postclosure Performance Assessment of a Geologic Repository at Yucca Mountain, NV (BSC 2004 [DIRS 170027]).

Postclosure performance assessment requirements determine the location and the annual exceedance probabilities for which site-specific ground motions are needed. For analyses 
supporting postclosure performance assessment, site-specific ground motions are developed for the waste emplacement level. Selection of annual exceedance probabilities is motivated by the requirement to "consider only events that have at least one chance in 10,000 of occurring over 10,000 years" (10 CFR 63.114(d) [DIRS 173273]). To address this requirement, ground motions are developed for PGV levels of $1.05 \mathrm{~m} / \mathrm{s}, 2.44 \mathrm{~m} / \mathrm{s}$, and $5.35 \mathrm{~m} / \mathrm{s}$, corresponding to annual exceedance probabilities of $1 \times 10^{-5}, 1 \times 10^{-6}$, and $1 \times 10^{-7}$ per year on the unbounded hazard curve at the waste emplacement level. Analyses using the developed ground motions form the basis for evaluating repository performance for seismic events with annual exceedance probabilities from $1 \times 10^{-4}$ per year to as low as $1 \times 10^{-8}$ per year.

A detailed site response model provides the basis for development of seismic time histories at the emplacement drifts (BSC 2004 [DIRS 170027]). Different approaches are used for developing time histories depending on how they will be used (e.g., in design or in evaluating postclosure repository performance). For Yucca Mountain, three approaches have been used to develop time histories: spectral matching, scaling to peak ground velocity, and scaling to peak ground velocity preceded by spectral conditioning. The spectral-matching approach is used primarily to develop time histories that will be used in design analyses and is not discussed further here.

The peak-ground-velocity scaling approaches are used to develop time histories for postclosure analyses. The goal of these analyses is to determine how the EBS components perform under earthquake loads that are significantly beyond their design basis. In addition to determining the consequences of these low-probability ground motions, another goal is to evaluate the variability in the consequences. Because much of the variability in consequences will be driven by random variability in the ground motion, the time histories for postclosure analyses are developed to capture and represent that random variability.

Peak ground velocity is selected as the scaling parameter because damage to underground structures has been correlated with peak ground velocity (McGarr 1984 [DIRS 163996], p. 206). PGV is appropriate for structural damage caused by sliding or impact under earthquake loads (Newmark and Rosenblueth 1971 [DIRS 151246], Sections 11.3.5 and 11.4). Finally, PGV is also appropriate for the response of a rock mass to dynamic loading because the change in stress across a weak compression wave $^{6}$ is directly proportional to the particle velocity. The abstractions in this document therefore use the horizontal PGV as the measure of the amplitude of the ground motion.

In the PGV-scaling approach, the earthquake recordings are scaled such that their peak ground velocity matches the peak ground velocity determined in the site-response analysis for a location of interest. The records may be scaled such that both horizontal components match the target horizontal peak ground velocity and the vertical component matches the target vertical peak ground velocity. Alternatively, one horizontal component may be scaled to the target horizontal peak ground velocity with the scaling of the other components done in a manner to maintain the intercomponent variability of the original recordings. Both of these methods have been used at Yucca Mountain.

\footnotetext{
6 A compression wave, also known as a p-wave, has particle velocity in the same direction as the direction of wave propagation. The wave is weak if the wave velocity is equal to the acoustic (compressional) velocity in the medium. An acoustic wave in air is an example of a weak compression wave.
} 
For each annual exceedance frequency of interest, 17 sets of time histories are developed. Each set of time histories consists of acceleration, velocity and displacement in each of two horizontal component directions and in the vertical component direction. The site-specific time histories are based on actual recordings of strong ground motion from earthquakes in the western United States and around the world (McGuire et al. 2001 [DIRS 157510], Appendix B). Recordings are selected to represent those earthquakes that dominate the seismic hazard at a given annual probability of exceedance. In other words, the recordings used as a basis for the time histories are selected to have a range of magnitudes and distances that corresponds to the magnitudes and distances of earthquakes making the dominant contribution to the seismic hazard at the given annual exceedance frequency. By basing the time histories on actual earthquake recordings and choosing records consistent with the seismic hazard, the resulting time histories exhibit realistic frequency content and phase characteristics as well as durations.

A variation of the PGV-scaling approach involves spectrally conditioning the original strong-ground-motion records before using them to develop time histories. Spectral conditioning modifies the original strong motion records such that their response spectra reflect to a greater degree the site conditions at Yucca Mountain. Conditioning can be done with respect to the PSHA reference rock outcrop conditions (referred to as Point A in Figure 6.4-1) or to the waste emplacement level conditions (referred to as Point B in Figure 6.4-1) that reflect the site response. Conditioning can be thought of as a weak spectral match. A strong spectral match is not desired in this case because it would tend to reduce the random variability of the original recordings.

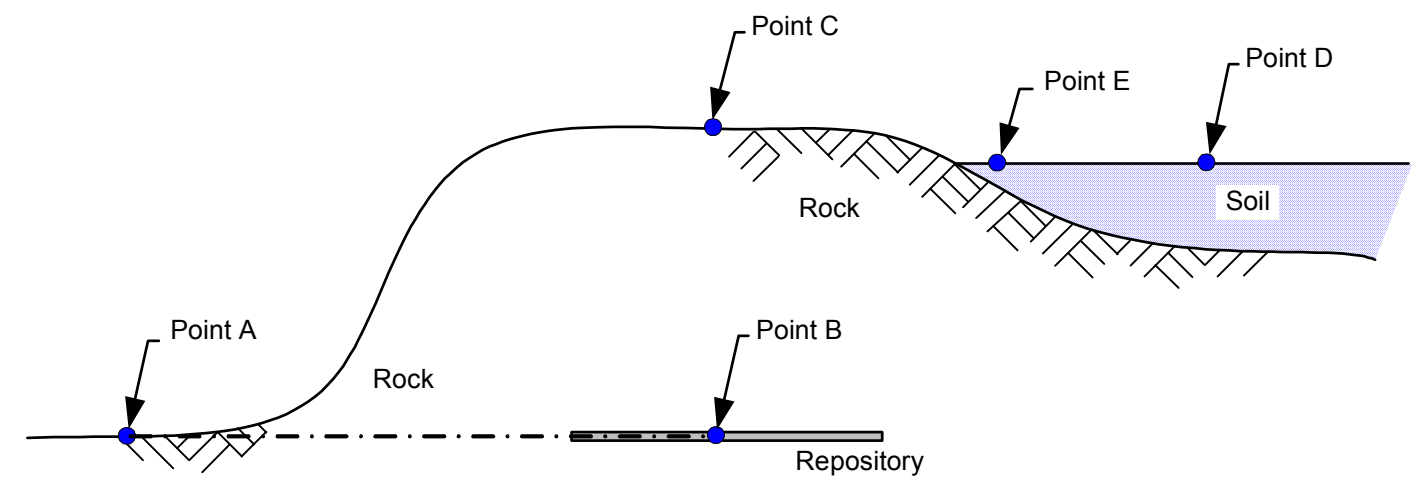

LEGEND

Modified from CRWMS M\&O 1998

Point "A" - Reference rock outcrop

Point "B" - Repository elevation

Point "C" - At rock surface

Point "D" - At surface of significant soil layer over rock

Point "E" - At surface of shallow soil layer over rock

Source: Modified from CRWMS M\&O 1998 [DIRS 103731].

Figure 6.4-1. Schematic Diagram Showing Location of Points A and B

For the 2.44-m/s PGV level, two suites of 17 sets of time histories each were developed. The 17 sets of recorded strong ground motion that form part of the basis for the time histories were 
selected to represent the range of magnitudes and distances consistent with the range indicated by the PSHA. The first suite consists of time histories for which both horizontal components were scaled to the site-specific horizontal peak ground velocity and the vertical component was scaled to the site-specific vertical peak ground velocity. The observed intercomponent variability is therefore not maintained for the first suite. Also, the records used to generate the time histories were not spectrally conditioned prior to scaling.

A second suite of time histories for the $2.44 \mathrm{~m} / \mathrm{s}$ PGV level was developed by first spectrally conditioning the records to weakly match Yucca Mountain site conditions based on the response spectra for the PSHA reference rock outcrop. Specifically, the ratios between mean response spectra for average western U.S. conditions and mean response spectra for the PSHA reference rock outcrop at Yucca Mountain were determined. The western U.S. response spectra are considered typical of the strong ground motion records forming the basis for Yucca Mountain time histories. These smooth ratios, or transfer functions, were then applied to the naturally irregular response spectrum for each of the strong ground motion records to be used in generating time histories. Finally, the modified response spectra formed targets for weak spectral matches of the original records. Following this conditioning, the records were scaled to the site-specific peak ground velocity. In this case, only one horizontal component was scaled to the peak ground velocity and the other components were scaled by the same factor to preserve the intercomponent variability of the original records.

Two suites of 17 sets of time histories were also developed for the $5.35-\mathrm{m} / \mathrm{s}$ PGV level. For both of these suites, the records forming the basis for the time histories were spectrally conditioned prior to scaling. In one case, they were spectrally conditioned to weakly match the response spectra for the PSHA reference rock outcrop, similar to the approach for the second suite of ground motions for the $2.44-\mathrm{m} / \mathrm{s}$ PGV level. In the second case, they were conditioned to the site-specific response spectra for the waste emplacement area.

Analyses of rockfall and EBS structural response have used the most current suite of ground motions that were available when the studies were performed. The original EBS structural response calculations for the $2.44-\mathrm{m} / \mathrm{s}$ PGV level ground motions were performed with the first suite of ground motions, wherein the time histories are scaled to the known values of PGV in the horizontal and vertical directions; intercomponent variability was not preserved. The original EBS structural response calculations for the 5.35-m/s PGV level ground motions were performed with the first suite of ground motions that were spectrally conditioned to the reference rock outcrop and preserved the intercomponent variability of the original records. More recent kinematic calculations for multiple waste packages are based on the 2.44-m/s PGV level ground motions with weak spectral conditioning for a reference rock outcrop (see Point $A$ in Figure 6.4-1) and on the $5.35-\mathrm{m} / \mathrm{s}$ and $1.05-\mathrm{m} / \mathrm{s}$ PGV level ground motions with weak spectral conditioning for the emplacement level (see Point B in Figure 6.4-1). Each set of the ground motions for the kinematic calculations preserve intercomponent variability.

\subsubsection{Bounded PGV Hazard Curve at the Emplacement Drifts}

The hazard curve at Point A is unbounded, in the sense that PGV continues to increase (albeit more slowly) with decreasing values of the exceedance frequency. This general behavior leads to $\mathrm{PGV}$ values that exceed $5.35 \mathrm{~m} / \mathrm{s}$ for annual exceedance frequencies below $10^{-7}$ per year. 
These PGV values are extremely large and may not be physically realizable for the seismic sources and geologic conditions in and around Yucca Mountain. In particular, the physical properties of the lithophysal rocks at the emplacement drift level are expected to provide physical limits on the PGV experienced at that location (Point B) (BSC 2004 [DIRS 170137]).

A recent study (BSC 2005 [DIRS 170137]) has estimated the limits for maximum shear strain in the lithophysal rock, based on existing large-core compression testing and on numerical analyses of fracturing limits using field-mapped lithophysae geometries. The maximum shear strain can be related to the in situ response by using the site response model (Section 6.4.2) to determine the dynamic shear strains induced at the repository horizon as a function of the PGV level of the ground motion. The PGV levels equivalent to the maximum shear strains define a distribution of horizontal PGV values that are consistent with the observation that failure or fracturing of the lithophysae has not occurred in approximately 12.8 million years. The final result of this study is a bounded hazard curve for horizontal PGV at the repository waste emplacement level (DTN: MO0501BPVELEMP.001 [DIRS 172682]).

The points on the bounded hazard curve are listed in Table 6.4-1. The bounded and unbounded hazard curves at Point B are compared in Figure 6.4-2. With the bounded hazard, the value of PGV never exceeds $4.07 \mathrm{~m} / \mathrm{s}$ for annual exceedance frequencies greater than or equal to $10^{-8}$ per year. It follows that structural response calculations based on ground motions at the $5.35-\mathrm{m} / \mathrm{s}$ PGV level will exceed the expected response at the site, even at the lowest annual probability level $\left(10^{-8}\right.$ per year) that is considered in TSPA. Stated differently, the range of PGV for the structural response calculations encompasses the PGV range on the (bounded) hazard curve for the $10^{-4}$ to $10^{-8}$ annual exceedance frequencies considered by TSPA.

Table 6.4-1. Bounded Hazard Curve for Horizontal PGV at the Emplacement Drifts

\begin{tabular}{|c|c|}
\hline Horizontal PGV $\mathbf{( m / s )}$ & Mean Annual Exceedance Frequency (1/yr) \\
\hline 0.4019 & $1.000 \times 10^{-04}$ \\
\hline 0.60 & $3.826 \times 10^{-05}$ \\
\hline 0.80 & $1.919 \times 10^{-05}$ \\
\hline 1.05 & $9.955 \times 10^{-06}$ \\
\hline 1.20 & $6.682 \times 10^{-06}$ \\
\hline 1.40 & $3.812 \times 10^{-06}$ \\
\hline 1.60 & $2.136 \times 10^{-06}$ \\
\hline 1.80 & $1.288 \times 10^{-06}$ \\
\hline 2.00 & $8.755 \times 10^{-07}$ \\
\hline 2.20 & $6.399 \times 10^{-07}$ \\
\hline 2.44 & $4.518 \times 10^{-07}$ \\
\hline 2.60 & $3.504 \times 10^{-07}$ \\
\hline 2.80 & $2.507 \times 10^{-07}$ \\
\hline 3.00 & $1.731 \times 10^{-07}$ \\
\hline 3.20 & $1.137 \times 10^{-07}$ \\
\hline 3.40 & $7.168 \times 10^{-08}$ \\
\hline 3.60 & $4.362 \times 10^{-08}$ \\
\hline 3.80 & $2.508 \times 10^{-08}$ \\
\hline 4.00 & $1.319 \times 10^{-08}$ \\
\hline 4.20 & $5.967 \times 10^{-09}$ \\
\hline
\end{tabular}

Source: DTN: MO0501BPVELEMP.001 [DIRS 172682].

NOTE: *Horizontal PGV values have been converted from $\mathrm{cm} / \mathrm{s}$ to $\mathrm{m} / \mathrm{s}$ by dividing by 100 . 


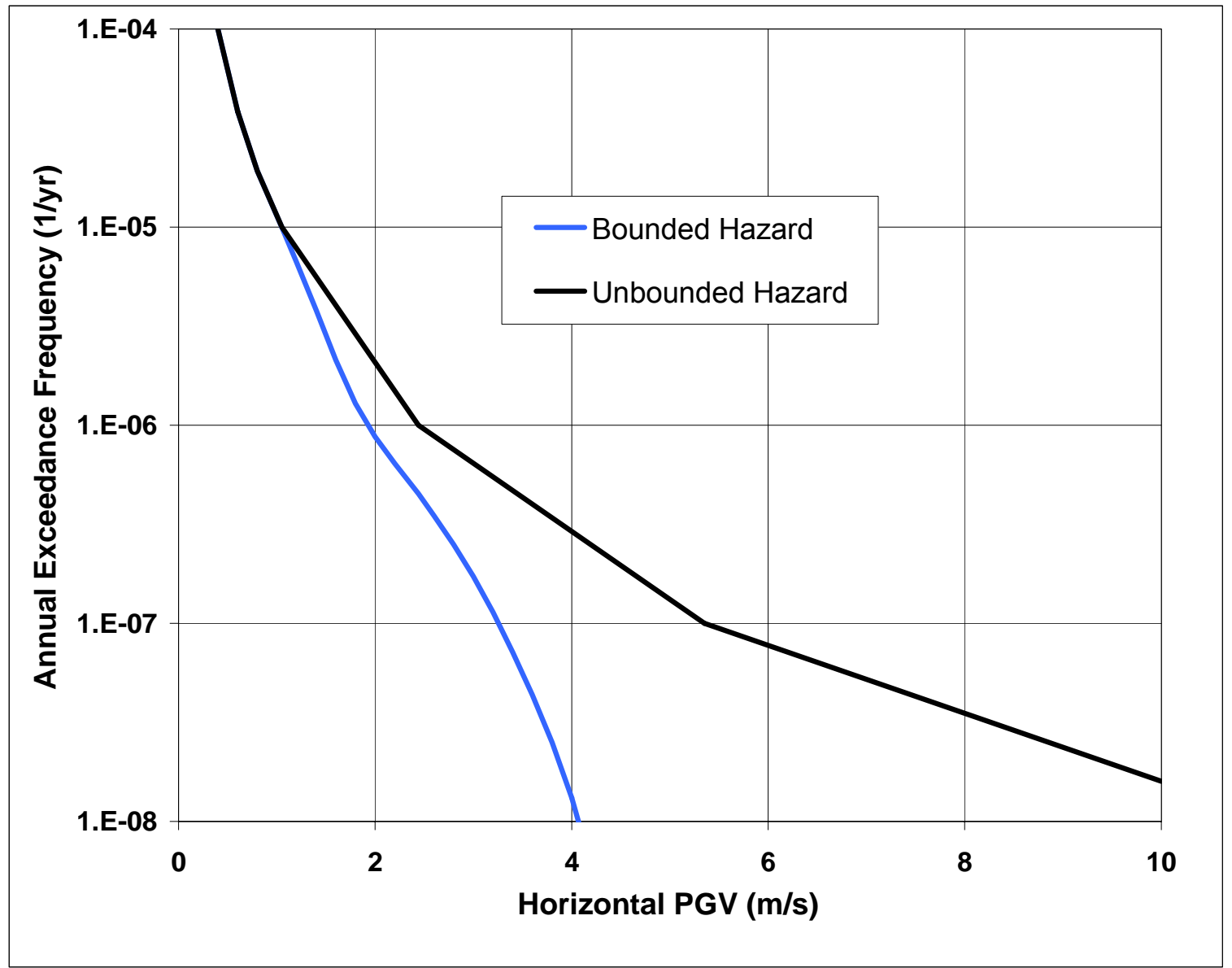

Source: MO0501BPVELEMP.001 [DIRS 172682] for the bounded hazard curve at Point B; Tables 4-1 and 6.1-1 for PGV values on the unbounded hazard curve at Point $B$ with exceedance frequencies greater than or equal to $10^{-7}$ per year.

NOTE: The exceedance frequency corresponding to $1,000 \mathrm{~cm} / \mathrm{s}$ on the unbounded hazard curve is based on a power law extrapolation. ${ }^{7}$

Figure 6.4-2. Bounded and Unbounded Hazard Curves for Horizontal Peak Ground Velocity at Point B, the Repository Waste Emplacement Level

While the hazard curve for horizontal PGV has been bounded, only the "first" horizontal component, H1, of the ground motions is scaled to a given value of PGV (such as $2.44 \mathrm{~m} / \mathrm{s}$ or $5.35 \mathrm{~m} / \mathrm{s}$ ). The second horizontal component, $\mathrm{H} 2$, and the vertical component, $\mathrm{V}$, are not directly scaled, but are scaled to maintain the intercomponent variability in the original accelerogram. The resulting PGVs for the $\mathrm{H} 2$ and $\mathrm{V}$ components may exceed the scaled PGV for the $\mathrm{H} 1$ component and may exceed the maximum PGV value on the bounded hazard curve, $4.07 \mathrm{~m} / \mathrm{s}$.

\footnotetext{
7 The exceedance frequency at $1,000 \mathrm{~cm} / \mathrm{s}$ is estimated from a power law fit to the points at the $10^{-6}$ and $10^{-7}$ annual exceedance frequencies on the unbounded hazard curve: $\left(244 \mathrm{~cm} / \mathrm{s}, 10^{-6} 1 / \mathrm{yr}\right)$ and $\left(535 \mathrm{~cm} / \mathrm{s}, 10^{-7} 1 / \mathrm{yr}\right)$. For a power law fit of $\lambda=a(P G V)^{b}$ to these data, $b$ and $a$ are calculated to be $b=\log \left(10^{-6} / 10^{-7}\right) / \log (244 / 535)=-2.9329$, and $a=\left(10^{-6}\right) /(244)^{-2.9329}=10.046$. The value of $\lambda$ at $1,000 \mathrm{~cm} / \mathrm{s}$ on the unbounded hazard curve is then given by $\lambda=a(P G V)^{b}=(10.046)(1,000)^{-2.9329}=1.597 \times 10^{-8} 1 / \mathrm{yr}$.
} 


\subsection{DAMAGED AREA ABSTRACTIONS FOR VIBRATORY GROUND MOTION}

This Section defines the damaged area abstraction for the waste package and the failure abstraction for the Zircalloy cladding in response to vibratory ground motion. The response of the rock mass and emplacement drifts to vibratory ground motion and the potential for rockfall induced by vibratory ground motion to cause mechanical damage to the drip shield, waste package, and cladding are discussed in Section 6.6.

The total damage to the waste package has two separate components: damage from end-to-end impacts of adjacent waste packages and damage from waste package-pallet impacts. The calculations that define the damage from end-to-end impacts and the abstraction of the resulting damaged areas are discussed in Section 6.5.1. The calculations that define the damage from waste package-pallet impacts and the abstraction of the resulting damaged areas are presented in Section 6.5.2. The total damage to the waste package is given by the sum of these two individual abstractions.

The development of separate damage abstractions for end-to-end impacts versus waste package-pallet impacts reflects the new data from kinematic calculations with multiple waste packages (BSC 2005 [DIRS 173172], Sections 5.4.1 and 5.4.2). Previous calculations for damaged areas on the waste package are based on the response of a single waste package contained within rigid walls (BSC 2004 [DIRS 167083]). This approach does not represent the potential for synchronous motion of adjacent waste packages to reduce end-to-end impacts. The potential for synchronous motion is accounted for in the kinematic calculations with multiple waste packages.

The results from the kinematic calculations provide the basis for the new damage abstraction from end-to-end impacts of adjacent waste packages. This damage abstraction is developed in a two step process: first, the kinematic calculations define the number, velocity, and angle of impacts between adjacent waste packages and, second, the impact velocities are converted to damaged area. This second step is based on a catalog or look-up table for damaged area from end-on impacts as a function of impact velocity. The second step is necessary because the finite-element grid for the kinematic calculations is designed to accurately represent the gross rigid body motions and interactions of multiple packages, but is not fine enough to accurately predict the residual stress distribution from the end-to-end or waste package-pallet impacts. This limitation in the kinematic calculations is avoided by using a look-up Table that is based on calculations with a highly refined finite-element grid. The catalog or look-up table is described in Section 6.5.1.2 and the procedure for calculating the damaged areas with the catalog is discussed in Section 6.5.1.3.

The limitation on the use of the kinematic calculations also extends to waste package-pallet impacts: the finite-element grid in the kinematic calculations is not fine enough to directly calculate residual stress distributions from waste package-pallet impacts. The damage abstraction for waste package-pallet impacts is, therefore, based on the previous calculations for a single waste package contained within rigid walls (BSC 2004 [DIRS 167083]) because the grid for the single waste package calculations is fine enough to represent the damaged areas on the surface of the waste package from waste package-pallet impacts. The new abstraction for damaged areas from waste package-pallet impacts is described in Section 6.5.2. 
The potential for damage from lateral impacts between the waste package and drip shield, abbreviated as waste package-drip shield impacts, is not included in the seismic damage abstractions for TSPA. The basis for not including the potential damage from waste package-drip shield impacts is based on several observations: (i) the damaged areas from side-on impacts of a waste package on an elastic surface are significantly less than the damaged areas from end-on impacts on an elastic surface, (ii) waste package-drip shield impacts occur much less frequently and with lower impact velocities than the end-to-end impacts in the single waste package calculations, implying that the damaged areas from end-to-end impacts will be significantly greater than the damaged areas from waste package-drip shield impacts, (iii) cross-drift calculations for a waste package and a drip shield surrounded by rockfall demonstrate that significant lateral impact velocities only occur for ground motions at the 2.44-m/s PGV level with PGV values beyond the relevant range on the bounded hazard curve for TSPA, and (iv) the conservatism in the approach for calculating damaged areas from end-to-end impacts encompasses the potential contribution to damaged areas for waste package-drip shield impacts. Each of these observations is explained in Section 6.5.3.1.

Finally, the abstraction for failure of the Zircalloy cladding is discussed in Section 6.5.6.

In this section, damage is synonymous with a damaged area that exceeds the residual stress threshold for Alloy 22, resulting in enhanced susceptibility to accelerated stress corrosion cracking and the formation of pathways for radionuclide transport from the waste package. Permanent structural deformation does not always result in damage because the residual stress may be below the stress threshold for Alloy 22. No damage is equivalent to zero percent damaged area on the surface of the package, so there is no transport of radionuclides from the waste package.

In this section, end-to-end impact indicates the impact between two adjacent waste packages in the axial direction from the kinematic calculations. End-on impact is reserved for the calculation of a single waste package impacting an elastic surface with a highly refined finite-element mesh; the end-on impact calculations provide the basis for the catalog of damaged areas (Section 6.5.1.2) and are completely separate from the kinematic calculations.

\subsubsection{Abstraction for Waste Package Damage from End-to-End Impacts}

This abstraction defines the damage generated by end-to-end impacts of adjacent waste packages in response to vibratory ground motion. To this end, two suites of kinematic calculations (Section 6.5.1.1) have been performed to determine the timing and velocities of end-to-end impacts in a drift filled with multiple waste packages. The impact parameters from both suites of calculations are converted to damaged area by interpolating within a catalog or lookup table of damaged areas, as described in Sections 6.5.1.2 and 6.5.1.3. The catalog defines damaged areas at five values of impact velocity and four values of impact angle that span the range of impact parameters observed in the kinematic calculations. The resulting damaged areas are then abstracted as a function of the horizontal peak ground velocity (PGV), as described in Sections 6.5.1.4 and 6.5.1.5. 


\subsubsection{Kinematic Calculations for End-to-End Impacts}

Two suites of kinematic calculations have been performed with multiple waste packages to determine the kinematic parameters and damaged areas due to end-to-end impacts between adjacent packages (BSC 2005 [DIRS 173172], Sections 5.4.1 and 5.4.2). The two suites are based on different computational techniques with different numbers and types of waste packages. The two suites represent alternate technical approaches to the kinematic calculations, allowing this uncertainty to be propagated into the waste package damage abstraction for TSPA.

A total of 51 calculations have been performed for each suite: the first with LS-DYNA, (BSC 2005 [DIRS 173172], Section 5.4.1; DTN: MO0504SPALSDYN.000 [DIRS 173338]) and the second with UDEC, (BSC 2005 [DIRS 173172] Section 5.4.2; DTN: MO0503SPAUDECW.000 [DIRS 173337]). Each suite evaluates the kinematic response for 17 ground motion time histories at each of three PGV levels: $1.05 \mathrm{~m} / \mathrm{s}, 2.44 \mathrm{~m} / \mathrm{s}$, and $5.35 \mathrm{~m} / \mathrm{s}$. Each calculation produces kinematic data for end-to-end impacts on the three central 21-PWR waste packages. It is useful to consider the three central packages for two reasons. First, this approach provides 153 observations of damaged areas, rather than 51 observations for the central waste package alone. And second, any variability in damaged areas between the three central packages is incorporated into the damage abstraction. The impact data from other packages are not considered because the free boundaries at either end of the string of waste packages can alter the number and velocity of impacts for packages closer to these ends.

The kinematic calculations do not represent the dynamic response of the invert to the ground motion. Instead, the top surface of the invert moves synchronously with the ground motions, as though it is a rigid surface. The impact of representing the dynamic response of the invert is analyzed in BSC 2005 ([DIRS 173172] Attachment VIII). For these calculations, the invert is represented as a cohesionless, granular material that is subjected to ground motions at the 2.44 and $5.35 \mathrm{~m} / \mathrm{s}$ PGV levels. The computational results demonstrate that the rigid representation has relatively little impact on amplification of ground motions or on permanent deflection of the invert surface. The simpler representation of the invert as a rigid surface is therefore retained for the kinematic calculations.

\subsection{Calculations with LS-DYNA}

Each finite-element calculation with LS-DYNA is a quasi-three-dimensional analysis for a group of seven waste packages (BSC 2005 [DIRS 173172], Section 5.4.1). The finite-element representation describes the full three-dimensional geometry of the waste packages and their associated pallets, but only allows motion in two directions: the vertical direction and the longitudinal direction (along the drift axis). Exclusion of motion in the transverse horizontal direction eliminates a degree of freedom in the LS-DYNA calculations relative to a fully threedimensional calculation. This reduction in the degrees of freedom forces more motion along the drift axis than in a fully three dimensional calculation, conservatively promoting more waste package interaction in the LS-DYNA calculations. The quasi-three-dimensional approach is an appropriate starting point for the kinematic calculations with LS-DYNA. 


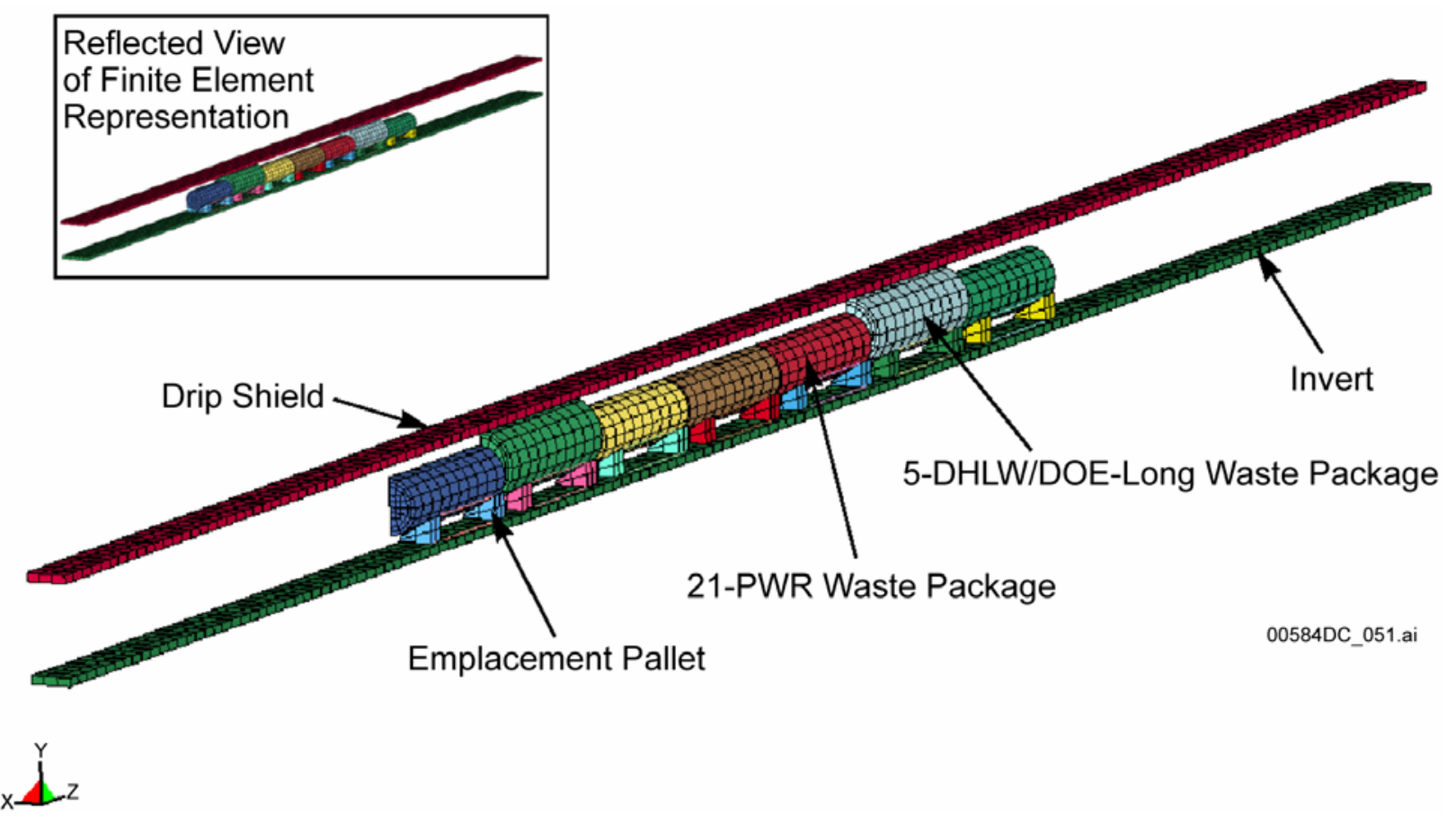

Source: BSC 2005 [DIRS 173172], Figure 5-4.

Figure 6.5-1. Finite-Element Representation for the LS-DYNA Calculations

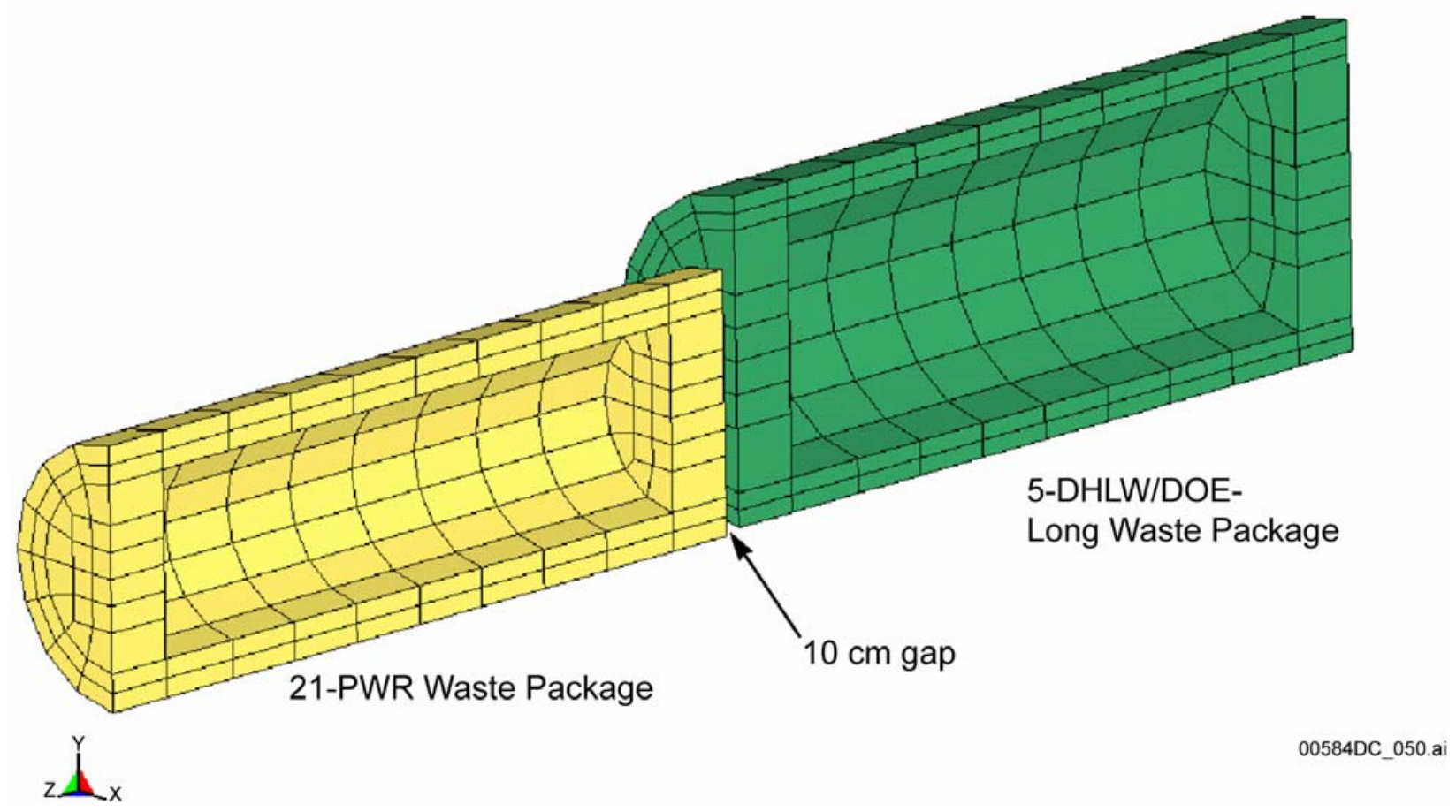

Source: BSC 2005 [DIRS 173172], Figure 5-5.

Figure 6.5-2. Geometry of 21-PWR and DHLW Long Packages, Shown from the Symmetry Plane Side. Adjacent Waste Packages Are Initially $10 \mathrm{~cm}$ Apart 
The LS-DYNA finite-element representation includes multiple waste packages, their emplacement pallets, and a rigid representation of the invert and drip shield (Figure 6.5-1). Two types of waste packages are represented: the 21-PWR package and the DOE High Level Waste (DHLW) Long package. The group of seven waste packages in Figure 6.5-1 has five 21-PWR packages and two DHLW-Long packages. The three central 21-PWR packages are "sandwiched" between a single DHLW package on either side. The DHLW packages are in turn "sandwiched" by a single 21-PWR package on each side of the group of seven. These latter waste packages have a free boundary on their outside ends - their longitudinal motion is not restricted.

The invert and drip shield extend beyond the waste packages by the length of four packages to accommodate relative longitudinal motion of the packages. The drip shield and invert move synchronously with the free field ground motion, which corresponds to a drip shield that is pinned to the invert by rockfall from a collapsed drift.

The waste packages are represented as hollow cylinders with end caps (Figure 6.5-2). The inner diameter and end cap thickness of the waste packages are selected as convenient dimensions to approximate the inner cavity of the waste packages and to produce material densities on the same order as the density of other components in the finite-element representation, with the intent of maintaining reasonable computational time steps. A detailed description of the component geometries and configuration in the LS-DYNA analyses is provided in (BSC 2005 [DIRS 173172], Attachment I).

Seventeen ground motion time histories scaled to three different levels of longitudinal PGV are used as boundary conditions for the calculations. The three PGV levels are $1.05 \mathrm{~m} / \mathrm{s}, 2.44 \mathrm{~m} / \mathrm{s}$, and $5.35 \mathrm{~m} / \mathrm{s}$. Since the value of PGV is controlled for only one horizontal component of the ground motion, the controlled component can be oriented randomly in the horizontal plane. For these calculations, the controlled horizontal component is oriented in the longitudinal direction because it simplifies the abstraction process (see the discussion in Section 6.5.1.5.2 regarding "stripes" versus a "cloud" of data points) and because the physical response of the system is expected to correlate most strongly with the longitudinal component of ground motion, rather than the transverse component of ground motion.

Only the longitudinal and vertical components of each ground motion are applied to the finite element representation. The resulting response is symmetric about the vertical plane through the longitudinal axis (i.e., the $y-z$ plane in Figure 6.5-2). With this symmetry plane, there is no transverse displacement and no rotation out of the symmetry plane (about the y-axis or z-axis).

The stochastic (uncertain) input parameters for the simulations are the 17 ground motion time histories at each PGV level, the metal-to-metal friction coefficients, and the metal-to-rock friction coefficients. A Monte Carlo sampling scheme defines the appropriate combinations of ground motion and friction coefficients (BSC 2005 [DIRS 173172], Attachment X). The metal-to-metal and metal-to-rock friction coefficients are independently sampled for each waste package/pallet from uniform distributions with a lower bound of 0.2 and an upper bound of 0.8 . The static and dynamic friction coefficients are taken to be the same. 
All interactions between components in the LS-DYNA finite-element representation use viscous damping. This damping factor has been calibrated through numerical testing to provide a reasonable value for the coefficient of restitution (COR) (BSC 2005 [DIRS 173172], Attachment I, Section I-3.3.1). The target value for the COR is 0.6 for the combined response of the waste package, pallet, and invert. Numerical testing for the calculated response in a drop test of the waste package on the invert and pallet achieved a COR of 0.65 , closely matching the target COR. The target value of 0.6 is considered an upper bound on the expected COR for the impact of large, multicomponent structures. The use of a bounding value for the COR minimizes the viscous damping in the LS-DYNA calculations, providing a conservative but reasonable representation of energy dissipation in the impact process.

The 7 package representation for the LS-DYNA simulations are a portion of the approximately 100 packages in an emplacement drift, so it is important to determine this representation does not unduly affect the kinematic response of the three middle waste packages in Figure 6.5-1. The response for multiple waste packages was analyzed in a variety of configurations, which included a baseline representation of a single 21-PWR waste package between fixed adjacent waste packages, 5 to 13 waste packages with a single, central DHLW-Long package, and 13 waste packages with five middle 21-PWR waste packages between two DHLW-Long packages. The initial results from these calculations indicated that it is advantageous to have multiple DHLW-Long packages in the waste package representation. Additional calculations compared various configurations with two DHLW Long packages surrounding a group of central 21-PWR waste packages. Based on comparisons of number of impacts, maximum impact forces, and simulation animations, the seven waste package configuration with three central 21-PWR waste packages between two DHLW packages (Figure 6.5-1) was selected for the LS-DYNA calculations (BSC 2005 [DIRS 173172], Attachment I, Section I-3.3.4). This seven waste package configuration also approximates the anticipated mix of emplaced waste package sizes. For example, 21-PWR-sized packages account for almost 65 percent of the inventory for TSPA-LA (BSC 2005 [DIRS 173501], Table 13, for the 21-PWR absorber plate, 21-PWR control rod, and 44-BWR absorber plate), and the proportion of 21-PWR sized packages in the 7 package representation is 71 percent.

The finite-element representation in LS-DYNA provides a reasonable representation of the impact kinematics between multiple waste packages, and is considered appropriate for its intended use for several reasons. First, the calculations are based on standard, commercially available software (LS-DYNA) that has demonstrated the capability to accurately analyze impact processes and kinematic response. Second, the appropriate number of waste packages to accurately represent the kinematic response of the three central waste packages has been carefully investigated. Third, the finite-element grid for the kinematic calculations provides a reasonable representation of the three-dimensional geometries of packages and pallets that can accurately resolve the gross rigid body motions of and contacts between these bodies. Fourth, the major parameter uncertainties are represented in the calculations. The uncertainties due to ground motions and friction coefficients are directly represented by random sampling of inputs for the calculations. The uncertainty in contact damping is bounded by adjusting the viscous damping factor to provide a conservative but reasonable representation of energy dissipation in the impact process. Finally, the potential uncertainties in material properties are not represented in the calculations because the materials in the waste package will be fabricated to design specifications that follow standard values in handbooks and industrial publications, and because 
the sensitivity to variation in standard material properties is expected to be minor in comparison to that produced by the uncertainties in ground motions and friction coefficients.

\subsubsection{2 ～Kinematic Data from LS-DYNA}

Kinematic calculations with LS-DYNA were performed for 17 ground motions at each of three PGV levels: $1.05 \mathrm{~m} / \mathrm{s}, 2.44 \mathrm{~m} / \mathrm{s}$, and $5.35 \mathrm{~m} / \mathrm{s}$. The results for the three central 21-PWR waste packages are summarized in Table 6.5-1 (BSC 2005 [DIRS 173172] Table 5-2). Table 6.5-1 includes the number of impacts greater than $0.85 \mathrm{~m} / \mathrm{s}$, which is the velocity threshold for nonzero damage as explained in Section 6.5.1.2. Table 6.5-1 also presents the maximum impact velocities for each realization. There are no impacts above $0.85 \mathrm{~m} / \mathrm{s}$ at the $1.05-\mathrm{m} / \mathrm{s}$ PGV motion level, so there is no damage at this level. At the $2.44-\mathrm{m} / \mathrm{s}$ PGV level, impacts above $0.85 \mathrm{~m} / \mathrm{s}$ occur in 9 (out of 17) realizations. A large number of impacts are predicted at the $5.35-\mathrm{m} / \mathrm{s} \mathrm{PGV}$ level, although the $5.35-\mathrm{m} / \mathrm{s}$ PGV level is beyond the scope of TSPA because the minimum annual exceedance frequency of $10^{-8}$ per year for TSPA corresponds to a PGV of $4.07 \mathrm{~m} / \mathrm{s}$ on the bounded hazard curve (Section 6.4.3). Table 6.5-1 does not present information on relative impact angle because the catalog of damaged areas is based on the mean value of the damaged areas at $1^{\circ}, 5^{\circ}$, and $8^{\circ}$, as explained in Section 6.5.1.2.

Table 6.5-1. Summary of Impact Data from LS-DYNA Kinematic Calculations

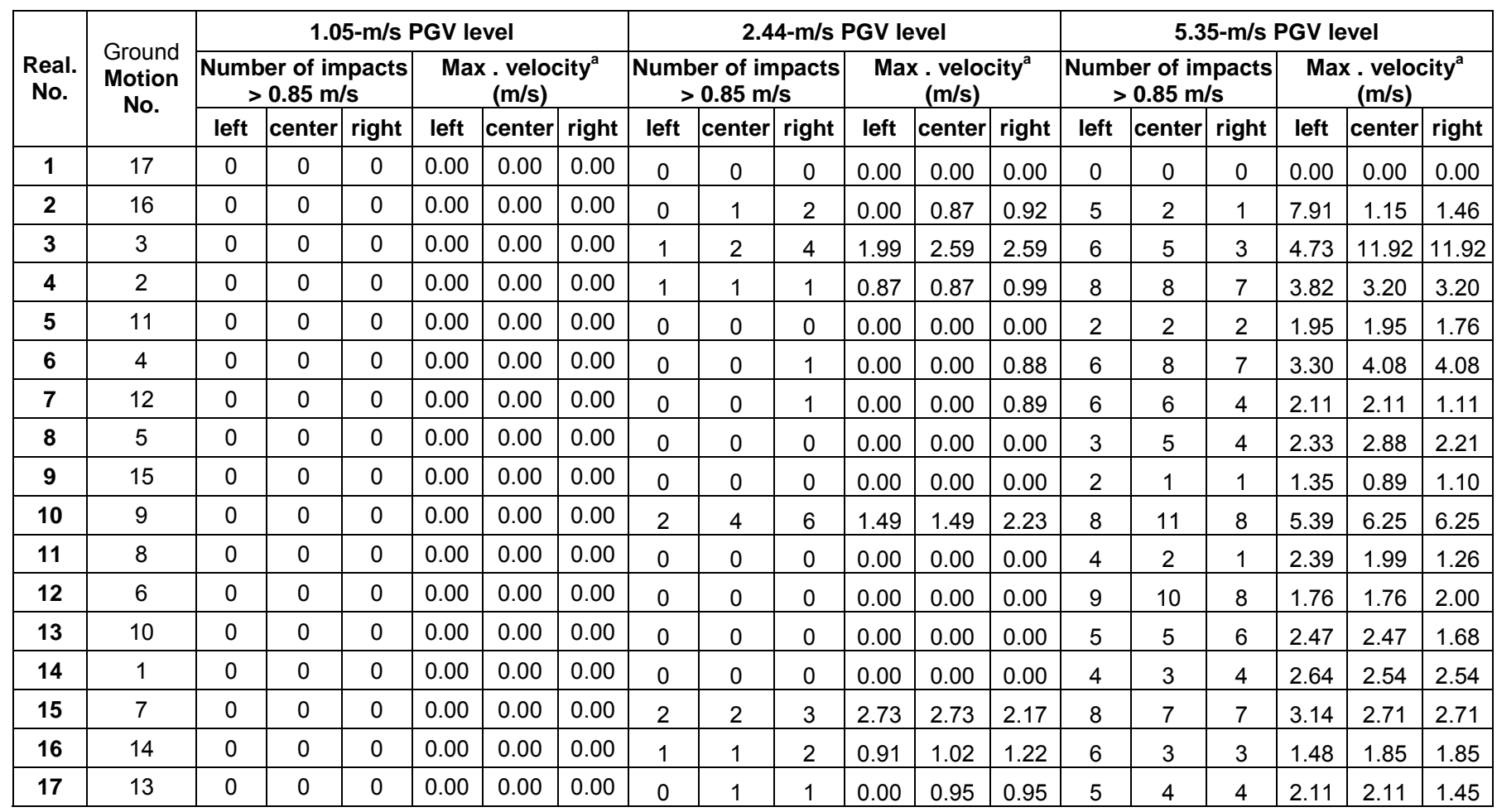

Source: BSC 2005 [DIRS 173172], Table 5-2.

${ }^{\mathrm{a}}$ If greater than $0.85 \mathrm{~m} / \mathrm{s}$.

\subsection{Calculations with UDEC}

Each discrete-element calculation with UDEC is a two-dimensional analysis for a group of twenty-one waste packages (BSC 2005 [DIRS 173172], Section 5.4.2). The two-dimensional 
analysis represents a vertical cross-section through the packages and their associated pallets, a portion of which is shown in Figure 6.5-3. Pallets and waste packages are represented as rectangular blocks located beneath the drip shields. The length and height of a block representing a waste package is equal to the length and diameter, respectively, of the waste package. The length of a block representing an emplacement pallet is equal to the length of the pallet. The height of a block representing an emplacement pallet is equal to the minimum height of the waste package above the invert, as shown in Figure 6.5-4. The two-dimensional geometry excludes motion in the horizontal direction, transverse to the drift axis. This exclusion eliminates a degree of freedom in the UDEC calculations relative to a fully three-dimensional calculation. This reduction in the degrees of freedom forces more motion along the drift axis than in a fully three dimensional calculation, conservatively promoting more waste package interaction in the UDEC calculations.

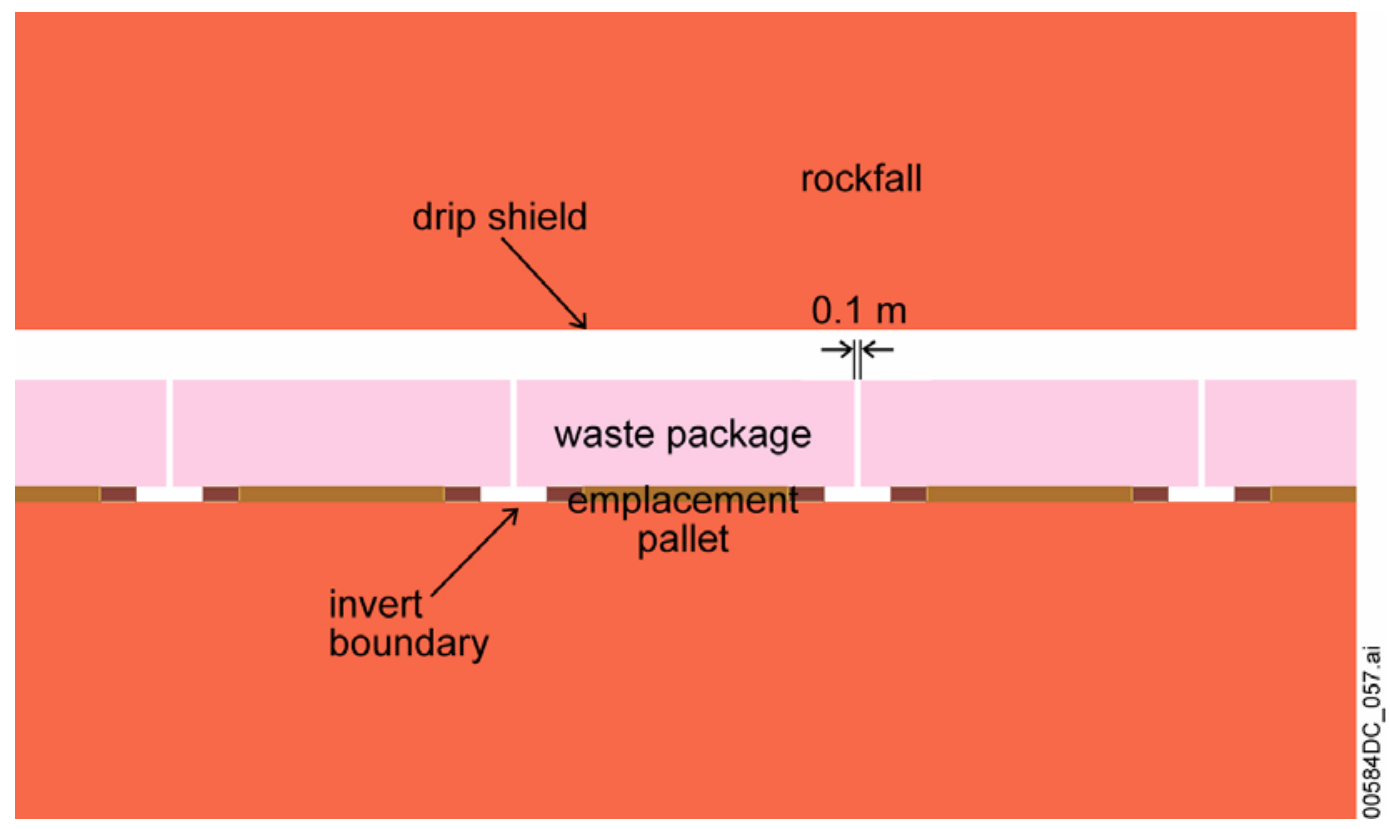

Source: BSC 2005 [DIRS 173172], Figure 5-7.

Figure 6.5-3. Geometric Representation for the Two-Dimensional UDEC Calculations

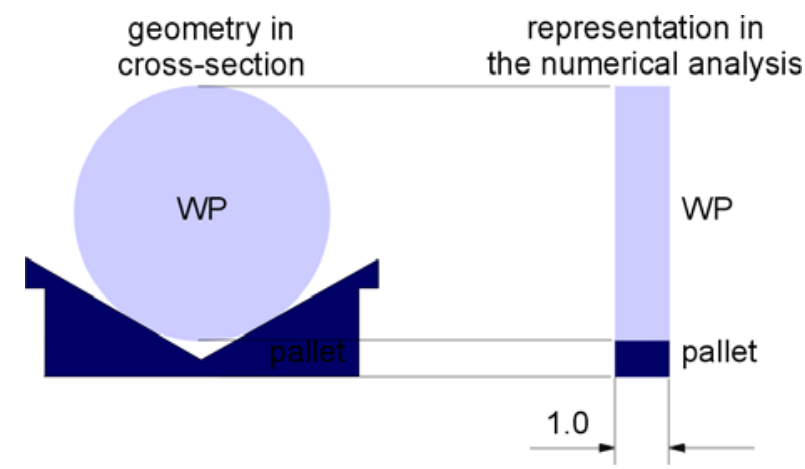

Source: BSC 2005 [DIRS 173172], Figure 5-8.

Figure 6.5-4. Comparison of the Actual Geometry and its Representation in the Numerical Analysis 
Each waste package in the analysis is a 21-PWR waste package type. The mass assigned to each block in the numerical representation is equal (per unit out-of-plane thickness, see Figure 6.5-4) to the mass of the body that it represents. This approach preserves the contacts between adjacent packages in the two-dimensional geometry, but does not preserve the three-dimensional moments of inertia of the packages or pallets. A more detailed description of the numerical representation of the three-dimensional system in the two-dimensional geometry is provided in BSC (2005 [DIRS 173172], Attachment II).

The drip shield and all boundaries move synchronously with the free field ground motion. This approach is equivalent to a drip shield that is pinned to the invert by rockfall from a collapsed drift. The outermost waste packages have a free boundary. The initial distance between an end of the string of waste packages and the vertical boundaries, which represent the ends of the emplacement drift, is approximately five package lengths. These boundary conditions are similar to the boundary conditions for the LS-DYNA calculations.

The UDEC calculations use hysteretic damping to dissipate a portion of the impact energy between two bodies. Different normal contact stiffnesses are assigned to the loading and unloading phases of the contact process. The ratio of the unloading stiffness to the loading stiffness is the main parameter that controls energy dissipation in hysteretic damping. This parameter is calibrated through numerical testing to match the metal-to-metal COR for the drop of the waste package on the pallet and to match the metal-to-rock COR for the drop of the pallet on the invert. The target values for metal-to-metal COR and for metal-to-rock COR are 0.6 and 0.2 , respectively. The numerical testing showed that stiffness ratios of 2.7 and 50.0 resulted in responses that closely matched the target values for the CORs. The values of 0.6 and 0.2 are upper bounds on the expected coefficients of restitution for impacts of a large, complex structure. The use of bounding values minimizes the hysteretic damping in the UDEC calculations, providing a conservative but still reasonable representation of the kinematic process.

Seventeen ground motion time histories scaled to three different levels of longitudinal PGV are used as boundary conditions for the calculations. The three PGV levels are $1.05 \mathrm{~m} / \mathrm{s}, 2.44 \mathrm{~m} / \mathrm{s}$, and $5.35 \mathrm{~m} / \mathrm{s}$. The first horizontal component of the ground motion, with a PGV of $1.05 \mathrm{~m} / \mathrm{s}$, $2.44 \mathrm{~m} / \mathrm{s}$ or $5.35 \mathrm{~m} / \mathrm{s}$, is aligned with the longitudinal direction (along the emplacement drift) for the reasons explained in Section 6.5.1.1.1. Only two components of each ground motion are applied to the finite element representation: the longitudinal component and the vertical component. The two-dimensional representation prevents block motion in the transverse horizontal direction.

The information that is archived for all twenty one waste packages includes: (a) the times for all impacts; (b) the location of impacts relative to the local coordinate system; and (c) the relative impact velocities decomposed into normal and tangential directions relative to the impacted surface. Impacts between adjacent packages, between packages and pallets, and between packages and drip shields (i.e., the upper boundary) are archived. Although the impact information is recorded for all waste packages, the waste package damage abstraction is based on the kinematic data for the three packages in the middle of the string.

The 21 waste packages in the UDEC simulations are a portion of the approximately 100 packages in an emplacement drift, so it is important to verify that the number of packages in 
the numerical simulation does not affect the kinematic response of the three waste packages in the middle of the string. Qualitative review of the results from the numerical simulations shows that end effects from the free boundaries propagate at most 6 or 8 packages in from either end. As an example, the final waste package configuration in response to ground motion 7 at the 5.35-m/s PGV level is shown in Figure 6.5-5. Ground motion 7 is one of the strongest ground motions at this PGV level. Figure 6.5-5 also presents the contours of horizontal displacement and details of displacements at the end of the string.

Figure 6.5-5 shows that 3 packages on the left end and 8 packages on the right end have drifted away from the middle of the string during the ground motion. On the right side, the end package completely fell off the pallet. The packages that are within the regions of influence of the free ends will have fewer impacts and lower impact velocities because of the increased spacing between adjacent packages. On the other hand, the three waste packages in the middle of the string will not be significantly affected by end effects because the ten packages in the middle of the string are largely unaffected by end effects. It follows that 21 packages are sufficient to simulate end-to-end impacts of adjacent packages for the three central packages.

The finite-difference representation in UDEC provides a reasonable representation of the impact kinematics between multiple waste packages, and is considered appropriate for its intended use for several reasons. First, the calculations are based on standard, commercially available software (UDEC) that has demonstrated the capability to accurately analyze kinematic response for granular media. Second, the appropriate number of waste packages to accurately represent the kinematic response of the three central waste packages has been carefully investigated. Third, the finite-element grid for the kinematic calculations provides a reasonable representation of the package and pallet geometries that can accurately resolve the gross rigid body motions of and contacts between these bodies. Note that this representation is two-dimensional in UDEC, rather than the three-dimensional representation in LS-DYNA. Fourth, the major parameter uncertainties are represented in the calculations. The uncertainties due to ground motions and friction coefficients are directly represented by random sampling of inputs for the calculations. The uncertainty in contact damping is bounded by adjusting the hysteretic damping to provide a conservative but reasonable representation of energy dissipation in the impact process. Finally, the potential uncertainties in material properties are not represented in the calculations because the materials in the waste package will be fabricated to design specifications that follow standard values in handbooks and industrial publications and because the sensitivity to variation in standard material properties is expected to be minor in comparison to that produced by the uncertainties in ground motions and friction coefficients. 

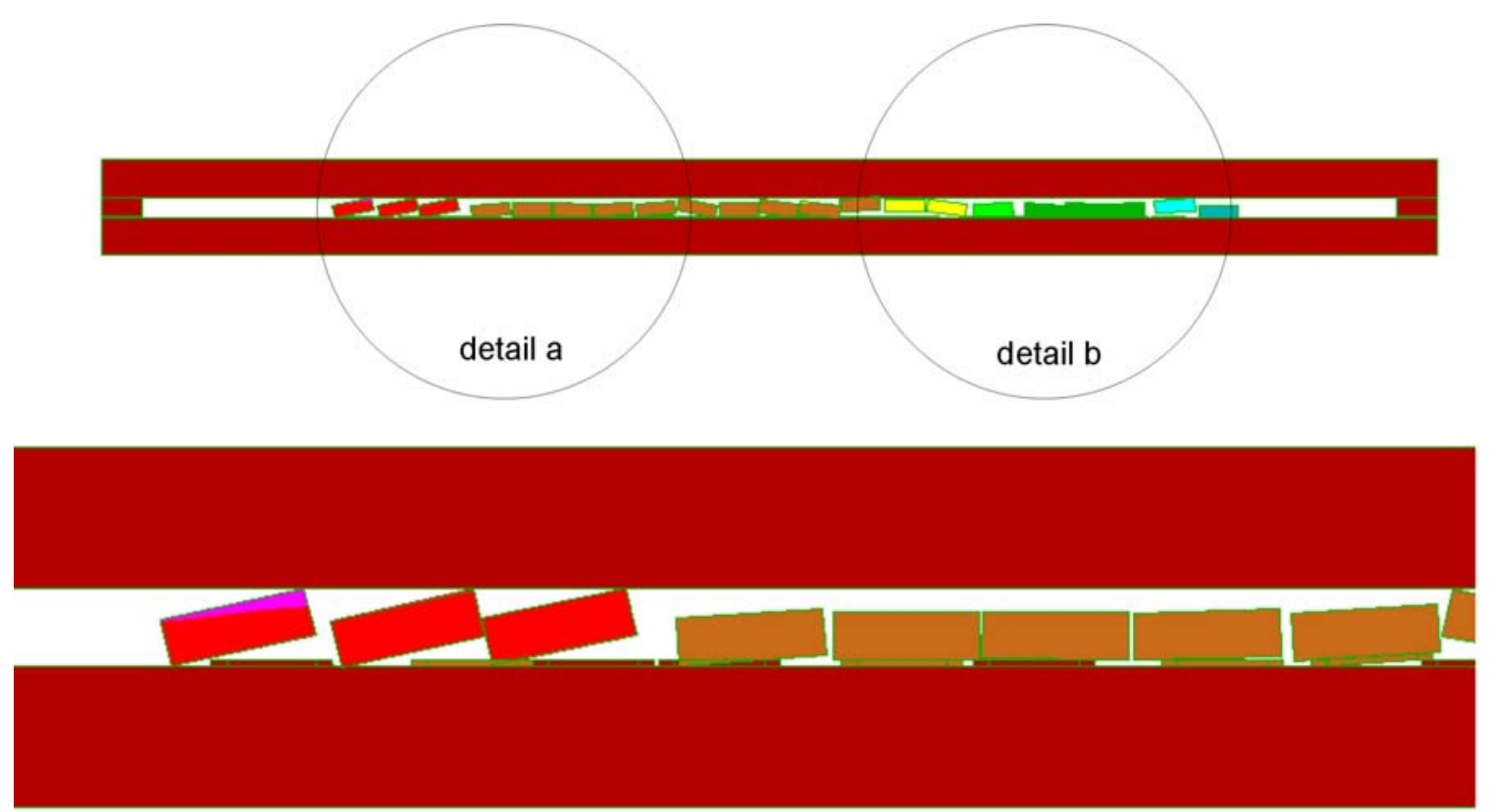

detail a

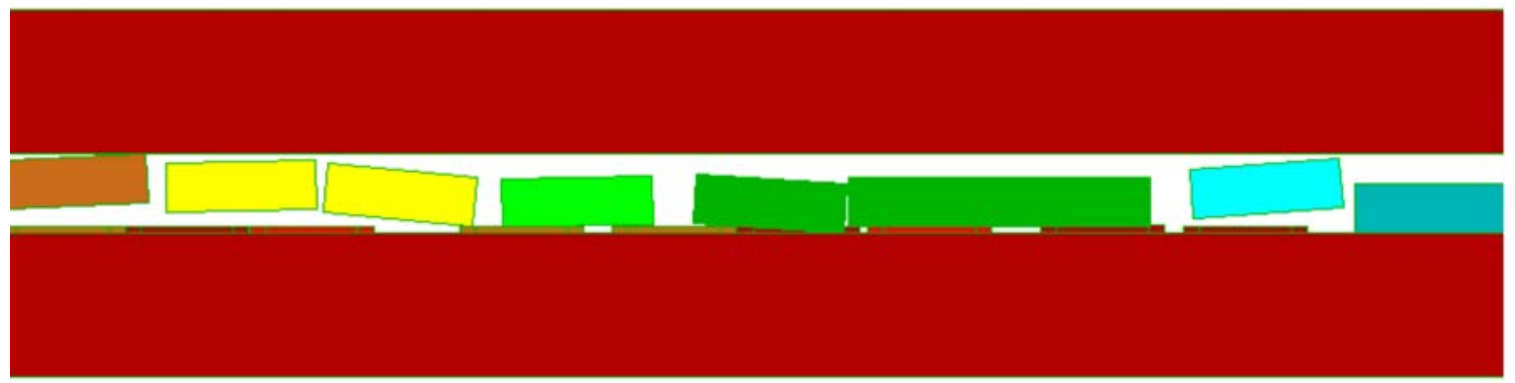

detail b
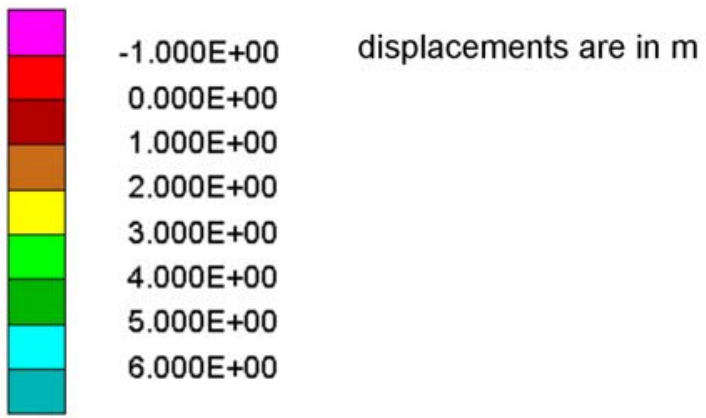

Source: BSC 2005 [DIRS 173172], Figure 5-10.

Figure 6.5-5. Displacement Contours (m) At The End of Ground Motion 7 at the 5.35-m/s PGV Level

\subsection{Kinematic Data from UDEC}

Kinematic calculations with UDEC were performed for 17 ground motions at each of three PGV levels: $1.05 \mathrm{~m} / \mathrm{s}, 2.44 \mathrm{~m} / \mathrm{s}$, and $5.35 \mathrm{~m} / \mathrm{s}$. The results for the three central 21-PWR waste packages are summarized in Table 6.5-2 (BSC 2005 [DIRS 173172], Table 5-3). Table 6.5-2 includes the number of impacts greater than $0.85 \mathrm{~m} / \mathrm{s}$, which is the velocity threshold for nonzero 
damage as explained in Section 6.5.1.2. Table 6.5-2 also presents the maximum impact velocities for each realization. There are only two impacts with velocity greater than $0.85 \mathrm{~m} / \mathrm{s}$ from all realizations at the $1.05-\mathrm{m} / \mathrm{s}$ PGV level. At the $2.44-\mathrm{m} / \mathrm{s}$ PGV level, impacts above $0.85 \mathrm{~m} / \mathrm{s}$ occur in 10 realizations. A large number of impacts with relatively large impact velocities are predicted at the $5.35-\mathrm{m} / \mathrm{s}$ PGV level. It is worthwhile to note that the $5.35-\mathrm{m} / \mathrm{s}$ PGV level is beyond the scope of TSPA because the minimum annual exceedance frequency of $10^{-8}$ per year for TSPA corresponds to a PGV of $4.07 \mathrm{~m} / \mathrm{s}$ on the bounded hazard curve (Section 6.4.3). Table 6.5-2 does not present information on relative impact angle because the catalog of damaged areas is based on the mean value of the damaged areas at $1^{\circ}, 5^{\circ}$, and $8^{\circ}$, as explained in Section 6.5.1.2.

Table 6.5-2. Summary of Impact Data from UDEC Kinematic Calculations

\begin{tabular}{|c|c|c|c|c|c|c|c|c|c|c|c|c|c|c|c|c|c|c|c|}
\hline \multirow{3}{*}{$\begin{array}{c}\text { Real. } \\
\text { No. }\end{array}$} & \multirow{3}{*}{$\begin{array}{c}\text { Ground } \\
\text { Motion } \\
\text { No. }\end{array}$} & \multicolumn{6}{|c|}{ 1.05-m/s PGV level } & \multicolumn{6}{|c|}{ 2.44-m/s PGV level } & \multicolumn{6}{|c|}{ 5.35-m/s PGV level } \\
\hline & & \multicolumn{3}{|c|}{\begin{tabular}{|c} 
Number of impacts \\
$>0.85 \mathrm{~m} / \mathrm{s}$ \\
\end{tabular}} & \multicolumn{3}{|c|}{$\begin{array}{c}\text { Max . velocity }{ }^{\mathrm{a}} \\
(\mathrm{m} / \mathrm{s})\end{array}$} & \multicolumn{3}{|c|}{$\begin{array}{c}\text { Number of impacts } \\
>0.85 \mathrm{~m} / \mathrm{s}\end{array}$} & \multicolumn{3}{|c|}{$\begin{array}{c}\text { Max . velocity }{ }^{\mathrm{a}} \\
(\mathrm{m} / \mathrm{s})\end{array}$} & \multicolumn{3}{|c|}{$\begin{array}{c}\text { Number of impacts } \\
>0.85 \mathrm{~m} / \mathrm{s} \\
\end{array}$} & \multicolumn{3}{|c|}{$\begin{array}{c}\text { Max . velocity }{ }^{a} \\
(\mathrm{~m} / \mathrm{s})\end{array}$} \\
\hline & & left & center & right & left & center & right & left & center $\mathrm{r}$ & right & left & center & right & left & center & right & left & center & right \\
\hline 1 & 17 & 0 & 0 & 0 & 0.00 & 0.00 & 0.00 & 0 & 0 & 0 & 0.00 & 0.00 & 0.00 & 5 & 5 & 7 & 1.73 & 1.71 & 1.86 \\
\hline 2 & 16 & 0 & 0 & 0 & 0.00 & 0.00 & 0.00 & 0 & 0 & 0 & 0.00 & 0.00 & 0.00 & 17 & 13 & 12 & 2.29 & 3.11 & 3.24 \\
\hline 3 & 3 & 2 & 1 & 0 & 0.96 & 0.87 & 0.00 & 2 & 2 & 2 & 1.13 & 1.64 & 1.75 & 11 & 9 & 12 & 4.17 & 6.06 & 6.16 \\
\hline 5 & 11 & 0 & 0 & 0 & 0.00 & 0.00 & 0.00 & 0 & 0 & 0 & 0.00 & 0.00 & 0.00 & 11 & 13 & 7 & 1.99 & 2.04 & 2.42 \\
\hline 6 & 4 & 0 & 0 & 0 & 0.00 & 0.00 & 0.00 & 3 & 1 & 0 & 0.90 & 0.90 & 0.00 & 27 & 31 & 32 & 3.93 & 3.87 & 2.96 \\
\hline 7 & 12 & 0 & 0 & 0 & 0.00 & 0.00 & 0.00 & 0 & 0 & 0 & 0.00 & 0.00 & 0.00 & 28 & 24 & 22 & 3.04 & 3.18 & 3.17 \\
\hline 8 & 5 & 0 & 0 & 0 & 0.00 & 0.00 & 0.00 & 0 & 0 & 0 & 0.00 & 0.00 & 0.00 & 11 & 12 & 12 & 2.93 & 4.27 & 4.48 \\
\hline 9 & 15 & 0 & 0 & 0 & 0.00 & 0.00 & 0.00 & 0 & 0 & 1 & 0.00 & 0.00 & 1.76 & 9 & 8 & 9 & 1.80 & 1.82 & 2.09 \\
\hline 13 & 10 & 0 & 0 & 0 & 0.00 & 0.00 & 0.00 & 0 & 0 & 0 & 0.00 & 0.00 & 0.00 & 9 & 14 & 12 & 3.37 & 2.54 & 2.21 \\
\hline 14 & 1 & 0 & 0 & 0 & 0.00 & 0.00 & 0.00 & 0 & 1 & 1 & 0.00 & 0.91 & 0.92 & 17 & 14 & 17 & 5.76 & 5.74 & 3.89 \\
\hline 15 & 7 & 0 & 0 & 0 & 0.00 & 0.00 & 0.00 & 6 & 8 & 8 & 5.22 & 2.71 & 4.37 & 26 & 27 & 28 & 5.10 & 7.08 & 6.12 \\
\hline 16 & 14 & 0 & 0 & 0 & 0.00 & 0.00 & 0.00 & 0 & 0 & 0 & 0.00 & 0.00 & 0.00 & 9 & 6 & 9 & 3.15 & 3.19 & 1.78 \\
\hline 17 & 13 & 0 & 0 & 0 & 0.00 & 0.00 & 0.00 & 4 & 1 & 0 & 1.16 & 1.24 & 0.00 & 28 & 28 & 26 & 5.72 & 5.72 & 5.18 \\
\hline
\end{tabular}

Source: BSC 2005 [DIRS 173172], Table 5-3.

${ }^{\mathrm{a}}$ If greater than $0.85 \mathrm{~m} / \mathrm{s}$.

\subsubsection{Catalog of Damaged Areas for End-On Impacts}

The long duration of the ground motions and the representation of multiple waste packages in the kinematic calculations preclude the use of a highly refined finite-element mesh. In this situation, it is more accurate to perform a set of very detailed "sidebar" calculations of the impact process using representative values for impact velocities and impact angles. These "sidebar" calculations determine the damage to a 21-PWR waste package from end-on impact on an elastic plate (BSC 2005 [DIRS 173172], Section 5.4.3 and BSC 2005 [DIRS 173178], Tables 2 and 3). These "sidebar" analyses" are completely separate from the kinematic calculations described in Section 6.5.1.1. The elastic plate is referred to as an "unyielding" surface in the documentation 
for the sidebar analyses (BSC 2005 [DIRS 173172], Section 5.4.3). The plate will be referred to as an elastic surface, with the understanding that it has finite thickness.

The sidebar calculations provide a parametric study for end-on impacts of a 21-PWR waste package on an elastic surface. The parameters of the study include five values of impact velocity: $1 \mathrm{~m} / \mathrm{s}, 2 \mathrm{~m} / \mathrm{s}, 4 \mathrm{~m} / \mathrm{s}, 6 \mathrm{~m} / \mathrm{s}$ and $10 \mathrm{~m} / \mathrm{s}$, and four values of the impact angle: $0^{\circ}, 1^{\circ}, 5^{\circ}$, and $8^{\circ}$. The selected ranges of impact velocity and impact angle are sufficiently wide to encompass all velocities and angles encountered in the end-to-end impacts generated by the kinematic calculations.

The use of an elastic surface reduces the computational mesh by a factor of two and also provides a conservative representation of the damaged area. The damaged area with an elastic surface will generally be greater than the damaged area with an adjacent waste package because the elastic surface has a high modulus of elasticity and a fixed boundary that limits displacements on the side of the plate away from the waste package. These features maximize the impact stresses and deformation of the waste package (for a given impact velocity and impact angle) in comparison to an adjacent waste package.

Material properties are based on a temperature of $150^{\circ} \mathrm{C}$. As noted in Assumption 5.3, a temperature of $150^{\circ} \mathrm{C}$ is conservative for over 97 percent of the first 10,000 years after repository closure. Calculations have also been performed at $100^{\circ} \mathrm{C}$ and $200^{\circ} \mathrm{C}$ to evaluate the sensitivity of damaged area (i.e., the area that exceeds the residual stress threshold) to temperature, but only the results for $150^{\circ} \mathrm{C}$ are incorporated into the catalog of damaged areas from end-on impacts.

These structural response calculations provide a reasonable representation of the end-on impact for a single waste package and are considered appropriate for defining the catalog of damaged areas. The calculations are based on standard, commercially available software (LS-DYNA) that has demonstrated the capability to accurately analyze impact processes and kinematic response. Appropriate mesh refinement studies have been performed to ensure that the damaged areas are largely independent of the finite-element grid. It is not necessary to represent uncertainties in ground motions or friction coefficients because these calculations have a single, end-on impact at a given impact velocity and impact angle. The uncertainty in contact damping is bounded by having no energy dissipation in the contact process itself, although there is energy dissipation due to plastic yielding of the waste package. The potential uncertainties in material properties are not represented in the calculations because the waste package will be fabricated to design specifications that follow standard values in handbooks and industrial publications, and because the sensitivity of damaged area to variation in standard material properties is expected to be minor in comparison to the sensitivity of damaged area to uncertainty in ground motions and friction coefficients.

Further details of the mesh refinement studies are documented in 21-PWR Waste Package End Impacts - A Mesh Study (BSC 2005 [DIRS 173178], Tables 2 and 3). The final results for the damaged areas are summarized in Table 6.5-3 for the residual stress thresholds of 80 percent and 90 percent of the yield strength (YS) of Alloy 22 at $150^{\circ} \mathrm{C}$. The damaged areas are also presented graphically in Figure 6.5-6. 
Table 6.5-3. Catalog of Damaged Areas from End-On Impact of a 21-PWR Waste Package on an Elastic Surface

\begin{tabular}{|c|c|c|c|c|c|c|c|c|}
\hline \multirow{2}{*}{$\begin{array}{l}\text { Impact } \\
\text { Velocity }\end{array}$} & \multicolumn{4}{|c|}{$\begin{array}{l}\text { Damaged Area }\left(\mathrm{m}^{2}\right) \text { for Stress Threshold of } \\
80 \text { Percent of } \mathrm{YS} \text { as Function of Impact Angle }\end{array}$} & \multicolumn{4}{|c|}{$\begin{array}{l}\text { Damaged Area }\left(\mathrm{m}^{2}\right) \text { for Stress Threshold of } \\
90 \text { Percent of YS as Function of Impact Angle }\end{array}$} \\
\hline & $0^{\circ}$ & $1^{\circ}$ & $5^{\circ}$ & $8^{\circ}$ & $0^{\circ}$ & $1^{\circ}$ & $5^{\circ}$ & $8^{\circ}$ \\
\hline $1 \mathrm{~m} / \mathrm{s}$ & 0.0 & 0.0020 & 0.0027 & 0.0020 & 0.0 & 0.0017 & 0.0014 & 0.0012 \\
\hline $2 \mathrm{~m} / \mathrm{s}$ & 0.0024 & 0.0282 & 0.0130 & 0.0105 & 0.0 & 0.0035 & 0.0052 & 0.0051 \\
\hline $4 \mathrm{~m} / \mathrm{s}$ & 0.0122 & 0.0421 & 0.0651 & 0.0474 & 0.0122 & 0.0126 & 0.0288 & 0.0212 \\
\hline $6 \mathrm{~m} / \mathrm{s}$ & 0.0264 & 0.0521 & 0.1466 & 0.0967 & 0.0124 & 0.0222 & 0.0655 & 0.0335 \\
\hline $10 \mathrm{~m} / \mathrm{s}$ & 0.0419 & 0.0571 & 0.2822 & 0.2244 & 0.0377 & 0.0259 & 0.1542 & 0.1206 \\
\hline
\end{tabular}

Source: BSC 2005 [DIRS 173178], Tables 2 and 3.

YS = Yield Strength

The damaged area data in Figure 6.5-6 has a complex angular dependence that has been simplified for the purpose of determining damaged areas from end-to-end impacts. The simplification is motivated by two factors:

- The kinematic calculations are two-dimensional analyses that exclude the transverse horizontal component of each ground motion. This transverse horizontal component may increase or decrease the relative impact angle between two adjacent waste packages. Given the uncertainty in impact angle, it is reasonable to simplify the dependence shown in Figure 6.5-6.

- Interpolation of damaged areas at small relative impact angles may not be accurate. The damaged areas near zero degrees may be artificially low because the geometry for the end-on impact generally cannot be duplicated by the impact between two adjacent waste packages, as explained next.

The end-on impact calculations for the catalog generally produce damage at the $0^{\circ}$ impact angle that is quite small relative to the damage at $5^{\circ}$. Small damage at $0^{\circ}$ is most probably caused by the fact that the waste package is perfectly aligned with the elastic surface. Perfect alignment will spread the impact load over a large surface area, thereby reducing the residual stress concentrations and the resulting damage area on the waste package. But perfect alignment generally does occur during the impact between two adjacent waste packages. The typical contact between two packages will often be the corner of one package impacting the trunnion sleeve or the lid of the adjacent package, rather than perfect alignment of the trunnion sleeve on one package with the end lid on the other package.

In this situation, the catalog of damaged areas has been simplified by assigning the mean value of the damaged areas at $1^{\circ}, 5^{\circ}$, and $8^{\circ}$ as the damaged area at a given impact velocity. This approach eliminates interpolation for impact angles near $0^{\circ}$. This approach also eliminates the potential sensitivity to changes in impact angle generated by the transverse horizontal component of the ground motion. Equal weighting of the damaged areas at $1^{\circ}, 5^{\circ}$, and $8^{\circ}$ is a reasonable approximation because these values span the range of impact angles observed in the kinematic calculations. Figure 6.5-7 plots the mean values overlayed over the full data catalog of damaged areas and Table 6.5-4 presents the resulting mean values. 


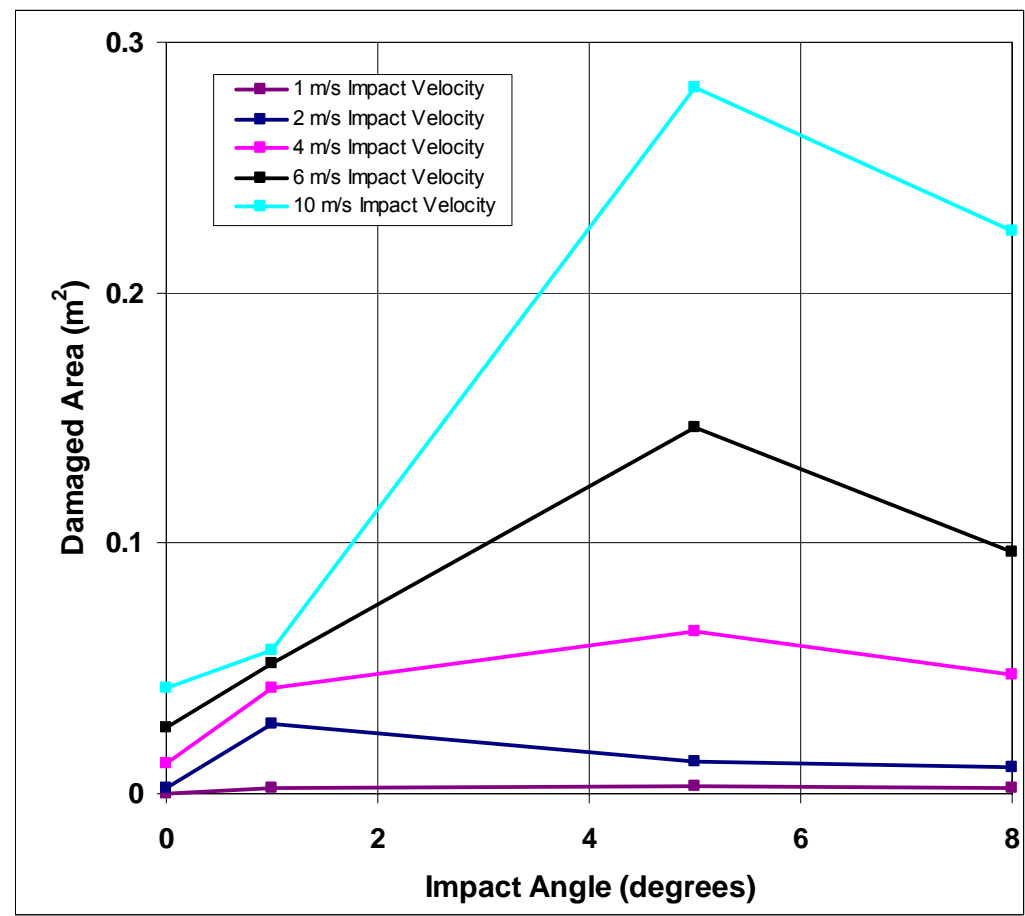

(a) Damaged Area from End-On Impacts for a Residual Stress Threshold of 80 Percent of Yield Strength

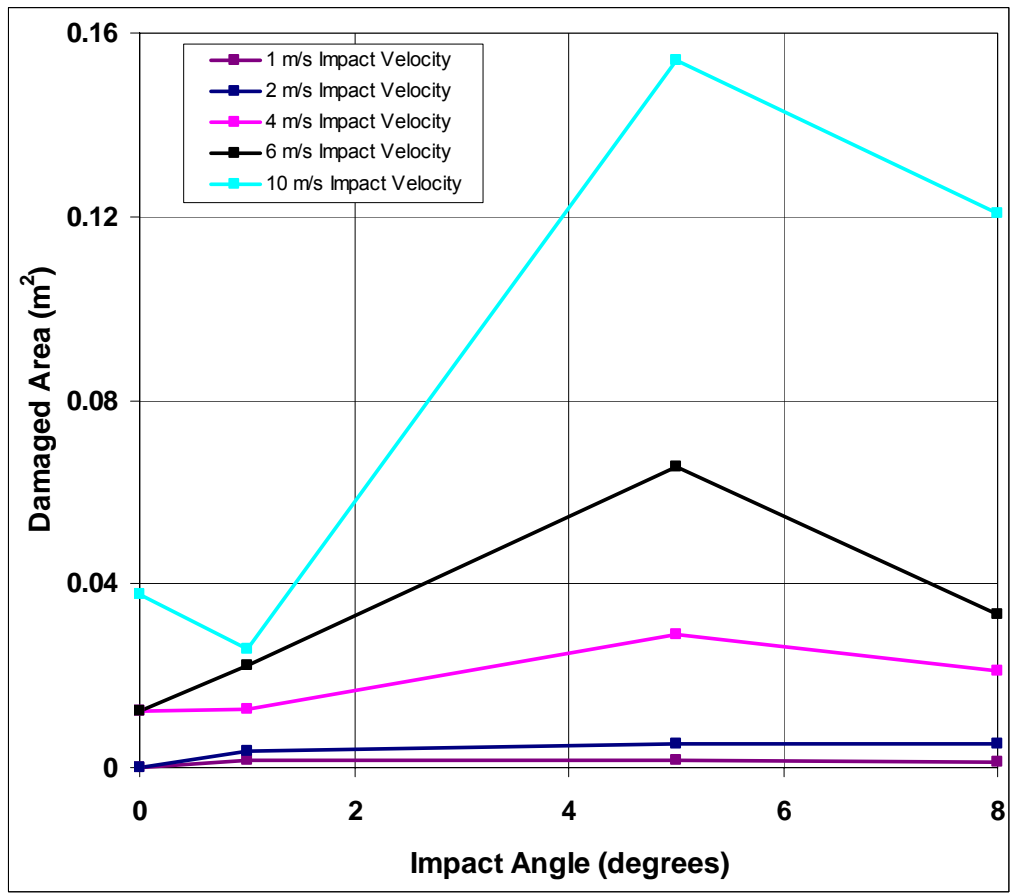

(b) Damaged Area from End-On Impacts for a Residual Stress Threshold of 90 Percent of Yield Strength Source: BSC 2005 [DIRS 173178] Tables 2 and 3; graphics created in Appendix A.

Figure 6.5-6. Catalog of Damaged Area Data for End-On Impact of a Waste Package on an Elastic Surface 


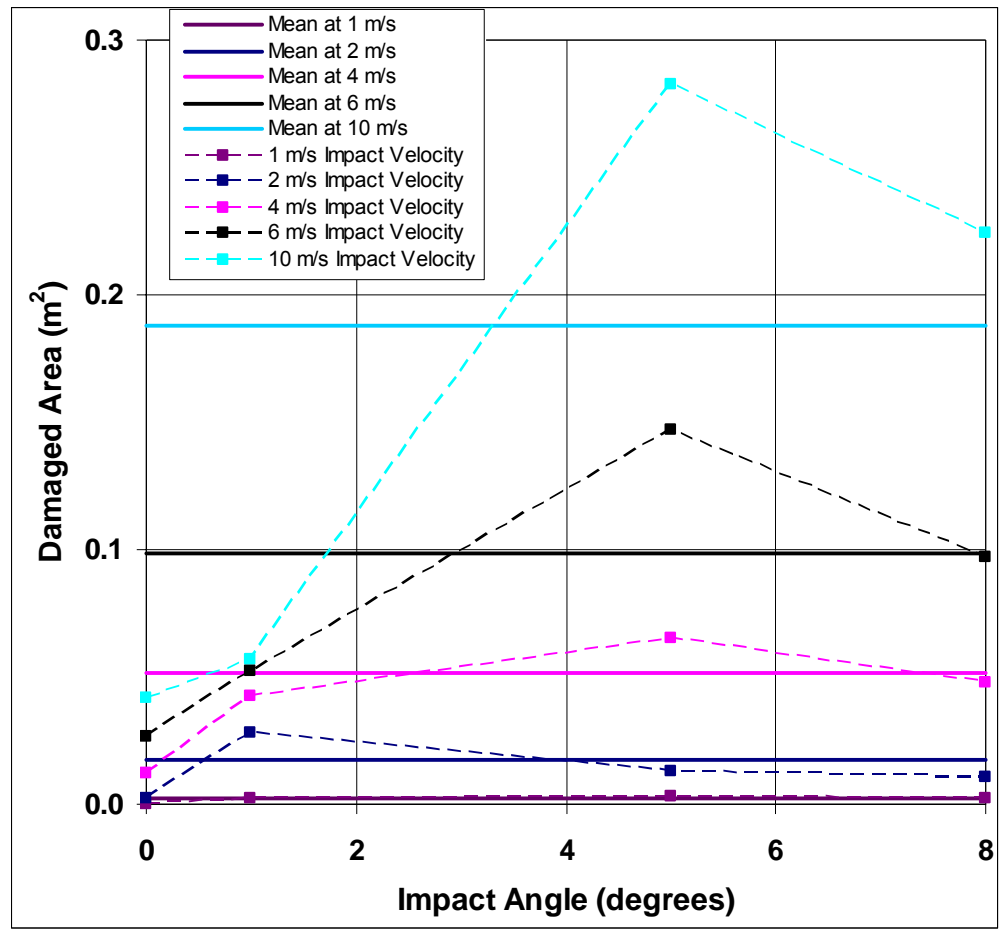

(a) Mean Damaged Area from End-On Impacts for a Residual Stress Threshold of 80 Percent of Yield Strength

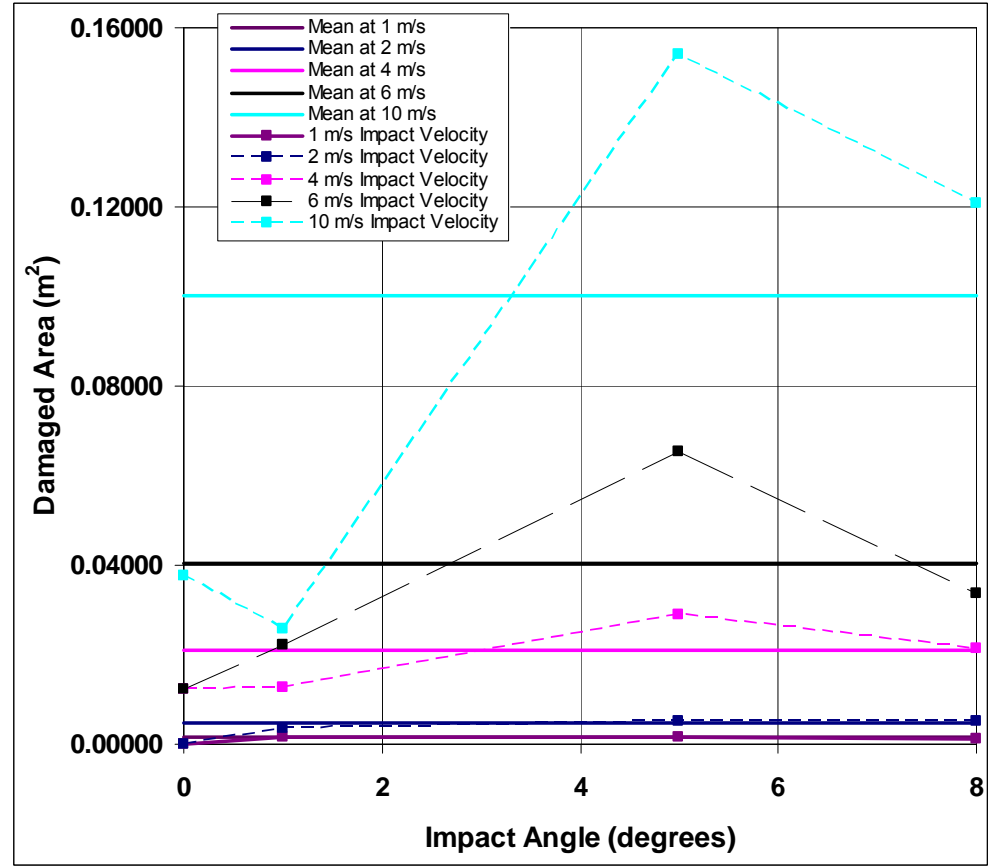

(b) Mean Damaged Area from End-On Impacts for a Residual Stress Threshold of 90 Percent of Yield Strength

Source: BSC 2005 [DIRS 173178] Tables 2 and 3; graphics created in Appendix A.

Figure 6.5-7. Mean Value of Damaged Area for Impact Angles of $1^{\circ}, 5^{\circ}$ and $8^{\circ}$ at a Given Impact Velocity in the Catalog of Damaged Area Data for End-On Impact of a Waste Package 
Table 6.5-4. Mean Damaged Areas for $1^{\circ}, 5^{\circ}$, and $8^{\circ}$ End-On Impacts of a 21-PWR Waste Package on an Elastic Surface

\begin{tabular}{|c|c|c|}
\hline $\begin{array}{c}\text { Impact } \\
\text { Velocity }\end{array}$ & $\begin{array}{c}\text { Mean Damaged Area }\left(\mathbf{m}^{2}\right) \text { for } \\
\text { Stress Threshold of 80 Percent of } \\
\text { YS }\end{array}$ & $\begin{array}{c}\text { Mean Damaged Area }\left(\mathbf{m}^{2}\right) \text { for } \\
\text { Stress Threshold of 90 Percent of } \\
\text { YS }\end{array}$ \\
\hline $1 \mathrm{~m} / \mathrm{s}$ & 0.00223 & 0.00143 \\
\hline $2 \mathrm{~m} / \mathrm{s}$ & 0.0172 & 0.0046 \\
\hline $4 \mathrm{~m} / \mathrm{s}$ & 0.0515 & 0.0209 \\
\hline $6 \mathrm{~m} / \mathrm{s}$ & 0.0985 & 0.0404 \\
\hline $10 \mathrm{~m} / \mathrm{s}$ & 0.1879 & 0.1002 \\
\hline
\end{tabular}

Source: BSC 2005 [DIRS 173178], Tables 2 and 3, repeated in Table 6.5-2.

YS $=$ Yield Strength

The mean damaged areas in Table 6.5-4 have nonzero values, even at the smallest impact velocity of $1 \mathrm{~m} / \mathrm{s}$. In order to use the results in Table 6.5-4 to determine damaged areas from end-to-end impacts, it is necessary to define a velocity threshold corresponding to no damage. The velocity threshold is estimated by extrapolating the mean damaged curve for a residual stress threshold of 80 percent of yield strength. The mean damaged area curve is plotted in Figure 6.5-8 as a function of the impact velocity. A simple linear extrapolation of the points at $1 \mathrm{~m} / \mathrm{s}$ and $2 \mathrm{~m} / \mathrm{s}$ indicates that the x-intercept of the curve corresponds to $0.851 \mathrm{~m} / \mathrm{s}$. The velocity threshold has been rounded to $0.85 \mathrm{~m} / \mathrm{s}$ for the purpose of calculating damaged areas from end-to-end impacts of adjacent packages. This velocity threshold is also appropriate at 90 percent residual stress threshold because damaged area for the 80 percent stress threshold is always equal to or greater than the damaged area for the 90 percent residual stress threshold.

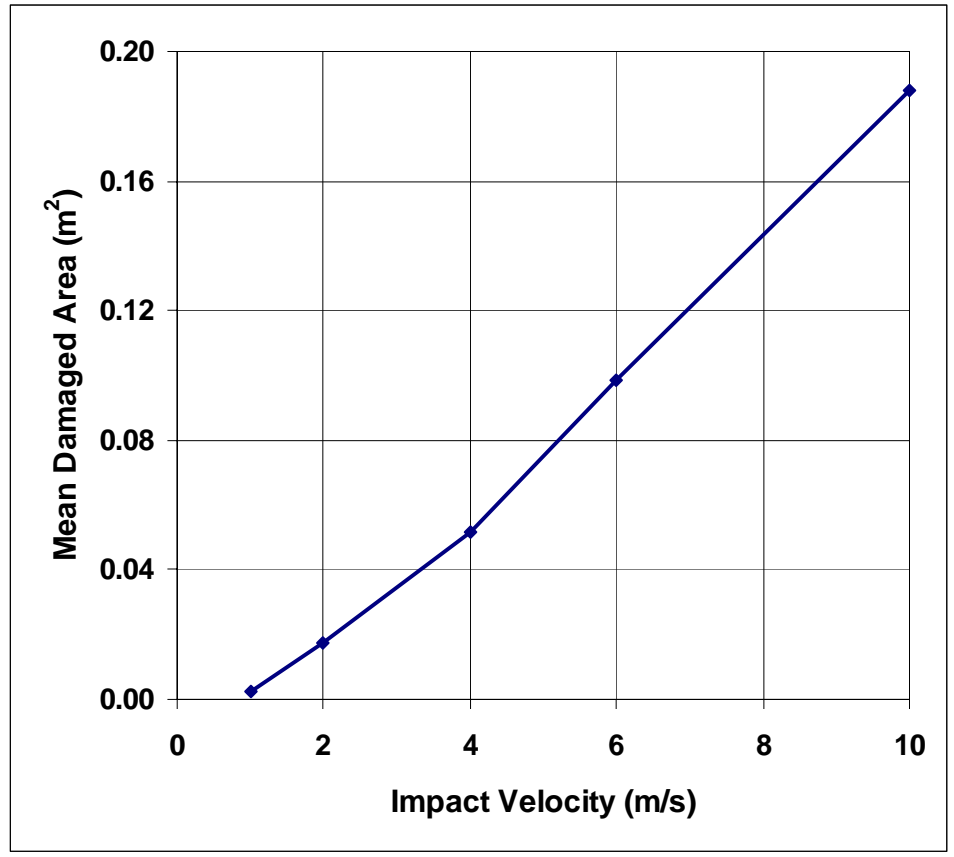

Source: Table 6.5-4; graphic created in Appendix A.

Figure 6.5-8. Mean Damaged Areas as a Function of Impact Velocity for a Residual Stress Threshold of 80 Percent of Yield Strength. 


\subsubsection{Calculation of Damaged Areas for End-to-End Impacts}

The mean damaged areas in Table $6.5-4$ and the velocity threshold of $0.85 \mathrm{~m} / \mathrm{s}$ (corresponding to zero damage) provide the basis for determining damaged areas from end-to-end impacts of adjacent waste packages in the kinematic calculations. The methodology for determining total damaged area uses the relative impact velocity between adjacent packages from the kinetic analyses (defined in the spreadsheets in DTN: MO0504SPALSDYN.000 [DIRS 173338] and in DTN: MO0503SPAUDECW.000 [DIRS 173337]) as an interpolation parameter between the given impact velocities in Table 6.5-4. The total damaged area is then defined as the sum of the damaged areas from the individual impacts.

The damaged area calculation for UDEC Realization 3 at the 2.44-m/s PGV level is illustrated in Table 6.5-5. The data in the first six columns is based on output from the UDEC calculation for the central waste package. The data in the last two columns is based on Table 6.5-4 and the velocity threshold of $0.85 \mathrm{~m} / \mathrm{s}$. The first, second, third, and sixth impacts in Table 6.5-5 have zero damaged area because the magnitude of the normal impact velocity is less than $0.85 \mathrm{~m} / \mathrm{s}$. The fourth and fifth impacts in Table 6.5-5 have nonzero damaged areas because the magnitude of the velocity is greater than $0.85 \mathrm{~m} / \mathrm{s}$. The nonzero damaged areas are determined by linear interpolation using the catalog of damaged areas in Table 6.5-4. For example, the damaged area for the fourth impact at a residual stress threshold of 80 percent of the yield strength of Alloy 22 is calculated as follows:

$$
\begin{aligned}
D A & =\frac{\left(0.0172 \mathrm{~m}^{2}-0.00223 \mathrm{~m}^{2}\right)}{(2 \mathrm{~m} / \mathrm{s}-1 \mathrm{~m} / \mathrm{s})}(1.64 \mathrm{~m} / \mathrm{s}-1 \mathrm{~m} / \mathrm{s})+0.00223 \mathrm{~m}^{2} \\
& =0.0118 \mathrm{~m}^{2},
\end{aligned}
$$

where the points $\left(1 \mathrm{~m} / \mathrm{s}, 0.00223 \mathrm{~m}^{2}\right)$ and $\left(2 \mathrm{~m} / \mathrm{s}, 0.0172 \mathrm{~m}^{2}\right)$ are based data in Table $6.5-4$. The result in equation 6-2 matches the numerical value for the fourth impact in the seventh column of Table 6.5-5. The total damaged area for the residual stress threshold of 80 percent of the yield strength of Alloy 22 is the sum of the damaged areas in the seventh column for the six impacts.

\begin{tabular}{|c|c|c|c|c|c|c|c|}
\hline $\begin{array}{l}\text { Time } \\
\text { (s) }\end{array}$ & $\begin{array}{c}\text { X-Coord. } \\
(\mathrm{m})\end{array}$ & $\begin{array}{c}\text { Y-Coord. } \\
(\mathrm{m})\end{array}$ & $\begin{array}{c}\text { V-Norm. } \\
(\mathrm{m} / \mathrm{s})\end{array}$ & $\begin{array}{l}\text { V-Tan. } \\
(\mathrm{m} / \mathrm{s})\end{array}$ & $\begin{array}{c}\text { Impact } \\
\text { Angle }\left({ }^{\circ}\right)\end{array}$ & $\begin{array}{c}\text { DA for } \\
80 \text { Percent } \\
\text { YS } \\
\left(\mathrm{m}^{2}\right)\end{array}$ & $\begin{array}{c}\text { DA for } \\
90 \text { Percent } \\
\text { YS } \\
\left(\mathrm{m}^{2}\right) \\
\end{array}$ \\
\hline $4.63 \mathrm{E}+00$ & $-8.08 E-05$ & $1.71 \mathrm{E}+00$ & 2.88E-01 & $6.72 \mathrm{E}-01$ & $1.25 \mathrm{E}-01$ & 0 & 0 \\
\hline $4.26 \mathrm{E}+00$ & $5.03 E+00$ & 2.37E-02 & $-4.22 \mathrm{E}-01$ & $1.42 \mathrm{E}+00$ & 4.98E-01 & 0 & 0 \\
\hline $3.35 \mathrm{E}+00$ & 5.98E-06 & $1.71 \mathrm{E}+00$ & 3.63E-01 & $-5.00 \mathrm{E}+00$ & $5.42 \mathrm{E}+00$ & 0 & 0 \\
\hline $3.14 \mathrm{E}+00$ & $5.03 E+00$ & $1.71 \mathrm{E}+00$ & $-1.64 E+00$ & 7.59E-01 & $3.22 \mathrm{E}+00$ & 1.18E-02 & $3.46 \mathrm{E}-03$ \\
\hline $3.12 E+00$ & $-8.17 \mathrm{E}-05$ & 1.94E-02 & 1.17E+00 & $-1.55 E+00$ & $1.75 \mathrm{E}+00$ & 4.84E-03 & 1.98E-03 \\
\hline $3.04 \mathrm{E}+00$ & $5.03 E+00$ & $5.58 \mathrm{E}-01$ & 4.64E-02 & $1.57 \mathrm{E}+00$ & $1.21 \mathrm{E}+00$ & 0 & 0 \\
\hline \multicolumn{6}{|c|}{ Total Damaged Area for Normal End-to-End Impacts $>0.85 \mathrm{~m} / \mathrm{s}\left(\mathrm{m}^{2}\right)$ : } & 1.67E-02 & $5.44 \mathrm{E}-03$ \\
\hline
\end{tabular}

Table 6.5-5. Illustration of Damaged Area Calculation - Realization 3 at 2.44-m/s PGV for UDEC

Source: Worksheet "Real3 GM3" in 21- PWRs 1e-6 damage with 0.85 mps Cutoff to central WP.xls. This file is included in the CD in Appendix G.

Notes: $\quad \mathrm{X}$-Coord. = x-coordinate; $\mathrm{Y}$-Coord. = y-coordinate; $\mathrm{V}$-Norm. $=$ normal (relative) impact velocity; $\mathrm{V}$-Tan. = tangential (relative) impact velocity; $\mathrm{DA}=$ damaged area; $\mathrm{YS}=$ yield strength. 
This methodology has two significant conservatisms:

- The relative impact velocity between adjacent waste packages from the kinematic calculations is ideally a factor of two less than the equivalent end-on impact velocity for interpolation in Table 6.5-4. As a concrete example, a $1 \mathrm{~m} / \mathrm{s}$ end-on impact of a single waste package onto an elastic surface is equivalent to the impact of two adjacent, identical packages with velocities of $+1 \mathrm{~m} / \mathrm{s}$ and $-1 \mathrm{~m} / \mathrm{s}$, for a total relative velocity of $2 \mathrm{~m} / \mathrm{s}$. Stated differently, the elastic surface provides a plane of symmetry for the end-on impact calculations, and this plane of symmetry implies that packages are moving in equal and opposite directions on either side of the plane for the kinematic calculations, resulting in the factor of two difference for equal packages.

- The simple summation of damage from individual impacts overestimates the damage if impacts occur in the same location or if the damaged areas from adjacent impacts overlap significantly.

The methodology for analyzing damaged area does not incorporate the factor of two between end-on impact velocity and relative impact velocity. Adjacent packages are not always equal in mass and in their geometric configuration. The factor will be reduced below two for unequal packages, but the exact reduction is uncertain at this time. In addition, impact of the corner of one waste package onto the lid of the adjacent waste package is not represented in the calculations for end-on impacts onto an elastic surface. The potential reduction in damaged areas due to the factor of two has therefore been excluded from the damage abstractions.

Similarly, the two-dimensional kinematic calculations do not represent the potential variation in impact location from a three-dimensional process. Until three-dimensional results are available to quantify the variability in impact location, a simple summation of the damaged areas from individual impacts is appropriate for the abstraction of waste package damage.

This methodology has been applied to the kinematic output from the two suites of calculations discussed in Section 6.5.1.1. The damaged area calculations for the 80 percent and the 90 percent residual stress criteria are documented in Excel files that are archived on a compact disk in Appendix $\mathrm{G}$ of this report. The names of these Excel files and their contents are summarized in Table 6.5-6.

\subsubsection{Abstraction of Damaged Areas for End-to-End Impacts}

Four abstractions have been developed to represent the damaged areas from end-to-end impacts:

- Damaged areas from kinematic calculations with LS-DYNA for a residual stress threshold of 80 percent of the yield strength of Alloy 22

- Damaged areas from kinematic calculations with LS-DYNA for a residual stress threshold of 90 percent of the yield strength of Alloy 22

- Damaged areas from kinematic calculations with UDEC for a residual stress threshold of 80 percent of the yield strength of Alloy 22 
- Damaged areas from kinematic calculations with UDEC for a residual stress threshold of 90 percent of the yield strength of Alloy 22

Table 6.5-6. Listing of Spreadsheets with Damaged Area Calculations for the Kinematic Calculations

\begin{tabular}{|c|c|}
\hline Name of Excel File & Description of Content \\
\hline LLNL_Impact_Velocities_E-5.xls & $\begin{array}{l}\text { Kinematic results for LS-DYNA calculations with } 17 \\
\text { ground motions at the } 1.05-\mathrm{m} / \mathrm{s} \text { PGV level. There are no } \\
\text { damaged areas in this file because all relative impact } \\
\text { velocities are below } 0.85 \mathrm{~m} / \mathrm{s} \text {. }\end{array}$ \\
\hline LLNL_Damage_E-6 with $0.85 \mathrm{mps}$ Cutoff.xls & $\begin{array}{l}\text { Kinematic results and associated damaged areas for } \\
\text { LS-DYNA calculations with } 17 \text { ground motions at the } \\
\text { 2.44-m/s PGV level }\end{array}$ \\
\hline LLNL_Damage_E-7 with $0.85 \mathrm{mps}$ Cutoff.xls & $\begin{array}{l}\text { Kinematic results and associated damaged areas for } \\
\text { LS-DYNA calculations with } 17 \text { ground motions at the } \\
5.35-\mathrm{m} / \mathrm{s} \text { PGV level }\end{array}$ \\
\hline $\begin{array}{l}\text { 21-PWRs 1e-5 damage with } 0.85 \mathrm{mps} \text { Cutoff to central } \\
\text { WP.xls }\end{array}$ & $\begin{array}{l}\text { Kinematic results and associated damaged areas for the } \\
\text { UDEC calculations with } 17 \text { ground motions at the } \\
1.05-\mathrm{m} / \mathrm{s} \text { PGV level; central waste package }\end{array}$ \\
\hline $\begin{array}{l}\text { 21-PWRs 1e-5 damage with } 0.85 \mathrm{mps} \text { Cutoff to center } \\
\text { right WP.xls }\end{array}$ & $\begin{array}{l}\text { Kinematic results and associated damaged areas for the } \\
\text { UDEC calculations with } 17 \text { ground motions at the } \\
1.05-\mathrm{m} / \mathrm{s} \text { PGV level; center right waste package }\end{array}$ \\
\hline $\begin{array}{l}\text { 21-PWRs 1e-5 damage with } 0.85 \mathrm{mps} \text { Cutoff to center } \\
\text { left WP.xls }\end{array}$ & $\begin{array}{l}\text { Kinematic results and associated damaged areas for the } \\
\text { UDEC calculations with } 17 \text { ground motions at the } \\
\text { 1.05-m/s PGV level; center left package }\end{array}$ \\
\hline $\begin{array}{l}\text { 21-PWRs 1e-6 damage with } 0.85 \mathrm{mps} \text { Cutoff to central } \\
\text { WP.xls }\end{array}$ & $\begin{array}{l}\text { Kinematic results and associated damaged areas for the } \\
\text { UDEC calculations with } 17 \text { ground motions at the } \\
2.44-\mathrm{m} / \mathrm{s} \text { PGV level; central waste package }\end{array}$ \\
\hline $\begin{array}{l}\text { 21-PWRs 1e-6 damage with } 0.85 \mathrm{mps} \text { Cutoff to center } \\
\text { right WP.xls }\end{array}$ & $\begin{array}{l}\text { Kinematic results and associated damaged areas for the } \\
\text { UDEC calculations with } 17 \text { ground motions at the } \\
2.44-\mathrm{m} / \mathrm{s} \text { PGV level; center right waste package }\end{array}$ \\
\hline $\begin{array}{l}\text { 21-PWRs 1e-6 damage with } 0.85 \mathrm{mps} \text { Cutoff to center } \\
\text { left WP.xls }\end{array}$ & $\begin{array}{l}\text { Kinematic results and associated damaged areas for the } \\
\text { UDEC calculations with } 17 \text { ground motions at the } \\
2.44-\mathrm{m} / \mathrm{s} \text { PGV level; center left package }\end{array}$ \\
\hline $\begin{array}{l}\text { 21-PWRs 1e-7 damage with } 0.85 \mathrm{mps} \text { Cutoff to central } \\
\text { WP.xls }\end{array}$ & $\begin{array}{l}\text { Kinematic results and associated damaged areas for the } \\
\text { UDEC calculations with } 17 \text { ground motions at the } \\
5.35-\mathrm{m} / \mathrm{s} \text { PGV level; central waste package }\end{array}$ \\
\hline $\begin{array}{l}\text { 21-PWRs 1e-7 damage with } 0.85 \mathrm{mps} \text { Cutoff to center } \\
\text { right WP.xls }\end{array}$ & $\begin{array}{l}\text { Kinematic results and associated damaged areas for the } \\
\text { UDEC calculations with } 17 \text { ground motions at the } \\
5.35-\mathrm{m} / \mathrm{s} \text { PGV level; center right waste package }\end{array}$ \\
\hline $\begin{array}{l}\text { 21-PWRs 1e-7 damage with } 0.85 \mathrm{mps} \text { Cutoff to center left } \\
\text { WP.xls }\end{array}$ & $\begin{array}{l}\text { Kinematic results and associated damaged areas for the } \\
\text { UDEC calculations with } 17 \text { ground motions at the } \\
5.35-\mathrm{m} / \mathrm{s} \text { PGV level; center left package }\end{array}$ \\
\hline
\end{tabular}

Source: Files are available on the CD in Appendix G.

The decision to develop four separate abstractions, rather than one combined abstraction, is motivated by the following considerations: (i) four separate abstractions allow direct representation of the epistemic uncertainty in TSPA from the computational approaches (LS-DYNA versus UDEC) and from the residual stress thresholds ( 80 percent versus 90 percent), and (ii) the damaged areas for these four cases exhibit statistically significant differences. There is approximately a factor of three increase in damaged area between the 90 percent and the 80 percent residual stress threshold for a given computational approach, and there is approximately a factor of three increase in damaged areas between the damaged areas for 
LS-DYNA and UDEC. These factors are generally greater than the standard error of the four individual data sets, so it is incorrect to combine the data from the four cases.

Each abstraction, however, is based on the same three relationships:

- The probability of no damage as a function of PGV.

- A power law fit to the nonzero damaged areas as a function of PGV. This power law fit is conditional on the existence of nonzero damage, based on the first relationship. This power law fit is equivalent to a least squares linear fit for the natural logarithm of damaged area versus the natural logarithm of PGV. The natural logarithm, rather than the logarithm to base 10, has been used throughout the abstraction process. The natural logarithm will be abbreviated as "In" in the text.

- A fit with a normal distribution for the residuals of nonzero damaged area in $\ln$-ln space. This fit is again conditional on the existence of nonzero damage. The residual is defined as the difference between the natural logarithm of the nonzero damaged area and the natural logarithm of the power law fit at the appropriate value of PGV. This normal distribution in $\ln -\ln$ space is equivalent to a ln-normal distribution in "physical" space. The standard deviation of the normal fit in $\ln -\ln$ space is constant, independent of PGV.

Since each abstraction is based on the same relationships, the statistical analysis is illustrated for the damaged areas from LS-DYNA calculations with a residual stress threshold of 80 percent of the yield strength of Alloy 22 in the next subsections. The other three abstractions are treated equivalently and combined in Section 6.5.3. The basis for the four abstractions is documented in the Excel file entitled WP-WP Damage Abstraction with 0.85mps Cutoff Rev00d.xls. This file is available on the compact disk in Appendix G of this report.

\subsubsection{Abstraction of Damaged Areas for LS-DYNA Results with 80 Percent Residual Stress Threshold}

The damaged areas from the LS-DYNA calculations with a residual stress threshold of 80 percent of the yield strength of Alloy 22 are presented in Table 6.5-7. As a reminder, the LS-DYNA calculations represent a total of 7 waste packages; the three central packages are 21-PWR waste packages. Table 6.5-7 presents the damaged areas for these three packages, labeled as center, center-right, and center-left, at the $2.44-\mathrm{m} / \mathrm{s}$ and $5.35-\mathrm{m} / \mathrm{s} \mathrm{PGV}$ ground motion levels. There are 17 observations at each PGV level, corresponding to the 17 ground motion (GM) time histories at each PGV level. Summary statistics for the center, center-left, and center right package include the mean, the standard deviation, the mean of the natural logarithm of the nonzero observations, the median or geometric mean of the nonzero observations, the standard deviation of the natural logarithm of the nonzero observations, and the fraction with no damage. Summary statistics are also presented for the three waste packages at the $2.44-\mathrm{m} / \mathrm{s}$ and the $5.35-\mathrm{m} / \mathrm{s}$ PGV ground motion levels. No results are presented for the $1.05-\mathrm{m} / \mathrm{s}$ PGV level because the relative end-to-end impact velocity is below the velocity threshold of $0.85 \mathrm{~m} / \mathrm{s}$ for initiation of damage in each of the 17 observations.

The summary statistics in Table 6.5-7 indicate that the arithmetic standard deviation is greater than the arithmetic mean for a given package and PGV level. If a normal distribution is used to 
describe the scatter of these data, it would be severely truncated on the lower end to avoid negative damaged areas. The need for truncation can be avoided by using a ln-normal distribution to represent the data scatter in the abstractions.

Table 6.5-7. Damaged Areas from the LS-DYNA Analyses for the Three Central Waste Packages with a Residual Stress Threshold of 80 Percent of the Yield Strength of Alloy 22

\begin{tabular}{|c|c|c|c|c|c|c|}
\hline & \multicolumn{3}{|c|}{ PGV-Longitudinal $=2.44 \mathrm{~m} / \mathrm{s}$} & \multicolumn{3}{|c|}{ PGV-Longitudinal $=5.35 \mathrm{~m} / \mathrm{s}$} \\
\hline & $\begin{array}{c}\text { Damaged } \\
\text { Area } \\
\text { Center-Left } \\
\left(\mathrm{m}^{2}\right)\end{array}$ & $\begin{array}{c}\text { Damaged } \\
\text { Area } \\
\text { Center } \\
\left(\mathrm{m}^{2}\right)\end{array}$ & $\begin{array}{c}\text { Damaged } \\
\text { Area } \\
\text { Center-Right } \\
\left(\mathbf{m}^{2}\right)\end{array}$ & $\begin{array}{c}\text { Damaged } \\
\text { Area } \\
\text { Center-Left } \\
\left(\mathrm{m}^{2}\right)\end{array}$ & $\begin{array}{c}\text { Damaged } \\
\text { Area } \\
\text { Center } \\
\left(\mathrm{m}^{2}\right)\end{array}$ & $\begin{array}{c}\text { Damaged } \\
\text { Area } \\
\text { Center-Right } \\
\left(\mathrm{m}^{2}\right) \\
\end{array}$ \\
\hline Ground Motion No. 1 & 0 & 0 & 0 & 0 & 0 & 0 \\
\hline Ground Motion No. 2 & 0 & $3.42 \mathrm{E}-04$ & $1.44 \mathrm{E}-03$ & 1.54E-01 & 8.19E-03 & $9.10 \mathrm{E}-03$ \\
\hline Ground Motion No. 3 & $1.71 \mathrm{E}-02$ & $3.11 \mathrm{E}-02$ & $3.71 \mathrm{E}-02$ & $1.52 \mathrm{E}-01$ & $3.35 \mathrm{E}-01$ & $2.86 \mathrm{E}-01$ \\
\hline Ground Motion No. 4 & $3.13 \mathrm{E}-04$ & $3.13 \mathrm{E}-04$ & $2.13 \mathrm{E}-03$ & 1.87E-01 & $1.57 \mathrm{E}-01$ & $9.61 \mathrm{E}-02$ \\
\hline Ground Motion No. 5 & 0 & 0 & 0 & 1.80E-02 & $2.68 \mathrm{E}-02$ & $2.40 \mathrm{E}-02$ \\
\hline Ground Motion No. 6 & 0 & 0 & $3.72 \mathrm{E}-04$ & $9.58 \mathrm{E}-02$ & 1.93E-01 & $1.40 \mathrm{E}-01$ \\
\hline Ground Motion No. 7 & 0 & 0 & 5.36E-04 & 4.96E-02 & $3.02 E-02$ & 6.33E-03 \\
\hline Ground Motion No. 8 & 0 & 0 & 0 & $5.84 \mathrm{E}-02$ & $7.40 \mathrm{E}-02$ & $3.95 \mathrm{E}-02$ \\
\hline Ground Motion No. 9 & 0 & 0 & 0 & 8.03E-03 & $5.66 \mathrm{E}-04$ & 3.70E-03 \\
\hline Ground Motion No. 10 & $9.76 \mathrm{E}-03$ & $1.41 \mathrm{E}-02$ & $3.19 \mathrm{E}-02$ & $2.60 \mathrm{E}-01$ & $2.72 \mathrm{E}-01$ & $2.84 \mathrm{E}-01$ \\
\hline Ground Motion No. 11 & 0 & 0 & 0 & 4.37E-02 & $2.32 \mathrm{E}-02$ & $6.13 \mathrm{E}-03$ \\
\hline Ground Motion No. 12 & 0 & 0 & 0 & $5.52 \mathrm{E}-02$ & 6.53E-02 & $5.22 \mathrm{E}-02$ \\
\hline Ground Motion No. 13 & 0 & 0 & 0 & 4.43E-02 & 5.09E-02 & 2.84E-02 \\
\hline Ground Motion No. 14 & 0 & 0 & 0 & 4.09E-02 & $3.81 \mathrm{E}-02$ & $5.67 \mathrm{E}-02$ \\
\hline Ground Motion No. 15 & $4.44 \mathrm{E}-02$ & $4.98 \mathrm{E}-02$ & $4.00 \mathrm{E}-02$ & $7.43 \mathrm{E}-02$ & $6.69 \mathrm{E}-02$ & $6.45 \mathrm{E}-02$ \\
\hline Ground Motion No. 16 & 9.23E-04 & $2.55 E-03$ & 8.10E-03 & $2.88 \mathrm{E}-02$ & $2.57 \mathrm{E}-02$ & $2.20 \mathrm{E}-02$ \\
\hline Ground Motion No. 17 & 0 & $1.41 \mathrm{E}-03$ & $1.41 \mathrm{E}-03$ & $3.26 \mathrm{E}-02$ & $3.28 \mathrm{E}-02$ & $2.56 \mathrm{E}-02$ \\
\hline Mean & 0.0043 & 0.0059 & 0.0072 & 0.0767 & 0.0823 & 0.0673 \\
\hline Standard Deviation & 0.0113 & 0.0139 & 0.0141 & 0.0712 & 0.0985 & 0.0896 \\
\hline Mean of $\operatorname{Ln}(D A>0)$ & -5.3735 & -5.6167 & -5.4949 & -2.8575 & -3.1512 & -3.3656 \\
\hline $\begin{array}{r}\text { Median }= \\
\text { Exp }(\text { Mean }(\operatorname{Ln}(\mathrm{DA}>0)))\end{array}$ & 0.0046 & 0.0036 & 0.0041 & 0.0574 & 0.0428 & 0.0345 \\
\hline $\begin{array}{r}\begin{array}{r}\text { Standard Deviation of } \\
\operatorname{Ln}(\mathrm{DA}>0)\end{array} \\
\end{array}$ & 2.0765 & 2.0780 & 1.8460 & 0.9029 & 1.5239 & 1.3123 \\
\hline Fraction without Damage & 0.71 & 0.59 & 0.47 & 0.06 & 0.06 & 0.06 \\
\hline & \multicolumn{3}{|c|}{$\begin{array}{l}\text { Summary Statistics for the } \\
\text { Three Waste Packages }\end{array}$} & \multicolumn{3}{|c|}{$\begin{array}{l}\text { Summary Statistics for the } \\
\text { Three Waste Packages }\end{array}$} \\
\hline Mean of $\operatorname{Ln}(D A>0)$ & \multicolumn{3}{|l|}{-5.507} & \multicolumn{3}{|c|}{-3.1248} \\
\hline $\begin{array}{r}\text { Median= } \\
\text { Exp(Mean }(\operatorname{Ln}(D A>0))\end{array}$ & \multicolumn{3}{|l|}{0.0041} & \multicolumn{3}{|l|}{0.0439} \\
\hline $\begin{array}{r}\text { Standard Deviation of } \\
\operatorname{Ln}(\mathrm{DA}>0)\end{array}$ & \multicolumn{3}{|l|}{1.879} & \multicolumn{3}{|l|}{1.26} \\
\hline Fraction without Damage & \multicolumn{3}{|l|}{0.588} & \multicolumn{3}{|l|}{0.059} \\
\hline
\end{tabular}

Source: Worksheet entitled: ABSTR for LS-DYNA $80 \%$ YS, in the file WP-WP Damage Abstraction with 0.85mps Cutoff Rev00d.xls. File is on the CD in Appendix G.

Notes: $\quad \mathrm{DA}=$ damaged area; $\mathrm{DA}>0=$ nonzero damaged areas only; the Median is also called the geometric mean. 
The average response of the data could be described by a least squares fit using a power law or using a straight line. The power law has been selected because it has significantly greater coefficient of determination (i.e., $r^{2}$ value) with the data than a linear fit.

Observations with zero damage cannot be included in a ln-normal distribution. Two options were considered for representing the observations with zero damage: assigning a small nonzero value to each observation with zero damage, or defining the probability of no damage as a function of PGV. The preferred approach is to define the probability of no damage because it eliminates the arbitrariness in selecting the magnitude of the small nonzero value.

\subsection{Probability of No Damage}

The first relationship in the abstraction is definition of the probability of no damage as a function of PGV. This function is based on the following observations:

- The probability of no damage is 1.0 at $1.05 \mathrm{~m} / \mathrm{s}$. All of the LS-DYNA calculations at the $1.05-\mathrm{m} / \mathrm{s}$ PGV ground motion level have zero damaged areas because the end-to-end impact velocities are below the $0.85 \mathrm{~m} / \mathrm{s}$ velocity threshold for damage.

- The probability of no damage is 0.588 at $2.44 \mathrm{~m} / \mathrm{s}$. This value is an average for the center, center-left, and center-right packages, as shown by the last row in Table 6.5-7.

- The probability of no damage is 0.059 at $5.35 \mathrm{~m} / \mathrm{s}$, based on the average of the three central waste packages (see the last row in Table 6.5-7).

The first and second observations imply that the probability of no damage first drops below 1 for a PGV value between $1.05 \mathrm{~m} / \mathrm{s}$ and $2.44 \mathrm{~m} / \mathrm{s}$. For the purposes of this abstraction, this PGV value is conservatively set to $1.05 \mathrm{~m} / \mathrm{s}$. The third observation implies that the probability of no damage becomes zero at a PGV value above $5.35 \mathrm{~m} / \mathrm{s}$. For the purposes of this abstraction, this $\mathrm{PGV}$ value is conservatively set to $5.35 \mathrm{~m} / \mathrm{s}$. The points for the probability function are listed in Table 6.5-8

Table 6.5-8. Data Points for Abstraction of the Probability of No Damage

\begin{tabular}{|c|c|}
\hline $\begin{array}{c}\text { PGV Value } \\
(\mathbf{m} / \mathbf{s})\end{array}$ & $\begin{array}{c}\text { Probability of No Damage } \\
(-)\end{array}$ \\
\hline 1.05 & 1.0 \\
\hline 2.44 & 0.588 \\
\hline 5.35 & 0.0 \\
\hline
\end{tabular}

These three points are fit with a power law function of the following form:

$$
\begin{aligned}
P_{N D} & =1 & & \text { for } P G V \leq 1.05, \\
& =\alpha(5.35-P G V)^{\beta} & & \text { for } 1.05<P G V<5.35, \\
& =0 & & \text { for } P G V \geq 5.35,
\end{aligned}
$$


where $P_{N D}$ is the probability of no damage, $P G V$ is the horizontal peak ground velocity in the units of $\mathrm{m} / \mathrm{s}$, and $\alpha$ and $\beta$ are constants. Note that the form of the power law guarantees that $P_{N D}$ is zero at $5.35 \mathrm{~m} / \mathrm{s}$. A simple fit to the data points at $1.05 \mathrm{~m} / \mathrm{s}$ and $2.44 \mathrm{~m} / \mathrm{s}$ results in the following relationship for $P_{N D}$ :

$$
\begin{aligned}
P_{N D} & =1 & & \text { for } P G V \leq 1.05, \\
& =(0.1376)(5.35-P G V)^{1.36} & & \text { for } 1.05<P G V<5.35, \\
& =0 & & \text { for } P G V \geq 5.35 .
\end{aligned}
$$

Figure 6.5-9 is a plot of the relationship for probability of no damage as a function of PGV.

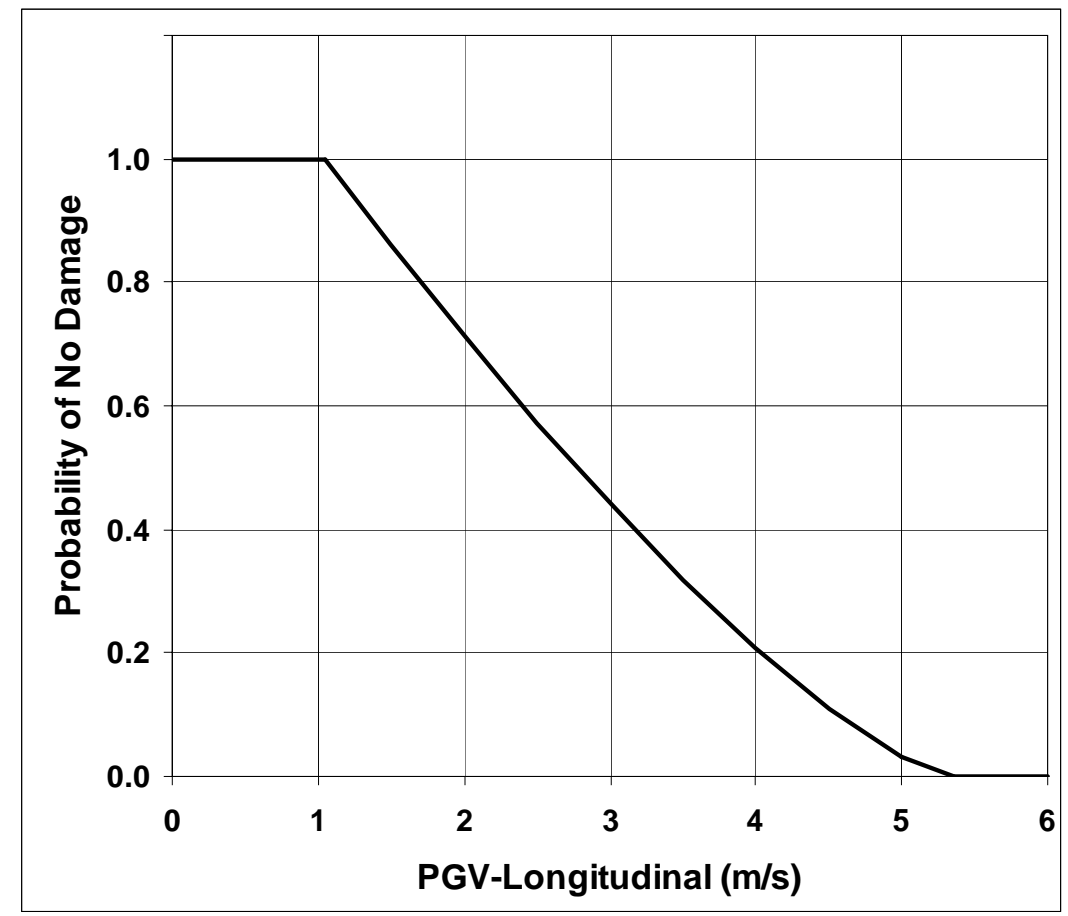

Source: Worksheet ABSTR for LS-DYNA $80 \%$ YS, in the file WP-WP Damage Abstraction with $0.85 m p s$ Cutoff Rev00d.xIs. This file can be found on the CD in Appendix G.

Figure 6.5-9. Probability of No Damage As a Function of PGV

\subsection{Power Law Fit to the Nonzero Damaged Areas}

A power law fit to the nonzero damaged areas (conditional on the existence of damage) is the second relationship in the abstraction. The power law fit to the nonzero damaged areas in Table 6.5-7 is presented in Figure 6.5-10. Figure 6.5-10(a) presents the power law least squares fit generated by Excel, and Figure 6.5-10(b) presents the equivalent (linear) fit for the natural logarithm of the nonzero damaged areas as a function of $\ln (\mathrm{PGV})$. The coefficient of determination for the power law fit is 0.36 . This value can be compared to the coefficient of determination for a linear fit, which is found to be 0.15 (the linear trendline is not shown in Figure 6.5-10). The power law fit has a significantly higher coefficient of determination than the linear fit. 


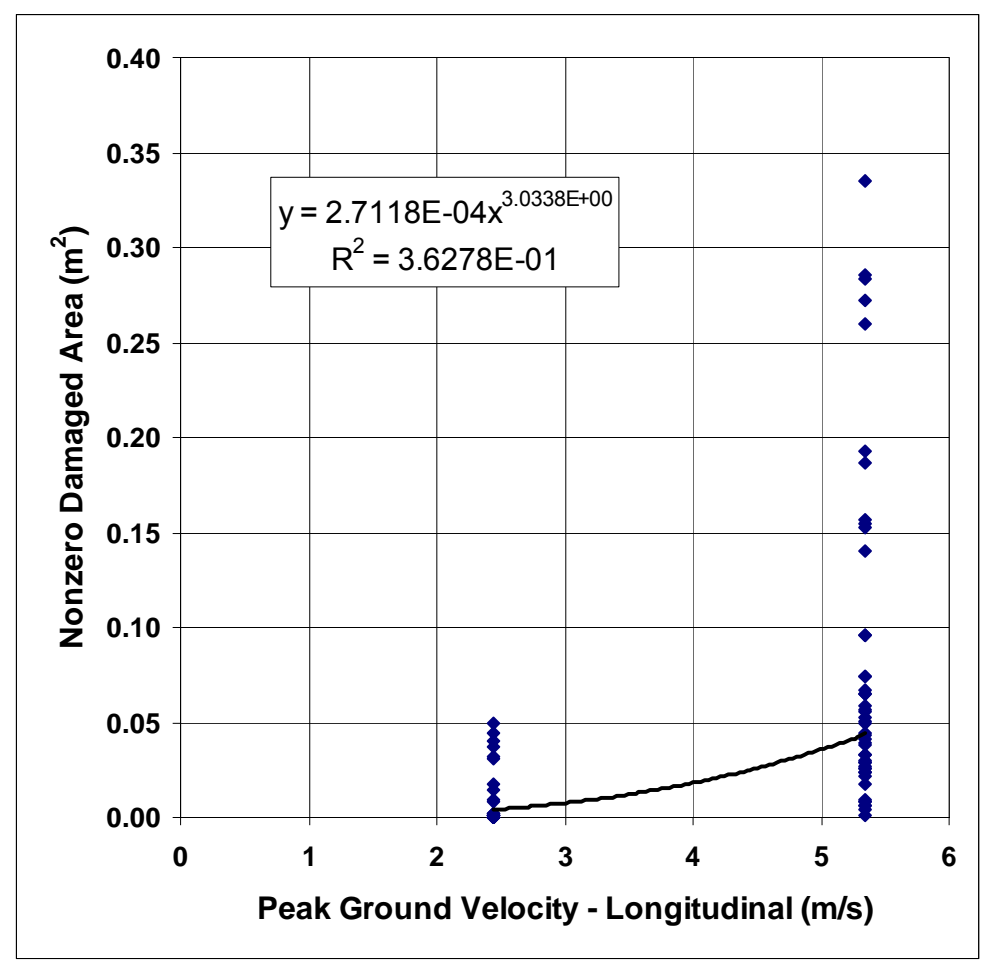

(a) Power Law Fit to the Nonzero Damaged Areas

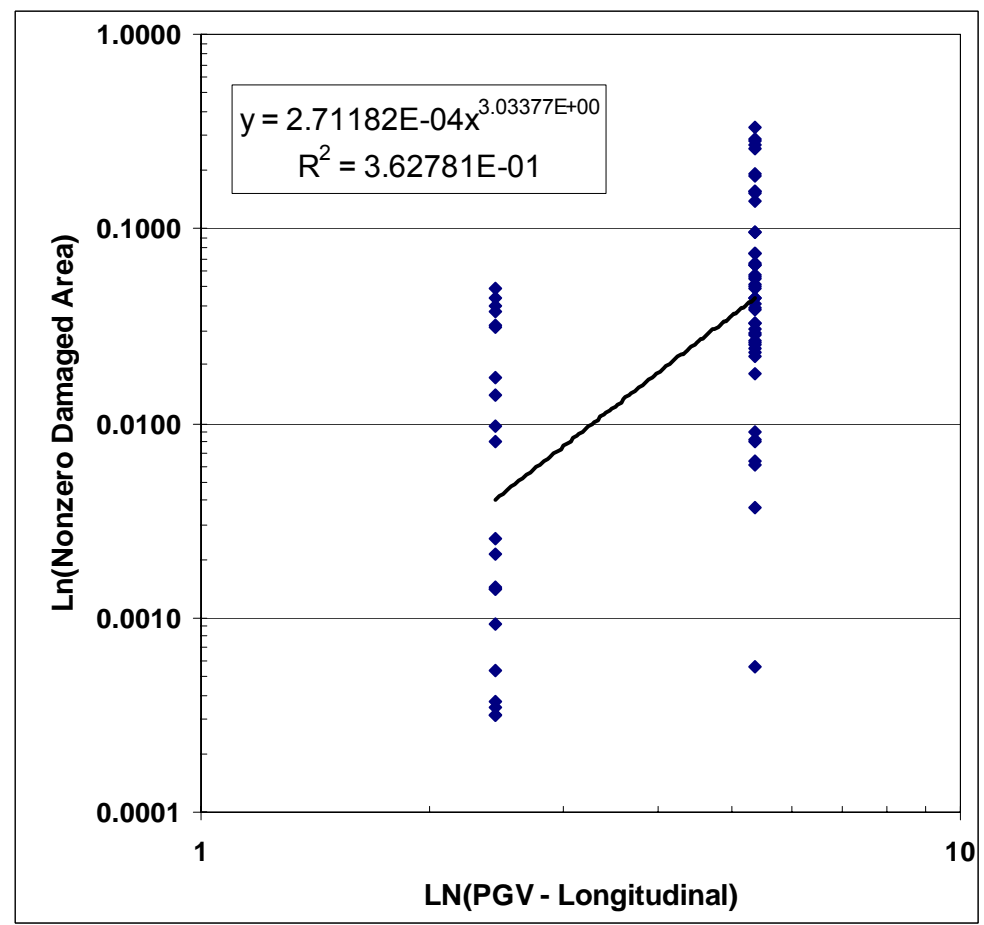

(b) Power Law Fit in Ln-Ln Representation

Source: Worksheet ABSTR for LS-DYNA 80\% YS, in the file WP-WP Damage Abstraction with 0.85mps Cutoff Rev00d.xls. This file can be found on the CD in Appendix G.

Figure 6.5-10. Power Law Fit to the Nonzero Damaged Areas for LS-DYNA with a Residual Stress Threshold of 80 Percent of the Yield strength of Alloy 22 
The data in Figure 6.5-10 fall into "stripes" because the first horizontal component of PGV has been oriented in the longitudinal direction, parallel with the drift axis. The first horizontal component has a fixed value of $2.44 \mathrm{~m} / \mathrm{s}$ or $5.35 \mathrm{~m} / \mathrm{s}$, so damaged areas plot above one of these two values of PGV. The selection of the longitudinal direction for the first horizontal component is motivated by the engineering judgment that damage from end-to-end impacts is expected to correlate more strongly with the longitudinal, rather than the transverse, component of ground motion. In addition, the presence of stripes simplifies the statistical analysis.

\subsection{Comparison of Residuals for Nonzero Damaged Area Versus a Normal Distribution in Ln-Ln Space}

Figure 6.5-11 presents a cumulative probability distribution plot for the residuals of the natural logarithm of the nonzero damaged areas versus a cumulative normal distribution. Figure 6.5-11 demonstrates that the residuals follow a normal distribution in $\ln$-ln space with a mean of zero and a standard deviation of 1.463. This standard deviation is based on the residuals for all the nonzero data points. A quantile plot provides a more discriminating comparison of the residuals versus a $\ln$-normal distribution. Figure 6.5-12 presents the quantile plot for the residuals. This plot demonstrates that a normal distribution provides a reasonable representation of the residuals in $\ln -\ln$ space.

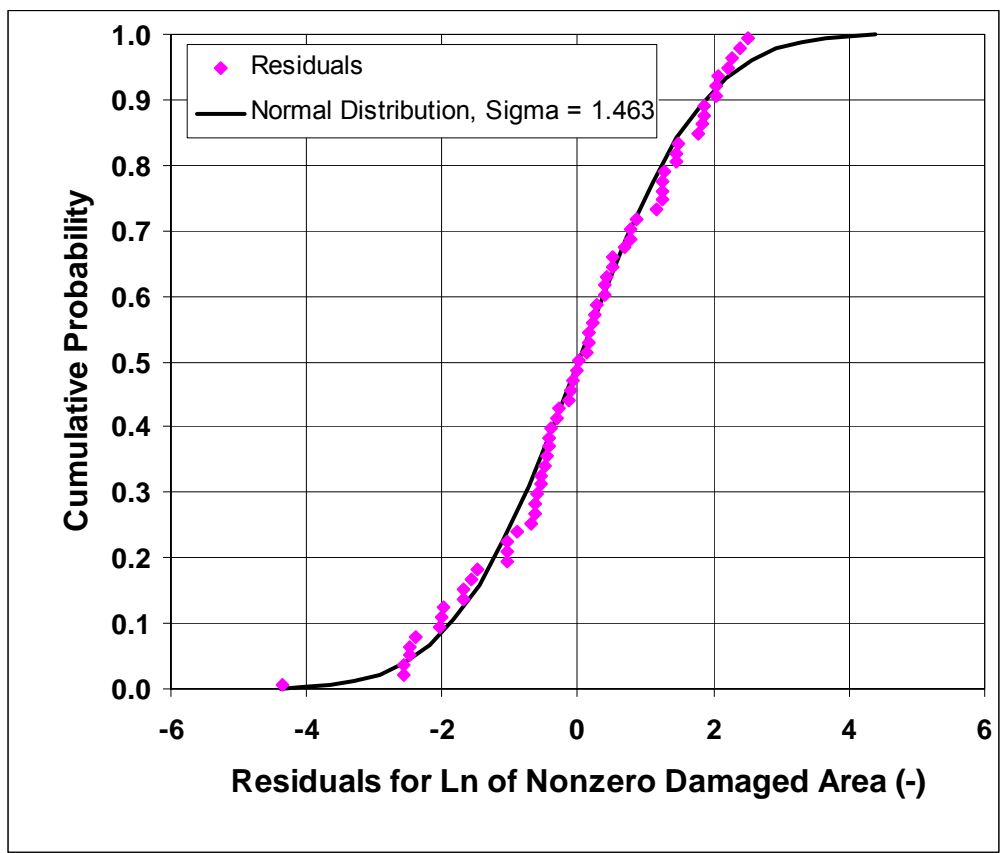

Source: Worksheet ABSTR for LS-DYNA $80 \%$ YS, in the file WP-WP Damage Abstraction with 0.85mps Cutoff Rev00d.xls. This file can be found on the CD in Appendix G.

Figure 6.5-11. Comparison of the Cumulative Distribution for the Natural Logarithm of the Residuals for Nonzero Damaged Areas with a Cumulative Normal Distribution 


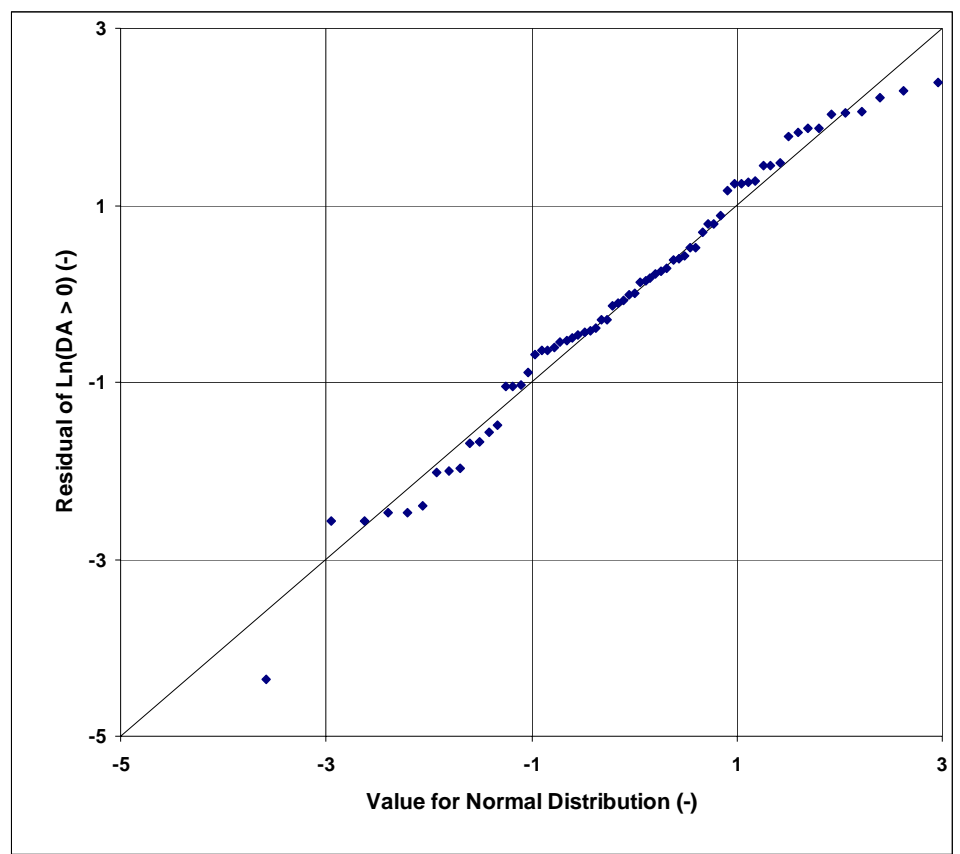

Source: Worksheet ABSTR for LS-DYNA $80 \%$ YS, in the file WP-WP Damage Abstraction with 0.85mps Cutoff Rev00d.xls. This file can be found on the CD in Appendix G.

Figure 6.5-12. Quantile Plot for the Natural Logarithm of the Residuals for Nonzero Damaged Areas Versus a Normal Distribution

\subsection{Comparison of Abstraction with Data for Nonzero Damaged Areas}

Figure 6.5-13 overlays the nonzero damaged areas from Figure 6.5-10 with the 0.05 and 0.95 nonexceedance probability curves for a ln-normal distribution with the standard deviation of 1.483 determined in Figures 6.5-11 and 6.5-12. The 0.05 to 0.95 nonexceedance probability curves generally encompass all of the data points for nonzero damaged areas, with the 0.95 nonexceedance probability curve significantly exceeding all damaged areas at the $5.35-\mathrm{m} / \mathrm{s}$ PGV level. This behavior is consistent with Figure 6.5-12, wherein the residuals for a normal distribution exceed the residuals for the four rightmost data points in Figure 6.5-12. This comparison provides confidence that the ln-normal distribution provides an appropriate abstraction for the nonzero damaged areas from end-to-end impacts. 


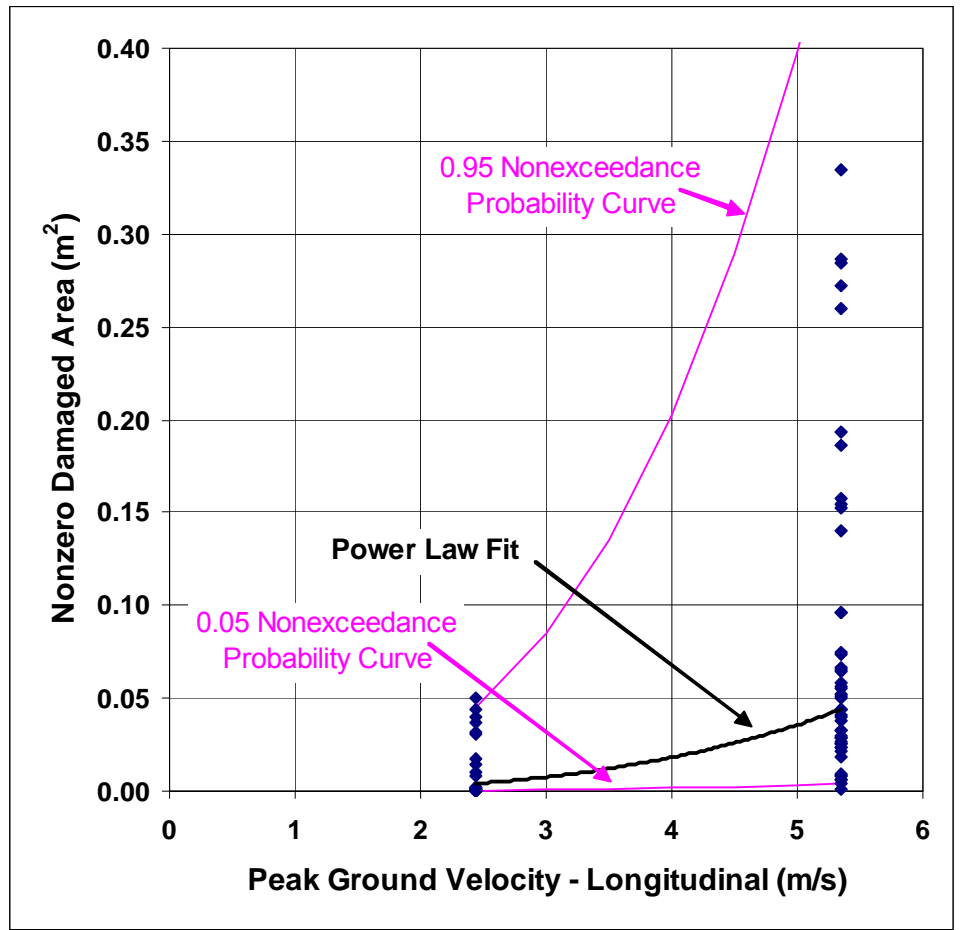

Source: Worksheet ABSTR for LS-DYNA 80\% YS, in the file WP-WP Damage Abstraction with 0.85mps Cutoff Rev00d.xls. This file can be found on the CD in Appendix G.

Figure 6.5-13. Comparison of Data for Nonzero Damaged Areas With the 0.05 and 0.95 Nonexceedance Probability Curves for the Ln-Normal Distribution

\subsubsection{Conversion to Percent Surface Area}

The damage abstractions for end-to-end impacts produce damaged area in square meters, based on the mechanical response of the 21-PWR waste package. It is reasonable to calculate damage for the 21-PWR waste package type because this package type comprises 64.6 percent of the total inventory of waste packages. In calculating this percentage, it is noted that the 21-PWR package type with absorber plates, the 21-PWR package type with control rods, and the 44-BWR package type have very similar nominal length, nominal diameter, and nominal loaded weight (BSC 2005 [DIRS 173501], Table 1). The numbers of these package types in the LA inventory are 4299, 95, and 2831, respectively, out of a total of 11,184 packages, or 64.6 percent of the total inventory (BSC 2005 [DIRS 173501], Table 13).

TSPA requires damage estimates for commercial spent nuclear fuel (CSNF) and codisposal (CDSP) package types. The damage for these package types is estimated by converting the damaged area in square meters to a percent of total surface area for the 21-PWR waste package type. The total surface area for the 21-PWR package is based on a nominal length of 5024.4-mm (BSC 2005 [DIRS 173501], Table 1) and on the diameter of the outer barrier (i.e., the outer barrier) of 1637-mm (BSC 2005 [DIRS 173501], Table 1, to drawing 000-MW0-DSU0-00402-000-00B). The surface area, including the two circular end caps, is given by $0.5^{*} \pi^{*}(1.637 \mathrm{~m})^{2}+\pi^{*}(1.637 \mathrm{~m}) *(5.0244 \mathrm{~m})=30.05 \mathrm{~m}^{2}$. Total surface area is appropriate here because the end-on waste package impacts at positive impact angle result in damaged area on the end cap and side of the waste package. Areas from the end-to-end damage 
abstraction are converted to a percent damage by dividing by $30.05 \mathrm{~m}^{2}$, and this percent damage is applied to the CSNF and CDSP packages in the TSPA model.

\subsubsection{Abstraction for Damage from Waste Package-Pallet Impacts}

This abstraction defines the damage generated by impacts of the waste package on its pallet in response to vibratory ground motion. The damage generated by waste package-pallet impacts is based on detailed structural response calculations for a single waste package contained within rigid walls (BSC 2004 [DIRS 167083]). These structural response calculations provide a direct analysis of the damaged areas on the sides of the waste package from waste package-pallet impacts. That is, the damage from waste package-pallet impacts is determined by analyzing the results of the finite-element calculations to determine the element areas where the residual stress exceeds 80 percent or 90 percent of the yield strength of Alloy 22. A damage catalog and velocity threshold are not required for this direct analysis of the finite-element results. The resulting damaged areas are then abstracted as a function of the horizontal peak ground velocity (PGV).

The kinematic calculations discussed in Section 6.5.1.1 cannot be used directly or indirectly to estimate the damage from waste package-pallet impacts. The kinematic calculations are not zoned finely enough to directly calculate the damaged areas from waste package-pallet impacts. In addition, a catalog or lookup table for converting kinematic parameters from waste package-pallet impacts into damaged areas is not available. The finite-element calculations for a single waste package contained within rigid walls provide the most accurate estimate of the damaged areas from waste package-pallet impacts, so these data form the basis for this damaged abstraction.

The potential for damage from impacts between the waste package and drip shield is included in the structural response calculations for a single waste package; however, the damage is negligible because the drip shield is unrestrained and can be moved freely by the much heavier waste package (BSC 2004 [DIRS 167083], Assumption 3.15). In particular, the drift is unfilled at the time of the seismic event and the potential coupling between rockfall and the dynamic motion of the EBS components during the seismic event is not included in the structural response calculations.

A total of 20 calculations for dynamic waste package structural response are performed for the suite of ground motions with a PGV of $2.44 \mathrm{~m} / \mathrm{s}$ (BSC 2004 [DIRS 167083], Section 6.1; BSC 2004 [DIRS 171717], Section 6.2). These calculations are based on 15 ground motions that do not include spectral conditioning and do not preserve intercomponent variability of the original records (BSC 2004 [DIRS 167083], Section 6.1) and on 5 ground motions that do include spectral conditioning to a reference rock outcrop (Point A in Figure 6.4-1) and do preserve intercomponent variability (BSC 2004 [DIRS 171717], Section 6.2). The latter 5 analyses were performed primarily to determine the sensitivity of damaged area to these aspects of the ground motions. A total of 16 calculations for dynamic waste package response are performed for the suite of ground motions with a PGV of $5.35 \mathrm{~m} / \mathrm{s}$ (BSC 2004 [DIRS 167083], Section 6.2). These calculations are based on 15 ground motions that are spectrally conditioned to a reference rock outcrop (called Point A in Figure 6.4-1) and preserve the intercomponent variability of the original records (BSC 2004 [DIRS 167083], Section 6.2). 
Two additional calculations are performed with ground motions 5 and 15 to help complete a full suite of results (BSC 2004 [DIRS 171717], Section 6.1). Finally, a total of 15 calculations for dynamic waste package response are performed for the suite of ground motions with a PGV of $1.05 \mathrm{~m} / \mathrm{s}$ (BSC 2004 [DIRS 171717], Section 6.3). The structural response calculations at the $1.05-\mathrm{m} / \mathrm{s}$ PGV level were performed with a suite of ground motions that were spectrally conditioned to the emplacement drifts (called Point B in Figure 6.4-1) and preserved the intercomponent variability of the original records. Section 6.4.2 has further details on the methodology for deriving site-specific ground motions.

These values for PGV correspond to the peak of the first horizontal velocity component, which is in a horizontal plane and transverse to the longitudinal direction, along the centerline of the drift, for these calculations. However, the abstraction for damage from waste package-pallet impacts is based on PGV-longitudinal for consistency with the abstraction of end-to-end damage in Section 6.5.1. A tabulation of the values of PGV-longitudinal for the $1.05-\mathrm{m} / \mathrm{s}, 2.44-\mathrm{m} / \mathrm{s}$, and $5.35-\mathrm{m} / \mathrm{s}$ PGV levels provides the relevant values of PGV-longitudinal for these abstractions (BSC 2004 [DIRS 166107], Tables X-2 through X-5).

The stochastic (uncertain) input parameters for the simulations are the 15 sets of three-component ground motion time histories, the metal-to-metal friction coefficient, and the metal-to-rock friction coefficient. A Monte Carlo sampling scheme defines the appropriate combinations of ground motion and friction coefficients (BSC 2004 [DIRS 169999], Section 6.4) for each PGV level. The same sets of ground motion time histories (accelerograms) are also used for the analyses of drip shield damage from vibratory ground motions described in Section 6.6.1. The structural response calculations for a single waste package have energy dissipation due to plastic deformation of the outer corrosion barrier and emplacement pallet; however, there is no energy dissipation in the contact process itself, so it is not necessary to define a COR for these calculations.

These structural response calculations provide a reasonable representation of the waste package-pallet impacts for a single waste package, and are considered appropriate for the intended use for several reasons. First, the calculations are based on standard, commercially available software (LS-DYNA) that has demonstrated the capability to accurately analyze impact processes and kinematic response. Second, appropriate mesh refinement studies have been performed to ensure that the damaged areas on the surface of the waste package can be accurately predicted by the finite-element grid. In particular, a mesh-sensitivity study indicates that the mesh size does not have a significant effect on the calculation results at the $2.44 \mathrm{~m} / \mathrm{s}$ PGV level, which is located approximately midway between the minimum and maximum PGV levels of $0.4019-\mathrm{m} / \mathrm{s}$ and $4.07-\mathrm{m} / \mathrm{s}$, respectively, sampled for TSPA (BSC 2004 [DIRS 167083], Attachment IX-1). Third, the major parameter uncertainties are represented in the calculations. The uncertainties due to ground motions and friction coefficients are directly represented by random sampling of inputs for the calculations. The uncertainty in contact damping is bounded by assuming that there is no energy dissipation in the contact process, although there is energy dissipation from plastic deformation of the waste package and pallet. Finally, the potential uncertainties in material properties are not represented in the calculations because the materials in the waste package will be fabricated to design specifications that follow standard values in handbooks and industrial publications, and because the sensitivity to variation in standard 
material properties is expected to be minor in comparison to that produced by the uncertainties in ground motions and friction coefficients.

The structural response calculations do not represent the dynamic response of the invert to the ground motion. Instead, the invert moves synchronously with the ground motion, as though it is a rigid surface. The impact of representing the invert as a non-rigid surface is analyzed in BSC 2005 ([DIRS 173172] Attachment VIII). For these calculations, the invert is represented as a cohesionless, granular material that is subjected to ground motions at the 2.44 and $5.35 \mathrm{~m} / \mathrm{s}$ PGV levels. The computational results with the granular invert demonstrate that the rigid representation has relatively little impact on amplification of ground motions or on permanent deflection of the invert surface. The simpler representation of the invert as a rigid surface is therefore retained for the structural response calculations.

The damage to the waste package is determined by comparing the residual first principal stress on the waste package outer barrier to the failure criterion defined in Section 6.3.2. More specifically, two residual stress thresholds are used to define the damaged area on the outer barrier of the waste package. The two stress thresholds are 80 and 90 percent of the yield strength of Alloy 22. These values correspond to the lower and upper bound of the uniform distribution for the residual stress threshold defined in Section 6.3.2. The area on the outer barrier of the waste package for which the residual first principal stress exceeds the residual stress threshold is referred to as the "damaged area" throughout this document.

\subsubsection{Damage from Waste Package-Pallet Impacts}

The damaged areas from waste package-pallet impacts for realizations with horizontal PGV values of $1.05 \mathrm{~m} / \mathrm{s}, 2.44 \mathrm{~m} / \mathrm{s}$, and $5.35 \mathrm{~m} / \mathrm{s}$ are summarized in Table $6.5-9$ (BSC 2005 [DIRS 173500], Tables 1 and 2; BSC 2004 [DIRS 171717] Tables 6.1-4, 6.2-7, and 6.3-6). The results for Realization 8 at the 2.44-m/s PGV level is not presented in Table 6.5-9 because an input error ${ }^{8}$ was discovered for this calculation during the checking process. The results for realization 2 at the $5.35-\mathrm{m} / \mathrm{s}$ PGV level are not presented in Table $6.5-9$ because the impacts between package and pallet are outside the finely meshed region of the outer barrier, thereby reducing the numerical accuracy of the damage calculation for this realization.

The failure criterion for Alloy 22 is defined as a uniform distribution between 80 and 90 percent of the yield strength (Section 6.3.1). In other words, there is uncertainty in the value of the appropriate residual stress threshold for Alloy 22. Table 6.5-9 presents damaged areas at the two extremes (80 percent and 90 percent) of the residual stress threshold. Since the damaged area is defined by the elements of the finite-element grid whose residual stress exceeds the value of the residual stress threshold, it follows that the damaged area for the 90 percent threshold is always less than or equal to the damaged area for the 80 percent threshold.

\footnotetext{
8 The three initial velocity components do not correspond to the beginning of the acceleration time history for Realization 8 at the $2.44 \mathrm{~m} / \mathrm{s}$ PGV level. Consequently, the velocity and displacement time histories are not appropriately specified, so the results from this realization are not included in the abstraction process.
} 
Table 6.5-9. Damaged Area from Waste Package-Pallet Impacts at 2.44-m/s, 5.35-m/s, and 1.05-m/s PGV Levels

\begin{tabular}{|c|c|c|c|c|c|c|c|c|c|c|}
\hline \multirow[b]{3}{*}{$\begin{array}{c}\text { Realization } \\
\text { Number }\end{array}$} & \multirow[b]{3}{*}{$\begin{array}{l}\text { Ground } \\
\text { Motion } \\
\text { Number }\end{array}$} & \multicolumn{9}{|c|}{ Damaged Area on the Waste Package } \\
\hline & & \multicolumn{3}{|c|}{$\begin{array}{l}\text { Waste Package-Pallet } \\
\text { Damaged Area at 2.44-m/s } \\
\text { PGV-Transverse Level } \\
\left(\mathrm{m}^{2}\right)\end{array}$} & \multicolumn{3}{|c|}{$\begin{array}{c}\text { Waste Package-Pallet } \\
\text { Damaged Area at 5.35-m/s } \\
\text { PGV-Transverse Level } \\
\left(\mathrm{m}^{2}\right)\end{array}$} & \multicolumn{3}{|c|}{$\begin{array}{l}\text { Waste Package-Pallet } \\
\text { Damaged Area at 1.05-m/s } \\
\text { PGV-Transverse Level } \\
\left(\mathrm{m}^{2}\right)\end{array}$} \\
\hline & & $\begin{array}{l}\text { PGV- } \\
\text { Long. } \\
(\mathrm{m} / \mathrm{s})\end{array}$ & $\begin{array}{c}80 \% \text { Yield } \\
\text { Strength }\end{array}$ & $\begin{array}{c}90 \% \text { Yield } \\
\text { Strength }\end{array}$ & $\begin{array}{l}\text { PGV- } \\
\text { Long. } \\
(\mathrm{m} / \mathrm{s})\end{array}$ & $\begin{array}{c}80 \% \text { Yield } \\
\text { Strength }\end{array}$ & $\begin{array}{c}90 \% \text { Yield } \\
\text { Strength }\end{array}$ & $\begin{array}{l}\text { PGV- } \\
\text { Long. } \\
(\mathrm{m} / \mathrm{s})\end{array}$ & \begin{tabular}{|c|}
$80 \%$ Yield \\
Strength
\end{tabular} & $\begin{array}{l}90 \% \text { Yield } \\
\text { Strength }\end{array}$ \\
\hline 1 & 7 & 2.44 & 0.0029 & 0.0014 & 5.31 & 0.20 & 0.17 & 0.89 & 0 & 0 \\
\hline 2 & $16^{d}$ & 2.44 & 0 & 0 & $N / A^{c}$ & $N / A^{c}$ & $N / A^{c}$ & 0.67 & 0 & 0 \\
\hline 3 & 4 & 2.43 & 0.0050 & 0 & 5.69 & 0.096 & 0.083 & 1.00 & 0 & 0 \\
\hline 4 & 8 & 2.44 & 0.030 & 0.0064 & 8.81 & 0.12 & 0.096 & 1.52 & 0.0014 & 0 \\
\hline 5 & 11 & 2.44 & 0.0015 & 0 & 5.61 & 0.093 & 0.071 & 1.26 & 0 & 0 \\
\hline 6 & 1 & 2.43 & 0.025 & 0.0028 & 4.28 & 0.046 & 0.024 & 0.83 & 0.0015 & 0 \\
\hline 7 & 2 & 2.44 & 0.017 & 0 & 5.89 & 0.038 & 0.028 & 1.25 & 0 & 0 \\
\hline 8 & 13 & $N / A^{a}$ & $N / A^{a}$ & $\mathrm{~N} / \mathrm{A}^{\mathrm{a}}$ & 6.65 & 0.095 & 0.068 & 1.04 & 0 & 0 \\
\hline 9 & 10 & 2.38 & 0.0035 & 0 & 1.72 & 0.0052 & 0.0035 & 0.32 & 0 & 0 \\
\hline 10 & 9 & 2.44 & 0 & 0 & 17.91 & 0.16 & 0.14 & 3.58 & 0 & 0 \\
\hline 11 & 5 & 2.43 & 0.012 & 0.0037 & 5.64 & 0.032 & 0.0070 & 1.67 & 0 & 0 \\
\hline 12 & 6 & 2.43 & 0.0039 & 0 & 2.90 & 0.062 & 0.041 & 0.46 & 0.0040 & 0.0014 \\
\hline 13 & 12 & 2.43 & 0 & 0 & 5.95 & 0.027 & 0.018 & 0.70 & 0 & 0 \\
\hline 14 & 14 & 2.44 & 0.010 & 0.0043 & 2.75 & 0.020 & 0.016 & 0.41 & 0 & 0 \\
\hline 15 & 3 & 2.43 & 0.0078 & 0.0015 & 14.09 & 0.0045 & 0 & 2.62 & 0.028 & 0.014 \\
\hline $2^{\mathrm{b}}$ & $15^{\prime}$ & 1.53 & 0 & 0 & 3.36 & $0.0080^{c}$ & $0.0020^{c}$ & & & \\
\hline $3^{b}$ & $4^{\prime}$ & 2.60 & 0.0014 & 0 & \multirow{4}{*}{\multicolumn{6}{|c|}{$\begin{array}{l}\text { (Additional calculations were not performed at the } 1.05 \mathrm{~m} / \mathrm{s} \text { and } \\
5.35-\mathrm{m} / \mathrm{s} \text { PGV levels because these ground motions already } \\
\text { included spectral conditioning and intercomponent variability.) }\end{array}$}} \\
\hline $4^{b}$ & $8^{\prime}$ & 4.02 & 0.0032 & 0 & & & & & & \\
\hline $6^{b}$ & $1^{\prime}$ & 1.95 & 0.0081 & 0.0014 & & & & & & \\
\hline $15^{\mathrm{b}}$ & $3^{\prime}$ & 6.43 & 0.043 & 0.010 & & & & & & \\
\hline
\end{tabular}

Sources: BSC 2005 [DIRS 173500], Table 1 and Table 2; BSC 2004 [DIRS 171717] Tables 6.1-4, 6.2-7, and 6.3-6; BSC 2004 [DIRS 166107], Appendix X, Tables X-2, X-3, X-4, and X-5.

${ }^{a}$ Results for realization 8 are not presented because of an error in the input file for this calculation.

${ }^{b}$ Additional calculations were performed primarily to determine the sensitivity of damaged area to spectral conditioning and intercomponent variability of the ground motions at the 2.44-m/s PGV level (BSC 2004 [DIRS 171717], Sections 6.1 and 6.2). These ground motions are denoted as 2', 3', 4', 6', and 15' to indicate the differences in the ground motion time histories.

${ }^{\mathrm{C}}$ Results for realization 2 with ground motion 16 are not presented because the kinematics of the waste package are such that the impacts between package and pallet occur outside the finely meshed region of the outer barrier. Results for realization 2 with ground motion 15' are not exact because the waste package-pallet impacts occur partly outside the finely zoned mesh on the outer barrier, but are included in the statistical analyses because the data lie within the range of the other realizations at the 5.35-m/s PGV level (BSC 2004 [DIRS 171717], Section 6.1.3).

d Calculations are performed with 15 ground motions numbered $1,2,3, \ldots, 14$, and 16 . Seventeen sets of ground motion time histories were initially developed from which 15 sets were selected for these postclosure analyses. Ground motion \#16 was initially substituted for ground motion \#15 because of concerns about its response spectrum. Subsequent analyses with ground motion \#15' at the 2.44-m/s and 5.35-m/s PGV levels (fifth line from the bottom in the table) indicate that ground motion \#15' does not result in anomalous behavior (BSC 2004 [DIRS 171717], Section 6.2).

NOTES: PGV-Long. Is the horizontal component of ground motion in the longitudinal direction, along the drift axis. The abstraction for damage from waste package-pallet impacts is based on the value of PGV-longitudinal for consistency with the damage abstraction for end-to-end impacts 


\subsubsection{Abstraction of Damaged Areas from Waste Package-Pallet Impacts}

The technical approach to developing abstractions for the damaged areas from waste package-pallet impacts is identical to that for the damaged areas from end-to-end impacts of adjacent waste packages. Two abstractions have been developed to represent the damaged areas from waste package-pallet impacts:

- Damaged areas from dynamic structural response calculations (with LS-DYNA) for a residual stress threshold of 80 percent of the yield strength of Alloy 22

- Damaged areas from dynamic structural response calculations (with LS-DYNA) for a residual stress threshold of 90 percent of the yield strength of Alloy 22

The decision to develop two separate abstractions, rather than one combined abstraction, is motivated by: (i) separate abstractions allow direct representation of the epistemic uncertainty in TSPA from the residual stress thresholds ( 80 percent versus 90 percent), and (ii) the damaged areas for these two cases exhibit statistically significant differences. Each abstraction, however, is based on the same three relationships, as discussed in the next subsections:

- The probability of no damage as a function of PGV.

- A power law fit to the nonzero damaged areas as a function of PGV. This power law fit is conditional on the existence of nonzero damage, based on the first relationship. This power law fit is equivalent to a least squares linear fit for the natural logarithm of nonzero damaged area versus the natural logarithm of PGV.

- A fit with a normal distribution for the residuals of nonzero damaged area in $\ln -\ln$ space, again conditional on damage occurring. The residual is defined as the difference between the natural logarithm of the nonzero damaged area and the natural logarithm of the power law fit at the appropriate value of PGV. This normal distribution in $\ln -\ln$ space is equivalent to a ln-normal distribution in "physical" space. The standard deviation of the normal fit in ln-ln space is constant, independent of PGV.

The statistical analysis is illustrated for the damaged areas with a residual stress threshold of 80 percent of the yield strength of Alloy 22 in the next subsections. The basis for both abstractions is documented in the Excel file entitled WP-Pallet Damage Area Abstraction Rev00e.xls. This file is available on the compact disk in Appendix G of this report.

\subsection{Probability of No Damage}

The first relationship in the abstraction is definition of the probability of no damage as a function of PGV-longitudinal. Definition of this function is more complex than for the end-to-end damage abstraction because the data in Table 6.5-9 form a "cloud" as a function of PGV-longitudinal, rather than two or three discrete stripes. The transverse horizontal velocity component had a fixed value of PGV for these finite-element calculations, but the intensity measure is PGV-longitudinal for consistency with the abstractions for end-to-end impacts. PGV-longitudinal is significantly different than PGV-transverse for ground motions that preserve the intercomponent variability of the original records, so the data points do not lie in stripes. 
Figure 6.5-14 presents the distribution of damaged areas as a function of PGV-longitudinal. Figure 6.5-14 does not include two points with extreme PGV-longitudinal values of $14.1 \mathrm{~m} / \mathrm{s}$ and $17.9 \mathrm{~m} / \mathrm{s}$. The damage state at these large PGV values has no impact on definition of the probability of no damage because the PGV range of interest has an upper bound of $4.07 \mathrm{~m} / \mathrm{s}$.

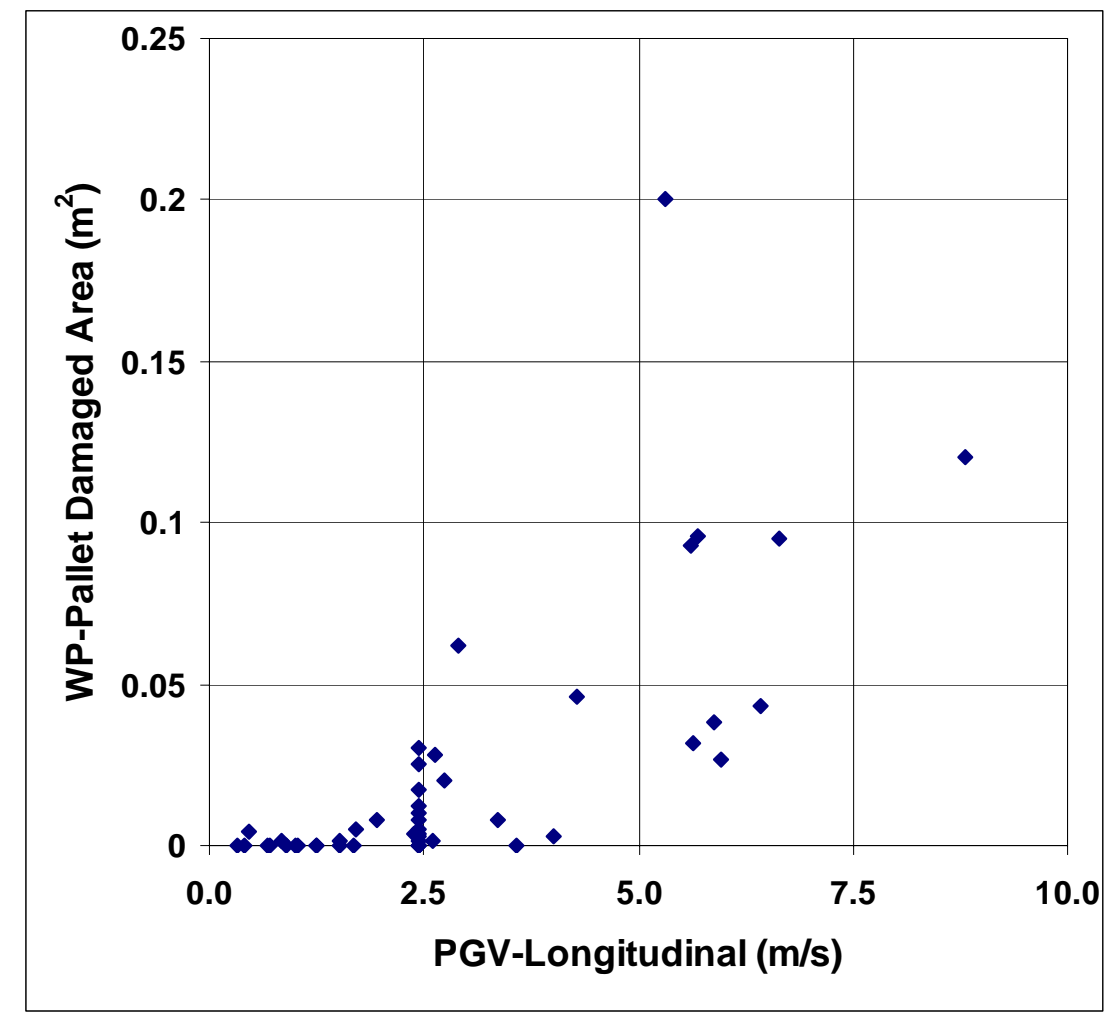

Source: Worksheet ABSTR for $80 \%$ YS, in the file WP-Pallet Damage Area Abstraction Rev00e.xIs. This file can be found on the CD in Appendix G; WP = waste package.

Figure 6.5-14. Distribution of Damaged Area Data (All Points) as a Function of PGV-Longitudinal

Definition of the probability of no damage is based on the following considerations:

- For PGV-longitudinal values less than or equal to $1 \mathrm{~m} / \mathrm{s}$, there are six calculations with no damage and two calculations with nonzero damage. The six calculations with no damage have PGV-longitudinal values of $0.32 \mathrm{~m} / \mathrm{s}, 0.41 \mathrm{~m} / \mathrm{s}, 0.67 \mathrm{~m} / \mathrm{s}, 0.70 \mathrm{~m} / \mathrm{s}$, $0.89 \mathrm{~m} / \mathrm{s}$, and $1.00 \mathrm{~m} / \mathrm{s}$. The two calculations with nonzero damage have PGV-longitudinal values of $0.46 \mathrm{~m} / \mathrm{s}$ and $0.83 \mathrm{~m} / \mathrm{s}$. (Nonzero damage can occur for small values of PGV-longitudinal because the PGV of the vertical or transverse horizontal components may be substantially greater than the PGV of the longitudinal component. However, this does not occur very often, based on the results in Figure 6.5-14.) Since the minimum value of PGV-longitudinal with nonzero damage is $0.46 \mathrm{~m} / \mathrm{s}$, it follows that the probability of no damage is less than 1 at PGV-longitudinal of $0.46 \mathrm{~m} / \mathrm{s}$.

Additional insight is available from structural response calculations with ground motions at the $0.384 \mathrm{~m} / \mathrm{s}$ and the $0.19-\mathrm{m} / \mathrm{s}$ PGV levels (BSC 2004 [DIRS 167083], Section 6.4; 
BSC 2004 [DIRS 171717], Section 6.4). These PGV levels correspond approximately to the $10^{-4}$ and $5 \times 10^{-4}$ annual exceedance frequencies on the hazard curve, and the calculations are identified by these frequencies in the reference documents. The structural response calculations, which are performed without system damping or contact damping, demonstrate that the relative motion between the waste package and pallet is practically nonexistent. For example, the maximum impact velocity between waste package and pallet is less than $0.006 \mathrm{~m} / \mathrm{s}$ and the relative vertical displacement between waste package and pallet varies between 0 to $0.3 \mathrm{~mm}$ at the $0.384-\mathrm{m} / \mathrm{s}$ PGV level (BSC 2004 [DIRS 167083], Section 6.4). Without significant relative motion or relative velocity between the waste package and pallet, the outer barrier of the package remains completely undamaged in either simulation. The PGV values for the individual ground motion components at the $0.384-\mathrm{m} / \mathrm{s}$ PGV level are $0.3838 \mathrm{~m} / \mathrm{s}$ (transverse horizontal), 0.4378 (longitudinal), and $0.4751 \mathrm{~m} / \mathrm{s}$ (vertical) (BSC 2004 [DIRS 166107], Table X-1). The latter two values are consistent with the data in Figure 6.5-14, wherein the onset of nonzero damage occurs for a PGV longitudinal of $0.46 \mathrm{~m} / \mathrm{s}$.

Based on this information, the threshold for the onset of the nonzero damage state is estimated to fall between PGV-longitudinal values of $0.384 \mathrm{~m} / \mathrm{s}$ and $0.46 \mathrm{~m} / \mathrm{s}$. While the threshold could be set to the average of these two values, a PGV-longitudinal threshold of $0.4 \mathrm{~m} / \mathrm{s}$, closer to the lower value, is selected because of uncertainty in the PGV value for the other ground motion components. The threshold value in the functional fit (Table 6.5-10 below) is set to $0.4019 \mathrm{~m} / \mathrm{s}$ because this value corresponds to the PGV value on the bounded hazard curve at $10^{-4}$ annual exceedance frequency. This value is consistent with the data in Table 6.5-9 from the structural response calculations of waste package-pallet impacts. This value is also consistent with results from the structural response calculations at the $0.19-\mathrm{m} / \mathrm{s}$ and $0.384-\mathrm{m} / \mathrm{s}$ PGV levels (BSC 2004 [DIRS 167083], Section 6.4; BSC 2004 [DIRS 171717], Section 6.4).

- There are 13 calculations with PGV-longitudinal between $2.42 \mathrm{~m} / \mathrm{s}$ and $2.45 \mathrm{~m} / \mathrm{s}$. Three of these 13 calculations have no damage, providing a probability of no damage at $2.44 \mathrm{~m} / \mathrm{s}$ of 0.231 . The high density of points between $2.42 \mathrm{~m} / \mathrm{s}$ and $2.45 \mathrm{~m} / \mathrm{s}$ is caused by the suite of ground motions that did not preserve intercomponent variability. In this case, the values of both the transverse and longitudinal components were scaled to a $\mathrm{PGV}$ value of $2.44 \mathrm{~m} / \mathrm{s}$, resulting in a mini-stripe in Figure 6.5-14 at this PGV value.

- All calculations with PGV-longitudinal equal to or greater than $4.02 \mathrm{~m} / \mathrm{s}$ have nonzero damage. On the other hand, realization 10 for the $1.05-\mathrm{m} / \mathrm{s}$ PGV level has zero damage with a PGV-longitudinal value of $3.58 \mathrm{~m} / \mathrm{s}$. Based on this information, the threshold for damage always occurring is estimated to fall between PGV-longitudinal values of $3.58 \mathrm{~m} / \mathrm{s}$ and $4.02 \mathrm{~m} / \mathrm{s}$. While this threshold could be set to the average of these two values, it is simply set to $4 \mathrm{~m} / \mathrm{s}$. This is a reasonable approximation because most realizations at this PGV level will have damage whether the threshold is set to $3.8 \mathrm{~m} / \mathrm{s}$ (the average value) or $4.0 \mathrm{~m} / \mathrm{s}$. 
The points for the probability function are listed in Table 6.5-10.

Table 6.5-10. Data Points for Probability of No Damage

\begin{tabular}{|c|c|}
\hline $\begin{array}{c}\text { PGV-Longitudinal } \\
(\mathbf{m} / \mathbf{s})\end{array}$ & $\begin{array}{c}\text { Probability of No Damage } \\
(-)\end{array}$ \\
\hline 0.4019 & 1.0 \\
\hline 2.44 & 0.231 \\
\hline 4.0 & 0.0 \\
\hline
\end{tabular}

These three points are fit with a power law of the following form:

$$
\begin{aligned}
P_{N D} & =1 & & \text { for } P G V \leq 0.4019, \\
& =\alpha(4.0-P G V)^{\beta} & & \text { for } 0.4019<P G V<4.0, \\
& =0 & & \text { for } P G V \geq 4.0,
\end{aligned}
$$

where $P_{N D}$ is the probability of no damage, $P G V$ is the peak ground velocity in units of $\mathrm{m} / \mathrm{s}$, and $\alpha$ and $\beta$ are constants. Solving for the values of $\alpha$ and $\beta$ results in the following relationship for $P_{N D}$ that is plotted in Figure 6.5-15:

$$
\begin{aligned}
P_{N D} & =1 & & \text { for } P G V \leq 0.4019, \\
& =(0.1049)(4.0-P G V)^{1.7613} & & \text { for } 0.4019<P G V<4.0, \\
& =0 & & \text { for } P G V \geq 4.0 .
\end{aligned}
$$

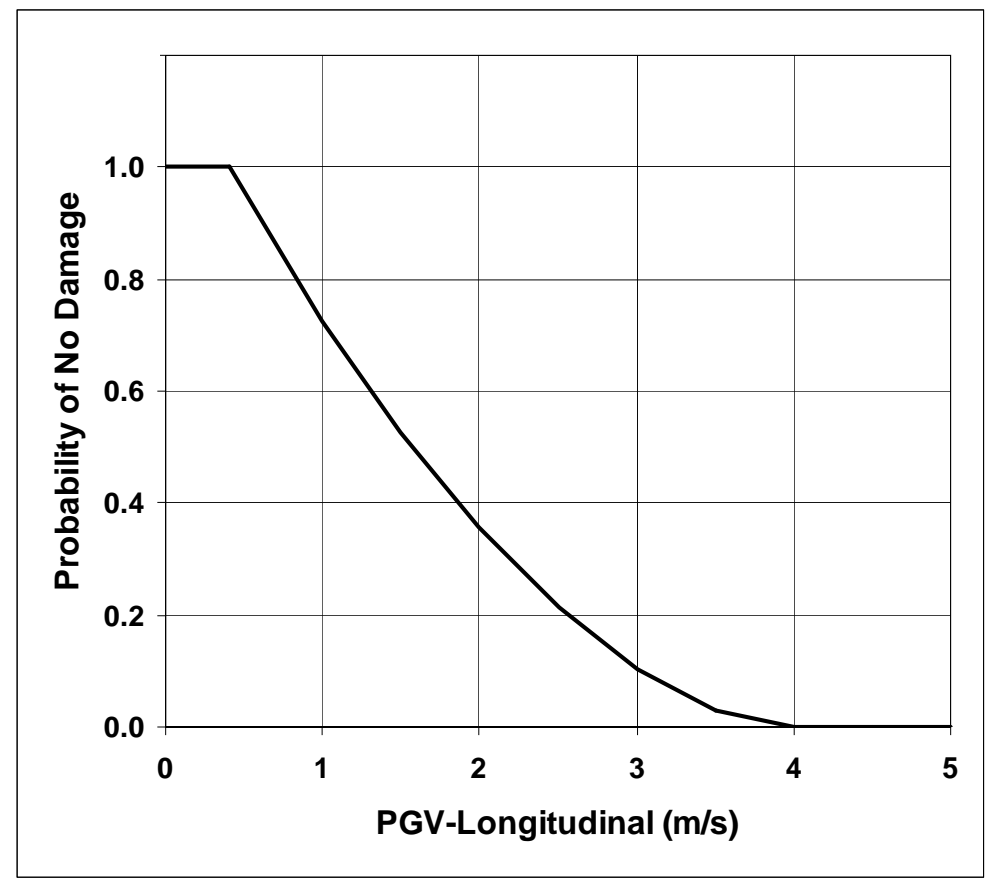

Source: Worksheet ABSTR for $80 \%$ YS, in the file WP-Pallet Damage Area Abstraction Rev00e.xIs. This file can be found on the CD in Appendix G.

Figure 6.5-15. Probability of No Damage as a Function of PGV-Longitudinal 


\subsection{Power Law Fit to the Nonzero Damaged Areas}

A linear fit and a power law fit were considered to represent the expected response of the nonzero damaged areas as a function of PGV. These fits are conditional on the occurrence of nonzero damage, based on the probability function defined in the previous subsection. Figure 6.5-16 compares the data with the linear and power law least squares trendlines generated by Excel. An important point about the data set in Figure 6.5-16 is that two data points have been dropped from the abstraction process. The two data points have PGV-longitudinal values of $14.1 \mathrm{~m} / \mathrm{s}$ and $17.9 \mathrm{~m} / \mathrm{s}$. These values are much greater than the maximum PGV of $4.07 \mathrm{~m} / \mathrm{s}$ at an annual exceedance frequency of $10^{-8}$ on the bounded hazard curve. The rationale for dropping these two points is twofold: (i) there is no need to skew the fit to the expected behavior at two points that far exceed the PGV levels of interest in TSPA, and (ii) the coefficient of determination of both fits is improved by dropping these two points. The same two points produced little change in the abstraction for the residual stress threshold of 90 percent of the yield strength of Alloy 22, so the points are retained in this other case.

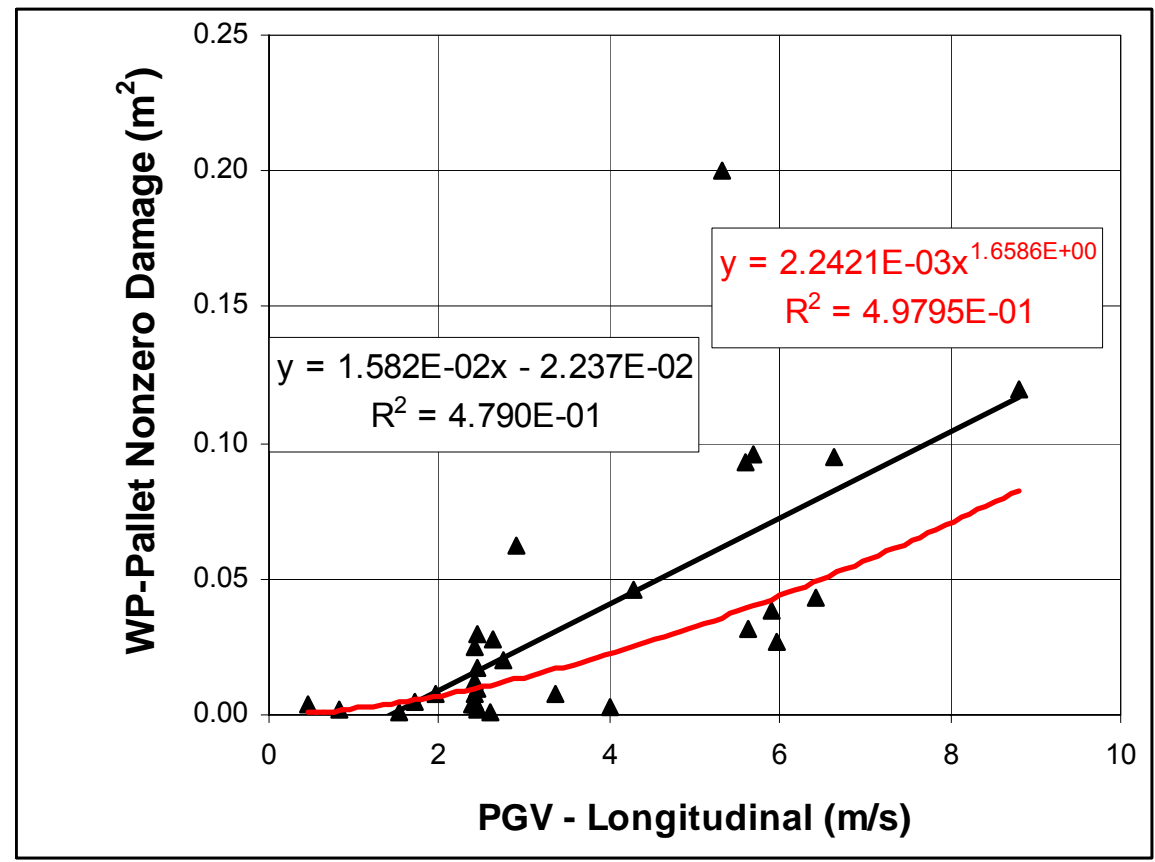

Source: $\quad$ Worksheet ABSTR for $80 \%$ YS, in the file WP-Pallet Damage Area Abstraction Rev00e.xIs. This file can be found on the CD in Appendix G; WP = waste package.

Figure 6.5-16. Comparison of Power Law and Linear Least Squares Fits to the Damaged Area Data

The coefficients of determination (i.e., the values of $\mathrm{R}^{2}$ in Figure 6.5-16) for the linear and power law fits are essential the same. However, the power law fit is preferable because of its behavior near smaller values of PGV, as shown in Figure 6.5-17. The linear fit crosses through zero damage at $1.4 \mathrm{~m} / \mathrm{s}$, but the data in Figure 6.5-17 show several points with nonzero damage below $1 \mathrm{~m} / \mathrm{s}$. The power law fit, on the other hand, falls more smoothly toward zero damage below $1 \mathrm{~m} / \mathrm{s}$, providing a more reasonable physical behavior. The power law least squares fit shown in Figures 6.5-16 and 6.5-17 is therefore the basis for the damage abstraction. 


\subsection{Comparison of Residuals for Nonzero Damaged Area Versus a Normal Distribution in Ln-Ln Space}

Figure 6.5-18 presents a cumulative probability distribution plot for the residuals of the natural logarithm of the nonzero damaged areas versus a cumulative normal distribution. These residuals are conditional on the occurrence of nonzero damage, based on the probability function defined in Section 6.5.2.2.1. This Figure demonstrates that the residuals follow a normal distribution in $\ln -\ln$ space with a mean of zero and a standard deviation of 1.023. This standard deviation is based on the residuals for the nonzero data points.

A quantile plot provides a more discriminating comparison of the residuals versus a ln-normal distribution. Figure 6.5-19 presents the quantile plot for the residuals. This plot demonstrates that a normal distribution provides a reasonable representation of the residuals in $\ln -\ln$ space.

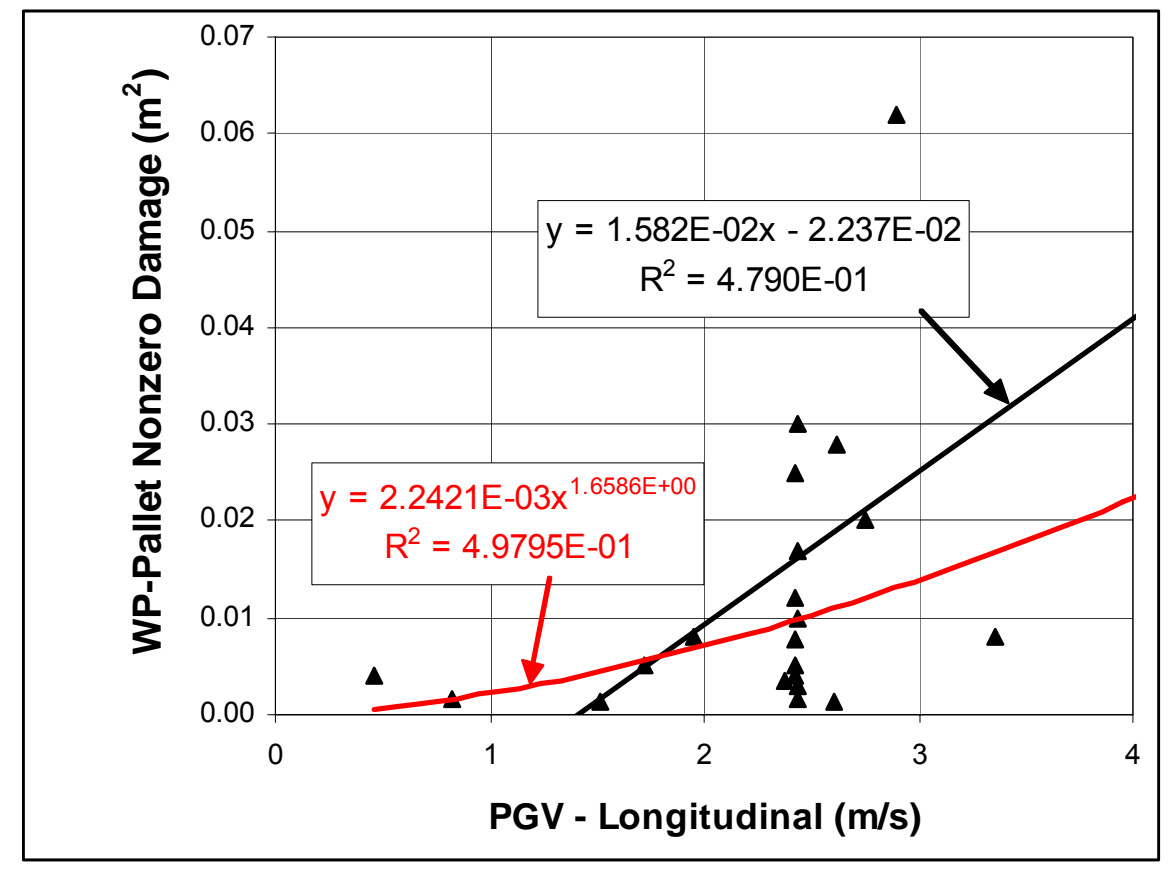

Source: Worksheet ABSTR for $80 \%$ YS, in the file WP-Pallet Damage Area Abstraction Rev00e.xIs. This file can be found on the CD in Appendix G; WP = waste package.

Figure 6.5-17. Comparison of Power Law and Linear Least Squares Fits At Smaller Values of PGV 


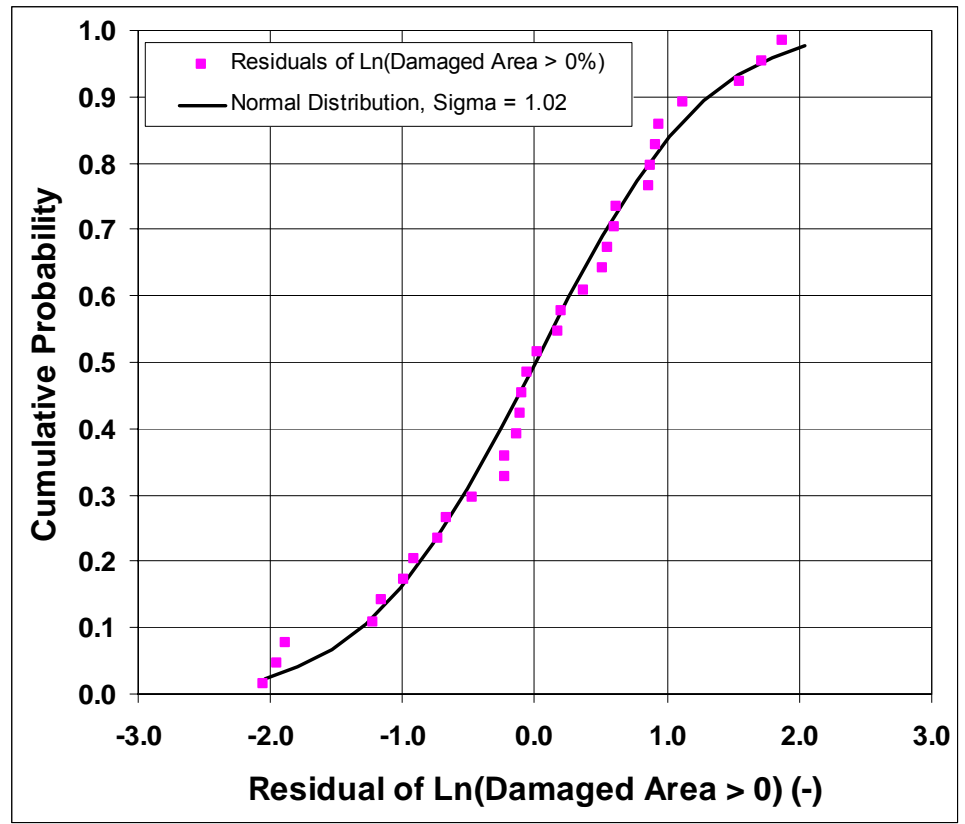

Source: Worksheet ABSTR for $80 \%$ YS, in the file WP-Pallet Damage Area Abstraction Rev00e.xls. This file can be found on the $C D$ in Appendix $G$.

Figure 6.5-18. Comparison of the Cumulative Distribution for the Residuals for Nonzero Damaged Areas in Ln-Ln Space with a Cumulative Normal Distribution

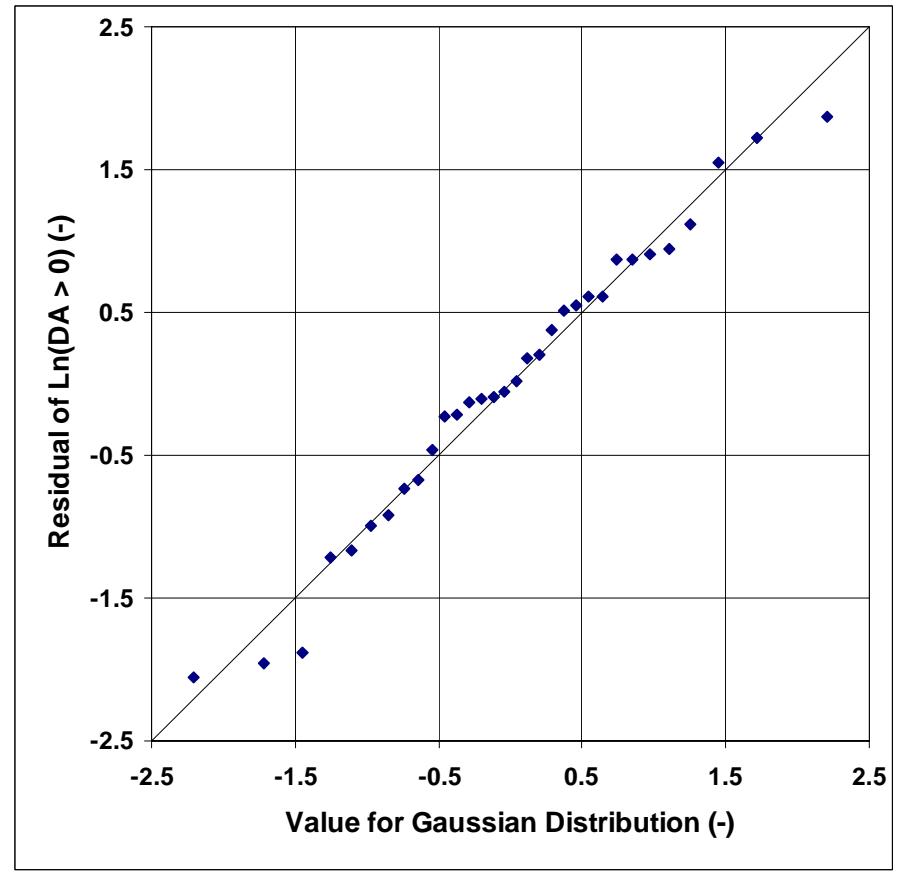

Source: Worksheet ABSTR for $80 \%$ YS, in the file WP-Pallet Damage Area Abstraction Rev00e.xls. This file can be found on the $C D$ in Appendix G; DA = damaged area.

Figure 6.5-19. Quantile Plot for the Residuals for Nonzero Damaged Areas in Ln-Ln Space Versus a Normal Distribution 
As a final check on the scatter in the normal distribution, the data were separated into three classes, as shown in Figure 6.5-20. The first class corresponds to data with $\ln (\mathrm{PGV})$ less than 0.86 , the second class corresponds to data with $\ln (\mathrm{PGV})$ between 0.86 and 1.05 , and the third class corresponds to data with $\ln (\mathrm{PGV})$ greater than 1.05 . These classes provide a convenient split of the data, although it is not possible to provide equal numbers of data points in each class because the data tend to group at $\ln (2.44)=0.89$. This grouping occurs because most ground motions at the $2.44-\mathrm{m} / \mathrm{s}$ PGV level do not preserve intercomponent variability, resulting in constant values for PGV-longitudinal.

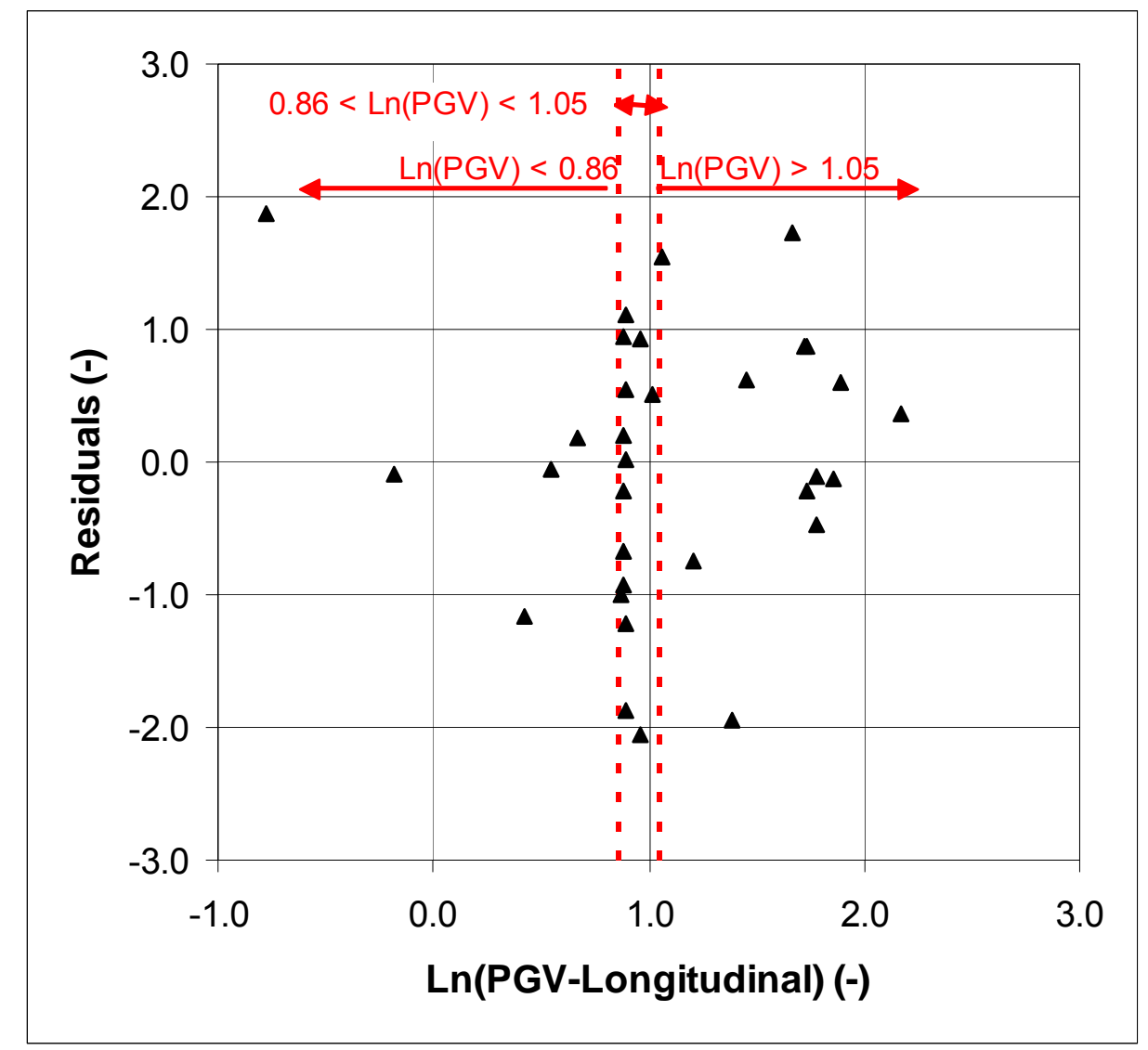

Source: Worksheet ABSTR for $80 \%$ YS, in the file WP-Pallet Damage Area Abstraction Rev00e.xIs. This file can be found on the CD in Appendix G.

Figure 6.5-20. Three Data Classes for Calculation of Standard Deviation are Identified by the Dashed Lines and Red Arrows

The standard deviations are listed in Table 6.5-11 for each of the three classes. These results demonstrate that the standard deviation of the data is reasonably constant over the range of PGV-longitudinal for the damage abstraction, consistent with the use of Excel's least squares fit with equal weighting of the data points. 
Table 6.5-11. Standard Deviations of the Three Classes

\begin{tabular}{|l|c|c|}
\hline \multicolumn{1}{|c|}{ Definition of Class } & Number of Points & Standard Deviation \\
\hline $\operatorname{Ln}($ PGV-longitudinal $)<0.86 \mathrm{~m} / \mathrm{s}$ & 5 & 1.09 \\
\hline $0.86 \mathrm{~m} / \mathrm{s} \leq \mathrm{Ln}(\mathrm{PGV}$-longitudinal $) \leq$ & 14 & 1.04 \\
$1.05 \mathrm{~m} / \mathrm{s}$ & 13 & 0.99 \\
\hline $\operatorname{Ln}(\mathrm{PGV}$-longitudinal $)>1.05 \mathrm{~m} / \mathrm{s}$ & & \\
\hline
\end{tabular}

Source: Worksheet ABSTR for $80 \%$ YS, in the file WP-Pallet Damage Area Abstraction Rev00e.xls in Appendix G.

\subsection{Comparison of Abstraction with Data for Nonzero Damaged Areas}

Figure 6.5-21 overlays the nonzero damaged areas from Figure 6.5-16 with the 0.05 and 0.95 nonexceedance probability curves for a ln-normal distribution with the standard deviation of 1.023 determined in Figures 6.5-18 and 6.5-19 and in Table 6.5-11. The 0.05 to 0.95 nonexceedance probability curves generally encompass all of the data points for nonzero damaged areas, with the 0.95 nonexceedance probability curve significantly exceeding all damaged areas above the $5.35-\mathrm{m} / \mathrm{s}$ PGV level. This conservatism will not have any impact on TSPA because the maximum value of $P G V$ is $4.07-\mathrm{m} / \mathrm{s}$, based on the bounding hazard curve presented in Section 6.4.3. This comparison provides confidence that the ln-normal distribution provides an appropriate abstraction for the nonzero damaged areas from waste package-pallet impacts.

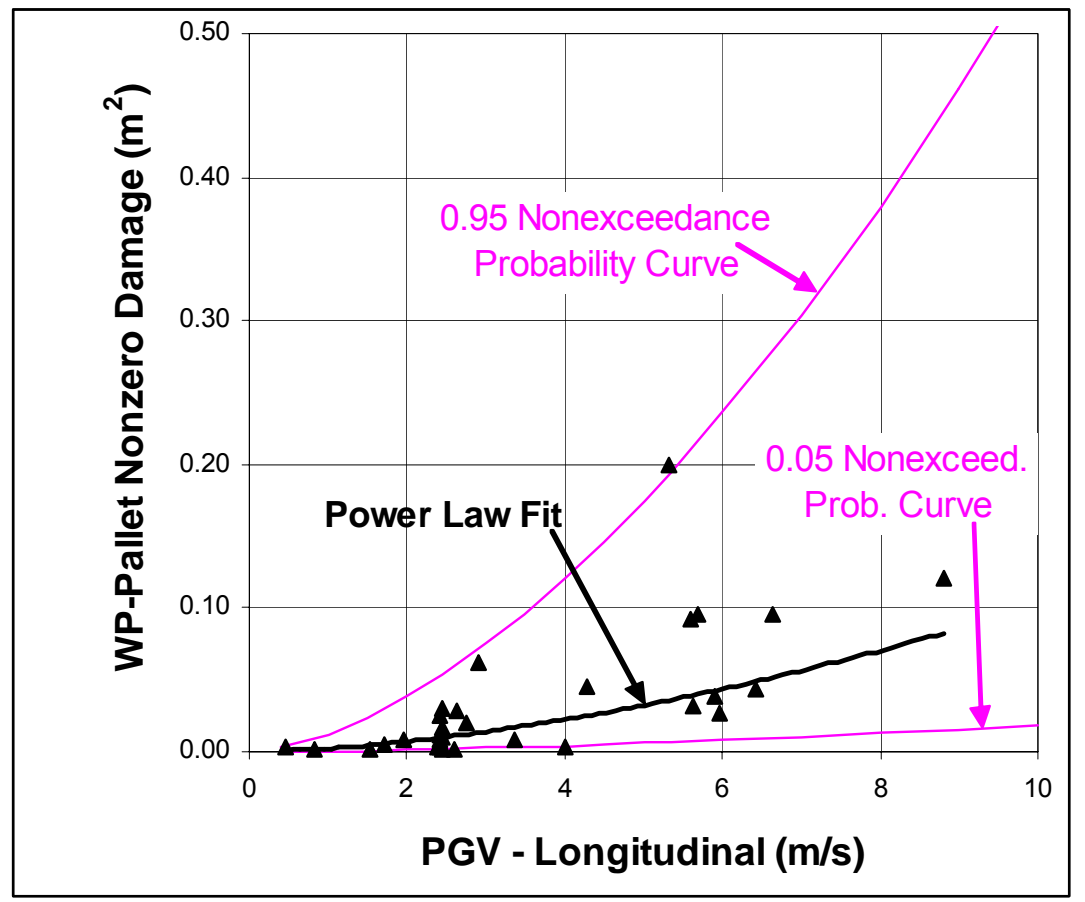

Source: Worksheet ABSTR for $80 \%$ YS, in the file WP-Pallet Damage Area Abstraction Rev00e.xIs. This file can be found on the CD in Appendix G; WP = waste package.

Figure 6.5-21. Comparison of Data for Nonzero Damaged Areas With the 0.05 and 0.95 Nonexceedance Probability Curves for the Ln-Normal Distribution 


\subsubsection{Conversion to Percent Surface Area}

The damage abstractions for waste package-pallet impacts produce damaged area in square meters, based on the mechanical response of the 21-PWR waste package. It is reasonable to calculate damage for the 21-PWR waste package type because this package type comprises 64.6 percent of the total inventory of waste packages (see discussion in Section 6.5.1.6). The TSPA-LA model requires damage estimates for commercial spent nuclear fuel (CSNF) and codisposal (CDSP) package types. The damage for these package types is estimated by converting the damaged area in square meters to a percent of total surface area for the 21-PWR waste package type. The total surface area for the 21-PWR package in the waste package-pallet impact calculations is $28.2 \mathrm{~m}^{2}$ (BSC 2004 [DIRS 167083], Section 6.1.1). This value differs from the surface area of the 21-PWR package in the recent kinematic calculations, $30.05 \mathrm{~m}^{2}$, because of changes in the package design. Areas from the waste package-pallet abstraction are converted to a percent damage by dividing by $28.2 \mathrm{~m}^{2}$, and this percent damage is applied to the CSNF and CDSP packages in the TSPA-LA model.

\subsubsection{Final Abstraction for Waste Package Damage}

\subsubsection{Analysis of Waste Package-Drip Shield Impacts}

The potential for damage from lateral impacts between the waste package and drip shield is not included in the seismic damage abstractions for TSPA. The basis for not including damage from waste package-drip shield impacts is based on several observations: (i) the damaged areas from side-on impacts of a waste package on an elastic surface are significantly less than the damaged areas from end-on impacts on an elastic surface, (ii) waste package-drip shield impacts occur much less frequently and with lower impact velocities than end-to-end impacts in the single waste package calculations, implying that the damaged areas from end-to-end impacts are significantly greater than from waste package-drip shield impacts, (iii) cross-drift calculations for a waste package and a drip shield surrounded by rockfall demonstrate that significant lateral impact velocities between the waste package and drip shield only occur for ground motions at the 2.44-m/s PGV level that are beyond the PGV values on the bounded hazard curve, and (iv) the conservatism in the approach for calculating damaged areas from end-to-end impacts encompasses the potential increase in damaged areas for waste package-drip shield impacts. Each of these observations is explained in this section.

Table 6.5-12 summarizes the damaged areas from end-on impacts of the waste package versus side-on impacts of the waste package for selected values of impact velocity and angle of impact (BSC 2004 [DIRS 162293], Table 4). Table 6.5-12, which is based on the 80 percent residual stress threshold for Alloy 22, does not include the data for an impact velocity of $20 \mathrm{~m} / \mathrm{s}$ in (BSC 2004 [DIRS 162293], Table 4) because none of the end-to-end impacts in Section 6.5.1 exceed $12 \mathrm{~m} / \mathrm{s}$. Table 6.5-12 also does not include data for a $0^{\circ}$ impact angle because perfect alignment during the impact process is very improbable, as explained in Section 6.5.1.2.

The ratios of damaged areas for end-on to side-on impacts vary between 3.0 and 20.9 (or infinite in three cases), implying that damage from end-on impacts is typically much greater than damage from side-on impacts throughout the ranges of impact velocities $(1 \mathrm{~m} / \mathrm{s}$ to $10 \mathrm{~m} / \mathrm{s})$ and impact angles $\left(1^{\circ}\right.$ to $\left.8^{\circ}\right)$ that are relevant to damaged areas. 
Table 6.5-12. Comparison of Damaged Areas $\left(\mathrm{m}^{2}\right)$ From End-On and Side-On Impacts of a Waste Package for a Residual Stress Threshold of 80 percent of the YS of Alloy 22

\begin{tabular}{|c|c|c|c|c|c|c|c|}
\cline { 3 - 8 } \multicolumn{2}{c|}{} & $\begin{array}{c}\mathbf{1}^{\mathbf{0}} \\
\text { End-On } \\
\text { Impact }\end{array}$ & $\begin{array}{c}\mathbf{1}^{\mathbf{0}} \\
\text { Side-On } \\
\text { Impact }\end{array}$ & $\begin{array}{c}\text { Area } \\
\text { Ratio }\end{array}$ & $\begin{array}{c}\mathbf{8}^{\circ} \\
\text { End-On } \\
\text { Impact }\end{array}$ & $\begin{array}{c}\mathbf{8}^{\circ} \\
\text { Side-On } \\
\text { Impact }\end{array}$ & $\begin{array}{c}\text { Area } \\
\text { Ratio }\end{array}$ \\
\hline \multirow{4}{*}{$\begin{array}{c}\text { Impact Velocity } \\
(\boldsymbol{m} / \mathbf{s})\end{array}$} & $\mathbf{1}$ & 0.0033 & 0 & $\infty$ & 0.0011 & 0 & $\infty$ \\
\cline { 2 - 9 } & $\mathbf{2}$ & 0.0221 & 0.0020 & 11.1 & 0.0113 & 0 & $\infty$ \\
\cline { 2 - 8 } & $\mathbf{4}$ & 0.0734 & 0.0063 & 11.7 & 0.0716 & 0.0068 & 10.5 \\
\cline { 2 - 8 } & $\mathbf{6}$ & 0.1665 & 0.0204 & 8.2 & 0.1082 & 0.0153 & 7.1 \\
\cline { 2 - 8 } & $\mathbf{1 0}$ & 0.0834 & 0.0283 & 3.0 & 0.1061 & 0.0508 & 20.9 \\
\hline
\end{tabular}

Source: BSC 2003 [DIRS 162293], Table 4.

Note: $\quad$ Area Ratio $=($ End-On Impact Area $) /($ Side-On Impact Area $)$

YS = Yield Strength

Table 6.5-13 summarizes the frequency and maximum velocities of end-to-end impacts versus waste package-drip shield impacts for the single waste package calculations (BSC 2004 [DIRS 167083], Tables 6.1.3-1 through 6.1.3-5 and Tables 6.1.2-1 through 6.1.2-15). The data summarized in Table 6.5-13 are for the 2.44-m/s PGV level. This PGV level is appropriate because it is approximately midway between the minimum PGV value of $0.4019-\mathrm{m} / \mathrm{s}$ and the maximum PGV value of $4.07-\mathrm{m} / \mathrm{s}$ sampled for TSPA. The single waste package calculations are useful for this comparison because of their fully three-dimensional geometry, in contrast to the kinematic calculations which have a two dimensional geometry that does not include motion in the transverse horizontal direction. While the single waste package calculations cannot represent synchronous motion, it is more important to capture the transverse horizontal motion in comparing the potential for waste package-drip shield impacts versus end-to-end impacts. Section 6.5.2 has a general description of the single waste package calculations.

The comparison of waste package-drip shield and end-to-end impacts in Table 6.5-13 demonstrates that there are very few waste package-drip shield impacts in comparison to end-to-end impacts at the 2.44-m/s PGV level. In addition, the maximum waste package-drip shield impact velocity is usually significantly less than the maximum end-to-end impact velocity in a given realization. This comparison implies that the damaged areas from end-to-end impacts will be significantly greater than the damaged areas from waste package-drip shield impacts for the ground motions at the $2.44-\mathrm{m} / \mathrm{s}$ PGV level.

The comparison in Table 6.5-13 is confirmed by the results from the two-dimensional cross-drift calculations for a waste package and drip shield that is surrounded by rubble from a collapsed drift (BSC 2005 [DIRS 173172], Section 5.6.1). The data from the cross-drift calculations, presented in Table 6.5-14, confirms that many realizations have no waste package-drip shield impacts, similar to the results in the second column of Table 6.5-13. 
Table 6.5-13. Comparison of Damaged Areas $\left(\mathrm{m}^{2}\right)$ From End-On and Side-On Impacts of a Waste Package for a Residual Stress Threshold of 80 percent of the YS of Alloy 22

\begin{tabular}{|c|c|c|c|c|}
\hline & Waste Package-Drip Shield (Lateral) Impacts & \multicolumn{2}{|c|}{ End-to-End Impacts } \\
\cline { 2 - 5 } Realization No. & No. of Impacts & $\begin{array}{c}\text { Max. Impact Velocity } \\
(\mathrm{m} / \mathrm{s})\end{array}$ & No. of Impacts & $\begin{array}{c}\text { Max. Impact Velocity } \\
(\mathrm{m} / \mathrm{s})\end{array}$ \\
\hline 1 & 0 & $\mathrm{~N} / \mathrm{A}$ & 3 & 1.5 \\
\hline 2 & 0 & $\mathrm{~N} / \mathrm{A}$ & 3 & 1.8 \\
\hline 3 & 0 & $\mathrm{~N} / \mathrm{A}$ & 9 & 3.9 \\
\hline 4 & 1 & 2.9 & 4 & 3.5 \\
\hline 5 & 0 & $\mathrm{~N} / \mathrm{A}$ & 14 & 4.4 \\
\hline 6 & 0 & $\mathrm{~N} / \mathrm{A}$ & 7 & 4.0 \\
\hline 7 & 1 & 1.2 & 7 & 4.5 \\
\hline 8 & 0 & $\mathrm{~N} / \mathrm{A}$ & 5 & 2.8 \\
\hline 9 & 5 & 4.1 & 10 & 1.6 \\
\hline 10 & 0 & $\mathrm{~N} / \mathrm{A}$ & 3 & 2.8 \\
\hline 11 & 1 & 1.8 & 7 & 3.0 \\
\hline 12 & 0 & $\mathrm{~N} / \mathrm{A}$ & 7 & 2.0 \\
\hline 13 & 0 & $\mathrm{~N} / \mathrm{A}$ & 5 & 1.4 \\
\hline 14 & 0 & $\mathrm{~N} / \mathrm{A}$ & 3 & 2.0 \\
\hline 15 & 1 & 1.2 & 1 & \\
\hline
\end{tabular}

Sources: BSC 2004 [DIRS 167083], Tables 6.1.3-1 through 6.1.3-5 and Tables 6.1.2-1 through 6.1.2-15. YS $=$ Yield Strength

Table 6.5-14. Comparison of Maximum Waste Package-Drip Shield Impact Velocities from the Cross-Drift Calculations with PGV Values for the Transverse and Vertical Components at the $2.44-\mathrm{m} / \mathrm{s}$ PGV Level.

\begin{tabular}{|c|c|c|c|c|}
\hline Realization No. & Ground Motion No. & $\begin{array}{c}\text { PGV-Transverse } \\
(\mathrm{m} / \mathrm{s})\end{array}$ & $\begin{array}{c}\text { PGV-Vertical } \\
(\mathrm{m} / \mathrm{s})\end{array}$ & $\begin{array}{c}\text { Max. Impact Velocity } \\
(\mathrm{m} / \mathrm{s})\end{array}$ \\
\hline 1 & 17 & 1.60 & 1.75 & 0 \\
\hline 2 & 16 & 1.58 & 2.12 & 0 \\
\hline 3 & 3 & 6.43 & 6.09 & 0.35 \\
\hline 4 & 2 & 2.69 & 2.33 & 0 \\
\hline 5 & 11 & 2.56 & 1.28 & 0.669 \\
\hline 6 & 4 & 2.60 & 2.97 & 0.195 \\
\hline 7 & 12 & 2.71 & 1.95 & 0 \\
\hline 8 & 5 & 2.57 & 1.14 & 0.41 \\
\hline 9 & 15 & 1.53 & 4.54 & 1.27 \\
\hline 10 & 9 & 8.17 & 4.57 & 0 \\
\hline 11 & 8 & 4.02 & 1.54 & 0 \\
\hline 12 & 6 & 1.32 & 2.71 & 1.85 \\
\hline 13 & 10 & 0.78 & 0.84 & 0 \\
\hline 14 & 1 & 1.95 & 1.11 & 0 \\
\hline 15 & 7 & 2.42 & 6.37 & 2.46 \\
\hline 16 & 14 & 1.26 & 3.37 & \\
\hline 17 & 13 & 3.04 & & \\
\hline
\end{tabular}

Sources: $\quad$ BSC 2005 [DIRS 173172], Table V-5; BSC 2004 [DIRS 166107], Appendix X, Table X-3

Note: $\quad$ The cross-drift calculations are based on all 17 ground motion time histories, while the single waste package calculations in Table 6.5-13 are based on a subset of 15 ground motions. 
The data in Table 6.5-14 also demonstrate that a waste package-drip shield impact velocity above $1 \mathrm{~m} / \mathrm{s}$ only occurs for ground motions with a PGV component greater than $4 \mathrm{~m} / \mathrm{s}$, approximately the maximum PGV value for the $10^{-8}$ annual exceedance frequency on the bounded hazard curve. For example, realization numbers 3, 10, 11, and 15 have maximum lateral impact velocities above $1 \mathrm{~m} / \mathrm{s}$, and the corresponding maximum PGV value for either component is $6.43 \mathrm{~m} / \mathrm{s}, 8.17 \mathrm{~m} / \mathrm{s}, 4.02 \mathrm{~m} / \mathrm{s}$, and $6.37 \mathrm{~m} / \mathrm{s}$, respectively. On the other hand, the other ground motions result in maximum waste package-drip shield impact velocities below $0.669 \mathrm{~m} / \mathrm{s}$. The results with the cross-drift calculations confirm that waste package-drip shield impact velocities are expected to be less than $1 \mathrm{~m} / \mathrm{s}$ when ground motion components are at or below a PGV of $4 \mathrm{~m} / \mathrm{s}$. In this situation, the damage from waste package-drip shield impacts is anticipated to be minor in comparison to that from end-to-end impacts and from waste package-pallet impacts.

Finally, the methodology for calculating damage from end-to-end impacts has two significant conservatisms: (1) the catalog of end-on damage assumes a plane of symmetry, equivalent to an impact velocity that is one-half the relative impact velocity between two adjacent packages. However, the calculation of damaged areas does not include the potential reduction in relative impact velocity by a factor of two; and (2) a simple summation of damage from individual impacts overestimates the damage if impacts occur in the same location or if the damaged areas from adjacent impacts overlap significantly.

Based on these observations, the potential damage from waste package-drip shield impacts is not included in the seismic damage abstractions because the damaged areas from side-on impacts are significantly less than the damaged areas from end-on impacts, because the damaged areas from end-to-end impacts are expected to be significantly greater than the damaged areas from waste package-drip shield impacts, and because the conservatism in the approach for calculating damaged areas from end-to-end impacts encompasses the potential increase in damaged areas for waste package-drip shield impacts.

\subsubsection{Total Damage Abstraction for the Waste Package}

The results in Sections 6.5.1 and 6.5.2 provide damage abstractions for end-to-end impacts of adjacent waste packages and for waste package-pallet impacts. The methodology for combining these multiple abstractions within the TSPA framework is described in this section.

Within each realization of the TSPA, the guidelines for combining the damage abstractions are as follows:

- The total damaged area is defined as the sum of the damaged areas from end-to-end impacts and from waste package-pallet impacts. The damage abstractions for end-to-end impacts and for waste package-pallet impacts are treated as uncorrelated parameters to provide robust sampling across the full range of seismically-induced damage.

- The results from the LS-DYNA and the UDEC kinematic calculations for end-to-end impacts are represented as equally probable in TSPA. There is insufficient information to select one kinematic approach over the other at the present time, so it is reasonable to represent both abstractions in TSPA on an equal basis. An advantage of using both 
abstractions is that the uncertainty in the computational methodologies for end-to-end impacts is directly represented in TSPA.

- Abstractions define the damaged areas at 80 percent and 90 percent of the yield strength of Alloy 22. However, the residual stress threshold for Alloy 22 is based on a uniform distribution between 80 percent and 90 percent of the yield strength of Alloy 22. The damaged area is linearly interpolated between the known values at 80 percent and 90 percent of yield strength to define the damage area at intermediate values of the residual stress threshold. The linear interpolation between the damaged areas at 80 percent and 90 percent of the yield strength are identical within a given realization, providing perfect correlation between the damaged areas from end-to-end impacts and from waste package-pallet impacts with regard to the effective residual stress threshold for Alloy 22.

For a given kinematic approach (i.e., once LS-DYNA or UDEC is selected), the abstractions for residual stress thresholds of 80 percent and 90 percent of the yield strength of Alloy 22 are sampled in an identical fashion statistically. In particular, the value of the random number for determining the probability of no damage is identical for both abstractions and the sampling of the ln-normal distributions about the power law is therefore perfectly correlated. This latter statement means that the sampling of both ln-normal distributions will return values corresponding to the same quantile from both ln-normal distributions.

The damage to the waste package is applied to all waste packages in the repository, except for those packages that experience early time failures from manufacturing defects or from defects that occur during emplacement. There is no spatial variability for damage to the waste package.

As explained in Sections 6.3.4 and 6.3.5, TSPA-LA requires the effective area for transport through the waste package, rather than the damaged area that exceeds the residual stress threshold for Alloy 22. The effective area is determined by the density of stress corrosion cracks (SCCs) and the area of individual cracks in the regions where the residual stress exceeds the residual stress threshold. The product of the crack density per unit surface area, $\rho_{S C C}$, and the area per crack, $A_{S C C}$ defines the effective area of the SCC network per unit area of damaged surface. This product ranges from 0.00328 to 0.0131 at room temperature (DTN: MO0403SPASCRKD.000 [DIRS 168105]). Stated differently, the effective area of a crack network is a factor of 76 to 305 less than the damaged surface area that exceeds the residual stress threshold.

For TSPA-LA, the crack network on the waste package provides a pathway for diffusive transport of radionuclides out of the waste package. The factor defining the effective area for diffusive transport is sampled from a uniform distribution with a lower bound of 0.00328 and an upper bound of 0.0131 . The sampled value for the factor is then multiplied by the sampled value for the combined damaged areas from end-to-end and waste package-pallet impacts. This procedure directly incorporates the uncertainty in the distribution of damaged areas and the uncertainty in the factor defining the effective area of a crack network into TSPA-LA.

Advective flow through the network of stress corrosion cracks on the waste package is not included in TSPA, as discussed in Section 6.3.5. A comprehensive technical analysis of the 
potential for advective flow through the SCC network in the waste package indicates that advective flux will be insignificant (BSC 2005 [DIRS 173781], Section 6.2.63). The potential flow through SCCs is so small that its omission from TSPA has an insignificant effect on the magnitude and timing of radionuclide releases to the accessible environment. Advective flow of seepage through SCCs on the waste package outer barrier is excluded from TSPA on the basis of low consequence.

\subsubsection{Drip Shield Damage from Ground Motion}

The mechanical response of the drip shield to vibratory ground motions has the potential to damage the drip shield as a barrier to flow. This loss of integrity could occur because of damaged areas on the drip shield (i.e., those areas that exceed the residual stress threshold for Titanium Grade 7) from impacts between the drip shield and the waste package, emplacement pallet, invert, and drift wall. Loss of integrity as a barrier to flow could also occur because of separation between two adjacent drip shields. Separation is an important consideration because it neutralizes the drip shield as a flow barrier and rockfall barrier.

Structural response calculations determine the damaged areas on the drip shield under vibratory ground motions. However, the presence of damaged areas and the associated network of stress corrosion cracks are excluded from TSPA-LA because the advective flux of liquid through the drip shield is predicted to be negligible (see discussion in Section 6.3.6). This conclusion is based on the combination of several factors: (1) there are few damaging rockfall events, (2) creep and stress relaxation in dented areas on the drip shield may eliminate formation of through-wall cracks, and (3) capillary effects, evaporation, and plugging in tight cracks can significantly limit the amount of seepage water that can flow through cracks in the drip shields. Because the advection of liquid and solids through the drip shield will be minor, its omission from TSPA-LA will have an insignificant effect on the magnitude and time of the resulting radionuclide releases to the accessible environment (BSC 2005 ([DIRS 173781], Section 6.2.64 and Appendix C).

The same structural response calculations also determine the onset and degree of drip shield separation. However, as discussed in Section 6.5.5, drip shield separation is excluded from TSPA-LA because the ground motion amplitudes that are sufficient to separate the drip shields are also large enough to partially or completely collapse drifts in the lithophysal or nonlithophysal zones of the repository. The presence of rockfall, either as larger rock blocks or small fragments around the drip shield, causes frictional loads on the sides of the drip shield. Rockfall can also cause gravitational loads on top of the drip shield if the rockfall completely covers the drip shield. The presence of even small frictional or gravitational loads has been shown to restrain the relative motion between adjacent drip shields, thereby preventing drip shield separation (BSC 2004 [DIRS 169753], Section 5.3).

In summary, damage to the drip shield from vibratory ground motion is not included in the TSPA-LA. The structural response calculations for the drip shield are briefly summarized in the next two subsections, followed by a summary of the analysis that excludes drip shield separation from TSPA-LA. 


\subsubsection{Structural Response Calculations}

Damage to the drip shield from vibratory ground motion is determined by structural response calculations (BSC 2004 [DIRS 172448]). A set of 15 calculations for the dynamic response of the drip shield was performed for a set of 15 ground motions with a PGV of $2.44 \mathrm{~m} / \mathrm{s}$. A similar set of calculations was also performed for a PGV of $5.35 \mathrm{~m} / \mathrm{s}$. The stochastic (uncertain) input parameters for the 15 calculations are the 15 sets of three-component ground-motion time histories, the metal-to-metal friction coefficient, and the metal-to-rock friction coefficient. A Monte Carlo sampling scheme defines the appropriate combinations of ground-motion time histories and friction coefficients (BSC 2004 [DIRS 169999], Section 6.4). The set of 15 ground-motion time histories for these analyses is identical with that for the analyses of rockfall induced by vibratory ground motion and for waste package structural response. The drift is unfilled at the time of the seismic event and the potential coupling between rockfall and the dynamic motion of the EBS components during the event is not included in the analyses.

These calculations incorporate the potential for corrosion to degrade the drip shield by reducing the thickness of the drip shield plates by $2 \mathrm{~mm}$. This thickness reduction is a conservative representation of material loss by general corrosion over the first 10,000 years after repository closure and a reasonable representation of barrier degradation for 20,000 years after repository closure. These calculations evaluate mechanical properties at $150^{\circ} \mathrm{C}$ to represent the potential degradation in mechanical strength if a seismic hazard occurs during the initial thermal pulse after repository closure (Assumption 5.3). The objectivity of the finite-element mesh was also demonstrated (BSC 2004 [DIRS 172448], Attachment III).

The damage to the drip shield is determined by comparing the residual first principal stress on the drip-shield plates to the failure criterion for Titanium Grade 7, which is defined in Section 6.3.3. The results from each structural response calculation are evaluated to determine the elements in the plates whose residual stress exceeds 50 percent of the yield strength of Titanium Grade 7; the failed elements are then converted into a damaged surface area. This conversion conservatively considered that if a single element on the surface of the waste package fails, then the elements beneath this element also fail.

The structural response calculations do not represent the dynamic response of the invert to the ground motion. The invert is represented as an elastic body whose surface responds instantaneously and uniformly with the given ground motion, as though it is a rigid surface. The impact of representing the dynamic response of the invert is analyzed in BSC 2005 ([DIRS 173172] Attachment VIII). For these calculations, the invert is represented as a cohesionless, granular material that is subjected to ground motions at the 2.44 and $5.35 \mathrm{~m} / \mathrm{s} \mathrm{PGV}$ levels. The computational results demonstrate that the rigid representation has relatively little impact on amplification of ground motions or on permanent deflection of the invert surface. The simpler representation of the invert as a rigid surface is therefore retained for the structural response calculations. 


\subsubsection{Drip Shield Damage}

The results of the structural response calculations for ground motions at the $0.19 \mathrm{~m} / \mathrm{s}, 2.44 \mathrm{~m} / \mathrm{s}$, and $5.35-\mathrm{m} / \mathrm{s}$ PGV levels are summarized as follows:

- One simulation performed at the $0.19-\mathrm{m} / \mathrm{s}$ PGV level indicates that there is no damage to the drip shield (BSC 2005 [DIRS 173303], Calculation Results I). This simulation is based on the single (three component) ground motion that was developed for preclosure design purposes at the $0.19-\mathrm{m} / \mathrm{s}$ PGV level. More specifically, the drip shields do not separate and no area of the drip shield exceeds the residual stress threshold of 50 percent of the yield strength of Titanium Grade 7.

- Fourteen simulations were performed to completion at the $2.44-\mathrm{m} / \mathrm{s}$ PGV level. The results of these calculations do not indicate any separation of drip shields. The data for damaged area on the drip shield (BSC 2005 [DIRS 173303], Table 4) indicates that the mean percent damaged area is 0.70 percent and the maximum percent damaged area is 2.13 percent. As with the waste package calculations for the $2.44-\mathrm{m} / \mathrm{s}$ PGV level, ground motion \#16 was substituted for ground motion \#15 because of its anomalous response spectrum (see footnote $d$ to Table 6.5-9 for additional details).

The suite of ground motions for computing drip shield response at the 2.44-m/s PGV level does not include intercomponent variability (Section 6.4.2). In this situation, it is possible that some realizations might experience drip shield separation if the structural response calculations had been performed with a suite of ground motions that include intercomponent variability. The damage abstraction for TSPA-LA is based on the results for ground motions without intercomponent variability, which indicate no separation. This is a reasonable approach because the damage areas for the $2.44-\mathrm{m} / \mathrm{s}$ PGV level are generally small, indicating limited potential for the large relative displacements in the vertical direction that are required to separate adjacent drip shields.

- Five simulations performed at the 5.35-m/s PGV level indicate separation of adjacent drip shields in each calculation (BSC 2005 [DIRS 173303], Calculation Results III). The ground motions become very intense at $5.35 \mathrm{~m} / \mathrm{s}$, resulting in large displacements and high-speed impacts for the unanchored repository components.

Separation occurs between adjacent drip shields because of plastic deformation of the drip shield and because of the large magnitude of the ground motions. In fact, each of the five simulations demonstrates that a drip shield rides over its adjacent neighbor, implying that a separation must occur somewhere in the emplacement drift. The degree to which the drip shield rides over its neighbor is substantial, on the order of 10 to 25 percent of the length of the drip shield (BSC 2004 [DIRS 172448], Figures IV-3 through IV-7). These separations represent a lower bound because four of the five numerical simulations terminated before the end of the ground-motion time history.

The prediction of drip shield separation for the 5.35-m/s PGV level is very idealized for two reasons. First, the finite-element representation has rigid boundaries (that move with the invert) at the axial ends of the computational space, and the presence of rigid boundaries amplifies the interaction between adjacent drip shields. The ground motions 
are expected to be synchronous over the length scale of the drip shields in an emplacement drift. Synchronous ground motions will generally lead to synchronous motions of the drip shields, all other factors being equal. However, synchronous motion of adjacent drip shields is destroyed once a drip shield impacts either rigid boundary at the ends of the computational space. The resulting asynchronicity increases the relative motion and impacts between adjacent drip shields, decreasing the onset time for and increasing the degree of drip shield separation in the calculations. The second reason is that the presence of rockfall is not included in the structural response calculations for the drip shields, as explained in the next section. The ground motion amplitudes at the $5.35-\mathrm{m} / \mathrm{s}$ PGV level are large enough to cause rockfall in both the lithophysal and nonlithophysal zones (BSC 2004 [DIRS 166107], Sections 6.4.2.2.2 and 6.3.1.6.4). The presence of rubblized backfill and larger rock blocks around the drip shields restricts the relative vertical displacement between adjacent drip shields, reducing the potential for separation at extreme ground motions.

\subsubsection{Rockfall Prevents Drip Shield Separation}

Drip shield separation is excluded from TSPA-LA because (1) ground motion amplitudes that are sufficient to cause drip shield separation are also large enough to partially or completely collapse drifts in the repository, (2) rockfall occurs within the first second or two of the arrival of these large amplitude ground motions, and (3) a kinematic study indicates that small static loads from rubble or frictional loads between EBS components are sufficient to eliminate separation of drip shields. In this situation, rockfall provides restraints on the motion of the drip shields, preventing differential motion that could lead to separation.

Ground motion amplitudes near and above the 2.44-m/s PGV level are large enough to cause rockfall in both the lithophysal and nonlithophysal zones. In the lithophysal zones, drift collapse is observed at approximately the 2-m/s PGV level (BSC 2004 [DIRS 166107], Section 6.4.2.2.2, fourth bullet under subheading 'Discussion'). Figure 6.5-22 presents an example of rockfall in lithophysal rock for the case of a peak ground velocity of $3.33 \mathrm{~m} / \mathrm{sec}$ for three rock quality levels that span the expected strength range. Collapse of the drifts occurs for the full range of rock quality levels in Figure 6.5-22, covering the drip shield with rubble. Partial collapse of drifts occurs for peak ground velocities below $2 \mathrm{~m} / \mathrm{sec}$, resulting in rubble constraint to the sidewalls of drip shield. In the nonlithophysal zones, significant collapse is observed at $2.44 \mathrm{~m} / \mathrm{s}$ and at $5.35 \mathrm{~m} / \mathrm{s}$ (BSC 2004 [DIRS 166107], Section 6.3.1.6.4).

The collapse in the lithophysal rock is coincident with the arrival of the first strong ground motion-i.e., collapse occurs within seconds of the arrival of the first pulse of the accelerogram (BSC 2004 [DIRS 166107], Section 6.4.2.2.2). Large blocks also start to fall from the drift walls in the nonlithophysal zones shortly after the arrival of the ground motion (BSC 2004 [DIRS 166107], Section 6.3.1.6.1). 

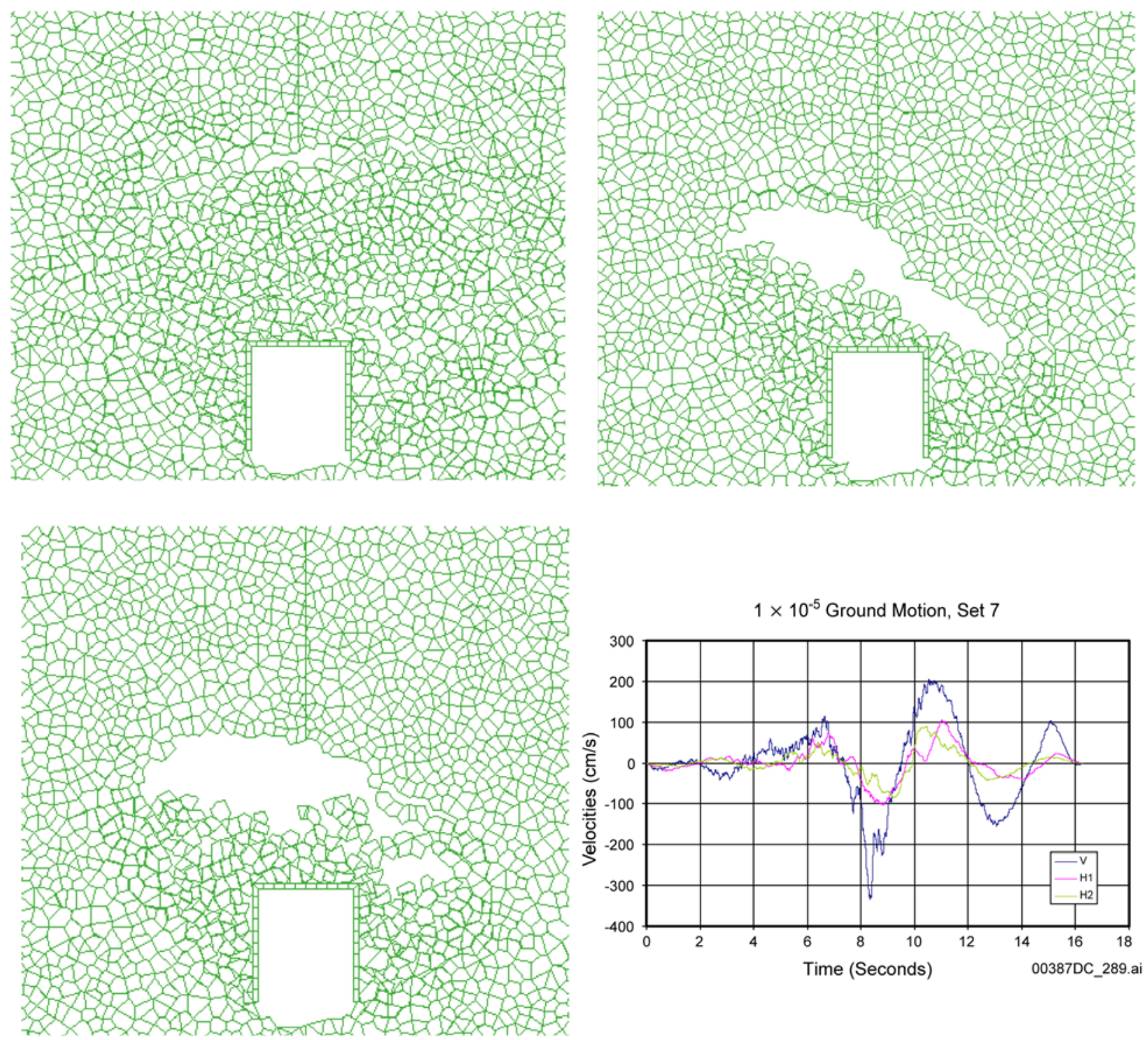

Source: BSC 2004 [DIRS 166107], Figure 6-127.

NOTE: (upper left) Rock Strength Category $1\left(40.6 \mathrm{~m}^{2} / \mathrm{m}\right.$ drift length), (upper right) Category $5\left(19.7 \mathrm{~m}^{2} / \mathrm{m}\right)$, (lower left) Category $3\left(15.4 \mathrm{~m}^{2} / \mathrm{m}\right.$ ), and (lower right) Ground Motion History 7, PGV=333 cm/sec.

Figure 6.5-22. Collapse of Emplacement Drifts for the Full Range of Rock Qualities of Lithophysal Rock for Peak Ground Velocity of $333 \mathrm{~cm} / \mathrm{sec}$

In either the lithophysal or nonlithophysal zones, rockfall occurs at PGV levels substantially lower than the 5.35-m/s PGV level that results in drip shield separation (Section 6.5.4.2). It follows that the drip shield is partly surrounded by rockfall whenever separation could potentially occur, and this rockfall occurs within the first few seconds of the ground motion. The larger rock blocks or the smaller rock fragments provide normal and shear confinement to the sidewalls and possibly the crown of the drip shield. The horizontal acceleration imparted to the drip shield by the ground motion will be resisted by the weight of the rockfall and by the frictional forces between the rock and the drip shield plates and between the footings and the invert. The exterior bulkhead structure of the drip shield (Figure 6.5-23) provides an additional 
physical restraint or "locking" mechanism between the drip shield and rubble that will constrain lateral movement. Thus, the presence of rockfall around the drip shields will restrict the relative displacements that are required to separate adjacent drip shields, so that separation is not expected to occur, even for extreme ground motions.

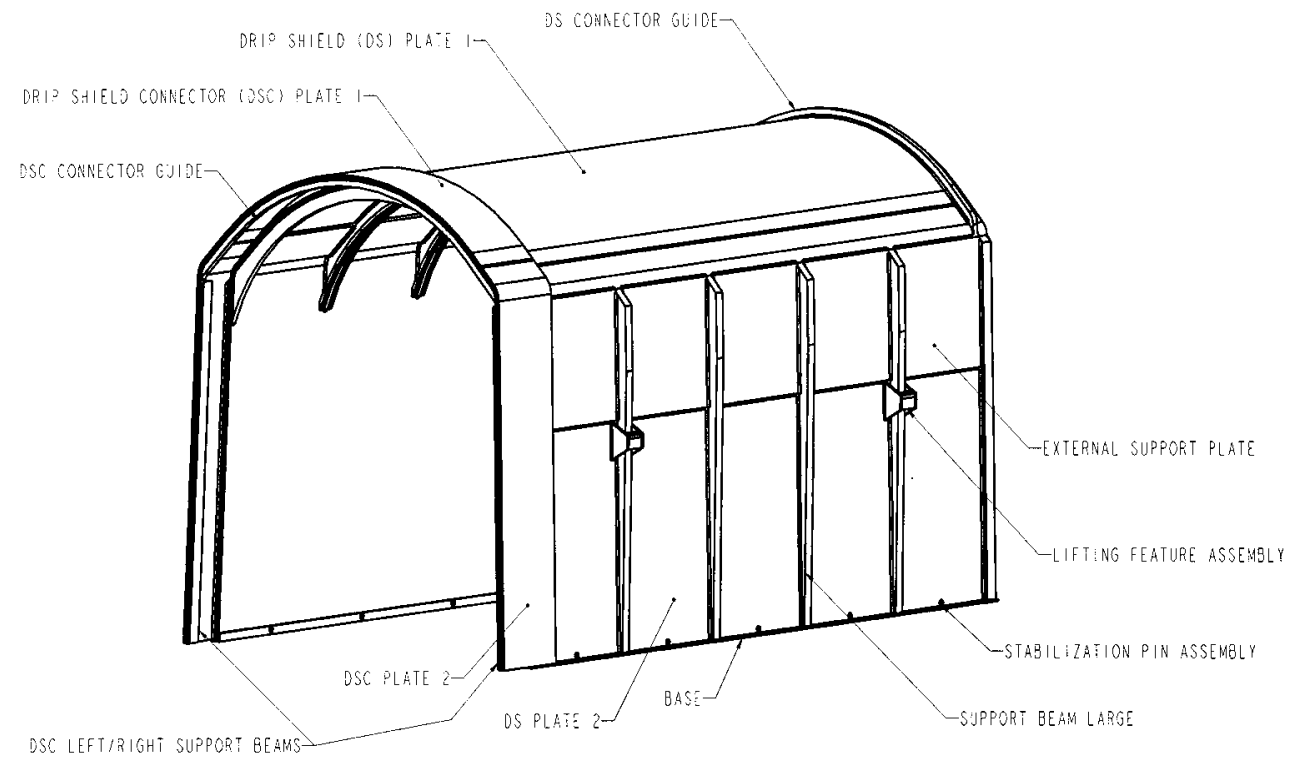

Source: BSC 2004 [DIRS 168275].

Figure 6.5-23. Geometry of the Drip Shield—Side View

Smaller, more frequent seismic events will also provide rockfall around the drip shield. Smaller events are much more probable during a 10,000-year period. For a Poisson process (Assumption 5.2), smaller seismic events with a rate of $3 \times 10^{-6}$ per year are about 10 times more probable than more extreme events with a rate of $3 \times 10^{-7}$ per year. These smaller events can contribute to the buildup of rockfall around the drip shield before an extreme event occurs. Ground motions greater than the $1.5-\mathrm{m} / \mathrm{s}$ PGV level, which corresponds to the $3 \times 10^{-6}$ per year annual exceedance frequency on the bounded hazard curve (Table 6.4-1), generate rockfall from partial collapse of the drifts in the lithophysal zones (BSC 2004 [DIRS 166107], Section 6.4.2.2.2). Since these higher probability (e.g., $3 \times 10^{-6}$ ) events are ten times more likely than the lower probability $3 \times 10^{-7}$ events, which corresponds to ground motions greater than the 2.7-m/s PGV level on the bounded hazard curve (Table 6.4-1), it is reasonable to expect that some rubble would exist in the drift and provide some confinement for the drip shield prior to the occurrence of a high amplitude, very low probability ground motion that could potentially result in drip shield separation.

A kinematic study of drip shield motion (BSC 2004 [DIRS 169753], Section 5.3) has confirmed that a relatively small amount of rubble can constrain the asynchronous motion of the drip shields and prevent drip shield separation. This study considers the kinematic response of multiple drip shields in a single emplacement drift under vibratory ground motion. Analyses were conducted for emplacement drifts that are open, partly filled with collapsed rock, and completely filled with collapsed rock. The drip shields remain connected for almost all cases, 
even for open drifts with extreme ground motions at the 5.35-m/s PGV level. Separation is only observed in the very unrealistic case that there is no metal-to-metal friction, an open drift, and the $5.35-\mathrm{m} / \mathrm{s}$ PGV ground motion. However, the kinematic calculations demonstrate that a small weight of rock or a small amount of friction force is sufficient to stabilize the motion of the drip shields and prevent drip shield separation. Since rockfall in the lithophysal or nonlithophysal zones occurs at PGV levels substantially lower than the 5.35-m/s PGV level that results in drip shield separation (Section 6.5.4.2), and since smaller, more frequent seismic events may also provide rockfall around the drip shield, the weight of the rockfall and the associated friction forces will be present to prevent drip shield separation.

\subsubsection{Failure Abstraction for the Fuel Rod Cladding from Ground Motion}

The mechanical response of the waste package to vibratory ground motion can produce dynamic impacts between adjacent waste packages, between the waste package and its emplacement pallet, and between the waste package and the drip shield. During each of these impacts, the waste package may experience very high acceleration in the axial and lateral directions. These accelerations can be "transmitted" to the fuel rod assemblies and fuel rods. The assemblies and fuel rods may impact the lid of a waste package due to the end-on (axial) impact of adjacent waste packages, or be pushed sideways, toward the sidewall of the waste package, during impact with the emplacement pallet or drip shield. Either of these impacts has the potential to fail the fuel rod cladding. The focus in the following subsections is on axial impacts because these alone have the potential to buckle the fuel rods, resulting in perforation and failure of the cladding.

\subsubsection{Structural Response Calculations}

The maximum waste package velocities from end-on impacts with the 15 ground motions at the 2.44-m/s PGV level vary between 1.4 to $4.5 \mathrm{~m} / \mathrm{s}$ (BSC 2004 [DIRS 167083], Tables 6.1.2-1 through 6.1.2-15). In other words, each realization with ground motions with $2.44-\mathrm{m} / \mathrm{s} \mathrm{PGV} \mathrm{has}$ an end-to-end impact velocity of at least $1.4 \mathrm{~m} / \mathrm{s}$. Similarly, the maximum waste package velocities for end-on impacts at the $5.35-\mathrm{m} / \mathrm{s}$ PGV level vary between $1.3 \mathrm{~m} / \mathrm{s}$ and $6.5 \mathrm{~m} / \mathrm{s}$ (BSC 2004 [DIRS 167083], Tables 6.2.2-1 through 6.2.2-15). That is, realizations for ground motions with $5.35-\mathrm{m} / \mathrm{s}$ PGV have an impact velocity of at least $1.3 \mathrm{~m} / \mathrm{s}$ (The minimum value for the $5.35-\mathrm{m} / \mathrm{s}$ PGV level is less than that for the $2.44-\mathrm{m} / \mathrm{s}$ PGV level because substantial stochastic variability in the 15 ground motions leads to substantial variability in waste package response.).

The resulting fuel assembly accelerations due to this range of impact velocities have been analyzed using a finite-element representation of the fuel assemblies. The maximum peak acceleration and the average peak acceleration for the assemblies in a waste package have been determined through detailed structural response calculations for a waste package with internal fuel rod assemblies impacting a rigid wall (BSC 2005 [DIRS 173500], Tables 3 and 4). The peak and average accelerations from the structural response calculations have been evaluated for cutoff frequencies of $450 \mathrm{Hertz}, 600 \mathrm{Hertz}$, and 1,000 Hertz. The accelerations for a cutoff frequency of 450 Hertz are repeated in Table 6.5-15. 
Table 6.5-15. Fuel Assembly Accelerations from Waste Package-to-Waste Package Impact Calculations for a 450 Hertz Cutoff Frequency

\begin{tabular}{|l|c|c|c|c|c|}
\hline \multirow{2}{*}{\multicolumn{1}{|c|}{ Parameter }} & \multicolumn{5}{|c|}{ Initial Impact Velocity (m/s) } \\
\cline { 2 - 6 } & $\mathbf{0 . 5}$ & $\mathbf{1}$ & $\mathbf{2}$ & $\mathbf{4}$ & $\mathbf{6}$ \\
\hline Maximum Peak Acceleration (g's) & 75 & 144 & 263 & 323 & 506 \\
\hline Average Peak Acceleration (g's) & 35 & 72 & 115 & 155 & 194 \\
\hline
\end{tabular}

Source: BSC 2004 [DIRS 173500], Tables 3 and 4.

The finite-element calculations for the fuel assembly accelerations do not include any damping. Impact calculations with no damping often produce acceleration time histories with peak values that are influenced by the spatial and temporal discretization of the calculations. In this situation, the output is typically filtered through a low-pass filter to determine a more realistic acceleration time history. The cutoff frequency for the filter is a compromise between damping the extraneous numerical noise while leaving the fundamental modes of the structure intact. Filtering the output below $400 \mathrm{Hertz}$ dampens the fundamental modes of waste package and fuel assembly, potentially leading to erroneous results. Filtering the output at greater than 1,000 Hertz preserves computational noise and can also lead to misleading results. A cutoff frequency of $450 \mathrm{Hertz}$ dampens the numerical noise but has minimal impact on the fundamental modes of fuel assembly and waste package (BSC 2003 [DIRS 162602], Appendix D).

\subsubsection{Cladding Failure from Buckling}

The minimum impact velocity for the $2.44 \mathrm{~m} / \mathrm{s}$ and $5.35-\mathrm{m} / \mathrm{s}$ PGV ground motions is $1.3 \mathrm{~m} / \mathrm{s}$, as noted in Section 6.5.6.1. Interpolating on the results in Table 6.5-15 for the known accelerations from impact calculations for velocities of $1 \mathrm{~m} / \mathrm{s}$ and $2 \mathrm{~m} / \mathrm{s}$, the maximum peak acceleration is $180 \mathrm{~g}^{\prime} \mathrm{s}^{9}$ and the average peak acceleration is $85 \mathrm{~g}$ 's ${ }^{10}$ for an impact at $1.3 \mathrm{~m} / \mathrm{s}$ with a $450 \mathrm{Hertz}$ cutoff frequency.

The integrity of fuel rod cladding during cask drop or tip over incidents has been extensively studied for zircalloy-clad light water reactor spent fuel assemblies (Chun et al. 1987 [DIRS 144357]; Sanders et al. 1992 [DIRS 102072]. The work by Chun et al. (1987 [DIRS 144357]) is more useful here because it explicitly calculates $g$-loads for axial buckling and for yielding due to side drops. The range of $g$-loads for failure due to axial buckling varies between $82 \mathrm{~g}$ 's for the Westinghouse $17 \times 17$ fuel assembly to $252 \mathrm{~g}$ 's for the Combustion Engineering 16×16 fuel assembly (Chun et al. 1987 [DIRS 144357], Table 4]). The range of $g$-loads for yielding due to side drops varies between $63 \mathrm{~g}$ 's for a Westinghouse $17 \times 17$ fuel assembly to $211 \mathrm{~g}$ 's for a Combustion Engineering $16 \times 16$ fuel assembly (Chun et al. 1987 [DIRS 144357], Table 4). The actual $g$-loads for failure may be lower because: (1) the weight of the fuel pellets is not transferred to the cladding (Chun et al. 1987 [DIRS 144357], page 2), and (2) the potential effects of cladding defects or existing failures are not included in the analysis. These effects increase the inertial mass or weaken the clad, possibly causing failure at lower $g$-loads.

9 Maximum peak acceleration at $1.3 \mathrm{~m} / \mathrm{s}=144 g$ 's $+(263 g$ 's $-144 g$ 's $) /(2 \mathrm{~m} / \mathrm{s}-1 \mathrm{~m} / \mathrm{s})(1.3 \mathrm{~m} / \mathrm{s}-1 \mathrm{~m} / \mathrm{s})=179.7 g$ 's.

10 Average peak acceleration at $1.3 \mathrm{~m} / \mathrm{s}=72 \mathrm{~g}$ 's $+\left(115 \mathrm{~g}\right.$ 's $\left.-72 g^{\prime} \mathrm{s}\right) /(2 \mathrm{~m} / \mathrm{s}-1 \mathrm{~m} / \mathrm{s})(1.3 \mathrm{~m} / \mathrm{s}-1 \mathrm{~m} / \mathrm{s})=84.9$ g's. 
Based on Table 6.5-15, end-on impacts of adjacent waste packages result in average fuel assembly accelerations of $85 \mathrm{~g}^{\prime} \mathrm{s}^{10}$ at the lowest impact velocity, and often much greater values for higher impact velocities. Simple fuel rod failure criteria indicate that clad failure occurs between $82 \mathrm{~g}$ 's and $252 \mathrm{~g}$ 's, depending on the type of fuel rod (Chun et al. 1987 [DIRS 144357], Table 4). In this situation, 100 percent perforation of the cladding is reasonable when a ground motion event occurs with a PGV of $2.44 \mathrm{~m} / \mathrm{s}$ or greater.

One calculation is available for the structural response of the waste package to a ground motion with PGV values of $0.19 \mathrm{~m} / \mathrm{s}$ and $0.384 \mathrm{~m} / \mathrm{s}$ (BSC 2004 [DIRS 167083], Sections 6.3 and 6.4). There is no damage to the cladding for these ground motions because there is no appreciable motion of the waste package and no impact between adjacent waste packages. However, the potential exists for more significant displacements and impacts at the $1.05-\mathrm{m} / \mathrm{s} \mathrm{PGV} \mathrm{level.}$

\subsubsection{Abstraction for Cladding Failure}

Cladding failure for ground motions at the $1.05-\mathrm{m} / \mathrm{s}$ PGV level is conservatively set to 100 percent. In addition, the cladding failure goes to zero at the $0.55-\mathrm{m} / \mathrm{s}$ PGV level. This approach is consistent with the results from the structural response calculations, whereby damage from vibratory ground motion first begins between the $0.384-\mathrm{m} / \mathrm{s}$ PGV level, corresponding to an exceedance frequency of about $10^{-4}$ per year, and the $1.05-\mathrm{m} / \mathrm{s}$ PGV level, corresponding to an exceedance frequency of $10^{-5}$ per year. The PGV value of $0.55 \mathrm{~m} / \mathrm{s}$ is an intermediate value, corresponding to an exceedance frequency of $5 \times 10^{-5}$ per year (Table 6.4-1). In other words, ground motions greater than those at the $0.384-\mathrm{m} / \mathrm{s}$ PGV level are required to damage the cladding.

The abstraction for cladding failure is then a simple look-up Table with a linear interpolation between the four points in Table 6.5-16, as illustrated in Figure 6.5-24. There is no uncertainty in this abstraction because the abstraction represents a conservative, bounding estimate for cladding response across the full range of PGV values. Cladding failure occurs within all waste packages for TSPA - there is no spatial variability in the damage.

Table 6.5-16. Abstraction for Cladding Failure from Vibratory Ground Motion

\begin{tabular}{|c|c|}
\hline $\begin{array}{c}\text { PGV Value } \\
(\mathbf{m} / \mathbf{s})\end{array}$ & $\begin{array}{c}\text { Cladding Failure } \\
(\mathbf{\% )}\end{array}$ \\
\hline 0.0 & 0 \\
\hline 0.55 & 0 \\
\hline 1.05 & 100 \\
\hline$>1.05$ & 100 \\
\hline
\end{tabular}




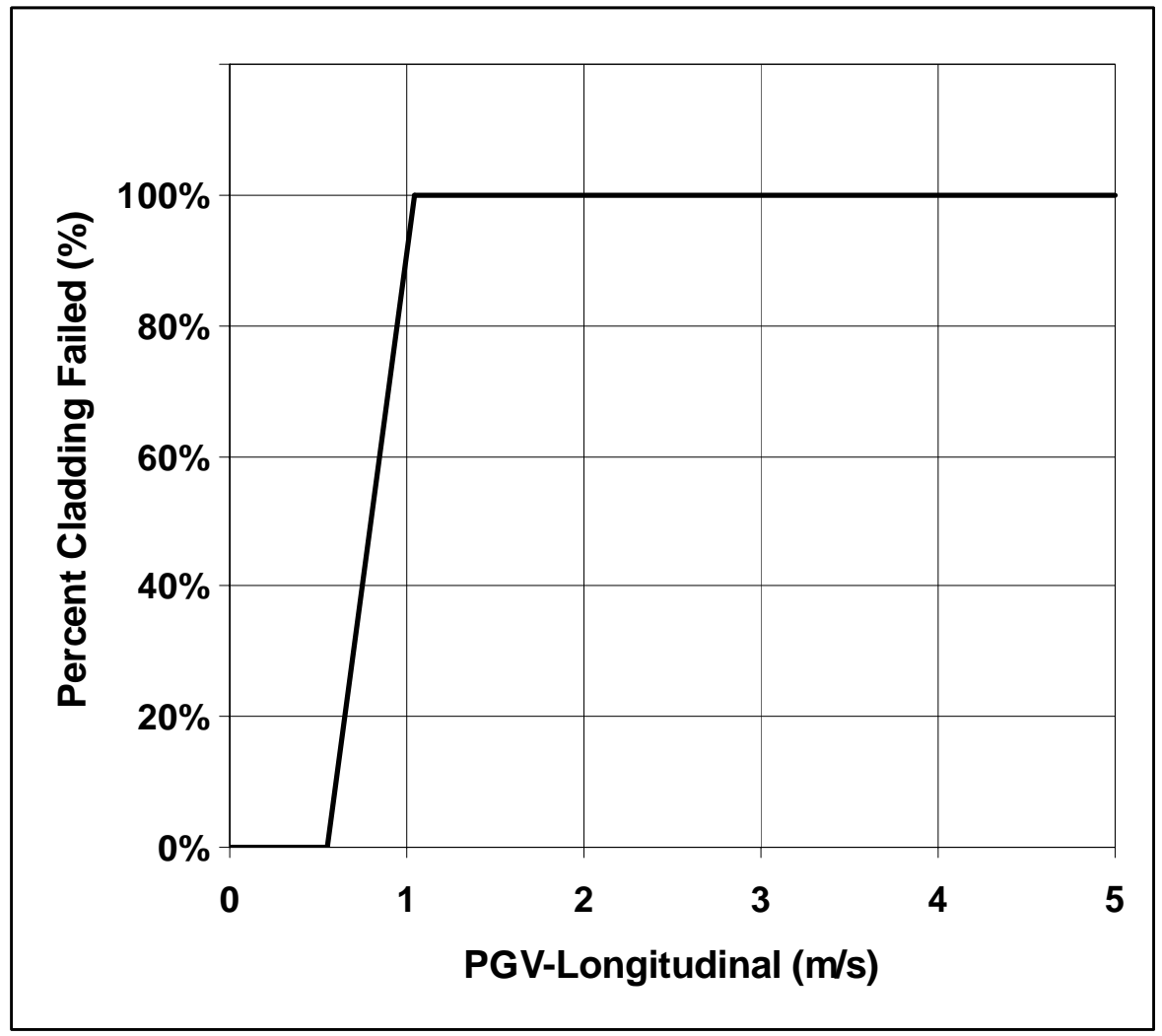

Figure 6.5-24. Damage Abstraction for Cladding Failure Via Perforation

\subsection{RESPONSE TO ROCKFALL}

Rockfall induced by vibratory ground motion has the potential to damage the drip shield and waste package as barriers to flow and transport. Rockfall refers to the large rock blocks that may be ejected from the nonlithophysal zones of the repository during vibratory ground motion. Rockfall also refers to the rubblized material that may surround the drip shield and fill the drifts during catastrophic collapse of drifts in lithophysal zones of the repository. Detailed rockfall analyses have been performed for both of these failure mechanisms under vibratory ground motions (BSC 2004 [DIRS 166107]).

The mechanical response of the drip shield has been analyzed for the impacts from large rock blocks and under the static load from rubblized backfill. Drip shield damage due to rock impact and the potential for waste package damage from rockfall have been considered to determine the damage to the drip shield and waste package from rockfall.

Damage to EBS components from rockfall has not been included in TSPA-LA. Table 6.6-1 summarizes the relevant analyses and key results that support excluding damage from rockfall from the seismic scenario class for TSPA-LA. As an example, consider the impact from a large rock block on the drip shield (first row in Table 6.6-1). This impact may result in deformation and residual stress that exceed the residual stress threshold for accelerated stress corrosion cracking. However, the resulting network of stress corrosion cracks are not a pathway for advective flow and have been screened out of TSPA (BSC 2005 [DIRS 173781], Section 6.2.64 
and Appendix C). The rockfall and structural response calculations for this analysis are discussed in Sections 6.6.1.1 and 6.6.1.2, respectively. The drip shield therefore remains structurally intact and can deflect rockfall and seepage away from the waste package, so rockfall-related damage to EBS components is excluded from the seismic scenario class.

\subsubsection{Drip Shield Damage from Rockfall in the Nonlithophysal Zone}

The potential source of damage to the drip shield in the nonlithophysal zones arises from the large rock blocks that may be shaken loose from the drift walls and fall onto the drip shield in response to vibratory ground motion (BSC 2004 [DIRS 166107], Section 6.3). Large rock blocks have the potential to deform the drip shield, resulting in accelerated stress corrosion cracking in areas that exceed the residual stress threshold for Titanium Grade 7. Large rock blocks also have the potential to collapse the drip shield. However, damage to the drip shield from large rock blocks in the nonlithophysal zones is not included in TSPA-LA because the associated crack network is not a pathway for advective flow (BSC 2005 [DIRS 173781], Section 6.2.64) and because impact by the largest rock block does not collapse the drip shield onto the waste package, as explained in Section 6.6.1.2. The drip shield therefore remains structurally intact and can deflect rockfall and flow away from the waste package.

\subsubsection{Nonlithophysal Rockfall Analyses}

Geologic structure and rock strength define the failure mode in the nonlithophysal rock. The failure mode in these rocks results from stress-induced yield in the intact rock or along joint surfaces, followed by gravity-induced drop of discrete rock blocks that are ejected from the walls of the drift. Analysis of rockfall in the nonlithophysal zone requires ground motion time histories, fracture geometries, and fracture properties as input parameters or boundary conditions for the analyses. To ensure adequate representation of uncertainty and variability in block size and impact energy, 50 realizations are performed for ground motions at the $1.05-\mathrm{m} / \mathrm{s}$ and 2.44-m/s PGV levels and 42 realizations are performed for ground motions at the $5.35-\mathrm{m} / \mathrm{s} \mathrm{PGV}$ level. At each PGV level, the input for the individual rockfall calculations draws from a set of 15 ground motions combined with 105 synthetic fracture patterns. The Drift Degradation Analysis model report (BSC 2004 [DIRS 166107], Section 6.3) provides a detailed description of the nonlithophysal rockfall analyses with the 3DEC computer program.

Based on the results of these analyses, a set of representative blocks and representative impact locations was selected to span the range of block impacts from the 3DEC analyses. The idea behind this approach is to perform a limited set of analyses that span the range of rock sizes, rock velocities, and rock impact points on the drip shield. This limited set of analyses then provides the basis for determining the structural response of the drip shield (1) to the maximum rock block in the nonlithophysal zone, and (2) to the smaller blocks that can be ejected during drift collapse in the lithophysal zone. 
Table 6.6-1. Summary of Rockfall Damage to EBS Component

\begin{tabular}{|c|c|c|c|}
\hline Damage Mechanism & $\begin{array}{l}\text { Relevant Analyses } \\
\text { (Section Ref.) }\end{array}$ & $\begin{array}{l}\text { Key Results } \\
\text { (Section Ref.) }\end{array}$ & $\begin{array}{l}\text { Status in TSPA } \\
\text { (Section Ref.) }\end{array}$ \\
\hline $\begin{array}{l}\text { Impact of rock blocks } \\
\text { in nonlithophysal } \\
\text { zones }\end{array}$ & $\begin{array}{l}\text { - Rockfall analyses with 3DEC } \\
(6.6 .1 .1) \\
\text { - Drip shield structural } \\
\text { response calculations for } \\
\text { representative rock blocks } \\
(6.6 .1 .2)\end{array}$ & $\begin{array}{l}\text { - Drip shield does not } \\
\text { buckle or collapse, even } \\
\text { from impact of the } \\
\text { largest rock block } \\
\text { (6.6.1.2) } \\
\text { - Drip shield does not } \\
\text { contact the waste } \\
\text { package, even for } \\
\text { impact of the largest } \\
\text { rock block (6.6.1.2) }\end{array}$ & $\begin{array}{l}\text { - Drip shield remains } \\
\text { structurally intact and can } \\
\text { deflect rockfall and } \\
\text { seepage away from the } \\
\text { waste package } \\
(6.6 .1 .2)(6.3 .6) \\
\text { - Drip shield damage from } \\
\text { rock blocks excluded from } \\
\text { TSPA }\end{array}$ \\
\hline $\begin{array}{l}\text { Damage from drift } \\
\text { collapse in lithophysal } \\
\text { zones }\end{array}$ & $\begin{array}{l}\text { - Rockfall analyses for static } \\
\text { loads from drift collapse } \\
\text { (6.6.2.1) } \\
\text { - Drip shield structural } \\
\text { response calculations under } \\
\text { static load (6.6.2.2) }\end{array}$ & $\begin{array}{l}\text { - Drift collapse produces } \\
\text { small rock fragments } \\
\text { with little capacity to } \\
\text { damage drip shield } \\
(6.6 .2 .1) \\
\text { - Drip shield does not } \\
\text { buckle or collapse under } \\
\text { static loads (6.6.2.2) } \\
\text { - Drip shield does not } \\
\text { collapse or undergo } \\
\text { excessive deformation } \\
\text { from creep in response } \\
\text { to static loads (6.6.2.2) }\end{array}$ & $\begin{array}{l}\text { - Drip shield remains } \\
\text { structurally intact and can } \\
\text { deflect rockfall away from } \\
\text { the waste package } \\
(6.6 .2 .2) \\
\text { - Drip shield damage under } \\
\text { static load excluded from } \\
\text { TSPA }\end{array}$ \\
\hline $\begin{array}{l}\text { Damage to the waste } \\
\text { package and cladding }\end{array}$ & $\begin{array}{l}\text { - Drip shields do not separate } \\
\text { and can deflect rockfall away } \\
\text { from the waste package } \\
\text { (6.5.5) } \\
\text { - Drip shield structural } \\
\text { response calculations for } \\
\text { degree of separation (6.5.4) } \\
\text { - Rockfall analyses in } \\
\text { lithophysal zones (6.6.2.1) }\end{array}$ & $\begin{array}{l}\text { - Drip shields do not } \\
\text { separate and can deflect } \\
\text { rockfall away from the } \\
\text { waste package (6.5.5) } \\
\text { - Rock fragments in } \\
\text { lithophysal zone } \\
\text { (85 percent of } \\
\text { repository) have little } \\
\text { capacity to damage } \\
\text { waste package (6.6.3) }\end{array}$ & $\begin{array}{l}\text { - Drip shields do not } \\
\text { separate or collapse under } \\
\text { rockfall loads and can } \\
\text { deflect rockfall away from } \\
\text { the waste package (6.5.5) } \\
\text { - Damage to waste package } \\
\text { and cladding from rockfall } \\
\text { excluded from TSPA }\end{array}$ \\
\hline
\end{tabular}

\subsubsection{Structural Response Calculations}

Damage to the drip shield from impact of individual rock blocks is determined by structural response calculations (BSC 2004 [DIRS 168993]), supplemented by the results in (BSC 2005 [DIRS 174052]). The objectives of the initial calculations (BSC 2004 [DIRS 168993]) are to determine the areas on the drip shield where the residual stress exceeds the threshold value (50 percent of yield strength) for Titanium Grade 7 and to determine the potential for buckling and collapse. Six representative rock sizes impact the drip shield from three different angles: vertically downward onto the top of the drip shield, at a $60^{\circ}$ angle (with the horizontal) onto the transition region between the top and side of the drip shield, and into the side wall at a $40^{\circ}$ angle with the horizontal. The block impacts the drip shield edge-on to maximize damage. These calculations incorporate the potential for corrosion to degrade the drip shield by reducing the thickness of the drip shield plates by $2 \mathrm{~mm}$. This thickness reduction is a conservative representation of material loss by general corrosion over the first 10,000 years after repository closure and a reasonable representation of barrier degradation for 20,000 years after repository closure. The 20,000-year period is selected to demonstrate that repository performance remains 
robust well after the first 10,000 years following repository closure. These calculations also evaluate mechanical properties at $150^{\circ} \mathrm{C}$ to represent the potential degradation in mechanical strength if a seismic hazard occurs during the initial thermal pulse after repository closure.

The objectives of the supplemental calculations (BSC 2005 [DIRS 174052]) are to determine permanent deflection of the drip shield for edge-on and corner-on impacts and to determine the associated damaged areas. Six representative rock blocks impact vertically downward on the drip shield in an edge-or or corner-on orientation. These blocks include a 28.29 metric ton (MT) block with the maximum kinetic energy of 706,914 Joules. Other features of the supplemental calculations are similar to the initial calculations, including a reduction in plate thickness by 2 $\mathrm{mm}$ to represent general corrosion and evaluation of material properties at $150^{\circ} \mathrm{C}$.

The initial and supplemental calculations provide a conservative estimate of damaged area on the drip shield from rock block impact. The calculations are conservative because (1) an individual rock block cannot shatter on impact with the drip shield, (2) the residual stress failure criterion for titanium Grade 7 is conservatively set to $50 \%$ of the yield strength to represent the potential for long-term degradation of the material, (4) the potential for creep to reduce the stress intensity driving SCCs through the titanium plates is ignored, and (5) blocks are always oriented so that their center of mass is directly above the point or edge of impact.

A key result from the initial suite of calculations is that the maximum vertical displacement in the drip shield components takes place in the longitudinal stiffener during the vertical impact of the 11.5 MT rock block with a kinetic energy of 348,174 Joules (BSC 2004 [DIRS 168993], Section 6). The maximum peak dynamic displacement is $25.4 \mathrm{~cm}(254 \mathrm{~mm})$ (BSC 2004 [DIRS 168993], Figure II-5). A key result from the supplemental calculations is that the permanent deflection for the 28.29 MT block with the maximum kinetic energy is $0.114 \mathrm{~m}$ and $0.129 \mathrm{~m}$ for edge-on and corner-on impacts, respectively (BSC 2005 [DIRS 174052], Tables 7-5 and 7-6). The drip shield does not buckle or collapse from any of the impacts (BSC 2005 [DIRS 174052], Figures 7-14 to 7-20). In addition, the maximum displacements are less than the minimum clearance, $367.1 \mathrm{~mm}$, between the interior height of the drip shield and the top of any waste package (BSC 2004 [DIRS 168489], Figure 1). It follows that the drip shield does not contact any waste package even for an impact by the rock block with the maximum kinetic energy, thereby preventing rockfall from directly or indirectly contacting the waste package and cladding.

Table 6.6-2 shows the damage results from the initial calculations for the rock blocks generated by ground motions with PGV between $2.44 \mathrm{~m} / \mathrm{s}$ and $5.35 \mathrm{~m} / \mathrm{s}$ (BSC 2005 [DIRS 173303], Tables 2 and 3). The information in Table 6.6-2 provides data on the potential for smaller rock blocks to damage the drip shield, and is useful for the analysis of damage in the lithophysal zones in the next section. 
Table 6.6-2. Damaged Area from Individual Rock Blocks Impacting the Drip Shield

\begin{tabular}{|c|c|c|c|}
\hline \multirow[b]{2}{*}{$\begin{array}{l}\text { Rock Mass and } \\
\text { Kinetic Energy } \\
\text { (MT and Joules) }\end{array}$} & \multicolumn{3}{|c|}{ Damaged area $\left(\mathrm{m}^{2} ;\right.$ and as a \% of Total Drip Shield Surface Area) } \\
\hline & $\begin{array}{l}\text { Rockfall Onto Top } \\
\text { Of Drip Shield } \\
\left(90^{\circ} \text { from horizontal) }\right.\end{array}$ & $\begin{array}{l}\text { Rockfall Onto Drip } \\
\text { Shield Corner } \\
\left(60^{\circ} \text { from horizontal) }\right.\end{array}$ & $\begin{array}{l}\text { Rockfall Onto Drip } \\
\text { Shield Side-Wall } \\
\left(40^{\circ} \text { from horizontal) }\right.\end{array}$ \\
\hline $\begin{array}{c}0.25 \text { MT Rock } \\
(\sim 0 \mathrm{~J})\end{array}$ & $\begin{array}{c}0.0 \\
(0.00 \%) \\
\end{array}$ & $\begin{array}{c}0.0 \\
(0.00 \%) \\
\end{array}$ & $\begin{array}{c}0.0 \\
(0.00 \%) \\
\end{array}$ \\
\hline $\begin{array}{c}0.11 \text { MT Rock } \\
(42 \mathrm{~J})\end{array}$ & $\begin{array}{c}0.0 \\
(0.00 \%) \\
\end{array}$ & $\begin{array}{c}0.0 \\
(0.00 \%) \\
\end{array}$ & $\begin{array}{c}0.0 \\
(0.00 \%) \\
\end{array}$ \\
\hline $\begin{array}{c}0.15 \text { MT Rock } \\
(902 \mathrm{~J})\end{array}$ & $\begin{array}{l}0.0015 \\
(0.00 \%)\end{array}$ & $\begin{array}{c}0.0091 \\
(0.02 \%) \\
\end{array}$ & $\begin{array}{c}0.0 \\
(0.00 \%) \\
\end{array}$ \\
\hline $\begin{array}{c}\text { 3.3 MT Rock } \\
(24712 \mathrm{~J})\end{array}$ & $\begin{array}{c}0.548 \\
(1.43 \%)\end{array}$ & $\begin{array}{c}0.416 \\
(1.09 \%)\end{array}$ & $\begin{array}{c}0.0 \\
(0.00 \%)\end{array}$ \\
\hline $\begin{array}{c}\text { 14.5 MT Rock } \\
(163083 \mathrm{~J})\end{array}$ & $\begin{array}{c}3.508 \\
(9.17 \%) \\
\end{array}$ & $\begin{array}{c}0.612 \\
(1.60 \%)\end{array}$ & $\begin{array}{c}0.079 \\
(0.21 \%)\end{array}$ \\
\hline $\begin{array}{c}\text { 11.5 MT Rock } \\
(348174 \mathrm{~J})\end{array}$ & $\begin{array}{c}4.304 \\
(11.25 \%) \\
\end{array}$ & $\begin{array}{c}2.835 \\
(7.41 \%)\end{array}$ & $\begin{array}{c}1.126 \\
(2.94 \%)\end{array}$ \\
\hline
\end{tabular}

Source: BSC 2005 [DIRS 173303], Tables 2 and 3.

MT = metric ton; $\mathrm{J}=$ joules .

\subsubsection{Drip Shield Damage from Rockfall in the Lithophysal Zone}

Two potential sources of damage to the drip shield have been considered in the lithophysal zone: damage from the individual rock fragments that fall onto the drip shield and the static load on the drip shield from drift collapse. The individual rock fragments are too small to do significant damage to the drip shield and the mean static loads from a collapsed drift are not predicted to collapse the drip shield. Damage to the drip shield from rockfall in the lithophysal zone is not included in the drip shield damage abstraction for TSPA-LA, but is discussed here for completeness.

\subsubsection{Lithophysal Rockfall Analyses}

In the lithophysal zones, the rock mass has very low compressive strength and is permeated with void spaces of varying size. Average joint spacing is less than 1 meter, and at certain locations this spacing is much smaller, on the order of 0.1 meters (BSC 2004 [DIRS 166107], Section 6.1.4.1). The drifts in the lithophysal zone are predicted to collapse into small fragments with particle sizes of centimeters to decimeters (BSC 2004 [DIRS 166107], Section 8.1) under the loads imposed by vibratory ground motions with a PGV of $2.0 \mathrm{~m} / \mathrm{s}$ or greater. The Drift Degradation Analysis model report (BSC 2004 [DIRS 166107] Section 6.4) provides a detailed description of the lithophysal rockfall analyses.

The small fragments from lithophysal failure have little capability to damage the drip shield because the small mass and energy of the individual fragments cannot cause significant permanent deformation of the drip shield, as shown by the top rows of Table 6.6-2. As an example, consider a fragment that is a cube 0.1 -meter (4-inches) on a side. The volume of this fragment is $0.001 \mathrm{~m}^{3}$ and its mass is $2.3 \mathrm{~kg}(0.0023 \mathrm{MT})$, assuming a tuff density of $2,300 \mathrm{~kg} / \mathrm{m}^{3}$. The velocity of this fragment is approximated as $7.7 \mathrm{~m} / \mathrm{s}$ for a 3-meter drop under gravitational acceleration, and the associated kinetic energy is 59 Joules. A comparison of the mass and 
kinetic energy of the 0.1 meter fragment with the second row in Table 6.6-2 indicates that there is no damage from the impact of this fragment on the drip shield.

The probability of large coherent (key) blocks being generated by the collapse process in the lithophysal zones is very low (BSC 2004 [DIRS 166107], Section 6.4.3), so their presence is not considered in this analysis.

\subsubsection{Structural Response to Static Loads}

Drift collapse in the lithophysal zones can impose a static load on the drip shield from the weight of the natural backfill that fills the drifts as a result of the collapse. The structural response of the drip shield to the static rock loads in the lithophysal zones after complete collapse of the emplacement drift have been analyzed for six cases using a discontinuum representation of the host rock (BSC 2004 [DIRS 166107], Section 6.4.2.5 and Figure 6-174). The average pressures on the top, left side, and right side of the drip shield for the 6 cases are $128 \mathrm{kPa}, 42 \mathrm{kPa}$, and $62 \mathrm{kPa}$, respectively. The maximum mean pressures on the top, left side, and right side are $155 \mathrm{kPa}, 70 \mathrm{kPa}$, and $129 \mathrm{kPa}$, respectively. These mean pressures are an average over the individual elements of the finite-element model on the top, left side, or right side of the structure. The peak local pressure on an individual element is $700 \mathrm{kPa}$ (all data from BSC 2004 [DIRS 166107], Section 6.4.2.5). The drip shield is does not buckle or collapse under these loads. To estimate a factor-of-safety for structural stability of the drip shield under quasi-static load, the density of the rubble was progressively increased by $2.5,3$, and 4 times. This approach is appropriate because it increases the vertical and lateral pressures in tandem, without additional assumptions about extreme vertical or lateral loads. The drip shield does not buckle or collapse at density multiplication factors of 2.5 and 3. The drip shield undergoes severe plastic deformation in its support beams at a density multiplication factor of 4 . The conclusion from this discontinuum rockfall analysis is that there is a factor of safety of approximately 3 for the drip shield under static loading (BSC 2004 [DIRS 166107], Section 6.4.2.5).

Titanium is observed to undergo creep under static loads. The long-term creep of the drip shield has therefore been analyzed for the static loading in a collapsed drift (BSC 2005 [DIRS 174715]). The static loading utilizes the six loading cases derived from a discontinuum representation of the collapsed host rock (BSC 2004 [DIRS 166107], Section 6.4.2.5 and Figure 6-174). The creep response of titanium is simulated using a single-component power law whose coefficients are based on curve fits that bound laboratory creep data for titanium samples. The primary data for the curve fits are based on 27-year uniaxial creep tests on commercially pure titanium (Drefahl et al. 1985 [DIRS 174820]). The resulting coefficients in the power law cover a wide range of stress conditions and a temperature of $150^{\circ} \mathrm{C}$, providing a conservative representation of creep for Titanium Grade 7 and Grade 24.

The mechanical coupling between drip shield deformation and the loading from the surrounding natural backfill must be included for realistic structural response calculations. An analysis of the deformability of the natural backfill provides an effective spring constant between the intact emplacement drift wall and the drip shield outer surface (BSC 2005 [DIRS 173172] Attachment IX). This spring constant couples drip shield deformation with the backfill loads by developing a reactive backpressure (i.e., a confinement) that tends to inhibit further creep deformation. 
The creep calculations demonstrate that the drip shield is stable over the 10,000-year period after closure for the six loading cases. The maximum creep displacement after 10,000 years is approximately $5.5 \mathrm{~cm}$, and the maximum creep strain is less than 5 percent, which is well below the tertiary creep rupture strain limit for titanium (BSC 2005 [DIRS 174715], Section 3.2, Assumption 3.2.9). Based on these creep analyses, collapse of the drip shield from creep of titanium is screened out from TSPA for the 10,000-year period after repository closure.

\subsubsection{Damage to the Waste Package and Cladding from Rockfall}

Damage to the waste package and cladding from rockfall has not been included in the abstractions for TSPA-LA. The waste package and cladding are not damaged because the drip shield remains structurally intact for seismic events with a PGV up to $5.35 \mathrm{~m} / \mathrm{s}$, deflecting even the largest rock blocks away from the waste package. The drip shield also does not separate for ground motions with a PGV up to $5.35 \mathrm{~m} / \mathrm{s}$ (Section 6.5.5). It is therefore reasonable to screen out damage to the waste package and cladding from rockfall because the drip shield remains able to deflect rockfall up to the maximum PGV level $(4.07 \mathrm{~m} / \mathrm{s})$ that is considered in the TSPA-LA.

\subsection{RESPONSE TO FAULT DISPLACEMENT}

In addition to inducing severe ground motion/acceleration as discussed in the previous sections, seismic events can also result in fault displacements within the emplacement drifts. Fault displacement could impact key EBS components in two ways:

- Separation between adjacent drip shields could allow a pathway for seepage to contact the waste packages, thereby potentially accelerating corrosion-induced waste package failure.

- Mechanical damage to the waste packages, drip shields, and fuel rod cladding caused directly by the fault displacement.

Potential faulting within the emplacement drifts that has a reasonable likelihood of slipping during the 10,000 years following repository closure generally results in very small displacements associated with the faults. With the exception of the Solitario Canyon fault and the Ghost Dance fault, which are immediately outside the western and eastern boundaries of the emplacement drifts, a fault displacement of greater than $0.1 \mathrm{~cm}$ is associated with a mean annual exceedance frequency of less than $10^{-5}$ per year. For such low-frequency events, there is significant uncertainty and variability in the expected magnitude of the fault displacement developed by the PSHA. Given the lack of precision in the estimated fault displacement magnitudes for very low frequency events, a highly detailed calculation of drip shield and waste package response to such events is not warranted. Rather, the focus is on the potential for the waste package to be pinned when fault displacement is greater than the available clearance around the waste package for unfilled and filled drifts. Thus, the response calculations presented herein are intentionally simplistic and conservative.

For a fault displacement that occurs along an emplacement drift, a sudden discontinuity in the floor and roof of the drift may occur. This would result in one portion of the drift being displaced vertically relative to the adjacent section. Such a discontinuity in the drift axis could cause separation of adjacent drip shields, and if severe enough, could cause shearing of a waste 
package at that location. The discussion in this Section identifies the conditions under which these damage mechanisms could occur.

\subsubsection{Clearance Between EBS Components and the Drift}

To determine the response of the drip shield, waste package and cladding to a fault displacement, consider the layout within the emplacement drift, shown schematically in Figure 6.7-1. The emplacement drift itself is nominally $5,500 \mathrm{~mm}$ in diameter. Within the drift, the steel support beams and associated ballast form a level invert whose top surface is $863.6 \mathrm{~mm}$ above the lowest part of the drift floor (BSC 2004 [DIRS 170074]). Sitting on this invert floor is the waste package emplacement pallet, which raises the waste package off the invert floor. While the actual elevation difference between the invert floor and the bottom of the waste package varies depending on the specific diameter of the waste package, the exact value is not important for this analysis. As indicated in the discussion that follows, this elevation difference is not actually used in the analysis.

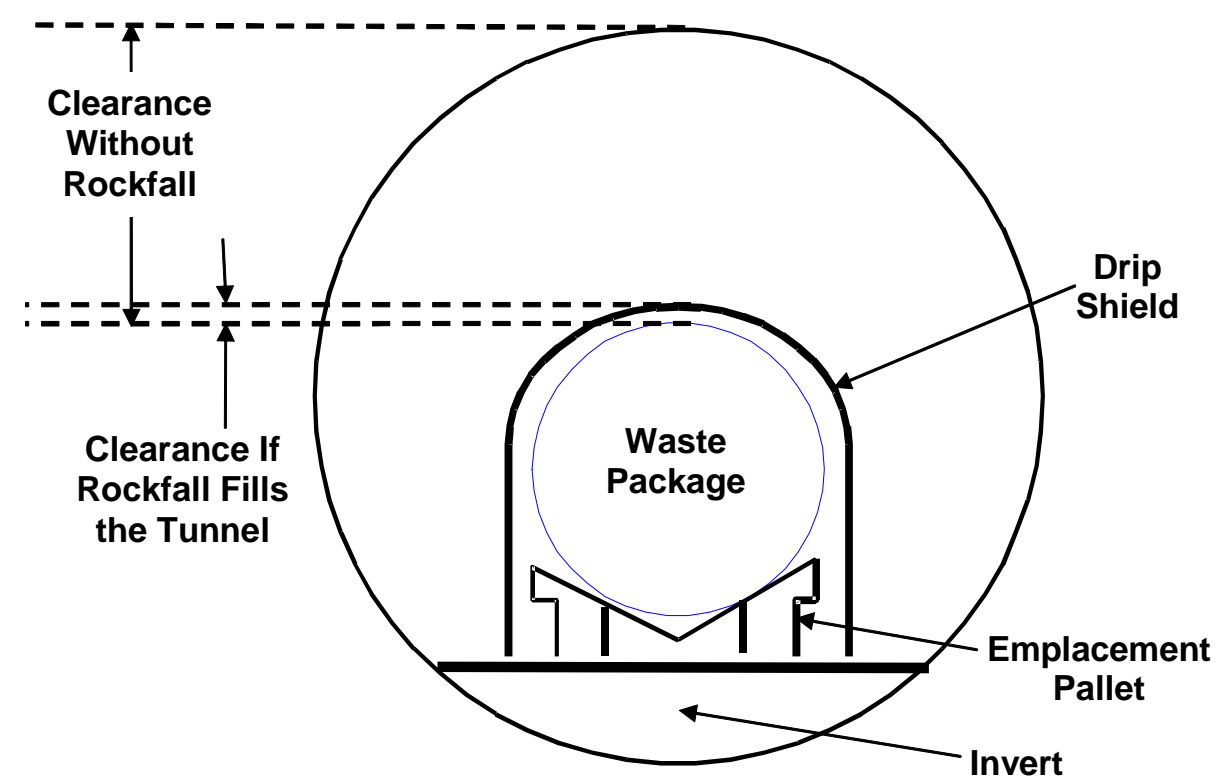

Not to Scale

Figure 6.7-1. Schematic Diagram of EBS Components Illustrating the Clearances for Fault Displacement

The drip shield is also sitting on the invert floor. The drip shield has an external height of 2,885.62 mm (BSC 2005 [DIRS 173303], Table 1), rounded up to 2,886 $\mathrm{mm}$ for this analysis. The internal height of the drip shield, defined as the distance from the invert floor to the lowest point on the underside of the top of the drip shield, is 2,716 mm (BSC 2004 [DIRS 168489], Figure 1). There is then a clearance of $1,751 \mathrm{~mm}$ between the top of the drip shield and the drift roof. A summary of these parameters, which are independent of waste package design, along with the source of the values, is provided in Table 6.7-1. 
Table 6.7-1. Emplacement Drift Configuration Dimensions that are Independent of the Waste Package

\begin{tabular}{|l|c|l|}
\hline \multicolumn{1}{|c|}{ Description } & Value & \multicolumn{1}{c|}{ Source } \\
\hline Emplacement Drift Diameter & $5.5 \mathrm{~m}$ & BSC 2005 [DIRS 173498], Figure 1 \\
\hline Invert Thickness (maximum) & $863.6 \mathrm{~mm}$ & BSC 2004 [DIRS 170074] \\
\hline Drip Shield Height - Exterior & $2885.62 \mathrm{~mm}$ & BSC 2005 [DIRS 173303], Table 1 \\
\hline Drip Shield Height - Interior & $2716 \mathrm{~mm}$ & BSC 2004 [DIRS 168489], Figure 1 \\
\hline Clearance from Top of Drip Shield to Roof of Drift & $1751 \mathrm{~mm}$ & $\begin{array}{l}\text { Calculated: } \\
(5500-863.6-2885.62=1750.78)\end{array}$ \\
\hline
\end{tabular}

Table 6.7-2 summarizes the exterior dimensions of the various waste package designs (BSC 2005 [DIRS 173501], Table 1), rounded to five significant figures. The most important parameter for the analyses presented herein is the outside diameter of the waste package outer barrier, which is seen to vary between $1,294 \mathrm{~mm}$ and 2,045 $\mathrm{mm}$. Also shown in Table 6.7-2 is the calculated clearance between the top of the waste package and the underside of the drip shield in the undisturbed state, without the pallet. This clearance is defined as the interior height of the drip shield less the outside diameter of the waste package outer barrier. The elevation of the package above the invert is not included in calculating the clearance, as explained below. This clearance varies between $671 \mathrm{~mm}$ and $1,422 \mathrm{~mm}$, depending on waste package type. Table 6.7-2 also shows the clearance between the top of the waste package and underside of the drip shield for selected packages with the pallet in place. The presence of the pallet reduces the clearance by $270.9 \mathrm{~mm}$ to $303.9 \mathrm{~mm}$.

Table 6.7-2. Waste Package Dimensions and Clearance Between Drip Shield and Waste Package

\begin{tabular}{|c|c|c|c|c|c|}
\hline Package Type & $\begin{array}{c}\text { Outside } \\
\text { Diameter of } \\
\text { Waste } \\
\text { Package } \\
\text { Outer } \\
\text { Barrier } \\
\text { (mm) }\end{array}$ & $\begin{array}{c}\text { Nominal } \\
\text { Length } \\
(\mathrm{mm})\end{array}$ & $\begin{array}{c}\text { Clearance } \\
\text { Without } \\
\text { Pallet } \\
(\mathrm{mm})\end{array}$ & $\begin{array}{c}\text { Clearance } \\
\text { With } \\
\text { Pallet } \\
(\mathrm{mm})\end{array}$ & $\begin{array}{c}\text { Difference in } \\
\text { Clearances } \\
(\mathrm{mm})\end{array}$ \\
\hline 44-BWR & 1675.1 & 5024.4 & 1041 & 765.2 & 275.8 \\
\hline 24-BWR & 1294.1 & 5024.4 & 1422 & - & - \\
\hline 21-PWR & 1637.0 & 5024.4 & 1079 & 806.2 & 272.8 \\
\hline 12-PWR & 1313.2 & 5560.4 & 1403 & 1132.1 & 270.9 \\
\hline Naval-Long & 1863.7 & 5837.4 & 852 & 562.1 & 289.9 \\
\hline Naval-Short & 1863.7 & 5202.2 & 852 & 562.1 & 289.9 \\
\hline $\begin{array}{l}\text { 5-DHLW/DOE Spent } \\
\text { Nuclear Fuel -Short }\end{array}$ & 2044.7 & 3452.8 & 671 & 367.1 & 303.9 \\
\hline $\begin{array}{l}\text { 5-DHLW/DOE Spent } \\
\text { Nuclear Fuel -Long }\end{array}$ & 2044.7 & 5059.4 & 671 & 367.1 & 303.9 \\
\hline 2-MCO/2-DHLW & 1749.4 & 5059.4 & 967 & - & - \\
\hline
\end{tabular}

Source: BSC 2005 [DIRS 173501], Table 1 for nominal length; outside diameter of outer barrier defined by drawings identified in BSC 2005 [DIRS 173501], Table 1; clearance with pallet based on BSC 2004 [DIRS 170074].

NOTES: Clearance without pallet is calculated as the interior height of the drip shield minus the outside diameter of the waste package outer barrier, rounded to 4 significant digits. Difference in Clearances = Clearance Without Pallet - Clearance With Pallet.

$\mathrm{BWR}=$ boiling water reactor; DHLW = defense high-level radioactive waste; PWR = pressurized water reactor; $\mathrm{MCO}=$ multicanister overpack. 
The clearance between the top of the drip shield and the roof of the drift (Table 6.7-1) and the clearance between the top of the waste package and the bottom of the drip shield (Table 6.7-2) are measures of how much fault displacement could occur before the waste packages are potentially degraded through a shearing mechanism. At the start of a large seismic event, the clearance above the drip shield will be unimpeded because the drifts are expected to be unfilled before the seismic event and because a fault displacement can occur in a very short time in comparison to the ground motion. If a drift collapses from a large seismic event, the available clearance above the drip shield will be a function of the rubble filling a collapsed drift. Once a drift collapses, the space surrounding the drip shield will be partly or completely filled with loosely packed rock fragments. This loosely packed material still allows significant motion of the drip shield during the fault displacement, as explained below. For those drifts in the lower lithophysal zone of the repository, drift collapse is calculated to occur for ground motions with PGV values greater than or equal to $2.0 \mathrm{~m} / \mathrm{s}$ (BSC 2004 [DIRS 166107], Section 6.4.2.2.2).

The actual response of the EBS components to a fault displacement scenario is complicated. As a conservative simplification, the fault displacement is analyzed considering:

- The fault is perpendicular to the drift axis with the displacement being purely vertical

- The fault displacement occurs at a discrete plane, creating a "knife-edge" discontinuity.

Vertical faulting is consistent with the faults investigated at the site. As part of the exploratory studies of the site, the Enhanced Characterization of the Repository Block (ECRB) Cross-Drift was dug through a representative part of the repository footprint to obtain visual evidence of both rock stratigraphy and faulting. The results of this investigation (Mongano et al. 1999 [DIRS 149850], pp. 51 to 59) found evidence for four faults along the length of the ECRB Cross-Drift between the Ghost Dance and Solitario Canyon faults that bound the location of the emplacement drifts. One of these was the Sundance fault, the other three are unnamed faults that showed between one and a few meters of cumulative faulting from multiple seismic events. In each of these cases, the measured displacements were characterized as vertical, which is consistent with the assumption made herein. By treating the faults as perpendicular to the drift axis, no credit is taken for sideways movement of the waste packages that could lessen the degree to which fault displacement could cause damage.

An actual fault zone has a finite width over which the displacement could occur. However, based on the observations reported in the investigation of the ECRB Cross-Drift (Mongano et al. 1999 [DIRS 149850], pp. 51 to 59), the width of the fault disturbed zone varied between just under a meter to a little over 2 meters. Thus, the width of the zone is less than the length of any waste package type. If during a single seismic faulting event, the total displacement were to be distributed over a sufficiently wide zone, a single waste package could potentially see less than the total fault displacement, resulting in a decreased probability of failure. By treating fault displacement as a sharp discontinuity in the drift floor/roof, the likelihood of damage to the waste package is increased. Thus, the overall treatment is conservative.

A sudden discontinuity in the drift floor would tend to raise one end of a drip shield and waste package. However, the other EBS components, specifically the invert and emplacement pallet, would also be affected. A significant amount of the invert ballast from the elevated portion of the drift is expected to fall into the lower drift segment. In addition, the steel supports in the 
invert and the emplacement pallet are expected to collapse at the plane of displacement, further degrading the integrity of the invert. Movement along a sudden discontinuity will also affect the rubble surrounding the drip shield after drift collapse. The rubble is a loosely packed material with a typical porosity in the 20 percent to 30 percent range. With this free space, the rubble has substantial movement in the plane of discontinuity and longitudinally along the drift axis during the fault displacement. The movement of the rubble will allow the drip shield to move with the fault displacement, rather than being rigidly pinned to the invert. In this situation, the effective clearance around the drip shield is expected to be significantly larger than space between the top of the waste package and bottom of the drip shield.

The exact details of these events are difficult to predict. For example, the timing of the fault displacement versus drift collapse is highly uncertain, so the full clearance between the top of the drip shield and the roof of the drift may not be available. On the other hand, the potential for substantial movement of rubble after drift collapse has been confirmed in ground motion analyses at the 2.44-m/s PGV level (BSC 2004 [DIRS 166107], Section 6.4.2.5.3). These simulations demonstrate that the rubble particles undergo large dynamic motion in response to displacements of the drift walls, similar to what would occur during a vertical fault displacement. It follows that the clearance between the top of the drip shield and the roof of the drift will be partly available, but the exact value is difficult to quantify.

As a simplification, the approximation is made that the clearance between the top of the waste package and the bottom of the drip shield is determined without the pallet. This is a reasonable approximation because the clearance between the top of the drip shield and the roof of the drift, $1751 \mathrm{~mm}$ (Table 6.7-1), is more than five times greater than the differences in clearance with or without the pallet, $270.9 \mathrm{~mm}$ to $303.9 \mathrm{~mm}$ (Table 6.7-2). In other words, the height of rubble above the drip shield is much greater than the difference in clearance due to the pallet. Since the porosity and dynamic motion of the rubble allows the drip shield to displace horizontally and vertically during the ground motion, the difference in clearance due to the pallet can be accommodated by drip shield displacements that are a small percentage of the height of the rubble. It follows that the potential for upward displacements of the drip shield into the large rubble-filled space between the top of drip shield and roof of the drift allows for vertical motions that can exceed the maximum difference $(303.9-\mathrm{mm})$ in clearance due to the pallet. It is then reasonable to exclude the presence of the pallet in defining clearances between components because of the potential for upward displacement of the drip shield. No credit is taken for any shifting of the ballast in the invert.

The maximum allowable displacement of the waste package before it is pinned also depends on the condition and dynamic response of the drift after the seismic event. In those cases where drift collapse does not occur from the ground motion or from gradual degradation of the host rock, then the allowable waste package displacement without damage is much greater than the free height under the drip shield. For example, upward displacement of the waste package could cause the drip shield to lift since there is no drift debris to hold it in place. In those cases where the drift collapses, the loosely packed rubble can still allow substantial dynamic movement of the drip shield. The maximum allowable fault displacement prior to waste package damage is determined without including the pallet, as explained above. The calculated clearances are summarized in Table 6.7-3. 
The values in Table 6.7-3 represent the failure criteria for waste packages and drip shields under fault displacement. Fault displacement in excess of these values is conservatively considered to fail the waste package, the overlying drip shield, and the internal cladding through direct shearing.

Failure of the drip shields could also occur without direct waste package damage. One mechanism for this is lifting of one drip shield relative to its neighbor, thereby creating a pathway for ingress of seepage water onto the waste package. However, drip shield failure without waste package damage will generally have low consequence for performance assessment, so it will be screened out from TSPA-LA based on low consequence and is not considered further herein.

Table 6.7-3. Maximum Allowable Displacement Before Waste Package is Pinned

\begin{tabular}{|l|c|c|}
\hline \multicolumn{1}{|c|}{ Package Type } & $\begin{array}{c}\text { Maximum Allowable Displacement } \\
\text { With Drift Collapse (mm) }\end{array}$ & $\begin{array}{c}\text { Maximum Allowable Displacement } \\
\text { Without Drift Collapse (mm) }\end{array}$ \\
\hline 44-BWR & 1041 & 2792 \\
\hline 24-BWR & 1422 & 3173 \\
\hline 21-PWR & 1079 & 2830 \\
\hline 12-PWR & 1403 & 3154 \\
\hline Naval-Long & 852 & 2603 \\
\hline Naval-Short & 852 & 2603 \\
\hline 5-DHLW/DOE Spent & & 2422 \\
Nuclear Fuel -Short & 671 & 2422 \\
\hline 5-DHLW/DOE Spent & 671 & 2717 \\
Nuclear Fuel -Long & 967 & \\
\hline 2-MCO/2-DHLW & & \\
\hline
\end{tabular}

NOTES: Maximum allowable displacement with drift collapse $=$ clearance without pallet in Table 6.7-2. Maximum allowable displacement without drift collapse is given by the interior height of the drip shield $(2716 \mathrm{~mm})$ minus the outer diameter of the waste package (Table 6.7-2) plus $1750.78 \mathrm{~mm}$, rounded to 4 significant digits.

BWR = boiling water reactor; DHLW = defense high-level radioactive waste; $\mathrm{PWR}=$ pressurized water reactor; $\mathrm{MCO}=$ multicanister overpack

\subsubsection{Faults Intersecting Emplacement Drifts}

The location, frequency, and magnitude of potential fault displacements within the emplacement drift footprint must be analyzed to determine the potential impacts of fault displacement on the Yucca Mountain repository. Such fault displacements could occur at known faults that intersect the emplacement drifts (based on surface mapping), or at other locations within the repository.

\subsubsection{Location of Known Faults}

Information on known faults intersecting the emplacement drifts is obtained from three sources. The traces for the Sever Wash fault, Drill Hole Wash fault, Pagany Wash fault, and the western splay off the main Ghost Dance fault relative to the repository are provided in BSC (2004 [DIRS 168180], Figure 4). The intersection of these traces with individual emplacement drifts is defined in BSC (2004 [DIRS 168180], Table 9); the western splay off the main Ghost Dance is denoted as the West Ghost Dance fault in Figure 4 and Table 9 of BSC 2004 [DIRS 168180]. The trace of the Sundance fault relative to the emplacement drifts is provided in the Geologic 
Framework Model (DTN: MO0012MWDGFM02.002 [DIRS 153777]). Lastly, the location of emplacement drifts relative to the geologic units is defined in by the Geologic Framework Model (DTN: MO0012MWDGFM02.002 [DIRS 153777]). From these three sources of information, the intersections of known faults with specific drifts and the local rock type (lithophysal or nonlithophysal) can be determined.

This information is summarized in Table 6.7-4, where drifts are identified by panel number and drift number, plus a designation for east or west when appropriate (see BSC 2004 [DIRS 172801], Figure 1, for the drift nomenclature). As can be seen from Table 6.7-4, there are 22 locations in the lithophysal zones where a known fault intersects an emplacement drift, plus another eight locations where such an intersection occurs in the nonlithophysal zones. Intersections where two rock types occur at an intersection are conservatively assigned to the lithophysal category because this is most restrictive in terms of clearance for the waste package. This information, along with the frequency of a fault displacement of sufficient magnitude to cause waste package failure at these locations, can be used to determine the frequency and consequence of waste package failure.

The potential drift intersections with the western splay off the main Ghost Dance fault are not included in Table 6.7-4 and are not included in the fault displacement damage abstraction for TSPA-LA. The western splay off the main Ghost Dance fault intersects drifts 2-17 through 2-27, at the southernmost end of panel 2 (BSC 2004 [DIRS 168180], Figure 4 and Table 9, denoted as the West Ghost Dance fault). Drifts 2-18 through 2-27 lie in a contingency area for repository development (BSC 2004 [DIRS 168370], Figure 2). This area has been designated as a contingency area because it is in the vicinity of the intensely fractured zone between Stations 42+00 and 51+50 of the ESF Main Drift (Albin et al. 1997 [DIRS 101367], discussion of the Third Domain on pages 69-72). Special mining procedures may be required for drift excavation and ground support in this area because of the ground conditions, and the utility of this emplacement area will be determined during repository development. Given the uncertainties in the use of the contingency area at this time, it is reasonable to exclude it from consideration in TSPA-LA.

\subsubsection{Faulting Other Than at Known Faults}

During a major seismic event, faulting could occur not only coincident with the location of well characterized, known faults, but also elsewhere in the repository. In characterizing the potential magnitude of fault displacement elsewhere in the repository (Section 6.7.3), rock conditions ranging from intact rock to the presence of existing small faults with about 2 meters of cumulative offset are considered. As is discussed in Section 6.7.3, the frequency of significant fault displacement $(>10 \mathrm{~cm})$ is low, even for the most extreme events with exceedance frequency of $10^{-8}$ per year, except where an existing fault is located with cumulative offset of about 2 meters. However, the exact location and number of such small faults is not known because they are not readily identified through surface mapping. Thus, it is necessary to estimate the density of such small faults based on either existing site data or natural analogues. 
Table 6.7-4. Intersections of Known Faults with Emplacement Drifts

\begin{tabular}{|l|l|l|}
\hline Fault Designator & $\begin{array}{c}\text { Drift Intersections in } \\
\text { Lithophysal } † \text { Zones }\end{array}$ & $\begin{array}{c}\text { Drift Intersections in } \\
\text { Nonlithophysal }{ }^{\mathrm{a}} \text { Zones }\end{array}$ \\
\hline Sundance fault & $1-6$ & $1-8$ \\
\hline & $1-7$ & $2-1$ \\
\hline Drill Hole Wash fault & $4-1$ & $3-10 \mathrm{E}$ \\
\hline & $4-2$ & $3-11 \mathrm{E}$ \\
\hline & $3-4 \mathrm{~W}$ & $3-12 \mathrm{E}$ \\
\hline & $3-5 \mathrm{~W}$ & - \\
\hline & $3-6 \mathrm{~W}$ & - \\
\hline & $3-7 \mathrm{~W}$ & - \\
\hline & $3-8 \mathrm{~W}$ & - \\
\hline & $3-9 \mathrm{~W}$ & - \\
\hline & $3-13 \mathrm{E}$ & \\
\hline & $3-14 \mathrm{E}$ & - \\
\hline & $3-15 \mathrm{E}$ & - \\
\hline & $3-16 \mathrm{E}$ & - \\
\hline & $3-17 \mathrm{E}$ & - \\
\hline Pagany Wash fault & $3-1 \mathrm{~W}$ & $3-5 \mathrm{E}$ \\
\hline & $3-1 \mathrm{E}$ & $3-6 \mathrm{E}$ \\
\hline & $3-2 \mathrm{E}$ & $3-7 \mathrm{E}$ \\
\hline & $3-3 \mathrm{E}$ & - \\
\hline & $3-4 \mathrm{E}$ & - \\
\hline Sever Wash fault & $3-2 \mathrm{E}$ & - \\
\hline & $3-3 \mathrm{E}$ & - \\
\hline
\end{tabular}

a Lithophysal zones are the RHHtop (top of Tptpul) and Tptpll strata (BSC 2004 [DIRS 168370], Table 8); Nonlithophysal zones are the Tptpmn and Tptpln strata (BSC 2004 [DIRS 168370], Table 8).

Sources: BSC 2004 [DIRS 168180], Table 9 for drift intersections with Sever Wash, Drill Hole Wash, and Pagany Wash faults.

DTN: MO0012MWDGFM02.002 [DIRS 153777] for drift intersections with Sundance fault and for locations of geologic units relative to fault traces and emplacement drifts. See Table 4-1 for the relevant Earthvision files.

BSC 2004 [DIRS 172801], Figure 1 for panel and drift nomenclature. 
One means of quantifying the likelihood of such smaller faults is through use of the data obtained from the characterization of the ECRB Cross-Drift (Mongano et al. 1999 [DIRS 149850], pp. 51 to 59). The ECRB Cross-Drift extends through the repository footprint near its north/south midpoint and spans the approximate east/west extent of the repository. Over the length of this drift, three small faults were identified with cumulative displacement of between about one meter and a few meters. This is thought to be generally representative of the density of small faults throughout the repository, so one can make an estimate of the number of such small faults that might intersect the emplacement drifts. In reviewing the repository layout (BSC 2004 [DIRS 172801], Figure 1), it can be seen that there are 57 emplacement drifts that span the entire north to south extent of the repository (designated 3-1 W through 3-22 W, 1-1 through 1-8, and 2-1 through 2-27). While in several cases these drifts are much shorter than the ECRB Cross-Drift, for abstraction purposes the three unknown small faults intersect the repository footprint along its entire north to south extent. Emplacement drifts 2-18 through 2-27 lie in the contingency area (BSC 2004 [DIRS 168370], Figure 2), in the vicinity of an intensely fractured zone (Albin et al. 1997 [DIRS 101367], discussion of the Third Domain on pages 69-2), and their development and use in the repository is uncertain at this time. Without drifts 2-18 through 2-27, there are a total of 47 drifts and 141 locations (47 times 3 ) where small faults have the potential to intersect the emplacement drifts.

Since the exact location of these potential faults is unknown, one cannot determine with certainty whether they would intersect the emplacement drifts in the lithophysal zones or not. To estimate the fraction of intersections corresponding to lithophysal zones, we use the fact that the estimated fraction of the overall repository in the lithophysal zone is 0.85 , based on the emplacement areas in the upper lithophysal zone, Tptpul, and in the lower lithophysal zone, Tptpl1 ${ }^{11}$. This fractional area is applied to the 141 small fault intersections to get a probability-weighted distribution of fault intersections versus rock stratigraphy. The result is 119.85 small fault intersections with drifts in lithophysal zones and 21.15 small fault intersections with drifts in nonlithophysal zones.

\subsubsection{Fault Displacement Hazards}

Magnitudes of fault displacement along two of the known faults (Sundance and Drill Hole Wash) as a function of probability are obtained from Probabilistic Seismic Hazard Analyses for Fault Displacement and Vibratory Ground Motion at Yucca Mountain, Nevada (CRWMS M\&O 1998 [DIRS 103731]; DTN: MO0401MWDRPSHA.000 [DIRS 166962]). In Section 8 of that document, the DOE has developed fault displacement hazard curves for fifteen faulting conditions mapped within the immediate vicinity of Yucca Mountain. Mean fault displacement hazard curves are used in the following analyses. The faulting conditions relevant to this abstraction are as follows:

- Site 2 - Solitario Canyon fault

- Site 3 - Drill Hole Wash fault

- Site 4 - Ghost Dance fault

11 The fraction of the repository in the Tptpul and Tptpll $=\left(224,398 \mathrm{~m}^{2}+4,013,268 \mathrm{~m}^{2}\right) /\left(4,983,152 \mathrm{~m}^{2}\right)=0.85$, based on the data in BSC (2004 [DIRS 168370], Table 8). 
- Site 5 - Sundance fault

- Site 7 - A generic location within the repository, approximately 100 meters east of the Solitario Canyon fault. The ground conditions at the generic location include intact rock (7d), a hypothetical fracture with no cumulative displacement (7c), a hypothetical shear with $10 \mathrm{~cm}$ of offset (7b), and a hypothetical small fault with 2 meter offset (7a).

- Site 8 - A generic location within the repository, midway between the Solitario Canyon fault and the Ghost Dance fault. The ground conditions at the generic location include intact rock (8d), a hypothetical fracture with no cumulative displacement (8c), a hypothetical shear with $10 \mathrm{~cm}$ of offset (8b), and a hypothetical small fault with 2 meter offset (8a).

Four known faults intersect the emplacement areas of the repository. These four faults are the Drill Hole Wash fault, the Sundance fault, the Pagany Wash fault, and the Sever Wash fault. It is assumed that displacements on the Pagany Wash and Sever Wash faults are identical to those on the Drill Hole Wash fault (Assumption 5.1).

Generic locations identified as Site 7 and Site 8 apply throughout the repository. Locations 7 a and/or 8a correspond to small hypothetical faults with about 2 meter offset. There are 141 intersections of these small faults with the emplacement drifts, based on the estimate in Section 6.7.2.2.

Table 6.7-5 provides the displacement values from the mean hazard curves as a function of the mean annual exceedance frequency (or probability) (DTN: MO0401MWDRPSHA.000 [DIRS 166962], data files associated with sites 2, 3, 4, 5, 7a-7d and 8a-8c are identified in Table 4-1 of this report). The first and third faults (Solitario Canyon and Ghost Dance Faults) in Table 6.7-5 are adjacent to the repository block and are not considered further because no waste packages lie on these faults. Locations 7 and 8 have essentially the same estimated hazard curves and fault displacements relative to the accuracy of the results in Probabilistic Seismic Hazard Analyses for Fault Displacement and Vibratory Ground Motion at Yucca Mountain, Nevada (CRWMS M\&O 1998 [DIRS 103731]; DTN: MO0401MWDRPSHA.000 [DIRS 166962]). Thus, this analysis does not distinguish between Sites 7a and 8a for estimating the consequences to waste packages that lie on these faults. 
Table 6.7-5. Fault Displacement from Mean Hazard Curves

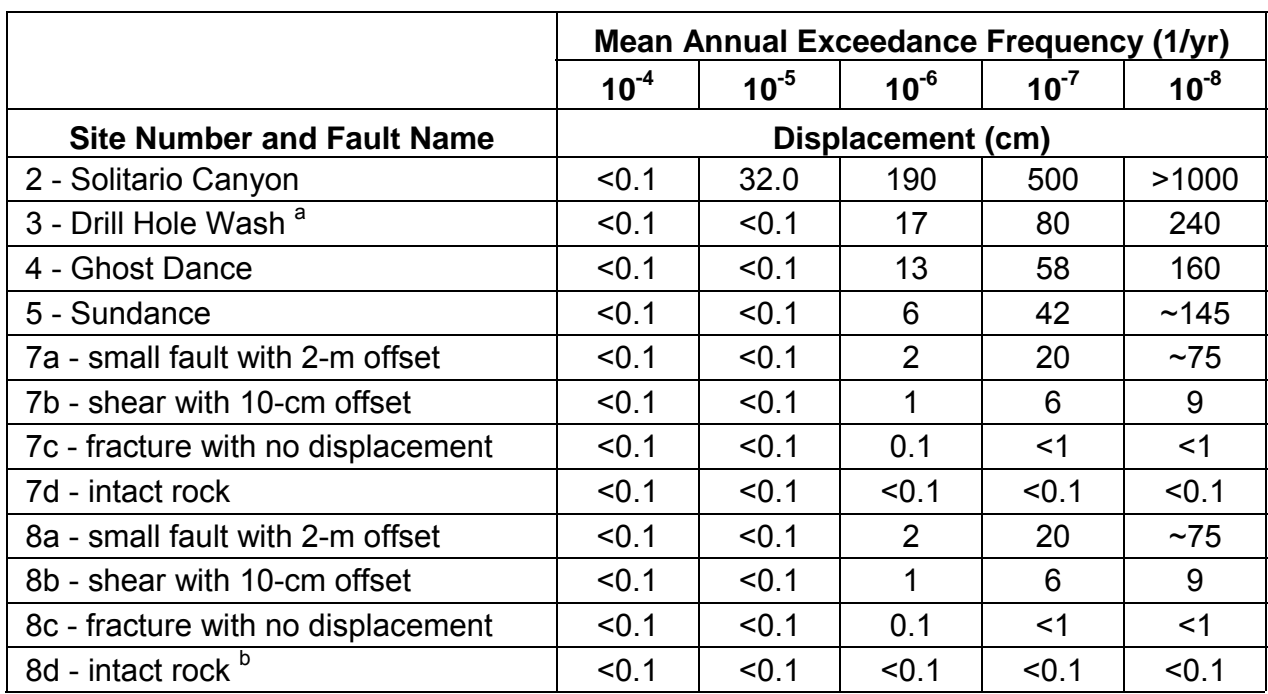

DTN: MO0401MWDRPSHA.000 [DIRS 166962]; data files associated with sites 2, 3, 4 , $5,7 a-7 d$ and $8 a-8 c$ are listed in Table 4-1 of this report. Displacements are calculated in the worksheet "Table 6.7-5 Calculations" in the file Appendix E Rev02.xls. This file is included on the CD in Appendix G.

${ }^{a}$ Also representative of Pagany Wash and Sever Wash faults.

b Data for Site 8d are based on the observation that the fault displacements for Sites 7a, $7 \mathrm{~b}$, and $7 \mathrm{c}$ are essentially identical with the fault displacements for Sites $8 \mathrm{a}, 8 \mathrm{~b}$, and $8 \mathrm{c}$, respectively. In this situation, the fault displacements at Site $8 \mathrm{~d}$ are anticipated to be very similar to the fault displacements at Site $7 \mathrm{~d}$ considering that both generic locations involve intact rock within the repository block. This observation is corroborated by information in CRWMS M\&O (1998 [DIRS 103731] Section 8.2.1, first paragraph), which indicates that displacements at Site $8 \mathrm{~d}$ are below $0.1 \mathrm{~cm}$ down to $10^{-8}$ per year annual exceedance frequency.

\subsubsection{Consequence for the Waste Packages}

A comparison of Table 6.7-5 with Table 6.7-3 shows that no waste package would be damaged by even the most extreme events with exceedance frequency of $10^{-8}$ per year at locations $7 \mathrm{~b}, 7 \mathrm{c}$, $7 \mathrm{~d}, 8 \mathrm{~b}, 8 \mathrm{c}$, and 8d. The waste packages will survive these events because the maximum displacement at these sites, $9 \mathrm{~cm}(90 \mathrm{~mm})$, is less than the available clearances in Table 6.7-3. However, several of the waste package designs could potentially fail due to fault displacement for hazards near the $10^{-8}$ per year level if they are directly over one of the four known faults (Drill Hole Wash, Sundance, Pagany Wash, and Sever Wash) intersecting the emplacement drifts. Further, the defense high-level radioactive waste (DHLW) waste packages could potentially fail when placed over the small hypothetical faults at Sites 7a and 8a. Thus, the frequency of waste package failure at a given fault location is a function of the clearance for the specific type of waste package emplaced there.

Waste package distribution by type is available in the design basis inventory (BSC 2005 [DIRS 173501], Table 15). This inventory is repeated in Table 6.7-6, along with the waste package dimensions. IED WASTE PACKAGE CONFIGURATION (BSC 2005 [DIRS 173501], Table 1), the source document for the waste package dimensions, does not provide information for the 5-DHLW Long/1 DOE Spent Nuclear Fuel - Short or the 5-DHLW Long Only waste package configurations. This is because these two configurations use the same waste package as 
the 5-DHLW Long/1 DOE Spent Nuclear Fuel - Long configuration with different assemblies loaded. Thus, the waste package exterior dimensions are the same for these three configurations.

Table 6.7-6. Design Basis Waste Package Dimensions and Inventory

\begin{tabular}{|l|c|c|c|}
\hline \multicolumn{1}{|c|}{ Waste Package Configuration } & $\begin{array}{c}\text { Waste Package } \\
\text { Length (m) }\end{array}$ & $\begin{array}{c}\text { Waste Package } \\
\text { Diameter (m) }\end{array}$ & Nominal Quantity \\
\hline 21-PWR with Absorber Plates & 5.0244 & 1.6370 & 4299 \\
\hline 21-PWR with Control Rods & 5.0244 & 1.6370 & 163 \\
\hline 12-PWR with Absorber Plates - Long & 5.5604 & 1.3132 & 2831 \\
\hline 44-BWR with Absorber Plates & 5.0244 & 1.6751 & 1147 \\
\hline 24-BWR with Absorber Plates & 5.0244 & 1.2941 & 1406 \\
\hline $\begin{array}{l}\text { 5-DHLW Short/1 DOE Spent Nuclear } \\
\text { Fuel - Short }\end{array}$ & 3.4528 & 2.0447 & 31 \\
\hline $\begin{array}{l}\text { 5-DHLW Long/1 DOE Spent Nuclear } \\
\text { Fuel - Long }\end{array}$ & 5.0594 & 2.0447 & 679 \\
\hline $\begin{array}{l}\text { 5-DHLW Long/1 DOE Spent Nuclear } \\
\text { Fuel - Short }\end{array}$ & 5.0594 & 2.0447 & 149 \\
\hline 5 HLW Long Only & 5.0594 & 2.0447 & 144 \\
\hline 2-MCO/2-HLW & 5.0594 & 1.7494 & 156 \\
\hline Naval-Short & 5.2022 & 1.8637 & 1.8637 \\
\hline Naval-Long & 5.8374 & & \\
\hline
\end{tabular}

Sources: BSC 2005 [DIRS 173501], Table 1 for nominal length; outside diameter of outer barrier defined by drawings referenced in BSC 2005 [DIRS 173501], Table 1.

BSC 2005 [DIRS 173501], Table 13 for nominal quantity.

NOTES: The diameter of the HLW packages is taken to be that of the DHLW packages in Table 6.7-2.

The length of the DHLW Short package is taken to be that of the 5-DHLW/DOE Spent Nuclear Fuel - Short package in Table 6.7-2.

The length of the DHLW Long and HLW Long packages is taken to be that of the 5-DHLW/DOE Spent Nuclear Fuel - Long package in Table 6.7-2.

$\mathrm{BWR}=$ boiling water reactor; $\mathrm{DHLW}=$ defense high-level radioactive waste; $\mathrm{PWR}=$ pressurized water reactor; $\mathrm{MCO}=$ multicanister overpack

To simplify the analysis, the inventory of waste packages is split into four groups. Waste packages of similar design (similar waste type) are grouped together, and the maximum diameter for the waste package types in each group is conservatively assigned to the group. These groupings are chosen to facilitate consequence assessment for the waste package groupings in TSPA-LA. The four groupings are as follows.

- PWR: includes 21-PWR with absorber plates, 21-PWR with control rods, and the 12-PWR Long with absorber plates.

- BWR: includes 44-BWR with absorber plates and 24-BWR with absorber plates. 
- Naval: includes Naval-Long and Naval-Short.

- HLW: includes 5-DHLW/1 DOE Spent Nuclear Fuel-Short, 5-DHLW/1 DOE Spent Nuclear Fuel-Long, and all other high-level radioactive waste (HLW) designs.

The waste package designs in bold letters are the ones with the largest diameter in the group, and thus are chosen to represent the diameter for all packages in that group. While the inclusion of the 12-PWR design with the PWR group, the 24-BWR design with the BWR group, and the 2-multicanister overpack/2-DHLW design with the HLW group conservatively accounts for the likelihood of failure for those waste package designs (by overestimating diameter), the impact of this approximation is small because in each case the number of such packages is small relative to the total number of packages in the group.

The percentage of the inventory of the waste packages for each group is calculated based on the total length of that waste package type versus the total length of all emplaced waste packages. Length is the appropriate parameter here because it more accurately represents the probability that a waste package is directly on a fault. These results are shown in Table 6.7-7. The average length per package type is shown for information only. It is used to calculate the fraction of waste packages by waste package type.

Table 6.7-7. Parameters for Simplified Groups of Waste Packages

\begin{tabular}{|c|c|c|c|c|c|c|}
\hline $\begin{array}{l}\text { Waste } \\
\text { Package } \\
\text { Group }\end{array}$ & $\begin{array}{l}\text { Effective } \\
\text { Waste } \\
\text { Package } \\
\text { Length } \\
\text { Leff }(m)\end{array}$ & $\begin{array}{c}\text { Maximum } \\
\text { Waste } \\
\text { Package } \\
\text { Diameter, } D_{\max } \\
\text { (m) }\end{array}$ & $\begin{array}{c}\text { Waste } \\
\text { Package } \\
\text { Surface Area } \\
\left(\mathrm{m}^{2}\right)\end{array}$ & $\begin{array}{c}\text { Nominal } \\
\text { Quantity } \\
(-)\end{array}$ & $\begin{array}{l}\text { Total Waste } \\
\text { Package Length } \\
\text { for Group }^{\mathrm{b}}(\mathrm{m})\end{array}$ & $\begin{array}{c}\text { Fraction of } \\
\text { Waste } \\
\text { Packages (\% of } \\
\text { Total Length) }\end{array}$ \\
\hline PWR & 5.0436 & 1.6370 & 30.15 & 4557 & 22984 & 42.0 \\
\hline BWR & 5.0244 & 1.6751 & 30.85 & 2915 & 14646 & 26.8 \\
\hline Naval & 5.5325 & 1.8637 & 37.85 & 300 & 1660 & 3.0 \\
\hline HLW & 4.5193 & 2.0447 & 35.60 & 3412 & 15420 & 28.2 \\
\hline
\end{tabular}

NOTE: $(-)=$ dimensionless.

${ }^{\text {a }}$ Surface Area $=(\pi / 2)\left(D_{\max }\right)^{2}+\pi D_{\max } L_{\text {eff }}$.

${ }^{b}$ Total Waste Package Length for Group $=\Sigma(\text { Length })_{i} \times(\text { Nominal Quantity })_{i}$ summed over the package types in each group, based on the lengths and nominal quantities in Table 6.7-6.

${ }^{\mathrm{C}}$ Effective Waste Package Length $=$ Leff $=$ Total Length $/$ Nominal Quantity.

$\mathrm{PWR}=$ pressurized water reactor, $\mathrm{BWR}=$ boiling water reactor

Using the maximum waste package diameter in Table 6.7-7 and the calculated maximum fault displacements before the waste package is pinned in Table 6.7-3, the following maximum fault displacement values (to cause waste package damage) are used in the analysis.

A determination of waste package failure is made by comparing the maximum allowable displacements in Table 6.7-8 with the fault displacement hazard curve in Table 6.7-5. As a reminder, the Solitario Canyon and main Ghost Dance faults are not included in this analysis because these faults lie outside the emplacement areas of the repository, and the western splay off the main Ghost Dance fault is not included in this analysis because its development and use in the vicinity of an intensely fractured zone is uncertain at this time. 
Table 6.7-8. Maximum Allowable Fault Displacements Before a Waste Package Group Is Pinned

\begin{tabular}{|c|c|c|}
\hline $\begin{array}{c}\text { Waste Package } \\
\text { Group }\end{array}$ & $\begin{array}{c}\text { Maximum Allowable Displacement } \\
\text { With Drift Collapse }\end{array}$ & $\begin{array}{c}\text { Maximum Allowable Displacement } \\
\text { Without Drift Collapse (mm) }\end{array}$ \\
\hline PWR & $1079 \mathrm{~mm}(107.9 \mathrm{~cm})$ & $2830 \mathrm{~mm}(283.0 \mathrm{~cm})$ \\
\hline BWR & $1041 \mathrm{~mm}(104.1 \mathrm{~cm})$ & $2792 \mathrm{~mm}(279.2 \mathrm{~cm})$ \\
\hline Naval & $852 \mathrm{~mm}(85.2 \mathrm{~cm})$ & $2603 \mathrm{~mm}(260.3 \mathrm{~cm})$ \\
\hline HLW & $671 \mathrm{~mm}(67.1 \mathrm{~cm})$ & $2422 \mathrm{~mm}(242.2 \mathrm{~cm})$ \\
\hline
\end{tabular}

$\mathrm{BWR}=$ boiling water reactor; $\mathrm{PWR}=$ pressurized water reactor, $\mathrm{HLW}=$ high-level radioactive waste.

Consider the case where drift collapse has not occurred. As can be seen from Table 6.7-8, the HLW waste package group is subject to potential failure when the fault displacement exceeds the maximum allowable displacement of 2,422 $\mathrm{mm}$. However, as can be seen from Table 6.7-5, the maximum fault displacement for any of the faults that intersect the emplacement drifts is $240 \mathrm{~cm}=2,400 \mathrm{~mm}$, which corresponds to a $10^{-8}$ fault displacement along the Drill Hole Wash fault (the Solitario Canyon fault has larger displacements, but no drifts in the current repository layout intersect this known fault). Thus, since the maximum fault displacement is less than the allowable displacement of $2,422 \mathrm{~mm}$, no damage to EBS components would be predicted without drift collapse. The same conclusion is valid for the other waste package designs, with even greater margin.

Now consider the case where drift collapse has occurred, as is expected in the lower lithophysal zones for seismic hazards with an annual exceedance frequency of $10^{-6}$ or less. First, it is evident from a comparison of Tables 6.7-8 and 6.7-5 that the BWR, PWR, and Naval waste packages are predicted to survive a fault displacement event for Sites 7a and 8a, even in the lower lithophysal zones. The maximum fault displacement in Table 6.7-5 for Sites 7 and 8 is $75 \mathrm{~cm}=750 \mathrm{~mm}$, less than the allowable fault displacement of $852 \mathrm{~mm}$ for the Naval group with drift collapse in the lower lithophysal units. Again, the same conclusion is valid for the BWR and PWR waste package designs, with even greater margin.

However, at mean annual exceedance frequencies between $10^{-7}$ per year and $10^{-8}$ per year, waste package failure may occur for any of the waste packages placed directly over the four known faults (Drill Hole Wash, Sundance, Pagany Wash, and Sever Wash faults) intersecting the emplacement drifts, as well as for the HLW waste package group placed over faults characterized by location 7a and 8a. In those cases, the fault displacement values in Table 6.7-5 exceed the maximum allowable displacements summarized in Table 6.7-8 for the case of drift collapse.

The probability of a fault displacement event severe enough to cause waste package failure is a function of both the specific fault (different fault displacements for a given probability) as well as the specific waste package design (different allowable displacements). The exceedance frequency is equal to the exceedance probability for values much less than one per year. To determine the probability associated with a fault displacement event severe enough to cause waste package damage, the fault displacement hazard curves from the Probabilistic Seismic Hazard Analyses for Fault Displacement and Vibratory Ground Motion at Yucca Mountain, Nevada (MO0401MWDRPSHA.000 [DIRS 166962]) are used. The relevant information is provided in file: ./displ/tot-haz/s3.frac_mean.gz of the DTN for the Drill Hole Wash fault, in file: .ddispl/tot_haz/s5.frac_mean.gz for the Sundance fault, and in files: 
.displ/tot-haz/s7a.frac_mean.gz and./displ/tot-haz/s8a.frac_mean.gz of the DTN for locations 7a and 8a. These curves show the predicted fault displacement as a function of probability of the event (a graphical presentation of the results in Table 6.7-5). Using the maximum allowable displacements from Table 6.7-8 (for each waste package group), the associated event probabilities are determined from the hazard curves in DTN: MO0401MWDRPSHA.000 [DIRS 166962]. The resulting fault exceedance probabilities that would cause waste package failure are summarized in Table 6.7-9. As previously stated, the Pagany Wash and Sever Wash faults are represented by the Drill Hole Wash fault (Assumption 5.1). Again, these results only apply to the lower lithophysal zone, which is predicted to collapse from seismic hazards at these annual exceedance frequencies.

As expected, the highest frequency fault displacement events leading to waste package failure are associated with the HLW waste packages, which have the largest diameter.

Table 6.7-9. Fault Exceedance Frequencies (per year) That Cause Failure in the Lower Lithophysal Zone $^{a}$

\begin{tabular}{|l|c|c|c|c|}
\hline \multicolumn{1}{|c|}{ Fault } & PWR & BWR & Naval & HLW \\
\hline Sundance & $<2 \times 10^{-8}$ & $<2 \times 10^{-8}$ & $<3 \times 10^{-8}$ & $<5 \times 10^{-8}$ \\
\hline Drill Hole Wash & $<5 \times 10^{-8}$ & $<5 \times 10^{-8}$ & $<1 \times 10^{-7}$ & $<2 \times 10^{-7}$ \\
\hline Pagany Wash & $<5 \times 10^{-8}$ & $<5 \times 10^{-8}$ & $<1 \times 10^{-7}$ & $<2 \times 10^{-7}$ \\
\hline Sever Wash & $<5 \times 10^{-8}$ & $<5 \times 10^{-8}$ & $<1 \times 10^{-7}$ & $<2 \times 10^{-7}$ \\
\hline $7 a / 8 a^{\text {b }}$ & N/A & N/A & N/A & $<2 \times 10^{-8}$ \\
\hline
\end{tabular}

${ }^{a}$ Drifts in the lithophysal zones are predicted to collapse from ground motions at these mean annual exceedance frequencies, so the maximum allowable displacement is based on Table 6.7-8 with drift collapse and Table 6.7-5 for fault displacement as a function of exceedance frequency.

b The value of $2 \times 10^{-8}$ is conservative for the hazard curve at sites $7 \mathrm{a} / 8 \mathrm{a}$. The plotted hazard curves at Sites $7 \mathrm{a} / 8 \mathrm{a}$ (CRWMS M\&O 1998 [DIRS 103731], Figures 8-8 and 8-11) indicate exceedance frequency values of about $1.2 \times 10^{-8}$ and $1.4 \times 10^{-8}$ corresponding to the allowable displacement of $671 \mathrm{~mm}$ for the HLW group. These exceedance frequencies are almost at the low probability cutoff for the scenario. The value entered in Table 6.7-9 has been conservatively rounded up to $2 \times 10^{-8}$.

$\mathrm{BWR}=$ boiling water reactor, $\mathrm{PWR}=$ pressurized water reactor, HLW = high-level radioactive waste.

There are two locations where the Sundance fault intersects the emplacement drifts in the lower lithophysal zone (from Table 6.7-4), 20 locations where either the Drill Hole Wash, Pagany Wash, or Sever Wash faults intersect the emplacement drifts in the lower or upper lithophysal zones (Table 6.7-4), and 119.85 locations (probability-weighted) where additional small faults intersect the emplacement drifts in the lower lithophysal zone (Section 6.7.2.2). Combining this information with the probability of finding a particular waste package group at a given point in the repository (Table 6.7-7), an estimate can be made of the expected number of each type of waste package at the four known faults (Drill Hole Wash, Sundance, Pagany Wash, and Sever Wash faults). This result is shown in Table 6.7-10. Note that the number of waste packages is not an integral number because it represents an average expectation of finding a particular waste package along a particular fault. The Pagany Wash, Sever Wash and Drill Hole Wash faults have been combined in Table 6.7-10 because they have the same fault displacement hazard curves. 
Table 6.7-10. Expected Number of Waste Packages Emplaced on Faults in Lithophysal Zones

\begin{tabular}{|l|c|c|c|c|c|}
\hline & PWR Group & BWR Group & Naval Group & HLW Group & Total \\
\hline Sundance & 0.84 & 0.54 & 0.06 & 0.56 & 2 \\
\hline Drill Hole Wash, etc. & 8.40 & 5.35 & 0.61 & 5.64 & 20 \\
\hline 7a/8a & 50.3 & 32.1 & 3.64 & 33.8 & 119.85 \\
\hline
\end{tabular}

NOTE: Total values are based on the spreadsheet in Appendix E. Sums of the contributions by fault are not exact because of round off.

BWR = boiling water reactor, $\mathrm{PWR}=$ pressurized water reactor, HLW $=$ high-level radioactive waste.

\subsubsection{Damage Abstraction for Fault Displacement}

The expected number of waste package failures in the lithophysal zones as a function of annual exceedance frequency is calculated by combining the results in Tables 6.7-9 and 6.7-10. These results are shown in Table 6.7-11. A spreadsheet with the details of this calculation is provided as Appendix E.

When a waste package fails by fault displacement, the damaged area on the waste package is determined by sampling a uniform distribution with a lower bound of $0 \mathrm{~m}^{2}$ and an upper bound equal to the area of the waste package lid, as explained below. The area of the lid for the PWR, BWR, Naval, and HLW groups is $2.105 \mathrm{~m}^{2}, 2.204 \mathrm{~m}^{2}, 2.728 \mathrm{~m}^{2}$ and $3.284 \mathrm{~m}^{2}$, respectively, based on maximum waste package diameters of $1.637 \mathrm{~m}, 1.6751 \mathrm{~m}, 1.8637 \mathrm{~m}$, and $2.0447 \mathrm{~m}$ in Table 6.7-7. For example, PWR group has a maximum diameter of $1.637 \mathrm{~m}$, corresponding to a lid area of $\pi(1.637 \mathrm{~m})^{2} / 4=2.105 \mathrm{~m}^{2}$; similar calculations are performed for the other waste package groups. The total damaged area from a faulting event is based on the weighted sum of the damage to each type of waste package.

Table 6.7-11. Expected Waste Package Failures versus Annual Exceedance Frequency

\begin{tabular}{|c|c|c|c|c|c|}
\hline \multirow{2}{*}{$\begin{array}{c}\text { Annual Exceedance } \\
\text { Frequency (1/yr) }\end{array}$} & \multicolumn{5}{|c|}{ Expected Number of Waste Package Failures } \\
\cline { 2 - 6 } & PWR & BWR & Naval & HLW & Total \\
\hline$>2 \times 10^{-7}$ & 0 & 0 & 0 & 0 & 0 \\
\hline $1 \times 10^{-7}$ to $2 \times 10^{-7}$ & 0 & 0 & 0 & 5.64 & 5.64 \\
\hline $5 \times 10^{-8}$ to $1 \times 10^{-7}$ & 0 & 0 & 0.61 & 5.64 & 6.24 \\
\hline $3 \times 10^{-8}$ to $5 \times 10^{-8}$ & 8.40 & 5.35 & 0.61 & 6.20 & 20.56 \\
\hline $2 \times 10^{-8}$ to $3 \times 10^{-8}$ & 8.40 & 5.35 & 0.67 & 6.20 & 20.62 \\
\hline $1 \times 10^{-8}$ to $2 \times 10^{-8}$ & 9.24 & 5.89 & 0.67 & 39.98 & 55.78 \\
\hline
\end{tabular}

NOTE: Total values are based on the spreadsheet in Appendix E. Sums of the contributions by waste package type are not exact because of round off.

BWR = boiling water reactor; PWR = pressurized water reactor, $\mathrm{HLW}=$ high-level radioactive waste.

The lower bound is appropriate for annual exceedance frequencies near $10^{-7}$ per year because a waste package that is minimally pinned from fault displacement is expected to have only minor crimping with a very small damaged area. The upper bound is appropriate for a fault that shears a waste package near its lid. In this case, the lid welds have the potential to fracture, separating 
the lid from the package and potentially exposing the entire waste form to seepage and release. The use of a uniform distribution is appropriate here because reasonable upper and lower bounds can be defined and because the use of this type of distribution maintains the uncertainty in the damaged area for this abstraction.

When a waste package fails from fault displacement, the associated drip shield and fuel rod cladding also fail as barriers to flow and transport. A sheared drip shield will allow all seepage to pass through it for TSPA; that is, the damaged area is taken as the total surface area of the drip shield so there is no flux splitting (diversion of seepage) on the drip shield. Similarly, fuel rod cladding becomes 100 percent perforated in response to a fault displacement that can shear a waste package. These damage abstractions for the drip shield and fuel rod cladding represent conservative, bounding approximations, particularly for annual exceedance frequencies near $10^{-7}$ per year.

\subsubsection{An Alternative Conceptual Model for Damage from Fault Displacement}

The analysis of waste package failure due to fault displacement presented herein provides a basis for estimating the number of potentially damage-inducing faults that intersect the emplacement drifts. This analysis uses the known location of larger faults (e.g., Sundance fault, Drill Hole Wash fault, etc.) relative to the planned location of the emplacement drifts, as well as an estimate of the density of smaller-displacement faults based on the observed fault density along the exploratory tunnel. The maximum allowable fault displacement before waste package damage occurs was shown to vary between $671 \mathrm{~mm}$ and 1,079 $\mathrm{mm}$ depending on waste package design (Table 6.7-8). Using this site-specific information, it is shown that there are 30 locations where known faults intersected the planned emplacement drifts (Table 6.7-4) plus an estimated 141 locations where unmapped faults could intersect the drifts (Section 6.7.2.2) for a total of 171 fault intersections. Of these, there are a maximum of 55.8 locations (probability weighted by waste package type and location within the repository footprint) that are calculated to cause waste package damage (Table 6.7-11) with an occurrence frequency between $2 \times 10^{-7}$ per year and $10^{-8}$ per year.

As an alternative conceptual model, we consider work published in "Methodologies for the Evaluation of Faulting at Yucca Mountain, Nevada" (Waiting et al. 2003 [DIRS 164449]). This paper presents an assessment of the consequences of fault displacement at Yucca Mountain based on historical earthquake activity in the Western United States. Four historic rupture events were considered to arrive at a median value for fault rupture density (length of faulting per unit area of surface). A conservative median value of $20 \mathrm{~km} / \mathrm{km}^{2}$ was obtained from this analysis of the four events considered. Using this value, along with a representative angle of 50 degrees between the typical drift orientation and the orientation of the faults and an 80 meter drift spacing, the authors determined that there would be 191 waste package locations where a fault would intersect an emplacement drift at Yucca Mountain. This result compares favorably to the 171 fault intersections calculated in this report.

The specific analog event considered by Waiting et al. (2003 [DIRS 164449]), for purposes of quantification, was the Borah Peak earthquake from 1983. Prior analysis of this event had shown that the maximum displacement for the Borah Peak earthquake was 2.7 meters, with an average displacement of approximately 1 meter. Given the fact that the mean annual exceedance 
frequency for 1 meter of displacement at Yucca Mountain ranges from approximately $10^{-6} / \mathrm{yr}$ for the Solitario Canyon fault to approximately $10^{-8} / \mathrm{yr}$ for the Sundance fault, the probability-weighted number of waste package failures is calculated to be between $1.91 \times 10^{-4}$ to $1.91 \times 10^{-6}$. Note that the upper end of this range applies only to the Solitario Canyon fault. As discussed in Section 6.7.3, no drifts intersect the Solitario Canyon fault or the main Ghost Dance fault for the current repository footprint. The largest fault displacement would be expected to correspond to the Drill Hole Wash fault. The mean annual exceedance frequency for one meter of displacement for this fault is on the order of $10^{-7} / \mathrm{yr}$. Thus, the probability-weighted number of waste package failures would be between $1.91 \times 10^{-5}$ to $1.91 \times 10^{-6}$.

The results presented in Table 6.7-11 are not stated in terms of probability-weighted number of waste package failures. Thus, a direct comparison with the results of the alternate model is not possible. However, it is straightforward to recast the Table 6.7-11 results in a compatible form. Considering the number of incremental waste packages that are calculated to fail within each probability range, the product of the annual exceedance frequency (using the upper end of the range) and the number of incremental waste packages calculated to fail represents the probability-weighted number of waste package failures for that exceedance interval. The sum of this result over the full range of exceedance frequencies gives the equivalent total number of probability-weighted waste package failures. Table 6.7-12 presents the details of this calculation.

So the probability-weighted number of waste package failures for the model in this report is $2.61 \times 10^{-6}$. This value is within the range of results provided by the alternative conceptual model, $1.91 \times 10^{-5}$ to $1.91 \times 10^{-6}$. Thus, the alternative conceptual model based on the use of analog data provides results that are consistent with the results of the model presented in this report for both the probability-weighted number of waste package failures and the number of fault intersections with the emplacement drifts. This comparison provides added confidence in the validity of the results presented herein.

Table 6.7-12. Calculation of Probability-Weighted Waste Package Failures

\begin{tabular}{|c|c|c|}
\hline $\begin{array}{c}\text { Exceedance Frequency } \\
\text { (Per Year) }\end{array}$ & $\begin{array}{c}\text { \# Incremental Waste } \\
\text { Package Failures }\end{array}$ & $\begin{array}{c}\text { Probability Weighted Waste } \\
\text { Package Failures }\end{array}$ \\
\hline $2 \times 10^{-7}$ & 5.64 & $1.13 \times 10^{-6}$ \\
\hline $1 \times 10^{-7}$ & 0.60 & $0.06 \times 10^{-6}$ \\
\hline $5 \times 10^{-8}$ & 14.32 & $0.72 \times 10^{-6}$ \\
\hline $3 \times 10^{-8}$ & 0.06 & $0.002 \times 10^{-6}$ \\
\hline $2 \times 10^{-8}$ & 35.16 & $0.70 \times 10^{-6}$ \\
\hline Totals & $\mathbf{5 5 . 7 8}$ & $\mathbf{2 . 6 1 \times 1 0 ^ { - 6 }}$ \\
\hline
\end{tabular}

Source: Data in Table 6.7-11 for Total Expected Number of Waste Package Failures provide the basis for calculating incremental waste package failures and probability weighted waste package failures. Calculation is explained in the two paragraphs preceding this Table and documented in Appendix E..

\subsubsection{Failure by Waste Package Type for Criticality Studies}

As noted in Section 6.7.4, the inventory of waste packages for the fault damage abstraction is divided into four groups: PWR, BWR, Naval, and HLW. While this grouping is convenient for 
TSPA, criticality analyses require a more detailed analysis of the potential for waste package failure by individual waste package type. This section applies the same methodology that is used for the fault damage abstraction to individual waste package types in support of criticality studies.

The information for the criticality analysis is consistent with the damage abstraction for fault displacement in TSPA-LA, but represents a finer level of detail. This detail is necessary because individual waste package types have different outside diameters, while the four groups of waste packages for TSPA conservatively use the maximum package diameter for each group. The different outside diameters for individual package types result in different clearances between EBS components and different numbers of package failures for a given range of exceedance frequency. It is not possible to simply scale the results in Table 6.7-12 based on the inventory of a given package type because it is the outer diameter of a package type that determines the available clearance between EBS components, not the number of packages.

Tables 6.7-1 through 6.7-6 remain unchanged for the criticality analysis by waste package type. Table 6.7-7 is modified for 10 individual waste package types, as shown in Table 6.7-13. Appendix E provides details of the calculations for Tables 6.7-13 through 6.7-17.

Table 6.7-13. Parameters for Simplified Inventory for Criticality

\begin{tabular}{|c|c|c|c|c|}
\hline Waste Package Group & $\begin{array}{l}\text { Nominal } \\
\text { Length } \\
(\mathrm{m})\end{array}$ & $\begin{array}{c}\text { Nominal } \\
\text { Quantity } \\
(-)\end{array}$ & $\begin{array}{l}\text { Total Length } \\
\text { for Package } \\
\text { Type }^{\mathrm{a}}(\mathrm{m})\end{array}$ & $\begin{array}{c}\text { Fraction of Waste } \\
\text { Packages (\% of } \\
\text { Total Length) } \\
\end{array}$ \\
\hline 21-PWR with Absorber Plates & 5.0244 & 4299 & 21600. & 39.48 \\
\hline 21-PWR with Control Rods & 5.0244 & 95 & 477.32 & 0.87 \\
\hline 12-PWR with Absorber Plates - Long & 5.5604 & 163 & 906.35 & 1.66 \\
\hline 44-BWR with Absorber Plates & 5.0244 & 2831 & 14224. & 26.00 \\
\hline 24-BWR with Absorber Plates & 5.0244 & 84 & 422.05 & 0.77 \\
\hline $\begin{array}{l}\text { 5-DHLW Short/1 DOE Spent Nuclear Fuel } \\
\text { - Short }\end{array}$ & 3.4528 & 1147 & 3960.4 & 7.24 \\
\hline 5-DHLW/DOE - Long ${ }^{\mathrm{b}}$ & 5.0594 & 2116 & 10706. & 19.57 \\
\hline 2-MCO/2-HLW & 5.0594 & 149 & 753.85 & 1.38 \\
\hline Naval-Short & 5.2022 & 144 & 749.12 & 1.37 \\
\hline Naval-Long & 5.8374 & 156 & 910.63 & 1.66 \\
\hline \multicolumn{2}{|l|}{ TOTALS } & 11,184 & 54709. & 100.00 \\
\hline
\end{tabular}

Sources: BSC 2005 [DIRS 173501], Table 1 for nominal length; BSC 2005 [DIRS 173501], Table 13 for nominal quantity.

NOTE: (-)=dimensionless.

a Total Length for Package Type $=($ Nominal Length $) \times$ (Nominal Quantity), rounded to 5 significant figures .

b 5-DHLW-DOE Long Package represents three package types: 5-DHLW Long/1 DOE Spent Nuclear Fuel - Long, 5-DHLW Long/1 DOE Spent Nuclear Fuel - Short, the 5 HLW Long Only Package Types. The clearances for these three package types are identical because they have the same nominal length and outer diameter of outer barrier (Table 6.7-7), so their damage from fault displacement is also identical.

$\mathrm{BWR}$ = boiling water reactor; $\mathrm{DHLW}=$ defense high-level radioactive waste; $\mathrm{PWR}=$ pressurized water reactor; $\mathrm{MCO}$ = multicanister overpack, DHLW = defense high-level radioactive waste, $\mathrm{HLW}=$ high-level radioactive waste, $\mathrm{DOE}=$ U.S. Department of Energy.

Table 6.7-14 presents the calculated maximum fault displacements before each waste package is pinned. This Table is essentially identical with Table 6.7-3, although the 21-PWR waste 
package type has two entries, with absorber plates and with control rods, in Table 6.7-14, versus one entry in Table 6.7-3. The maximum allowable fault displacements in Table 6.7-14 are based on a collapsed drift because the fault displacements for the most severe event considered by TSPA are insufficient to pin a waste package when the emplacement drift does not collapse.

Table 6.7-14. Maximum Allowable Displacement With Drift Collapse Before Waste Package is Pinned

\begin{tabular}{|l|c|c|}
\hline \multicolumn{1}{|c|}{ Package Type } & $\begin{array}{c}\text { Waste Package Outer Diameter } \\
(\mathbf{m m})\end{array}$ & $\begin{array}{c}\text { Maximum Allowable } \\
\text { Displacement With Drift } \\
\text { Collapse (mm) }\end{array}$ \\
\hline 21-PWR with Absorber Plates & 1637.0 & 1079 \\
\hline 21-PWR with Control Rods & 1637.0 & 1079 \\
\hline 12-PWR with Absorber Plates - Long & 1313.2 & 1403 \\
\hline 44-BWR with Absorber Plates & 1675.1 & 1041 \\
\hline 24-BWR with Absorber Plates & 1294.1 & 1422 \\
\hline 5-DHLW Short/1 DOE Spent Nuclear Fuel & 2044.7 & 671 \\
\hline - Short & 2044.7 & 671 \\
\hline 5-DHLW/DOE - Long & 1749.4 & 967 \\
\hline 2-MCO/2-HLW & 1863.7 & 852 \\
\hline Naval-Short & 1863.7 & 852 \\
\hline Naval-Long & & \\
\hline
\end{tabular}

NOTE: $\quad$ Outside diameter of outer barrier defined by drawings identified in BSC 2005 [DIRS 173501], Table 1; Maximum allowable displacement with drift collapse is the clearance without pallet in Table 6.7-2. Clearance without pallet is calculated in Table 6.7-1 as the interior height of the drip shield minus the outside diameter of the package outer barrier, rounded to 4 significant figures.

$\mathrm{BWR}=$ boiling water reactor; PWR = pressurized water reactor; $\mathrm{MCO}=$ multicanister overpack, $\mathrm{HLW}=$ high-level radioactive waste.

A comparison of the maximum allowable displacements in Table 6.7-14 with the fault displacement hazard curves provides a basis for determining failure of the different waste package types for the faults within the repository block. The Solitario Canyon and main Ghost Dance faults are not included in this analysis because these faults lie outside the emplacement areas of the repository, and the western splay off the main Ghost Dance fault is not included in this analysis because its development in the vicinity of an intensely fractured zone is uncertain at this time.

Waste package failure may occur for any of the waste packages placed directly over the four known faults intersecting the emplacement drifts, as well as for the HLW waste package group placed over faults characterized by location 7a and 8a. The frequency of a fault displacement event severe enough to cause waste package failure is a function of both the specific fault (different fault displacements for a given exceedance frequency) as well as the specific waste package type (different allowable displacements). The fault displacement hazard curves from the Probabilistic Seismic Hazard Analyses for Fault Displacement and Vibratory Ground Motion at Yucca Mountain, Nevada (MO0401MWDRPSHA.000 [DIRS 166962]) are used to determine the annual exceedance frequency associated with a displacement severe enough to cause damage (see calculations in Appendix E). The fault displacement hazard curves are provided in file: ./displ/tot-haz/s3.frac_mean.gz for the Drill Hole Wash fault, in file: .ddispl/tot_haz/s5.frac_mean.gz for the Sundance fault, and in files: ./displ/tot_haz/s7a.frac_mean.gz and ./displ/tot-haz/s8a.frac_mean.gz for locations 7a and 8a. These curves show the predicted fault displacement as a function of exceedance frequency. 
Using the maximum allowable displacements from Table 6.7-14, the resulting fault exceedance probabilities that would cause waste package failure are summarized in Table 6.7-15. The Pagany Wash and Sever Wash faults are represented by the Drill Hole Wash fault (Assumption 5.1).

Table 6.7-15. Fault Exceedance Frequencies (Per Year) That Cause Failure in Lithophysal Zones ${ }^{a}$

\begin{tabular}{|l|c|c|c|}
\hline \multicolumn{1}{|c|}{ Package Type } & Sundance & $\begin{array}{c}\text { Drill Hole Wash, } \\
\text { Pagany Wash, \& } \\
\text { Sever Wash }\end{array}$ & 7a/8a $^{\mathbf{b}}$ \\
\hline 21-PWR with Absorber Plates & $<1.8 \times 10^{-8}$ & $<5.2 \times 10^{-8}$ & $\mathrm{~N}^{\mathrm{b}}$ \\
\hline 21-PWR with Control Rods & $<1.8 \times 10^{-8}$ & $<5.2 \times 10^{-8}$ & $\mathrm{~N} / \mathrm{A}$ \\
\hline 12-PWR with Absorber Plates - Long & $<1.1 \times 10^{-8}$ & $<3.1 \times 10^{-8}$ & $\mathrm{~N} / \mathrm{A}$ \\
\hline 44-BWR with Absorber Plates & $<2.0 \times 10^{-8}$ & $<5.5 \times 10^{-8}$ & $\mathrm{~N} / \mathrm{A}$ \\
\hline 24-BWR with Absorber Plates & $<1.1 \times 10^{-8}$ & $<3.1 \times 10^{-8}$ & $\mathrm{~N} / \mathrm{A}$ \\
\hline $\begin{array}{l}\text { 5-DHLW Short/1 DOE Spent Nuclear Fuel - } \\
\text { Short }\end{array}$ & $<4.3 \times 10^{-8}$ & $<1.3 \times 10^{-8}$ & $<1.4 \times 10^{-8}$ \\
\hline 5-DHLW/DOE - Long & $<4.3 \times 10^{-8}$ & $<1.3 \times 10^{-8}$ & $<1.4 \times 10^{-8}$ \\
\hline 2-MCO/2-HLW & $<2.3 \times 10^{-8}$ & $<6.4 \times 10^{-8}$ & $\mathrm{~N} / \mathrm{A}$ \\
\hline Naval-Short & $<2.8 \times 10^{-8}$ & $<7.9 \times 10^{-8}$ & N/A \\
\hline Naval-Long & $<2.8 \times 10^{-8}$ & $<7.9 \times 10^{-8}$ & N/A \\
\hline
\end{tabular}

${ }^{a}$ Drifts in lithophysal zones are predicted to collapse from ground motions at these mean annual exceedance frequencies, so the maximum allowable displacement is based on Table 6.7-14 with drift collapse. All exceedance frequencies are rounded up from the exact interpolated values in Appendix $E$.

${ }^{b}$ Exceedance frequency based on the maximum value for Sites $7 a$ and $8 a$. N/A indicates that the interpolated values for exceedance frequency are less than $1 \times 10^{-8}$ per year and are excluded from the analysis. $\mathrm{BWR}=$ boiling water reactor; $\mathrm{DHLW}=$ defense high-level radioactive waste; $\mathrm{PWR}=$ pressurized water reactor; $\mathrm{MCO}=$ multicanister overpack; $\mathrm{DOE}=\mathrm{U} . \mathrm{S}$ Department of Energy; HLW = high-level radioactive waste.

There are two locations where the Sundance fault intersects the emplacement drifts in the lithophysal zones (from Table 6.7-4), 20 locations where either the Drill Hole Wash, Pagany Wash, or Sever Wash faults intersect the emplacement drifts in the lithophysal zones (Table 6.7-4), and 119.85 locations (probability-weighted) where additional small faults intersect the emplacement drifts in the lower lithophysal zone (Section 6.7.2.2). Combining this information with the probability of finding a particular waste package group at a given point in the repository (see last column of Table 6.7-13), the expected number of each type of waste package found at the four known faults is shown in Table 6.7-16. The number of intersections for locations $7 \mathrm{a}$ and $8 \mathrm{a}$ has been rounded up to 120 in Table 6.7-16.

The expected number of waste package failures as a function of annual exceedance frequency can be calculated by combining the results in Tables 6.7-15 and 6.7-16. These results are shown in Table 6.7-17. 
Table 6.7-16. Expected Number of Waste Package Types Emplaced on Faults

\begin{tabular}{|l|c|c|c|}
\hline \multicolumn{1}{|c|}{ Package Type } & Sundance & $\begin{array}{c}\text { Drill Hole Wash, } \\
\text { Pagany Wash, } \\
\text { \& Sever Wash }\end{array}$ & 7a/8a \\
\hline 21-PWR with Absorber Plates & 0.7896 & 7.8962 & 47.3774 \\
\hline 21-PWR with Control Rods & 0.0174 & 0.1745 & 1.0470 \\
\hline 12-PWR with Absorber Plates - Long & 0.0331 & 0.3313 & 1.9880 \\
\hline 44-BWR with Absorber Plates & 0.5200 & 5.1999 & 31.1992 \\
\hline 24-BWR with Absorber Plates & 0.0154 & 0.1543 & 0.9257 \\
\hline $\begin{array}{l}\text { 5-DHLW Short/1 DOE Spent Nuclear Fuel - } \\
\text { Short }\end{array}$ & 0.1448 & 1.4478 & 8.6867 \\
\hline 5-DHLW/DOE - Long & 0.3914 & 3.9137 & 23.4820 \\
\hline 2-MCO/2-HLW & 0.0276 & 0.2756 & 1.6535 \\
\hline Naval-Short & 0.0274 & 0.2739 & 1.6431 \\
\hline Naval-Long & 0.0333 & 0.3329 & 1.9974 \\
\hline TOTALS & 2.0000 & 20.0000 & 120.00 \\
\hline
\end{tabular}

Table 6.7-17. Failure of Waste Package Types by Annual Exceedance Probability

\begin{tabular}{|c|c|c|c|c|c|c|}
\hline \multirow[b]{2}{*}{ Package Type } & \multicolumn{6}{|c|}{ Exceedance Frequency Range (Per Year) } \\
\hline & $>2 \times 10^{-7}$ & $1 \times 10^{-7}-2 \times 10^{-7}$ & $6 \times 10^{-8}-1 \times 10^{-7}$ & $4 \times 10^{-8}-6 \times 10^{-8}$ & $2 \times 10^{-8}-4 \times 10^{-8}$ & $1 \times 10^{-8}-2 \times 10^{-8}$ \\
\hline $\begin{array}{l}\text { 21-PWR with Absorber } \\
\text { Plates }\end{array}$ & 0 & 0 & 0 & 7.90 & 7.90 & 8.69 \\
\hline $\begin{array}{l}\text { 21-PWR with Control } \\
\text { Rods }\end{array}$ & 0 & 0 & 0 & 0.17 & 0.17 & 0.19 \\
\hline $\begin{array}{l}\text { 12-PWR with Absorber } \\
\text { Plates - Long }\end{array}$ & 0 & 0 & 0 & 0 & 0.33 & 0.36 \\
\hline $\begin{array}{l}\text { 44-BWR with Absorber } \\
\text { Plates }\end{array}$ & 0 & 0 & 0 & 5.20 & 5.20 & 5.72 \\
\hline $\begin{array}{l}\text { 24-BWR with Absorber } \\
\text { Plates }\end{array}$ & 0 & 0 & 0 & 0 & 0.15 & 0.17 \\
\hline $\begin{array}{l}\text { 5-DHLW Short/1 DOE } \\
\text { Spent Nuclear Fuel - } \\
\text { Short }\end{array}$ & 0 & 1.45 & 1.45 & 1.59 & 1.59 & 10.28 \\
\hline 5-DHLW/DOE - Long & 0 & 3.91 & 3.91 & 4.31 & 4.31 & 27.79 \\
\hline 2-MCO/2-HLW & 0 & 0 & 0.28 & 0.28 & 0.30 & 0.30 \\
\hline Naval-Short & 0 & 0 & 0.27 & 0.27 & 0.30 & 0.30 \\
\hline Naval-Long & 0 & 0 & 0.33 & 0.33 & 0.37 & 0.37 \\
\hline TOTALS & 0 & 5.36 & 6.24 & 20.05 & 20.62 & 54.17 \\
\hline
\end{tabular}

$\mathrm{DHLW}=$ defense high-level radioactive waste; $\mathrm{MCO}=$ multicanister overpack, DOE = U.S. Department of Energy, HLW = high-level radioactive waste.

\subsection{POST-SEISMIC CHANGES IN THE LOCAL ENVIRONMENT}

A large seismic event, involving both vibratory ground motion and/or fault displacement, has the potential to change the local environment around the emplacement drifts. The most obvious physical change is that the emplacement drifts in the lithophysal zone are predicted to collapse at approximately the 2.0-m/s PGV ground motion level (BSC 2004 [DIRS 166107], 
Section 6.4.2.2.2), and by inference at greater ground motion levels. Drift collapse alters the shape of the drift and fills it with a natural backfill, resulting in the following potential process-level changes in and around the engineered barrier system:

- Seepage may increase because an irregular drift shape reduces the effectiveness of the drift wall as a capillary barrier and because of a loosening of the fractures around the drift.

- Temperature of the drip shield and waste package may increase relative to an unfilled drift because the backfill provides an insulating blanket on top of the drip shield.

- Localized corrosion may increase because of increased temperature and because of rock and water contact with the drip shield or waste package.

- The dissolution rates of CSNF and HLW glass increase with temperature.

\subsubsection{Change in Seepage Flux into the Drifts}

A change in the seepage flux into the emplacement drifts in the lithophysal zones is being incorporated into the seismic abstractions for TSPA-LA. The seepage into the emplacement drifts in the lithophysal zones is determined in an analogous manner as ambient seepage by using the seepage Table for collapsed drifts as provided in DTN: LB0307SEEPDRCL.002 [DIRS 164337], file: ResponseSurfaceSMPACollapsedDrift.dat. This Table is invoked after a seismic event occurs, provided the PGV amplitude is large enough to collapse the drifts. The seepage fluxes provided in this Table are considered conservative.

For the seismic scenario class in TSPA, all ground motions with PGV equal to or greater than $0.384 \mathrm{~m} / \mathrm{s}$ will be considered large enough to collapse the drifts in the lithophysal zones. This threshold for collapse was originally based on output from rockfall analyses at two PGV levels: drifts in the lithophysal zone do not collapse for the $0.19-\mathrm{m} / \mathrm{s}$ PGV level of ground motion (BSC 2004 [DIRS 166107], Section 6.4.2.2.1) but do collapse for the 2.44-m/s PGV level. The response of lithophysal rock at intermediate values of PGV was not available. Recent rockfall analyses have determined that a PGV of approximately $2 \mathrm{~m} / \mathrm{s}$ is a more reasonable threshold for drift collapse in the lithophysal zones (BSC 2004 [DIRS 166107] Section 6.4.2.2.2, 4th bullet under subheading 'Discussion'). However, the seismic scenario class continues to use the value of $0.384 \mathrm{~m} / \mathrm{s}$ because the technical basis for the $2.0 \mathrm{~m} / \mathrm{s}$ threshold for collapse was established after the start of TSPA-LA model development. The value of $0.384 \mathrm{~m} / \mathrm{s}$ is considered conservative because it results in more seepage into the drifts and higher waste package temperatures (Section 6.8.2).

With this threshold, drifts in the lithophysal zones always collapse after a seismic event in the TSPA because PGV is always greater than or equal to $0.4019 \mathrm{~m} / \mathrm{s}$, the value that corresponds to the $10^{-4}$ annual exceedance frequency on the bounded hazard curve (Table 6.4-1). No further changes are made for fault displacement because fault displacement occurs simultaneously with vibratory ground motion in the seismic scenario class. 
There is no change in the seepage flux into the emplacement drifts in the nonlithophysal zones after a seismic event. This is appropriate for two reasons. First, the seepage abstraction already includes an enhancement factor for limited collapse of the emplacement drifts, such as when large rock blocks are ejected without catastrophic drift collapse. Second, complete drift collapse is not observed for ground motion amplitudes at the 5.35-m/s PGV level in the nonlithophysal rock (BSC 2004 [DIRS 166107], Section 6.3.1.6.4). Since the 5.35-m/s PGV level is beyond the maximum PGV value of $4.07 \mathrm{~m} / \mathrm{s}$ considered by TSPA, complete collapse of drifts in the nonlithophysal rock will not occur in TSPA-LA.

\subsubsection{Changes for a Collapsed Drift}

The presence of rubble around the drip shield may cause changes in the temperature and relative humidity of EBS components. A parameter study was conducted to examine the impact of drift collapse on in-drift thermohydrologic parameters (BSC 2005 [DIRS 173944], Section 6.3.7). The Multiscale Thermohydrologic Model (MSTHM) was used to examine the effect of a drift filled with natural backfill on waste package and invert temperature and relative humidity at the waste package and invert. The collapsed drift is represented as having twice its initial diameter (i.e., $11 \mathrm{~m}$ total), and is filled with natural backfill with a bulking factor of 0.231 . The thermal conductivity of the natural backfill $\left(K_{t h}\right)$ is defined as the intact rock thermal conductivity of the Tptpll multiplied by the factor $(1 /(1+\mathrm{BF}))$ where $\mathrm{BF}$ is the bulking factor. Two thermal conductivity values (a "high" case based on a bulking factor of 0.231 , and a "low" case which is taken to be one-half the "high" case value) of the dry and wet backfill thermal conductivity were used in the analyses, as shown in Table 6.8-1. The appropriate range for the bulking factor, 0.2 to 0.4, is discussed in BSC (2004 [DIRS 166107], Section 6.4.2.5.2 under Bulking).

Table 6.8-1. Thermal Conductivity of Rubble

\begin{tabular}{|c|c|c|c|}
\hline Property & $\begin{array}{l}\text { Intact Host-Rock } \\
\text { Property Value }\end{array}$ & $\begin{array}{l}\text { Host-Rock Rubble Property } \\
\text { Value }\end{array}$ & $\begin{array}{c}\text { Basis for Rubble Property } \\
\text { Value }\end{array}$ \\
\hline $\begin{array}{l}\text { Bulk dry thermal } \\
\text { conductivity }\end{array}$ & $1.28 \mathrm{~W} / \mathrm{m}-\mathrm{K}$ & $\begin{array}{l}1.0 \mathrm{~W} / \mathrm{m}-\mathrm{K}\left(\text { High- } K_{\text {th }} \text { case }\right) \\
0.5 \mathrm{~W} / \mathrm{m}-\mathrm{K}\left(\text { Low- } K_{\text {th }} \text { case }\right)\end{array}$ & $\begin{array}{l}\text { Intact Value } \times 1 /(1+\mathrm{BF}) \\
\left(\text { High- } K_{\text {th }} \text { rubble value }\right) / 2\end{array}$ \\
\hline $\begin{array}{l}\text { Bulk wet thermal } \\
\text { conductivity }\end{array}$ & $1.89 \mathrm{~W} / \mathrm{m}-\mathrm{K}$ & $\begin{array}{l}\left.1.515 \mathrm{~W} / \mathrm{m}-\mathrm{K} \text { (High- } K_{\text {th }} \text { case }\right) \\
\left.0.7575 \mathrm{~W} / \mathrm{m}-\mathrm{K} \text { (Low-K } K_{\text {th }} \text { case }\right)\end{array}$ & $\begin{array}{l}\text { Intact Value } \times 1 /(1+\mathrm{BF}) \\
\left(\text { High }-K_{\text {th }} \text { rubble value }\right) / 2\end{array}$ \\
\hline
\end{tabular}

Source: BSC 2005 [DIRS 173944], Table 6.2-3.

Figure 6.8-1 shows the in-drift thermohydrologic parameters as functions of time from repository closure for the case of the "hottest" waste package, which is the 21-PWR absorber plate commercial spent nuclear fuel (CSNF). These plots show three cases: a) an open, noncollapsed drift, b) a collapsed, rubble-filled drift with high- $K_{t h}$ for the rubble, and c) a collapsed, rubble-filled drift with low- $K_{t h}$. The temperature or any of the other environmental parameters follow the intact drift curve until the time of collapse. At that point, the temperature and other parameters translate vertically to one of the other curves, depending on the thermal conductivity of the rubble. TSPA implements the changes for waste package temperature and waste package relative humidity shown conceptually in Figures 6.8-1(a) and (c). TSPA does not implement the change in invert temperature or the reduction in liquid phase saturation in the rubble or in the invert, as shown in Figures 6.8-1(b), (d) and (e), after drift collapse. 

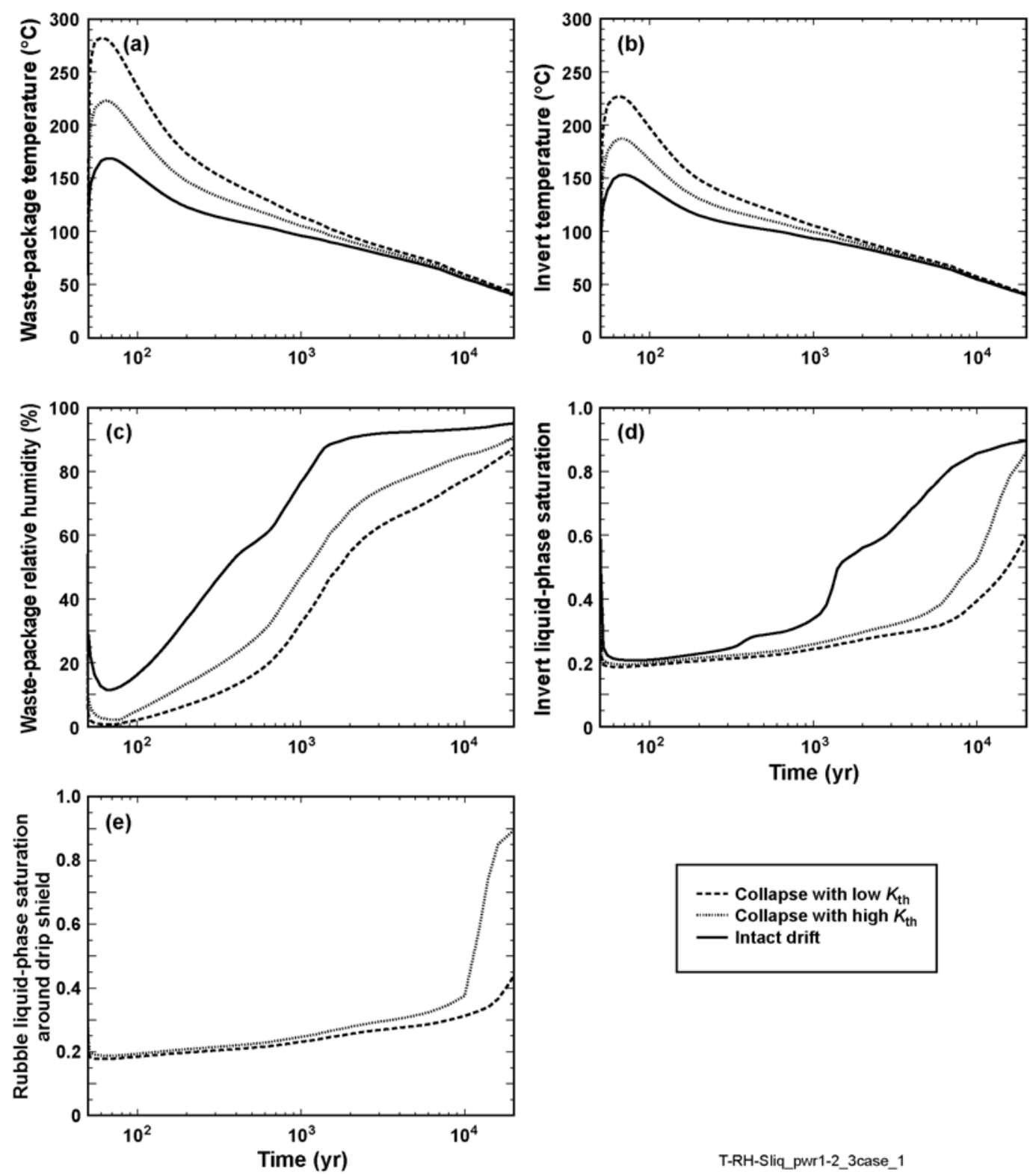

Source: BSC 2005 [DIRS 173944] Figure 6.3-57.

NOTES: Thermohydrologic response for the mean infiltration flux at the P2WR5C10 location, which is in the Tptpll (tsw35) unit (see BSC 2005 [DIRS 173944], Figure 6.3-1 for location). The cases are: (1) intact-drift (nominal) case, (2) low-probability-seismic collapsed drift with high- $\mathrm{K}_{\text {th }}$ host-rock rubble, and (3) low-probability-seismic collapsed drift with low- $K_{\text {th }}$ rubble. The plotted parameters are (a) waste package temperature, (b) invert temperature, (c) waste package relative humidity, (d) invert liquid-phase saturation, and (e) matrix liquid-phase saturation of the rubble surrounding the drip shield.

The digital results for the temperature time histories are defined in (DTN: LL040310323122.044 [DIRS 168769], files: Twp_dh/w-l1_3case.dat, Twp_dh/w-s1_3case.dat, Twp_bwr1-1_3case.dat, Twp_bwr1-2_3case.dat, Twp_bwr2-1_3case.dat, Twp_pwr1-1_3case.dat, Twp_pwr1-2_3case.dat, and Twp_pwr2-1_3case.dat). The digital results for the relative humidity time histories are defined in (DTN: LL040310323122.044 [DIRS 168769], files: RHwp_dh/w-I1_3case.dat, RHwp_dh/w-s1_3case.dat, RHwp_bwr1-1_3case.dat, RHwp_bwr1-2_3case.dat, RHwp_bwr2-1_3case.dat, RHwp_pwr1-1_3case.dat, RHwp_pwr1-2_3case.dat, and RHwp_pwr2-1_3case.dat).

Figure 6.8-1. Thermal-Hydrologic Response for the 21-PWR Absorber Plate CSNF (pwr1-2) Waste Package 
Examination of the waste package temperature history (Figure 6.8-1(a)) shows that significant impact to peak waste package temperature results only if drift collapse occurs within the first 100 to 200 years after closure. After that time, the waste package temperature remains below the peak temperature for the intact drift case that occurs within about 20 to 30 years after closure. The total time during which the waste package surface remains above boiling for the "hottest" waste package case is approximately 1,000 years for the intact drift, 1,500 years for the high- $K_{t h}$ case and 2,000 years for the low $K_{t h}$ case. The relative humidity at the waste package decreases significantly for collapsed drift because of the increase in local temperature.

When a TSPA model can accept temperature and relative humidity time histories from these eight representative waste package emplacement configurations, then the data are applied directly to all waste packages in lithophysal zones after drift collapse. When a TSPA model can only accept input for the CSNF or the codisposal waste package types, than a choice must be made among these eight time histories.

The recommended choice for the CSNF waste package groups is based on the BWR or PWR configuration in the MSTHM that produces a temperature history closest to the mean response for these types of packages. The mean response is a reasonable approach here because there are substantial uncertainties in predictions of the thermal conductivity of the rubble and backfill around the drip shield. The analyses with high and low values for thermal conductivity are designed to represent this uncertainty, and the waste package configuration with the mean thermal response captures this effect. The recommended choice for the co-disposal waste package groups cannot be based on the mean because there are only two DHLW configurations, so the recommended choice is to use the configuration with the maximum temperature change.

Table 6.8-2 summarizes the maximum temperature change for the six PWR/BWR configurations from the MSTHM analyses with the lower bound for thermal conductivity.

Table 6.8-2. Maximum Temperature Change for MSTHM Configurations with Low Thermal Conductivity

\begin{tabular}{|c|c|}
\hline $\begin{array}{c}\text { MSTHM Waste } \\
\text { Package Configuration }\end{array}$ & Maximum Temperature Change $\left({ }^{\circ} \mathrm{C}\right)^{\mathrm{a}}$ \\
\hline BWR 1-2 & 126.77 \\
\hline BWR 1-1 & 119.88 \\
\hline BWR 2-1 & 118.76 \\
\hline PWR 1-1 & 90.01 \\
\hline PWR 2-1 & 111.75 \\
\hline PWR 1-2 & 121.81 \\
\hline Mean Value & 114.83 \\
\hline \multicolumn{2}{|c|}{$\begin{array}{l}\text { Each file in DTN: LL040310323122.044 [DIRS 168769] defines time dependent } \\
\text { temperatures for the following cases: (i) no backfill, denoted by T0, (ii) backfill with } \\
\text { low thermal conductivity, denoted by T_I, and (iii) backfill for high thermal } \\
\text { conductivity, denoted by T_h. The files also define the temperature change } \\
\text { between the low thermal conductivity and no backfill cases, denoted by T_I-T0, } \\
\text { and the temperature change between the high thermal conductivity and no backfill } \\
\text { cases, denoted by T_h - T0. The data for maximum temperature change are } \\
\text { based on the maximum value in the T_ I- T0 case. }\end{array}$} \\
\hline \multicolumn{2}{|c|}{ BWR = boiling water reactor; MSTHM = Multiscale Thermohydrological Model. } \\
\hline
\end{tabular}


The maximum temperature change for the PWR 2-1 package is $111.75^{\circ} \mathrm{C}$, which is closest to the mean of these six cases. The recommended choice is to use the PWR 2-1 time histories for temperature and relative humidity, files: Twp_pwr2-1_3case.dat and RHwp_pwr2-1_3case.dat, respectively, for the TSPA models based on CSNF waste package groupings.

The maximum temperature changes for the DHLW-11 and DHLW-s1 waste package emplacement configurations are $99.85^{\circ} \mathrm{C}$ and $122.98^{\circ} \mathrm{C}$, respectively. The recommended choice is to use the DHLW-s1 time histories for temperature and relative humidity, files: Twp_dhlw-s1_3case.dat and RHwp_dhlw-s1_3case.dat, respectively, for the TSPA models based on co-disposal waste package groupings.

For the seismic scenario class in TSPA, all ground motions with PGV equal to or greater than $0.384 \mathrm{~m} / \mathrm{s}$ will be considered large enough to collapse the drifts in the lithophysal zones. This threshold for collapse was originally based on output from rockfall analyses at two PGV levels: drifts in the lithophysal zone do not collapse for the $0.19-\mathrm{m} / \mathrm{s}$ PGV level of ground motion (BSC 2004 [DIRS 166107], Section 6.4.2.2.1) but do collapse for the 2.44-m/s PGV level. The response of lithophysal rock at intermediate values of PGV was not available. Recent rockfall analyses have determined that a PGV of approximately $2 \mathrm{~m} / \mathrm{s}$ is a more reasonable threshold for drift collapse in the lithophysal zones (BSC 2004 [DIRS 166107] Section 6.4.2.2.2, 4th bullet under subheading 'Discussion'). However, the seismic scenario class continues to use the value of $0.384 \mathrm{~m} / \mathrm{s}$ because the technical basis for the $2.0 \mathrm{~m} / \mathrm{s}$ threshold for collapse was established after the start of TSPA-LA model development. The value of $0.384 \mathrm{~m} / \mathrm{s}$ is considered conservative because it results in more seepage into the drifts and higher waste package temperatures (Section 6.8.2).

There is no change in temperature or relative humidity for the emplacement drifts in the nonlithophysal zones because the drifts are not expected to be completely filled with rock blocks in the nonlithophysal zones (BSC 2004 [DIRS 166107], Section 6.3.1.6.4). In this situation, the top and sides of the drip shield will not be completely covered with rock blocks and rubble, so the nominal temperature and nominal relative humidity time histories are more appropriate for this case.

\subsection{SEISMIC SCENARIO CLASS}

The impact of seismic hazards on repository performance is being represented in a separate scenario class, called the seismic scenario class, for TSPA-LA. The rationale for defining a separate scenario class is based on several key observations:

- Seismic events with annual frequencies down to $10^{-8}$ per year must be considered by TSPA-LA.

10 CFR 63.114 [DIRS 173273], Requirements for Performance Assessment, states that:

Any performance assessment used to demonstrate compliance with $\S 63.113$ must: (d) Consider only events that have at least one chance in 10,000 of occurring over 10,000 years. 
Seismic events with very large ground motion amplitudes/fault displacements, corresponding to annual exceedance frequencies down to $10^{-8}$ per year, must be considered by TSPA-LA, even though their probability is very low during the first 10,000 years following repository closure.

- Events with very small annual frequencies of occurrence cannot be accurately represented in the nominal scenario class. A separate scenario class for seismic hazards is desirable.

Accurate representation of events with annual frequency of occurrence down to $10^{-8}$ per year would require millions of realizations in the nominal scenario class, which is not computationally feasible. The alternative is to define a separate scenario class for seismic hazards that determines dose in a probability-weighted manner, as explained below.

- The mean dose time history is the main parameter for compliance determinations.

Radionuclide release limits for the repository are expressed in terms of the mean of the distribution of projected doses to the reasonably maximally exposed individual, per 10 CFR 63.303 and 63.311 [DIRS 173273]. Calculation of releases from the seismic scenario class must generate mean dose for consistency with the nominal scenario class.

Damage from seismic events is represented as a network of stress corrosion cracks for the damaged areas wherein the residual tensile stress exceeds a given threshold for Alloy 22 on the surfaces of the waste package or for Titanium Grade 7 on the surfaces of the drip shield. The probability distributions for these damaged areas are a function of the amplitude of the seismic event. For example, the amplitude of a ground motion is defined through the horizontal PGV, and the damage abstractions for the waste package evaluate a probability of no damage as a function of PGV and a damaged area (conditional on damage occurring) based on a power law fit to the median response and In-normal variability about the median response (Sections 6.5.1 through 6.5.3). The individual damage abstractions for the waste package and the fuel rod cladding are based on the results from structural response calculations, kinematic calculations, and rockfall analyses, as discussed in Sections 6.5 through 6.8 .

The seismic scenario class is based on a single seismic event that occurs at a randomly chosen time in each realization of the TSPA-LA. That is, the conditional probability of a seismic event is one for each realization, even though the exceedance frequency range for these events varies from $10^{-4}$ per year down to $10^{-8}$ per year. The damage from this single event is based on the damage abstractions for the waste package and the fuel rod cladding. The damaged areas on the waste package define a network of stress corrosion cracks that are potential pathways for transport through the EBS. The damage to the drip shield from vibratory ground motion and from rockfall induced by vibratory ground motion has been screened out of TSPA-LA. The damage to the fuel rod cladding is expressed as the percent of cladding that is perforated in each waste package. The seepage flux for the emplacement drifts in the lithophysal zones changes after a major seismic event that can collapse the drifts. Once radionuclides are released from the EBS, flow and transport in the unsaturated zone and the saturated zone are based on the same 
models and algorithms as for the nominal scenario class. Biosphere calculations and biosphere parameters for the seismic scenario class are also unchanged from the nominal scenario class.

Each realization of the seismic scenario class determines an annual dose time history for a single seismic event with a specific value for $P G V_{i}$ between $0.4019 \mathrm{~m} / \mathrm{s}$ and $4.07 \mathrm{~m} / \mathrm{s}$, corresponding to a mean annual exceedance frequency $\lambda$ between $10^{-4}$ and $10^{-8}$ per year, respectively. These dose time histories do not represent the mean dose, as called for in 10 CFR 63.303 [DIRS 173273], because a single such event always occurs in each realization. A mean dose time history is calculated using a probability-weighted average of all the realizations for the seismic scenario class. The weighting factor for each realization corrects for the actual expected number of seismic events and for importance sampling based on the use of log-uniform distributions.

\subsubsection{Computational Approach}

The mean dose for the seismic scenario class is based on a set of $R$ realizations that have robust sampling of all levels of seismic events (i.e., for the ranges of PGV levels and fault displacement amplitudes) with the potential to generate releases from the EBS. The following discussion explains how these $R$ realizations are generated using a Monte Carlo computational procedure in the TSPA.

The $R$ realizations represent the future performance of the repository for the seismic hazards of ground motion and fault displacement. These realizations represent the combined epistemic and aleatory uncertainty in the TSPA-LA model for the seismic scenario class. Epistemic uncertainty is captured by those stochastic parameters that represent the "lack of knowledge" uncertainty in various processes. Aleatory uncertainty is captured by the stochastic parameters that represent the randomness of processes, such as the uncertainty in the timing and amplitude of seismic events.

The TSPA-LA model for the seismic scenario class is very similar to the TSPA-LA model for the nominal scenario class, with the following major exceptions: (1) damaged area on the waste package is determined by sampling stochastic parameters in an abstraction for waste package damage, rather than by the waste package degradation analysis for corrosion processes; (2) the damaged area on the waste package is represented as a network of stress corrosion cracks, rather than as large breaches on the package, (3) the failure of fuel rod cladding is represented as a percent of fuel rods perforated in each waste package at the time of the seismic event, and (4) a single seismic event occurs at a random time during each realization. The primary output from each of these $R$ realizations is a time history of dose to the reasonably maximally exposed individual.

The value of the horizontal peak ground velocity, $P G V_{i}$, and its associated annual exceedance frequency, $\lambda_{i}$, are determined by a Monte Carlo process that samples appropriate distributions for these parameters in the $i^{\text {th }}$ realization. Since $P G V$ and $\lambda$ are functionally related, it is sufficient to sample one parameter or the other; $\lambda$ is sampled for TSPA-LA.

$\lambda_{i}$ is determined by sampling a log-uniform distribution with lower bound $\lambda_{\min }$ and upper bound $\lambda_{\max }$. The sampling for the annual exceedance frequency uses a logarithmic scale, rather than a linear scale, to ensure robust sampling throughout the relevant frequency range. This approach 
ensures adequate representation of very low frequency events with high PGV levels that may result in large doses. The use of a log-uniform distribution is a computational device for accelerating convergence to the mean or expected values in a Monte Carlo scheme; it does not represent the physical response of the site. The bounds of the log-uniform distribution must be chosen to encompass the seismic events with the potential to release significant radionuclides from the EBS. Values of $\lambda_{\max }$ and $\lambda_{\min }$ for the seismic scenario class are $10^{-4}$ per year and $10^{-8}$ per year, respectively, because this range spans the response of the system, from no damage at $10^{-4}$ per year to the regulatory probability limit at $10^{-8}$ per year.

Once the value of the annual exceedance frequency $\left(\lambda_{i}\right)$ is determined for the $i^{\text {th }}$ realization, the corresponding value of the peak ground velocity $\left(P G V_{i}\right)$ is calculated. The relationship between PGV and $\lambda$ is defined by the mean bounded hazard curve, and is site- and location-specific (Section 6.4).

The mean bounded hazard curve for vibratory ground motion and the mean hazard curves for fault displacements are central to the seismic scenario class. These mean hazard curves represent both aleatory and epistemic uncertainties in the hazards (Sections 6.4.1 and 6.4.2). The seismic scenario class is based on the mean hazard, considering the range of epistemic uncertainty for a given value of PGV. This is a reasonable approach because the mean (epistemic) estimate of the (aleatory) mean dose is linear in the exceedance frequency, $\lambda$, for a given value of PGV. The derivation of the mean bounded hazard curve is described in Peak Ground Velocities for Seismic Events at Yucca Mountain, Nevada (BSC 2005 [DIRS 170137]). Analysis of the geologic conditions at Yucca Mountain and other corroborating evidence provides a basis for estimating the maximum feasible or bounding value of PGV at the emplacement drifts. The numerical values for this hazard curve are defined in Table 6.4-1.

Once the value for $P G V_{i}$ is known, the abstractions for the damaged area on the waste package (Sections 6.5.1 through 6.5.3) and for failure of the fuel rod cladding (Section 6.5.6) are evaluated. For example, each waste package damage abstraction is based on three relationships: (i) the probability that there will be no damage as a function of PGV, (ii) a power law representation for the median values of the nonzero damaged areas, again as a function of PGV, and (iii) a ln-normal distribution for the distribution of damage about the median values. (The natural logarithm is abbreviated as "ln" and the common logarithm to base 10 is abbreviated as "log" in this document. The median is also called the geometric mean.) These relationships can be evaluated and/or sampled for a given value of $P G V_{i}$ to determine the damaged area on the waste package. This approach explicitly includes the variability from the structural response calculations in the TSPA-LA model through sampling.

Damage from fault displacement occurs simultaneously with damage from vibratory ground motion. The sampled value of $\lambda_{i}$ determines the number of damaged waste packages by type, based on the abstraction in Table 6.7-11 (Section 6.7). The damaged area from fault displacement is determined by sampling a distribution with a lower bound of 0 and an upper bound based on the lid area for each type of waste package.

Simultaneous damage from fault displacement and vibratory ground motion is a reasonable approach for the seismic scenario class. One significant nearby earthquake induces both ground motions and local fault displacements. On the other hand, all the known on-site faults and small 
hypothetical faults with a 2 meter cumulative offset (Sites 7a/8a in the PSHA) move simultaneously in the abstraction for TSPA-LA. The potential correlations among displacements on different faults in the PSHA were not considered during the expert elicitation for the PSHA, and little information is available to support development of correlations for dependent or independent displacement along the known faults. The abstraction is conservative.

\subsubsection{Computational Algorithm}

The computational algorithm has been split into 13 simple operations to document the procedure for this scenario class. The first 11 operations define the constant parameters, stochastic parameters, and formulas that represent the epistemic and aleatory uncertainty for the TSPA-LA model. The modifications for post-seismic event response are summarized in Operations 12 and 13. Each realization of the TSPA-LA model is based on a single sampling of the stochastic parameters from the first 11 operations. Repeated samplings of the stochastic parameters during the $R$ realizations generate a full suite of future histories for the TSPA-LA model.

A list of the 13 operations in the computational procedure follows. The parameters for the computational procedure are listed in Table 6.9-1.

1. Determine the mean annual exceedance frequency, $\lambda_{i}$, for the $i^{\text {th }}$ realization.

The value of $\lambda$ is sampled from a log-uniform distribution between $\lambda_{\min }$ and $\lambda_{\max }$. A log-uniform distribution ensures robust sampling in each decade of the distribution. The values of $\lambda_{\min }, \lambda_{\max }$, and $\lambda_{i}$ are represented by the parameters LAMBDA_MIN, LAMBDA_MAX, and LAMBDA, respectively, in Table 6.9-1.

2. Determine the corresponding value of PGV on the hazard curve, $\lambda=\lambda$ (PGV).

The value of $P G V_{i}$ is determined by a Table lookup, using the mean bounded hazard curve for the emplacement drifts. The interpolation between points in this Table (see the definition of PGV in Table 6.9-1) is based on a linear interpolation using the values of $\log (\lambda)$ and $\log (P G V)$ at individual points. This is referred to as a $\log \log$ interpolation scheme in Table 6.9-1. The resulting value of $P G V_{i}$ is denoted simply as PGV in Table 6.9-1. The subscript $i$ has been dropped from PGV and from all other parameters in Table 6.9-1 because all values in Table 6.9-1 are on a per realization basis.

3. Determine which of the four possible damage states ((i) end-to-end and waste package-pallet impact damage, (ii) end-to-end impact damage only, (iii) waste package-pallet impact damage only, and (iv) no impact damage) occurs in this realization. Compare a randomly sampled number between 0 and 1 to the damage state sampled from a cumulative discrete distribution. The discrete probability levels in the cumulative discrete distribution are a function of the probability of no damage from end-to-end impacts and/or waste package-pallet impacts. The sampled random number is denoted as PROB_DAM_RAND in Table 6.9-1. 
The probability of no end-to-end impact damage is denoted as PROB_NODAM_DYNA or PROB_NODAM_UDEC in Table 6.9-1 for LS-DYNA and for UDEC, respectively. The probability of no end-to-end impact damage for this realization is denoted as PROB_NODAM in Table 6.9-1 and is defined as:

$$
\begin{aligned}
\text { PROB_NODAM }= & \text { If }(\text { SOURCE }=1, \text { PROB_NODAM_DYNA, } \\
& \text { else PROB_NODAM_UDEC }) .
\end{aligned}
$$

The probability of no damage for waste package-pallet impacts in this realization is denoted as PROB_NODAM_PALLET_80 for the 80 percent residual stress threshold and PROB_NODAM_PALLET_90 for the 90 percent residual threshold in Table 6.9-1. The probability of no damage for the realization is based on sampling a uniform distribution with a lower bound of PROB_NODAM_PALLET_90 and an upper bound of PROB_NODAM_PALLET_80. This probability is denoted as PROB_NODAM_PALLET in Table 6.9-1. This parameter is perfectly correlated with the parameters DA_DYNA, DA_UDEC and DA_PALLET (see operation (7) below) to maintain comparable values of the residual stress threshold.

The damage state is denoted by DAMAGE_STATE in Table 6.9-1. The value of DAMAGE STATE is 0 for no damage to the waste package, 1 for damage from waste package-pallet impacts only, 2 for damage from end-to-end impacts only, and 3 for damage from both end-to-end and waste package-pallet impacts. The damage state is calculated as:

\section{If PROB_DAM_RAND $<=$ PROB_NODAM*PROB_NODAM_PALLET, DAMA GE STATE $=3$}

else if, PROB DAM RAND $<=$ PROB NODAM, DAMAGE STATE $=2$ else if, PROB_DAM_RAND $<=($ PROB_NODAM + PROB_NODAM_PALLET - PROB_NODAM*PROB_NODAM_PALLET), DAMAGE_STATE $=1$ else, DAMAGE_STATE $=0$.

The damage state variable, NODAM_SWITCH equals 1 if end-to-end impact damage occurs and equals 0 if no end-to-end impact damage occurs in this realization. The damage state variable, NODAM_SW_PALLET, equals 1 if waste package-pallet impact damage occurs and equals 0 if no waste package-pallet impact damage occurs in this realization.

4. Determine the fraction of damaged waste package surface area due to end-to-end impacts in response to vibratory ground motion for each realization.

The damaged waste package surface area from end-to-end impacts is a random variable with parameters that are functions of $P G V_{i}$. The damage abstraction for end-to-end impacts represents the results of two separate sets of kinematic calculations, with LS-DYNA and with UDEC. Each set of kinematic calculations is evaluated for the two extreme values of the residual stress threshold for initiation of stress corrosion cracking in Alloy 22: 80 percent and 90 percent of the yield strength 
(YS). In effect, there are four data sets for the damage abstraction for end-to-end impacts:

1. Damaged areas based on LS-DYNA for a residual stress threshold of 80 percent of the YS of Alloy 22

2. Damaged areas based on LS-DYNA for a residual stress threshold of 90 percent of the YS of Alloy 22

3. Damaged areas based on UDEC for a residual stress threshold of 80 percent of the YS of Alloy 22

4. Damaged areas based on UDEC for a residual stress threshold of 80 percent of the YS of Alloy 22

The four data sets are maintained separately in TSPA because the four sets have differences that are statistically significant, because this approach provides for a direct representation of the epistemic uncertainty within each data set in TSPA, and because this approach provides for a direct representation of the uncertainty in the computational methodologies in TSPA.

Each of these four data sets is represented by three relationships: (i) the probability that there will be no damage, (ii) a power law representation for the median (i.e., the geometric mean) values of the nonzero damaged areas, and (iii) a ln-normal distribution for the distribution of damage about the median values. The first two relationships are a function of $\mathrm{PGV}$; the standard deviation for the ln-normal distribution is a constant, independent of PGV. The following procedure is recommended for computing the end-to-end damage with this four-part abstraction:

a) Determine the data source for the kinematic calculations, LS-DYNA or UDEC, for this realization. The two sources are sampled on a 50-50 basis using a discrete distribution that is denoted as SOURCE in Table 6.9-1. SOURCE $=1$ for LS-DYNA and SOURCE $=2$ for UDEC.

b) Determine the nonzero damaged area for both the 80 percent and 90 percent residual stress thresholds by calculating the median damage from a power law and then sampling a ln-normal distribution about the power law. This operation is conditional on the results from operation 3(b) determining that nonzero damage occurs in this realization. The power law corresponds to the line that provides a least squares fit for the natural logarithm of the nonzero damaged area as a function of the natural logarithm of longitudinal PGV. The residuals about this line follow a normal distribution (in $\ln$ (Damaged Area) space) with a constant standard deviation, independent of PGV. The power law fits of the ln-normal distributions are denoted as MEDIAN_DYNA_80, MEDIAN_DYNA_90, MEDIAN_UDEC_80, and MEDIAN_UDEC_90 in Table 6.9-1. The standard deviations of the residuals for the ln-normal distributions are denoted as SD_DYNA_80, SD_DYNA_90, SD_UDEC_80, and SD_UDEC_90 in Table 6.9-1. The sampled values of the ln-normal distributions are denoted as DA_DYNA_80, DA_DYNA_90, DA_UDEC_80, and DA_UDEC_90 in Table 6.9-1. 
The values of DA_DYNA_80 and DA_DYNA_90 are perfectly correlated to maintain similar epistemic uncertainty in damaged area relative to the median value from the power law fit. The values of DA_UDEC_80 and DA_UDEC_90 are also perfectly correlated for the same reason.

c) Determine the damaged area from end-to-end impacts for the data source in this realization by sampling a uniform distribution between the lower and upper bounds for the residual stress threshold. For LS-DYNA, the uniform distribution has a lower bound of DA_DYNA_90, an upper bound of DA_DYNA_80, and the damaged area is denoted by DA_DYNA in Table 6.9-1. If the data source is UDEC, then the uniform distribution has a lower bound of DA_UDEC_90, an upper bound of DA_UDEC_80, and the damaged area is denoted by DA_UDEC in Table 6.9-1.

d) Determine the final damaged area from end-to-end impacts depending on the source for this realization. The final damage area for end-to-end impacts is denoted as DA_WPtoWP in Table 6.9-1, based on the test:

$$
\text { DA_WPtoWP }=\operatorname{If}\left(\mathrm{SOURCE}=1, \mathrm{DA} \_ \text {DYNA, else DA_UDEC }\right) \text {. }
$$

e) Determine the fraction of damaged area from end-to-end impacts by dividing the damaged area by the surface area of the 21-PWR waste package. The surface area of the 21-PWR waste package, $30.05 \mathrm{~m}^{2}$, is denoted as SURFAREA_21PWR in Table 6.9-1. The damage fraction is denoted as DAMFRAC_WPtoWP in Table 6.9-1. The formula for the damage fraction is:

\section{DAMFRAC_WPtoWP $=$ NODAM_SWITCH*DA_WPtoWP/SURFAREA_21PWR}

This damage fraction is applied to all waste package types in the TSPA model.

5. Determine the fraction of damaged waste package surface area due to waste package-pallet impacts in response to vibratory ground motion for each realization. The damage abstraction for waste package-pallet impacts is similar to the individual abstractions for end-to-end impacts, although there is only one source of data as explained below.

The damaged waste package surface area from waste package-pallet impacts is a random variable with parameters that are functions of $P G V_{i}$. The damage abstraction for waste package-pallet impacts represents the results of a single set of structural response calculations (with LS-DYNA) for two extreme values of the residual stress threshold: 80 percent and 90 percent of the YS of Alloy 22. The damage abstractions at 80 percent and 90 percent of YS are represented by three relationships: (i) the probability that there will be no damage, (ii) a power law representation for the median (i.e., the geometric mean) values of the nonzero damaged areas, and (iii) a ln-normal distribution for the distribution of damage areas about the median values. The first two relationships are a function of PGV; the standard deviation for the ln-normal 
distribution is a constant, independent of PGV. The following procedure is recommended for computing the waste package-pallet damage:

a) Determine the nonzero damaged area for both the 80 percent and 90 percent residual stress thresholds by calculating the median damage from a power law and then sampling a ln-normal distribution about the power law. This operation is conditional on the results from operation 3 determining that nonzero damage occurs in this realization. The power law corresponds to the line that provides a least squares fit for the natural logarithm of nonzero damaged areas as a function of the natural logarithm of longitudinal PGV. The residuals about this line follow a normal distribution in $\ln$ (Damaged Area) space with a constant standard deviation, independent of PGV. The medians (power law fits) are denoted as MEDIAN_PALLET_80 and MEDIAN_PALLET_90, in Table 6.9-1. The standard deviations of the ln-normal distributions are denoted as SD_PALLET 80 and SD_PALLET_90 in Table 6.9-1. The ln-normal distributions are denoted as DA_PALLET_80 and DA_PALLET_90 in Table 6.9-1. The values of DA_PALLET_80 and DA_PALLET_90 are perfectly correlated to maintain similar epistemic uncertainty in damaged area relative to the median value from the power law fit.

b) Determine the damaged area from waste package-pallet impacts by sampling a uniform distribution with a lower bound of DA_PALLET_90 and an upper bound of DA_PALLET_80. This damaged area is denoted by DA_PALLET in Table 6.9-1. DA_PALLET is perfectly correlated with DA_DYNA-DA_UDEC and PROB_NODAM_PALLET (see operation (7) below) to maintain equivalent values of the residual stress threshold throughout this realization.

c) Determine the fraction of damaged area from waste package-pallet impacts by dividing the damaged area by the surface area of the 21-PWR waste package. The surface area of the 21-PWR waste package, $28.2 \mathrm{~m}^{2}$, is denoted as SURFAREA_21PWR_PALLET in Table 6.9-1. (The package surface area matches the design represented in the structural response calculations, but differs from the value in operation 4(e) because of changes in package design.) The damage fraction is denoted as DAMFRAC_PALLET in Table 6.9-1. The formula for the damage fraction is:

$$
\begin{aligned}
\text { DAMFRAC_PALLET } & =\text { DA_PALLET } * \text { NODAM_SW_PALLET } \\
& \text { /SURFAREA_21PWR_PALLET }
\end{aligned}
$$

This damage fraction is applied to all waste package types in the TSPA model.

6. Determine the total damaged fraction for all waste packages by summing the contributions from end-to-end impacts and from waste package-pallet impacts:

DAMFRAC_TOTAL $=$ DAMFRAC_WPtoWP + DAMFRAC_PALLET 
7. There are four parameters that are determined by sampling a uniform distribution between 80 percent and 90 percent residual stress threshold values. These are DA_DYNA (operation 4(c)), DA_UDEC (operation 4(c)), PROB_NODAM_PALLET (operation 3), and DA_PALLET (operation 5(b)). They are perfectly correlated to maintain equivalent values of the residual stress threshold throughout the realization. This correlation can be implemented by sampling a single uniform distribution between 0 and 1 . This distribution is denoted as WP_DAMAGE_UNCERTAINTY in Table 6.9-1. The resulting sampled value can be used to interpolate between the 80 percent and 90 percent values for each of the four parameters. This is equivalent to sampling a uniform distribution between the 80 percent and 90 percent residual stress threshold values. As an example, the calculation of DA_PALLET would be given by

\section{DA_PALLET $=$ WP_DAMAGE_UNCERTAINTY *(DA_PALLET_80 - DA_PALLET_90)+DA_PALLET_90 (Eq. 6-13)}

8. Determine the effective transport area through the damaged area on the waste package. The effective transport area is based on the geometry and gap widths for a network of tight SCCs (Section 6.3.5). The scaling factor that determines the effective transport area is a stochastic parameter because there is uncertainty in the geometry, orientation, and gap width for the SCC network. The scaling factor is sampled from a uniform distribution whose lower and upper bounds span the full range of SCC geometries considered (Sections 6.3.5 and 6.3.6). The scaling factor is applied to all waste packages in the repository (i.e., there is no spatial variability).

- The upper bound of the uniform distribution is 0.0131, and represented in Table 6.9-1 by the parameter SCALE_FACTOR_MAX.

- The lower bound of the uniform distribution is 0.00328 . This value is represented by the parameter SCALE_FACTOR_MIN in Table 6.9-1.

- The sampled value of the scaling factor is denoted as SCALE_FACTOR in Table 6.9-1.

- The effective flow/transport area for any type of waste package, as a fraction of the total surface area, is denoted as WP_TRANS_AREA and calculated as:

$$
\text { WP_TRANS_AREA }=\text { DAMFRAC_TOTAL } * \text { SCALE_FACTOR. (Eq. 6-14) }
$$

Significant advective flow through the network of tight SCCs on the waste package or the drip shield has been screened out of TSPA (Section 6.3.5 and (BSC 2005 [DIRS 173781], Section 6.2.63)).

9. Direct, structural deformation of the drip shield from vibratory ground motion and from rockfall induced by vibratory ground motion is not included in the seismic scenario class for TSPA-LA because the associated SCCs are expected to limit advective flow to insignificant levels (Section 6.3.6 and (BSC 2005 [DIRS 173781], Section 6.2.64)). Drip shield separation has also been screened out of TSPA (see discussion in Section 6.5.5). 
10. Fuel rod cladding does not fail for a ground motion with a PGV level of $0.55 \mathrm{~m} / \mathrm{s}$ or less (Section 6.5.6). Cladding experiences complete failure (i.e., 100 percent of the cladding is perforated in all waste packages) at the time of the seismic event for ground motions with PGV amplitude of $1.05 \mathrm{~m} / \mathrm{s}$ or greater (Section 6.5.6).

The abstraction for fuel rod cladding failure is defined in Table 6.9-1 with a linear interpolation for the percent failed cladding between the appropriate values of PGV. In other words, percent failed cladding is (1) zero for PGV values less than $0.55 \mathrm{~m} / \mathrm{s}$, (2) 100 percent for PGV values greater than $1.05 \mathrm{~m} / \mathrm{s}$, and (3) based on a linear interpolation for intermediate values of $\mathrm{PGV}$ between the end points with 0 percent failed cladding at $0.55-\mathrm{m} / \mathrm{s}$ PGV and 100 percent failed cladding at $1.05-\mathrm{m} / \mathrm{s}$ PGV. This failure abstraction applies to the fraction of cladding that is not initially damaged.

This parameter is denoted by CLAD_DAMAGE_GM in Table 6.9-1. There is no uncertainty in this failure abstraction because it is a bounding estimate for fuel rod cladding failure. The percent of failed cladding is applied to all fuel assemblies in the repository (i.e., there is no spatial variability), except for any assemblies with initial cladding failures.

11. Determine the percent failed area on the waste packages in the lithophysal zones due to fault displacement. The expected number of waste packages that fail, as a function of annual exceedance frequency, is defined in Table 6.9-1. Fractional values for failed waste packages are rounded to the nearest integer.

- The expected number of waste packages that fail from fault displacement is a small fraction of the total packages in the repository because few waste packages are located on known faults. In addition, these failures only occur for a small fraction of the realizations in the seismic scenario class because there are no failures from fault displacement for a displacement less than $671 \mathrm{~mm}$ (Table 6.7-3). Displacements greater than $671 \mathrm{~mm}$ first occur on the Drill Hole Wash fault, the Pagany Wash fault, and the Sever Wash fault at an annual frequency of occurrence less than or equal to $2 \times 10^{-7}$ per year (Table 6.7-9), corresponding to the $2.92-\mathrm{m} / \mathrm{s} \mathrm{PGV} \mathrm{level}{ }^{12}$ on the bounded hazard curve. In this situation, damage from fault displacement only occurs for PGV values greater than $2.92 \mathrm{~m} / \mathrm{s}$, and a special waste package group(s) or bin(s) is used to represent the waste package failures from fault displacement.

- The thermohydrologic and seepage environment for the special group(s) or bin(s) are chosen independently and randomly. For example, if the fault-failed packages are binned into two groups for commercial spent nuclear fuel (CSNF) and codisposal (CDSP) packages, then two randomly chosen environments are used for each of the two groups.

12 The exceedance frequency $2 \times 10^{-7} 1 / \mathrm{yr}$ is bracketed by the points $\left(2.507 \times 10^{-7} 1 / \mathrm{yr}, 2.8 \mathrm{~m} / \mathrm{s}\right)$ and $\left(1.731 \times 10^{-7}\right.$ $1 / \mathrm{yr}, 3.0 \mathrm{~m} / \mathrm{s})$ on the bounded hazard curve. For a power law fit of $\lambda=a(P G V)^{b}$ between points, $b$ and $a$ are defined as $\quad b=\log \left(2.507 \times 10^{-7} / 1.731 \times 10^{-7}\right) / \log (2.8 / 3)=-5.3685$ and $a=\left(2.507 \times 10^{-7}\right) /(2.8)^{-5.3685}=6.3055 \times 10^{-5}$. The corresponding value of PGV at $2 \times 10^{-7} 1 / \mathrm{yr}$ is then $P G V=(\lambda / a)^{1 / b}=\left(2 \times 10^{-7} / 6.3055 \times 10^{-5}\right)^{-0.1863}=2.92 \mathrm{~m} / \mathrm{s}$. 
- When a waste package fails by fault displacement, the failed area per representative waste package is determined by sampling a uniform distribution with a lower bound of $0 \mathrm{~m}^{2}$ and an upper bound equal to the area of the waste package lid. These sampled distributions are denoted by FAILED_AREA_PWR, FAILED_AREA_BWR, FAILED_AREA_NAVAL, and FAILED_AREA_HLW in Table $\overline{6} .9-1$.

- The area of the lid for the PWR, BWR, Naval, and HLW groups is $2.105 \mathrm{~m}^{2}$, $2.204 \mathrm{~m}^{2}, 2.728 \mathrm{~m}^{2}$, and $3.2836 \mathrm{~m}^{2}$, respectively. These areas are denoted as LID_AREA_PWR, LID_AREA_BWR, LID_AREA_NAVAL, and LID_AREA_HLW in Table 6.9-1.

- The surface area of a package in the PWR, BWR, Naval, and HLW groups is $30.15 \mathrm{~m}^{2}, 30.85 \mathrm{~m}^{2}, 37.85 \mathrm{~m}^{2}$, and $35.60 \mathrm{~m}^{2}$, respectively. These areas are denoted as SURF_AREA_PWR, SURF_AREA_BWR, SURF_AREA_NAVAL, and SURF_AREA_HLW in Table 6.9-1.

- The fraction of failed area for the CSNF (PWR, BWR, and Naval) waste package types is calculated as:

FRACTION_FAILED_CSNF $=$ FAILED_AREA_CSNF/SURF_AREA_CSNF

where

FAILED_AREA_CSNF $=$ NO_PWR_FAILURES*FAILED_AREA_PWR

+ NO_BWR_FAILURES*FAILED_AREA_BWR

+ NO_NAVĀL_FAILURES*FAILED_AREA_NAVAL

(Eq. 6-16)

and

SURF_AREA_CSNF $=$ NO_PWR_FAILURES*SURF_AREA_PWR

+ NO_BWR_FAILURES*SURF_AREA_BWR

+ NO_NAVĀL_FAILURES*SURF_AREA_NAVAL

(Eq. 6-17)

The fraction of failed area for the CDSP (HLW) waste package type is given by:

FRACTION_FAILED_CSDP $=$ FAILED_AREA_HLW/SURF_AREA_HLW.

These failed areas allow advective flow and advective and diffusive transport.

- The number of package failures for the four waste package types are denoted by NO_PWR_FAILURES, NO_BWR_FAILURES, NO_NAVAL_FAILURES, and NO_HLW_FAILURES in Table 6.9-1. 
- If a waste package is damaged by fault displacement, the associated drip shield is taken to be 100 percent damaged. There is no flux splitting (i.e., diversion of seepage) for these failed drip shields. The number of impacted drip shields is then identical to the total number of waste packages that will be damaged by the fault displacement. The parameters NO_DRIP_SHIELD_FD and DRIP_SHIELD_DAMAGE_FD in Table 6.9-1 define the number and amount of damage to the drip shields from fault displacement.

- Fuel rod cladding in waste packages that are damaged by a fault displacement is taken to be 100 percent perforated. The 100 percent perforation applies to all the fuel assemblies in the number of waste packages that are damaged by the fault displacement. The parameters NO_CLAD_FD and CLAD_DAMAGE_FD in Table 6.9-1 define the number and amount of damage to the cladding from fault displacement.

12. Modify the seepage in the lithophysal zones after the seismic event.

The seepage into the emplacement drifts in the lithophysal zones is determined by using the seepage Table for collapsed drifts, as provided in LB0307SEEPDRCL.002 [DIRS 164337], file: ResponseSurfaceSMPACollapsedDrift.dat (Section 6.8.1). This seepage Table is invoked after a seismic hazard occurs, provided the hazard is large enough to collapse the drifts. For TSPA-LA, all ground motions with a PGV greater than $0.384 \mathrm{~m} / \mathrm{s}$ will be considered large enough to collapse drifts in the lithophysal zones (Section 6.8.1). Recent rockfall analyses have determined that a PGV of approximately $2 \mathrm{~m} / \mathrm{s}$ is a more reasonable threshold for drift collapse in the lithophysal zones (BSC 2004 [DIRS 166107] Section 6.4.2.2.2, 4th bullet under subheading 'Discussion'). However, the seismic scenario class continues to use the value of $0.384 \mathrm{~m} / \mathrm{s}$ because the technical basis for the $2.0 \mathrm{~m} / \mathrm{s}$ threshold for collapse was established after the start of TSPA-LA model development. The value of $0.384 \mathrm{~m} / \mathrm{s}$ is considered conservative because it results in more seepage into the drifts and higher waste package temperatures (Section 6.8.2). COLLAPSE_THRESH_LITH in Table 6.9-1 defines the PGV threshold $(0.384 \mathrm{~m} / \mathrm{s})$ for collapse in lithophysal zones.

There is no change in the seepage flux into nonlithophysal zones after a seismic hazard occurs (Section 6.8.1). The parameter COLLAPSE_THRESH_NONLITH in Table 6.9-1 defines the PGV threshold for collapse in nonlithophysal zones. COLLAPSE_THRESH_NONLITH is set to $5.35 \mathrm{~m} / \mathrm{s}$ (Section 6.8.1). There is no collapse in nonlithophysal zones with this value because $P G V_{i}$ is always less than $4.07 \mathrm{~m} / \mathrm{s}$ for TSPA-LA (Section 6.4.3).

13. Modify the temperature and relative humidity on the waste after drift collapse in the lithophysal zones.

The temperature and relative humidity of the waste package after drift collapse will be defined by the data in DTN: LL040310323122.044 [DIRS 168769]: temperature time histories defined in files: Twp_dhlw-l1_3case.dat, Twp_dhlw-s1_3case.dat, Twp_bwr1-1_3case.dat, Twp_bwr1-2_3case.dat, Twp_bwr2-1_3case.dat, 
Twp_pwr1-1_3case.dat, Twp_pwr1-2_3case.dat, and Twp_pwr2-1_3case.dat; relative humidity time histories defined in files: RHwp_dhlw-l1_3case.dat, RHwp_dhlw-s1_3case.dat, RHwp_bwr1-1_3case.dat, RHwp_bwr1-2_3case.dat, RHwp_bwr2-1_3case.dat, RHwp_pwr1-_3case.dat, RHwp_pwr1-2_3case.dat, and RHwp_pwr2-1 3case.dat. If a TSPA-LA model cannot accept eight waste package emplacement configurations in this DTN, then the PWR 2-1 and DHLW-s1 configurations are recommended for defining the temperature and relative humidity changes for CSNF and co-disposal waste package groups in TSPA-LA. These new histories are used for seismic hazards with a PGV level greater than $0.384 \mathrm{~m} / \mathrm{s}$. There is no change in the temperature and relative humidity for the nonlithophysal zones because the drifts do not collapse in the nonlithophysal zones (Section 6.8.1), and the amount of rubble is generally expected to be insufficient to completely cover the top and sides of the drip shield.

Table 6.9-1. Definition of Parameters for the Seismic Scenario Class

\begin{tabular}{|c|c|c|}
\hline Parameter Name & Description, Units, and Type & Definition \\
\hline LAMBDA & $\begin{array}{l}\text { Distribution of annual exceedance } \\
\text { frequency for the seismic scenario class } \\
\text { Units: }\{1 / y r\} \\
\text { Type: Distribution sampled once per } \\
\text { realization }\end{array}$ & $\begin{array}{l}\text { Log-Uniform Distribution: } \\
\text { Minimum Value: LAMBDA_MIN } \\
\text { Maximum Value: LAMBDA_MAX }\end{array}$ \\
\hline LAMBDA_MIN & $\begin{array}{l}\text { Minimum annual exceedance frequency } \\
\text { Units: }\{1 / y r\} \\
\text { Type: Data }\end{array}$ & $1 \times 10^{-8}$ per year \\
\hline LAMBDA_MAX & $\begin{array}{l}\text { Maximum annual exceedance frequency } \\
\text { Units: }\{1 / y r\} \\
\text { Type: Data }\end{array}$ & $1 \times 10^{-4}$ per year \\
\hline PGV & $\begin{array}{l}\text { Value of PGV for this realization } \\
\text { Units: }\{\mathrm{m} / \mathrm{s}\} \\
\text { Type: Lookup table, function of } \\
\text { LAMBDA }\end{array}$ & $\begin{array}{l}\text { Table lookup as a function of the value of } \\
\text { LAMBDA for this realization. Use log-log } \\
\text { interpolation between } \lambda \text { values: } \\
\begin{array}{ll}\lambda(1 / \mathrm{yr}) & \text { PGV }(\mathrm{m} / \mathrm{s}) \\
1.000 \times 10^{-4} & 0.4019 \\
3.826 \times 10^{-5} & 0.6 \\
1.919 \times 10^{-5} & 0.8 \\
9.955 \times 10^{-6} & 1.05 \\
6.682 \times 10^{-6} & 1.2 \\
3.812 \times 10^{-6} & 1.4 \\
2.136 \times 10^{-6} & 1.6 \\
1.288 \times 10^{-6} & 1.8 \\
8.755 \times 10^{-7} & 2.0 \\
6.399 \times 10^{-7} & 2.2 \\
4.518 \times 10^{-7} & 2.44 \\
3.504 \times 10^{-7} & 2.6 \\
2.507 \times 10^{-7} & 2.8 \\
1.731 \times 10^{-7} & 3.0 \\
1.137 \times 10^{-7} & 3.2 \\
7.168 \times 10^{-8} & 3.4 \\
4.362 \times 10^{-8} & 3.6 \\
2.508 \times 10^{-8} & 3.8 \\
1.319 \times 10^{-8} & 4.0 \\
5.967 \times 10^{-9} & 4.2\end{array}\end{array}$ \\
\hline
\end{tabular}


Table 6.9-1. Definition of Parameters for the Seismic Scenario Class (Continued)

\begin{tabular}{|c|c|c|}
\hline Parameter Name & Description, Units, and Type & Definition \\
\hline SOURCE & $\begin{array}{l}\text { Discrete distribution for the source of the } \\
\text { engineering data for the end-to-end } \\
\text { damage abstraction; Value is } 1 \text { for } \\
\text { LS-DYNA or } 2 \text { for UDEC } \\
\text { Units: }\{-\}^{\mathrm{a}} \\
\text { Type: Distribution sampled once per } \\
\text { realization } \\
{ }^{\mathrm{a}}\{-\} \text { indicates a dimensionless quantity }\end{array}$ & $\begin{array}{l}\text { Discrete distribution: } \\
\text { Value }=1 \text { with probability of } 0.5 \text { (for } \\
\text { LS-DYNA) } \\
\text { Value }=2 \text { with probability of } 0.5 \text { (for UDEC) }\end{array}$ \\
\hline PROB_DAM_RAND & $\begin{array}{l}\text { Random number between } 0 \text { and } 1 \text { that } \\
\text { determines the damage state in this } \\
\text { realization } \\
\text { Units: }\{-\} \\
\text { Type: Distribution sampled once per } \\
\text { realization }\end{array}$ & $\begin{array}{l}\text { UNIFORM distribution: } \\
\text { Lower bound }=0 \\
\text { Upper bound }=1\end{array}$ \\
\hline DAMAGE_STATE & $\begin{array}{l}\text { Cumulative discrete distribution for the } \\
\text { waste package damage state in this } \\
\text { realization. Value is } 3,2,1 \text {, or } 0 \\
\text { Units: }\{-\} \\
\text { Type: Distribution sampled once per } \\
\text { realization }\end{array}$ & $\begin{array}{l}\text { CUMULATIVE DISCRETE distribution: } \\
=3 \text {, both end-to-end and waste } \\
\text { package-pallet impact damage occurs; } \\
=2 \text {, only end-to-end impact damage } \\
\text { occurs; } \\
=1 \text {, only waste package-pallet impact } \\
\text { damage occurs; } \\
=0, \text { no impact damage occurs. }\end{array}$ \\
\hline PROB_NODAM_DYNA & $\begin{array}{l}\text { Probability of no damage for DYNA } \\
\text { Units: }\{-\} \\
\text { Type: Function of PGV }\end{array}$ & $\operatorname{MAX}\left(\operatorname{MIN}\left[1,(0.1376)(5.35-\mathrm{PGV})^{1.360}\right], 0\right)$ \\
\hline PROB_NODAM_UDEC & $\begin{array}{l}\text { Probability of no damage for UDEC } \\
\text { Units: }\{-\} \\
\text { Type: Function of PGV }\end{array}$ & $\begin{array}{l}\left.\text { MAX(MIN }\left[1,(0.3823)(4.0-P G V)^{0.8137}\right], 0\right) \\
\text { Note: If PGV is greater than } 4.0 \mathrm{~m} / \mathrm{s} \text {, reset } \\
\text { the term }(4.0-\mathrm{PGV}) \text { to zero. }\end{array}$ \\
\hline PROB_NODAM & $\begin{array}{l}\text { Probability of no damage for this } \\
\text { realization } \\
\text { Units: }\{-\} \\
\text { Type: Switch }\end{array}$ & $\begin{array}{l}\text { If (SOURCE=1, PROB_NODAM_DYNA, } \\
\text { Else PROB_NODAM_UDEC) }\end{array}$ \\
\hline NODAM_SWITCH & $\begin{array}{l}\text { Switch defining the occurrence of } \\
\text { damage from end-to-end impacts in this } \\
\text { realization. } \\
\text { Units: }\{-\} \\
\text { Type: Switch }\end{array}$ & $\begin{array}{l}=1 \text { if no end-to-end damage occurs; } \\
=0 \text { if end-to-end damage occurs. }\end{array}$ \\
\hline $\begin{array}{l}\text { WP_DAMAGE_UNCER } \\
\text { TAINTY }\end{array}$ & $\begin{array}{l}\text { Uniform distribution that defines the } \\
\text { correlation between the four parameters } \\
\text { DA_DYNA, DA_UDEC, } \\
\text { PROB_NODAM_PALLET, and } \\
\text { DA_PALLET } \\
\text { Units: }\{-\} \\
\text { Type: Distribution sampled once per } \\
\text { realization }\end{array}$ & $\begin{array}{l}\text { UNIFORM distribution: } \\
\text { Lower bound }=0 \\
\text { Upper bound }=1\end{array}$ \\
\hline MEDIAN_DYNA_80 & $\begin{array}{l}\text { Median value of damaged area for a } \\
\text { power law fit for the LS-DYNA data with } \\
\text { an } 80 \text { percent residual stress failure } \\
\text { criterion } \\
\text { Units: }\left\{\mathrm{m}^{2}\right\} \\
\text { Type: Function }\end{array}$ & $\left(2.712 \times 10^{-4}\right) \mathrm{PGV}^{3.0338}$ \\
\hline
\end{tabular}


Table 6.9-1. Definition of Parameters for the Seismic Scenario Class (Continued)

\begin{tabular}{|c|c|c|}
\hline Parameter Name & Description, Units, and Type & Definition \\
\hline MEDIAN_DYNA_90 & $\begin{array}{l}\text { Median value of damaged area for a } \\
\text { power law fit for the LS-DYNA data with } \\
\text { a } 90 \text { percent residual stress failure } \\
\text { criterion } \\
\text { Units: }\left\{\mathrm{m}^{2}\right\} \\
\text { Type: } \text { Function }\end{array}$ & $\left(2.029 \times 10^{-4}\right) \mathrm{PGV}^{2.6101}$ \\
\hline MEDIAN_UDEC_80 & $\begin{array}{l}\text { Median value of damaged area for a } \\
\text { power law fit for the UDEC data with an } \\
80 \text { percent residual stress failure criterion } \\
\text { Units: }\left\{\mathrm{m}^{2}\right\} \\
\text { Type: Function }\end{array}$ & $\left(9.665 \times 10^{-4}\right) \mathrm{PGV}^{3.1475}$ \\
\hline MEDIAN_UDEC_90 & $\begin{array}{l}\text { Median value of damaged area for a } \\
\text { power law fit for the UDEC data with a } \\
90 \text { percent residual stress failure criterion } \\
\text { Units: }\left\{\mathrm{m}^{2}\right\} \\
\text { Type: Function }\end{array}$ & $\left(4.850 \times 10^{-4}\right) \mathrm{PGV}^{2.9477}$ \\
\hline SD_DYNA_80 & $\begin{array}{l}\text { Standard deviation of the residuals of the } \\
\text { natural log of damaged area relative to } \\
\text { the natural log of the median (i.e., the } \\
\text { power law fit) for the LS-DYNA data with } \\
\text { an } 80 \text { percent residual stress failure } \\
\text { criterion } \\
\text { Units: }\{-\} \\
\text { Type: Data }\end{array}$ & 1.463 \\
\hline SD_DYNA_90 & $\begin{array}{l}\text { Standard deviation of the residuals of the } \\
\text { natural log of damaged area relative to } \\
\text { the natural log of the median (i.e., the } \\
\text { power law fit) for the LS-DYNA data with } \\
\text { a } 90 \text { percent residual stress failure } \\
\text { criterion } \\
\text { Units: }\{-\} \\
\text { Type: Data }\end{array}$ & 1.393 \\
\hline SD_UDEC_80 & $\begin{array}{l}\text { Standard deviation of the residuals of the } \\
\text { natural log of damaged area relative to } \\
\text { the natural log of the median (i.e., the } \\
\text { power law fit) for the UDEC data with an } \\
80 \text { percent residual stress failure criterion } \\
\text { Units: }\{-\} \\
\text { Type: Data }\end{array}$ & 1.253 \\
\hline SD_UDEC_90 & $\begin{array}{l}\text { Standard deviation of the residuals of the } \\
\text { natural log of damaged area relative to } \\
\text { the natural log of the median (i.e., the } \\
\text { power law fit) for the UDEC data with a } \\
90 \text { percent residual stress failure criterion } \\
\text { Units: }\{-\} \\
\text { Type: Data }\end{array}$ & 1.164 \\
\hline DA_DYNA_80 & $\begin{array}{l}\text { Damaged area for a In-normal } \\
\text { distribution, based on the LS-DYNA data } \\
\text { with an } 80 \text { percent residual stress failure } \\
\text { criterion } \\
\text { Units: }\left\{\mathrm{m}^{2}\right\} \\
\text { Type: Distribution } \\
\text { NB: This parameter and DA_DYNA_90 } \\
\text { are perfectly correlated. }\end{array}$ & $\begin{array}{l}\text { LN-NORMAL distribution: } \\
\text { Median = MEDIAN_DYNA_80 } \\
\text { Standard deviation= SD_DYNA_80 }\end{array}$ \\
\hline
\end{tabular}


Table 6.9-1. Definition of Parameters for the Seismic Scenario Class (Continued)

\begin{tabular}{|c|c|c|}
\hline Parameter Name & Description, Units, and Type & Definition \\
\hline DA_DYNA_90 & $\begin{array}{l}\text { Damaged area for a In-normal } \\
\text { distribution, based on the LS-DYNA data } \\
\text { with a } 90 \text { percent residual stress failure } \\
\text { criterion } \\
\text { Units: }\left\{\mathrm{m}^{2}\right\} \\
\text { Type: Distribution } \\
\text { NB: This parameter and DA_DYNA_80 } \\
\text { are perfectly correlated. }\end{array}$ & $\begin{array}{l}\text { LN-NORMAL distribution: } \\
\text { Median = MEDIAN_DYNA_90 } \\
\text { Standard deviation = SD_DYNA_90 }\end{array}$ \\
\hline DA_UDEC_80 & $\begin{array}{l}\text { Damaged area for a In-normal } \\
\text { distribution, based on the UDEC data } \\
\text { with an } 80 \text { percent residual stress failure } \\
\text { criterion } \\
\text { Units: }\left\{\mathrm{m}^{2}\right\} \\
\text { Type: Distribution } \\
\text { NB: This parameter and DA_UDEC_90 } \\
\text { are perfectly correlated. }\end{array}$ & $\begin{array}{l}\text { LN-NORMAL distribution: } \\
\text { Median = MEDIAN_UDEC_80 } \\
\text { Standard deviation = SD_UDEC_80 }\end{array}$ \\
\hline DA_UDEC_90 & $\begin{array}{l}\text { Damaged area for a In-normal } \\
\text { distribution, based on the UDEC data } \\
\text { with a } 90 \text { percent residual stress failure } \\
\text { criterion } \\
\text { Units: }\left\{\mathrm{m}^{2}\right\} \\
\text { Type: Distribution } \\
\text { NB: This parameter and DA_UDEC_80 } \\
\text { are perfectly correlated. }\end{array}$ & $\begin{array}{l}\text { LN-NORMAL distribution: } \\
\text { Median = MEDIAN_UDEC_90 } \\
\text { Standard deviation = SD_UDEC_90 }\end{array}$ \\
\hline DA_DYNA & $\begin{array}{l}\text { Damaged area for the LS-DYNA source } \\
\text { data, based on interpolating between the } \\
\text { damaged areas for the } 80 \text { and } \\
90 \text { percent residual stress failure criteria } \\
\text { Units: }\left\{\mathrm{m}^{2}\right\} \\
\text { Type: Function } \\
\text { NB: The sampled value for } \\
\text { WP_DAMAGE_UNCERTAINTY is used } \\
\text { to interpolate between the } 80 \text { and } \\
90 \text { percent residual stress threshold } \\
\text { values. } \\
\text { This parameter and DA_UDEC, } \\
\text { PROB_NODAM_PALLET and } \\
\text { DA_PALLET are perfectly correlated } \\
\text { because the interpolations between the } \\
\text { values at the } 80 \text { and } 90 \text { percent residual } \\
\text { stress thresholds are based on the same } \\
\text { value of WP_DAMAGE_UNCERTAINTY. }\end{array}$ & $\begin{array}{l}\text { WP_DAMAGE_UNCERTAINTY } \\
\text { *(DA_DYNA_80-DA_DYNA_90) } \\
\text { + DA_DYNA_90 }\end{array}$ \\
\hline
\end{tabular}


Table 6.9-1. Definition of Parameters for the Seismic Scenario Class (Continued)

\begin{tabular}{|c|c|c|}
\hline Parameter Name & Description, Units, and Type & Definition \\
\hline DA_UDEC & $\begin{array}{l}\text { Damaged area for the UDEC source } \\
\text { data, based on interpolating between the } \\
\text { damaged areas for the } 80 \text { and } \\
90 \text { percent residual stress failure criteria } \\
\text { Units: }\left\{\mathrm{m}^{2}\right\} \\
\text { Type: Function } \\
\text { NB: The sampled value for } \\
\text { WP_DAMAGE_UNCERTAINTY is used } \\
\text { to interpolate between the } 80 \text { and } \\
90 \text { percent residual stress threshold } \\
\text { values. } \\
\text { This parameter and DA_DYNA, } \\
\text { PROB_NODAM_PALLET and } \\
\text { DA_PALLET are perfectly correlated } \\
\text { because the interpolations between the } \\
\text { values at the } 80 \text { and } 90 \text { percent residual } \\
\text { stress thresholds are based on the same } \\
\text { value of WP_DAMAGE_UNCERTAINTY. }\end{array}$ & $\begin{array}{l}\text { WP_DAMAGE_UNCERTAINTY } \\
\text { *(DA_UDEC_80 - DA_UDEC_90) } \\
\text { + DA_UDEC_90 }\end{array}$ \\
\hline DA_WPtoWP & $\begin{array}{l}\text { Damaged area for end-to-end impacts } \\
\text { Units: }\left\{\mathrm{m}^{2}\right\} \\
\text { Type: Switch }\end{array}$ & $\begin{array}{l}\text { If (SOURCE=1, DA_DYNA, } \\
\text { Else DA_UDEC) }\end{array}$ \\
\hline SURFAREA_21PWR & $\begin{array}{l}\text { Surface area of the } 21-P W R \text { waste } \\
\text { package for the kinematic calculations of } \\
\text { end-to-end impacts of adjacent waste } \\
\text { packages } \\
\text { Units: }\left\{\mathrm{m}^{2}\right\} \\
\text { Type: Data }\end{array}$ & 30.05 \\
\hline DAMFRAC_WPtoWP & $\begin{array}{l}\text { Fraction of surface area on the waste } \\
\text { package damaged by end-to-end } \\
\text { impacts. Includes factor of } \\
\text { NODAM_SWITCH to represent the } \\
\text { fraction of realizations without damage } \\
\text { from end-to-end impacts } \\
\text { Units: }\{-\} \\
\text { Type: Function }\end{array}$ & $\begin{array}{l}\text { DA_WPtoWP * NODAM_SWITCH / } \\
\text { SURFAREA_21PWR }\end{array}$ \\
\hline $\begin{array}{l}\text { PROB_NODAM_PALLE } \\
\text { T_80 }\end{array}$ & $\begin{array}{l}\text { Probability of no damage for waste } \\
\text { package-Pallet impacts for } 80 \text { percent } \\
\text { residual stress threshold } \\
\text { Units: }\{-\} \\
\text { Type: Function of PGV }\end{array}$ & $\begin{array}{l}\text { MAX(MIN }\left(1,(0.1049)(4.0-P G V)^{1.7613}, 0\right) \\
\text { Note: If PGV is greater than } 4.0 \mathrm{~m} / \mathrm{s} \text {, reset } \\
\text { the term }(4.0-\mathrm{PGV}) \text { to zero. }\end{array}$ \\
\hline $\begin{array}{l}\text { PROB_NODAM_PALLE } \\
\text { T_90 }\end{array}$ & $\begin{array}{l}\text { Probability of no damage for waste } \\
\text { package-Pallet impacts for } 90 \text { percent } \\
\text { residual stress threshold } \\
\text { Units: }\{-\} \\
\text { Type: Function of PGV }\end{array}$ & $\begin{array}{l}\operatorname{MAX}\left(\operatorname{MIN}\left(1,(0.0 .3859)(4.0-P G V)^{0.7436}, 0\right)\right. \\
\text { Note: If PGV is greater than } 4.0 \mathrm{~m} / \mathrm{s} \text {, reset } \\
\text { the term }(4.0-\mathrm{PGV}) \text { to zero. }\end{array}$ \\
\hline
\end{tabular}


Table 6.9-1. Definition of Parameters for the Seismic Scenario Class (Continued)

\begin{tabular}{|c|c|c|}
\hline Parameter Name & Description, Units, and Type & Definition \\
\hline $\begin{array}{l}\text { PROB_NODAM_PALLE } \\
\mathrm{T}\end{array}$ & $\begin{array}{l}\text { Probability of no damage for waste } \\
\text { package-pallet impacts } \\
\text { Units: }\{-\} \\
\text { Type: Function } \\
\text { NB: The sampled value for } \\
\text { WP_DAMAGE_UNCERTAINTY is used } \\
\text { to interpolate between the } 80 \text { and } \\
90 \text { percent residual stress threshold } \\
\text { values. } \\
\text { This parameter and DA_DYNA, } \\
\text { DA_UDEC, and DA_PALLET are } \\
\text { perfectly correlated because the } \\
\text { interpolations between the values at the } \\
80 \text { and } 90 \text { percent residual stress } \\
\text { thresholds are based on the same value } \\
\text { of WP_DAMAGE_UNCERTAINTY }\end{array}$ & $\begin{array}{l}\text { WP_DAMAGE_UNCERTAINTY } \\
\text { *(PROB_NODAM_PALLET_80- } \\
\text { PROB_NODAM_PALLET_90) } \\
\text { + PROB_NODAM_PALLET_90 }\end{array}$ \\
\hline NODAM_SW_PALLET & $\begin{array}{l}\text { Switch defining the occurrence of } \\
\text { damage from waste package-pallet } \\
\text { impacts in this realization } \\
\text { Units: }\{-\} \\
\text { Type: Switch }\end{array}$ & $\begin{array}{l}=0 \text { if no damage occurs from waste } \\
\text { package-pallet impacts; } \\
=1 \text { if damage occurs from waste } \\
\text { package-pallet impacts. }\end{array}$ \\
\hline MEDIAN_PALLET_80 & $\begin{array}{l}\text { Median value of damaged area for a } \\
\text { power law fit to waste package-pallet } \\
\text { damage with an } 80 \text { percent residual } \\
\text { stress failure criterion } \\
\text { Units: }\left\{\mathrm{m}^{2}\right\} \\
\text { Type: Function } \\
\end{array}$ & $\left(2.242 \times 10^{-3}\right) \mathrm{PGV}^{1.6586}$ \\
\hline MEDIAN_PALLET_90 & $\begin{array}{l}\text { Median value of damaged area for a } \\
\text { power law fit to waste package-pallet } \\
\text { damage with a } 90 \text { percent residual stress } \\
\text { failure criterion } \\
\text { Units: }\left\{\mathrm{m}^{2}\right\} \\
\text { Type: Function }\end{array}$ & $\left(1.369 \times 10^{-3}\right) \mathrm{PGV}^{1.6860}$ \\
\hline SD_PALLET_80 & $\begin{array}{l}\text { Standard deviation of the residuals of the } \\
\text { natural log of damaged area versus the } \\
\text { natural log of the median (i.e., the power } \\
\text { law fit) for waste package-pallet damage } \\
\text { with an } 80 \text { percent residual stress failure } \\
\text { criterion } \\
\text { Units: }\{-\} \\
\text { Type: Data }\end{array}$ & 1.023 \\
\hline SD_PALLET_90 & $\begin{array}{l}\text { Standard deviation of the residuals of the } \\
\text { natural log of damaged area versus the } \\
\text { natural log of the median (i.e., the power } \\
\text { law fit) for waste package-pallet damage } \\
\text { with a } 90 \text { percent residual stress failure } \\
\text { criterion } \\
\text { Units: }\{-\} \\
\text { Type: Data }\end{array}$ & 1.048 \\
\hline DA_PALLET_80 & $\begin{array}{l}\text { Damaged area for a In-normal } \\
\text { distribution, based on the data for waste } \\
\text { package-pallet impacts with an } \\
80 \text { percent residual stress failure criterion } \\
\text { Units: }\left\{\mathrm{m}^{2}\right\} \\
\text { Type: Distribution }\end{array}$ & $\begin{array}{l}\text { LN-NORMAL distribution: } \\
\text { Median = MEDIAN_PALLET_80 } \\
\text { Standard deviation = SD_PALLET_80 }\end{array}$ \\
\hline
\end{tabular}


Table 6.9-1. Definition of Parameters for the Seismic Scenario Class (Continued)

\begin{tabular}{|c|c|c|}
\hline Parameter Name & Description, Units, and Type & Definition \\
\hline DA_PALLET_90 & $\begin{array}{l}\text { Damaged area for a In-normal } \\
\text { distribution, based on the data for waste } \\
\text { package-pallet impacts with an } \\
90 \text { percent residual stress failure criterion } \\
\text { Units: }\left\{\mathrm{m}^{2}\right\} \\
\text { Type: Distribution } \\
\text { NB: This parameter and } \\
\text { DA_PALLET_ } 80 \text { are perfectly correlated. }\end{array}$ & $\begin{array}{l}\text { LN-NORMAL distribution: } \\
\text { Median = MEDIAN_PALLET_90 } \\
\text { Standard deviation = SD_PALLET_90 }\end{array}$ \\
\hline DA_PALLET & $\begin{array}{l}\text { Damaged area for waste package-pallet } \\
\text { impacts based on interpolating between } \\
\text { the damaged areas for the } 80 \text { and } \\
90 \text { percent residual stress failure criteria } \\
\text { Units: }\left\{\mathrm{m}^{2}\right\} \\
\text { Type: The sampled value for } \\
\text { WP_DAMAGE_UNCERTAINTY is used } \\
\text { to interpolate between the } 80 \text { and } \\
90 \text { percent residual stress threshold } \\
\text { values. } \\
\text { This parameter and DA_DYNA, } \\
\text { DA_UDEC, and } \\
\text { PROB_NODAM_PALLET are perfectly } \\
\text { correlated because the interpolations } \\
\text { between the values at the } 80 \text { and } \\
90 \text { percent residual stress thresholds are } \\
\text { based on the same value of } \\
\text { WP_DAMAGE_UNCERTAINTY }\end{array}$ & $\begin{array}{l}\text { WP_DAMAGE_UNCERTAINTY } \\
{ }^{*}(\text { DA_PALLET_80 - DA_PALLET_90) } \\
\text { + DA_PALLET_90 }\end{array}$ \\
\hline $\begin{array}{l}\text { SURFAREA_21PWR_P } \\
\text { ALLET }\end{array}$ & $\begin{array}{l}\text { Surface area of the } 21-P W R \text { waste } \\
\text { package for the waste package-pallet } \\
\text { impact calculations } \\
\text { Units: }\left\{\mathrm{m}^{2}\right\} \\
\text { Type: Data }\end{array}$ & 28.2 \\
\hline DAMFRAC_PALLET & $\begin{array}{l}\text { Fraction of surface area on the waste } \\
\text { package damaged by WP-pallet impacts. } \\
\text { Includes factor of NODAM_SW_PALLET } \\
\text { to represent the fraction of realizations } \\
\text { without damage from waste } \\
\text { package-pallet impacts } \\
\text { Units: }\{-\} \\
\text { Type: Function }\end{array}$ & $\begin{array}{l}\text { DA_PALLET * NODAM_SW_PALLET / } \\
\text { SURFAREA_21PWR_PALLET }\end{array}$ \\
\hline DAMFRAC_TOTAL & $\begin{array}{l}\text { Total fraction of damaged surface area } \\
\text { from waste package-waste package and } \\
\text { waste package-pallet impacts } \\
\text { Units: }\{-\} \\
\text { Type: Function }\end{array}$ & $\begin{array}{l}\text { DAMFRAC_WPtoWP + } \\
\text { DAMFRAC_PALLET }\end{array}$ \\
\hline $\begin{array}{l}\text { SCALE_FACTOR_ } \\
\text { MIN }\end{array}$ & $\begin{array}{l}\text { Minimum value of scale factor for } \\
\text { defining the transport area of a network } \\
\text { of SCCs on the waste package } \\
\text { Units: }\{-\} \\
\text { Type: Constant }\end{array}$ & 0.00328 \\
\hline $\begin{array}{l}\text { SCALE_FACTOR_ } \\
\text { MAX }\end{array}$ & $\begin{array}{l}\text { Maximum value of scale factor for } \\
\text { defining the area of a network of SCCs } \\
\text { on the waste package } \\
\text { Units: }\{-\} \\
\text { Type: Constant }\end{array}$ & 0.0131 \\
\hline
\end{tabular}


Table 6.9-1. Definition of Parameters for the Seismic Scenario Class (Continued)

\begin{tabular}{|c|c|c|}
\hline Parameter Name & Description, Units, and Type & Definition \\
\hline SCALE_FACTOR & $\begin{array}{l}\text { Scale factor distribution for the area of a } \\
\text { network of SCCs on the waste package } \\
\text { for this realization } \\
\text { Units: }\{-\} \\
\text { Type: Distribution sampled once per } \\
\text { realization }\end{array}$ & $\begin{array}{l}\text { Uniform Distribution: } \\
\text { Minimum Value: SCALE_FACTOR_MIN } \\
\text { Maximum Value: SCALE_FACTOR_MAX }\end{array}$ \\
\hline WP_TRANS_AREA & $\begin{array}{l}\text { Effective fractional area for transport } \\
\text { through a network of SCCs on the waste } \\
\text { package } \\
\text { Units: }\{-\} \\
\text { Type: Function }\end{array}$ & DAMFRAC_TOTAL * SCALE_FACTOR \\
\hline CLAD_DAMAGE_GM & $\begin{array}{l}\text { Percent failed (perforated) cladding from } \\
\text { vibratory ground motion } \\
\text { Units: }\{\%\} \\
\text { Type: Table look-up as function of PGV } \\
\text { This damage is applied to all fuel } \\
\text { assemblies, except for assemblies with } \\
\text { initial clad damage or initial clad failures. }\end{array}$ & 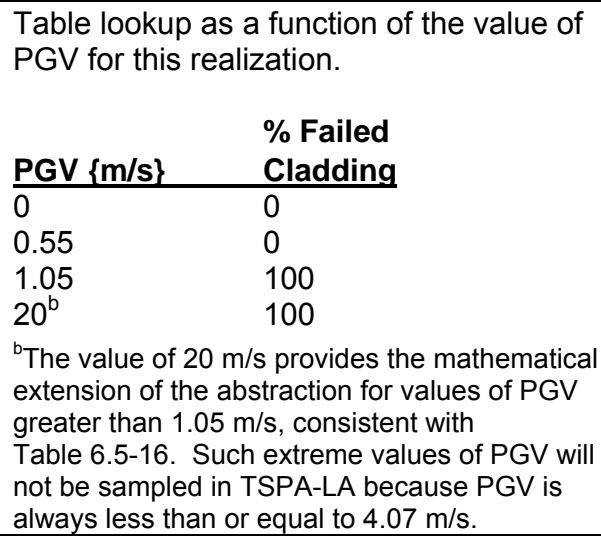 \\
\hline LID_AREA_PWR & $\begin{array}{l}\text { Lid area of the PWR waste package } \\
\text { group for fault displacement } \\
\text { Units: }\left\{\mathrm{m}^{2}\right\} \\
\text { Type: Data }\end{array}$ & $2.105 \mathrm{~m}^{2}$ \\
\hline LID_AREA_BWR & $\begin{array}{l}\text { Lid area of the BWR waste package } \\
\text { group for fault displacement } \\
\text { Units: }\left\{\mathrm{m}^{2}\right\} \\
\text { Type: Data }\end{array}$ & $2.204 \mathrm{~m}^{2}$ \\
\hline LID_AREA_NAVAL & $\begin{array}{l}\text { Lid area of the Naval waste package } \\
\text { group for fault displacement } \\
\text { Units: }\left\{\mathrm{m}^{2}\right\} \\
\text { Type: Data }\end{array}$ & $2.728 \mathrm{~m}^{2}$ \\
\hline LID_AREA_HLW & $\begin{array}{l}\text { Lid area of the HLW waste package } \\
\text { group for fault displacement } \\
\text { Units: }\left\{\mathrm{m}^{2}\right\} \\
\text { Type: Data }\end{array}$ & $3.284 \mathrm{~m}^{2}$ \\
\hline FAILED_AREA_PWR & $\begin{array}{l}\text { Distribution of failed area on the PWR } \\
\text { waste package group for fault } \\
\text { displacement } \\
\text { Units: }\left\{\mathrm{m}^{2}\right\} \\
\text { Type: Distribution sampled once per } \\
\text { realization }\end{array}$ & $\begin{array}{l}\text { UNIFORM Distribution: } \\
\text { Minimum Value: } 0.0 \\
\text { Maximum Value: LID_AREA_PWR }\end{array}$ \\
\hline FAILED_AREA_BWR & $\begin{array}{l}\text { Distribution of failed area on the BWR } \\
\text { waste package group for fault } \\
\text { displacement } \\
\text { Units: }\left\{\mathrm{m}^{2}\right\} \\
\text { Type: Distribution sampled once per } \\
\text { realization }\end{array}$ & $\begin{array}{l}\text { UNIFORM Distribution: } \\
\text { Minimum Value: } 0.0 \\
\text { Maximum Value: LID_AREA_BWR }\end{array}$ \\
\hline
\end{tabular}


Table 6.9-1. Definition of Parameters for the Seismic Scenario Class (Continued)

\begin{tabular}{|c|c|c|}
\hline Parameter Name & Description, Units, and Type & Definition \\
\hline $\begin{array}{l}\text { FAILED_AREA_ } \\
\text { NAVAL }\end{array}$ & $\begin{array}{l}\text { Distribution of failed area on the Naval } \\
\text { waste package group for fault } \\
\text { displacement } \\
\text { Units: }\left\{\mathrm{m}^{2}\right\} \\
\text { Type: Distribution sampled once per } \\
\text { realization }\end{array}$ & $\begin{array}{l}\text { UNIFORM Distribution: } \\
\text { Minimum Value: } 0.0 \\
\text { Maximum Value: LID_AREA_NAVAL }\end{array}$ \\
\hline FAILED_AREA_HLW & $\begin{array}{l}\text { Distribution of failed area on the HLW } \\
\text { waste package group for fault } \\
\text { displacement } \\
\text { Units: }\left\{\mathrm{m}^{2}\right\} \\
\text { Type: Distribution sampled once per } \\
\text { realization }\end{array}$ & $\begin{array}{l}\text { UNIFORM Distribution: } \\
\text { Minimum Value: } 0.0 \\
\text { Maximum Value: LID_AREA_HLW }\end{array}$ \\
\hline SURF_AREA_PWR & $\begin{array}{l}\text { Surface area for a waste package in the } \\
\text { PWR group for fault displacement } \\
\text { Units: }\left\{\mathrm{m}^{2}\right\} \\
\text { Type: Data }\end{array}$ & $30.15 \mathrm{~m}^{2}$ \\
\hline SURF_AREA_BWR & $\begin{array}{l}\text { Surface area for a waste package in the } \\
\text { BWR group for fault displacement } \\
\text { Units: }\left\{\mathrm{m}^{2}\right\} \\
\text { Type: Data }\end{array}$ & $30.85 \mathrm{~m}^{2}$ \\
\hline $\begin{array}{l}\text { SURF_AREA_ } \\
\text { NAVAL }\end{array}$ & $\begin{array}{l}\text { Surface area for a waste package in the } \\
\text { Naval group for fault displacement } \\
\text { Units: }\left\{\mathrm{m}^{2}\right\} \\
\text { Type: Data }\end{array}$ & $37.85 \mathrm{~m}^{2}$ \\
\hline SURF_AREA_HLW & $\begin{array}{l}\text { Surface area for a waste package in the } \\
\text { HLW group for fault displacement } \\
\text { Units: }\left\{\mathrm{m}^{2}\right\} \\
\text { Type: Data }\end{array}$ & $35.60 \mathrm{~m}^{2}$ \\
\hline $\begin{array}{l}\text { FRACTION_FAILED_A } \\
\text { REA_PWR }\end{array}$ & $\begin{array}{l}\text { Fraction of failed surface area on PWR } \\
\text { waste package group from fault } \\
\text { displacement } \\
\text { Units: }\{-\} \\
\text { Type: Function }\end{array}$ & FAILED_AREA_PWR/SURF_AREA_PWR \\
\hline $\begin{array}{l}\text { FRACTION_FAILED_A } \\
\text { REA_BWR }\end{array}$ & $\begin{array}{l}\text { Fraction of failed surface area on BWR } \\
\text { waste package group from fault } \\
\text { displacement } \\
\text { Units: }\{-\} \\
\text { Type: Function }\end{array}$ & FAILED_AREA_BWR/SURF_AREA_BWR \\
\hline $\begin{array}{l}\text { FRACTION_FAILED_A } \\
\text { REA_NAVAL }\end{array}$ & $\begin{array}{l}\text { Fraction of failed surface area on Naval } \\
\text { waste package group from fault } \\
\text { displacement } \\
\text { Units: }\{-\} \\
\text { Type: Function }\end{array}$ & $\begin{array}{l}\text { FAILED_AREA_NAVAL/SURF_AREA_ } \\
\text { NAVAL }\end{array}$ \\
\hline $\begin{array}{l}\text { FRACTION_FAILED_A } \\
\text { REA_HLW }\end{array}$ & $\begin{array}{l}\text { Fraction of failed surface area on HLW } \\
\text { waste package group from fault } \\
\text { displacement } \\
\text { Units: }\{-\} \\
\text { Type: Function }\end{array}$ & FAILED_AREA_HLW/SURF_AREA_HLW \\
\hline
\end{tabular}


Table 6.9-1. Definition of Parameters for the Seismic Scenario Class (Continued)

\begin{tabular}{|c|c|c|}
\hline Parameter Name & Description, Units, and Type & Definition \\
\hline $\begin{array}{l}\text { NO_PWR } \\
\text { FAILURES }\end{array}$ & $\begin{array}{l}\text { Number of failed PWR waste packages } \\
\text { from fault displacement } \\
\text { Units: }\{-\} \\
\text { Type: Step function of annual } \\
\text { exceedance frequency, } \lambda \text {. Fractional } \\
\text { values are be rounded to the nearest } \\
\text { integer. } \\
\text { NB: All fault-failed PWR packages are } \\
\text { located in a single, randomly chosen } \\
\text { thermohydraulic and seepage } \\
\text { environment for CSNF packages in each } \\
\text { realization. }\end{array}$ & $\begin{array}{l}\text { Table lookup as a function of the value of } \lambda \\
\text { for this realization. } \\
\begin{array}{ll}\lambda(\mathbf{1} / \mathrm{yr}) & \text { \# Failures }(-) \\
5 \times 10^{-8} & 0 \\
3 \times 10^{-8} \text { to } 5 \times 10^{-8} & 8.40 \\
2 \times 10^{-8} \text { to } 3 \times 10^{-8} & 8.40 \\
1 \times 10^{-8} \text { to } 2 \times 10^{-8} & 9.24\end{array}\end{array}$ \\
\hline $\begin{array}{l}\text { NO_BWR } \\
\text { FAILURES }\end{array}$ & $\begin{array}{l}\text { Number of failed BWR waste packages } \\
\text { from fault displacement } \\
\text { Units: }\{-\} \\
\text { Type: Step function of annual } \\
\text { exceedance frequency, } \lambda \text {. Fractional } \\
\text { values are rounded to the nearest } \\
\text { integer. } \\
\text { NB: All fault-failed BWR packages are } \\
\text { located in a single, randomly chosen } \\
\text { thermohydraulic and seepage } \\
\text { environment for CSNF packages in each } \\
\text { realization. }\end{array}$ & $\begin{array}{l}\text { Table lookup as a function of the value of } \lambda \\
\text { for this realization. } \\
\begin{array}{ll}\lambda(\mathbf{1} / \mathrm{yr}) & \text { \# Failures }(-) \\
5 \times 10^{-8} & 0 \\
3 \times 10^{-8} \text { to } 5 \times 10^{-8} & 5.35 \\
2 \times 10^{-8} \text { to } 3 \times 10^{-8} & 5.35 \\
1 \times 10^{-8} \text { to } 2 \times 10^{-8} & 5.89\end{array}\end{array}$ \\
\hline $\begin{array}{l}\text { NO_NAVAL_- } \\
\text { FAILURES }\end{array}$ & $\begin{array}{l}\text { Number of failed Naval waste packages } \\
\text { from fault displacement } \\
\text { Units: }\{-\} \\
\text { Type: Step function of annual } \\
\text { exceedance frequency, } \lambda \text {.Fractional } \\
\text { values are rounded to the nearest } \\
\text { integer. } \\
\text { NB: All fault-failed Naval packages are } \\
\text { located in a single, randomly chosen } \\
\text { thermohydraulic and seepage } \\
\text { environment for CSNF packages in each } \\
\text { realization. The environments for CSNF } \\
\text { and CDSP packages are chosen } \\
\text { independently. }\end{array}$ & $\begin{array}{l}\text { Table lookup as a function of the value of } \lambda \\
\text { for this realization. } \\
\begin{array}{ll}\lambda(\mathbf{1} / \mathrm{yr}) & \text { \# Failures }(-) \\
>1 \times 10^{-7} & 0 \\
5 \times 10^{-8} \text { to } 1 \times 10^{-7} & 0.61 \\
3 \times 10^{-8} \text { to } 5 \times 10^{-8} & 0.61 \\
2 \times 10^{-8} \text { to } 3 \times 10^{-8} & 0.67 \\
1 \times 10^{-8} \text { to } 2 \times 10^{-8} & 0.67\end{array}\end{array}$ \\
\hline NO_HLW_FAILURES & $\begin{array}{l}\text { Number of failed HLW packages from } \\
\text { fault displacement } \\
\text { Units: }\{-\} \\
\text { Type: Step function of annual } \\
\text { exceedance frequency, } \lambda . \lambda \text {. Fractional } \\
\text { values are rounded to the nearest } \\
\text { integer. } \\
\text { NB: All fault-failed HLW packages are } \\
\text { located in a single, randomly chosen } \\
\text { thermohydraulic and seepage } \\
\text { environment for CDSP packages in each } \\
\text { realization. The environments for CSNF } \\
\text { and CDSP packages are chosen } \\
\text { independently. }\end{array}$ & $\begin{array}{l}\text { Table lookup as a function of the value of } \lambda \\
\text { for this realization. } \\
\begin{array}{ll}\boldsymbol{\lambda}(\mathbf{1} / \mathrm{yr}) & \text { \# Failures }(-) \\
>2 \times 10^{-7} & 0 \\
1 \times 10^{-7} \text { to } 2 \times 10^{-7} & 5.64 \\
5 \times 10^{-8} \text { to } 1 \times 10^{-7} & 5.64 \\
3 \times 10^{-8} \text { to } 5 \times 10^{-8} & 6.20 \\
2 \times 10^{-8} \text { to } 3 \times 10^{-8} & 6.20 \\
1 \times 10^{-8} \text { to } 2 \times 10^{-8} & 39.98\end{array}\end{array}$ \\
\hline
\end{tabular}


Table 6.9-1. Definition of Parameters for the Seismic Scenario Class (Continued)

\begin{tabular}{|c|c|c|}
\hline Parameter Name & Description, Units, and Type & Definition \\
\hline $\begin{array}{l}\text { NO_DRIP_SHIELD_ } \\
\text { FD }\end{array}$ & $\begin{array}{l}\text { Number of drip shields damaged by fault } \\
\text { displacement. } \\
\text { Units: }\{-\} \\
\text { Type: Function }\end{array}$ & $\begin{array}{l}\text { NO_PWR_FAILURES + } \\
\text { NO_BWR_FAILURES + } \\
\text { NO_NAVAL_FAILURES + } \\
\text { NO_HLW_FAILURES }\end{array}$ \\
\hline $\begin{array}{l}\text { DRIP_SHIELD_DAMAG } \\
\text { E_FD }\end{array}$ & $\begin{array}{l}\text { Magnitude of drip shield damage for all } \\
\text { waste packages failed by fault } \\
\text { displacement. } \\
\text { Units: }\{\%\} \\
\text { Type: Constant }\end{array}$ & $100 \%$ \\
\hline NO_CLAD_FD & $\begin{array}{l}\text { Number of waste packages with cladding } \\
\text { damaged by fault displacement. } \\
\text { Units: }\{-\} \\
\text { Type: Function }\end{array}$ & $\begin{array}{l}\text { NO_PWR_FAILURES + } \\
\text { NO_BWR_FAILURES + } \\
\text { NO_NAVAL_FAILURES + } \\
\text { NO_HLW_FAILURES }\end{array}$ \\
\hline CLAD_DAMAGE_FD & $\begin{array}{l}\text { Magnitude of clad damage in all waste } \\
\text { packages failed by fault displacement. } \\
\text { Units: }\{\%\} \\
\text { Type: Constant }\end{array}$ & $100 \%$ \\
\hline $\begin{array}{l}\text { COLLAPSE } \\
\text { THRESH_LITH }\end{array}$ & $\begin{array}{l}\text { The minimum value of PGV that results } \\
\text { in complete collapse of emplacement } \\
\text { drifts in the lithophysal zones of the } \\
\text { repository } \\
\text { Units: }\{\mathrm{m} / \mathrm{s}\} \\
\text { Type: Constant }\end{array}$ & $\begin{array}{l}0.384 \mathrm{~m} / \mathrm{s}^{\mathrm{c}} \\
{ }^{\mathrm{c} D r i f t s} \text { in the lithophysal zones always collapse } \\
\text { after a seismic event because PGV is always } \\
\text { greater than or equal to } 0.4019 \mathrm{~m} / \mathrm{s} \text {, which } \\
\text { corresponds to the } 10^{-4} \text { annual exceedance } \\
\text { frequency on the bounded hazard curve. }\end{array}$ \\
\hline $\begin{array}{l}\text { COLLAPSE_- } \\
\text { THRESH_NONLITH }\end{array}$ & $\begin{array}{l}\text { The minimum value of PGV that results } \\
\text { in complete collapse of emplacement } \\
\text { drifts in the nonlithophysal zones of the } \\
\text { repository } \\
\text { Units: }\{\mathrm{m} / \mathrm{s}\} \\
\text { Type: Constant }\end{array}$ & $\begin{array}{l}5.35 \mathrm{~m} / \mathrm{s}^{\mathrm{d}} \\
{ }^{\mathrm{d}} \text { This value is equivalent to no collapse in the } \\
\text { nonlithophysal zones because the value of PGV } \\
\text { is always less than or equal to } 4.07 \mathrm{~m} / \mathrm{s} \text {. }\end{array}$ \\
\hline
\end{tabular}

NOTE: The symbol "(-)" denotes a dimensionless parameter.

CSNF = commercial spent nuclear fuel; PWR = pressurized water reactor; BWR - boiling water reactor; CDSP = codisposal; PGV = peak ground velocity; HLW = high-level radioactive waste; SCC = stress corrosion crack.

\subsubsection{Limitations}

There are two important limitations for the seismic scenario class for TSPA-LA: the duration of the simulations, and the possibility of rockfall in the drifts before the seismic event.

The seismic scenario class for TSPA-LA is designed for a duration of 20,000 years. This design limitation arises from two factors. The first factor relates to the parameters for the structural response calculations, namely structural thicknesses and mechanical properties for the drip shield and waste package. The thicknesses of the drip shield and waste package have been reduced to represent the potential degradation of these structures by general corrosion over the first 10,000 years to 20,000 years after repository closure. The mechanical properties of Alloy 22 and of Titanium Grade 7 have been evaluated at an elevated temperature, $150^{\circ} \mathrm{C}$, which provides conservative values for over 97 percent of the first 10,000 years following repository closure for the high temperature operating model and for 100 percent of the time for the low temperature operating mode. This approach is highly conservative from a risk assessment viewpoint because materials will be stronger than represented in the structural response calculations for about 
97 percent of the realizations in the TSPA-LA. The definition of structural thickness and material properties may change if the duration of the seismic scenario class is extended beyond 20,000 years.

The second factor for the design limitation related to the duration of the seismic scenario class is that coupled effects from multiple seismic events (i.e., that drift collapse after the first seismic event can alter conditions for the second seismic event) are not considered because seismic hazards with the potential to have a significant impact on engineered barriers are anticipated to occur very rarely during the 20,000 year period. This is a reasonable approach for events that occur with an annual frequency of $10^{-5}$ per year or less over a 10,000 year or 20,000 year period. This is also a reasonable approach for annual exceedance frequencies between $10^{-4}$ and $10^{-5}$ per year if the corresponding ground motions and fault displacements produce small damage to EBS components (as is true for these abstractions).

The second limitation is related to the condition of the drifts at the time of the seismic event. Structural response calculations for the drip shield and waste package do not include backfill around the drip shield at the time of the seismic event. This representation is consistent with the present design that does not include engineered backfill but may become invalid if long-term fatigue of the tuff rock causes drift degradation and substantial collapse before a second seismic event with the potential to damage EBS components occurs.

\subsection{VERIFICATION OF SCIENTIFIC ANALYSES}

The abstractions for cladding damage from vibratory ground motions and for the EBS damage from fault displacement are stochastic distributions whose parameters are a function of the amplitude or the exceedance frequency of the ground motion. These abstractions are considered scientific analyses because they are based on standard engineering and statistical techniques that bound the component response. Since these abstractions are not models, they are not validated per LP-SIII.10Q-BSC, Models. Verification that these abstractions are an accurate representation of the variability and uncertainty in damage to the EBS components is discussed below.

- Damage to Fuel Rod Cladding from Vibratory Ground Motion

The abstraction for damage to the cladding has 100 percent of the cladding perforated after a ground motion with PGV of $1.05 \mathrm{~m} / \mathrm{s}$ or larger occurs. This is a conservative, bounding approach (see discussion in Section 6.5.6) that does not require further verification.

- Damage to EBS Components from Fault Displacement

The abstraction for damage to the waste package and drip shield from fault displacement is based on the mean hazard curves for displacement of known faults in the repository block and on the available clearances between EBS components. The analysis of damage from fault displacement demonstrates that there is no damage from faulting until an annual exceedance frequency less than $2 \times 10^{-7}$ per year is reached. In other words, only the largest fault displacements have the potential to damage the EBS components. 
If a package is damaged by fault displacement, the damaged area on the waste package is defined as a uniform distribution with a lower bound of 0 and an upper bound given by the lid area. The lower bound represents a situation with minor crimping of the waste package; the upper bound represents a situation in which the welds fail and the lid completely separates from the waste package. These damage states are intended to be bounding conditions because there is high uncertainty in the state of the drift, the invert, and the EBS components after a major fault displacement.

If a package is damaged by fault displacement, the damaged area on the drip shield surrounding that package is 100 percent. This total damage state is a bounding condition because some fault displacements produce minimal crimping between the waste package and drip shield. Similarly, the fuel rod cladding is 100 percent perforated for a fault displacement that damages the waste package.

The damage abstraction for fault displacement has been compared to an alternative conceptual model proposed by (Waiting et al. 2003 [DIRS 164449]). There is reasonable agreement between the damage abstraction in this report and the alternative conceptual model, considering that the alternate model is based on historical data for fault displacement in the western United States and that the damage abstraction is based on hazard curves specific to Yucca Mountain. For example, the number of fault intersections predicted by the damage abstraction is 171, versus 191 for the alternative conceptual model. Similarly, the probability weighted number of waste package failures is predicted to be $2.3 \times 10^{-6}$ for the damage abstraction, within the range of $1.9 \times 10^{-6}$ to $1.9 \times 10^{-5}$ for the alternative conceptual model. This agreement provides added confidence in the damage abstraction for fault displacement. 


\section{VALIDATION}

The Seismic Consequence Abstraction report develops abstractions for the response of EBS components to seismic hazards at a geologic repository in Yucca Mountain, Nevada. It also defines the methodology for using these abstractions in a seismic scenario class for the TSPA-LA. The seismic hazards addressed are vibratory ground motion, fault displacement, and rockfall induced by ground motion. The EBS components are the drip shield, waste package, and the fuel rod cladding. Consistent with the intended use, the Technical Work Plan For: Analysis of Waste Package and Drip Shield Response to Vibratory Ground Motion and Revision of the Seismic Consequence Abstraction (BSC 2005 [DIRS 173171]) specifies model validation level of confidence III for the waste package consequence abstraction.

No validation activities are required for the drip shield because it is predicted to remain intact, deflecting seepage and rockfall away from the waste package (BSC 2005 [DIRS 173171], Section 2.2.2.3). The abstractions for cladding damage from vibratory ground motion and for damage to EBS components from fault displacement are considered scientific analyses because they are based on standard engineering techniques that bound the component response, rather than the results from detailed engineering calculations or other scientific analyses. Since these abstractions are conservative, bounding approaches, rather than models, they are not validated per LP-SIII.10Q-BSC (BSC 2005 [173171], Section 2.2.2.6, last paragraph).

\section{Confidence Building During Model Development to Establish Scientific Basis and Accuracy for Intended Use}

The applicable TWP (BSC 2005 [DIRS 173171], Section 2.2.2.2) specifies criteria for Confidence Building During Model Development. Additionally, the development of the model should be documented in accordance with the requirements of Section 5.3.2(b) of LP-SIII.10Q-BSC. The development of the Seismic Consequences Abstraction has been conducted according to these criteria, as follows:

1. Selection of input parameters and/or input data, and a discussion of how the selection process builds confidence in the model. [LP-SIII.10Q-BSC 5.3.2(b) (1) and LP-2.29Q-BSC Attachment 3 Level I (a)]

The types and quality of the data selected as input builds confidence in the model. The inputs to the Seismic Consequences Abstraction have all been obtained from controlled sources. Section 4.1 provides a discussion of the inputs and Table 4-1 identifies the data and design parameters used. Additional information that corroborates Table 4-1 and therefore builds additional confidence is discussed in Section 6.1.4. Discussions of parameter ranges and uncertainties are covered throughout Section 6. Model assumptions have been described in Section 5. Thus, this requirement can be considered satisfied.

2. Description of calibration activities, and/or initial boundary condition runs, and/or run convergences, simulation conditions set up to span the range of intended use and avoid inconsistent outputs, and a discussion of how the activity or activities build confidence in the model. Inclusion of a discussion of impacts of any non-convergence runs [(LP-SIII.10Q-BSC 5.3.2(b)(2) and LP-2.29Q-BSC Attachment 3 Level I (e)]. 
The Seismic Consequences Abstractions for waste package damage and drip shield response are functional relationships based on structural response calculations and kinematic calculations documented elsewhere, therefore detailed discussions regarding initial and boundary conditions, run convergences and non-convergences associated with the structural response calculations are not included in this report. The Seismic Consequences Abstraction spans the range of intended use by covering the full range of peak ground velocities from the bounded PGV hazard curve; by defining the failure mechanisms, residual stress thresholds, and failure morphology for the waste package and drip shield; by consideration of responses to rockfall; and by responses to fault displacement.

The seismic failure criteria for Alloy 22 and Titanium Grade 7 have been selected in a conservative manner. The failure criteria are based on considerations of accelerated corrosion due to residual stress, rather than the ultimate tensile failure stress of Alloy 22 or Titanium Grade 7. In fact, none of the structures reached ultimate tensile failure in the structural calculations. The rationale for selection of the residual stress thresholds for failure is documented in Sections 6.3.2 and 6.3.3, based on information in Stress Corrosion Cracking of the Drip Shield, the Waste Package Outer Barrier, and the Stainless Steel Structural Material (BSC 2004 [DIRS 172203], p. 6-7 in Section 6.2.1). The conservative approach to defining the residual stress thresholds for failure provides a safety margin that helps to enhance confidence in the seismic failure criteria. The failure criteria are considered appropriate for their intended use because they are a conservative interpretation of the experimental data for the corrosion of Alloy 22 and Titanium Grade 7 under conditions relevant to Yucca Mountain and are consistent with current scientific understanding.

The total damage to the waste package has two separate components: damage from end-to-end impacts of adjacent waste packages (Section 6.5.1) and damage from waste package-pallet impacts (Section 6.5.2). The total damage to the waste package is given by the sum of these two individual abstractions.

Damage from end-to-end impacts is based on kinematic calculations that represent the potential for adjacent waste packages to experience synchronous motion in an emplacement drift (Section 6.5.1). Two suites of kinematic calculations have been performed with multiple waste packages to determine the kinematic parameters and damaged areas due to end-to-end impacts between adjacent packages (BSC 2005 [DIRS 173172], Sections 5.4.1 and 5.4.2). The two suites are based on different computational techniques with different numbers and types of waste packages. The kinematic impact data for each suite are converted to damaged areas based on a catalog or look-up Table of damage as a function of impact velocity and impact velocity (Sections 6.5.1.2 and 6.5.1.3; BSC 2005 [DIRS 173172], Section 5.4.3 and BSC 2005 [DIRS 173178], Tables 2 and 3). The damaged areas from both suites of kinematic results are independently abstracted, allowing the uncertainty in alternate technical approaches to be propagated into the waste package damage abstraction for TSPA.

Damage from waste package-pallet impacts is based on detailed structural response calculations for a single waste package contained within rigid walls (Section 6.5.2 and 
BSC 2004 [DIRS 167083]). These structural response calculations provide a direct analysis of the damaged areas on the sides of the waste package from waste package-pallet impacts. That is, the damage from waste package-pallet impacts is determined by analyzing the residual stress state of the finite-element mesh to determine the element areas where the residual stress exceeds 80 percent or 90 percent of the yield strength of Alloy 22.

This requirement can be considered satisfied.

3. Discussion of the impacts of uncertainties to the model results including how the model results represent the range of possible outcomes consistent with important uncertainties. [(LP-SIII.10Q-BSC 5.3.2(b)(3) and LP-2.29Q-BSC Attachment 3 Level 1 (d) and (f)].

The calculations of damaged areas on the waste package and drip shield due to vibratory ground motions and rockfall induced by vibratory ground motions exhibit substantial variability induced by the uncertainties in seismic ground motions and other input parameters. This variability has been directly propagated into the TSPA-LA by defining stochastic parameters that are sampled during each realization of the seismic scenario class. A more detailed discussion can be found in Section 8.2 under Acceptance Criterion 3: Data Uncertainty Is Characterized and Propagated Through the Model Abstraction. Treatment of model uncertainty is discussed in Section 8.2 under Acceptance Criterion 4: Model Uncertainty Is Characterized and Propagated Through the Model Abstraction.

4. Formulation of defensible assumptions and simplifications. [LP-2.29Q-BSC Attachment 3 Level I (b)].

Discussion of assumptions is provided in Section 5. The basis for the simplifications in the seismic damage abstractions is provided in Sections 6.5.1 through 6.5.6 and Section 6.7.

5. Consistency with physical principles, such as conservation of mass, energy, and momentum. [LP-2.29Q-BSC Attachment 3 Level I (c)]

Consistency with physical principles, such as conservation of mass, energy, and momentum, is maintained because the abstractions are based on detailed structural response calculations. Structural calculations for the response of large engineered components (e.g., waste package, drip shield, or cladding) due to impact and vibration is a well-established technology. The deformation of these types of structures can be evaluated with standard, commercially available finite-element programs. As a result, there is high confidence in the results from the computational process because of the extensive testing of commercial software on a wide variety of problems, including impact calculations. In addition, each computational study is based on a mesh refinement analysis and other supporting calculations that provide additional confidence in the results. No changes to the finite-element software are needed for these calculations. These engineering codes have been qualified for their intended use under 
LP-SI.11Q-BSC and the engineering calculations are performed under AP-3.12Q or LP-3.12Q-BSC (for the recent kinematic calculations).

The abstractions for waste package response to vibratory ground motions are stochastic distributions whose parameters are a function of the amplitude of the ground motion. These distributions, also called damage abstractions, are based on information from detailed structural response calculations. These distributions are model abstractions because they represent this detailed computational information in a simplified manner for TSPA-LA. The underlying information for the model abstractions are created by models that have been validated under LP-SIII.10Q-BSC or by engineering calculations with software qualified under LP-SI.11Q-BSC. The status of the engineering calculations for structural response, of the rockfall models and analyses, and of the failure criteria are discussed next, followed by a discussion of the validation of the individual model abstractions.

The results from the engineering calculations are considered appropriate for their intended use for several reasons. First, the calculations are based on standard, commercially available software that has demonstrated the capability to accurately analyze impact processes and kinematic response. Second, the finite-element representation of EBS components is designed (via mesh refinement studies) to accurately represent the potential damage from the impact processes. And lastly, the ground motions for the calculations are based on state-of-the-art techniques for representing seismic phenomena. On the other hand, two features of the boundary conditions for these engineering calculations are notable for their conservatism. First, the structural response calculations for a single waste package simulations have a rigid boundary (that moves with the invert) at the axial ends of the computational space. The presence of a rigid boundary tends to amplify the number and intensity of end-to-end impacts for the single waste package simulations. The second feature of the boundary conditions is that the very low frequency ground motions at the $5.35-\mathrm{m} / \mathrm{s}$ PGV level are considered physically unrealizable, as discussed in Section 6.4.3.

The rockfall analyses are also performed with commercially available software, although it is necessary to modify the software for computational efficiency, for the representation of fractures with short or intermittent trace lengths, and for constitutive relationships for tuff. Because of these modifications, the rock mechanics codes are qualified and the models validated for their intended application to lithophysal and nonlithophysal tuffs in accordance with LP-SIII.10QBSC. This model validation is documented in Section 7 of Drift Degradation Analysis (BSC 2004 [DIRS 166107]).

\section{Confidence Building After Model Development to Support the Scientific Basis of the Model}

The model abstraction for waste package response to vibratory ground motion is a simple numerical fit to the failed surface area as a function of PGV. The fit involves selecting an appropriate function to represent the mean or median damage as a function of PGV and selecting an appropriate distribution about the mean or median to represent the variability of damage. The appropriate distributions and functional fits for the waste package have been developed and documented in Microsoft Excel spreadsheets. The numerical values in these spreadsheets have been verified during the checking process for this model report. These spreadsheets are 
described in Appendices $\mathrm{A}$ and $\mathrm{B}$ and $\mathrm{E}$ of this report, and provided electronically on a $\mathrm{CD}$ (Appendix G). Details of the validation process for the model abstractions are as follows:

\section{- Abstraction for Damage to the Waste Package from Ground Motion}

The abstraction for damage to the waste package is based on a probability of no damage and a power law fit to the median nonzero damage with a ln-normal distribution. The selection of the power law fits and the ln-normal distributions is justified by the comparisons shown in Figures 6.5-10 through 6.5-13 in Section 6.5.1 and Figures 6.5-16 through 6.5-19 and Figure 6.5-21 in Section 6.5.2. Figures 6.5-11, 6.5-12, 6.5-18, and 6.5-19 provide direct evidence that the residuals for damaged area about the power law closely follow a normal distribution in $\ln$ (Damaged Area) space. In addition, the ln-normal distribution is not truncated, so very large damaged areas can be sampled in TSPA, as shown in Figures 6.5-13 and 6.5-21. As an aside, the mean dose is directly determined by the mean damaged area at a given value of PGV, so mean dose is insensitive to the exact form of the variance about the power law.

The level of confidence required for validation of the damage abstraction for the waste package under vibratory ground motion is high (Level III) because damage to the waste package is a significant factor in determining dose in TSPA calculations. The abstraction for damage to the waste package has been validated by (1) corroboration of the abstraction results with damaged areas from structural response calculations, and by (2) an independent technical review. The independent technical review has been performed by two individuals, Prof. C. Allin Cornell and Dr. Robert P. Kennedy. Their reviews build and expand upon the first technical review that was performed by Dr. Kennedy for the original waste package damage abstraction (BSC 2004 [DIRS 167780], Attachment III). The first technical review is not repeated in this report because the original waste package damage abstraction has been completely superseded and replaced by the abstraction in Sections 6.5.1 through 6.5.3 of this report. The model validation review criteria for either validation activity are (BSC 2005 [DIRS 173171], Section 2.2.2.2):

1. Is the model abstraction reasonable and appropriate for its intended use?

2. For given inputs, are the outputs of the model abstraction reasonable?

3. Are limitations of the model abstraction adequately described?

Corroboration of Abstraction Model. The input data for development of the waste package damage abstraction are documented in BSC 2005 [DIRS 173172], Sections 5.4.1, 5.4.2, 5.4.3, and 5.6.1, BSC 2005 [DIRS 173178], Tables 2 and 3, DTN: MO0503SPAUDECW.000 [DIRS 173337], DTN: MO0504SPALSDYN.000 [DIRS 173338], BSC 2004 [DIRS 171717] Tables 6.1-4, 6.2-7, and 6.3-6, (BSC 2004 [DIRS 166107], Tables X-2 through X-5), and IED WASTE PACKAGE DAMAGE FROM VIBRATORY GROUND MOTION AND FUEL ASSEMBLY ACCELERATION (BSC 2005 [DIRS 173500], Tables 1 and 2). 
1. Is the model abstraction reasonable and appropriate for its intended use?

The technical approach for the waste package damage abstractions is that the damaged areas are fit with three relationships: (i) the probability of no damage as a function of PGV-longitudinal, (2) a power law fit to the nonzero damaged areas, and (3) a ln-normal fit to the residuals for damaged area about this power law. The power law fit and the ln-normal distribution for the residuals provide an excellent representation of the damaged areas at the $1.05 \mathrm{~m} / \mathrm{s}$, the $2.44 \mathrm{~m} / \mathrm{s}$ and the $5.35-\mathrm{m} / \mathrm{s}$ PGV levels. The power law representation provides an accurate fit to the median damaged areas at these three PGV levels, as shown by the comparisons in Figures 6.5-10, 6.5-16, and 6.5-17. A 1n-normal distribution spans the full range of damaged areas observed in the structural response calculations, as shown by the comparisons in Figures 6.5-13 and 6.5-21. In this situation, the model abstractions provide a reasonable and appropriate representation of damaged area for the seismic scenario class in TSPA.

Alternate approaches were evaluated for the damage abstractions. The alternate approaches included regression analysis for all damaged areas, as opposed to the nonzero damaged areas, and the use of uniform and normal distributions to represent the variance about the mean or median (geometric mean) response. The regression analysis for all damaged areas did not improve on the recommended regression based on a probability of no damage and a power law fit to the nonzero damaged areas. A ln-normal distribution provided a better representation of the variance about the median than a uniform distribution or a normal distribution. These results were confirmed through the independent technical review performed by Dr. R.P. Kennedy, who could not identify an improved regression fit to the damaged area data. Dr. Kennedy's review is summarized later in this Section and the complete text is in Appendix D.

2. For given inputs, are the outputs of the model abstraction reasonable?

The standard deviation for the normal distributions in $\ln$-ln space is between 1.16 to 1.46 for end-to-end impacts and between 1.02 and 1.04 for waste package-pallet impacts (Table 6.9-1). These large values for standard deviation mean that the ln-normal distributions span a wide range of damaged areas for TSPA. In addition, the ln-normal distributions are not truncated, so damaged areas significantly greater than the observed data may be sampled in TSPA. Clearly, there is a reasonable fit to the median damaged area and the untruncated ln-normal distributions span the wide range of damaged area data. The potential for large damaged areas is conservatively represented by the untruncated ln-normal distributions in the abstractions. The outputs of the model abstraction provide a reasonable representation of the full range of damaged areas on the waste packages from end-to-end impacts and from waste package-pallet impacts. 
3. Are limitations of the model abstraction adequately described?

The general limitations of the abstractions for the seismic scenario class are identified in Section 8.1. The specific limitations for the structural response calculations and kinematic calculations that provide the data for the waste package damage abstraction are: (1) the use of unbounded ground motion time histories as boundary conditions for the structural response calculations and kinematic calculations, (2) the potential for rockfall to occur during the seismic event is not represented in the calculations, (3) geometric simplifications: the kinematic calculations are two-dimensional and the single waste package calculations that determine damaged areas for waste package-pallet impacts have rigid end walls, and (4) the damaged area catalog for end-to-end impacts is based on relative velocity, conservatively excluding the potential damage reduction from the fact that the effective impact velocity between two equal packages moving with opposite velocities is one-half the relative velocity. Conversely, the damaged area catalog does not include the potential for corner impacts on the lid of the waste package.

In a more general sense, the first model validation activity is considered successful when the abstraction accurately represents the mean or median damage level and when the abstraction bounds the range of damage determined by the structural response calculations. The information provided under items (1), (2), and (3) confirms that the waste package damage abstractions can be successfully compared and corroborated with the underlying damaged area data generated by the structural response calculations and the kinematic calculations.

Independent Technical Review By Prof. C. Allin Cornell. An independent technical review of the waste package damage abstractions has been performed by Prof. C. Allin Cornell of Stanford University. The key points from Prof. Cornell's review are first summarized, followed by a response to the limitations identified by Prof. Cornell. The complete text of Prof. Cornell's review is in Appendix C.

\section{Regarding the Ground Motions}

- "The range of PGV values used covers that of interest as defined on one end by the onset of non-zero damage and at the other by PGV values beyond the $10^{-8}$ annual probability level."

- "For the purposes of the waste package abstraction, however, samples of such three-component accelerograms are precisely what are required to estimate the response and damage to the EBS."

- "Despite the broad variability observed in the response and damage the range of PGV and the sample size is sufficient in my view to provide an adequate abstraction of the damaged area probability distribution for the primary TSPA objective. As will be elaborated on below I believe the focus should be on the mean value of the damaged area as a function of PGV. Given the (conditional) standard deviations of In (nonzero) 
damaged areas of about 1 to 1.5 and total sample sizes of about 40, the standard error of estimation of the conditional mean of the (nonzero) damaged area is about 15 to $25 \%$. The sample size may not be sufficient to confirm the extreme tails of the damaged area conditional distributions but the mean dose estimates are insensitive to these tails."

\section{Dynamic Response of the EBS}

- "The dynamic response computations have now been separated into two approaches, one kinematic to captured waste package - waste package (WP-WP) impact statistics and one fully deformable to obtain damaged areas for waste package-pallet (WP-P) impacts. The latter (based on the nonlinear analysis of a single waste package on a pallet surrounded by non-yielding surfaces) are the same analyses used in the initial abstraction (BSC 2004 [DIRS 167780], Section 6.5) reviewed previously by Dr. Robert Kennedy (BSC 2004 [DIRS 167780], Attachment III) and need not be reviewed again here. This author concurs that they provide a reasonable and appropriate representation of the damaged areas due to this portion of the impacts and that the inputs and outputs are reasonable."

- "The new analyses are the 2D kinematic analyses of multiple waste packages designed to estimate the velocities and angles of the end-to-end WP-WP impacts for subsequent use in calculating damaged areas. These new analyses are a major step forward in capturing the multi-package effects that were missing from the previous, conservative single-package analyses of WP-WP impacts. ...... In addition, the significant differences in results between the two modeling efforts (LSDYNA and UDEC) underline the difficulty of the mechanical analysis problem, its sensitivity to details of the modeling and the current limits to our understanding of the finer points of such analyses. Further sensitivity and comparative studies are likely to bring sharper insight into the problem and less uncertainty in the conclusions. The use of weighted results from both LSDYNA and UDEC analyses reflects that uncertainty and provides an appropriate and adequate abstraction for the present purposes."

\section{Damaged Area Estimates}

- "As was true in the previous version of the Seismic Consequence Abstraction the WPWP damaged areas are estimated from the list of impacts with their velocities and angles using results from fine-mesh studies of a waste package impacting a non-yielding flat surface. This approach has therefore been reviewed and found appropriate previously by Dr. Kennedy; this reviewer concurs. The process has been modified somewhat (and likely made more conservative) by averaging over impact angles to remove the low value of damage implied by near-zero angles. This is an improvement. This reviewer agrees that use of the relative velocity between packages is conservative but that failure to capture impacts of WP corners into lids is not (Section 6.5.1.3)."

\section{Damaged Area Probability Distributions}

- "The primary output of the TSPA is the mean dose at 10,000 years. It is physically reasonable that the seismic contribution to this mean will be approximately proportional 
to the mean damaged area (as release from the package(s) is similarly likely approximately proportional to damaged area at the small percentage areas of interest). Therefore the mean dose will be comparatively insensitive to either the shape of the damaged area distribution or its standard deviation."

- "The fits of these two damaged area parameter values versus PGV seem very reasonable and quite appropriate for the TSPA use."

- "All together the output - primarily mean damaged area versus PGV - appears to be reasonable given the inputs (ground motion samples, EBS models, and response to damaged area relationships)."

\section{Limitations}

- "Limitations to the new waste package abstraction include the issues of corner-on-lid WP-WP damage characterization and the as-yet un-understood differences between the two sets of $2 D$ kinematic analyses mentioned above. Other limitations include significant conservatisms such as the unbounded PGV of the perpendicular component (a factor only in the WP-P damage case) and the use of relative package velocities in the estimation of WP-WP damaged areas. Limitations whose impacts are less predictable include the use of only a $2 D$ representation of the waste packages kinematics in the WP-WP case, the use of only a single waste package in the WP-P case, and the dependence on a single multiple waste package configuration. The report would benefit in Section 6.5.3 from a comparison between the damaged areas versus PGV predictions for the WP-WP and WP-P cases. I believe it would be sufficient to show simply the mean damaged area vs. PGV for the two cases."

\section{Project Response to Limitations}

- Differences in kinematic studies. The potential differences between the calculations with UDEC and LS-DYNA have been evaluated in BSC (2005 [DIRS 173172], Section 5.4). The difference in the contact damping mechanisms, viscous versus hysteretic, appears to be the major cause of the differences between the UDEC and LS-DYNA results. More important than the sources of the differences, the abstractions for TSPA represent the damaged areas from both suites of kinematic calculations (Section 6.5.3), thereby propagating any uncertainty related to the technical approaches with UDEC and LS-DYNA directly into TSPA (see Operation 4 in Section 6.9.2).

- Conservatism in ground motions. There is significant conservatism in the ground motion time histories. While the hazard curve for horizontal PGV has been bounded (Section 6.4.3), only the horizontal longitudinal component is scaled to a given PGV value. The horizontal transverse component and the vertical component are not bounded, introducing a very significant conservatism in the kinematic calculations and the structural response calculations at the $2.44-\mathrm{m} / \mathrm{s}$ and $5.35-\mathrm{m} / \mathrm{s}$ PGV levels.

- Conservatism in relative impact velocity. There is a very significant conservatism in the interpretation of relative impact velocity for interpolation within the damaged area 
catalog for end-on impacts. The relative impact velocity between adjacent waste packages from the kinematic calculations is ideally a factor of two less than the equivalent end-on impact velocity for interpolation in Table 6.5-4. Stated differently, the elastic surface provides a plane of symmetry for the end-on impact calculations, and this plane of symmetry implies that packages are moving in equal and opposite directions on either side of the plane for the kinematic calculations, resulting in a relative velocity that is a factor of two greater than the end-on impact velocity. Damaged area is drastically reduced if the relative impact velocity in the kinematic calculations is divided by two before interpolating within the damaged area catalog. Also see Dr. Kennedy's review comments on this issue, directly following Prof. Cornell's review.

The conservatisms in ground motions and in relative impact velocity have been retained in the abstractions because they tend to compensate for the potential nonconservatisms from corner-on-lid contact versus end-to-end contact and for the potential differences from the use of two-dimensional versus three-dimensional kinematic representations (although the two-dimensional kinematic representations have one less degree of freedom and are therefore probably conservative with respect to the three-dimensional representations). Engineering approaches are a necessary part of the analysis process because of the complexity of performing three-dimensional multi-body calculations for the EBS components in an emplacement drift. In this situation, the conservatisms in the abstractions are designed to account for the approximations that are inherent in the engineering approaches.

The results from Prof. Cornell's independent review fulfill the requirements in BSC (2005 [DIRS 173171], Section 2.2.2.2) as follows:

1. Is the model abstraction reasonable and appropriate for its intended use?

- The use of three-component ground motions and the range of PGV values for these ground motions are reasonable and appropriate.

- The sample size (number of ground motions) is sufficient to provide an adequate abstraction of the damaged area probability distribution, bearing in mind that the primary TSPA objective is to define the mean damaged area as a function of PGV.

- The new two-dimensional kinematic calculations are a major step forward in capturing the multi-package effects that are missing from the previous single-package analyses.

- The use of a damaged area catalog to define damaged areas from end-to-end impacts is appropriate. The use of mean damaged areas for nonzero impact angles in the catalog is an improvement. The use of the relative impact velocity as an interpolation parameter that defines damaged areas is conservative. 
- The use of weighted results from UDEC and LS-DYNA for damage from end-to-end impacts provides an appropriate and adequate abstraction.

- The fits for the probability of no damage and the mean nonzero damaged area as functions of PGV are reasonable and appropriate for use in TSPA.

2. For given inputs, are the outputs of the model abstraction reasonable?

- The primary output from the damage abstraction, the mean damaged area versus PGV, appears to be reasonable and quite appropriate for use in TSPA.

- The output from the single-package analyses provides a reasonable and appropriate representation of the damaged areas due to waste package-pallet impacts.

- The fits for the probability of no damage and the mean nonzero damaged area as functions of PGV provide appropriate output for use in TSPA.

3. Are limitations of the model abstraction adequately described?

The limitations identified by Prof. Cornell, both conservative and unconservative, and the project response to these limitations are summarized on the preceding pages.

Independent Technical Review By Dr. Robert P. Kennedy. A second independent technical reviews of the waste package damage abstractions has been performed by Dr. Robert P. Kennedy of RPK Structural Engineering. The conclusions from Dr. Kennedy's review are repeated here. The complete text of Dr. Kennedy's review is in Appendix D.

"In my judgment, the current waste package damage abstraction represents the highest quality damage abstraction that can be developed from the existing analytical studies of the seismic response of the waste packages. Any further improvements should be concentrated on improving the input data as opposed to further development of damage abstractions from the existing analytical studies. It is not clear to me whether any further improvements are necessary. However, if further improvements are judged to be warranted, the following areas are candidates for improvement:

1. Develop an improved suite of ground motion time histories anchored to longitudinal peak ground velocities $P G V_{L}$ ranging from $1.0 \mathrm{~m} / \mathrm{sec}$ to $4.2 \mathrm{~m} / \mathrm{sec}$. The current suite of time histories appear to contain some unreasonably high vertical $P G V_{V}$ and peak ground accelerations PGA for a given longitudinal $P G V_{L}$. These limited number of unreasonably high ground motion $P G V_{V}$ and $P G A$ values are likely to have introduced some conservative bias to the high end of the damage area estimates. Unfortunately, revising the suite of ground motion records would require all of the time-history waste 
package response studies and the damage abstractions to have to be redone. My judgement is that the current damage estimates are conservative and that improving the suite of time-history records would lead to such an extensive redo of work that it is probably not necessary.

2. Reinvestigate the catalog of damaged areas for end on impacts. The current catalog is for a single waste package impacting a rigid boundary. This condition only strictly applies to the case of perfectly symmetric impacts between adjacent casks. This perfectly symmetric impact situation is extremely unlikely. It is much more likely that the corner edge of one waste package impacts the lid of the adjacent waste package. This impact situation probably warrants additional study. If no further study is performed, one should continue to use the relative impact velocity between waste packages as opposed to half of this velocity when using the current catalog (Table 6.5-2)13 of damage area as a function of impact velocity."

Project Response. As noted in the project response to Prof. Cornell's review, only the horizontal longitudinal component of a ground motion is limited to the PGV value on the bounded hazard curve. The horizontal transverse component and the vertical component are not bounded, introducing a very significant conservatism in the kinematic calculations and the structural response calculations at the $5.35-\mathrm{m} / \mathrm{s}$ PGV level. There is also a significant conservatism in the use of the relative impact velocity, rather than one-half the relative impact velocity, for defining damage based on the catalog of damaged areas from end-on impacts. This latter conservatism is intended to encompass potential corrections for corner-to-lid impacts of adjacent waste packages, as Dr. Kennedy implies in Item (2) above.

The results from Dr. Kennedy's independent review fulfill the requirements in BSC (2005 [DIRS 173171], Section 2.2.2.2) as follows:

1. Is the model abstraction reasonable and appropriate for its intended use?

- The LS-DYNA and UDEC technical approaches represent practical, high quality calculations of the impact kinematics for a string of waste packages.

- The use of a damage catalog to define the damaged areas for the kinematic calculations with LS-DYNA and UDEC is appropriate, provided the relative impact velocity (rather than one-half the relative impact velocity) is the basis for interpolation within the catalog.

- The damage abstractions for end-to-end impacts of adjacent waste packages are reasonable. The fit to the probability of no damage and the power law fit to the median nonzero damaged area as functions of longitudinal PGV are reasonable. Finally, the use of a ln-normal distribution to represent the dispersion about the power law fit is reasonable.

\footnotetext{
${ }^{13}$ Editorial Note: The corresponding table number in the final version of this report is Table 6.5-4.
} 
- The damage abstractions for waste package-pallet impacts are reasonable. The fit to the probability of no damage and the power law fit to the median nonzero damaged area as functions of longitudinal PGV are reasonable. Finally, the use of a ln-normal distribution to represent the dispersion about the power law fit is reasonable.

- The use of weighted results from UDEC and LS-DYNA for damage from end-to-end impacts provides an appropriate and adequate abstraction.

2. For given inputs, are the outputs of the model abstraction reasonable?

- The damage abstractions for end-to-end impacts provide a reasonable fit to the data for damaged area, and Dr. Kennedy did not identify an improved fit.

- The damage abstractions for waste package-pallet impacts provide a reasonable fit to the damaged area data, and Dr. Kennedy did not identify an improved fit.

3. Are limitations of the model abstraction adequately described?

The limitations identified by Dr. Kennedy and the project response to these limitations are summarized on the previous page.

As discussed in Section 6.10, the abstractions for cladding damage from vibratory ground motions and for EBS damage from fault displacement are considered scientific analyses because they are based on standard statistical techniques that bound the component response. Since these abstractions are not models, they are not validated per LP-SIII.10Q-BSC.

The abstraction for EBS damage from fault displacement is based on standard engineering and statistical techniques that bound the response of the waste package, drip shield, and cladding, rather than the results from detailed engineering calculations or other scientific analyses. Since the damage abstraction for fault displacement is a conservative, bounding approach, rather than a model, it is not validated per LP-SIII.10Q-BSC. Section 6.7 describes the bounding approach for damage from fault displacement.

The abstraction for damage to the cladding from vibratory ground motion results in 100 percent of the cladding being perforated in response to a ground motion with PGV of $1.05 \mathrm{~m} / \mathrm{s}$ or larger (Table 6.5-16). This is a bounding approach, as discussed in Section 6.5.6, which does not require further verification and is consistent with the available information and scientific understanding.

\section{Validation Summary}

The Seismic Consequences Abstraction and its components have been validated by applying acceptance criteria based on an evaluation of the model's relative importance to the potential performance of the repository system. All validation requirements defined in the applicable TWP (BSC 2005 [DIRS 173171], Section 2.2.2.2) have been fulfilled. For the damage abstraction of the waste package under vibratory ground motion, this included corroboration of 
abstraction results with computational data, and independent technical review. Requirements for confidence building during model development have also been satisfied. The model development activities and post development validation activities described establish the scientific bases for the Seismic Consequences Abstraction. Based on this, the Seismic Consequences Abstraction and its components are considered to be sufficiently accurate and adequate for the representation of seismically-induced damage to EBS components in TSPA and to the level of confidence required by each abstraction component's relative importance to the potential performance of the repository system. 


\section{CONCLUSIONS}

\subsection{SUMMARY}

The purpose of this work is to develop abstractions for the response of EBS components to seismic hazards at a geologic repository at Yucca Mountain, Nevada, and to define the methodology for using these abstractions in a seismic scenario class for the TSPA-LA. The seismic hazards are vibratory ground motion, fault displacement, and rockfall due to ground motion. The EBS components are the drip shield, the waste package, and the fuel cladding. The following abstractions for seismically-induced damage have been developed:

- Damage to the waste package from vibratory ground motions

- Damage to the drip shield from vibratory ground motions

- Damage to the fuel rod cladding from end-to-end impacts of adjacent waste packages

- Damage to the waste package, drip shield and fuel rod cladding from fault displacement.

The recommended implementation of these abstractions and their associated input parameters for TSPA-LA is defined in Section 6.9.2 and Table 6.9-1. This computational algorithm can also be referenced through the output DTN: MO0508SPACOMPA.002. The recommended implementation of damage from fault displacement for criticality analyses is defined in Section 6.7.7. The results in Section 6.7.7 can also be referenced through the output DTN: MO0508SPACOMPA.002.

Damage to the drip shield from rockfall in the lithophysal zones is not abstracted for TSPA-LA because the lithophysal zone is expected to shatter into small fragments that cannot produce damaged areas on the drip shield.

The seismic scenario class is designed to efficiently determine the mean dose for seismic events with annual frequencies down to $10^{-8}$ per year. The seismic scenario class is based on a single seismic hazard occurring at a randomly chosen time in each realization of the TSPA-LA. That is, the conditional probability of a seismic event is 1 for each realization. The damage from this single event is based on the abstractions for the drip shield, the waste package and the fuel rod cladding. The damaged areas on the EBS components define pathways for flow and transport through the EBS. Once radionuclides are released from the EBS, flow and transport in the unsaturated zone and the saturated zone are based on the same models and algorithms as for the nominal scenario class. Biosphere calculations and parameters for the seismic scenario class are also unchanged from the nominal scenario class.

Each realization of the seismic scenario class determines an annual dose time history for a single seismic hazard with known value of PGV and fault displacement. These dose time histories do not represent the mean dose, as called for in 10 CFR 63.303 [DIRS 173273], because a single hazard always occurs in each realization. However, a mean dose time history can be calculated using a probability-weighted average of all the realizations for the seismic scenario class. The weighting factor for each realization corrects for the expected number of seismic events in each realization and for the logarithmic sampling of the hazard curve for PGV and of the time of the seismic event. 
The major limitations of the postclosure abstractions for the seismic scenario class are as follows:

- The structural response calculations include degradation of the waste package and drip shield over a 20,000-year time frame, which includes the initial 10,000 years following repository closure.

- Coupled effects from multiple seismic events (i.e., that drift collapse during the first seismic event can alter conditions for the response of EBS components during the second seismic event) are not considered because seismic hazards with the potential to have a significant impact on engineered barriers are anticipated to occur very rarely during the 10,000 years following repository closure. More specifically, seismic hazards with the greatest potential to damage the engineered barriers correspond to large disruptive events with annual exceedance frequencies much less than $10^{-4}$ per year (Section 6.5 of this report), so there is only a very small probability that multiple events with the potential to induce significant damage will occur over a 10,000-year or 20,000-year period.

- Spatial variability has not been represented in the damage abstractions for EBS components under ground motion.

- Structural response calculations for the drip shield and waste package do not include backfill around the drip shield at the time of the seismic event. This representation is consistent with the present design that does not include an engineered backfill, is consistent with the results from drift degradation analyses under nominal repository conditions, and is consistent with rockfall analyses that indicate complete drift collapse does not occur until peak ground velocity exceeds a threshold of $2 \mathrm{~m} / \mathrm{s}$ in the lithophysal regions of the repository.

- Structural response calculations are based on the 21-PWR waste package (Section 6.5.1.1). The design for the 21-PWR package is very similar to the design of the 44-BWR package, and these two package types account for almost 65 percent of the packages in the inventory for TSPA-LA (BSC 2005 [DIRS 173501], Table 11, for the 21-PWR AP, 21-PWR control rod, and 44-BWR absorber plate). It is reasonable to base damage estimates on the 21-PWR waste package because it is the dominant package design in the repository.

- The ground motions for structural response calculations were created using different approaches for intercomponent variability and for spectral conditioning. Section 6.4.2 provides a discussion on the methodology for defining the suites of ground motions that are used in the structural response calculations.

Two restrictions for subsequent use are identified here: (1) the structural response of degraded EBS components may need to be reconsidered if the duration of TSPA calculations is greater than 20,000 years, and (2) the appropriateness of determining mean dose from a single seismic event in each realization may need to be reconsidered if the duration of TSPA calculations is greater than 20,000 years. 


\subsection{HOW THE ACCEPTANCE CRITERIA ARE ADDRESSED}

\section{Acceptance Criterion 1: System Description and Model Integration Are Adequate.}

(1) Total system performance assessment adequately incorporates important design features, physical phenomena, and couplings, and uses consistent and appropriate assumptions throughout the mechanical disruption of engineered barrier abstraction process;

Response: Section 6 explains the basis for the damage abstractions for the waste package (Sections 6.5.1 through 6.5.3), drip shield (Sections 6.5.4 and 6.5.5) and fuel rod cladding (Section 6.5.6) in response to vibratory ground motion and fault displacement. The structural response calculations in Section 6.5.1 through 6.5.6 include the mechanical coupling between the EBS components in defining damaged areas on the drip shield and waste package or percent failed cladding. Section 6.6 considers the potential damage to the EBS components from rockfall induced by vibratory ground motion. Finally, Section 6.8 defines the thermal and hydrological changes to the in-drift environment after a seismic event. These sections collectively address the methodology for incorporating design features, seismic response, and mechanical/thermal/hydrologic coupling within the damage abstractions for the seismic scenario class. Specific aspects of the methodology are as follows:

- The abstractions for damaged areas on the waste package and cladding are based on a statistically robust sampling of uncertain parameters, including the ground motion time histories, rock fracture patterns, rock compressive strength, and friction coefficients (Sections 6.5.1 through 6.5.7). The abstractions are based on rockfall analyses and structural response calculations that use consistent assumptions and consistent material properties.

- All abstractions are based on the mean hazard curves for ground motion and fault displacement, as discussed in Section 6.4. This is consistent with Brocoum (2001 [DIRS 159576], enclosure).

- Degradation of the drip shield and waste package is addressed for the first 10,000 years to 20,000 years after repository closure by reducing the thickness of the outer barrier of the waste package and the thickness of the drip shield plates by $2 \mathrm{~mm}$.

- Material properties for structural response calculations are based on a temperature of $150^{\circ} \mathrm{C}$, resulting in conservative values for 97 percent of the first 10,000 years after closure for the high temperature operating mode, as discussed in Assumption 5.3. This choice is even more conservative over the first 20,000 years after repository closure.

- Drip shield damage from rockfall induced by vibratory ground motion in the lithophysal and nonlithophysal zones is analyzed but not included in the damage abstractions (Section 6.6). Rockfall is analyzed with state-of-the-art computer codes that are used for other drift degradation analyses. 
- All relevant seismic-related FEPs are considered in Section 6.2. The seismic-related FEPs in Table 6.2-1 are directly included in these abstractions. The seismic-related FEPs for damage to EBS components from seismic-induced rockfall and from seismic-induced drift collapse are screened out of TSPA-LA, based on the arguments summarized in Table 6.2-2.

(2) The description of geological and engineering aspects of design features, physical phenomena, and couplings, that may affect mechanical disruption of engineered barriers, is adequate. For example, the description may include materials used in the construction of engineered barrier components, environmental effects (e.g., temperature, water chemistry, humidity, radiation, etc.) on these materials, and mechanical-failure processes and concomitant failure criteria used to assess the performance capabilities of these materials. Conditions and assumptions in the abstraction of mechanical disruption of engineered barriers are readily identified and consistent with the body of data presented in the description.

Response: The structural response calculations and kinematic calculations in Section 6.5.1 through 6.5.6 include the mechanical coupling between the EBS components in defining damaged areas on the drip shield and waste package or percent failed cladding. Section 6.6 considers the potential damage to the EBS components from rockfall induced by vibratory ground motion. Finally, Section 6.8 defines the thermal and hydrological changes to the in-drift environment after a seismic event. These sections collectively address the methodology for incorporating design features, physical phenomena, and the mechanical/thermal/hydrologic coupling between these phenomena within the damage abstractions for the seismic scenario class. Specific aspects of the methodology are as follows

- All abstractions are based on the mean hazard curves for ground motion and fault displacement, as discussed in Section 6.4. This is consistent with Brocoum (2001 [DIRS 159576], enclosure).

- Degradation of the drip shield and waste package is addressed for the first 10,000 years to 20,000 years after repository closure by reducing the thickness of the outer barrier of the waste package and the thickness of the drip shield plates by $2 \mathrm{~mm}$.

- Material properties for structural response calculations are based on a temperature of $150^{\circ} \mathrm{C}$, resulting in conservative values for 97 percent of the first 10,000 years after closure for the high temperature operating mode, as discussed in Assumption 5.3. This choice is even more conservative over the first 20,000 years after repository closure.

- The failure criteria for Alloy 22 and Titanium Grade 7 are based on a residual stress threshold for initiation of stress corrosion cracking, as explained in Sections 6.3.2 and 6.3.3. The experimental basis for these failure criteria are defined in these sections. 
(3) The abstraction of mechanical disruption of engineered barriers uses assumptions, technical bases, data, and models that are appropriate and consistent with other related U.S. Department of Energy abstractions. For example, assumptions used for mechanical disruption of engineered barriers are consistent with the abstraction of degradation of engineered barriers (Section 2.2.1.3.1 of the Yucca Mountain Review Plan). The descriptions and technical bases provide transparent and traceable support for the abstraction of mechanical disruption of engineered barriers;

Response: The seismic scenario class is represented as a separate scenario class in TSPA. The rationale for this approach is explained in Section 6.9. The seismic scenario class generally uses the same assumptions, technical bases, data and models as the nominal scenario class. Major exceptions are: (1) the failure mechanisms for the waste package and drip shield and cladding, as discussed in Section 6.3, (2) changes to the in-drift seepage, temperature, and relative humidity after a seismic event (Section 6.8), and (3) alternate flow diversion (also called flux splitting) for the drip shield after failure from fault displacement (Section 6.7.5, last paragraph). Specific aspects of the seismic scenario class are as follows:

- All abstractions are based on the mean hazard curves for ground motion and fault displacement, as discussed in Section 6.4. This is consistent with Brocoum (2001 [DIRS 159576], enclosure).

- The analysis of rockfall for the seismic scenario class and for the nominal scenario class is based on the same set of computer codes (Section 6.6 and BSC 2004 [DIRS 166107]). Similarly, the LS-DYNA code is used for both design calculations and structural response calculations for the seismic scenario class (Section 6.5).

- The residual stress threshold for failure of Alloy 22 is also used as the threshold for initiation of stress corrosion cracking in the representation of corrosion processes on the waste package, as discussed in Sections 6.3.2 and 6.3.3.

(4) Boundary and initial conditions used in the total system performance assessment abstraction of mechanical disruption of engineered barriers are propagated throughout its abstraction approaches;

Response: The rockfall analyses and structural response calculations use the same sets of ground motions at the 2.44-m/s PGV level and the 5.35-m/s PGV level. Other boundary and initial conditions that ensure consistency are as follows:

- The abstractions for damaged areas on the waste package and cladding are based on a statistically robust sampling of uncertain parameters, including the ground motion time histories, rock fracture patterns, rock compressive strength, and friction coefficients (Sections 6.5.1 through 6.5.7). The abstractions are based on rockfall analyses and structural response calculations that use consistent boundary conditions and initial conditions.

- All abstractions are based on the mean hazard curves for ground motion and fault displacement, as discussed in Section 6.4. This is consistent with Brocoum (2001 [DIRS 159576], enclosure). 
- Degradation of the drip shield and waste package is addressed for the first 10,000 years to 20,000 years after repository closure by reducing the thickness of the outer barrier of the waste package and the thickness of the drip shield plates by $2 \mathrm{~mm}$.

- Material properties for structural response calculations are based on a temperature of $150^{\circ} \mathrm{C}$, resulting in conservative values for 97 percent of the first 10,000 years after closure for the high temperature operating mode, as discussed in Assumption 5.3.

(5) Sufficient data and technical bases to assess the degree to which features, events, and processes have been included in this abstraction are provided.

Response: The seismic-related FEPs in Table 6.2-1 are directly included in these abstractions. The seismic-related FEPs for damage to EBS components from seismic-induced rockfall and from seismic-induced drift collapse are screened out of TSPA-LA, based on the arguments summarized in Table 6.2-2. Damage to EBS components from ground motion, rockfall, drift collapse, and shear due to fault displacement have been considered in the abstractions for the seismic scenario class or in the structural response calculations that support the abstractions.

\section{Acceptance Criterion 2: Data Are Sufficient for Model Justification.}

(1) Geological and engineering values, used in the license application to evaluate mechanical disruption of engineered barriers, are adequately justified. Adequate descriptions of how the data were used, interpreted, and appropriately synthesized into the parameters are provided.

Response: The underlying data for geologic properties and for engineering material properties are generally not directly used in the development of the seismic damage abstractions, with the exception of the residual stress failure criteria for Alloy 22 and for Titanium Grade 7. Justification of the appropriate values is provided through external references. These justifications are based on experimental data for stress corrosion cracking, on handbook values and on manufacturer's literature for the elastic and inelastic properties of EBS component materials, and on expert elicitation. Specific source documents that support development of the seismic scenario class are as follows:

- The residual stress failure criteria are based on experimental data for the initiation of stress corrosion cracking in Alloy 22 and Titanium Grade 7 (BSC 2004 [DIRS 172203], Section 6.2.1).

- The constitutive relationships for Alloy 22 and for Titanium Grade 7 are based on material properties in the published literature. More specifically, the Young's modulus, Poisson's ratio, yield strength, and friction factors are based on data in published literature (BSC 2004 [DIRS 167083] Section 5).

- Hazard curves are based on the results of an expert elicitation (CRWMS M\&O 1998 [DIRS 103731]; DTN: MO0401MWDRPSHA.000 [DIRS 166962], with files listed in Table 4-1). The ground motion time histories for the rockfall analyses and 
structural response calculations have been developed in a manner that is consistent with and builds upon the results of this expert elicitation.

(3) Data on geology of the natural system, engineering materials, and initial manufacturing defects, used in the total system performance assessment abstraction, are based on appropriate techniques. These techniques may include laboratory experiments, site-specific field measurements, natural analog research, and process-level modeling studies. As appropriate, sensitivity or uncertainty analyses used to support the U.S. Department of Energy total system performance assessment abstraction are adequate to determine the possible need for additional data.

Response: Similar in response to subcriterion 1 above, the underlying data for the seismic scenario class are based on experimental data for stress corrosion cracking, on handbook values and manufacturer's literature for the elastic and inelastic properties of EBS component materials, and on expert elicitation. Specific sources that support development of the seismic scenario class are as follows:

- The residual stress failure criteria are based on experimental data for the initiation of stress corrosion cracking in Alloy 22 and Titanium Grade 7 (BSC 2004 [DIRS 172203], Section 6.2.1).

- The constitutive relationships for Alloy 22 and for Titanium Grade 7 are based on material properties in the published literature. More specifically, the Young's modulus, Poisson's ratio, yield strength, and friction factors are based on data in published literature (BSC 2004 [DIRS 167083] Section 5).

- Hazard curves are based on the results of an expert elicitation (CRWMS M\&O 1998 [DIRS 103731]; DTN: MO0401MWDRPSHA.000 [DIRS 166962], with files listed in Table 4-1). The ground motion time histories for the rockfall analyses and structural response calculations have been developed in a manner that is consistent with and builds upon the results of this expert elicitation.

(4) Engineered barrier mechanical failure models for disruption events are adequate. For example, these models may consider effects of prolonged exposure to the expected emplacement drift environment, material test results not specifically designed or performed for the Yucca Mountain site, and engineered barrier component fabrication flaws.

Response: The potential failure modes of EBS components are analyzed in Section 6.3.1. Based on this discussion, accelerated stress corrosion cracking is the expected failure mechanism for EBS components during a seismic event, rather than puncture or tearing at the ultimate tensile strain. The constitutive relationships for Alloy 22 and for Titanium Grade 7 are based on material properties in the published literature. More specifically, the Young's modulus, Poisson's ratio, yield strength, and friction factors are based on data in published literature, as summarized in BSC (2004 [DIRS 167083] Section 5). 


\section{Acceptance Criterion 3: Data Uncertainty Is Characterized and Propagated Through the Model Abstraction.}

Data uncertainty is explicitly included in the seismic abstractions for TSPA-LA. In the PSHA, parameter uncertainty and model uncertainty were directly incorporated into the seismic hazard curves that are direct inputs to the fault displacement damage abstraction and the computational methodology for the seismic scenario class. Parameter uncertainty is also included in the ground motion time histories that are direct inputs to the rockfall analyses and structural response calculations that provide the basis for the damage abstractions. Uncertainty in the input parameters for the structural response calculation and rockfall analyses is described next, followed by information on Subcriteria (1), (2), and (3) for this acceptance criterion.

\section{Uncertainty in Input Parameters for Structural Response Calculations}

The structural response calculations for the waste package response and drip shield under vibratory ground motions include three major sources of uncertainty: (1) the ground motion time histories (aleatory uncertainty), (2) the metal-to-metal friction coefficient (epistemic uncertainty), and (3) the metal-to-rock friction coefficient (epistemic uncertainty):

- Multiple three-component ground motion time histories are used to represent the uncertainty in the seismic forcing functions at PGV levels of $1.05 \mathrm{~m} / \mathrm{s}, 2.44 \mathrm{~m} / \mathrm{s}$, and $5.35 \mathrm{~m} / \mathrm{s}$. One horizontal component of each ground motion set is scaled to have the same horizontal PGV because its uncertainty has been incorporated into the hazard curves during the PSHA. The peak ground acceleration and the duration of the time histories span a wide range of response. For example, the peak ground acceleration for the first horizontal ground motion component at the 2.44-m/s PGV level ranges from about $1.5 \mathrm{~g}$ to $7 \mathrm{~g}$.

- The metal-to-metal friction coefficient between the waste package and emplacement pallet varies from 0.2 to 0.8 to represent the uncertainty in its value. The friction coefficient affects the onset of sliding and dissipation of energy for the EBS components as a function of the amplitude of the ground motion. The static and dynamic friction coefficients are taken to be equal within the broad range $(0.2$ to 0.8$)$ defined for this parameter. However, the importance of friction is anticipated to diminish with increasing ground motion level because the EBS components begin to slide almost immediately for high amplitude ground motions.

- The metal-to-rock friction coefficient between the emplacement pallet and the invert or between the drip shield and the invert varies from 0.2 to 0.8 to represent the uncertainty in its value. Again, the friction coefficient affects the onset of sliding and dissipation of energy for the unanchored EBS components as a function of the amplitude of the ground motion. However, the importance of friction is anticipated to diminish with increasing amplitude of the ground motions.

The selection of friction coefficients as major sources of uncertainty, in addition to the ground motions, is based on the potential for frictional forces to influence the kinematics of EBS components. Variability in ground motions is often the most significant uncertainty in structural 
response calculations for nuclear plant components. Variability of friction coefficients may be important if damage varies significantly with the relative motions or impacts between adjacent structures.

The variations of these uncertain input parameters are simultaneously included in the fifteen structural response calculations at each seismic hazard level. This is accomplished by a Monte Carlo procedure that ensures robust sampling of the uncertain parameters over their full ranges (Sections 6.5.1 and 6.5.4). The Monte Carlo procedure and the sampled values of the three uncertain input parameters are described and documented in Sampling of Stochastic Input Parameters for Rockfall and Structural Response Calculations Under Vibratory Ground Motion (BSC 2004 [DIRS 169999], Section 6.4).

The results from the structural response calculations are post-processed to determine the damaged areas on the drip shield or waste package. The seismic damage abstractions for the waste package and drip shield make use of a residual stress threshold as a failure criterion (Sections 6.3.2 and 6.3.3). If the residual stress from mechanical damage exceeds the stress threshold for the barrier, then the affected area(s) are represented as a network of stress corrosion cracks. The residual stress threshold for the waste package is based on a uniform distribution between 80 and 90 percent of the yield strength for Alloy 22 (Sections 6.3.2 and 6.3.3). Post-processing of the output from waste package calculations determines the damaged areas corresponding to both 80 and 90 percent of the yield strength of Alloy 22 (BSC 2004 [DIRS 167083], Tables 6.4.1-2 and 6.4.2-2). The residual stress threshold for titanium is (very) conservatively set to a constant value of 50 percent of the yield strength of Titanium Grade 7, so no uncertainty is propagated into TSPA-LA for damaged area on the drip shield from vibratory ground motion.

\section{Uncertainty in Input Parameters for Rockfall Analyses}

All rockfall analyses include the ground motion time histories as a major source of uncertainty (Section 6.6). Fifteen ground motions represent the uncertainty in the seismic forcing functions at the $1.05-\mathrm{m} / \mathrm{s}, 2.44-\mathrm{m} / \mathrm{s}$, and $5.35-\mathrm{m} / \mathrm{s}$ PGV levels. In the lithophysal units, the rock compressive strength is an uncertain input parameter that is represented as five discrete levels of rock strength, ranging from low $(5 \mathrm{MPa})$ to high $(30 \mathrm{MPa})$. In the nonlithophysal units, the synthetic fracture pattern is an uncertain input parameter. The synthetic fracture pattern is a representation of the fracture system geometry in three dimensions. 105 synthetic fracture patterns define the fracture geometry (but not the fracture properties; see below) are used in the rockfall analyses for the nonlithophysal units. The variations in these uncertain parameters are simultaneously included in the rockfall analyses at each seismic hazard level (BSC 2004 [DIRS 166107]).

The stochastic input parameters for the rockfall analyses are based on engineering judgment. For example, the rock compressive strength is a key parameter for drift failure in a continuum material, while the fracture geometry is a key parameter for identifying the size and location of rock blocks that can be shaken loose from the walls of a drift. Fracture properties such as cohesion and sliding friction can also be important in the nonlithophysal units, but are conservatively represented rather than being incorporated into the stochastic sampling scheme. 
The results from the rockfall analyses are not direct inputs to TSPA-LA. Rockfall analyses for lithophysal units predict drift collapse at PGV levels of $2 \mathrm{~m} / \mathrm{s}$ and greater; however, the strong seismic waves are predicted to shatter the lithophysal rock into small fragments that cannot damage the drip shield or waste package as a barrier to seepage.

Rockfall analyses for the nonlithophysal units predict a wide range of block sizes and velocities that can be ejected from the drift walls and impact the drip shield. More specifically, each rockfall analysis for the nonlithophysal unit predicts a complex, time-dependent sequence of rock blocks that impact the drip shield at varying locations and velocities. These impacts can cause damage to the drip shield if the block has enough mass and kinetic energy.

\section{Propagation of Uncertainty Into TSPA}

The calculations of damaged area on the waste package and drip shield due to vibratory ground motions exhibit substantial variability induced by the uncertainties in seismic ground motions and other input parameters. This variability has been directly represented in TSPA-LA by defining stochastic parameters that are sampled during each realization of the seismic scenario class. For example:

- For a given value of PGV, damage to the waste package from vibratory ground motion is represented as (i) the probability of no damage, (ii) if damage occurs, a power law fit represents the median damaged area on the waste package, and (iii) a ln-uniform distribution of damage about the median value; this ln-uniform distribution is sampled for each realization of the seismic scenario class. The probability of no damage is shown in Figures 6.5-9 and 6.5-15. The range of data for the power law fit is shown in Figures 6.5-10, 6.5-16, and 6.5-17. The distribution of points about the power law fit is shown in Figures 6.5-11, 6.5-12, 6.5-18, and 6.5-19. The comparison of the 0.05 and 0.95 nonexceedance probability curves for the ln-normal distribution with the nonzero damaged area data is shown in Figures 6.5-13 and 6.5-21.

- The uncertainty in the residual stress threshold for Alloy 22 has been propagated into the abstraction for TSPA-LA. The damage for end-to-end impacts of the waste packages is based on separate damage abstractions for the 80 and 90 percent Alloy 22 failure criteria. Similarly, the damage for waste package-pallet impacts is based on separate damage abstractions for the 80 and 90 percent Alloy 22 failure criteria. This approach directly maintains the range in damaged areas due to the uncertainty in failure criterion in the TSPA calculations for the seismic scenario class.

The abstraction for failure of fuel rod cladding does not propagate uncertainty into TSPA-LA because it is based on a simplified response that is bounded with two damage states: zero damage below PGV of $0.55 \mathrm{~m} / \mathrm{s}$ and 100 percent damage for PGV values of $1.05 \mathrm{~m} / \mathrm{s}$ and greater. 


\section{Discussion for Subcriteria (1), (2), and (3)}

(1) Models use parameter values, assumed ranges, probability distributions, and bounding assumptions that are technically defensible, reasonably account for uncertainties and variabilities, and do not result in an under-representation of the risk estimate;

Response: The above discussion directly addresses the technical defensibility, uncertainty, and variabilities in parameter values. Specific examples include:

- Rockfall models and structural response calculations use parameter values and parameter ranges that are defensible and account for variabilities in rock properties and fracture patterns and uncertainties in ground motion time histories and friction coefficients.

- A major uncertainty in the response of the lithophysal zone is the rock compressive strength. This parameter is sampled from 5 levels for the rockfall analyses.

- Material properties for structural response calculations are based on a temperature of $150^{\circ} \mathrm{C}$, which is conservative over 97 percent of the time for the first 10,000 years after closure. This choice is even more conservative for the first 20,000 years after repository closure (Assumption 5.3).

(2) Process-level models used to represent mechanically disruptive events, within the emplacement drifts at the proposed Yucca Mountain repository, are adequate. Parameter values are adequately constrained by Yucca Mountain site data, such that the effects of mechanically disruptive events on engineered barrier integrity are not underestimated. Parameters within conceptual models for mechanically disruptive events are consistent with the range of characteristics observed at Yucca Mountain.

Response: The LS-DYNA code and the UDEC code are used to determine the mechanical response of EBS components to vibratory ground motion. LS-DYNA is used for both design calculations and for the structural response calculations for the seismic scenario class (Section 6.5). The analysis of rockfall for the seismic scenario class and for the nominal scenario class is based on state-of-the-art computer codes, including UDEC, that can represent continuum and discontinuous response of rock in the lithophysal and nonlithophysal units of the repository (Section 6.6 and BSC 2004 [DIRS 166107]). The appropriateness of the parameters within LS-DYNA and for the rockfall analyses with UDEC are discussed in underlying documents, such as Drift Degradation Analysis (BSC 2004 [DIRS 166107]), and are beyond the scope of this document.

(3) Uncertainty is adequately represented in parameter development for conceptual models, process-level models, and alternative conceptual models considered in developing the assessment abstraction of mechanical disruption of engineered barriers. This may be done either through sensitivity analyses or use of conservative limits. 
Response: The discussion preceding Subcriterion (1) directly addresses the incorporation of parameter uncertainty into the abstraction process. Specific examples include:

- A major uncertainty in the response of the lithophysal zone is the rock compressive strength. This parameter is sampled from five levels for the rockfall analyses.

- A major uncertainty in the response of the nonlithophysal zone is the fracture geometry and fracture properties. These uncertainties are represented by the use of numerous synthetic joint fracture patterns that are generated in a statistically sound manner and incorporated into the rockfall analyses for the nonlithophysal zones.

- Material properties for structural response calculations are based on a temperature of $150^{\circ} \mathrm{C}$, which is conservative over 97 percent of the time for the first 10,000 years after closure. This choice is even more conservative for the first 20,000 years after repository closure (Assumption 5.3).

- Thicknesses of the waste package outer barrier and drip shield plates have been reduced by $2 \mathrm{~mm}$ to conservatively account for general corrosion over the first 10,000 years to 20,000 years after closure.

- Uncertainty and variability in damaged areas of the waste package and drip shield are represented in the abstractions as a sampled distribution (Sections 6.5.3 and 6.5.6). This uncertainty is directly incorporated into the abstractions for TSPA-LA.

\section{Acceptance Criterion 4: Model Uncertainty Is Characterized and Propagated Through the Model Abstraction.}

The seismic consequence abstractions have considered alternative conceptual models. The kinematic calculations include two alternate technical approaches, based on LS-DYNA and UDEC, and also provide different representations of the mean or median damage and the distribution of damage about the mean or median for the damage from end-to-end impacts. Model uncertainty has been directly incorporated into the hazard curves that are direct inputs to the fault displacement damage abstraction and the computational methodology for the seismic scenario class.

The distribution of damaged areas on the waste package has been analyzed for the $2.44-\mathrm{m} / \mathrm{s}$, $5.35-\mathrm{m} / \mathrm{s}$ and $1.05-\mathrm{m} / \mathrm{s} \mathrm{PGV} \mathrm{level} \mathrm{ground} \mathrm{motions.} \mathrm{The} \mathrm{damaged} \mathrm{areas} \mathrm{for} \mathrm{end-to-end} \mathrm{impacts} \mathrm{of}$ adjacent waste packages are based on kinematic calculations with multiple waste packages. Kinematic calculations have been performed with LS-DYNA and UDEC using slightly different modeling approaches and modeling assumptions (Section 6.5.1.1). The uncertainty in the kinematic approaches has been propagated into the abstraction for TSPA-LA by providing separate damage abstractions for UDEC and for LS-DYNA. This approach directly maintains the uncertainty in damaged area due to the computational approaches in the seismic scenario class for TSPA. Note that the damage abstraction for waste package-pallet impacts is based on the results from LS-DYNA analyses, without an alternate computational technique, so the corresponding uncertainty cannot be propagated forward into TSPA. 
The damage abstraction for fault displacement has been compared to an alternative conceptual model proposed by Waiting et al. (2003 [DIRS 164449]). There is reasonable agreement between the damage abstraction in this report and the alternative conceptual model, considering that the alternate model is based on historical data for fault displacement in the western United States and that the damage abstraction is based on hazard curves specific to Yucca Mountain. For example, the number of fault intersections predicted by the damage abstraction is 171, versus 191 for the alternative conceptual model. Similarly, the probability weighted number of waste package failures is predicted to be $2.3 \times 10^{-6}$ for the damage abstraction, within the range of $1.9 \times 10^{-6}$ to $1.9 \times 10^{-5}$ for the alternative conceptual model. This agreement provides added confidence in the damage abstraction for fault displacement.

\section{Discussion for Subcriteria (2) and (3)}

(2) Consideration of conceptual model uncertainty is consistent with available site characterization data, laboratory experiments, field measurements, natural analog information and process-level modeling studies; and the treatment of conceptual model uncertainty does not result in an under-representation of the risk estimate;

Response: The above discussion directly addresses how conceptual model uncertainty has been incorporated into the abstractions for the seismic scenario class. Specific examples include:

- The hazard curves for vibratory ground motion and fault displacement were developed from an expert elicitation (CRWMS M\&O 1998 [DIRS 103731). This elicitation process explicitly considered conceptual model uncertainty during its development of the hazard curves.

- Grid convergence studies and alternate finite-element representations have been evaluated for the rockfall models (BSC 2004 [DIRS 166107]) and for the structural response calculations (BSC 2004 [DIRS 167083], Attachments VI, VII, VIII, and IX) (BSC 2004 [DIRS 173178]). An alternate damaged area interpolation scheme has also been investigated (BSC 2004 [DIRS 170843]). Calculations and analyses have been performed with the most appropriate numerical representations, so this particular source of model uncertainty is not propagated through the damage abstractions for TSPA-LA.

(3) Appropriate alternative modeling approaches are investigated that are consistent with available data and current scientific knowledge, and appropriately consider their results and limitations using tests and analyses that are sensitive to the processes modeled.

Response: The discussion before Subcriterion (2) directly addresses how alternate modeling approaches are addressed. Specific examples include:

- The hazard curves for vibratory ground motion and fault displacement are developed from a expert elicitation (CRWMS M\&O 1998 [DIRS 103731). The individual groupings of experts developed and weighted alternative conceptual models for defining the seismic hazards at Yucca Mountain. 
- Grid convergence studies and alternate finite element representations have been performed for the rockfall models (BSC 2004 [DIRS 166107]) and for the structural response calculations (BSC 2004 [DIRS 167083], Attachments VI, VII, VIII, and IX; and BSC 2004 [DIRS 173178]). An alternate damaged area interpolation scheme has also been investigated (BSC 2004 [DIRS 170843]). Calculations and analyses have been performed with the most appropriate numerical representations, so this particular source of model uncertainty is not propagated through the damage abstractions for TSPA-LA.

- Alternative modeling approaches have been evaluated for the conceptual and computational models of lithophysal and nonlithophysal rock (BSC 2004 [DIRS 166107]), but are beyond the scope of this document.

- The damage abstraction for fault displacement has been compared to an alternative conceptual model proposed by Waiting et al. (2003 [DIRS 164449]).

\section{Acceptance Criterion 5: Model Abstraction Output Is Supported by Objective Comparisons.}

(1) Models implemented in this total system performance assessment abstraction provide results consistent with output from detailed process-level models and/or empirical observations (laboratory and field testings and/or natural analogs).

The consistency of the abstractions, with the detailed output from structural response calculations, are summarized in Table 8.2-1.

(2) Outputs of mechanical disruption of engineered barrier abstractions reasonably produce or bound the results of corresponding process-level models, empirical observations, or both.

Response: Objective comparisons between the calculated damage to EBS components and the corresponding abstractions for TSPA-LA are summarized in Table 8.2-1.

(3) Well-documented procedures, that have been accepted by the scientific community to construct and test the mathematical and numerical models, are used to simulate mechanical disruption of engineered barriers.

Response: The objective comparisons in Table 8.2-1 are an accepted method for comparing abstractions with the underlying data from structural response calculations or for defining the bounding response of EBS components. 
Table 8.2-1. Comparison of Seismic Abstractions with Objective Evidence

\begin{tabular}{|c|c|}
\hline Abstraction & Objective Comparison \\
\hline $\begin{array}{l}\text { Damage to Waste Package from Ground } \\
\text { Motion }\end{array}$ & $\begin{array}{l}\text { The abstraction for damage to the waste package is } \\
\text { based on kinematic calculations for damage from } \\
\text { end-to-end impacts and on structural response } \\
\text { calculations for waste package-pallet impacts. For the } \\
\text { end-to-end impacts, four separate abstractions are } \\
\text { provided for two computational approaches, with } \\
\text { LS-DYNA or UDEC, and for two residual stress failure } \\
\text { criteria, } 80 \text { percent and } 90 \text { percent of the yield strength of } \\
\text { Alloy } 22 \text {. Figures } 6.5-10 \text { through } 6.5-13 \text { compare the } \\
\text { damaged area observations to a power law fit and to a } \\
\text { In-normal distribution about the power law fit for the } \\
\text { LS-DYNA results with a residual stress failure criterion of } \\
80 \text { percent of the yield strength of Alloy } 22 \text {. For the } \\
\text { waste package-pallet impacts, two separate abstractions } \\
\text { are provided for the LS-DYNA results with residual stress } \\
\text { failure criteria of } 80 \text { percent and } 90 \text { percent of the yield } \\
\text { strength of Alloy } 22 \text {. Figures } 6.5-16 \text { through } 6.5-19 \text { and } \\
\text { Figure } 6.5-21 \text { compare the damaged area observations } \\
\text { to a power law fit and to a In-normal distribution about } \\
\text { the power law for the residual stress failure criterion of } \\
80 \text { percent of the yield strength of Alloy } 22 \text {. }\end{array}$ \\
\hline & $\begin{array}{l}\text { The spreadsheets on the } C D \text { in Appendix } G \text { provide } \\
\text { similar comparisons for all six abstractions. The plots in } \\
\text { these spreadsheets provide objective evidence of the } \\
\text { adequacy of the waste package damage abstraction. An } \\
\text { independent technical review has also been performed } \\
\text { for this damage abstraction to provide increased } \\
\text { confidence in the model abstraction. }\end{array}$ \\
\hline $\begin{array}{l}\text { Damage to Drip Shield from Ground Motion } \\
\text { (only for validation testing of the TSPA-LA } \\
\text { model) }\end{array}$ & $\begin{array}{l}\text { The abstraction for drip shield separation from ground } \\
\text { motion is based on a uniform distribution. The upper } \\
\text { limit of this uniform distribution provides an upper bound } \\
\text { for the separation at a PGV of } 5.35 \mathrm{~m} / \mathrm{s} \text {, providing } \\
\text { objective evidence of its adequacy. }\end{array}$ \\
\hline $\begin{array}{l}\text { Damage to Fuel Rod Cladding from Ground } \\
\text { Motion }\end{array}$ & $\begin{array}{l}\text { The abstraction for damage to the cladding has that } \\
100 \text { percent of the cladding perforated after a ground } \\
\text { motion with PGV of } 1.05 \mathrm{~m} / \mathrm{s} \text { or larger occurs. This } \\
\text { scientific analysis is based on a conservative, bounding } \\
\text { approach. }\end{array}$ \\
\hline $\begin{array}{l}\text { Damage to Waste Package, Drip Shield, } \\
\text { and Fuel Rod Cladding from Fault } \\
\text { Displacement }\end{array}$ & $\begin{array}{l}\text { The abstraction for damage to the waste package and } \\
\text { drip shield from fault displacement is based on the } \\
\text { hazard curves for displacement of known faults in the } \\
\text { repository block and available clearances for EBS } \\
\text { components. The analysis of fault displacement } \\
\text { demonstrates that there is only damage from fault } \\
\text { displacement with a } 2 \times 10^{-7} \text { per year annual exceedance } \\
\text { frequency, or less (Table } 6.7-11) \text {. In this situation, } \\
\text { damage from fault displacement is a very low probability } \\
\text { occurrence. In addition, a maximum of } 56 \text { packages is } \\
\text { affected by fault displacement (Table } 6.7-11 \text { ). In this } \\
\text { situation, it is appropriate to verify this scientific analysis } \\
\text { through the normal checking process for model reports. }\end{array}$ \\
\hline
\end{tabular}

EBS = engineered barrier system; PGV = peak ground velocity; TSPA-LA = total system performance assessment - license application. 
INTENTIONALLY LEFT BLANK 


\section{INPUTS AND REFERENCES}

The following is a list of the references cited in this document. Column 2 represents the unique six digit numerical identifier (the Document Input Reference System number), which is placed in the text following the reference callout (e.g., BSC 2004 [DIRS 170027]). The purpose of these numbers is to assist in locating a specific reference. Within the reference list, multiple sources by the same author (e.g., BSC 2003) are sorted alphabetically by title.

\subsection{DOCUMENTS CITED}

Albin, A.L.; Singleton, W.L.; Moyer, T.C.; Lee, A.C.; Lung, R.C.; Eatman, 101367 G.L.W.; and Barr, D.L. 1997. Geology of the Main Drift - Station 28+00 to 55+00, Exploratory Studies Facility, Yucca Mountain Project, Yucca Mountain, Nevada. Milestone SPG42AM3. Denver, Colorado: Bureau of Reclamation and U.S. Geological Survey. ACC: MOL.19970625.0096.

Andresen, P.L.; Emigh, P.W.; Young, L.M.; and Gordon, G.M. 2001. "Stress 167840 Corrosion Cracking of Annealed and Cold Worked Titanium Grade 7 and Alloy 22 in $110^{\circ} \mathrm{C}$ Concentrated Salt Environments." Corrosion/2001, 56th Annual Conference \& Exposition, March 11-16, 2001, Houston, Texas, USA. Paper No. 01130, Houston, Texas: NACE International. TIC: 255671.

Brocoum, S. 2001. "Transmittal of Report Addressing Key Technical Issues (KTI) 159576 Structural Deformation and Seismicity (SDS)." Letter from S. Brocoum (DOE/YMSCO) to C.W. Reamer (NRC), October 25, 2001, OL\&RC:TCG-0140, with enclosure. ACC: MOL.20020304.0297; MOL.20030714.0094.

BSC 2003. 21-PWR Waste Package Side and End Impacts. 000-00C-DSU0162293 01000-000-00B. Las Vegas, Nevada: Bechtel SAIC Company.

ACC: ENG.20030227.0067.

BSC 2003. Drop of Waste Package on Emplacement Pallet - A Mesh Study. 000-00C-DSU0-02200-000-00A. Las Vegas, Nevada: Bechtel SAIC Company. ACC: ENG.20030915.0001; ENG.20050817.0019.

BSC 2003. Maximum Accelerations on the Fuel Assemblies of a 21-PWR Waste Package During End Impacts. 000-00C-DSU0-01100-000-00A. Las Vegas, Nevada: Bechtel SAIC Company. ACC: ENG.20030327.0002; ENG.20050817.0015.

BSC 2004. Additional Structural Calculations of Waste Package Exposed to 171717 Vibratory Ground Motion. 000-00C-WIS0-01700-000-00B. Las Vegas, Nevada: Bechtel SAIC Company. ACC: ENG.20041027.0001; ENG.20050826.0008.

BSC 2004. Alternative Damaged Area Evaluation for Waste Package Exposed to Vibratory Ground Motion. 000-00C-WIS0-01900-000-00A. Las Vegas, Nevada: Bechtel SAIC Company. ACC: ENG.20040420.0010. 
BSC 2004. Characterize Framework for Seismicity and Structural Deformation at 168030 Yucca Mountain, Nevada. ANL-CRW-GS-000003 REV 00 [Errata 001]. Las Vegas, Nevada: Bechtel SAIC Company. ACC: MOL.20000510.0175; DOC.20040223.0007.

BSC 2004. D\&E / PA/C IED Emplacement Drift Configuration and Environment. 168489 800-IED-MGR0-00201-000-00B. Las Vegas, Nevada: Bechtel SAIC Company. ACC: ENG.20040326.0001.

BSC 2004. D\&E / PA/C IED Subsurface Facilities. 800-IED-WIS000103-000-00A. Las Vegas, Nevada: Bechtel SAIC Company. ACC: ENG.20040309.0028.

BSC 2004. D\&E / PA/C IED Subsurface Facilities. 800-IED-WIS0168180 00104-000-00A. Las Vegas, Nevada: Bechtel SAIC Company. ACC: ENG.20040309.0029.

BSC 2004. D\&E/RIT IED Subsurface Facilities [Sheet 1 of 4]. 800-IED-WIS000101-000-00B. Las Vegas, Nevada: Bechtel SAIC Company. ACC: ENG.20041130.0002.

BSC 2004. Design and Engineering, Interlocking Drip Shield Configuration. 168275 000-M00-SSE0-00101-000-00B. Las Vegas, Nevada: Bechtel SAIC Company. ACC: ENG.20040305.0020.

BSC 2004. Development of Earthquake Ground Motion Input for Preclosure 170027 Seismic Design and Postclosure Performance Assessment of a Geologic Repository at Yucca Mountain, NV. MDL-MGR-GS-000003 REV 01. Las Vegas, Nevada: Bechtel SAIC Company. ACC: DOC.20041111.0006.

BSC 2004. Drift Cross Section Showing Emplaced Waste Package and Drip Shield. 800-M00-WIS0-00101-000-00A. Las Vegas, Nevada: Bechtel SAIC Company. ACC: ENG.20040420.0013.

BSC 2004. Drift Degradation Analysis. ANL-EBS-MD-000027 REV 03. 166107 Las Vegas, Nevada: Bechtel SAIC Company. ACC: DOC.20040915.0010; DOC.20050419.0001.

BSC 2004. Drip Shield Structural Response to Rock Fall. 000-00C-SSE0168993 00300-000-00A. Las Vegas, Nevada: Bechtel SAIC Company. ACC: ENG.20040405.0019; ENG.20050817.0026.

BSC 2004. General Corrosion and Localized Corrosion of Waste Package Outer Barrier. ANL-EBS-MD-000003 REV 02. Las Vegas, Nevada: Bechtel SAIC Company. ACC: DOC.20041004.0001. 
BSC 2004. Mechanical Assessment of the Drip Shield Subject to Vibratory Motion 169753 and Dynamic and Static Rock Loading. CAL-WIS-AC-000002 REV 00A. Las Vegas, Nevada: Bechtel SAIC Company. ACC: DOC.20041028.0004.

BSC 2004. Sampling of Stochastic Input Parameters for Rockfall Calculations and for Structural Response Calculations Under Vibratory Ground Motion. ANL-EBS169999 PA-000009 REV 01. Las Vegas, Nevada: Bechtel SAIC Company. ACC: DOC.20040901.0004.

BSC 2004. Seismic Consequence Abstraction. MDL-WIS-PA-000003 REV 00 167780 Errata 1. Las Vegas, Nevada: Bechtel SAIC Company. ACC: DOC.20030818.0006; DOC.20040218.0002.

BSC 2004. Stress Corrosion Cracking of the Drip Shield, the Waste Package 172203 Outer Barrier, and the Stainless Steel Structural Material. ANL-EBS-MD-000005 REV 02. Las Vegas, Nevada: Bechtel SAIC Company.

ACC: DOC.20041028.0008; DOC.20050621.0003.

BSC 2004. Structural Calculations of Drip Shield Exposed to Vibratory Ground Motion. 000-00C-WIS0-02500-000-00A. Las Vegas, Nevada: Bechtel SAIC Company. ACC: ENG.20041111.0002; ENG.20050817.0032.

BSC 2004. Structural Calculations of Waste Package Exposed to Vibratory Ground Motion. 000-00C-WIS0-01400-000-00A. Las Vegas, Nevada: Bechtel SAIC Company. ACC: ENG.20040217.0008; ENG.20050817.0038;

ENG.20050823.0023.

BSC 2005. 21-PWR Waste Package End Impacts - A Mesh Study. 000-00C-WIS0173178 02100-000-00B. Las Vegas, Nevada: Bechtel SAIC Company.

ACC: ENG.20050207.0032; ENG20050817.0036.

BSC 2005. Creep Deformation of the Drip Shield. CAL-WIS-AC-000004

174715

REV 0A. Las Vegas, Nevada: Bechtel SAIC Company.

BSC 2005. Drip Shield Structural Response to Rock Fall Supplemental Calculation. 000-00C-SSE0-00700-000-00A. Las Vegas, Nevada: Bechtel SAIC Company. ACC: ENG.20050707.0002.

BSC 2005. Engineered Barrier System Features, Events, and Processes. ANL-WIS-PA-000002 REV 04. Las Vegas, Nevada: Bechtel SAIC Company. ACC: DOC.20050725.0003.

BSC 2005. Features, Events, and Processes: Disruptive Events. ANL-WISMD-000005 REV 03. Las Vegas, Nevada: Bechtel SAIC Company. 
BSC 2005. IED Interlocking Drip Shield and Emplacement Pallet [Sheet 1 of 1]. 800-IED-WIS0-00401-000-00E. Las Vegas, Nevada: Bechtel SAIC Company. ACC: ENG.20050301.0007.

BSC 2005. IED Subsurface Facilities Ground Support Configuration [Sheet 1

173498 of 1]. 800-IED-WIS0-01601-000-00A. Las Vegas, Nevada: Bechtel SAIC Company. ACC: ENG.20050406.0003.

BSC 2005. IED Waste Package Configuration [Sheet 1 of 1]. 800-IED-WIS000601-000-00A. Las Vegas, Nevada: Bechtel SAIC Company.

ACC: ENG.20050406.0005.

BSC 2005. IED Waste Package Damage from Vibratory Ground Motion and Fuel 173500 Assembly Acceleration [Sheet 1 of 1]. 800-IED-WIS0-00901-000-00A. Las Vegas, Nevada: Bechtel SAIC Company. ACC: ENG.20050406.0008.

BSC 2005. Mechanical Assessment of the Waste Package Subject to Vibratory Ground Motion. CAL-WIS-AC-000001 REV 0B. Las Vegas, Nevada: Bechtel SAIC Company. ACC: DOC.20050823.0001.

BSC 2005. Multiscale Thermohydrologic Model. ANL-EBS-MD-000049 REV 03. 173944 Las Vegas, Nevada: Bechtel SAIC Company. ACC: DOC.20050711.0001.

BSC 2005. Peak Ground Velocities for Seismic Events at Yucca Mountain, Nevada. ANL-MGR-GS-000004 REV 00. Las Vegas, Nevada: Bechtel SAIC Company. ACC: DOC.20050223.0002; DOC.20050725.0002.

BSC 2005. Q-List. 000-30R-MGR0-00500-000-002. Las Vegas, Nevada: Bechtel 174269 SAIC Company. ACC: ENG.20050805.0006.

BSC 2005. Technical Work Plan for: Analysis of Waste Package and Drip Shield 173171 Response to Vibratory Ground Motion and Revision of the Seismic Consequence Abstraction. TWP-MGR-GS-000004 REV 00. Las Vegas, Nevada: Bechtel SAIC Company. ACC: DOC.20050405.0007.

Budnitz, R.J.; Apostolakis, G.; Boore, D.M.; Cluff, L.S.; Coppersmith, K.J.; 103635 Cornell, C.A.; and Morris, P.A. 1997. Recommendations for Probabilistic Seismic Hazard Analysis: Guidance on the Uncertainty and Use of Experts.

NUREG/CR-6372. Two volumes. Washington, D.C.: U.S. Nuclear Regulatory Commission. TIC: 235076; 235074.

Chun, R.; Witte, M.; and Schwartz, M. 1987. Dynamic Impact Effects on Spent 144357 Fuel Assemblies. UCID-21246. Livermore, California: Lawrence Livermore National Laboratory. ACC: HQX.19881020.0031. 
CRWMS M\&O 1998. Probabilistic Seismic Hazard Analyses for Fault

103731

Displacement and Vibratory Ground Motion at Yucca Mountain, Nevada.

Milestone SP32IM3, September 23, 1998. Three volumes. Las Vegas, Nevada:

CRWMS M\&O. ACC: MOL.19981207.0393.

DOE (U.S. Department of Energy) 2004. Quality Assurance Requirements and

Description. DOE/RW-0333P, Rev. 16. Washington, D.C.: U.S. Department of Energy, Office of Civilian Radioactive Waste Management.

ACC: DOC.20040907.0002.

Drefahl, K.; Wincierz, P.; Zwicker, U.; and Delarbre, P. [1985]. "230 000 h Creep

174820

Properties of Titanium Produced from Electrolytic and Sponge Material and

TiAl6V4 Alloy at $20^{\circ} \mathrm{C}$." Titanium Science and Technology Proceedings of the

Fifth International Conference on Titanium, Congress-Center, Munich, FRG,

September 10-14, 1984]. [4], 2387-2394. Oberrursel, West Germany: Deutsche

Gesellschaft fur Metallkunde. TIC: 257549.

McGarr, A. 1984. "Some Applications of Seismic Source Mechanism Studies to

163996

Assessing Underground Hazard." Proceedings of the 1st International Congress on

Rockbursts and Seismicity in Mines, Johannesburg, 1982. Gay, N.C. and

Wainwright, E.H., eds. Pages 199-208. Johannesburg, South Africa: South

African Institute of Mining and Metallurgy. TIC: 254652.

McGuire, R.K.; Silva, W.J.; and Costantino, C.J. 2001. Technical Basis for

157510

Revision of Regulatory Guidance on Design Ground Motions: Hazard-and

Risk-Consistent Ground Motion Spectra Guidelines. NUREG/CR-6728.

Washington, D.C.: U.S. Nuclear Regulatory Commission. TIC: 251294.

Menges, C.M. and Whitney, J.W. 1996. "Distribution of Quaternary Faults in the

106342

Site Area." Chapter 4.2 of Seismotectonic Framework and Characterization of

Faulting at Yucca Mountain, Nevada. Whitney, J.W., ed. Milestone 3GSH100M.

Denver, Colorado: U.S. Geological Survey. TIC: 237980.

ACC: MOL.19970129.0041.

Mongano, G.S.; Singleton, W.L.; Moyer, T.C.; Beason, S.C.; Eatman, G.L.W.;

149850

Albin, A.L.; and Lung, R.C. 1999. Geology of the ECRB Cross Drift - Exploratory Studies Facility, Yucca Mountain Project, Yucca Mountain, Nevada. Deliverable SPG42GM3. Denver, Colorado: U.S. Geological Survey.

ACC: MOL.20000324.0614.

Newmark, N.M. and Rosenblueth, E. 1971. Fundamentals of Earthquake

Engineering. Civil Engineering and Engineering Mechanics Series. Englewood

Cliffs, New Jersey: Prentice-Hall. TIC: 248548.

NRC (U.S. Nuclear Regulatory Commission) 2003. Yucca Mountain Review Plan,

Final Report. NUREG-1804, Rev. 2. Washington, D.C.: U.S. Nuclear Regulatory Commission, Office of Nuclear Material Safety and Safeguards. TIC: 254568. 
Sanders, T.L.; Seager, K.D.; Rashid, Y.R.; Barrett, P.R.; Malinauskas, A.P.;

102072

Einziger, R.E.; Jordan, H.; Duffey, T.A.; Sutherland, S.H.; and Reardon, P.C. 1992. A Method for Determining the Spent-Fuel Contribution to Transport Cask Containment Requirements. SAND90-2406. Albuquerque, New Mexico: Sandia National Laboratories. ACC: MOV.19960802.0116.

Waiting, D.J.; Stamatakos, J.A.; Ferrill, D.A.; Sims, D.W.; Morris, A.P.; 164449

Justus, P.S.; and Ibrahim, A.K. 2003. "Methodologies for the Evaluation of Faulting at Yucca Mountain, Nevada." Proceedings of the 10th International High-Level Radioactive Waste Management Conference (IHLRWM), March 30-April 2, 2003, Las Vegas, Nevada. Pages 377-387. La Grange Park, Illinois: American Nuclear Society. TIC: 254559.

\subsection{CODES, STANDARDS, REGULATIONS, AND PROCEDURES}

10 CFR 63. 2005 Energy: Disposal of High-Level Radioactive Wastes in a 173273 Geologic Repository at Yucca Mountain, Nevada. ACC: MOL.20050405.0118.

LP-2.14Q-BSC, Rev. 0, ICN 1. Document Review. Washington, D.C.: U.S. Department of Energy, Office of Civilian Radioactive Waste Management. ACC: DOC.20050727.0005.

AP-2.22Q, Rev. 1, ICN 1. Classification Analyses and Maintenance of the Q-List. Washington, D.C.: U.S. Department of Energy, Office of Civilian Radioactive Waste Management. ACC: DOC.20040714.0002.

LP-2.29Q-BSC, Rev. 0, ICN 1. Planning for Science Activities. Washington, D.C.: U.S. Department of Energy, Office of Civilian Radioactive Waste Management. ACC: DOC.20050718.0002.

AP-3.12Q, Rev. 2, ICN 2. Design Calculations and Analyses. Washington, D.C.: U.S. Department of Energy, Office of Civilian Radioactive Waste Management. ACC: DOC.20040318.0002.

LP-3.12Q-BSC, Rev. 0, ICN 0. Design Calculations and Analyses. Washington, D.C.: U.S. Department of Energy, Office of Civilian Radioactive Waste Management. ACC: DOC.20050518.0007.

LP-3.15Q-BSC, Rev. 0, ICN 2. Managing Technical Product Inputs. Washington, D.C.: U.S. Department of Energy, Office of Civilian Radioactive Waste Management. ACC: DOC.20050801.0010.

LP-SIII.10Q-BSC, Rev. 0, ICN 1. Models. Washington, D.C.: U.S. Department of Energy, Office of Civilian Radioactive Waste Management.

ACC: DOC.20050623.0001. 
LP-SV.1Q-BSC, Rev. 0, ICN 0. Control of the Electronic Management of Information. Washington, D.C.: U.S. Department of Energy, Office of Civilian Radioactive Waste Management. ACC: DOC.20050531.0002.

LP-SI.11Q-BSC, Rev. 0, ICN 1. Software Management. Washington, D.C.: U.S. Department of Energy, Office of Civilian Radioactive Waste Management. ACC: DOC.20041005.0008.

\subsection{SOURCE DATA, LISTED BY DATA TRACKING NUMBER}

LB0307SEEPDRCL.002. Seepage Into Collapsed Drift: Data Summary. 164337

Submittal date: $07 / 21 / 2003$.

LL040310323122.044. Input and Output Files of the MSTHM

168769

Micro-Abstractions for the Collapsed-Drift Cases for the TSPA-LA

Low-Probability Seismic Scenario. Submittal date: 03/26/2004.

MO0012MWDGFM02.002. Geologic Framework Model (GFM2000).

153777

Submittal date: $12 / 18 / 2000$.

MO0210PGVPB107.000. Design Peak Ground Velocity for the Repository Level (Point B) at $10^{-7}$ Annual Exceedance Probability. Submittal date: 10/17/2002.

MO0303DPGVB106.002. Design Peak Ground Velocity for the Repository Level (Point B) at $10^{-6}$ Annual Exceedance Probability.

Submittal date: $03 / 10 / 2003$.

MO0401MWDRPSHA.000. Results of the Yucca Mountain Probabilistic 166962

Seismic Hazard Analysis (PSHA). Submittal date: 01/21/2004.

MO0401SEPPGVRL.022. Peak Ground Velocity for the Repository Level (Point B) at $10^{-5}$ Annual Exceedance Frequency. Submittal date: 01/26/2004.

MO0403SPASCRKD.000. Seismic Crack Density Model Outputs for LA. Submittal date: $03 / 09 / 2004$.

MO0404PGVRL104.000. Peak Ground Velocity for the Repository Level 162713

162712 (Point B) at $10^{-4}$ Annual Exceedance Frequency. Submittal date: 04/23/2004.

MO0407SEPFEPLA.000. LA FEP List. Submittal date: 07/20/2004.

170760

MO0501BPVELEMP.001. Bounded Horizontal Peak Ground Velocity Hazard at 172682 the Repository Waste Emplacement Level. Submittal date: 01/11/2005. 
MO0503SPAUDECW.000. Kinematic Data from UDEC for End-to-End Impacts

between Adjacent Waste Packages. Submittal date: 03/08/2005.

MO0504SPALSDYN.000. Kinematic Data from LS-DYNA for End-to-End

173338

Impacts between Adjacent Waste Packages. Submittal date: 04/07/2005.

TBV-7585

\subsection{PRODUCT OUTPUT, LISTED BY DATA TRACKING NUMBER}

MO0508SPACOMPA.002. Computational Algorithm for the Seismic Scenario for TSPA. Submittal date: 08/24/2005. 


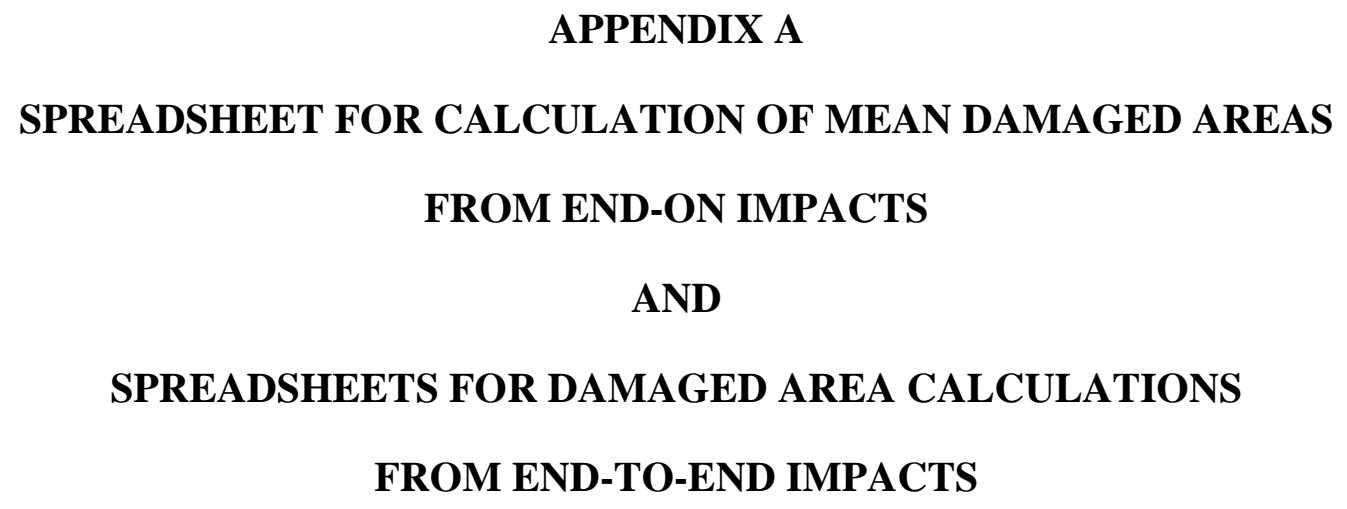




\section{A.1 MEAN DAMAGED AREAS FROM END-ON IMPACTS}

The Excel workbook "End-On Damage Catalog.xls" calculates the mean values for damaged area as a function of impact velocity. This workbook also estimate the velocity threshold at which damaged area becomes zero for the residual stress threshold of 80 percent of the yield strength of Alloy 22. This workbook has two worksheets, " $80 \%$ of YS" and " $90 \%$ of YS", that document the mean value calculations for residual stress thresholds of 80 percent and 90 percent of the yield strength for Alloy 22, respectively. These worksheets are also the source for Figures 6.5-6 through 6.5-8 in the main body of this report. A copy of the file "End-On Damage Catalog.xls" is included on the CD in Appendix G of this report.

\section{Formulas, Input Data, and Output Data}

The calculation of mean damaged area uses the standard AVERAGE statistical function in Excel. The input data for calculation of the mean values comes from (BSC 2005 [DIRS 173178], Table 2) for a residual stress threshold of 80 percent of the yield strength of Alloy 22 and (BSC 2005 [DIRS 173178], Table 3) for a residual stress threshold of 90 percent of the yield strength of Alloy 22. Only the damaged areas for impact angles of $1^{\circ}, 5^{\circ}$, and $8^{\circ}$ are averaged, as explained in Section 6.5.1.2. The output data from the spreadsheet are the mean values, which are found in cells G6 through G10 of either worksheet. These output data are used for the calculation of end-to-end damaged areas, as discussed in Section A.2.

The mean damaged areas are also used to define the velocity threshold at which damaged area becomes zero. The damaged areas at the impact velocities closest to zero are given by $(1 \mathrm{~m} / \mathrm{s}$, $\left.0.00223 \mathrm{~m}^{2}\right)$ and $\left(2 \mathrm{~m} / \mathrm{s}, 0.0172 \mathrm{~m}^{2}\right)$. The slope and $\mathrm{x}$-intercept of the line between these two points are given by:

$$
\begin{gathered}
\text { slope }=\frac{(0.0172-0.00223)}{(2-1)}=0.015, \\
x-\text { intercept }=1 \mathrm{~m} / \mathrm{s}-\frac{0.00223 \mathrm{~m}^{2}}{\text { slope }}=0.85 \mathrm{~m} / \mathrm{s} .
\end{gathered}
$$

The x-intercept in equation A-2 defines the velocity threshold for zero damaged area. The output data from this calculation is the velocity threshold, which is used for calculation of the end-to-end damaged areas discussed in Section A.2.

\section{Detailed Description of Excel Workbooks}

Finite-element calculations have been performed to determine the damaged areas from end-on impacts of a waste package on an elastic surface (BSC 2005 [DIRS 173178], Tables 2 and 3). The results from these calculations form the basis for the catalog or lookup table of damaged areas as a function of impact velocity and impact angle. There are five values of impact velocity: $1 \mathrm{~m} / \mathrm{s}, 2 \mathrm{~m} / \mathrm{s}, 4 \mathrm{~m} / \mathrm{s}, 6 \mathrm{~m} / \mathrm{s}$ and $10 \mathrm{~m} / \mathrm{s}$, and four values of the impact angle: $0^{\circ}, 1^{\circ}, 5^{\circ}$, and $8^{\circ}$ in the catalog. The selected ranges of impact velocity and impact angle are sufficiently wide to encompass all velocities and angles encountered in the end-to-end impacts generated by the kinematic calculations discussed in Section 6.5.1.1. 
The results for damaged area as a function of impact velocity and impact angle are found in cells C6 through F10 of either worksheet. These areas are repeated in Table A-1, which is identical with Table 6.5-3 in the main body of this report. The angular dependence of damage in Table A-1 has been simplified for the purpose of determining damaged areas from end-to-end impacts. For a given impact velocity, the damaged area is determined as the mean value of the damaged areas at $1^{\circ}, 5^{\circ}$, and $8^{\circ}$. The mean values are calculated in cells G6 through G10 in either worksheet. The resulting mean values are summarized in Table A-2 (identical with Table 6.5-4 in the main body of this report).

The graphics for Figures 6.5-6(a) and 6.5-7(a) are presented in cells A17 through G45 and in cells $\mathrm{H} 17$ through O45, respectively, in the "80\% of YS" worksheet. The graphics for Figures 6.5-6(b) and 6.5-7(b) are presented in cells A17 through G45 and in cells H17 through $\mathrm{O} 45$, respectively, in the "90\% of YS" worksheet.

Table A-1. Catalog of Damaged Areas from End-On Impact on an Elastic Surface

\begin{tabular}{|c|c|c|c|c|c|c|c|c|}
\hline \multirow{2}{*}{$\begin{array}{l}\text { Impact } \\
\text { Velocity }\end{array}$} & \multicolumn{4}{|c|}{$\begin{array}{l}\text { Damaged Area }\left(\mathrm{m}^{2}\right) \text { for Stress Threshold of } \\
80 \% \text { of Yield Strength as a Function of Impact } \\
\text { Angle }\end{array}$} & \multicolumn{4}{|c|}{$\begin{array}{l}\text { Damaged Area }\left(\mathrm{m}^{2}\right) \text { for Stress Threshold of } \\
90 \% \text { of Yield Strength as a Function of Impac } \\
\text { Angle }\end{array}$} \\
\hline & $0^{\circ}$ & $1^{\circ}$ & $5^{\circ}$ & $8^{\circ}$ & $0^{\circ}$ & $1^{\circ}$ & $5^{\circ}$ & $8^{\circ}$ \\
\hline $1 \mathrm{~m} / \mathrm{s}$ & 0.0 & 0.0020 & 0.0027 & 0.0020 & 0.0 & 0.0017 & 0.0014 & 0.0012 \\
\hline $2 \mathrm{~m} / \mathrm{s}$ & 0.0024 & 0.0282 & 0.0130 & 0.0105 & 0.0 & 0.0035 & 0.0052 & 0.0051 \\
\hline $4 \mathrm{~m} / \mathrm{s}$ & 0.0122 & 0.0421 & 0.0651 & 0.0474 & 0.0122 & 0.0126 & 0.0288 & 0.0212 \\
\hline $6 \mathrm{~m} / \mathrm{s}$ & 0.0264 & 0.0521 & 0.1466 & 0.0967 & 0.0124 & 0.0222 & 0.0655 & 0.0335 \\
\hline $10 \mathrm{~m} / \mathrm{s}$ & 0.0419 & 0.0571 & 0.2822 & 0.2244 & 0.0377 & 0.0259 & 0.1542 & 0.1206 \\
\hline
\end{tabular}

Source: BSC 2005 [DIRS 173178], Tables 2 and 3.

Table A-2. Mean Damaged Areas for $1^{\circ}, 5^{\circ}$, and $8^{\circ}$ End-On Impacts on an Elastic Surface

\begin{tabular}{|c|c|c|}
\hline $\begin{array}{c}\text { Impact } \\
\text { Velocity }\end{array}$ & $\begin{array}{c}\text { Mean Damaged Area }\left(\mathbf{m}^{2}\right) \text { for } \\
\text { Stress Threshold of 80\% of Yield } \\
\text { Strength }\end{array}$ & $\begin{array}{c}\text { Mean Damaged Area }\left(\mathbf{m}^{2}\right) \text { for } \\
\text { Stress Threshold of 90\% of Yield } \\
\text { Strength }\end{array}$ \\
\hline $1 \mathrm{~m} / \mathrm{s}$ & 0.00223 & 0.00143 \\
\hline $2 \mathrm{~m} / \mathrm{s}$ & 0.0172 & 0.0046 \\
\hline $4 \mathrm{~m} / \mathrm{s}$ & 0.0515 & 0.0209 \\
\hline $6 \mathrm{~m} / \mathrm{s}$ & 0.0985 & 0.0404 \\
\hline $10 \mathrm{~m} / \mathrm{s}$ & 0.1879 & 0.1002 \\
\hline
\end{tabular}

Source: Cells G7 through G11 in either worksheet in the workbook "End-On Damage Catalog.xIs".

The mean damaged areas in Table A-2 for the residual stress threshold of 80 percent of YS form the basis for estimating the velocity threshold for the onset of nonzero damage. The velocity threshold is estimated by extrapolating the mean damaged curve below $1 \mathrm{~m} / \mathrm{s}$. A simple linear extrapolation of the damaged areas at $1 \mathrm{~m} / \mathrm{s}$ and $2 \mathrm{~m} / \mathrm{s}$ indicates that the $\mathrm{x}$-intercept of the curve corresponds to $0.851 \mathrm{~m} / \mathrm{s}$. This calculation can be found in cells $\mathrm{N} 3$ through $\mathrm{O} 6$ of the worksheet " $80 \%$ of YS". The adjacent plot, in cells P1 through W25, provides the basis for Figure 6.5-8 in the main body of the report. 


\section{A.2 DAMAGED AREA CALCULATIONS FOR END-TO-END IMPACTS}

The mean damaged areas in Table A-2 and the velocity threshold of $0.85 \mathrm{~m} / \mathrm{s}$ (corresponding to the onset of nonzero damage) provide the basis for determining damaged areas from end-to-end impacts of adjacent waste packages in the kinematic calculations. The methodology for calculating damaged area uses the relative impact velocity from the kinetic analyses as the interpolation parameter in Table A-2. The total damaged area is then defined as the sum of the damaged areas from the individual impacts.

This methodology has been applied to the kinematic output from the two suites of calculations discussed in Section 6.5.1.1. The damaged area calculations for the 80 percent and the 90 percent residual stress criteria are documented in the Excel files identified in Table A-3. A copy of all files in Table A-3 is included on the CD in Appendix G of this report.

\section{Formulas, Input Data, and Output Data}

Interpolation between points in the damaged area catalog uses the standard Excel function FORECAST. The summation of damaged areas uses the standard SUM function in Excel. The input data for the damaged area catalog comes from the results of the Excel workbook "End-On Damage Catalog.xls" discussed in Section A.1. The input data for the kinematic impact parameters from LS-DYNA is based on the spreadsheets in DTN: MO0504SPALSDYN.000 [DIRS 173338]. The input data for the kinematic impact parameters from UDEC is in DTN: MO0503SPAUDECW.000 [DIRS 173337]. The output data from the spreadsheets are the damaged areas for 17 ground motion time histories at the $1.05-\mathrm{m} / \mathrm{s}, 2.44-\mathrm{m} / \mathrm{s}$, and $5.35-\mathrm{m} / \mathrm{s}$ PGV levels. These data are the basis for the damage abstractions from end-to-end impacts with LS-DYNA and with UDEC. The development of the damage abstractions is discussed in Appendix B.

\section{A.2.1 Analysis of Kinematic Data from LS-DYNA Calculations}

The Excel workbooks "LLNL_Damage_E-6 with 0.85mps Cutoff.xls" and "LLNL_Damage_E-7 with 0.85mps Cutoff.xls" contain the analysis of damaged areas for the center, center-right, and center-left waste packages. Each file has 17 worksheets, one for each of the 17 realizations/ground motions. The contents in key columns or cells of each worksheet are as follows:

- Column A identifies the center-right, center, and center-left waste package as cask I, J, and $\mathrm{K}$, respectively.

- Column E has the relative impact velocity for the set of impact to each package.

- Columns F and G have the damaged areas for all impacts greater than $0.85 \mathrm{~m} / \mathrm{s}$ at the residual stress thresholds of 80 percent and 90 percent of the yield strength of Alloy 22.

- Cells J11 through L16 have the damaged area catalog defined by Table A-2. 
Table A-3. Listing of Excel Files with Damaged Area Calculations for the Kinematic Calculations

\begin{tabular}{|c|c|}
\hline Name of Excel File & Description of Content \\
\hline LLNL_Impact_Velocities_E-5.xIs & $\begin{array}{l}\text { Kinematic results for LS-DYNA calculations with } \\
17 \text { ground motions at the } 1.05-\mathrm{m} / \mathrm{s} \text { PGV level. There are } \\
\text { no damaged areas in this file because all relative impact } \\
\text { velocities are below } 0.85 \mathrm{~m} / \mathrm{s} \text {. }\end{array}$ \\
\hline LLNL_Damage_E-6 with $0.85 \mathrm{mps}$ Cutoff.xls & $\begin{array}{l}\text { Kinematic results and associated damaged areas for } \\
\text { LS-DYNA calculations with } 17 \text { ground motions at the } \\
\text { 2.44-m/s PGV level }\end{array}$ \\
\hline LLNL_Damage_E-7 with $0.85 \mathrm{mps}$ Cutoff.xls & $\begin{array}{l}\text { Kinematic results and associated damaged areas for } \\
\text { LS-DYNA calculations with } 17 \text { ground motions at the } \\
\text { 5.35-m/s PGV level }\end{array}$ \\
\hline $\begin{array}{l}\text { 21-PWRs 1e-5 damage with } 0.85 m p s \text { Cutoff to central } \\
\text { WP.xls }\end{array}$ & $\begin{array}{l}\text { Kinematic results and associated damaged areas for the } \\
\text { UDEC calculations with } 17 \text { ground motions at the } \\
\text { 1.05-m/s PGV level; central waste package }\end{array}$ \\
\hline $\begin{array}{l}21-P W R s \text { 1e-5 damage with } 0.85 m p s \text { Cutoff to center } \\
\text { right WP.xls }\end{array}$ & $\begin{array}{l}\text { Kinematic results and associated damaged areas for the } \\
\text { UDEC calculations with } 17 \text { ground motions at the } \\
1.05-\mathrm{m} / \mathrm{s} \text { PGV level; center right waste package }\end{array}$ \\
\hline $\begin{array}{l}\text { 21-PWRs 1e-5 damage with } 0.85 \mathrm{mps} \text { Cutoff to center left } \\
\text { WP.xls }\end{array}$ & $\begin{array}{l}\text { Kinematic results and associated damaged areas for the } \\
\text { UDEC calculations with } 17 \text { ground motions at the } \\
1.05-\mathrm{m} / \mathrm{s} \text { PGV level; center left package }\end{array}$ \\
\hline $\begin{array}{l}\text { 21-PWRs 1e-6 damage with } 0.85 \mathrm{mps} \text { Cutoff to central } \\
\text { WP.xls }\end{array}$ & $\begin{array}{l}\text { Kinematic results and associated damaged areas for the } \\
\text { UDEC calculations with } 17 \text { ground motions at the } \\
2.44-\mathrm{m} / \mathrm{s} \text { PGV level; central waste package }\end{array}$ \\
\hline $\begin{array}{l}21-P W R s \text { 1e-6 damage with } 0.85 m p s \text { Cutoff to center } \\
\text { right WP.xls }\end{array}$ & $\begin{array}{l}\text { Kinematic results and associated damaged areas for the } \\
\text { UDEC calculations with } 17 \text { ground motions at the } \\
2.44-\mathrm{m} / \mathrm{s} \text { PGV level; center right waste package }\end{array}$ \\
\hline $\begin{array}{l}\text { 21-PWRs 1e-6 damage with } 0.85 \mathrm{mps} \text { Cutoff to center left } \\
\text { WP.xls }\end{array}$ & $\begin{array}{l}\text { Kinematic results and associated damaged areas for the } \\
\text { UDEC calculations with } 17 \text { ground motions at the } \\
2.44-\mathrm{m} / \mathrm{s} \text { PGV level; center left package }\end{array}$ \\
\hline $\begin{array}{l}\text { 21-PWRs 1e-7 damage with } 0.85 \mathrm{mps} \text { Cutoff to central } \\
\text { WP.xls }\end{array}$ & $\begin{array}{l}\text { Kinematic results and associated damaged areas for the } \\
\text { UDEC calculations with } 17 \text { ground motions at the } \\
5.35-\mathrm{m} / \mathrm{s} \text { PGV level; central waste package }\end{array}$ \\
\hline $\begin{array}{l}\text { 21-PWRs 1e-7 damage with } 0.85 \mathrm{mps} \text { Cutoff to center } \\
\text { right WP.xls }\end{array}$ & $\begin{array}{l}\text { Kinematic results and associated damaged areas for the } \\
\text { UDEC calculations with } 17 \text { ground motions at the } \\
5.35-\mathrm{m} / \mathrm{s} \text { PGV level; center right waste package }\end{array}$ \\
\hline $\begin{array}{l}\text { 21-PWRs 1e-7 damage with } 0.85 \mathrm{mps} \text { Cutoff to center left } \\
\text { WP.xls }\end{array}$ & $\begin{array}{l}\text { Kinematic results and associated damaged areas for the } \\
\text { UDEC calculations with } 17 \text { ground motions at the } \\
5.35-\mathrm{m} / \mathrm{s} \text { PGV level; center left package }\end{array}$ \\
\hline
\end{tabular}

Source: Files on the CD in Appendix G.

If an impact velocity is greater than $0.85 \mathrm{~m} / \mathrm{s}$, the interpolation for the damaged area is performed with Excel's FORECAST function using the velocities in the catalog that bracket the relative impact velocity from the kinematic calculation. It is not necessary to extrapolate beyond the catalog data for any impact velocity from the kinematic calculations.

The total damaged area for each package is calculated for all impacts greater than $1.0 \mathrm{~m} / \mathrm{s}$ and for all impacts greater than $0.85 \mathrm{~m} / \mathrm{s}$. These totals are found toward the top of each worksheet. The totals for impacts greater than $0.85 \mathrm{~m} / \mathrm{s}$ include the damaged areas from the appropriate impacts greater than $0.85 \mathrm{~m} / \mathrm{s}$ and less than $1.0 \mathrm{~m} / \mathrm{s}$, which are listed toward the bottom of each worksheet. 


\section{A.2.2 Analysis of Kinematic Data from UDEC Calculations}

The Excel workbooks identified in Table A-3 contain the analysis of damaged areas for the center, center-right, or center-left waste packages. Each file has 17 worksheets, one for each of the 17 realizations/ground motions. The contents in key columns or cells of each worksheet are as follows:

- Column D has the relative normal impact velocity for each impact to the package at the 2.44-m/s and 5.35-m/s PGV levels. Column D has the relative normal impact velocity for each impact to the package at the $1.05-\mathrm{m} / \mathrm{s}$ PGV level when there is nonzero damage (i.e., when a single velocity exceeds the $0.85 \mathrm{~m} / \mathrm{s}$ velocity threshold)..

- Columns H and I have the damaged areas for all impacts greater than $0.85 \mathrm{~m} / \mathrm{s}$ at the residual stress thresholds of 80 percent and 90 percent of the yield strength of Alloy 22 . These columns also have the damaged areas at the $1.05-\mathrm{m} / \mathrm{s}$ PGV level when there is nonzero damage.

- The damaged area catalog defined by Table A-2 is in columns B through D, below the body of the impact data.

If an impact velocity is greater than $0.85 \mathrm{~m} / \mathrm{s}$, the interpolation for the damaged area is performed with Excel's FORECAST function using the velocities in the catalog that bracket the relative impact velocity from the kinematic calculation. It is not necessary to extrapolate beyond the catalog data for any impact velocity from the kinematic calculations. The total damaged area for each package is calculated for all impacts greater than $0.85 \mathrm{~m} / \mathrm{s}$. These totals are found two rows beneath the listing of the impact data, in columns $\mathrm{H}$ and $\mathrm{I}$. 


\section{INTENTIONALLY LEFT BLANK}




\section{APPENDIX B}

SPREADSHEETS FOR DAMAGED AREA ABSTRACTIONS FROM END-TO-END IMPACTS AND FROM WASTE PACKAGE-PALLET IMPACTS 


\section{B.1 DAMAGED AREA ABSTRACTIONS FROM END-TO-END IMPACTS}

The Excel workbook “WP-WP Damage Abstraction with 0.85mps Cutoff Rev00d.xls" calculates the damage abstractions for end-to-end impacts as a function of PGV-longitudinal. This workbook has four worksheets, "ABSTR for LS-DYNA $80 \%$ YS", "ABSTR for LS-DYNA 90\% YS", "ABSTR for UDEC 80\% YS", and "ABSTR for UDEC 90\% YS". That is, there is a worksheet for each of the four damage abstractions for end-to-end impacts.

\section{Formulas, Input Data, and Output Data}

Calculations of mean values and standard deviations use the standard Excel functions AVERAGE and STDEV. Calculations of a normal distribution use the standard Excel function NORMDIST. Least squares fits to the data are based on Excel's trendline capability for a line or a power law. Residuals are defined as the difference between the natural logarithm of a damaged area and the natural logarithm of the damaged area on the power law fit at the corresponding value of PGV. The cumulative probability of the $i^{\text {th }}$ point out of $n$ total points is defined as $(0.5 / n+(I-1) / n)$. A power law of the form $D A=a(P G V)^{\mathrm{b}}$ passes through two data points $\left(P G V_{1}, D A_{1}\right)$ and $\left(P G V_{2}, D A_{2}\right)$ when the coefficients $a$ and $b$ have values $b=\left(\ln \left(D A_{1} / D A_{2}\right)\right) /\left(\ln \left(P G V_{1} / P G V_{2}\right)\right)$ and $a=D A_{1} /\left(P G V_{1}\right)^{b}$. A power law of the form $P_{N D}=a(V-$ $P G V)^{\mathrm{b}}$ passes through two data points $\left(P G V_{1}, P_{N D, 1}\right)$ and $\left(P G V_{2}, P_{N D, 2}\right)$ when the coefficients $a$ and $b$ have the values $b=\ln \left(P_{N D, 1} / P_{N D, 2}\right) / \ln \left(\left(V-P G V_{1}\right) /\left(V-P G V_{2}\right)\right)$ and $a=P_{N D, 1} /\left(V-P G V_{1}\right)^{b}$.

The input data for the damaged area abstractions for end-to-end impacts comes from the results of the Excel workbooks described in Appendix A.2. The output data from each of the worksheets are: (i) the probability of no damage as a function of PGV-longitudinal, (ii) the least squares power law fit to the damaged area as a function of PGV, and (iii) the standard deviation of the residuals of the damaged areas relative to the power law fit in $\ln -\ln$ space. These output data are the basis for the damage abstractions from end-to-end impacts discussed in Section 6.5.1.

\section{Detailed Description of Excel Workbooks}

The data for damaged areas for end-to-end impacts based on LS-DYNA are listed in columns D through I and rows 12 through 28. These data come directly from the spreadsheets described in Appendix A. Summary statistics can be found in the rows 29 through 40 . Columns K through S calculate the statistical parameters for the nonzero damaged areas. The power law fit to the nonzero damaged areas is defined graphically in cells B51 through G78. The comparison of the residuals to a cumulative normal distribution is presented in cells $\mathrm{T} 7$ through $\mathrm{Z} 31$. The data for the quantile plot is found in columns $\mathrm{U}, \mathrm{V}$ and $\mathrm{W}$, beginning at row 40 . The quantile plot is adjacent to these columns, beginning at cell X40. Finally, the probability of no damage is derived in the upper right hand corner of each worksheet. The relevant data is in columns AC through AE in rows 6 through 32, and the plot of probability of no damage as a function of PGV-longitudinal is adjacent to these cells.

The data for damaged areas for end-to-end impacts based on UDEC are listed in columns D through L and rows 11 through 27 . These data come directly from the spreadsheets described in Appendix A. Summary statistics can be found in the rows 28 through 39 . Columns N through V 
calculate the statistical parameters for the nonzero damaged areas. The power law fit to the nonzero damaged areas is defined graphically in cells E49 through K75 and in cells D52 through $\mathrm{J} 78$ for 80 percent of YS and 90 percent of YS, respectively. The comparison of the residuals to a cumulative normal distribution is presented in cells W6 through AD30. The data for the quantile plot is found in columns X, Y, and Z, beginning at row 39. The quantile plot is adjacent to these columns, beginning at cell AA39. Finally, the probability of no damage is derived in the upper right hand corner of each worksheet. The relevant data are in columns AF through $\mathrm{AH}$ in rows 5 through 31, and the plot of probability of no damage as a function of PGV-longitudinal is adjacent to these cells.

\section{B.2 DAMAGED AREA ABSTRACTIONS FROM WASTE PACKAGE-PALLET IMPACTS}

The Excel workbook "WP-Pallet Damage Area Abstraction Rev00e.xls" calculates the damage abstractions for waste package-pallet impacts as a function of PGV-longitudinal. This workbook has two worksheets, "ABSTR for $80 \%$ YS" and "ABSTR for 90\% YS". The structural response calculations for waste package-pallet impacts were performed with LS-DYNA. Damaged areas are calculated directly from the finite-element results, so there is no need for a catalog or lookup table of damaged areas. A complete description of these calculations is in Section 6.5.2 of the main body of this report.

\section{Formulas, Input Data, and Output Data}

Calculations of mean values and standard deviations use the standard Excel functions AVERAGE and STDEV. Calculations of a normal distribution use the standard Excel function NORMDIST. Least squares fits to the data are based on Excel's trendline capability for a line or a power law. Residuals are defined as the difference between the natural logarithm of a damaged area and the natural logarithm of the damaged area on the power law fit at the corresponding value of PGV. The cumulative probability of the $i^{\text {th }}$ point out of $n$ total points is defined as $(0.5 / n+(I-1) / n)$. A power law of the form $D A=a(P G V)^{\mathrm{b}}$ passes through two data points $\left(P G V_{1}, D A_{1}\right)$ and $\left(P G V_{2}, D A_{2}\right)$ when the coefficients $a$ and $b$ have values $b=\left(\ln \left(D A_{1} / D A_{2}\right)\right) /\left(\ln \left(P G V_{1} / P G V_{2}\right)\right)$ and $a=D A_{1} /\left(P G V_{1}\right)^{b}$. A power law of the form $P_{N D}=a(V-P G V)^{\mathrm{b}}$ passes through two data points $\left(P G V_{1}, P_{N D, 1}\right)$ and $\left(P G V_{2}, P_{N D, 2}\right)$ when the coefficients $a$ and $b$ have the values $b=\ln \left(P_{N D, 1} / P_{N D, 2}\right) / \ln \left(\left(V-P G V_{1}\right) /\left(V-P G V_{2}\right)\right)$ and $\mathrm{a}=P_{N D, 1} /\left(V-P G V_{1}\right)^{b}$.

The input data for the damaged area abstractions for waste package-pallet impacts comes from three sources: (i) damage statistics for a single waste package, based on a sampling of vibratory ground motions at the 2.44-m/s PGV level (BSC 2005 [DIRS 173500], Table 1), (ii) damage statistics for a single waste package, based on a sampling of vibratory ground motions at the 5.35-m/s PGV level (BSC 2005 [DIRS 173500], Table 2) and (BSC 2004 [DIRS 171717] Table 6.1-4 for Realization 11), and (iii) damage statistics for a single waste package, based on supplemental calculations for vibratory ground motions at the $5.35 \mathrm{~m} / \mathrm{s}, 2.44 \mathrm{~m} / \mathrm{s}$, and $1.05-\mathrm{m} / \mathrm{s}$ PGV levels (BSC 2004 [DIRS 171717], Tables 6.1-4, 6.2-7, and 6.3-6). The output data from each of the worksheets are: (i) the probability of no damage as a function of PGV-longitudinal, (ii) the least squares power law fit to the damaged area as a function of PGV-longitudinal, and (iii) the standard deviation of the residuals of the damaged areas relative to the power law fit in 
ln-ln space. These output data are the basis for the damage abstractions from waste package-pallet impacts discussed in Section 6.5.2.

\section{Detailed Description of Excel Workbooks}

The data for damaged areas for waste package-pallet impacts are listed in columns A through D. Columns E through $\mathrm{M}$ calculate the statistical parameters for the nonzero damaged areas, beginning at row 21. The power law fit to the nonzero damaged areas is defined graphically in cells H1 through K19. The plot in cells L1 through P19 provides an expanded view of the fit near a PGV-longitudinal of $1 \mathrm{~m} / \mathrm{s}$. The plot in cells Q1 through V19 presents the same fit in $\ln -\ln$ space, where the power law is a straight line. Finally, the plot in cells W1 through AC19 sorts the data into two or three classes for evaluating the variability of the standard deviation with PGV-longitudinal.

The comparison of the residuals to a cumulative normal distribution is presented in cells N20 through U47. The data for the quantile plot is found in columns AH, AI, and AJ, beginning at row 21. The quantile plot is directly adjacent to column AJ. Finally, the probability of no damage is derived in the upper right hand corner of each worksheet. The relevant data is in cells V21 through X46, and the plot of probability of no damage as a function of PGV-longitudinal is adjacent to these cells. 


\section{INTENTIONALLY LEFT BLANK}


APPENDIX C

INDEPENDENT TECHNICAL REVIEW BY PROF. C. ALLIN CORNELL OF WASTE PACKAGE DAMAGE ABSTRACTION FROM VIBRATORY GROUND MOTION 
Independent Technical Review of the New Waste Package Abstraction

(Sections 6.5.1-6.5.3 of the Seismic Consequence Abstraction)

A Report to Bechtel-SAIC

By Dr. C. Allin Cornell

July 25, 2005

\section{Introduction}

The net product of the seismic waste package abstraction is a conditional probability distribution of the waste package damaged area given a specific level of the vibratory ground motion, as a function of that level. The abstraction provides the link between the probabilistic characterization of the ground motion hazard and the TSPA assessment of the post-closure repository performance. The report presents this abstraction and the support for it in a clear and concise way. It is the author's conclusion that the abstraction is reasonable and appropriate for its intended use in the TSPA.

The input to the waste package damage abstraction is the level of ground motion as specified by the peak ground velocity PGV) of a horizontal component of the motion. The output is a probability distribution of the anticipated damaged area (as defined in the abstraction) that a representative waste package will suffer given a particular level of the ground motion. The key elements of the abstraction are the representation of the ground motions, the prediction of the dynamic response of the engineered barrier system (EBS) to a given sample of a seismic ground motion, the determination of the damaged area given the response, and a model of the full conditional probability distribution of damaged area as a function of ground motion level.

2. Elements of the Abstraction

\section{a. Ground motions.}

The representation of the ground motions is described in Section 6.4. For the current purposes the ground motions are scalar-parameterized by the PGV of the longitudinal horizontal component of the motion and represented (at each of several PGV levels) by samples of approximately 15 representative three-component accelerograms - all with common longitudinal PGV. The range of PGV values used covers that of interest as defined on one end by the onset of non-zero damage and at the other by PGV values beyond the $10^{-8}$ annual probability level. The review of these ground motions and their annual frequencies of exceedance are beyond the scope of this letter. For the purposes of the waste package abstraction, however, samples of such three-component accelerograms are precisely what are required to estimate the response and damage to the EBS. Despite the broad variability observed in the response and damage the range of $\mathrm{PGV}$ and the sample size is sufficient in my view to provide an adequate abstraction of the damaged area probability distribution for the primary TSPA objective. As will be elaborated on below I believe the focus should be on the mean value of the damaged area as a function of PGV. Given the (conditional) standard deviations of $\ln$ (nonzero) damaged areas of about 1 to 1.5 and 
total sample sizes of about 40, the standard error of estimation of the conditional mean of the (nonzero) damaged area is about 15 to $25 \%$. The sample size may not be sufficient to confirm the extreme tails of the damaged area conditional distributions but the mean dose estimates are insensitive to these tails.

\section{b. Dynamic Response of ESB}

The dynamic response computations have now been separated into two approaches, one kinematic to captured waste package - waste package (WP-WP) impact statistics and one fully deformable to obtain damaged areas for waste package-pallet (WP-P) impacts. The latter (based on the nonlinear analysis of a single waste package on a pallet surrounded by non-yielding surfaces) are the same analyses used in the initial abstraction (BSC 2004 [DIRS 167780], Section 6.5) reviewed previously by Dr. Robert Kennedy (BSC 2004 [DIRS 167780], Attachment III) and need not be reviewed again here. This author concurs that they provide a reasonable and appropriate representation of the damaged areas due to this portion of the impacts and that the inputs and outputs are reasonable.

The new analyses are the 2D kinematic analyses of multiple waste packages designed to estimate the velocities and angles of the end-to-end WP-WP impacts for subsequent use in calculating damaged areas. These new analyses are a major step forward in capturing the multi-package effects that were missing from the previous, conservative single-package analyses of WP-WP impacts. While the use of a single seven-package, free-end configuration to represent the many cases that will exist in the facility is a major simplification, based on various comparisons it appears that the particular configuration chosen is a conservative representation of other more realistic configurations such as the longer eleven package case presented in I-3.3.2 of Attachment I of BSC 2005 ([DIRS 173172]). For example, the comparative results shown in Table I-22 of I-3.3.4 can be shown to imply that the net mean damaged area predicted by the chosen seven-package configuration is about 3 times larger at $2.44 \mathrm{~m} / \mathrm{s}$ and about 1.5 times larger at $5.35 \mathrm{~m} / \mathrm{s}$ than the eleven package case. In addition, the significant differences in results between the two modeling efforts (LSDYNA and UDEC) underline the difficulty of the mechanical analysis problem, its sensitivity to details of the modeling and the current limits to our understanding of the finer points of such analyses. Further sensitivity and comparative studies are likely to bring sharper insight into the problem and less uncertainty in the conclusions. The use of weighted results from both LSDYNA and UDEC analyses reflects that uncertainty and provides an appropriate and adequate abstraction for the present purposes.

\section{c. Damaged Area Estimates}

As was true in the previous version of the Seismic Consequence Abstraction the WP-WP damaged areas are estimated from the list of impacts with their velocities and angles using results from fine-mesh studies of a waste package impacting a non-yielding flat surface. This approach has therefore been reviewed and found appropriate previously by Dr. Kennedy; this reviewer concurs. The process has been 
modified somewhat (and likely made more conservative) by averaging over impact angles to remove the low value of damage implied by near-zero angles. This is an improvement. This reviewer agrees that use of the relative velocity between packages is conservative but that failure to capture impacts of WP corners into lids is not (Section 6.5.1.3).

\section{d. Damaged Area Probability Distributions}

The results of multiple samples of damaged areas from the WP-WP and WP-P analyses at several PGV levels have been represented by a three-parameter probability distribution. The parameters are the probability of zero damage and the mean and standard deviation of the natural $\log$ of the nonzero damaged areas. The parameter values are functions of PGV. The nonzero damages are assumed to follow a lognormal probability distribution. The primary output of the TSPA is the mean dose at 10,000 years. It is physically reasonable that the seismic contribution to this mean will be approximately proportional to the mean damaged area (as release from the package(s) is similarly likely approximately proportional to damaged area at the small percentage areas of interest). Therefore the mean dose will be comparatively insensitive to either the shape of the damaged area distribution or its standard deviation. The product of one minus the probability of zero damage and the mean nonzero damage is the mean damaged area (at each PGV value). The fits of these two damaged area parameter values versus PGV seem very reasonable and quite appropriate for the TSPA use.

All together the output - primarily mean damaged area versus PGV - appears to be reasonable given the inputs (ground motion samples, EBS models, and response to damaged area relationships).

\section{Limitations}

Limitations to the new waste package abstraction include the issues of corner-on-lid WP-WP damage characterization and the as-yet un-understood differences between the two sets of 2D kinematic analyses mentioned above. Other limitations include significant conservatisms such as the unbounded PGV of the perpendicular component (a factor only in the WP-P damage case) and the use of relative package velocities in the estimation of WP-WP damaged areas. Limitations whose impacts are less predictable include the use of only a 2D representation of the waste packages kinematics in the WP-WP case, the use of only a single waste package in the WP-P case, and the dependence on a single multiple waste package configuration. The report would benefit in Section 6.5.3 from a comparison between the damaged areas versus PGV predictions for the WP-WP and WP-P cases. I believe it would be sufficient to show simply the mean damaged area vs. PGV for the two cases. 
INTENTIONALLY LEFT BLANK 
APPENDIX D

INDEPENDENT TECHNICAL REVIEW BY DR. ROBERT P. KENNEDY OF WASTE PACKAGE DAMAGE ABSTRACTION FROM VIBRATORY GROUND MOTION 


\section{Independent Technical Review of \\ Waste Package Damage Abstraction}

Robert P. Kennedy

June 24, 2005

\section{Introduction}

I have performed a detailed technical review of the waste package damage abstraction presented in Sections 6.5.1 through 6.5.3 of "Seismic Consequence Abstraction" (Ref. 1). I have reviewed both the data presented in these sections and the data documented in the Excel files on the compact disk in Appendix $\mathrm{H}^{*}$.

\section{Review Conclusions}

In my judgement, the current waste package damage abstraction represents the highest quality damage abstraction that can be developed from the existing analytical studies of the seismic response of the waste packages. Any further improvements should be concentrated on improving the input data as opposed to further development of damage abstractions from the existing analytical studies. It is not clear to me whether any further improvements are necessary. However, if further improvements are judged to be warranted, the following areas are candidates for improvement:

1. Develop an improved suite of ground motion time histories anchored to longitudinal peak ground velocities $\mathrm{PGV}_{\mathrm{L}}$ ranging from $1.0 \mathrm{~m} / \mathrm{sec}$ to $4.2 \mathrm{~m} / \mathrm{sec}$. The current suite of time histories appear to contain some unreasonably high vertical $\mathrm{PGV}_{\mathrm{V}}$ and peak ground accelerations PGA for a given longitudinal $P G V_{L}$. These limited number of unreasonably high ground motion $\mathrm{PGV}_{\mathrm{V}}$ and $\mathrm{PGA}$ values are likely to have introduced some conservative bias to the high end of the damage area estimates. Unfortunately, revising the suite of ground motion records would require all of the time-history waste package response studies and the damage abstractions to have to be redone. My judgement is that the current damage estimates are conservative and that improving the suite of time-history records would lead to such an extensive redo of work that it is probably not necessary.

2. Reinvestigate the catalog of damaged areas for end on impacts. The current catalog is for a single waste package impacting a rigid boundary. This condition only strictly applies to the case of perfectly symmetric impacts between adjacent casks. This perfectly symmetric impact situation is extremely unlikely. It is much more likely that the corner edge of one waste package impacts the lid of the adjacent waste package. This impact situation probably warrants additional study. If no further study is performed, one should continue to use the relative impact velocity between waste packages as opposed to half of this velocity when using the current catalog (Table 6.5-4) of damage area as a function of impact velocity. 
Specific comments are presented in the following sections.

\section{Comment on Kinematic Calculations for End-to-End Impacts}

Section 6.5.1.1 of Ref. 1 discusses two suites of kinematic calculations of end-to-end impacts between adjacent waste packages. In my judgement, both the LS-DYNA and the UDEC calculations represent practical high quality computations of the number of impacts and impact velocities between adjacent packages.

I strongly concur with the decision to equally weigh and use both the LS-DYNA and the UDEC suite of results in the end-to-end damage abstraction.

\section{Comment on Catalog of Damaged Areas for End-On Impacts}

The catalog of damaged areas for end-on impacts discussed in Section 6.5.1.2 of Ref. 1 probably represents the weakest link in the input data used for developing the waste package damage abstraction. The fundamental problem is that this catalog of damaged areas strictly only applies to perfectly symmetric impacts between adjacent waste packages. Such perfectly symmetric impacts are unlikely.

If the impacts were perfectly symmetric, then the catalog of damaged areas should be entered using 50 percent of the relative impact velocity between adjacent packages because of symmetry. However, it is much more likely that impacts are not symmetric. In fact, an impact of a corner edge of one package into the lid of the adjacent package might produce more damage than indicated from entering the catalog of damaged area using 100 percent of the relative impact velocity.

Given the existing data base, I concur with the use of Table $6.5-2 *$ of Ref. 1 to estimate damaged area per impact as a function of the relative impact velocity between adjacent waste packages. I would not concur with entering Table $6.5-2 *$ using only 50 percent of the relative impact velocity.

I also concur with the decision to treat the damaged area from each impact independent from the damaged area from other impacts so that the damaged area from all impacts are additive.

In summary, given the available data base, I concur with all decisions discussed in Section 6.5.1.3 of Ref. 1 for computing the total damaged area for end-to-end impacts. There are both conservative and possibly unconservative approximations in the defined approach. However, estimation of damage area from non-symmetric impacts probably warrants additional study.

\section{Comments on Damaged Area Abstraction for End-to-End Impacts}

The development of the damaged area abstraction for end-to-end impacts is discussed in Sections 6.5.1.4 and 6.5.1.5 of Ref. 1.

I concur with the decision to define the damaged area abstraction in terms of the longitudinal $\mathrm{PGV}_{\mathrm{L}}$. Furthermore, I concur with the decision to first estimate the probability of no damage as 
a function of $P G V_{L}$. Next, I concur with the estimation of damaged area for cases with damage using a power law fit versus $\mathrm{PGV}_{\mathrm{L}}$ for the median equation and a lognormal distribution of dispersion about this median equation.

After studying other ways to fit the available damage area versus $\mathrm{PGV}_{\mathrm{L}}$ data, I could not find any improvement over the damage abstraction documented in Ref. 1.

\section{Comment on Damaged Area Abstraction for WP-Pallet Impacts}

The development of the damaged area abstraction for WP-Pallet impacts is described in Section 6.5.2. The WP-Pallet impacts damaged area is also defined in terms of the longitudinal $P G V_{L}$. Again, the probability of no damage as a function of $\mathrm{PGV}_{\mathrm{L}}$ is estimated. For damage cases, a power law fit of median damaged area versus $\mathrm{PGV}_{\mathrm{L}}$ is obtained and the dispersion of damaged area about this median estimate is fit using a lognormal distribution. I concur completely with the approach used and the damage abstraction obtained.

I could not find any improved way to fit the available damage area versus $\mathrm{PGV}_{\mathrm{L}}$ data.

\section{Comment on Presentation of Results}

Using the estimated lognormally distributed dispersions, I recommend that it would be useful to plot the 5 percent and 95 percent non-exceedance probability lines on figures $6.5-5^{*}, 6.5-10^{*}$, and $6.5-11^{*}$ in order to illustrate better how the damage abstractions fit the available data.

\section{$\underline{\text { Reference }}$}

1. Seismic Consequence Abstraction, MDL-WIS-PA-000003, REV 02B, Bechtel SAIC Company, April 2005

*Editorial Notes: The corresponding Figure numbers in the final version of this report are Figures 6.5-10, 6.5-16, and 6.5-17, respectively. Figures 6.5-13 and 6.5-21 respond to this recommendation. The corresponding Table number in the final version of this report is Table 6.5-4. The corresponding Appendix in the final version of this report is Appendix G. 
INTENTIONALLY LEFT BLANK 


\section{APPENDIX E}

\section{SPREADSHEET FOR FAULT DISPLACEMENT DAMAGE ABSTRACTION}


The Excel workbook "Appendix E Rev02.xls" calculates the damage abstraction for fault displacement presented in Section 6.7 of this report. This workbook has two worksheets, "Tables", and "Table 6.7-5 Calculations". The "Tables" worksheet documents the calculations for Tables 6.7-1 through 6.7-7, for Tables 6.7-9 through 6.7-11, and for Tables 6.7-13 through 6.7-17 in Section 6.7. The "Table 6.7-5 Calculations" worksheet documents the fault displacements on the various hazard curves at annual exceedance frequencies of $10^{-4}, 10^{-5}, 10^{-6}$, $10^{-7}$, and $10^{-8}$ per year.

\section{Formulas, Input Data, and Output Data}

The formulas and input data for the "Tables" worksheet are documented in the notes for each of the individual tables. The primary output data from the "Tables" worksheet is Table 6.7-11, which defines the expected number of waste package failures by waste package type as a function of annual exceedance frequency. The secondary output data from the "Tables" worksheet is in Tables 6.7-13 through 6.7-17 which support criticality calculations.

Calculations within the "Table 6.7-5 Calculations" worksheet provide interpolated values of the fault displacement at Sites 2, 3, 4, 5, 7a-7d, and 8a-8c for annual exceedance frequencies of $10^{-4}$, $10^{-5}, 10^{-6}, 10^{-7}$, and $10^{-8}$ per year. Interpolation is based on a power law of the form $\lambda=a(d)^{\mathrm{b}}$, where $d$ is the fault displacement and $\lambda$ is the annual exceedance frequency. Given two points $\left(\lambda_{1}, d_{1}\right)$ and $\left(\lambda_{2}, d_{2}\right)$, the coefficients $a$ and $b$ have the values $b=\left(\log \left(\lambda_{1} / \lambda_{2}\right)\right) /\left(\log \left(d_{1} / d_{2}\right)\right)$ and $a=$ $\lambda_{1} /\left(d_{1}\right)^{b}$. The displacement, $d$, corresponding to a given value of $\lambda$ is then defined by $d=(\lambda / a)^{1 / b}$.

The input data for the "Table 6.7-5 Calculations" worksheet are the hazard curves is defined in DTN: MO0401MWDRPSHA.000 [DIRS 166962]. Individual input data files are defined in Table 4-1 for the various Sites. The output data from these calculations provide the values listed in Table 6.7-5.

A listing of the information in the "Tables" worksheet follows. 


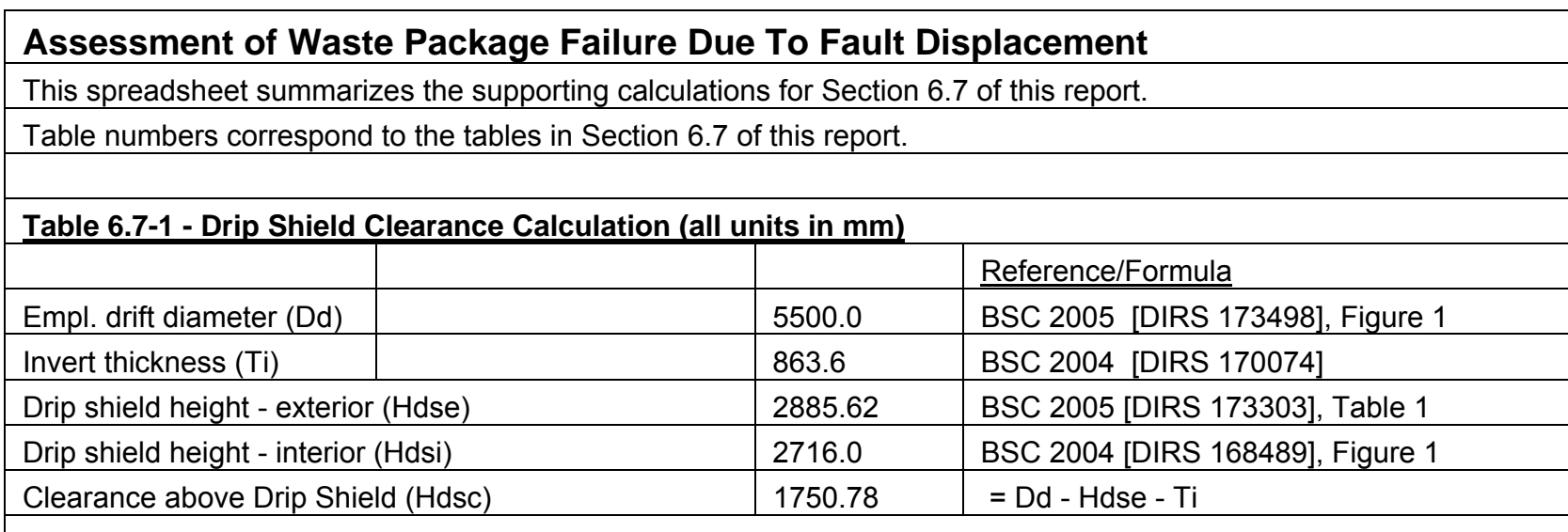

Table 6.7-2 - Waste Package to Drip Shield Clearance

Nominal length from BSC (2005 [DIRS 173501], Table 1); Outer diameter of outer barrier from drawings referenced in BSC (2005 [DIRS 173501], Table 1).

\begin{tabular}{|l|c|c|c|}
\hline & Outer & Nominal & \\
\hline & Diameter & Length & Clearance \\
\hline Package & $(\mathrm{mm})$ & $(\mathrm{mm})$ & $(\mathrm{mm})$ \\
\hline 44-BWR & 1675.1 & 5024.4 & 1041 \\
\hline 24-BWR & 1294.1 & 5024.4 & 1422 \\
\hline 21-PWR & 1637.0 & 5024.4 & 1403 \\
\hline 12-PWR & 1313.2 & 5560.4 & 852 \\
\hline Naval-Long & 1863.7 & 5837.4 & 852 \\
\hline Naval-Short & 1863.7 & 5202.2 & 671 \\
\hline $\begin{array}{l}\text { 5DHLW/DOE Spent Nuclear Fuel - } \\
\text { Short }\end{array}$ & 2044.7 & 3452.8 & 671 \\
\hline $\begin{array}{l}\text { 5DHLW/DOE Spent Nuclear Fuel - } \\
\text { Long }\end{array}$ & 2044.7 & 5059.4 & 967 \\
\hline 2-MCO/2-DHLW & 1749.4 & 5059.4 & \\
\hline
\end{tabular}

The formula for calculating the clearance is given by Hdsi - Outer Diameter of Waste Package.

\section{Table 6.7-3 - Maximum Allowable Fault Displacement (in $\mathrm{mm}$ )}

Two values are provided with and without drift collapse. In both cases, the behavior of the invert and pallet is approximated by treating the emplacement pallet as collapsed into the invert. No further collapse of the invert is accounted for.

With drift collapse, max allowable displacement $=\mathrm{Hdsi}-$ Outer Diameter of Waste Package.

Without drift collapse, max allowable displacement $=\mathrm{Hdsi}-$ Outer Diameter of Waste Package + Hdsc.

\begin{tabular}{|l|c|c|l|}
\hline \multicolumn{1}{|c|}{ Package } & with collapse & wlo collapse & \\
\hline 44-BWR & 1041 & 2792 & \\
\hline 24-BWR & 1422 & 3173 & \\
\hline 21-PWR & 1079 & 2830 & \\
\hline 12-PWR & 1403 & 3154 & \\
\hline Naval-Long & 852 & 2603 & \\
\hline Naval-Short & 852 & 2603 & \\
\hline 5DHLW/DOE Spent Nuclear Fuel-Short & 671 & 2422 & \\
\hline 5DHLW/DOE Spent Nuclear Fuel-Long & 671 & 2422 & \\
\hline 2-MCO/2-DHLW & 967 & 2717 & \\
\hline
\end{tabular}




\section{Table 6.7-4 - Faults Intersecting Drifts}

BSC (2004 [DIRS 168180], Table 9) defines drift intersections with Sever Wash fault, Drill Hole Wash fault, Pagany Wash fault, and the western splay off the main Ghost Dance fault (denoted as the West Ghost Dance fault in Table 9).

DTN: MO0012MWDGFM02.002 [DIRS 153777] defines drift intersections with Sundance fault and the locations of geologic units relative to fault traces and emplacement drifts.

BSC (2004 [DIRS 172801], Figure 1) defines the numbering of drifts and panels.

Western splay off the main Ghost Dance fault (called the West Ghost Dance in the reference) intersects drifts 2-17 through 2-27. Drifts 2-18 through 2-27 are in the contingency area.

Development is uncertain because this area is in the vicinity of an intensely fractured zone (Albin et al. 1997 [DIRS 101367], discussion of Third Domain on pp. 69 to 72). The western splay off the main Ghost Dance fault has therefore, not been included in TSPA-LA.

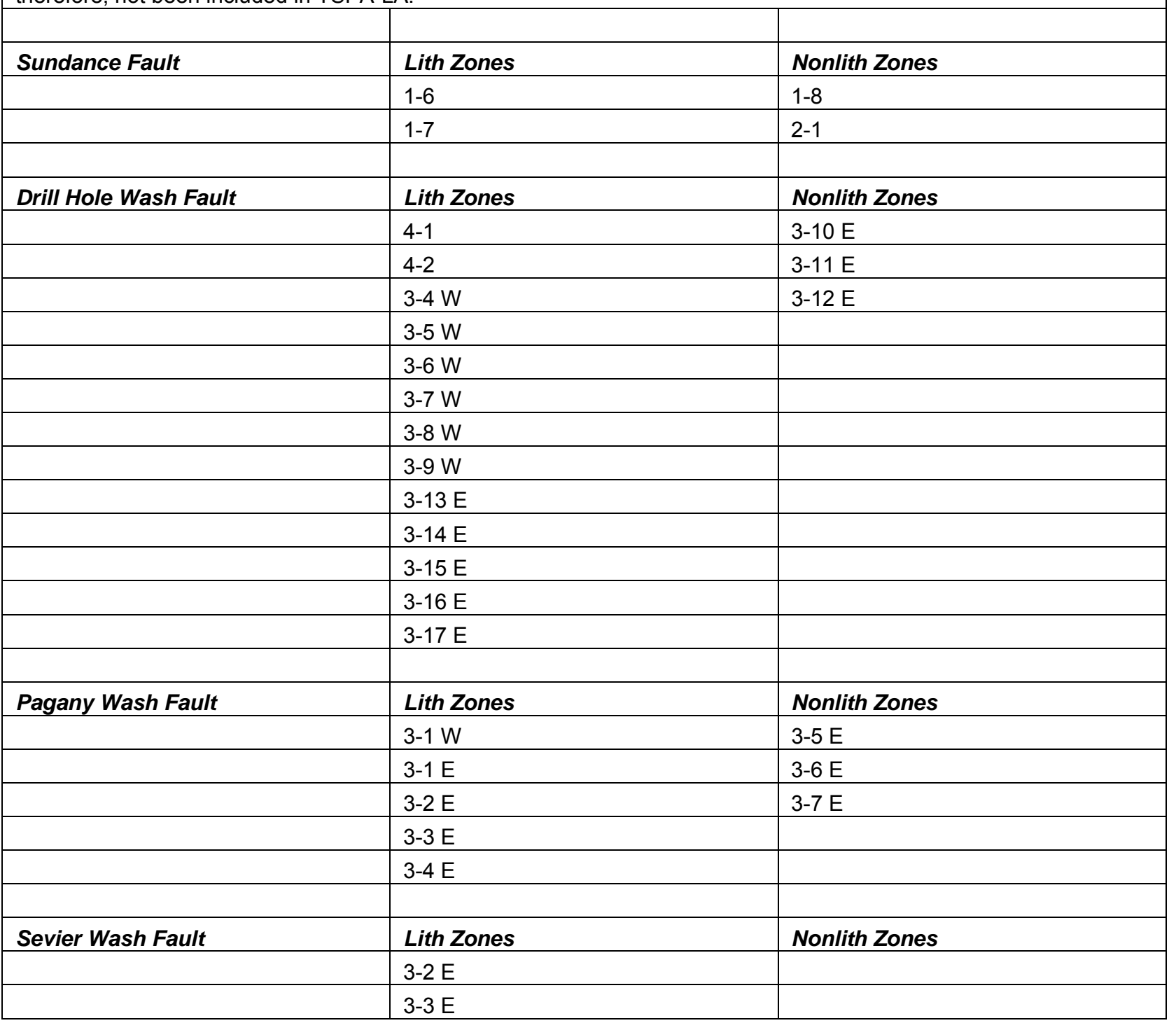


Seismic Consequence Abstraction

Table 6.7-5 - Fault Displacement Summary Information (in cm).

Based on DTN: MO0401MWDRPSHA.000 [DIRS 166962]; data files associated with Sites 2, 3, 4, 5, 7a-7d and 8a-8c are listed in Table 4-1 of this report. Displacements are calculated in the worksheet "Table 6.7-5 Calculations" in the file Appendix E Rev02.xls included on the CD in Appendix G.

Data for Site $8 \mathrm{~d}$ are based on the observation that the fault displacements for Sites $7 \mathrm{a}, 7 \mathrm{~b}$, and $7 \mathrm{c}$ are essentially identical with the fault displacements for Sites $8 \mathrm{a}, 8 \mathrm{~b}$, and $8 \mathrm{c}$, respectively. In this situation, the fault displacements at Site $8 \mathrm{~d}$ are anticipated to be very similar to the fault displacements at Site $7 \mathrm{~d}$. This observation is corroborated by information in CRWMS M\&O (1998 [DIRS 103731] Section 8.2.1, first paragraph), which indicates that displacements at Site $8 \mathrm{~d}$ are below $0.1 \mathrm{~cm}$ down to $10^{-8}$ per year annual exceedance frequency.

\begin{tabular}{|c|c|c|c|c|c|}
\hline & \multicolumn{5}{|c|}{ Mean Annual Exceedance Frequency } \\
\hline & $1.00 \mathrm{E}-04$ & 1.00E-05 & 1.00E-06 & 1.00E-07 & $1.00 \mathrm{E}-08$ \\
\hline Site Number and Fault Name & \multicolumn{5}{|c|}{ Displacement (cm) } \\
\hline 2 - Solitario Canyon (60 m offset) & $<0.1$ & 32.0 & 190 & 500 & $>1000$ \\
\hline 3 - Drill Hole Wash & $<0.1$ & $<0.1$ & 17 & 80 & 240 \\
\hline 4 - Ghost Dance & $<0.1$ & $<0.1$ & 13 & 58 & 160 \\
\hline 5 - Sundance & $<0.1$ & $<0.1$ & 6 & 42 & $\sim 145$ \\
\hline $7 a-$ small fault with $2 \mathrm{~m}$ offset & $<0.1$ & $<0.1$ & 2 & 20 & $\sim 75$ \\
\hline $7 \mathrm{~b}$ - shear with $10 \mathrm{~cm}$ offset & $<0.1$ & $<0.1$ & 1 & 6 & 9 \\
\hline 7c- fracture with no displacement & $<0.1$ & $<0.1$ & 0.1 & $<1$ & $<1$ \\
\hline $7 \mathrm{~d}-$ intact rock & $<0.1$ & $<0.1$ & $<0.1$ & $<0.1$ & $<0.1$ \\
\hline $8 a-$ small fault with $2 \mathrm{~m}$ offset & $<0.1$ & $<0.1$ & 2 & 20 & $\sim 75$ \\
\hline $8 b$ - shear with $10 \mathrm{~cm}$ offset & $<0.1$ & $<0.1$ & 1 & 6 & 9 \\
\hline $8 \mathrm{c}-$ fracture with no displacement & $<0.1$ & $<0.1$ & 0.1 & $<1$ & $<1$ \\
\hline $8 \mathrm{~d}-$ intact rock & $<0.1$ & $<0.1$ & $<0.1$ & $<0.1$ & $<0.1$ \\
\hline
\end{tabular}

Table 6.7-6 - Waste Package Inventory

BSC 2005 [DIRS 173501], Table 1 for nominal length; outside diameter of outer barrier defined In drawings referenced in BSC 2005 [DIRS 173501], Table 1. Waste package nominal quantity from BSC 2005 [DIRS 173501], Table 13.

\begin{tabular}{|l|c|c|c|c|c|}
\hline \multicolumn{1}{|c|}{ Waste Package Configuration } & $\begin{array}{c}\text { Waste } \\
\text { Package } \\
\text { Length } \\
(\mathbf{m})\end{array}$ & $\begin{array}{c}\text { Waste } \\
\text { Package } \\
\text { Diam. (m) }\end{array}$ & $\begin{array}{c}\text { Nominal } \\
\text { Quantity }\end{array}$ & & \\
\hline 21-PWR AP & 5.0244 & 1.6370 & 4299 & & \\
\hline 21-PWR CR & 5.0244 & 1.6370 & 95 & & \\
\hline 12-PWR AP Long & 5.5604 & 1.3132 & 163 & & \\
\hline 44-BWR AP & 5.0244 & 1.6751 & 2831 & & \\
\hline 24-BWR AP & 5.0244 & 1.2941 & 84 & & \\
\hline 5-DHLW Short/1 DOE Spent Nuclear Fuel - Short & 3.4528 & 2.0447 & 1147 & & \\
\hline 5-DHLW Long/1 DOE Spent Nuclear Fuel - Long & 5.0594 & 2.0447 & 1406 & & \\
\hline 5-DHLW Long/1 DOE Spent Nuclear Fuel - Short & 5.0594 & 2.0447 & 31 & & \\
\hline 5 HLW Long Only & 5.0594 & 2.0447 & 679 & & \\
\hline 2-MCO/2-HLW & 5.0594 & 1.7494 & 149 & & \\
\hline Naval-Short & 5.2022 & 1.8637 & 144 & & \\
\hline Naval-Long & 5.8374 & 1.8637 & 156 & & \\
\hline
\end{tabular}

$\mathrm{BWR}=$ boiling water reactor; $\mathrm{DHLW}=$ defense high-level radioactive waste; $\mathrm{MCO}=$ multicanister overpack; $\mathrm{CR}=$ control rod; $\mathrm{AP}=$ absorber plate. 


\begin{tabular}{|c|c|c|c|c|c|}
\hline \multicolumn{6}{|l|}{$1-5$} \\
\hline \multicolumn{2}{|l|}{ Waste Package } & Total & & & \\
\hline \multicolumn{2}{|c|}{ Configuration } & Length $(\mathrm{m})$ & \# Packages & Percent & \\
\hline PWR & 5.0436 & 22984 & 4557 & $42.0 \%$ & \\
\hline BWR & 5.0244 & 14646 & 2915 & $26.8 \%$ & \\
\hline Naval & 5.5325 & 1660 & 300 & $3.0 \%$ & \\
\hline HLW & 4.5193 & 15420 & 3412 & \multicolumn{2}{|c|}{$28.2 \%$} \\
\hline Total & & 54709 & 11184 & \multicolumn{2}{|c|}{$100 \%$} \\
\hline \multicolumn{6}{|c|}{$\begin{array}{l}\text { where Total Length is given by package length times number of packages, summed over each package } \\
\text { type in the group. }\end{array}$} \\
\hline \multicolumn{6}{|c|}{$\begin{array}{l}\text { Effective length is given by Total length } / \text { Total number of packages in group } \%=\text { Total length for that group } \\
\text { / Total length for all groups }\end{array}$} \\
\hline \multicolumn{6}{|c|}{ The PWR group includes the 21-PWR AP, 21-PWR CR, and 12-PWR AP Long packages. } \\
\hline \multicolumn{6}{|c|}{ The BWR group includes the 44-BWR AP and the 24-BWR AP packages. } \\
\hline \multicolumn{6}{|c|}{ The Naval group includes the Naval Long and Naval Short packages. } \\
\hline \multicolumn{6}{|c|}{ The HLW ground includes all DHLW packages. } \\
\hline \multicolumn{6}{|c|}{$\begin{array}{l}\mathrm{BWR}=\text { boiling water reactor, } \mathrm{HLW}=\text { high-level radioactive waste, } \mathrm{DHLW}=\text { defense high-level radioactive } \\
\text { waste; } \mathrm{CR}=\text { control rod; } \mathrm{AP}=\text { absorber plate. }\end{array}$} \\
\hline \multicolumn{6}{|c|}{ Table 6.7-9. Fault Exceedance Probabilities for Waste Package Failure } \\
\hline \multirow{4}{*}{\multicolumn{6}{|c|}{$\begin{array}{l}\text { Using DTN: MO0401MWDRPSHA.000 [DIRS 166962], along with the maximum allowable fault } \\
\text { displacements for each simplified waste package group as summarized in Table } 6.7-8 \text { of Section } 6.7 .4 \text {, one } \\
\text { can determine the exceedance probability required to cause failure for each waste package type. } \\
\text { This is done as follows: } \\
\text { - the allowable fault displacement is given by the value from Table } 6.7-8 \text { (w/ drift collapse) } \\
\text { - using figures 8-4 (Drill Hole Wash) and 8-6 (Sundance), the exceedance probability associated with that } \\
\text { magnitude of fault displacement is determined from the mean value curve for each waste package group. } \\
\text { - note that relative to the accuracy of these figures, the BWR and PWR groups are } \\
\text { Shown with the same probability. } \\
\text { - The Drill Hole Wash results apply to Pagany Wash and Sever Wash }\end{array}$}} \\
\hline & & & & & \\
\hline & & & & & \\
\hline & & & & & \\
\hline Fault & PWR & BWR & & & HLW \\
\hline Sundance & $<2 \times 10^{-8}$ & $<2 \times 10$ & & $10^{-8}$ & $<5 \times 10^{-8}$ \\
\hline Drill Hole Wash & $<5 \times 10^{-8}$ & $<5 \times 10$ & & $10^{-7}$ & $<2 \times 10^{-7}$ \\
\hline Pagany Wash & $<5 \times 10^{-8}$ & $<5 \times 10$ & & $10^{-7}$ & $<2 \times 10^{-7}$ \\
\hline Sever Wash & $<5 \times 10^{-8}$ & $<5 \times 10$ & & $10^{-7}$ & $<2 \times 10^{-7}$ \\
\hline Sites $7 a / 8 a$ & N/A & $\mathrm{N} / \mathrm{A}$ & & & $<2 \times 10^{-8}$ \\
\hline
\end{tabular}


Table 6.7-10 - Expected Number of Waste Packages Emplaced on Faults

Table 6.7-4 in Section 6.7.2.1 of the main report can be used to determine the total number of waste packages impacted by each fault in the lithophysal zones (based on number of fault intersections with each drift). The results in Table 6.7-7 can then be used to calculate the expected number of waste packages in each group that would be on a fault.

These results are summarized below.

\begin{tabular}{|l|c|c|c|c|c|}
\hline & Total & PWR & BWR & Naval & HLW \\
\hline Sundance & 2 & 0.84 & 0.54 & 0.06 & 0.56 \\
\hline Drill Hole, etc. & 20 & 8.40 & 5.35 & 0.61 & 5.64 \\
\hline Sites 7a/8a & 119.85 & 50.3 & 32.1 & 3.64 & 33.8 \\
\hline
\end{tabular}

Table 6.7-11 - Waste Packages Failed Versus Annual Exceedance Probability

The results of Table 6.7-9 and Table 6.7-10 in Section 6.7.4 of the main report can now be combined to provide the expected number of packages failed vs. the annual exceedance probability.

\begin{tabular}{|c|c|c|c|c|c|}
\hline \multirow{2}{*}{$\begin{array}{c}\text { Annual Exceed. } \\
\text { Prob. (1/yr) }\end{array}$} & \multicolumn{5}{|c|}{ Expected Number of Waste Package Failures } \\
\cline { 2 - 6 } & PWR & BWR & Naval & HLW & Total \\
\hline $2 \times 10^{-7}$ & 0 & 0 & 0 & 0 & 0.00 \\
\hline $1 \times 10^{-7}$ to $2 \times 10^{-7}$ & 0 & 0 & 0 & 5.64 & 5.64 \\
\hline $5 \times 10^{-8}$ to $1 \times 10^{-7}$ & 0 & 0 & 0.61 & 5.64 & 6.24 \\
\hline $3 \times 10^{-8}$ to $5 \times 10^{-8}$ & 8.40 & 5.35 & 0.61 & 6.20 & 20.56 \\
\hline $2 \times 10^{-8}$ to $3 \times 10^{-8}$ & 8.40 & 5.35 & 0.67 & 6.20 & 20.62 \\
\hline $1 \times 10^{-8}$ to $2 \times 10^{-8}$ & 9.24 & 5.89 & 0.67 & 39.98 & 55.78 \\
\hline
\end{tabular}

\section{Table 6.7-13 - Parameters for Simplified Inventory for Criticality}

Table 6.7-13 is a modified version of Table 6.7-7 with 10 waste package types

BSC 2005 [DIRS 173501] Table 1 for nominal length, Table 13 for nominal quantity.

\begin{tabular}{|l|c|c|c|c|}
\hline $\begin{array}{c}\text { Waste Package } \\
\text { Type }\end{array}$ & $\begin{array}{c}\text { Waste Package } \\
\text { Length } \\
(\mathbf{m})\end{array}$ & $\begin{array}{c}\text { Nominal Quantity } \\
(-)\end{array}$ & $\begin{array}{c}\text { Total Length for } \\
\text { Package Type (m) }\end{array}$ & $\begin{array}{c}\text { Fraction of Waste } \\
\text { Package (\% Total } \\
\text { Length) }\end{array}$ \\
\hline 21-PWR AP & 5.0244 & 4299 & 21600 & $39.48 \%$ \\
\hline 21-PWR CR & 5.0244 & 95 & 477.32 & $0.87 \%$ \\
\hline 12-PWR AP Long & 5.5604 & 163 & 906.35 & $1.66 \%$ \\
\hline 44-BWR AP & 5.0244 & 2831 & 14224 & $26.00 \%$ \\
\hline 24-BWR AP & 5.0244 & 84 & 422.05 & $0.77 \%$ \\
\hline $\begin{array}{l}\text { 5-DHLW Short/1 } \\
\text { DOE Spent Nuclear } \\
\text { Fuel Short }\end{array}$ & 3.4528 & 1147 & 3960.4 & $7.24 \%$ \\
\hline 5-DHLW/DOE Long & & & & \\
\hline 2 MCO/2 DHLW & 5.0594 & 2116 & 10706 & $19.57 \%$ \\
\hline Naval Short & 5.0594 & 149 & 753.85 & $1.38 \%$ \\
\hline Naval Long & 5.2022 & 144 & 749.12 & $1.37 \%$ \\
\hline \multicolumn{1}{|c|}{ TOTALS } & 5.8374 & 156 & 910.63 & $1.66 \%$ \\
\hline
\end{tabular}

${ }^{1}$ The 5-DHLW/DOE Long category includes the 5-DHLW Long/1 DOE Spent Nuclear Fuel - Long, the 5-DHLW Long/1 DOE Spent Nuclear Fuel - Short, and the 5 HLW Long Only package types.

$(-)=$ dimensionless; BWR = boiling water reactor; $\mathrm{DHLW}=$ defense high-level radioactive waste; $\mathrm{MCO}=$ multicanister overpack ; $\mathrm{CR}=$ control rod; $\mathrm{AP}=$ absorber plate. 


\begin{tabular}{|c|c|c|}
\hline \multicolumn{3}{|l|}{ Waste Package Is Pinned } \\
\hline \multicolumn{3}{|c|}{$\begin{array}{l}\text { Table 6.7-14 is a modified version of Table 6.7-3. Outer diameter of outer barrier of waste package defined by } \\
\text { drawings identified in BSC } 2005 \text { [DIRS 173501], Table 1. Interior height of drip shield is defined in BSC } 2004 \\
\text { [DIRS 168489], Figure 1. }\end{array}$} \\
\hline Waste Package Type & $\begin{array}{c}\text { Waste Package Outer Diameter } \\
(\mathrm{mm})\end{array}$ & $\begin{array}{l}\text { Max. Allowable Displ. With } \\
\text { Collapse (mm) }\end{array}$ \\
\hline 21-PWR AP & 1637.0 & 1079 \\
\hline 21-PWR CR & 1637.0 & 1079 \\
\hline 12-PWR AP Long & 1313.2 & 1403 \\
\hline 44-BWR AP & 1675.1 & 1041 \\
\hline 24-BWR AP & 1294.1 & 1422 \\
\hline $\begin{array}{l}\text { 5-DHLW Short/1 DOE Spent Nuclear } \\
\text { Fuel Short }\end{array}$ & 2044.7 & 671 \\
\hline 5-DHLW/DOE Long & 2044.7 & 671 \\
\hline $2 \mathrm{MCO} / 2 \mathrm{DHLW}$ & 1749.4 & 967 \\
\hline Naval Short & 1863.7 & 852 \\
\hline Naval Long & 1863.7 & 852 \\
\hline
\end{tabular}

$\mathrm{MCO}=$ multicanister overpack; $\mathrm{PWR}=$ pressurized water reactor; $\mathrm{BWR}=$ boiling water reactor; $\mathrm{CR}=$ control rod; $\mathrm{AP}$

$=$ absorber plate.

\section{Table 6.7-15 - Fault Exceedance Frequencies (Per Year) That Cause Failure in Lithophysal Zones}

Table 6.7-15 is a modified version of Table 6.7-9 with 10 waste package types. The interpolated values on the fault displacement hazard curves for Sites 3,5,7a, and 8a are calculated first.

PSHA displacement hazard curve for Site 5 (Sundance fault) is based on DTN: MO0401MWDRPSHA.000

[DIRS 166962], file: /displ/tot_haz/s5.frac_mean.gz.

\begin{tabular}{|c|c|c|c|}
\hline $\begin{array}{c}\text { Displacement } \\
\text { (cm) }\end{array}$ & $\begin{array}{c}\text { Mean Exceedance } \\
\text { Frequency } \\
\mathbf{( 1 / y r )}\end{array}$ & $\begin{array}{c}\text { Allowable Displ. (from } \\
\text { Table 6.7-13) } \\
\text { (cm) }\end{array}$ & $\begin{array}{c}\text { Interpolated Exceedance } \\
\text { Frequency (1/yr) }\end{array}$ \\
\hline $1.00 \mathrm{E}-01$ & $9.54 \mathrm{E}-06$ & $6.710 \mathrm{E}+01$ & $4.23 \mathrm{E}-08$ \\
\hline $2.00 \mathrm{E}-01$ & $8.28 \mathrm{E}-06$ & $8.520 \mathrm{E}+01$ & $2.77 \mathrm{E}-08$ \\
\hline $5.00 \mathrm{E}-01$ & $6.32 \mathrm{E}-06$ & $9.670 \mathrm{E}+01$ & $2.21 \mathrm{E}-08$ \\
\hline $1.00 \mathrm{E}+00$ & $4.34 \mathrm{E}-06$ & $1.041 \mathrm{E}+02$ & $1.92 \mathrm{E}-08$ \\
\hline $2.00 \mathrm{E}+00$ & $2.68 \mathrm{E}-06$ & $1.079 \mathrm{E}+02$ & $1.79 \mathrm{E}-08$ \\
\hline $5.00 \mathrm{E}+00$ & $1.11 \mathrm{E}-06$ & $1.403 \mathrm{E}+02$ & $1.06 \mathrm{E}-08$ \\
\hline $1.00 \mathrm{E}+01$ & $5.40 \mathrm{E}-07$ & $1.422 \mathrm{E}+02$ & \\
\hline $2.00 \mathrm{E}+01$ & $2.53 \mathrm{E}-07$ & & \\
\hline $5.00 \mathrm{E}+01$ & $7.14 \mathrm{E}-08$ & & \\
\hline $1.00 \mathrm{E}+02$ & $2.09 \mathrm{E}-08$ & & \\
\hline $2.00 \mathrm{E}+02$ & $5.21 \mathrm{E}-09$ & & \\
\hline & & & \\
\hline
\end{tabular}


PSHA displacement hazard curve for Site 3 (Drill Hole Wash fault) is based on DTN: MO0401MWDRPSHA.000 [DIRS 166962], file: /displ/tot_haz/s3.frac_mean.gz.

\begin{tabular}{|l|c|c|c|}
\hline $\begin{array}{c}\text { Displacement } \\
(\mathbf{c m})\end{array}$ & $\begin{array}{c}\text { Mean Exceedance } \\
\text { Frequency } \\
(\mathbf{1} / \mathbf{y r})\end{array}$ & $\begin{array}{c}\text { Allowable Displ. } \\
\text { (from Table 6.7-13) } \mathbf{( c m})\end{array}$ & $\begin{array}{c}\text { Interpolated Exceedance } \\
\text { Frequency (1/yr) }\end{array}$ \\
\hline $1.00 \mathrm{E}-01$ & $8.57 \mathrm{E}-06$ & $6.710 \mathrm{E}+01$ & $1.21 \mathrm{E}-07$ \\
\hline $2.00 \mathrm{E}-01$ & $7.86 \mathrm{E}-06$ & $8.520 \mathrm{E}+01$ & $7.89 \mathrm{E}-08$ \\
\hline $5.00 \mathrm{E}-01$ & $6.91 \mathrm{E}-06$ & $9.670 \mathrm{E}+01$ & $6.30 \mathrm{E}-08$ \\
\hline $1.00 \mathrm{E}+00$ & $5.98 \mathrm{E}-06$ & $1.041 \mathrm{E}+02$ & $5.49 \mathrm{E}-08$ \\
\hline $2.00 \mathrm{E}+00$ & $4.87 \mathrm{E}-06$ & $1.079 \mathrm{E}+02$ & $5.13 \mathrm{E}-08$ \\
\hline $5.00 \mathrm{E}+00$ & $3.06 \mathrm{E}-06$ & $1.403 \mathrm{E}+02$ & $3.09 \mathrm{E}-08$ \\
\hline $1.00 \mathrm{E}+01$ & $1.69 \mathrm{E}-06$ & $1.422 \mathrm{E}+02$ & \\
\hline $2.00 \mathrm{E}+01$ & $7.38 \mathrm{E}-07$ & & \\
\hline $5.00 \mathrm{E}+01$ & $2.03 \mathrm{E}-07$ & & \\
\hline $1.00 \mathrm{E}+02$ & $5.94 \mathrm{E}-08$ & & \\
\hline $2.00 \mathrm{E}+02$ & $1.56 \mathrm{E}-08$ & & \\
\hline
\end{tabular}

PSHA displacement hazard curve for Site 7a (100m East of SC, Cum. Displ. $=2 \mathrm{~m})$

DTN: MO0401MWDRPSHA.000 [DIRS 166962], file:/displ/tot_haz/s7a.frac_mean.gz.

\begin{tabular}{|c|c|c|c|}
\hline $\begin{array}{c}\text { Displacement } \\
(\mathbf{c m})\end{array}$ & $\begin{array}{c}\text { Mean Exceedance } \\
\text { Frequency (1/yr) }\end{array}$ & $\begin{array}{c}\text { Allowable Displ. (from } \\
\text { Table 6.7-13) (cm) }\end{array}$ & $\begin{array}{c}\text { Interpolated Exceedance } \\
\text { Frequency (1/yr) }\end{array}$ \\
\hline $1.00 \mathrm{E}-01$ & $7.02 \mathrm{E}-06$ & $6.710 \mathrm{E}+01$ & $1.19 \mathrm{E}-08$ \\
\hline $2.00 \mathrm{E}-01$ & $5.47 \mathrm{E}-06$ & $8.520 \mathrm{E}+01$ & $7.44 \mathrm{E}-09$ \\
\hline $5.00 \mathrm{E}-01$ & $3.11 \mathrm{E}-06$ & $9.670 \mathrm{E}+01$ & $5.80 \mathrm{E}-09$ \\
\hline $1.00 \mathrm{E}+00$ & $1.72 \mathrm{E}-06$ & $1.041 \mathrm{E}+02$ & $4.55 \mathrm{E}-09$ \\
\hline $2.00 \mathrm{E}+00$ & $1.04 \mathrm{E}-06$ & $1.079 \mathrm{E}+02$ & $1.24 \mathrm{E}-09$ \\
\hline $5.00 \mathrm{E}+00$ & $4.58 \mathrm{E}-07$ & $1.403 \mathrm{E}+02$ & $1.17 \mathrm{E}-09$ \\
\hline $1.00 \mathrm{E}+01$ & $2.10 \mathrm{E}-07$ & $1.422 \mathrm{E}+02$ & \\
\hline $2.00 \mathrm{E}+01$ & $8.63 \mathrm{E}-08$ & & \\
\hline $5.00 \mathrm{E}+01$ & $2.12 \mathrm{E}-08$ & & \\
\hline $1.00 \mathrm{E}+02$ & $5.43 \mathrm{E}-09$ & & \\
\hline $2.00 \mathrm{E}+02$ & $2.63 \mathrm{E}-10$ & & \\
\hline
\end{tabular}




\begin{tabular}{|c|c|c|c|}
\hline \multicolumn{4}{|c|}{$\begin{array}{l}\text { PSHA displacement hazard curve for Site 8a (Between SC and GD, Cum. Displ. }=2 m \text { ). } \\
\text { DTN: MO0401MWDRPSHA.000 [DIRS 166962], file: /displ/tot_haz/s8a.frac_mean.gz. }\end{array}$} \\
\hline $\begin{array}{c}\text { Displacement } \\
(\mathbf{c m})\end{array}$ & $\begin{array}{c}\text { Mean Exceedance } \\
\text { Frequency } \\
(1 / y r) \\
\end{array}$ & $\begin{array}{l}\text { Allowable Displ. (from } \\
\text { Table 6.7-13) (cm) }\end{array}$ & $\begin{array}{l}\text { Interpolated Exceedance } \\
\text { Frequency (1/yr) }\end{array}$ \\
\hline $1.00 \mathrm{E}-01$ & $6.72 \mathrm{E}-06$ & $6.710 \mathrm{E}+01$ & 1.33E-08 \\
\hline 2.00E-01 & $5.26 \mathrm{E}-06$ & $8.520 \mathrm{E}+01$ & 8.41E-09 \\
\hline $5.00 \mathrm{E}-01$ & 3.05E-06 & $9.670 \mathrm{E}+01$ & 6.59E-09 \\
\hline $1.00 \mathrm{E}+00$ & 1.70E-06 & $1.041 \mathrm{E}+02$ & 5.12E-09 \\
\hline $2.00 \mathrm{E}+00$ & $1.02 \mathrm{E}-06$ & $1.079 \mathrm{E}+02$ & 4.34E-09 \\
\hline $5.00 E+00$ & 4.52E-07 & $1.403 E+02$ & $1.28 \mathrm{E}-09$ \\
\hline $1.00 \mathrm{E}+01$ & 2.09E-07 & $1.422 \mathrm{E}+02$ & $1.21 \mathrm{E}-09$ \\
\hline $2.00 E+01$ & 8.91E-08 & & \\
\hline $5.00 \mathrm{E}+01$ & $2.36 \mathrm{E}-08$ & & \\
\hline $1.00 \mathrm{E}+02$ & $6.17 \mathrm{E}-09$ & & \\
\hline $2.00 \mathrm{E}+02$ & $2.48 \mathrm{E}-10$ & & \\
\hline \multicolumn{4}{|c|}{$\begin{array}{l}\text { The interpolated values for exceedance frequency correspond to the maximum allowable fault displacements before } \\
\text { a waste package type is damaged. These interpolated values are maximum values for exceedance frequency } \\
\text { because smaller frequencies have larger fault displacements. The maximum values of exceedance frequency are } \\
\text { listed in the following table, rounded up to two significant figures. The exceedance frequency for Sites } 7 a / 8 \text { a is the } \\
\text { maximum value for the Site } 7 \text { a and Site } 8 \text { a hazard curves. }\end{array}$} \\
\hline Waste Package Type & Sundance Fault & $\begin{array}{l}\text { Drill Hole Wash, Pagany } \\
\text { Wash, \& Sever Wash } \\
\text { Faults }\end{array}$ & Sites $7 \mathrm{a} / \mathbf{8 a}$ \\
\hline 21-PWR AP & $1.8 \mathrm{E}-08$ & $5.2 \mathrm{E}-08$ & 5.0E-09 \\
\hline 21-PWR CR & $1.8 \mathrm{E}-08$ & $5.2 \mathrm{E}-08$ & $5.0 \mathrm{E}-09$ \\
\hline 12-PWR AP Long & $1.1 \mathrm{E}-08$ & $3.1 \mathrm{E}-08$ & $2.0 \mathrm{E}-09$ \\
\hline 44-BWR AP & $2.0 \mathrm{E}-08$ & $5.5 \mathrm{E}-08$ & $6.0 \mathrm{E}-09$ \\
\hline 24-BWR AP & $1.1 \mathrm{E}-08$ & $3.1 \mathrm{E}-08$ & 2.0E-09 \\
\hline $\begin{array}{l}\text { 5-DHLW Short/1 DOE } \\
\text { Spent Nuclear Fuel Short }\end{array}$ & $4.3 \mathrm{E}-08$ & $1.3 \mathrm{E}-07$ & $1.4 \mathrm{E}-08$ \\
\hline 5-DHLW/DOE Long & 4.3E-08 & 1.3E-07 & $1.4 \mathrm{E}-08$ \\
\hline $2 \mathrm{MCO} / 2 \mathrm{DHLW}$ & 2.3E-08 & $6.4 \mathrm{E}-08$ & 7.0E-09 \\
\hline Naval Short & $2.8 \mathrm{E}-08$ & $7.9 \mathrm{E}-08$ & $9.0 \mathrm{E}-09$ \\
\hline Naval Long & $2.8 \mathrm{E}-08$ & $7.9 \mathrm{E}-08$ & $9.0 \mathrm{E}-09$ \\
\hline
\end{tabular}

$\mathrm{PWR}=$ pressurized water reactor; $\mathrm{AP}=$ absorber plate; $\mathrm{CR}=$ control rod; $\mathrm{BWR}=$ boiling water reactor; $\mathrm{DHLW}=$ defense high-level radioactive waste; $\mathrm{MCO}=$ multicanister overpack; DOE = U.S. Department of Energy. 


\begin{tabular}{|c|c|c|c|}
\hline \multicolumn{4}{|c|}{$\begin{array}{l}\text { Table } 6.7-16 \text { is a modified version of Table } 6.7-10 \text { with } 10 \text { waste package types. There are } 2 \text { locations and } 20 \\
\text { locations where the Sundance fault and the Drill Hole/Pagany Wash/ Sever Wash faults intersect emplacement drifts } \\
\text { in the lithophysal zones (Table } 6.74 \text { ). The number of locations where Sites } 7 a / 8 \text { a intersect emplacement drifts are } \\
\text { rounded up from } 119.85 \text { to } 120 .\end{array}$} \\
\hline Waste Package Type & Sundance Fault & $\begin{array}{c}\text { Drill Hole Wash, Pagany } \\
\text { Wash, \& Sever Wash } \\
\text { Faults }\end{array}$ & Sites $7 a / 8 a$ \\
\hline 21-PWR AP & 0.7896 & 7.8962 & 47.3774 \\
\hline 21-PWR CR & 0.0174 & 0.1745 & 1.0470 \\
\hline 12-PWR AP Long & 0.0331 & 0.3313 & 1.9880 \\
\hline 44-BWR AP & 0.5200 & 5.1999 & 31.1992 \\
\hline 24-BWR AP & 0.0154 & 0.1543 & 0.9257 \\
\hline $\begin{array}{l}\text { 5-DHLW Short/1 DOE } \\
\text { Spent Nuclear Fuel Short }\end{array}$ & 0.1448 & 1.4478 & 8.6867 \\
\hline 5-DHLW/DOE Long & 0.3914 & 3.9137 & 23.4820 \\
\hline $2 \mathrm{MCO} / 2 \mathrm{DHLW}$ & 0.0276 & 0.2756 & 1.6535 \\
\hline Naval Short & 0.0274 & 0.2739 & 1.6431 \\
\hline Naval Long & 0.0333 & 0.3329 & 1.9974 \\
\hline TOTALS & 2.0000 & 20.0000 & 120.00 \\
\hline
\end{tabular}

\begin{tabular}{|c|c|c|c|c|c|c|}
\hline \multicolumn{7}{|c|}{ Table $6.7-17$ is a modified version of Table $6.7-11$ with 10 waste package types. } \\
\hline Waste Package Type & $>2 \times 10^{-7}$ & $\begin{array}{c}1 \times 10^{-7} \\
\text { to } 2 \times 10^{-7} \\
\end{array}$ & $\begin{array}{c}6 \times 10^{-8} \\
\text { to } 1 \times 10^{-7} \\
\end{array}$ & $\begin{array}{c}4 \times 10^{-8} \\
\text { to } 6 \times 10^{-8}\end{array}$ & $\begin{array}{c}2 \times 10^{-8} \\
\text { to } 4 \times 10^{-8}\end{array}$ & $\begin{array}{c}1 \times 10^{-8} \\
\text { to } 2 \times 10^{-8}\end{array}$ \\
\hline 21-PWR AP & 0.00 & 0.00 & 0.00 & 7.90 & 7.90 & 8.69 \\
\hline 21-PWR CR & 0.00 & 0.00 & 0.00 & 0.17 & 0.17 & 0.19 \\
\hline 12-PWR AP Long & 0.00 & 0.00 & 0.00 & 0.00 & 0.33 & 0.36 \\
\hline 44-BWR AP & 0.00 & 0.00 & 0.00 & 5.20 & 5.20 & 5.72 \\
\hline 24-BWR AP & 0.00 & 0.00 & 0.00 & 0.00 & 0.15 & 0.17 \\
\hline $\begin{array}{l}\text { 5-DHLW Short/1 DOE Spent } \\
\text { Nuclear Fuel Short }\end{array}$ & 0.00 & 1.45 & 1.45 & 1.59 & 1.59 & 10.28 \\
\hline 5-DHLW/DOE Long & 0.00 & 3.91 & 3.91 & 4.31 & 4.31 & 27.79 \\
\hline $2 \mathrm{MCO} / 2 \mathrm{DHLW}$ & 0.00 & 0.00 & 0.28 & 0.28 & 0.30 & 0.30 \\
\hline Naval Short & 0.00 & 0.00 & 0.27 & 0.27 & 0.30 & 0.30 \\
\hline Naval Long & 0.00 & 0.00 & 0.33 & 0.33 & 0.37 & 0.37 \\
\hline TOTALS & 0.00 & 5.36 & 6.24 & 20.05 & 20.62 & 54.17 \\
\hline
\end{tabular}

$\mathrm{PWR}=$ pressurized water reactor, $\mathrm{AP}=$ absorber plate, $\mathrm{CR}=$ control rod; $\mathrm{BWR}=$ boiling water reactor; $\mathrm{DHLW}=$ defense high-level radioactive waste; $\mathrm{MCO}=$ multicanister overpack. 
APPENDIX F

LISTING OF ELECTRONIC FILES ON CD (APPENDIX G) 
The files listed in Table F-1 are provided on CD with this document. These files provide electronic versions of the spreadsheets identified in Appendices A, B, and E of this report.

Table F-1. Listing of Electronic Files on CD (Appendix G)

\begin{tabular}{|c|c|c|c|}
\hline File Name & $\begin{array}{l}\text { Date \& } \\
\text { Time }\end{array}$ & Size & Contents \\
\hline End-On Damage Catalog.xls & $\begin{array}{l}\text { 8/17/2005 } \\
5: 05 \text { PM }\end{array}$ & $37 \mathrm{~KB}$ & $\begin{array}{l}\text { Catalog of damaged areas from end-on } \\
\text { impacts }\end{array}$ \\
\hline LLNL_Impact_Velocities_E-5.xIs & $\begin{array}{l}2 / 15 / 2005 \\
10: 09 \text { AM }\end{array}$ & $43 \mathrm{~KB}$ & $\begin{array}{l}\text { Results of kinematic calculations with } \\
\text { LS-DYNA for the } 1.05-\mathrm{m} / \mathrm{s} \text { PGV level }\end{array}$ \\
\hline $\begin{array}{l}\text { LLNL_Damage_E-6 with } 0.85 \mathrm{mps} \\
\text { Cutoff.xls }\end{array}$ & $\begin{array}{l}2 / 16 / 2005 \\
12: 15 \mathrm{PM} \\
\end{array}$ & $221 \mathrm{~KB}$ & $\begin{array}{l}\text { Results of kinematic calculations \& damaged } \\
\text { areas for LS-DYNA at the } 2.44-\mathrm{m} / \mathrm{s} \text { PGV level }\end{array}$ \\
\hline $\begin{array}{l}\text { LLNL_Damage_E-7 with } 0.85 \mathrm{mps} \\
\text { Cutoff.xls }\end{array}$ & $\begin{array}{l}2 / 21 / 2005 \\
12: 32 \mathrm{PM}\end{array}$ & $227 \mathrm{~KB}$ & $\begin{array}{l}\text { Results of kinematic calculations \& damaged } \\
\text { areas for LS-DYNA at the } 2.44-\mathrm{m} / \mathrm{s} \text { PGV level }\end{array}$ \\
\hline $\begin{array}{l}\text { 21-PWRs 1e-5 damage with } 0.85 \mathrm{mps} \\
\text { Cutoff to center left WP.xls }\end{array}$ & $\begin{array}{l}2 / 16 / 2005 \\
11: 02 \text { PM }\end{array}$ & $77 \mathrm{~KB}$ & $\begin{array}{l}\text { Results of kinematic calculations \& damaged } \\
\text { areas for UDEC at the } 1.05-\mathrm{m} / \mathrm{s} \text { PGV level }\end{array}$ \\
\hline $\begin{array}{l}\text { 21- PWRs 1e-5 damage with } 0.85 \mathrm{mps} \\
\text { Cutoff to central WP.xls }\end{array}$ & $\begin{array}{l}2 / 16 / 2005 \\
11: 01 \mathrm{PM} \\
\end{array}$ & $79 \mathrm{~KB}$ & $\begin{array}{l}\text { Results of kinematic calculations \& damaged } \\
\text { areas for UDEC at the } 1.05-\mathrm{m} / \mathrm{s} \text { PGV level }\end{array}$ \\
\hline $\begin{array}{l}\text { 21-PWRs } 1 \text { e- } 5 \text { damage with } 0.85 \mathrm{mps} \\
\text { Cutoff to center right WP.xIs }\end{array}$ & $\begin{array}{l}2 / 16 / 2005 \\
10: 58 \text { PM }\end{array}$ & $75 \mathrm{~KB}$ & $\begin{array}{l}\text { Results of kinematic calculations \& damaged } \\
\text { areas for UDEC at the } 1.05-\mathrm{m} / \mathrm{s} \text { PGV level }\end{array}$ \\
\hline $\begin{array}{l}21-P W R s \text { 1e- } 6 \text { damage with } 0.85 \mathrm{mps} \\
\text { Cutoff to center right WP.xls }\end{array}$ & $\begin{array}{l}2 / 16 / 2005 \\
7: 31 \mathrm{PM}\end{array}$ & $120 \mathrm{~KB}$ & $\begin{array}{l}\text { Results of kinematic calculations \& damaged } \\
\text { areas for UDEC at the } 2.44-\mathrm{m} / \mathrm{s} \text { PGV level }\end{array}$ \\
\hline $\begin{array}{l}21-P W R s \text { 1e-6 damage with } 0.85 \mathrm{mps} \\
\text { Cutoff to center left WP.xIs }\end{array}$ & $\begin{array}{l}2 / 16 / 2005 \\
7: 05 \mathrm{PM}\end{array}$ & $126 \mathrm{~KB}$ & $\begin{array}{l}\text { Results of kinematic calculations \& damaged } \\
\text { areas for UDEC at the } 2.44-\mathrm{m} / \mathrm{s} \text { PGV level }\end{array}$ \\
\hline $\begin{array}{l}21-P W R s \text { 1e- } 6 \text { damage with } 0.85 \mathrm{mps} \\
\text { Cutoff to central WP.xls }\end{array}$ & $\begin{array}{l}2 / 16 / 2005 \\
6: 29 \mathrm{PM} \\
\end{array}$ & $120 \mathrm{~KB}$ & $\begin{array}{l}\text { Results of kinematic calculations \& damaged } \\
\text { areas for UDEC at the } 2.44-\mathrm{m} / \mathrm{s} \text { PGV level }\end{array}$ \\
\hline $\begin{array}{l}21-P W R s \text { 1e-7 damage with } 0.85 \mathrm{mps} \\
\text { cutoff to center left WP.xls }\end{array}$ & $\begin{array}{l}2 / 17 / 2005 \\
11: 17 \text { AM } \\
\end{array}$ & $335 \mathrm{~KB}$ & $\begin{array}{l}\text { Results of kinematic calculations \& damaged } \\
\text { areas for UDEC at the 5.35-m/s PGV level }\end{array}$ \\
\hline $\begin{array}{l}21-P W R s \text { 1e-7 damage with } 0.85 \mathrm{mps} \\
\text { Cutoff to center right WP.x/s }\end{array}$ & $\begin{array}{l}2 / 17 / 2005 \\
10: 48 \text { AM } \\
\end{array}$ & $286 \mathrm{~KB}$ & $\begin{array}{l}\text { Results of kinematic calculations \& damaged } \\
\text { areas for UDEC at the 5.35-m/s PGV level }\end{array}$ \\
\hline $\begin{array}{l}21-P W R s \text { 1e-7 damage with } 0.85 \mathrm{mps} \\
\text { Cutoff to central WP.xls }\end{array}$ & $\begin{array}{l}2 / 17 / 2005 \\
10: 23 \text { AM } \\
\end{array}$ & $283 \mathrm{~KB}$ & $\begin{array}{l}\text { Results of kinematic calculations \& damaged } \\
\text { areas for UDEC at the 5.35-m/s PGV level }\end{array}$ \\
\hline $\begin{array}{l}\text { WP-WP Damage Abstraction with } \\
0.85 \text { mps Cutoff Rev00d.xls }\end{array}$ & $\begin{array}{l}\text { 8/17/2005 } \\
\text { 3:31 PM }\end{array}$ & $270 \mathrm{~KB}$ & $\begin{array}{l}\text { Four abstractions of damaged areas for } \\
\text { end-to-end impacts }\end{array}$ \\
\hline $\begin{array}{l}\text { WP-Pallet Damage Area Abstraction } \\
\text { Rev00e.xls }\end{array}$ & $\begin{array}{l}\text { 8/17/2005 } \\
\text { 3:54 PM }\end{array}$ & $122 \mathrm{~KB}$ & $\begin{array}{l}\text { Two abstractions of damaged areas for waste } \\
\text { package-pallet impacts }\end{array}$ \\
\hline Appendix E Rev02.xIs & $\begin{array}{l}\text { 8/18/2005 } \\
10: 11 \mathrm{PM}\end{array}$ & $75 \mathrm{~KB}$ & $\begin{array}{l}\text { Electronic version of Appendix } E \text { and } \\
\text { calculations for Table } 6.7-5\end{array}$ \\
\hline
\end{tabular}

Source: directory of files on CD in Appendix G. 
INTENTIONALLY LEFT BLANK 
APPENDIX G

CD WITH ELECTRONIC FILES 
